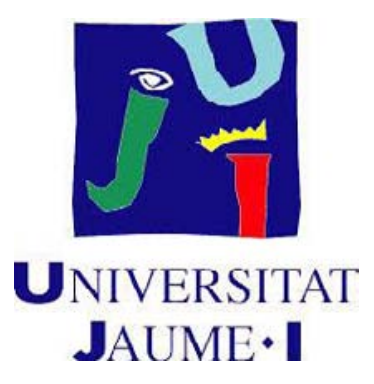

Escuela Superior de Tecnología y Ciencias Experimentales

Departamento de Física

\title{
Regulation and characterization of membrane protein channels and translocation of biologically active compounds
}

\author{
Ph.D. Thesis \\ Carmina Verdiá Báguena
}

Supervisors:

Vicente M. Aguilella Fernández, Ph.D.

Antonio Alcaraz González, Ph.D.

Castellón de la Plana, 2015 



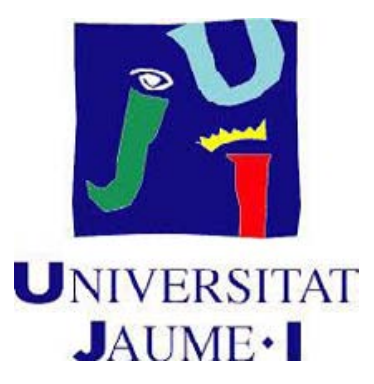

Escuela Superior de Tecnología y Ciencias Experimentales

Departamento de Física

\title{
Regulación y caracterización de proteínas de membrana y translocación de compuestos con actividad biológica
}

\author{
Ph.D. Thesis \\ Carmina Verdiá Báguena
}

Supervisors:

Vicente M. Aguilella Fernández, Ph.D.

Antonio Alcaraz González, Ph.D.

Castellón de la Plana, 2015 

The present Doctoral Thesis has been performed at the Department of Physics of Universitat Jaume I, Castellón de la Plana, under the supervision of Professors Vicente M. Aguilella Fernández and Antonio Alcaraz González.

The financial support for the realization of the Thesis was obtained from Universitat Jaume I (fellowship FPI-UJI 2010). 



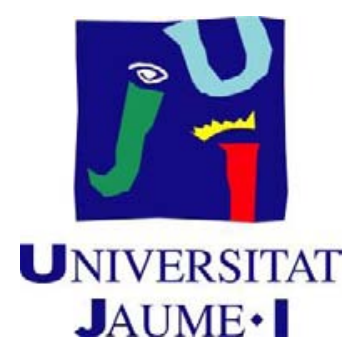

Dr. VICENTE MANUEL AGUILELLA FERNÁNDEZ, catedrático del Área de Física Aplicada en el Departamento de Física de la Universitat Jaume I de Castellón, y Dr. ANTONIO DIEGO ALCARAZ GONZÁLEZ, profesor titular del Área de Física Aplicada en el Departamento de Física de la Universitat Jaume I de Castellón,

CERTIFICAN: Que CARMINA VERDIÁ BÁGUENA ha realizado la presente memoria, "Regulación y caracterización de proteínas de membrana y translocación de compuestos con actividad biológica", bajo nuestra dirección en el Departamento de Física de la Universitat Jaume I y constituye su tesis doctoral.

Y para que conste a los efectos oportunos, en cumplimiento de la legislación vigente, firmamos el presente certificado en Castellón, a 6 de marzo de 2015. 



\section{Table of contents}

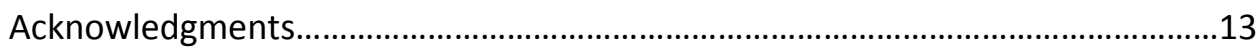

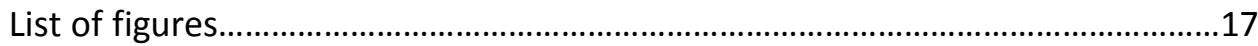

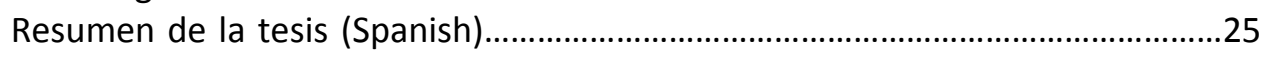

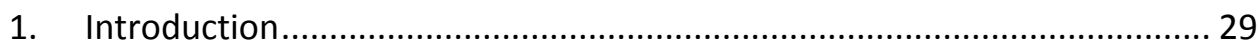

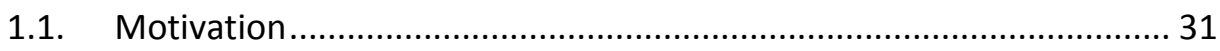

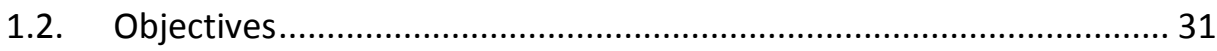

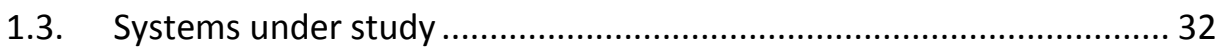

1.3.1. The bacterial porin OmpF from E.Coli ................................... 32

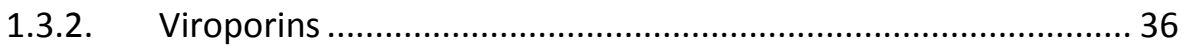

1.3.2.1. The Envelope protein of coronaviruses................................ 38

1.3.2.2. The Small Hydrophobic protein of human respiratory syncytial

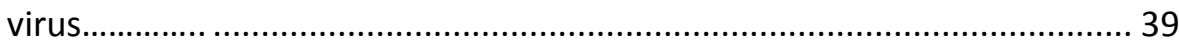

1.3.3. Cobaltabisdicarbollide (COSAN) ........................................... 41

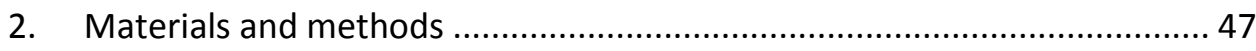

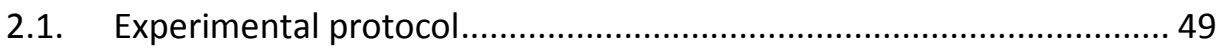

2.1.1. Teflon film hole perforation ............................................... 49

2.1.2. Electrode fabrication ........................................................ 50

2.1.3. Formation of the planar lipid bilayer.................................... 51

2.1.4. Protein insertion ................................................................... 53

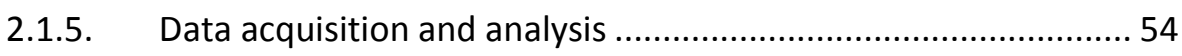

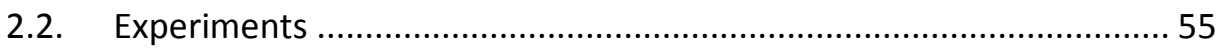

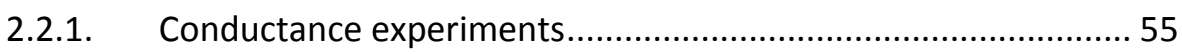

2.2.2. Reversal potential experiments............................................ 56

2.2.3. Inductively coupled plasma mass spectrometry (ICP-MS)......... 57

3. Ion transport modulation in the OmpF porin....................................... 61

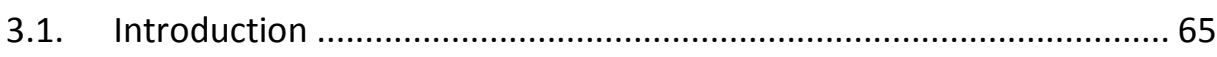

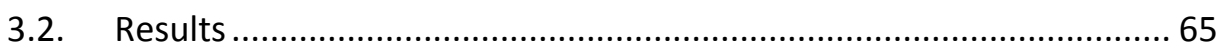

3.2.1. Study of the effect of $\mathrm{LaCl}_{3}$ on $\mathrm{OmpF}$ selectivity .......................6 65

3.2.2. Analysis of $\mathrm{LaCl}_{3}$ as modulator of OmpF conductance ................69 69 
3.2.3. On the role of $\mathrm{pH}$ in lanthanum-induced blocking ..................... 74

3.2.4. Insights on the lanthanum block mechanism ..........................76

3.2.5. Investigating the voltage dependence...................................... 77

3.2.6. Looking for a binding site for $\mathrm{La}^{3+}$ ions.....................................80

3.2.7. Understanding the asymmetry of lanthanum block ...................82

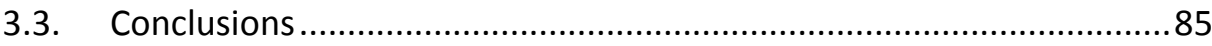

4. SARS-CoV E protein ion channel activity and its implication on virulence ..89

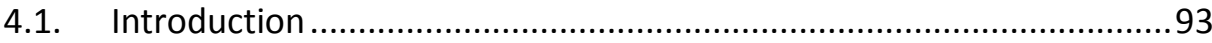

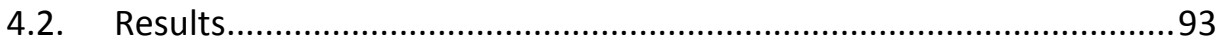

4.2.1. Channel conductance and ion selectivity in neutral membranes

4.2.1. Channel conductance and ion selectivity in charged membranes... 98

4.2.2. Relevance of the E protein channel activity in virus

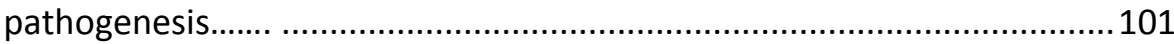

4.2.3. Locating residues involved in the ion channel activity ..............102

4.2.4. SARS-CoV E protein ion channel activity influence on virus

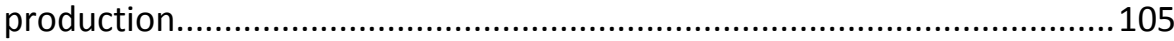

4.2.5. Influence of E protein ion channel activity in SARS-CoV

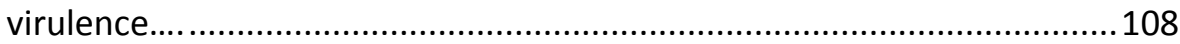

4.2.6. Analysis of the ion channel activity of revertant viruses ...........113

4.2.7. SARS-CoV E protein ion channel activity influence on growth in

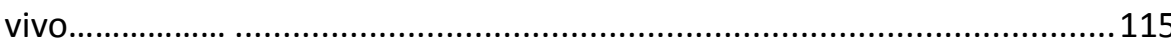

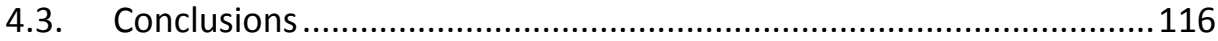

5. Influence of the lipid charge on non-specific biological ion channel

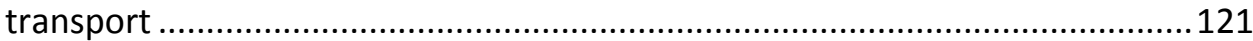

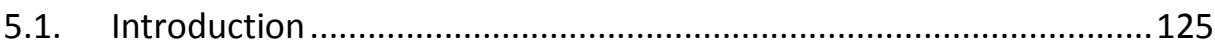

5.2. Lipid charges regulate channel conductance .................................125

5.2.1. The bacterial porin $\mathrm{OmpF}$, a protein channel .........................126

5.2.2. SARS-CoV E protein: evidence for a proteolipidic pore .............130

5.3. Lipid charges influence ion selectivity .........................................135 
5.3.1. Lipid charges on the membrane surface: the case of OmpF.... 135

5.3.2. Lipid molecules as pore building blocks: the case of SARS-CoV E protein............................................................................................. 136

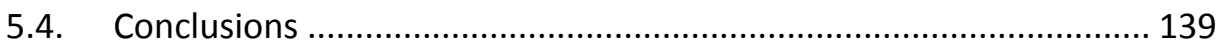

6. A viroporin from the human respiratory syncytial virus: channel activity and

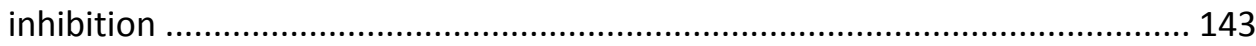

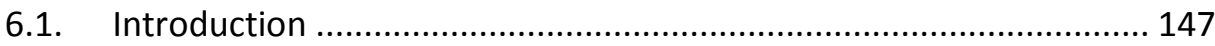

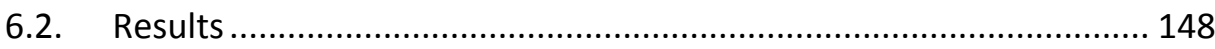

6.2.1. Ion channel current inhibition ............................................... 148

6.2.2. Pyronin B effect on SH mutants ......................................... 152

6.2.3. Characterization of SH protein ion channel activity ................. 155

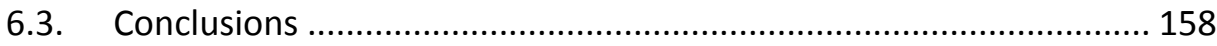

7. Interaction of amphiphilic molecules with membranes ........................ 161

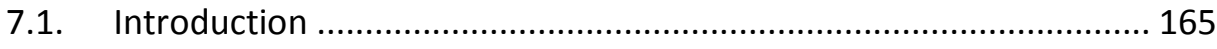

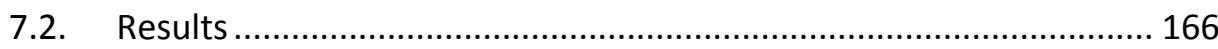

7.2.1. Interaction of COSAN and $\mathrm{I}_{2}$-COSAN with membranes ............. 166

7.2.2. Kinetics of COSAN translocation............................................. 168

7.2.3. COSAN encapsulated into liposomes .................................... 171

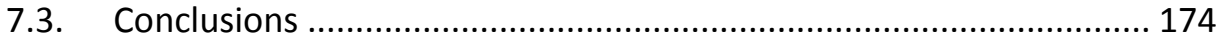

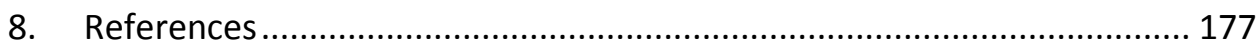

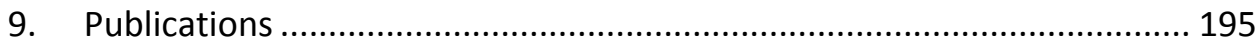





\section{Acknowledgments}

He dejado esta parte para el final. Y me he dado tiempo. Echo la vista atrás cuatro años cuando empezó esta historia. Siempre quise estudiar Química, no recuerdo haber querido otra cosa desde que empecé el bachillerato. Una de las razones fundamentales fueron dos profesores de Química que tuve, D. Paco y D. Andrés. Sentía profunda admiración por ellos. Años después cuando terminé la licenciatura conocí a Vicente, y por medio de él conocí el grupo de Biofísica de la UJI. Lo primero que pensé fue: ¿hay un grupo de biofísica aquí en la Uji? Tiene buena pinta, habrá que ver qué hacen... Y de repente tras meses de dudas sobre dónde caer para hacer la tesis, tuve claro dónde quería hacerla. Gracias a Vicente y a Toni las dudas de pronto se despejaron. Quería conocer y aprender el mundo de los canales. Y quería concerlo y aprenderlo aquí, en el Grupo de Biofísica.

Así que esta historia se hizo posible gracias a mis directores de Tesis. Tanto Vicente como Toni han sido referentes profesionales y personales para mí. He aprendido mucho de ciencia pero sobre todo he aprendido mucho de humanidad. Su trato siempre amable, su disponibilidad y empeño me han acompañado durante estos cuatro años. Aún recuerdo mi primer congreso, en Tenerife, el III RECl, en el que asistí con vosotros. Recuerdo la expectación, los nervios, la alegría y la ilusión que tenía. Pero sobre todo recuerdo vuestros ánimos a la benjamina, vuestro apoyo y paciencia. Estas palabras quedan muy cortas para agradeceros todo el bien que me habéis hecho. Gracias por acoger a una química y hacer posible este sueño. Gracias por vuestras charlas, consejos, ánimos y por haber confiado en mí. Sois muy importantes para mí y este trabajo os los debo a vosotros.

Cómo no, no me olvido del Grupo de Biofísica. A cada uno de vosotros, Lidón, Marcel, Andreu, Elena y María millones de gracias por todo vuestro cariño y por la ayuda prestada. A Elena quiero agradecerle aquel primer día que entré en el laboratorio y fue ella quien me enseñó por primera vez cómo formar una bicapa. Marcel y Andreu, nuestros maestros en informática que nos han ayudado en más de un apuro técnico... no sé qué haríamos sin vosotros. A Lidón, con la que he podido compartir horas de laboratorio y charlas que han hecho más llevadero el trabajo cuando algo no iba tan bien como uno espera. $\mathrm{Y}$ a María...qué te podría decir por aquí que no te haya dicho ya... mi AMIGA, así, en mayúsculas y grandote. Mil gracias por tu ayuda, tu compañía, tu paciencia. Eres 
como una hermana mayor para mí, con la que no sólo he compartido parte de este trabajo, sino muchísimas experiencias personales que deseo seguir compartiendo. Imola, San Diego, Philadelphia, Bilbao, Londres, Valencia, San Francisco son algunos de los lugares donde hemos compartido ciencia y vida. Que el camino no acabe aquí.

También quiero tener un recuerdo para Elisa, nuestra compi de Madrid, que me acompañó durante unos meses en el laboratorio. Las intensas horas de trabajo se hicieron mucho más llevaderas gracias a tu compañía. Tus proteínas del surfactante pulmonar me animaron en mis horas de laboratorio, pues pese a la dificultad tú estabas ahí, constante, sin perder la calma y siempre con una sonrisa. Pese al poco tiempo compartido, dejaste huella Elisa. Mil gracias.

Un agradecimiento muy especial para el Dr. Luis Enjuanes y todo su grupo de laboratorio del CNB. Vuestra ciencia ha sido clave para este trabajo y para mi desarrollo en el laboratorio. Gracias a vosotros he tenido la oportunidad de trabajar con canales tan apasionantes como las viroporinas. Gracias por vuestra confianza, vuestros consejos y empeño. No me olvido de mi compi en la distancia, José, mi compi por excelencia. Qué bonito ha sido trabajar contigo. Gracias José por tu alegría y esfuerzo. Sin ti esta tesis estaría coja. Espero que todo te vaya genial.

Per supost milions de gràcies a la Dra. Clara Viñas i al Dr. Francesc Teixidor. Gràcies per creure en nosaltres i fer possible el nostre projecte. Haveu format part de la meua formació científica. Per a mi treballar amb químics una altra volta ha sigut increïble. I no m’oblide de Màrius! Gràcies Màrius! La teua energia contagia, i ha sigut tot un plaer conèixer-vos i poder formar part de la vostra recerca. El tàndem Barcelona-Castelló funciona! Esperem que puguem continuar!

Y por último un recuerdo para mi familia ¡Qué importantes sois! Habéis sido parte de esto como los que más. Papá, mamá, nunca podré dejar de agradeceros todo lo que habéis hecho y continuáis haciendo por mí. Aquí parece que cerramos un ciclo que empezó hace cuatro años. Vuestro amor, comprensión, ternura y ánimos me han acompañado siempre. Mi vocación científica se gestó también en el seno de mi familia. Gente trabajadora y luchadora. Recuerdo el cartel que tiene mi hermano Pepe en su habitación de nuestra casa de Benicasim: Tú puedes ser lo que desees, sólo un obstáculo: tú mismo. Esta norma me la habéis inculcado desde siempre. Con unos padres como vosotros nada es imposible. Y por supuesto también me acuerdo de Pepe, mi hermano. No sabes cómo y cuánto me has acompañado en este camino, 
pese a la distancia. Y es que tú siempre estás presente, no importa donde estés. Desde Pamplona, Valencia, Málaga, Roma o Barcelona tú siempre estás aquí. Tu ejemplo personal y profesional me ha acompañado y guiado toda mi vida. Cuando de pequeña me preguntaban qué quería ser de mayor yo respondía: ¡Quiero ser como mi hermano! Al final no fui filósofa, pero también intento dar respuestas. Doy gracias por tenerte, sin duda el mejor hermano que podría haber imaginado. No sabes qué orgullosa estoy de ti. $Y$ por supuesto a mi abuela y mi tía, mil gracias. Contad con vosotras en nuestra familia es un privilegio, siempre me habéis animado y os habéis alegrado muchísimo con mis pequeños logros. Sois mis mayores fans y me encanta compartir con vosotras todo esto.

A mis amigos, también a vosotros os doy las gracias. Por aguantarme y no ponerme en el compromiso de querer saber para qué sirve lo que hago. En especial me acuerdo de Cris, Ángela y Elena...mis niñas. Os quiero mucho. ¡Cuántas cosas hemos vivido juntas! Prometo sacar más tiempo para estar con vosotras. Vuestros ánimos y charlas me han acompañado siempre. Espero contad con vosotras por siempre.

Y cómo no, mi agradecimiento más sincero para Salva. Aunque el último de esta lista, no el menos importante, al contrario, tenía reservado cerrar esto contigo. Qué puedo decir...has estado aquí desde que esto empezó. Nos conocimos cuando empezaba esta Tesis. Aún recuerdo cómo te taladraba con lo que hacía en el laboratorio y con qué interés me escuchabas. Gracias por tu cariño, comprensión, ternura y sobre todo por tu inmensa e inagotable paciencia. Gracias por estar siempre ahí, cogiéndo mi mano y recogiéndome cuando a veces las fuerzas parecen fallar. $Y$ sobre todo gracias por haber confiado siempre en mí...ante mi pregunta ¿y luego qué? tu respuesta siempre ha sido: pues luego, ia seguir! Quiero que sepas que admiro tu fuerza, tu voluntad, nobleza, alegría y el cariño que muestras a la gente que quieres. De corazón, gracias por formar parte de mi vida y de esta historia. Sigamos escribiendo muchas otras historias. Ya sabes que este año promete... 



\section{List of figures}

Figure 1.1 Different points of view of OmpF channel. 33

Figure 1.2 Location of magnesium ion in the crystal structure of the OmpF channel (CODE 2ZFG) resolved in $1 \mathrm{M} \mathrm{MgCl}_{2}$ by Yamashita and collaborators (Yamashita et al. 2008)._ 35

Figure 1.3 Characteristic stepwise voltage-induced gating of OmpF at very high voltages $(150 \mathrm{mV})$. Under negative voltage, only one monomer remains finally open, and the voltage switch does not reopen the two other closed monomers. 36

Figure 1.4 Schematic drawing of SARS-COV and its membrane proteins. Picture adapted from Holmes 2003. 38

Figure 1.5 Schematic drawing of RSV. From www.AlilaMedical Media.com. 40

Figure 1.6 NMR-based pentameric model of RSV SH protein in detergent DPC micelles (A) Side view; (B) $N$-terminal (cytoplasmic) view; (C) C-terminal (extracellular or lumenal) view; (D) Electrostatic surface of the assembly showing the mostly hydrophobic central lumen. The SH protein assembly spans the entire bilayer with an overall length of about $45 \AA$. . Taken from Surya et al 2013.

Figure 1.7 Structure of [3, 3'-Co- $\left.\left(1,2-\mathrm{C}_{2} \mathrm{~B}_{9} \mathrm{H}_{11}\right)_{2}\right]$ and its characteristic peanut shape. Taken from Bauduin et al. 2011. 42

Figure 1.8 Boron Neutron Capture Therapy is based on the ${ }^{10} B(n, \alpha){ }^{7}$ Li reaction, which can potentially deliver a very high and fatal radiation dose to cancerous cells by concentrating boron in them. 43

Figure 1.9 The X-ray structure of the complex between HIV-1 protease and [3, 3'-Co-( 1 , 2- $\left.\mathrm{C}_{2} \mathrm{~B}_{9} \mathrm{H}_{11}\right)_{2}$ J metallacarborane. From Cígler et al. Proc. Natl. Acad. Sci. U. S. A., 2005. 43

Figure 2.1 Experimental chamber with the two compartments separated by a teflon film.

Figure 2.2 (A) Device for the creation and visualization of holes in Teflon films (B) Representative holes obtained using the setup described in $(A)$. 50

Figure 2.3 (A) High-purity silver filaments (99.5\%), of $1 \mathrm{~mm}$ in diameter and $2 \mathrm{~cm}$ long, polished and connected to a cable. (B) Electrolysis process: silver filaments are immersed in $0.1 \mathrm{M} \mathrm{HCl}$ and connected to the positive pole of a current source. The negative pole is 
connected to a platinum filament. (C) Electrodes prepared for experiments, already encapsulated using $250 \mu \mathrm{L}$ pipette tips and agarose salt bridges. 51

Figure 2.4 Formation of the lipid bilayer by apposition of two monolayers. As the solution levels are raised, the two monolayers form the bilayer in the hole of the Teflon film. 52

Figure 2.5 Wave generator yielding a triangular shaped periodic voltage (left) and oscilloscope showing the current output from the system (right). The oscilloscope shows a square shaped wave, as an evidence of the formation of a good lipid bilayer. 53

Figure 2.6 Insertion of the protein channel into the bilayer. 53

Figure 2.7 Current recording. The trace shows the change in current level due to the channel insertion after applying $+100 \mathrm{mV}$. 54

Figure 2.8 (A) Axopatch 200B amplifier together with Axon Digidata 1440A digitizer (Molecular Devices, Sunnyvale, CA). (B) Detail of the interior of the double Faraday cage where the experimental chamber is connected to the pre-amplifier through the homemade electrodes. (C) General view of the setup, showing a double Faraday cage on a vibration isolation table. 55

Figure 3.1 Position of the magnesium ion in the crystal structure of the OmpF channel resolved in $1 \mathrm{M} \mathrm{MgCl}_{2}$ by Yamashita and coworkers (Yamashita et al. 2008). 66

Figure 3.2 Reversal potential versus $\mathrm{pH}$ in $\mathrm{KCl}, \mathrm{MgCl}_{2}, \mathrm{CaCl}_{2}$ and $\mathrm{LaCl}_{3}$ salts. 67

Figure 3.3 Reversal potential experiments varying the $\mathrm{pH}$ conditions in $0.1 / 1 \mathrm{M} \mathrm{KCl}$ (blue triangles) and in $0.1 / 1 \mathrm{M} \mathrm{KCl}$ with the presence of $5 \mathrm{mM} \mathrm{LaCl}_{3}$ (pink circles). 68

Figure 3.4 Reversal potential measurements in $\mathrm{KCl}$ asymmetric conditions with symmetric addition of trace amounts of $\mathrm{LaCl}_{3}$. 69

Figure 3.5 (A) Current-Voltage OmpF curves without and with the presence of millimolar concentrations of $\mathrm{LaCl}_{3}$. (B) Comparison of the change in channel conductance measured under positive and negative bias $\left( \pm 100 \mathrm{mV}\right.$ ) for several minute concentrations of $\mathrm{LaCl}_{3}$. All the experiments were performed at room temperature at $\mathrm{pH} 6$. 70

Figure 3.6 OmpF single channel recordings. 71

Figure 3.7 OmpF single channel current recordings in symmetric $0.1 \mathrm{M} \mathrm{KCl}$ solutions after the addition of $15 \mathrm{mM} \mathrm{LaCl}_{3}$ into cis (up) or trans side (down). 72 
Figure 3.8 Rectification ratio of current-voltage curves in OmpF is strongly dependent on the side of the channel where $\mathrm{LaCl}_{3}$ is added. Experiments were carried out in $0.1 \mathrm{M} \mathrm{KCl}$ solutions, $5 \mathrm{mM} \mathrm{LaCl}$, $\mathrm{pH}$. Channel current was recorded under $+100 \mathrm{mV}$. 73

Figure 3.9 Single channel current recordings show the effect of $\mathrm{pH}$ solutions on $\mathrm{La}^{3+}$ induced channel rectification. 75

Figure 3.10 Dependence of the OmpF current rectification on the acidity of the solution $0.1 \mathrm{M} \mathrm{KCl}+5 \mathrm{mM} \mathrm{LaCl}_{3}$. 75

Figure 3.11 Ideal double reciprocal plots of conductance versus [KCl] illustrate noncompetitive and competitive blocks. 76

Figure 3.12 Double reciprocal plots of measured single channel conductance versus [KCl] for control (pink circles) and for 2 and $5 \mathrm{mM} \mathrm{LaCl}_{3}$ concentrations. 77

Figure 3.13 Channel conductance of a single OmpF channel is affected by the presence of $\mathrm{LaCl}_{3}$ salt. 79

Figure 3.14 No effect induced by $\mathrm{La}^{3+}$ ions was observed in the D133R/E117R OmpF mutant. 81

Figure 3.15 Current rectification produced by $\mathrm{La}^{3+}$ ion varies with the OmpF mutant used in the experiment. 82

Figure 3.16 (A) Lateral representation of the OmpF channel obtained from the crystal structure (PDB code: 2OMF). 83

Figure 3.17 Average permeation rate of $\mathrm{La}^{3+}$ cations through OmpF determined by ICPMS. 84

Figure 4.1 Histograms of current jump amplitude at $+100 \mathrm{mV}$ and sample current recording of $E$ peptide in $1 \mathrm{M} \mathrm{KCl}$ (top) and $1 \mathrm{M} \mathrm{NaCl}$ (bottom). 94

Figure 4.2 Histograms of current jump amplitude at $+100 \mathrm{mV}$ and current recording of $E$ protein in $1 \mathrm{M} \mathrm{KCl}$ (top) and $1 \mathrm{M} \mathrm{NaCl}$ (bottom). 95

Figure 4.3 E protein shows a linear current-voltage relationship in $1 \mathrm{M} \mathrm{NaCl}$ (blue triangles) and in $1 \mathrm{M} \mathrm{KCl}$ solutions (pink squares). 96

Figure 4.4 Histograms of current jump amplitude for E protein (left) and E peptide (right) in membranes formed by negatively charged lipid, DPhPS. Each histogram contains 300 recording events. 
Figure 4.6 Sequence and representation of SARS-COV E protein peptides representing the transmembrane domain.

Figure 4.7 Current recordings of wt peptide and SARS-CoV E mutants. Mutants 1, 5 and 7 displayed similar current levels than wt peptide. Mutants 6 and 7 showed higher current levels. 104

Figure 4.8 Sample current recordings of mutants that do not show ion channel activity. Residues N15 and V25 are essential to observe membrane permeabilization by channel insertion. 105

Figure 4.9 SARS-COV genome is represented at the top, and the region expanded shows wt SARS-COV E protein sequence and the amino terminal ( $N$-terminal), transmembrane domain (TMD) and carboxy terminal (C-terminal). 106

Figure 4.10 Subcellular localization of r SARS-CoV-EIC E proteins. 106

Figure 4.11 Vero E6 and DBT-mA CE2 cells were infected at a $\mathrm{MOI}$ of 0.001 with mutant viruses lacking ion channel function (N15A,V25F), parental virus (wt) or a virus lacking $E$ gene (DE), and a viral progeny was titrated at the indicated times post-infection. 107

Figure 4.12 Effect of the E protein ion channel activity on viral fitness.. 108

Figure 4.13 Pathogenesis caused by r SARS-CoV EIC in BALB/C MICE. Groups of five 16 week-old BALB/c mice were mock infected or infected with 100000 PFU (plaque-forming unit) or either the parental virus or several clones of the mutant viruses lacking ion channel function. 109

Figure 4.14 r SARS-CoV EIC stability after serial infections. 111

Figure 4.15 Spatial distribution of the mutations obtained in rSARS-CoV-EIC after serial infections. 112

Figure 4.16 E protein IC activity of the rSARS-CoV-EIC evolved variants. 113

Figure 4.17 Pathogenesis caused by rSARS-CoV-EICrev in BALB/C mice. 114

Figure 4.18 Effects of SARS-CoV E protein IC activity on virus growth in BALB/C mice lungs. 
Figure 5.1 (A) Double logarithmic plot of the change of the OmpF single channel conductance with the conductivity of the bathing $\mathrm{KCl}$ solution at neutral $\mathrm{pH}$. 127

Figure 5.2 Change of single channel conductance with lipid surface charge density (proportional to the percentage of negatively charged DPhPS lipid in a DPhPC:DPhPS membrane). 128

Figure 5.3 Double logarithmic plot of the change of gramicidin A channel conductance with $\mathrm{CsCl}$ concentration at $\mathrm{pH}$ 7.4. Circles denote measurements in negatively charged DPhPS membranes and triangles correspond to neutral DPhPC membranes (Rostovtseva et al. 1998). 129

Figure 5.4 Histograms of the current jump amplitudes for E protein in neutral mebranes (top) and in negatively charged ones (down). 130

Figure 5.5 Variation of $E$ protein channel conductance in high $\mathrm{KCl}$ salt concentrations (1 $\mathrm{M} \mathrm{KCl}$ solutions). 131

Figure 5.6 Variation of E protein channel conductance in low $\mathrm{KCl}$ salt concentration._132

Figure 5.7 Double logarithmic plot of channel conductance versus bulk solution conductivity for E protein. 133

Figure 5.8 Channel conductance of E protein channel in neutral DPhPC (triangles) and negatively charged DPhPS (circles) at pH 6. 135

Figure 5.9 OmpF channel selectivity titration. 136

Figure 5.10 E protein channel titration. 137

Figure 6.1 SH channel activity and inhibition caused by pyronin B.. 148

Figure 6.2 Dose-response curve obtained in the presence of $0,2.5,3,5,7,10$ and $15 \mu M$ pyronin $B$. 149

Figure 6.3 Pyronin B binding significantly perturbed the chemical shifts of SH oligomer. 150

Figure 6.4 Mapping of pyronin B binding to SH protein.. 151

Figure 6.5 Histograms corresponding to the current jump amplitudes of SH TM, A39S, $121 \mathrm{~F}$ and $121 \mathrm{Y}$ mutants. 153 
Figure 6.6 Histograms corresponding to the current jump amplitudes of SH TM, A39S, $121 \mathrm{~F}$ and $121 \mathrm{Y}$ mutants in the presence of $10 \mu \mathrm{M}$ pyronin $\mathrm{B}$.

Figure 6.7 Channel conductance of SH protein and mutants and effect of pyronin $B$ on channel conductance at $1 \mathrm{M} \mathrm{KCl}$ in 3:1:1 DOPC:DOPS:DOPE membranes. 154

Figure 6.8 Channel conductance of SH protein at different $\mathrm{pH}$ conditions. 155

Figure 6.9 Current - voltage curves of SH protein, and mutants $\mathrm{H} 22 \mathrm{~F}, \mathrm{H} 51 \mathrm{~F}$ and $\mathrm{H} 22 \mathrm{~F}$ H51F. 156

Figure 6.10 Multiple alignment of SH proteins and homologs in human RSV, bovine RSV, parainfluenza virus 5 (PIV 5), and mumps virus (MuV). 157

Figure 7.1 (A) COSAN cluster (B) 3,3'-Co-(8-I-1,2- $\left.C_{2} B_{9} H_{11}\right)_{2} J, I_{2}-\operatorname{COSAN}$ 166

Figure 7.2 Typical current recording against time when COSAN is added into one side of the experimental chamber containing $10 \mu \mathrm{M} \mathrm{NaCl}$ at $\mathrm{pH} 6$. 167

Figure 7.3 Transport rate for different initial concentrations of H[COSAN], Na[COSAN] and $\mathrm{Na}\left[\mathrm{I}_{2}-\mathrm{COSAN}\right]$. 168

Figure 7.4 Permeation rate of $\mathrm{Na}[\mathrm{COSAN}], \mathrm{H}[\mathrm{COSAN}]$ and $\mathrm{Na}\left[\mathrm{I}_{2}-\mathrm{COSAN}\right]$ across neutral planar bilayers. 169

Figure 7.5 Cartoon that represents the two main processes implicated in the COSAN translocation: the partitioning into lipid phase and the diffusion across the membrane.

Figure 7.6 Permeation rate $(\mathrm{nM} / \mathrm{min})$ for of $\mathrm{H}$ [COSAN], $\mathrm{Na}$ [COSAN] and $\mathrm{Na}\left[I_{2}-\operatorname{COSAN}\right]$ in different lipid membrane compositions. 171

Figure 7.7 Direct visualization of the interaction between COSAN vesicles and liposomes. 172

Figure 7.8 Transport rate of bare $H[C O S A N]$ and the encapsulated $H[C O S A N]$ through synthetic neutral planar membranes. 173 




\section{Resumen de la tesis (Spanish)}

\section{Objeto y objetivos de la investigación}

El principal objetivo de la presente Tesis es caracterizar la actividad de transporte de diferentes canales iónicos, así como regular dicha actividad de transporte. Por otro lado la Tesis abarca el estudio del transporte a través de bicapas de moléculas con alto potencial biológico. En este sentido la presente Tesis abarca diferentes sistemas de estudio que comparten la capacidad de interactuar con las membranas lipídicas dando como resultado el transporte iónico a través de la formación de poros, o bien por medio de la translocación a través de la propia membrana.

Los objetivos concretos que recoge este trabajo son:

1) Estudio de la regulación del transporte iónico a través de canales mesoscópicos como la porina OmpF. Las proteínas transmembrana formadoras de canales constituyen el medio de comunicación de las células, por lo que la capacidad de regular sus funciones de transporte es clave para la construcción de dispositivos biológicos que puedan utilizarse en aplicaciones biotecnológicas varias.

2) Caracterización de la actividad de canal iónico de proteínas transmembrana procedentes de virus respiratorios. Estas proteínas conocidas como viroporinas están involucradas en el proceso de infección viral, por lo que la descripción de su actividad de canal es un paso imprescindible en la investigación de su papel en el proceso infeccioso. En esta Tesis se investiga la proteína de envuelta (E) del virus que produce el Síndrome Respiratorio Agudo y Grave (SARS), y la proteína hidrofóbica $(\mathrm{SH})$ del virus Sincitial Respiratorio (h VSR).

3) Análisis de la influencia de la carga de la membrana lipídica en la actividad de canal iónico de dos canales diferentes, como son los formados por la porina OmpF y la proteína E del SARS.

4) Estudio del transporte de moléculas con propiedades anfipáticas a través de bicapas lipídicas. En este punto se investiga cómo un metalcarborano que contiene boro en su estructura es capaz de atravesar las bicapas lipídicas. Dicho metalcarborano puede ser utilizado como agente anticancerígeno en la terapia conocida como BNCT, Boron-neutron capture therapy. 


\section{Planteamiento y metodología utilizados}

El estudio y caracterización de la regulación y transporte de las proteínas formadoras de canal se han llevado a cabo a partir de medidas electrofisiológicas experimentales.

El procedimiento experimental se basa en la técnica de reconstitución de canales conocida como voltage-clamp. A partir de esta técnica la proteína formadora de canal se reconstituye en una bicapa lipídica artificial. Para conseguirlo, se utiliza una celda con dos compartimentos separados por un film de Teflón de 12 a $15 \mu \mathrm{m}$ de grosor donde hay un orificio de unos 100-200 $\mu \mathrm{m}$ de diámetro. Es en este orificio donde el canal se reconstituye.

\section{Aportaciones originales}

Pese a que la reconstitución electrofisiológica de canales es una técnica que ha sido ampliamente utilizada para investigar la actividad de transporte de los canales iónicos, la presente Tesis presenta como novedad los sistemas que trata.

En este sentido, la caracterización de la actividad de canal iónico de las viroporinas es un tema emergente del que actualmente hay pocas publicaciones. Por otro lado, esta Tesis también trata de correlacionar dicha actividad de canal iónico con la infección viral, es decir, se combina la reconstitución electrofisiológica con otras técnicas de biología molecular para poder analizar cómo la función de canal influye en el proceso de infección viral.

También la investigación de la translocación de compuestos anfipáticos a través de bicapas lipídicas utilizando la técnica voltaje-clamp es un tema novedoso y pionero, pues hasta este momento no se había empleado esta técnica para el estudio del transporte de este tipo de moléculas a través de membranas artificiales.

Por último también resulta novedoso el uso de un canal iónico para regular sus propiedades de transporte aprovechando la interacción de iones multivalentes con el canal.

\section{Conclusiones y futuras líneas de investigación}

Las principales conclusiones de esta Tesis doctoral son:

1) La actividad de transporte del canal OmpF puede ser regulada por la presencia de sal de lantano. Bajo la presencia de cloruro de lantano tanto la 
conductancia como la selectividad iónica del canal son modificadas. Así, se ha conseguido regular a voluntad la función de transporte de una canal biológico, lo cual puede tener importantes aplicaciones biotecnológicas.

2) La actividad de canal iónico de la proteína de envuelta del SARS está relacionada en la patogénesis viral. Este punto es de vital relevancia para la investigación del mecanismo de infección del virus y el posible desarrollo de vacunas.

3) Se ha descrito el primer inhibidor de la actividad de transporte para la proteína hidrofóbica del virus sincitial, lo cual tiene una gran importancia para la investigación de posibles candidatos a vacunas contra el virus.

4) Se ha descrito por primera vez la translocación de un metalcarborano a través de bicapas artificiales. Dicho metalcarborano tiene interés biomédico para su uso en radioterapia para el tratamiento de determinados cánceres. Su estudio es de vital importancia para el desarrollo de nuevas alternativas. 




\subsection{MOTIVATION}

My Chemistry degree allowed me to know about the composition, structure, properties and dynamics of matter. Then, while I was doing a master degree in Molecular Biology and Pharmacology, I realized that biological systems are as complex as exciting because they build the most important devices responsible for life. I discovered that Biophysics offers me the possibility of investigating these biological systems at molecular level. Starting the Thesis in this area was the first step in my career as researcher.

In the beginning of my Thesis I started to work with the OmpF porin, a protein channel which has been thoroughly investigated and characterized in my group. Working with the OmpF channel let me to get familiar with the electrophysiology techniques. Then, thanks to Dr. Enjuanes and Dr. Torres I could apply the background obtained with the OmpF porin to investigate the channel function of other proteins that are physiologically relevant, the viroporins. Finally, Dr. Viñas and Dr. Teixidor proposed the study of the interaction between lipids and amphiphilic molecules synthetized by their laboratory. These compounds are boron-based macroanions that can form vesicles and membranes in aqueous solution similarly to lipid molecules. Cosanbased membranes have dimensions close to that of lipid-based cell membranes, raising the question of what happens if these synthetic and inorganic membranes meet their biological counterparts.

This Thesis emerges from the interest of different groups in gaining knowledge in the different mechanisms of membrane transport and their implications for life. Thanks to these collaborations this Thesis has been possible. It was fascinating and amazing to work every day feeling part of a project. I could learn a lot during this project, but the most important is being part of a scientific family that has always supported me during these four years.

\subsection{OBJECTIVES}

This Thesis deals with different systems. The first system studied is the OmpF porin, from the E. Coli. This porin allows us to investigate ways for modulating the ion transport properties at will. After that this Thesis deals with the characterization of the ion channel activity of viral proteins which is an emerging theme with a promising future since these proteins can be potential vaccine candidates against their viruses. Finally, we show how amphiphilic molecules interact with membranes. This last issue is crucial in the pharmacological area and in the build of drug-delivery systems because that the amphiphilic molecule investigated is a boron-based carborane which can be used in cancer therapy. 
Following these ideas the specific objectives of this Thesis can be summarized as follows:

1) OmpF porin ion transport modulation. Protein forming channels allow cell communication. In this sense the ability to control, understand and regulate at will the response of ion channels could be the starting point to create biological devices with a variety of biotechnological and analytical applications.

2) Ion transport activity characterization of proteins encoded by virus. In this Thesis we investigate the channel activity of two viral proteins from two respiratory viruses: the envelope protein of a coronavirus, and the small hydrophobic protein of syncytial virus. Along the chapters dedicated to these viroporins we focus on the ion transport inhibition by using drugs or by specific mutations. We also investigate how the channel function is involved in the virus infection.

3) Analysis of the role of the membrane lipid charge on the ion channel transport. We examine how the membrane environment affects to channel activity in two different membrane proteins (OmpF porin and Envelope protein of a Severe Acute Respiratory Syndrome Coronavirus).

4) The translocation of amphiphilic molecules across membranes. The macroanion cobaltabisdicarbollide (COSAN) present an unusual physicochemical property of being simultaneously hydrophobic and hydrophilic. The ability of this molecule to interact with planar membranes is characterized here for the first time.

\subsection{SYSTEMS UNDER STUDY}

\subsubsection{The bacterial porin OmpF from E.Coli}

The Outer membrane protein $\mathrm{F}(\mathrm{OmpF})$ is a general diffusion porin that forms wide, water-filled, voltage-gated pores in the outer membrane of $E$. coli (Delcour 2003; Nikaido 2003). It provides a translocation pathway for small molecules, water, and ions inward and outward through the outer membrane. $\mathrm{OmpF}$ is believed to be also the main pathway for $\beta$-lactam antibiotics (Nikaido 1989; Nestorovich et al. 2002; Ziervogel \& Roux 2013).

OmpF is a homo-trimeric protein, with three subunits being structurally and functionally identical (Rostovtseva et al. 2002; Nestorovich et al. 2002). In 1995 it was obtained one of the first 3D atomic structures of the OmpF porin with a resolution of $2.4 \AA$ from X-ray analysis of crystals grown in absence of 
salt. It is available in the Protein Data Bank (PDB) with 2OMF code (Cowan et al. 1995) (Figure $1.1 \mathrm{~A}$ and $\mathrm{B}$ ).

Each monomer contains 16 anti-parallel $\beta$-strands forming a $\beta$-barrel structure. Within each pore a long polypeptide loop (L3) runs along one side of the barrel wall and narrows the pore to create an "eyelet" region. This causes an asymmetric structure in the channel, which has relatively large entrances of $\sim 4$ $\mathrm{nm}$ in diameter and a narrow region with diameter $\sim 1 \mathrm{~nm}$ at approximately half of the channel length, which is around $5 \mathrm{~nm}$. The presence of this loop confers OmpF its characteristic hourglass shape, as Figure $1.1 \mathrm{C}$ shows.

A

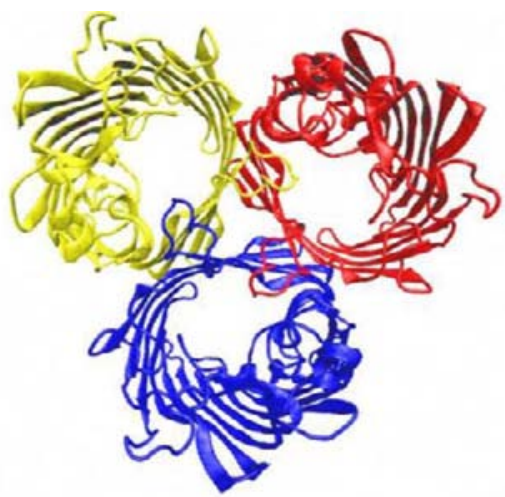

B

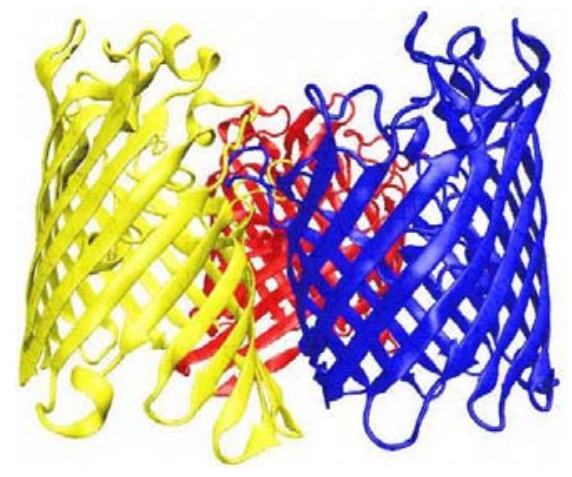

C

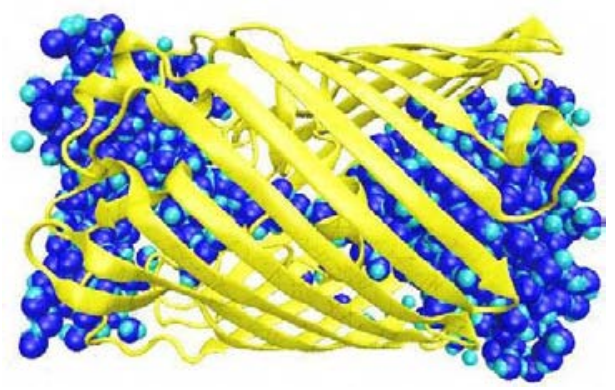

Figure 1.1 Different points of view of OmpF channel. (A) Front view of OmpF structure showing the three monomers obtained from Protein Data Bank (PDB CODE: 2OMF). (B) Lateral view of OmpF structure. (C) Hourglass shape of OmpF pore with water molecules inside the channel.

Each OmpF monomer contains 340 aminoacid residues being 102 of them ionizable residues (Karshikoff et al. 1994; Alcaraz et al. 2004; Varma \& Jakobsson 2004). The channel $\beta$-strands are amphipathic: they contain alternating polar and non-polar residues and the inter-strand interaction is fully 
saturated with $\mathrm{H}$-bonding. Altogether this creates a hydrophilic environment providing a water filled channel with weak selectivity, that allows the passage of small ions, water molecules, glucose and other nutrients (Cowan et al. 1995; Delcour 2003; Nikaido 2003) with an upper exclusion size limit corresponding to solute molecular weights $\mathrm{ca}$. $600 \mathrm{Da}$.

Loop L3 contains two acid residues (Aspartic D113 and Glutamic E117) facing three basic residues (Arginines R42, R82 and R132) (Tieleman \& Berendsen 1998; Karshikoff et al. 1994) which create a strong transversal electric field across the eyelet region. This field orientates water molecules and is responsible for the well separated paths for anions and cations when passing through the channel (Schirmer 1998; Phale et al. 2001; Im \& Roux 2002 a).

OmpF channel is slightly selective to cations at neutral $\mathrm{pH}$ and has not any ion specificity in salts of monovalent ions(Nestorovich et al. 2003; Nikaido 2003; Alcaraz et al. 2009; García-Giménez et al. 2010). In salts of monovalent cations the OmpF selectivity is almost determined by the electrostatic exclusion and accumulation originated by the channel charges. The effective charge of the channel is the main origin of OmpF ion selectivity (Alcaraz et al. 2004). Experiments varying pH conditions (Nestorovich et al. 2003; García-Giménez et al. 2009) and $p K_{a}$ calculation of the channel residues (Aguilella-Arzo et al. 2007) reinforce this idea. However, it is worth noting that studies indicate the presence of a binding site for cations (Saint et al. 1996; Suenaga et al. 1998; López et al. 2009) close to aspartate D113 (Danelon et al. 2003).

In contrast to what is observed in monovalent salts, in salts of divalent cations the selectivity is turned into anionic (Miedema et al. 2004; Vrouenraets et al. 2006; Alcaraz et al. 2009). The existence of the binding site for cations explains this selectivity. In fact, a publication of a $1.6 \AA \mathrm{OmpF}$ structure in $1 \mathrm{M}$ $\mathrm{MgCl}_{2}$ showed that one $\mathrm{Mg}^{2+}$ ion is bound in the pore eyelet between residues D113 and E117 of loop 3 (Yamashita et al. 2008), as Figure 1.2 displays. This feature has a crucial role on the anionic selectivity of the channel in divalent cation salts (Miedema et al. 2004; Vrouenraets et al. 2006; Alcaraz et al. 2009). 


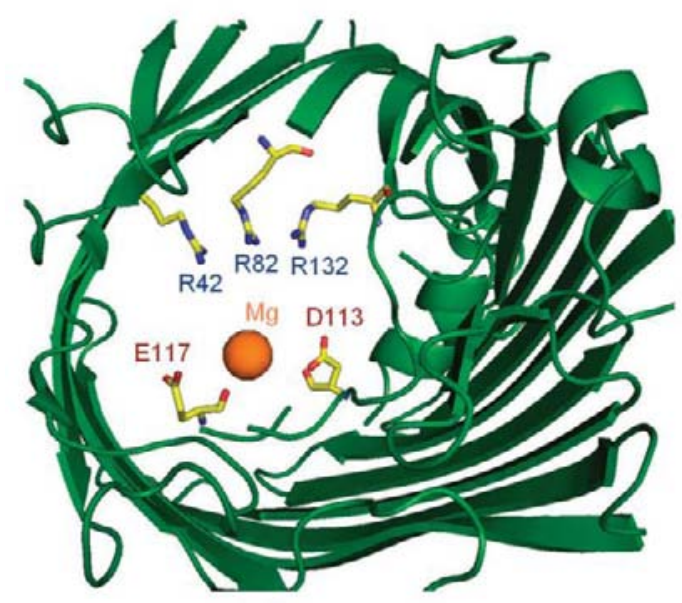

Figure 1.2 Location of magnesium ion in the crystal structure of the OmpF channel (CODE 2ZFG) resolved in $1 \mathrm{M} \mathrm{MgCl}_{2}$ by Yamashita and collaborators (Yamashita et al. 2008).

OmpF channel conductance is of the order of nanosiemens (Schindler \& Rosenbusch 1978) although its specific value depends on the conditions of each experiment, changing with concentration and solution pH (Alcaraz et al. 2006; Nestorovich et al. 2003). The 3D structure shows a slightly structural asymmetry. The conductance measurements show $1 \%$ rectification in $1 \mathrm{M} \mathrm{KCl}$ and almost $40 \%$ rectification in $0.01 \mathrm{M} \mathrm{KCl}$ (Danelon et al. 2003). These results indicate that the channel presents an asymmetric effective charge that produces the conductance asymmetry. However this asymmetry is only appreciable in diluted solutions.

Another important feature is that OmpF channel conductance is a strong function of $\mathrm{pH}$. Titration studies show that the reversible protonation of channel residues influences transport by direct interactions with ions passing through the channel (Nestorovich et al. 2003). In addition, OmpF exhibits gating under high applied voltages. The OmpF high-voltage induced closure, displayed in Figure 1.3, does not yield current asymmetry and is not immediately reversible. Because $\mathrm{OmpF}$ is a trimeric channel, an increase of the applied voltage leads to a channel closure that can be total (the three monomers at the same time), partial, or even sequential, as shown in Figure 1.3. Once the monomer is closed, for example, by a positive bias, reversing the polarity does not always restore the open monomer conductance, but the pore could remain some time with the same conductance state (as is seen in Figure 1.3 where eventually only one monomer remains open) or even fluctuate between different states. This characteristic three-step gating is useful to determine the number of inserted channels during experiments, by counting the current steps when applying a high external voltage. 


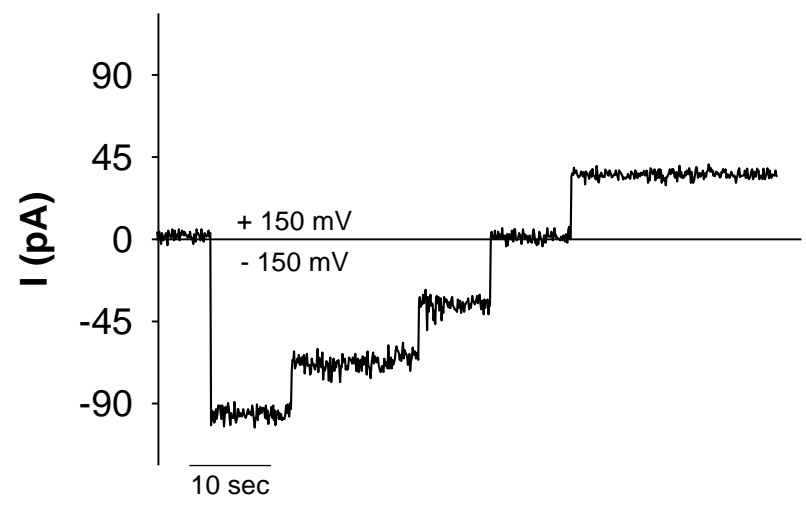

Figure 1.3 Characteristic stepwise voltage-induced gating of OmpF at very high voltages (150 mV). Under negative voltage, only one monomer remains finally open, and the voltage switch does not reopen the two other closed monomers.

\subsubsection{Viroporins}

Modulation of the cellular ion balance seems to be a common feature for viruses. Several highly pathogenic viruses encode at least one protein displaying ion channel (IC) activity. These proteins are known as viroporins. They play important roles in virus life cycle and can promote pathogenesis. The name of viroporins was first proposed when it was observed that several virus proteins shared common characteristics (Carrasco et al. 1993). A growing list of viroporins are being identified, especially in RNA viruses (Nieva et al. 2012). The $M 2$ protein of influenza $A$ virus, the $p 7$ protein of hepatitis $C$, the viroporin vpu of human immunodeficiency virus (HIV), and polivirus 2B proteins are only some examples of this list. In Table 1.1 a list of viroporins is shown.

These proteins are small (they are comprised of some 60-120 amino acids) and highly hydrophobic. They interact with membranes modifying the cell's permeability to ions or other small molecules. Viroporins are involved in virus entry, trafficking, morphogenesis, maturation and even virulence (Campanella et al. 2004; Wozniak et al. 2010). They are not essential for replication viruses, but their presence enhances virus growth.

Viroporins contain a highly hydrophobic domain able to form an amphiphilic $\alpha$-helix. The insertion of these proteins into membranes creates a typical hydrophilic pore with hydrophobic amino acid residues facing the phospholipid bilayer and hydrophilic residues forming part of the pore (Pinto et al. 1997; Agirre et al. 2002; Melton et al. 2002; Grice et al. 1997). 
Table 1.1 List of viroporins that have been identified. Adapted from Gonzalez \& Carrasco 2003 and Nieva et al 2012.

\begin{tabular}{|c|c|c|}
\hline Animal Virus & FAMILY & VIROPORIN-VIRUS \\
\hline & Retroviriade & Vpu-HIV \\
\hline & Picornaviriade & 2B-Virus coxsackie; 2B-Poliovirus; 2B-ECMV \\
\hline & Arterividae & E-PRRSV \\
\hline & Coronaviridae & $\begin{array}{c}\text { E, 3a, 8a- SARS-CoV; E-MHV } \\
\text { E-IBV; E, 4a-HCoV-229E } \\
\text { 3-PEDV }\end{array}$ \\
\hline \multirow{5}{*}{ RNA viruses } & Flavíviridae & $\begin{array}{l}\text { p7-HCV } \\
\text { p7-CSFV }\end{array}$ \\
\hline & Togavísidae & $\begin{array}{c}\text { 6K-Virus Sindbis } \\
\text { 6K-Virus Ross River } \\
\text { 6K-Virus Semliki Forest }\end{array}$ \\
\hline & Orthomyxoviridae & $\begin{array}{c}\text { M2, PB1-F2-Virus Influenza A } \\
\text { BM2-Virus influenza B } \\
\text { CM2-Virus Influenza C }\end{array}$ \\
\hline & Paramyxoviridae & SH-RSV \\
\hline & Reoviriade & NS3 \\
\hline \multirow{2}{*}{ DNA viruses } & Polyomaviridae & $\begin{array}{c}\text { Agno porotein-JCV } \\
\text { VP4-SV40 }\end{array}$ \\
\hline & Papilomaviridae & E5-HPV16 \\
\hline
\end{tabular}




\subsubsection{The Envelope protein of coronaviruses}

Coronaviruses are enveloped viruses that cause common colds in humans and several serious diseases in birds and mammals (Enjuanes et al. 2006). By the end of 2002, a novel coronavirus causing the Severe Acute Respiratory Syndrome (SARS), a respiratory illness that has been reported in Asia, North America and Europe, was described (Drosten et al. 2003; Ksiazek et al. 2003; Peiris et al. 2003). Between 2002 and 2003 SARS-CoV infected 8000 people worldwide and resulted mortal in the $10 \%$ of the cases. Since then, CoVs surveillance programs were intensified, and two more human coronaviruses have been identified as the causative agents of several cases of pneumonia and bronchiolitis (HCoV-HKU1 and HCoV-NL63)(Woo et al. 2005; Van der Hoek et al. 2004). Moreover, in 2012 a novel coronavirus infecting humans, the Midle East respiratory Syndrome Coronavirus (MERS-CoV) appeared in Saudi Arabia (Zaki et al. 2012; Chan et al. 2012; Chan et al. 2013).

The members of the Coronaviridae family are spherical viruses that have a plus-strand RNA genome around $30 \mathrm{~kb}$ in length. The coronavirus envelope essentially contains two major viral structural proteins embedded within the lipid envelope, the spike (S) glycoprotein and the membrane (M) glycoprotein. The $S$ protein is involved in virus fusion with host membranes during entry into cells, and the $M$ protein is essential in envelope formation and budding. A third minor but important protein is the envelope protein $(E)$. This $E$ protein is not essential for in vitro and in vivo coronavirus replication. However, its absence results in an attenuated virus, as observed in SARS-CoV (DeDiego et al. 2007). In addition there are other proteins within the lipid envelope, depending on the coronavirus species. In the case of SARS-CoV, it contains the proteins $3 a, 6,7 a$ and 7b (Schaecher et al. 2007; Chan et al. 2009) (Figure 1.4).

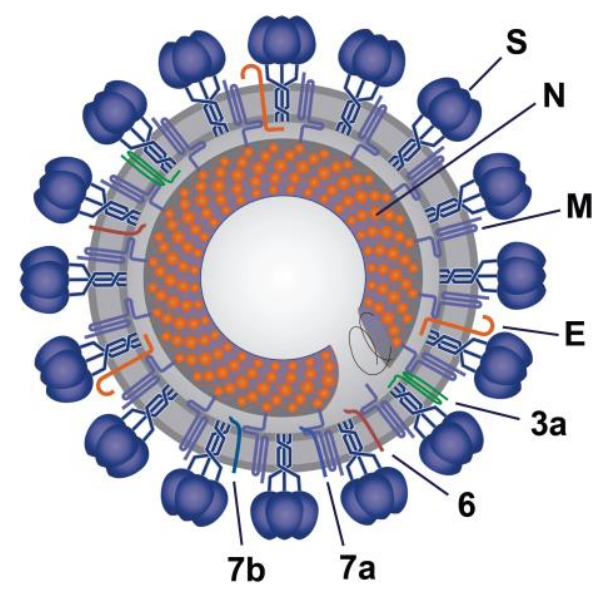

Figure 1.4 Schematic drawing of SARS-CoV and its membrane proteins. Picture adapted from Holmes 2003. 
E protein is incorporated at low copy number in the viral envelope (Maeda et al. 2001; Raamsman et al. 2000). However it has been observed that high amounts of $E$ protein are accumulated in cells during the infection, which indicates an important role during virus cycle. CoV E protein is distributed between endoplasmatic reticulum and Golgi apparatus membranes. Here it actively participates in virus budding, morphogenesis and trafficking (Corse \& Machamer 2000; Lim \& Liu 2001; Nal et al. 2005; Nguyen \& Hogue 1997; Raamsman et al. 2000; Ruch \& Machamer 2012).

Deletion of E gene in different CoVs may result in a complete abrogation of virus maturation and release, as observed for transmissible gastroenteritis virus (TGEV) (Ortego et al. 2007; Ortego et al. 2002) or in a reduction of virus growth, as described for mouse hepatitis virus (MHV) (Kuo \& Masters 2003) and SARS-CoV (DeDiego et al. 2007).

CoV E proteins are candidate members of a family of virus-encoded proteins that form ion channels (Gonzalez \& Carrasco 2003). In fact, it has been reported that $E$ protein of coronaviruses self-associates forming an oligomeric structure that delimits an ion conductive pore (Pervushin et al. 2009; Torres et al. 2006; Wilson et al. 2004; Wilson et al. 2006). Synthetic CoV E proteins of human coronavirus $229 \mathrm{E}$ (HCoV-229 E), MHV, SARS-CoV and avian infectious bronchitis virus (IBV), have displayed channel activity when reconstituted into planar lipid membranes.

In the case of the SARS-CoV, E protein is a 76 amino-acid that is located in the endoplasmatic reticulum-Golgi intermediate compartment (ERGIC) when expressed alone or during virus infection (Nieto-Torres et al. 2011). It has been reported that SARS-CoV E protein forms pentamers (Parthasarathy et al. 2008a; Torres et al. 2006) and this structure may be responsible for the ion channel activity.

\subsubsection{The Small Hydrophobic protein of human respiratory syncytial virus}

The small hydrophobic ( $\mathrm{SH}$ ) protein is a polypeptide encoded by the human respiratory syncytial virus (hRSV) and other paramyxoviruses. Human respiratory syncytial virus causes lower respiratory tract disease in infants, elderly and immunocompromised populations worldwide (Dowell et al. 1996). Up to 64 million reported cases of hRSV infection and 160000 deaths occur each year. hRSV can cause repeated reinfections through life. Although this virus was identified almost half a century ago, there are still no vaccines and its molecular mechanism of pathogenesis is still unknown. 
The hRSV genome contains a nonsegmented negative-stranded RNA of $\sim 15 \mathrm{~kb}$ that transcribes 11 proteins. Among these proteins we find the membrane proteins $\mathrm{F}, \mathrm{G}$ and $\mathrm{SH}$ (Figure 1.5). Proteins $\mathrm{F}$ and $\mathrm{G}$ play important roles during virus entry, attachment and fusion (Lamb 1993; Krusat \& Streckert 1997).

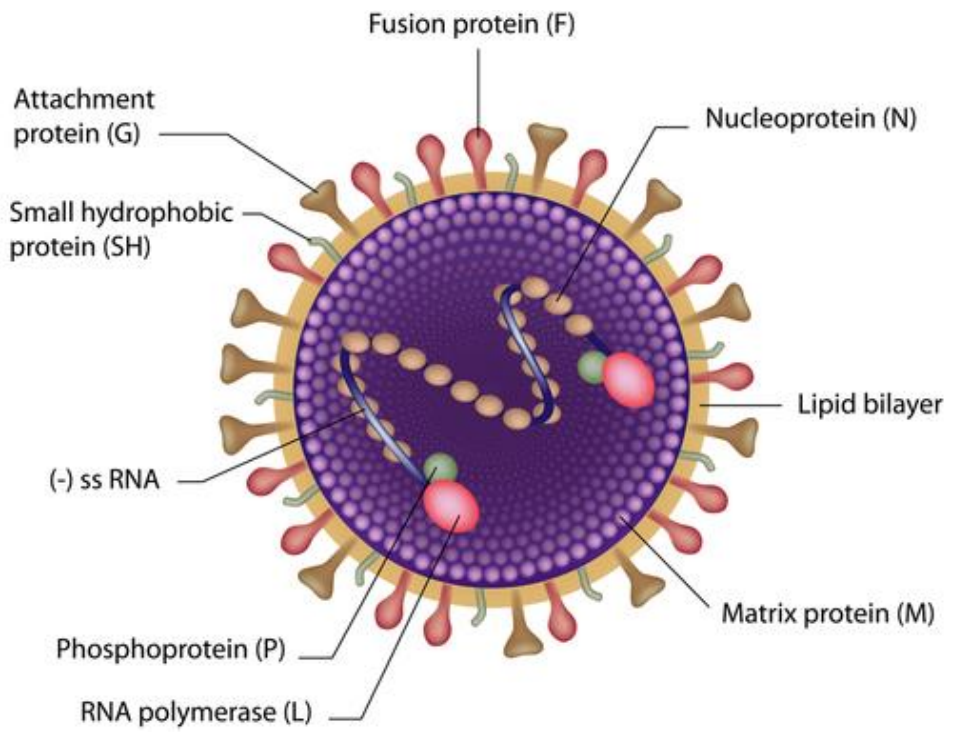

Figure 1.5 Schematic drawing of RSV . From www.AlilaMedical Media.com.

The SH protein of hRSV is a 64 amino acids long type II integral membrane proteins with a single predicted $\alpha$ - helical transmembrane domain (TM). The sequence of the SH protein is highly conserved, especially at the TM (Chen et al. 1999; Collins et al. 1990). In infected cells SH protein accumulates at the membranes of the Golgi complex, but it is also found in endoplasmatic reticulum and plasma membranes (Rixon et al. 2004). The role of the SH protein is not clear but its absence leads to a virus attenuation.

Some studies suggest an ancillary role in virus-mediated cell fusion (Techaarpornkul et al. 2001). Other studies have claimed that SH protein is able to inhibit apoptosis in several mammalian cell lines (Fuentes et al. 2007). In addition, it has been suggested that $\mathrm{SH}$ protein forms ion channels, since $\mathrm{SH}$ protein expressed in E.Coli can change the permeability of the bacterial membrane (Perez 1997). Furthermore, it has been reported that SH protein generates at least four oligomers in SDS that include dimers, trimers, tetramers and pentamers, (see Figure 1.6) (Collins \& Mottet 1993; Rixon et al. 2005). Thus, $\mathrm{SH}$ protein is expected to be a viroporin. 


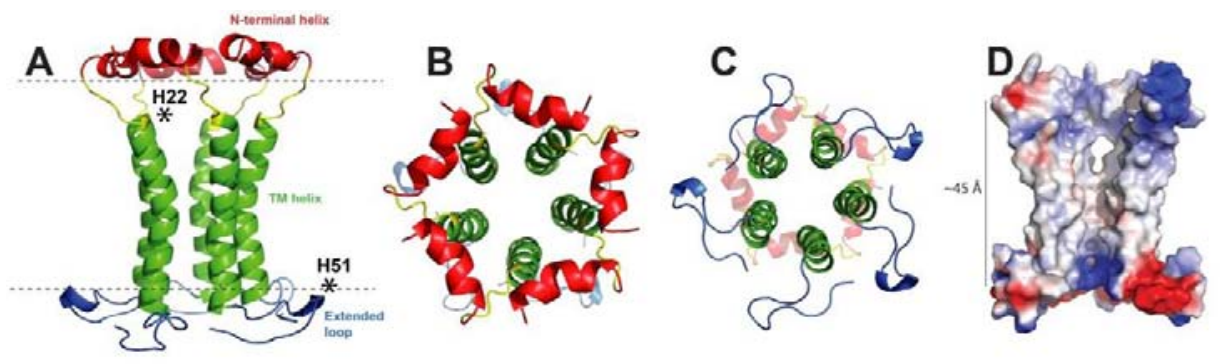

Figure 1.6 NMR-based pentameric model of RSV SH protein in detergent DPC micelles (A) Side view; (B) N- terminal (cytoplasmic) view; (C) C-terminal (extracellular or lumenal) view; (D) Electrostatic surface of the assembly showing the mostly hydrophobic central lumen. The $\mathrm{SH}$ protein assembly spans the entire bilayer with an overall length of about $45 \AA$. Taken from Surya et al 2013.

\subsubsection{Cobaltabisdicarbollide (COSAN)}

Metallacarboranes are a class of inorganic polyhedral clusters that contain carbon, boron, hydrogen, and metal atoms in various combinations. A typical metallacarborane is formed by a sandwich of two $\left[\mathrm{C}_{2} \mathrm{~B}_{9} \mathrm{H}_{11}\right]^{2-}$ (dicarbollide) clusters with a metal ion in the center. We can find two types of metallacarboranes depending on the location of the metal ion. On the one side, endo-metallacarboranes where the metal ion is sandwiched by the carborane cluster. On the other side, exo-metallacarboranes with the metal ion linked to the periphery of the carborane. The known and characterized metallacarboranes vary in size from 4 to 14 vertices in a single polyhedral framework. However most of them contain $C_{2} B_{3}, C_{2} B_{4}$ or $C_{2} B_{9}$ ligands (Grimes 2011a).

Metallacarboranes have a combination of features and properties including the rigidity of the cages and their relative rotary motion, hydrophobicity, as well as chemical and thermal stability due to delocalized charge. Due to these unique properties, these compounds have recently been inciting a growing interest for their potential uses in medicinal chemistry as novel pharmacophores or radioimaging agents (Armstrong \& Valliant 2007; Grimes 2011b).

One example of metallacarborane is the anion [3, 3'-Co $\left.\left(1,2-\mathrm{C}_{2} \mathrm{~B}_{9} \mathrm{H}_{11}\right)_{2}\right]$ ([COSAN] $\left.]^{-}\right)$. It is formed by two bulky and highly hydrophobic dicarbollide semicages, each of them bearing two negative charges that "sandwich" a cobalt (III) ion as the polar part (Figure 1.7). The remaining negative charge is dispersed 
over the whole molecule (Masalles et al. 2002). However its weakly polarised B$\mathrm{H}$ and $\mathrm{C}-\mathrm{H}$ bonds promote intermolecular interactions (Juárez-Pérez et al. 2010). This duality imparts an unusual physico-chemical property of being simultaneously hydrophobic and hydrophilic, and makes COSAN soluble in both water and oils. It has been reported that COSAN has the ability to form monolayer membranes and vesicles, posing the question of how these monolayer, inorganic, man-made membranes interact with biological membranes and what would be the consequences to living cells.

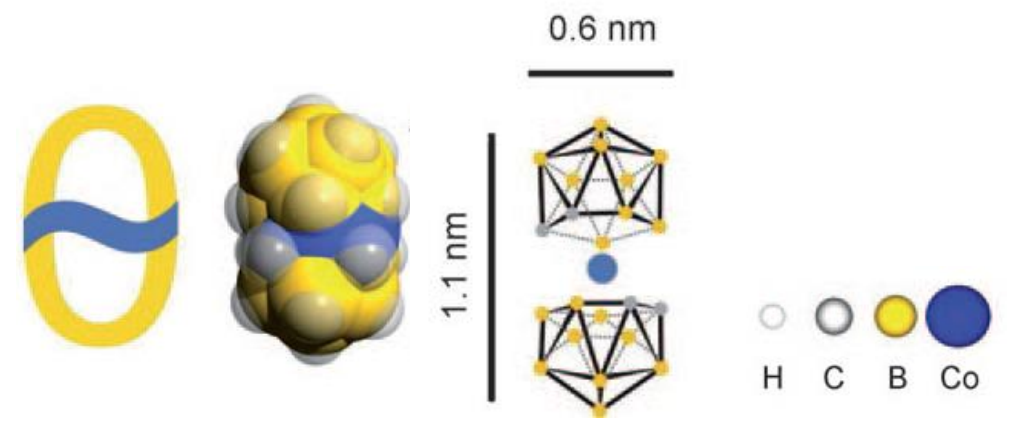

Figure 1.7 Structure of [3, 3'-Co- $\left.\left(1,2-\mathrm{C}_{2} \mathrm{~B}_{9} \mathrm{H}_{11}\right)_{2}\right]^{-}$and its characteristic peanut shape. Taken from Bauduin et al. 2011.

Some classes of metallacarboranes have important pharmacological advantages compared to traditional organic compounds. First of all, the icosahedral boron cluster framework is very stable to heat, oxidation and enzyme degradation. Secondly, these compounds do not interfere with cellular mechanism since their chemically distinct composition from biological systems. For this reason metallacarboranes are not toxic to humans. Some advances in the research of metallacarboranes in pharmacology include two principal areas: anti-cancer agents and the inhibition of human immunodeficiency virus 1 (HIV1) protease in anti-AIDS drug research. As anti-cancer agents, these compounds containing boron are been investigated for application in boron neutron capture therapy (BNCT).

BNCT is a binary radiation therapy modality that brings together two components that when kept separate have only minor effects on cells. The first component is a stable isotope of boron (boron-10) that can be concentrated in tumor cells by attaching it to tumor seeking compounds. The second is a beam of low-energy neutrons. Boron-10 in or adjacent to the tumor cells disintegrates after capturing a neutron and the high energy heavy charged particles produced destroy only the cells in close proximity to it, primarily cancer cells, leaving adjacent normal cells largely unaffected. Figure 1.8 shows the basis of the BNCT. COSAN is a potential candidate for BNCT due to its structure contains boron. 


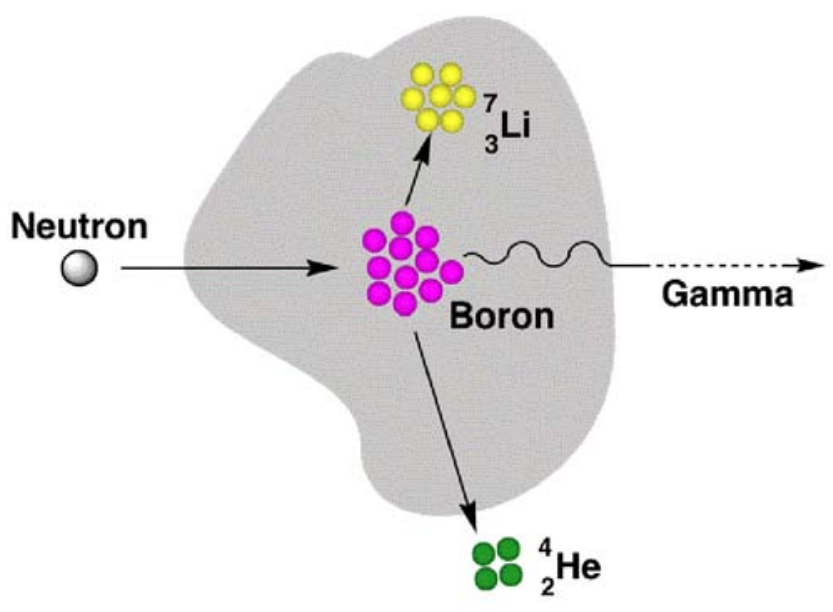

$$
\begin{gathered}
{ }^{10} \mathrm{~B}+n_{t h}(0.025 \mathrm{eV}) \rightarrow{ }^{4} \mathrm{He}^{2+}+{ }^{7} \mathrm{Li}^{3+}+2.79 \mathrm{MeV}(6 \%) \\
{ }^{10} \mathrm{~B}+n_{t h}\left(\begin{array}{c}
0.025 \mathrm{eV}) \\
\rightarrow{ }^{4} \mathrm{He}^{2+}+
\end{array}{ }^{7} \mathrm{Li}^{3+}+2.31 \mathrm{MeV}+\gamma(0.48 \mathrm{MeV})(94 \%)\right.
\end{gathered}
$$

Figure 1.8 Boron Neutron Capture Therapy is based on the ${ }^{10} B(n, \alpha){ }^{7}$ Li reaction, which can potentially deliver a very high and fatal radiation dose to cancerous cells by concentrating boron in them.

In addition, COSAN was discovered as powerful, specific, competitive and nontoxic inhibitor of HIV-1 protease. The X-ray crystallographic structure of the COSAN-binded to HIV-1 protease complex indicates the potential of this class of compounds, see Figure 1.9.

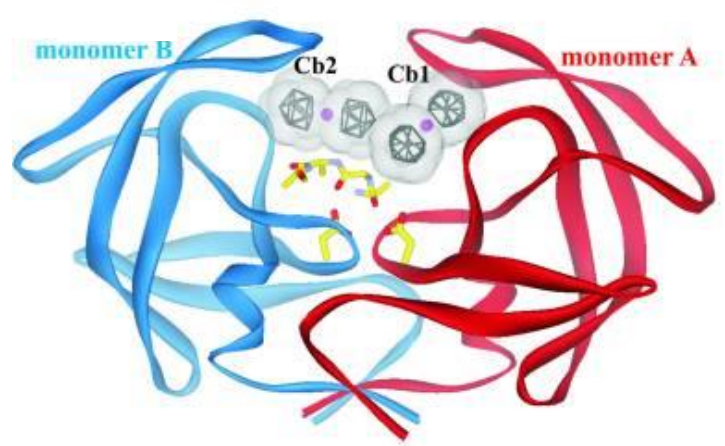

Figure 1.9 The X-ray structure of the complex between HIV-1 protease and [3, 3'-Co-( 1, 2$\left.\left.\mathrm{C}_{2} \mathrm{~B}_{9} \mathrm{H}_{11}\right)_{2}\right]^{-}$metallacarborane. From Cígler et al. Proc. Natl. Acad. Sci. U. S. A., 2005. 



Materials and methods 



\subsection{EXPERIMENTAL PROTOCOL}

The standard experimental protocol followed here for channel reconstitution into planar lipid bilayers and current recording has benefited from many suggestions and improvements learned from Bezrukov's group at NIH (Bezrukov \& Vodyanoy 1993) through visits of my supervisors and through the long-term collaborative work with Dr. Sergey M. Bezrukov and Dr. Tatiana K. Rostovtseva. This technique is known as voltage-clamp (V-clamp technique).

To achieve the channel reconstitution a chamber formed by two compartments, with $2 \mathrm{ml}$ capacity each one, is used. The chambers compartments are separated by a thin Teflon film, $10 \mu \mathrm{m}$ thick, with a handmade $\sim 100-130 \mu \mathrm{m}$ diameter orifice. In this orifice the planar lipid bilayer is formed and then the channel is reconstituted. With vacuum grease the joints between the film and the compartments are sealed. Figure 2.1 shows the experimental chamber that we use to carry out our experiments.

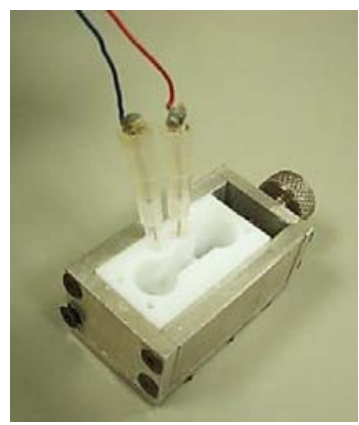

Figure 2.1 Experimental chamber with the two compartments separated by a teflon film.

\subsubsection{Teflon film hole perforation}

The size and the shape of the hole are essential to later obtain stable bilayers for channel reconstitution. Taking this into account suitable orifices are those with rounded edges and diameter between 100 and $150 \mu \mathrm{m}$.

The hole formation is achieved by using an incandescent platinum tip of around $15 \mu \mathrm{m}$ of diameter to the Teflon film. By a microscope connected to a charge-coupled device (CCD) camera the hole formation can be directly visualized (Figure 2.2 A). The final size of the orifices is controlled by adjusting the exposition time of the film to the incandescent tip. Typical samples obtained with this technique are shown in Figure 2.2 B. 

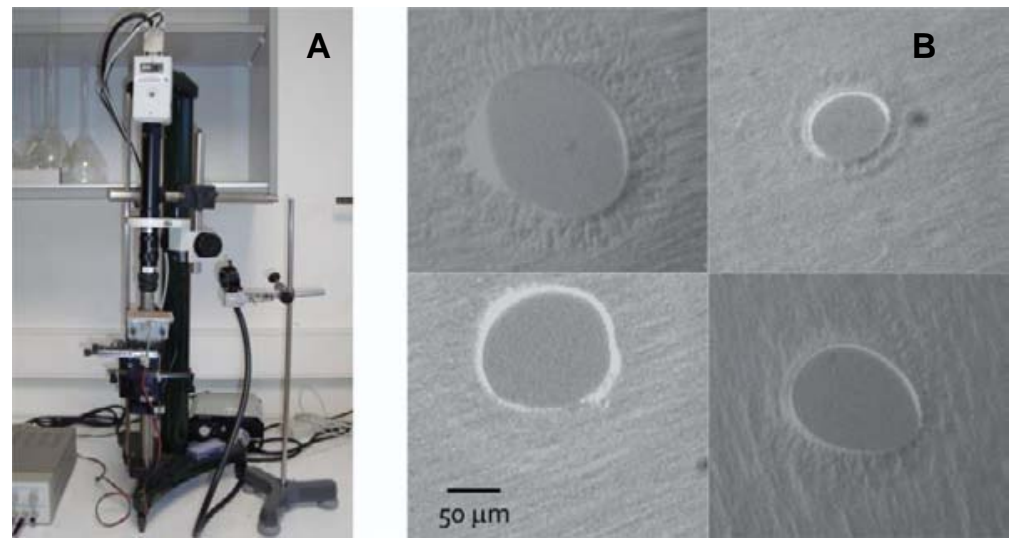

Figure 2.2 (A) Device for the creation and visualization of holes in Teflon films (B) Representative holes obtained using the setup described in $(A)$.

\subsubsection{Electrode fabrication}

The experimental chamber is connected to the signal amplifier by electrodes which are in contact with aqueous solutions. These electrodes must be able to measure electric currents in the order of picoamperes with a high resolution, so that, they must have a very low electric capacity (Bockris \& Reddy 1998). Having this in mind, commercial electrodes are not suitable for this type of experiments because of their glass and ceramic components display high electrical capacity. So the electrodes used in our experiments are prepared handmade in our laboratory in order to avoid these features.

First of all two high-purity silver filaments (99.5\%) of $1 \mathrm{~mm}$ diameter and $2 \mathrm{~cm}$ length are selected and polished to make them identical (Figure $2.3 \mathrm{~A}$ ). Then these filaments are exposed to electrolysis in this way: they are immersed in $0.1 \mathrm{M} \mathrm{HCl}$ solution and connected to the positive pole of a current generator, an electric current of $5 \mathrm{~mA} / \mathrm{cm}^{2}$ is applied for 3 hours while gentle agitation, to ensure the homogeneous deposit of chloride ions on the electrode surface. The negative pole is connected to a platinum filament in contact with the solution to close the electric circuit, see Figure 2.3 B.

The following step is to encapsulate the electrodes in salt bridges. This process is necessary because of the chloride present in the external surface of the electrodes reacts with the chloride of solutions in which the electrodes are immersed during the experiments. In addition, the salt bridge minimizes the contribution of the liquid junction potential to the overall experimental measurement. To make the salt bridge a $2 \mathrm{M} \mathrm{KCl}$ solution in gel phase is prepared by adding to the $\mathrm{KCl}$ solution $1.5 \%$ of agarose while continuous stirring at $120^{\circ} \mathrm{C}$. Once the gel phase is achieved, the $\mathrm{Ag} / \mathrm{AgCl}$ electrodes are assembled 
within standard $250 \mu$ pipette tips, filled with the agarose bridge (Figure $2.3 \mathrm{C}$ ). These electrodes accomplish the necessary requirements: high resolution and very low electrical capacity. Finally to maintain stable electrodes they are connected and immersed in a $2 \mathrm{M} \mathrm{KCl}$ solution.

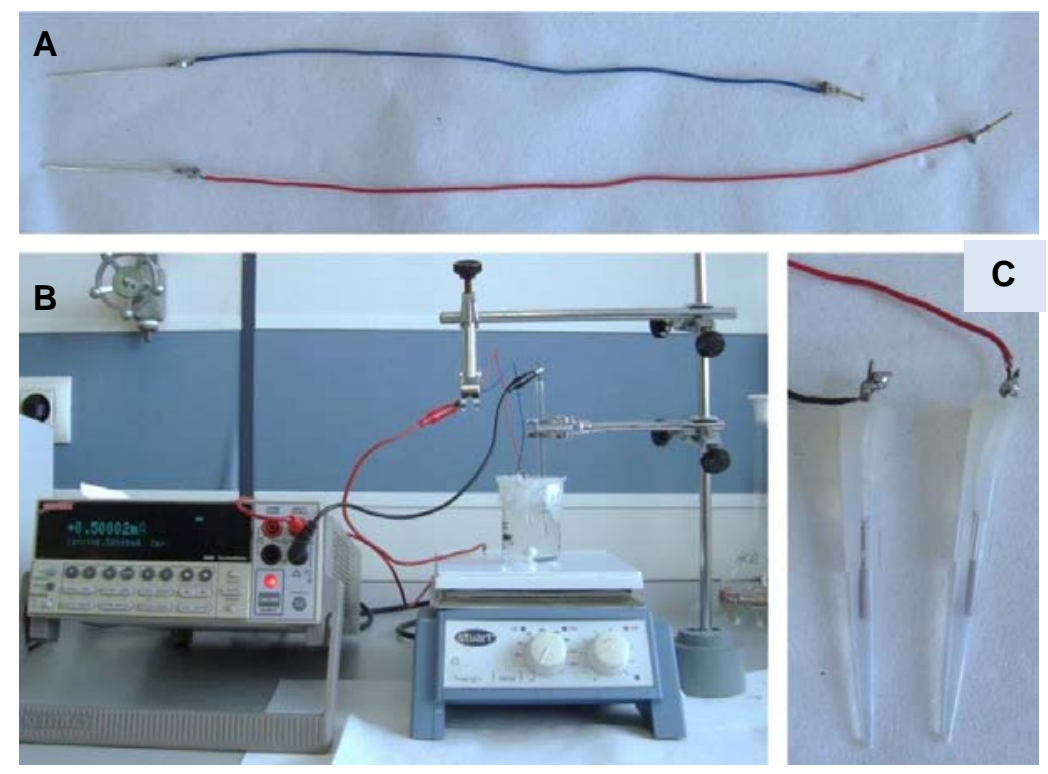

Figure $2.3(\mathrm{~A})$ High-purity silver filaments (99.5\%), of $1 \mathrm{~mm}$ in diameter and $2 \mathrm{~cm}$ long, polished and connected to a cable. (B) Electrolysis process: silver filaments are immersed in $0.1 \mathrm{M} \mathrm{HCl}$ and connected to the positive pole of a current source. The negative pole is connected to a platinum filament. (C) Electrodes prepared for experiments, already encapsulated using $250 \mu \mathrm{L}$ pipette tips and agarose salt bridges.

\subsubsection{Formation of the planar lipid bilayer}

To form the lipid bilayer in the orifice of the Teflon film the Montal Mueller technique is used (Montal \& Mueller 1972; Mueller et al. 1962). The planar lipid bilayer is formed by apposition of two lipid monolayers as follows: $10 \mu \mathrm{l}$ of lipid dissolved in pentane $(5 \mathrm{mg} / \mathrm{ml})$ is added on top of the electrolyte solutions that fill each cell compartment. The lipid chose can be different depending on what lipid bilayer composition it is necessary to carry out the experiment. In the experiments reported along this Thesis different lipids and compositions were used. We used neutral lipids as diphytanoyl phosphatidylcholine (DPhPC) and 1,2-dioleoyl-sn-glycero-3-phosphocoline (DOPC). Alternatively we performed experiments with negatively charged lipids as dyphytanoyl phosphatidylserine (DPhPS) and 1,2-di-(9Z-octadecenoyl)-snglycero-3-phospho-L-serine (DOPS) and with lipids containing negative curvature, such as 1,2-dioleoyl-sn-glycero-3-phosphoethanolamine (DOPE). We 
also performed experiments in bilayers containing pure lipid or in bilayers formed by mixture of different lipids, for instance with mixtures containing 3:1:1 DOPC:DOPS:DOPE.

Lipid solutions in their commercial form are dissolved in chloroform. It is necessary to evaporate the chloroform with argon gas and then lipids are dissolved in pentane (final concentration $5 \mathrm{mg} / \mathrm{mL}$ ). The reason for using pentane instead of chloroform is because that pentane is very volatile and it is less toxic than chloroform. After approximately 10 minutes the pentane is expected to be evaporated and a monolayer is expected to be coating the airwater interface of each compartment. Then the solution level is raised in each compartment so that the two lipid monolayers come into contact on the orifice and yielding the bilayer by apposition, as Figure 2.4 shows. It is important to note that the Teflon film is pretreated with a solution of hexadecane in pentane $1 \% \mathrm{v} / \mathrm{v}$ in order to confer certain lipophilicity to the film surface. This step is crucial to guarantee the right apposition of the monolayers on the orifice.
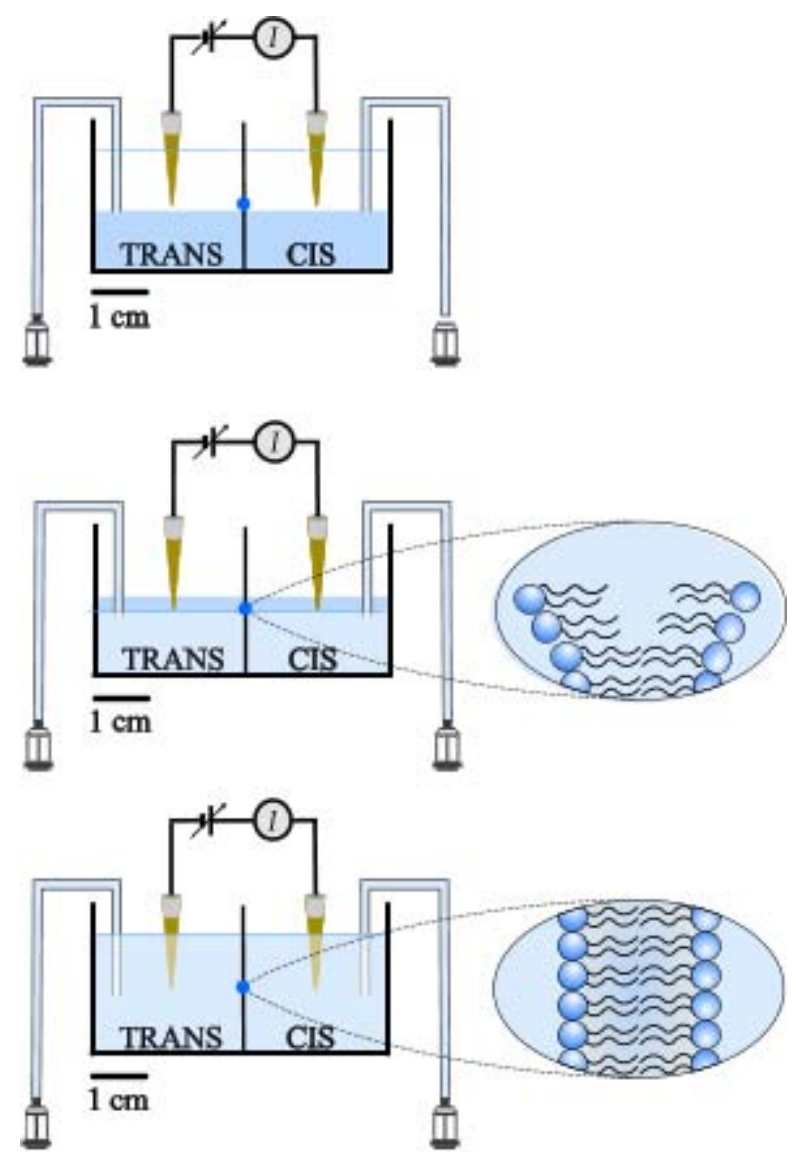

Figure 2.4 Formation of the lipid bilayer by apposition of two monolayers. As the solution levels are raised, the two monolayers form the bilayer in the hole of the Teflon film. 
To check the proper formation of the bilayer a periodic voltage with triangular shape is generated by a wave generator implemented in the setup. This signal is incorporated into the circuit as the input signal. When the input signal passes through the circuit it is converted into a square shape wave so the lipid bilayer acts as a capacitor. The output signal is registered and visualized in the oscilloscope (Figure 2.5). By this way the formation of the bilayer is monitored: the conversion of the triangular shape wave into square shape wave is the proof that bilayer is formed correctly.

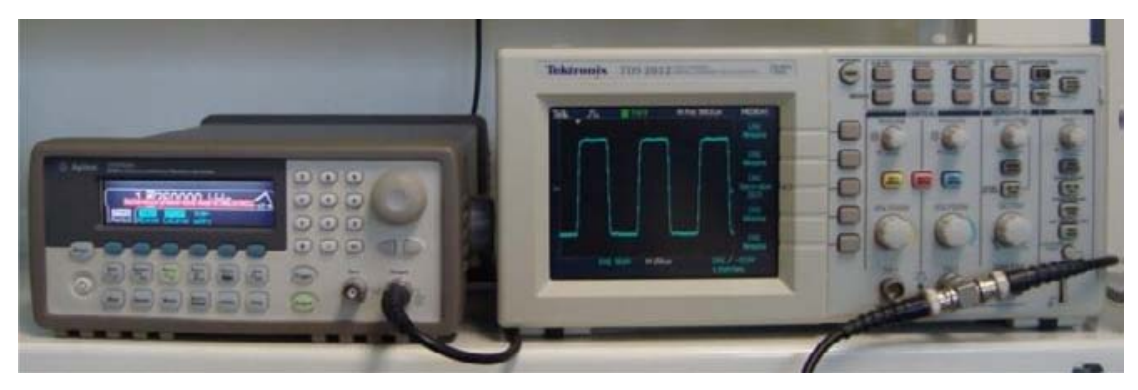

Figure 2.5 Wave generator yielding a triangular shaped periodic voltage (left) and oscilloscope showing the current output from the system (right). The oscilloscope shows a square shaped wave, as an evidence of the formation of a good lipid bilayer.

\subsubsection{Protein insertion}

To achieve the insertion of the protein in the bilayer around $1 \mu \mathrm{L}$ of protein is added at one compartment of the chamber, in our case in the cis side which is the side closer to the experimenter. In the case of OmpF the protein is dissolved in a buffer that contains $0.1 \mathrm{M} \mathrm{KCl}, 1 \%(\mathrm{v} / \mathrm{v})$ OctylPOE (Alexis, Switzerland). SARS-CoV E protein, SH syncytial protein and synthetic peptides derived from transmembrane domain of these proteins are immersed in the buffer containing acetonitrile:isopropanol (40:60).

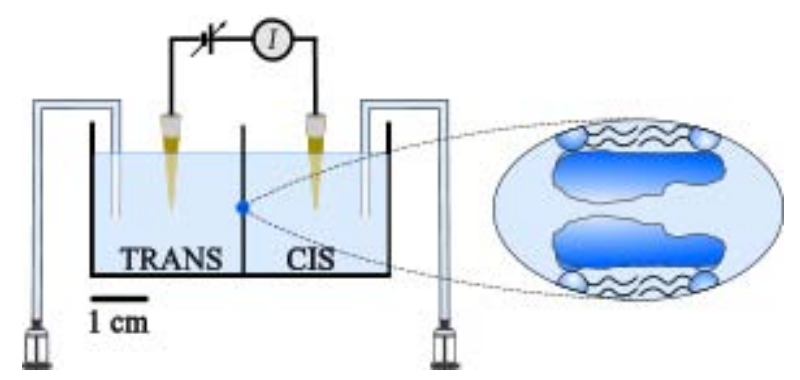

Figure 2.6 Insertion of the protein channel into the bilayer. 
After the addition of the protein to favor the channel insertion an external voltage is applied ( $100 \mathrm{mV})$. Channel activity is observed when an increase of current occurs. See Figure 2.7.

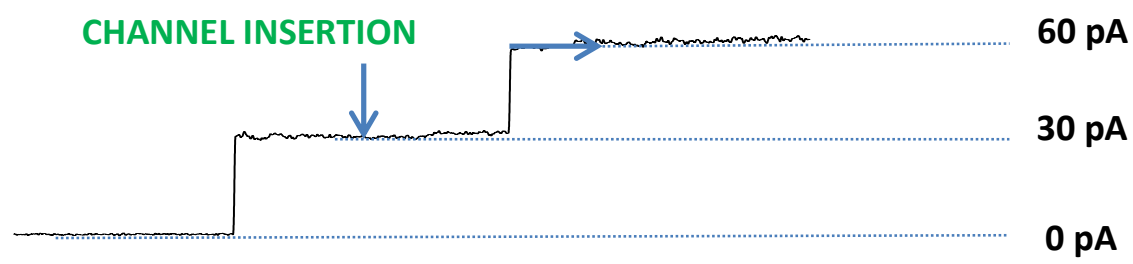

Figure 2.7 Current recording. The trace shows the change in current level due to the channel insertion after applying $+100 \mathrm{mV}$.

\subsubsection{Data acquisition and analysis}

The equipment for studying the channel activity is formed by an Axopatch $200 \mathrm{~B}$ amplifier of high resolution operating in the voltage-clamp mode (Axon Instruments, Molecular Devices, Sunnyvale, CA). Working in the voltage-clamp mode allows apply an external potential and record the current resulting of the channel activity. The signal is filtered by an in-line low-pass Bessel filter to reduce the high-frequency signals coming from the system wiring.

To isolate the experimental chamber from external noise a double Faraday cage which is located on a vibration isolation table. The setup is completed by a Axon Digidata 1140A digitizer, an oscilloscope and a wave generator. The digitizer transforms the analogical signal from the amplifier to a digital signal.

This digital data is registered in a computer and it is analyzed by the software Clampex 10 (Molecular Devices, Sunnyvale, CA). This software is a potent tool that allows analyzing the current recordings by different ways, including the analysis of histograms and statistical studies. Figure 2.8 shows the amplifier and the double Faraday cage. 
A

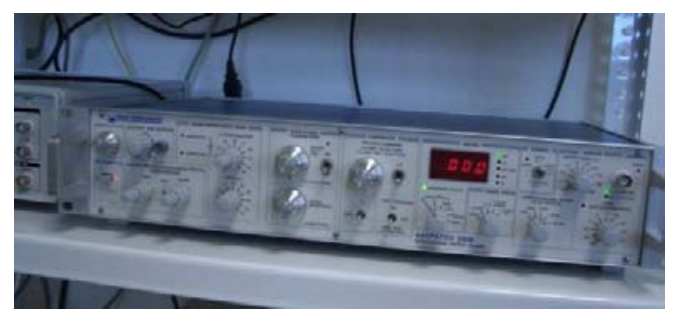

C

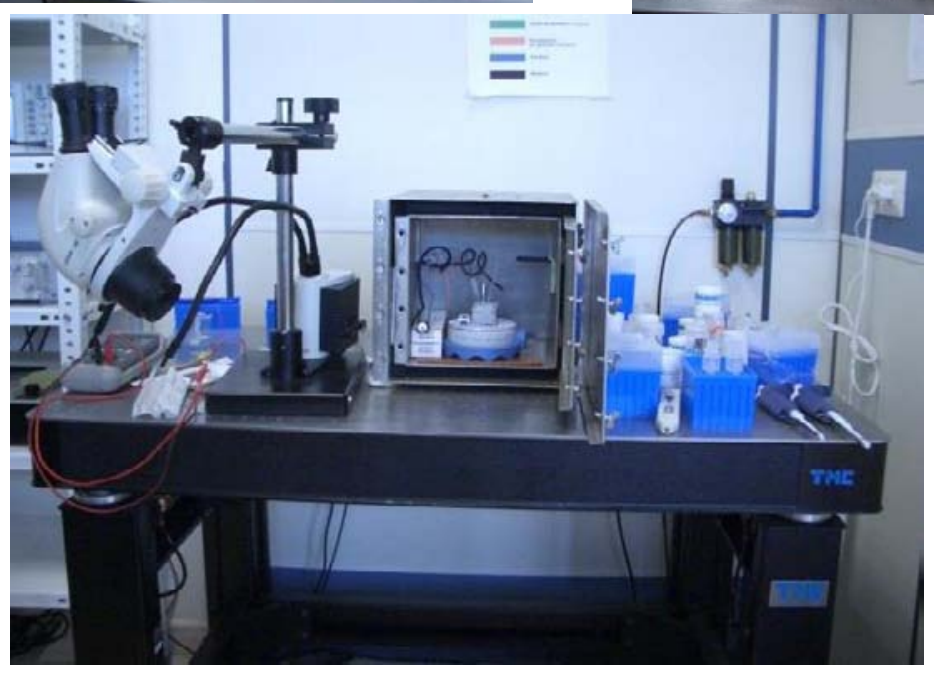

B

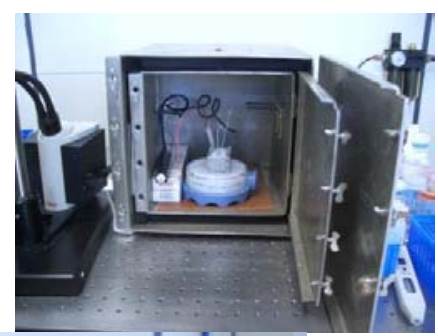

Figure 2.8 (A) Axopatch 200B amplifier together with Axon Digidata 1440A digitizer (Molecular Devices, Sunnyvale, CA). (B) Detail of the interior of the double Faraday cage where the experimental chamber is connected to the pre-amplifier through the home-made electrodes. (C) General view of the setup, showing a double Faraday cage on a vibration isolation table.

\subsection{EXPERIMENTS}

\subsubsection{Conductance experiments}

To characterize the ion transport through channels, the amplifier in the voltage-clamp mode is used for measuring electric current under different applied potential. In conductance experiments both sides of the chamber contain buffered electrolyte solution at same concentration and $\mathrm{pH}$ conditions. The protein is always added in the cis side. In order to achieve single channel experiments the amount of protein added in cis side is very low. Once the protein is added, by applying electric potential between both sides of the chamber it is possible to detect ion channel activity by means of the electric current that is registered and recorded by Clampex software. The events are recorded at high frequency and then traces were filtered using a Butterworth 
filter with a $100 \mathrm{~Hz}$ of frequency. The value of electric current is obtained by histograms and performing Gaussian peak fitting. Conductance is obtained by the quotient between the electric current obtained by the applied potential.

The experiments described along this Thesis deal with different protein channels. In the case of OmpF, the determination of single channel is easier than in the case of SARS-CoV E protein and SH Syncytial protein. OmpF has a defined conductance which means that the successive channel insertions are always multiple values of the single channel. However, in the case of E and $\mathrm{SH}$ proteins, the current recording are more complex and the determination of the single channel is more complicated. These proteins do not display a defined conductance level so it is necessary to analyze the current jump amplitudes registered. Then by a Gaussian fit, the mean value of current level is obtained.

\subsubsection{Reversal potential experiments}

Reversal potential $\left(E_{\text {rev }}\right.$ ) or zero current potential is the most popular way to characterize the ionic channel selectivity. The $E_{r e v}$ is obtained as follows. First, the lipid membrane is formed separating two compartments with different salt concentration. Second, channels are inserted. In order to favor the channel insertion we applied potential. Third, the ionic current observed is manually set to zero by adjusting the applied potential. The potential needed to achieve zero current is then corrected by the liquid junction potential calculated form Henderson's equation to obtain the $E_{\text {rev }}$. Each point is measured for at least three different experiments to ensure the reproducibility and calculate the standard deviation.

The LJP contribution is a consequence of the experimental method and gives no information about the ionic transport through the channel, so it must be subtracted. In the presented experimental setup, the measured zero current potential consists of the following three contributions:

$$
V_{\text {exp }}=V_{P_{\text {cis }}}-V_{P_{\text {trans }}}=\left(V_{P_{\text {cis }}}-V_{\text {cis }}\right)+\left(V_{\text {cis }}-V_{\text {trans }}\right)+\left(V_{\text {trans }}-V_{P_{\text {trans }}}\right)
$$

where $V_{P c i s}-V_{\text {cis }}$ and $V_{\text {trans }}-V_{\text {Ptrans }}$ are the LJP generated at the interfaces of the two saline bridges with the solutions in cis and trans sides, respectively, and $V_{\text {cis }}-V_{\text {trans }}$ is the voltage drop across the channel, the reversal potential. 
In the conductance measurements, cis and trans solutions have the same salt concentration, so the LJP's are equal in magnitude but opposite in sign. They cancel each other and yield no contribution to the experimental measurement. However, reversal potential measurements are done in asymmetrical conditions, so the LJP values should be considered. In this study, they were theoretically calculated from the Henderson's equation, which gives the diffusion potential that appears in an interface in the presence of an ion concentration gradient (Alcaraz et al. 2009):

$$
V_{L}-V_{R}=-\frac{R T}{F} \frac{\sum_{i} z_{i} D_{i}\left(c_{i, L}-c_{i, R}\right)}{\sum_{i} z_{i}^{2} D_{i}\left(c_{i, L}-c_{i, R}\right)} \ln \left(\frac{\sum_{i} z_{i}^{2} D_{i} c_{i, L}}{\sum_{i} z_{i}^{2} D_{i} c_{i, R}}\right)
$$

where subscript $i$ refers to the different ionic species in the solution, $L$ and $R$ correspond to the left and right side of the interface, $z_{i}$ are the valences and $D_{i}$ the diffusion coefficients taken from the literature (Robinson \& Stokes 2002). This equation is applied to calculate LJP, $V_{P \text { cis }}-V_{\text {cis }}$ and $V_{\text {trans }}-V_{\text {Ptrans. }}$.

In electrolyte solutions like $\mathrm{KCl}, \mathrm{CsCl}$ and $\mathrm{RbCl}$, the difference between the mobility of anions and cations is negligible so the contribution of the LJP to the measured zero current potential is very small $(\sim 1 \mathrm{mV})$, regardless of the concentration gradient used, and do not affect $E_{\text {rev }}$ measurements, which usually are of the order of $10 \mathrm{mV}$. However, as the relative mobility between anions and cations gets higher, LJP values also increase, as is the case of, for instance, $\mathrm{NaCl}, \mathrm{LiCl}, \mathrm{CaCl}_{2}$ and $\mathrm{MgCl}_{2}$. The contribution of the LJP in these cases is appreciable and cannot be neglected. In all reversal potential experiments performed in this work LJP was calculated and subtracted to the experimental values in order to obtain accurate $E_{\text {rev }}$ values.

\subsubsection{Inductively coupled plasma mass spectrometry (ICP-} MS).

In some of the experiments reported along this Thesis, we determine the concentration of some molecules or compounds in trans side to calculate the fluxes of these compounds. Particularly, we calculate the $\mathrm{La}^{3+}$ flux through OmpF channel and the COSAN flux through the membranes. These fluxes are determined by means of inductively coupled plasma mass spectrometry (ICP$\mathrm{MS})$. This technique is capable of detecting metals and several non-metals at concentrations as low as one part per trillion [Mermet 1999]. For this reason we use ICP-MS to detect the lanthanum and boron present in aqueous solutions. 
The experimental protocol was as follows. We added $\mathrm{LaCl}_{3}$ or COSAN solution (depending on the experiment) to the cis side. Then we took samples of the solution in the trans side and quantify the permeation rate of the compounds through the channel or bilayer.

ICP-MS measurements were performed using a quadrupole mass spectrometer Agilent 7500 cx with a collision cell (Agilent technologies, USA). The instrumental operating conditions are summarized in Table 2.1.

Table 2.1 ICP-MS operating conditions.

\begin{tabular}{|cc|}
\hline ICP-MS & $7500 \mathrm{cx}$ (Agilent) \\
\hline Forward power & $1500 \mathrm{w}$ \\
\hline Plasma gas flow & $15 \mathrm{~L} / \mathrm{min}$ \\
\hline Auxiliary gas flow & $0.90 \mathrm{~L} / \mathrm{min}$ \\
\hline Carrier gas flow & $0.95 \mathrm{~L} / \mathrm{min}$ \\
\hline Make up gas flow & $0.25 \mathrm{~L} / \mathrm{min}$ \\
\hline Nebulizer pump & $0.10 \mathrm{rps}$ \\
\hline Sample depth & $7.2 \mathrm{~mm}$ \\
\hline Monitoring masses & $\mathrm{m} / \mathrm{z} 139$ \\
\hline Integration time/mass & $1 \mathrm{~s}$ \\
\hline Detection & Electron multiplier \\
& (voltage:1650 v Analog \\
& $1180 \mathrm{v}$ Pulse) \\
\hline Spray chamber & $2{ }^{\circ} \mathrm{C}$ \\
\hline
\end{tabular}






\section{Ion transport modulation}

\section{in the $\mathrm{OmpF}$ porin}



Part of the studies included in the present chapter were published in the following articles:

"Electrostatic Interactions Drive the Nonsteric Directional Block of OmpF Channel by La ${ }^{3+\prime}$, Langmuir (2013) 29, 15320 - 15327. 



\subsection{INTRODUCTION}

Understanding the mechanisms by which biological channels regulate the transport of ions and the electric signal transduction at the molecular level has been an inspirational source to build nanofluidic devices and new synthetic biomimetic materials (Siwy \& Howorka 2010). Conductance in the pS-nS range, $\mathrm{pH}$-dependent ion selectivity, fluctuations of current between open and closed states, flux inhibition caused by protons or divalent cations, current rectification, among other phenomena are found both in synthetic and biological channels and can be useful for a variety of biotechnical and analytical applications (Macrae et al. 2009; Wilson et al. 2009; Maglia et al. 2009).

In this chapter we investigate how to regulate the channel conductance and ionic selectivity of the bacterial porin OmpF, a large and weakly selective channel in the outer membrane of E. Coli (Nikaido 2003; Delcour 2003; Danelon et al. 2003; Kobayashi 1985). We focused on this channel because it is a model system exceptionally well characterized both structurally and functionally. A number of studies provide valuable structure-function relationships at different levels of complexity (continuum electrostatics, BD and $\mathrm{MD}$ simulations) (Aguilella-Arzo et al. 2007; Aguilella et al. 2011; Im \& Roux 2002 b; Im \& Roux 2002 a; Faraudo et al. 2010). Taking advantage of this available knowledge we want to investigate the ability of multivalent cations to modify the ionic transport properties of OmpF porin, aiming to make this information useful in other nanosystems.

Among other effects, the presence of multivalent ions is important for the electrostatic regulation of the cell signaling by modifying the membrane surface charge as well as the ion channel function (Tatulian 1999). The fine sensitivity observed in many ion channels for tiny amounts of multivalent ions reinforces the idea that these pores are not passive filters but rather could act as externally activated valves within the biological membrane (Aguilella et al. 2011; Gurnev \& Bezrukov 2012). Given the reported role of lanthanum ions in biological systems (Feng et al. 2006; Lachaud et al. 2010; Wang et al. 2010) we explore here the way it interacts with the OmpF channel.

\subsection{RESULTS}

\subsubsection{Study of the effect of $\mathrm{LaCl}_{3}$ on OmpF selectivity}

The bacterial porin OmpF forms large weakly selective channels that do not display any ion specificity (Nestorovich et al. 2003; Nikaido 2003) This contrasts with the high ionic discrimination exhibited by narrow channels 
(potassium channels have a permeability ratio for $\mathrm{K}^{+}$over $\mathrm{Na}^{+}$higher than 100:1 and calcium channels select for $\mathrm{Ca}^{2+}$ over $\mathrm{Na}^{+}$with a ratio higher than 1000:1) (Aguilella et al. 2011; Corry 2006).

Previous studies reported that OmpF ionic selectivity in salts of monovalent cations is strongly dependent on $\mathrm{pH}$ solutions (Alcaraz et al. 2004; Alcaraz, Ramirez, et al. 2006; Aguilella-Arzo et al. 2007). OmpF channel is selective to cations in basic and neutral solutions whereas it is anion selective at low $\mathrm{pH}$. This channel property depends only barely on absolute electrolyte concentration and similar findings have been reported and analyzed in a number of studies (Nestorovich et al. 2003; Alcaraz et al. 2004; Aguilella-Arzo et al. 2007; Alcaraz, Ramirez, et al. 2006). The $p K_{a}$ determination of all titratable residues in the OmpF channel enables the rationalization of the $\mathrm{pH}$ dependent selectivity. The successive protonation and deprotonation of acidic and basic residues explains how this cation-selective channel (at basic and neutral $\mathrm{pH}$ ) turns into anion-selective (in an acidic environment).

In contrast, it has been observed that the measured reversal potential in presence of magnesium divalent cations is hardly sensitive to $\mathrm{pH}$ and $\mathrm{OmpF}$ shows anionic selectivity in the whole $\mathrm{pH}$ range. This indicates that divalent cations modify the physicochemical mechanism responsible for the $\mathrm{pH}$ sensitivity of the channel. It has been reported that $\mathrm{Mg}^{2+}$ cation binds in the selectivity filter between Asp113 and Glu117, see Figure 3.1 (Yamashita et al. 2008). The presence of the magnesium cation in the pore constriction has an important impact on the titration of the residues in the selectivity filter and on the effective charge of the channel that regulates the selective permeation of ions. Apart from the inhibition of the $\mathrm{pH}$ sensing mechanism, this binding is responsible for the selectivity inversion observed at neutral $\mathrm{pH}$ in the presence of magnesium cations. A similar trend is observed in $\mathrm{CaCl}_{2}$ salts (see Figure 3.2). Although the binding of $\mathrm{Ca}^{2+}$ cations has not been resolved yet, the experimental evidence suggests that $\mathrm{Ca}^{2+}$ may bind to the same channel residues than $\mathrm{Mg}^{2+}$ cations.

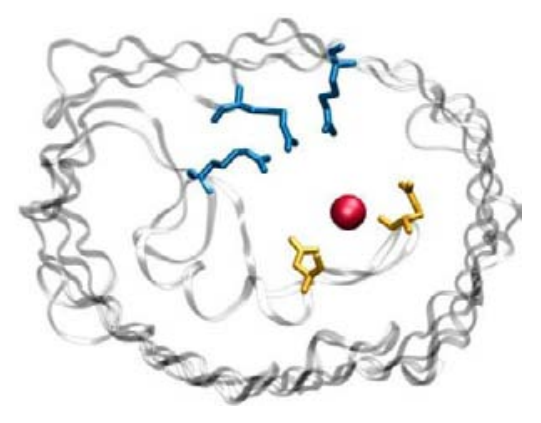

Figure 3.1 Position of the magnesium ion in the crystal structure of the OmpF channel resolved in $1 \mathrm{M} \mathrm{MgCl}_{2}$ by Yamashita and coworkers (Yamashita et al. 2008). 
Having the effect of divalent cations on OmpF ion selectivity in mind, we investigated the behavior of lanthanum ions. As Figure 3.2 displays, in $\mathrm{LaCl}_{3}$ the selectivity dependence on $\mathrm{pH}$ is lost as in salts of divalent cations. In the range of $\mathrm{pH}$ studied here, the channel displays an anionic selectivity. It is interesting to remark that in $\mathrm{LaCl}_{3}$ the anionic selectivity is higher than in salts of divalent cations, and the loss of sensitivity to the solution $\mathrm{pH}$ is emphasized. This indicates that $\mathrm{La}^{3+}$ cations are able to interact with $\mathrm{OmpF}$ residues modifying the physicochemical mechanism responsible for the $\mathrm{pH}$ sensitivity as divalent cations do.

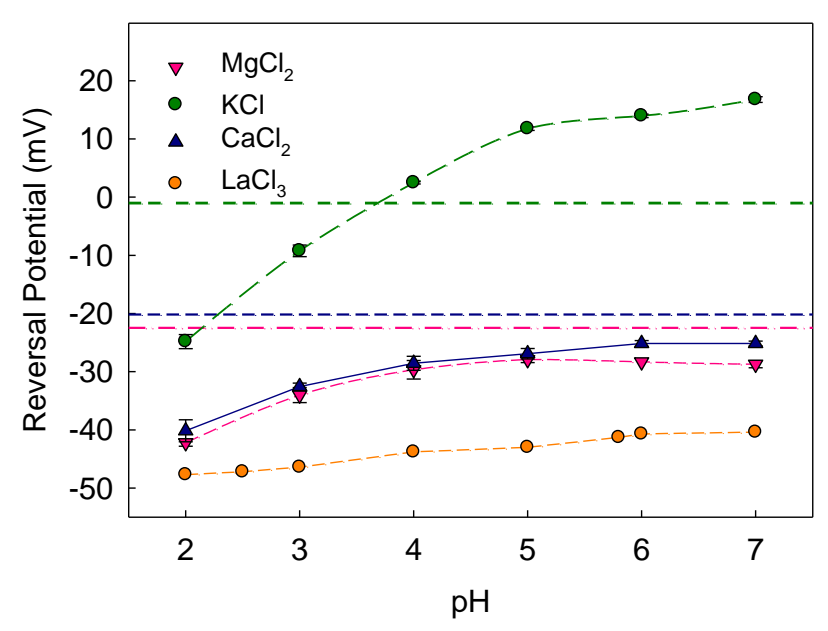

Figure 3.2 Reversal potential versus $\mathrm{pH}$ in $\mathrm{KCl}, \mathrm{MgCl}_{2}, \mathrm{CaCl}_{2}$ and $\mathrm{LaCl}_{3}$ salts. The experimental conditions were: 10 -fold salt concentration gradient $(0.1 \mathrm{M} / 1 \mathrm{M})$. Green dotted line represents the diffusion potential of $0.1 / 1 \mathrm{M} \mathrm{KCl}$, blue short dash line represents the diffusion potential of $0.1 / 1 \mathrm{M} \mathrm{CaCl}_{2}$ and pink dash-dot lines corresponds to the diffusion potential of $0.1 / 1 \mathrm{M} \mathrm{MgCl}_{2}$.

Then, we tested if trace amounts of $\mathrm{La}^{3+}$ ions could act as modulators of OmpF selectivity. To this end, reversal potential experiments after the addition of $5 \mathrm{mM} \mathrm{LaCl}_{3}$ were performed. Figure 3.3 shows the variation of the ion selectivity with $\mathrm{pH}$ solution without lanthanum salt and with the presence of 5 $\mathrm{mM}$ of lanthanum chloride. It is clear that millimolar concentration of $\mathrm{LaCl}_{3}$ decreases the cationic selectivity of OmpF channel and, finally, at $\mathrm{pH} 4$ the cationic selectivity is reversed into anionic. These results support the hypothesis that the interaction between $\mathrm{La}^{3+}$ ions and charged residues of OmpF produces a change in the effective charge of the channel causing a selectivity inversion. 


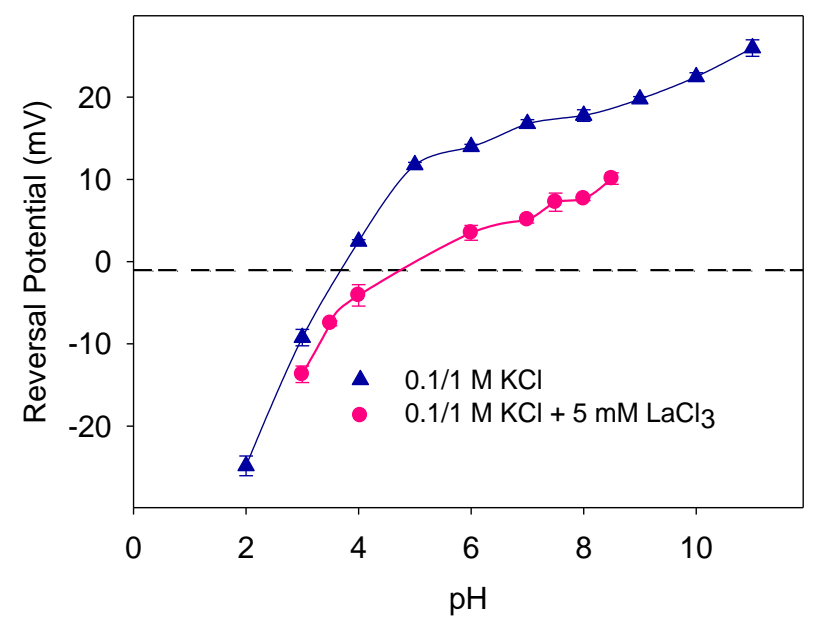

Figure 3.3 Reversal potential experiments varying the $\mathrm{pH}$ conditions in $0.1 / 1 \mathrm{M} \mathrm{KCl}$ (blue triangles) and in $0.1 / 1 \mathrm{M} \mathrm{KCl}$ with the presence of $5 \mathrm{mM} \mathrm{LaCl}_{3}$ (pink circles) in both sides of the chamber. Dotted line indicates the diffusion potential of $0.1 / 1 \mathrm{M} \mathrm{KCl}$.

Next, the OmpF selectivity was analyzed in reversal potential experiments performed at a constant concentration ratio but at different absolute concentration and with increasing $\mathrm{LaCl}_{3}$ concentrations. These experiments were carried out to study how screening effect may influence the ion selectivity inversion produced by lanthanum salt.

As Figure 3.4 displays, higher $\mathrm{LaCl}_{3}$ concentration is needed to achieve the selectivity inversion under high absolute $\mathrm{KCl}$ concentration. Under 15/150 $\mathrm{mM} \mathrm{KCl}$ the addition of $4 \mathrm{mM} \mathrm{LaCl}_{3}$ is enough to reverse ionic selectivity, whereas under $0.1 / 1 \mathrm{M} \mathrm{KCl}$ it is necessary to increase $\mathrm{LaCl}_{3}$ concentration up to $7 \mathrm{mM}$. These results indicate that screening exerted by $\mathrm{KCl}$ influences the selectivity inversion induced by $\mathrm{LaCl}_{3}$.

It is noteworthy that the inversion of ion selectivity in OmpF channel has been already reported in chloride salts of different multivalent ions (GarcíaGiménez et al. 2010; Alcaraz et al. 2009). However in these studies the lanthanum ions were the only ones responsible for the cation flux since the experiments were carried out in $\mathrm{LaCl}_{3}$ solutions. The drawback of those conditions is the large diffusion potentials originated by the concentration gradients of $\mathrm{LaCl}_{3}$ (due to the different mobilities of $\mathrm{La}^{3+}$ and $\mathrm{Cl}^{-}$) that render difficult the elucidation of the actual sources of the observed ion selectivity (García-Giménez et al. 2010). However, we overcome such difficulties using trace of amounts of $\mathrm{La}^{3+}$ ions superimposed on a $\mathrm{KCl}$ electrolyte solution. 


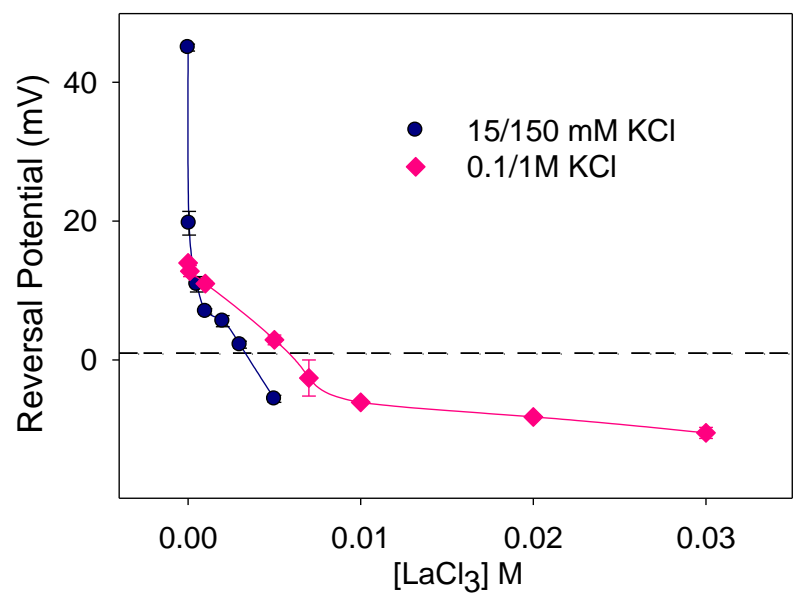

Figure 3.4 Reversal potential measurements in $\mathrm{KCl}$ asymmetric conditions with symmetric addition of trace amounts of $\mathrm{LaCl}_{3}$. The concentration of lanthanum chloride is varied under two 10 -fold $\mathrm{KCl}$ conditions of high $(0.1 / 1 \mathrm{M})$ and low $(15 / 150 \mathrm{mM})$ concentrations. As shown, in low $\mathrm{KCl}$ concentration the inversion of selectivity is obtained with less $\left[\mathrm{LaCl}_{3}\right]$ than in high $\mathrm{KCl}$ concentration. Dotted line corresponds to the diffusion potential of $0.1 / 1 \mathrm{M} \mathrm{KCl}$.

\subsubsection{Analysis of $\mathrm{LaCl}_{3}$ as modulator of $\mathrm{OmpF}$ conductance}

It is known that lanthanum was used as a substitute for calcium as a blocker of several nonselective channels such as those of the transient receptor potential-canonical (TRPC) family (Vazquez et al. 2004). Furthermore, many studies have reported the blocking activity of lanthanum in such different systems as connexin hemichannels, murin frontal cortex networks, tobacco BYcells, or the outward $\mathrm{K}^{+}$channel (Lachaud et al. 2010; Wang et al. 2010).

Most of these channels have in common pore dimensions comparable to the size of the permeating ions, so that only one ion at a time can cross the narrower parts of the channel, what it is known as single file transport (Hille 1978; Aguilella et al. 2011). In these systems the blocking is due to steric reasons: the channel eyelet is totally or partially obstructed by the blocker (Hui et al. 2002).

In this section we investigate the impact of lanthanum chloride on OmpF channel conductance. Taking into account the impact that millimolar concentrations of $\mathrm{LaCl}_{3}$ salt have on $\mathrm{OmpF}$ selectivity, it seems that lanthanum is an ideal candidate to modulate the OmpF channel current. To test this hypothesis, single channel recordings in $0.1 \mathrm{M} \mathrm{KCl}$ were performed. Once the channel was inserted, millimolar $\mathrm{LaCl}_{3}$ concentrations were added symmetrically on both sides of the experimental chamber. As it is shown in Figure 3.5 the 
addition of trace amounts of $\mathrm{LaCl}_{3}$ decreased the current only for positive potentials, whereas current for negative potentials remained unaltered. Another important feature is that increasing concentration of $\mathrm{LaCl}_{3}$ salt enhances the induced current asymmetry. Our experiments suggest that this concentration dependence saturates at $10 \mathrm{mM} \mathrm{LaCl}_{3}$ (Figure $3.5 \mathrm{~A}$ ).
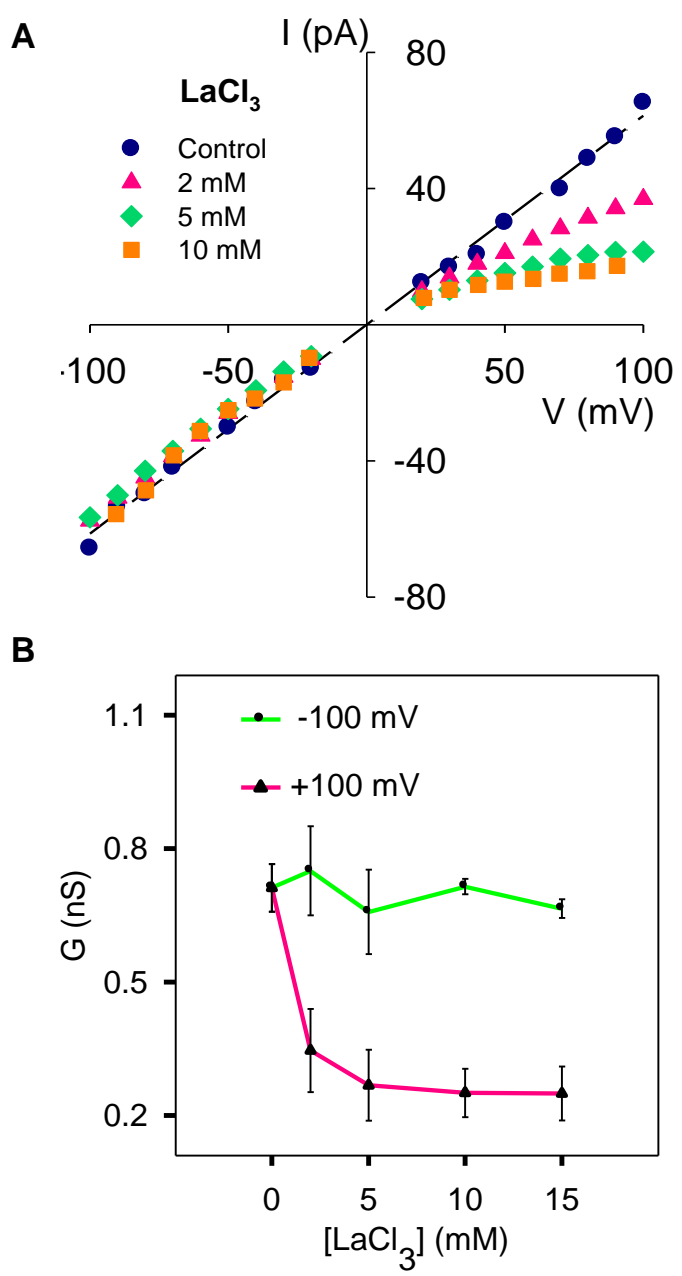

Figure 3.5 (A) Current-Voltage OmpF curves without and with the presence of millimolar concentrations of $\mathrm{LaCl}_{3}$. The addition of $\mathrm{LaCl}_{3}$ induces current rectification and decreases the current level only at positive potentials. (B) Comparison of the change in channel conductance measured under positive and negative bias $\left( \pm 100 \mathrm{mV}\right.$ ) for several minute concentrations of $\mathrm{LaCl}_{3}$. All the experiments were performed at room temperature at $\mathrm{pH} 6$.

The fact that $\mathrm{OmpF}$ conductance decreases with the addition of $\mathrm{LaCl}_{3}$ is not a unique feature of these trivalent cations. Similar OmpF current reduction has been reported in previous studies due a variety of reasons such as salt concentration, $\mathrm{pH}$ conditions, lipid charge, etc. (Alcaraz et al. 2004; Nestorovich 
et al. 2003). In particular, OmpF conductance is very sensitive to $\mathrm{pH}$ conditions. For instance, in $1 \mathrm{M} \mathrm{KCl}$ when the $\mathrm{pH}$ is lowered from $\mathrm{pH} 5$ to $\mathrm{pH} 1$, the channel conductance decreases by approximately a factor of 3 . This reduction in channel conductance is accompanied by a manifest current noise that could be attributed to the interaction between protons and some residues of the channel that produces flickering between different states. Random stepwise transients with amplitudes around $1 / 5$ of the monomer conductance are the major responsible for this noise (Nestorovich et al. 2003).

Having this in mind, one could think that the reduction in channel conductance induced by lanthanum cations follows a similar mechanism. If this hypothesis were right, the traces should show an increase in the current-noise due to this flickering between states. However, a look to the current recordings shows that no current-noise appeared so that the visual aspect of the traces is the same before and after the addition of lanthanum salt, see Figure 3.6 A.
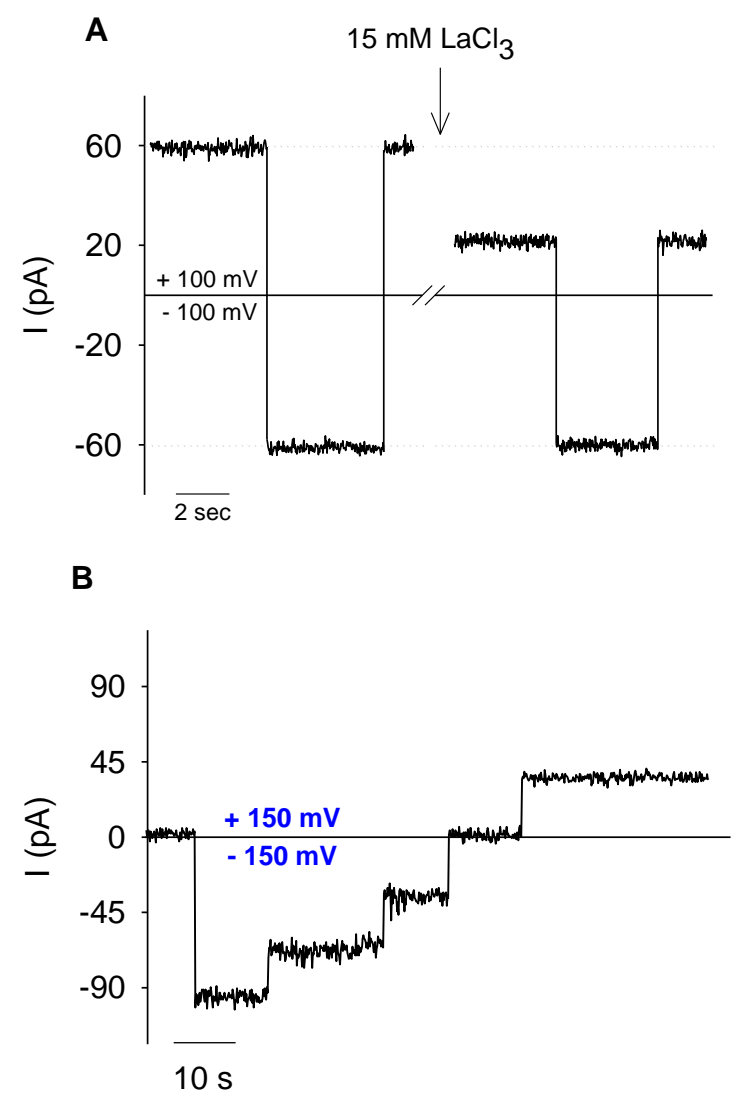

Figure 3.6 OmpF single channel recordings. (A) Current traces before the addition of $\mathrm{LaCl}_{3}$ (control) and after the addition of $15 \mathrm{mM}$ of $\mathrm{LaCl}_{3}$ on both sides of the chamber containing $0.1 \mathrm{M}$ $\mathrm{KCl}$. The channel current is reduced only for positive potential (B) current traces showing the characteristic stepwise gating of the OmpF channel at high voltages $(150 \mathrm{mV})$. 
Interestingly the lanthanum-induced blocking does not produce permanent changes in the channel. At negative potentials the channel current is the same as the control value. In this sense, the blocking effect of lanthanum is very different from other reported phenomena that yield conductance reduction in OmpF channel, such as the well-known gating induced by high voltage. The closure of channel by high voltage, as Figure 3.6 B displays, does not produce current asymmetry because the conductance decreased for both potentials. In addition the channel closure induces permanent changes in the channel, because the change on voltage polarity is not able to recover the conductance of the open channel.

As shown before, the reduction of channel current by lanthanum cations is only visible at positive potential although $\mathrm{LaCl}_{3}$ salt is added in both sides of the experimental chamber. To further analyze this channel feature we recorded the channel current upon addition of $\mathrm{LaCl}_{3}$ only into one side (either cis or trans) of the partition. As Figure 3.7 shows the channel current is only reduced when $\mathrm{LaCl}_{3}$ is added into cis side, the side of the protein addition. The addition of $\mathrm{LaCl}_{3}$ into trans side does not induce any change in the channel current.
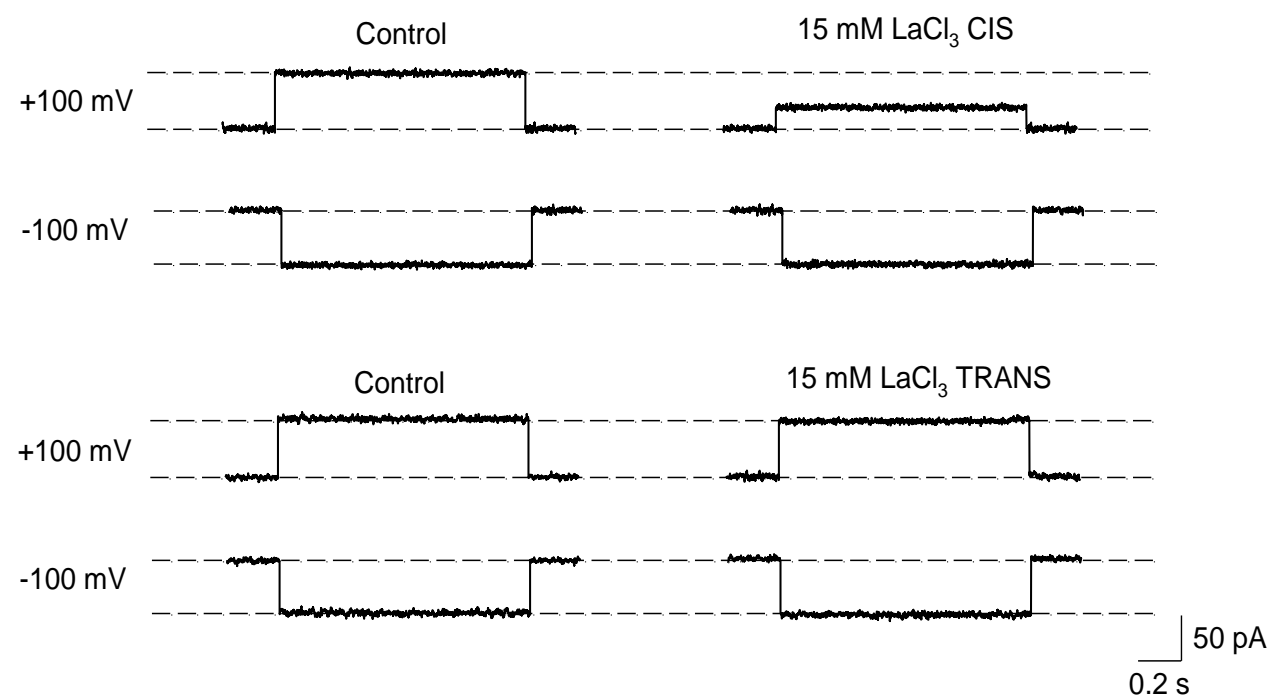

Figure 3.7 OmpF single channel current recordings in symmetric $0.1 \mathrm{M} \mathrm{KCl}$ solutions after the addition of $15 \mathrm{mM} \mathrm{LaCl}_{3}$ into cis (up) or trans side (down). The traces show that lanthanum ions reduce the unitary current only when they are incorporated at the side of the protein addition.

We analyzed the channel rectification when $\mathrm{LaCl}_{3}$ is added only in cis or in trans side and we compared the asymmetry ratio values (Figure 3.8). This parameter is defined as the magnitude of the quotient between current measured under opposite polarities $\left(I_{-V} / I_{+V}\right)$. By comparing the asymmetry ratio 
values it is clear that the addition of lanthanum chloride in the cis side it is a necessary and sufficient condition to achieve the current rectification. The asymmetry ratio when lanthanum is added only into cis side is almost identical than when lanthanum salt is added into both sides. On the contrary, addition of lanthanum salt into trans side does not produce any observable effect in channel current. These observations must be considered together with the channel orientation once reconstituted into the bilayer. Control experiments show that the channel conductance for negative voltages is higher than for positives ones ( $\mathrm{G}=80 \pm 8 \mathrm{pS}$ at negative potentials, $\mathrm{G}=75 \pm 9 \mathrm{pS}$ at positive potentials, in $100 \mathrm{mM} \mathrm{KCl} \mathrm{pH} \mathrm{6).} \mathrm{This} \mathrm{stresses} \mathrm{the} \mathrm{existence} \mathrm{of} \mathrm{a} \mathrm{pattern} \mathrm{that} \mathrm{is}$ related with a particular orientation of the protein during the insertion. Overall these results suggest that the interaction between $\mathrm{La}^{3+}$ cations and $\mathrm{OmpF}$ protein has a directional character.

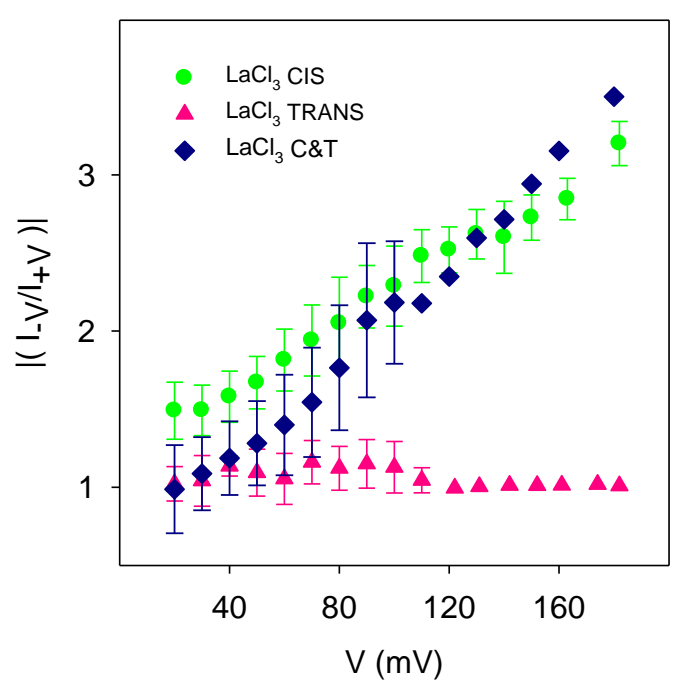

Figure 3.8 Rectification ratio of current-voltage curves in $\mathrm{OmpF}$ is strongly dependent on the side of the channel where $\mathrm{LaCl}_{3}$ is added. Experiments were carried out in $0.1 \mathrm{M} \mathrm{KCl}$ solutions, $5 \mathrm{mM}$ $\mathrm{LaCl}_{3}, \mathrm{pH}$ 6. Channel current was recorded under $+100 \mathrm{mV}$.

It is interesting to note that the levels of asymmetry ratio obtained in this study are comparable to the rectification values reported in others studies. For instance, Miedema and collaborators mutated some residues of the OmpF channel and obtained a rectification ratio of approximately 3 at $100 \mathrm{mV}$, which is very close to our values at the same voltage $(\sim 2.5)$. The ratios with other proteins such as modified Gramicidin A are similar, as it is the case of Macrae and collaborators, who achieved rectification ratios from 3.4 to 4.8 depending on the type of modification in the channel (Majd et al. 2010). 


\subsubsection{On the role of $\mathrm{pH}$ in lanthanum-induced blocking}

A variety of studies have reported that OmpF channel conductance is strongly dependent on the amount of protons present in solution (Benz et al. 1985; Alcaraz et al. 2012). It seems that both $\mathrm{La}^{3+}$ ions and $\mathrm{H}^{+}$ions share this distinctive feature: trace amounts of them are able to inhibit the flow of the more concentrated supporting electrolyte. In the case of protons it has been described that there is a competitive binding between proton and cations in the narrow constriction that explains the channel conductance reduction (Alcaraz et al. 2012).

Stimulated by these previous studies we extended the investigation to the effect of $\mathrm{pH}$ in the OmpF current decrease by lanthanum. To this end, we performed single-channel current experiments under neutral and acid $\mathrm{pH}$ before and after the addition of $\mathrm{LaCl}_{3}$ into cis side. As Figure 3.9 displays, the lanthanum-induced channel rectification is critically affected by the presence of protons. At $\mathrm{pH} 3$ no channel rectification is observed. It indicates that the channel residues involved in the channel $\mathrm{pH}$ sensing mechanism are somewhat also responsible for the lanthanum blocking.

To further analyze the effect of $\mathrm{pH}$ on lanthanum blocking, singlechannel current experiments were performed in solutions of different acidity before and after the addition of $5 \mathrm{mM} \mathrm{LaCl}_{3}$ under positive voltages. In Figure 3.10 $\mathrm{A}$ the ratio between the current after and before the addition of lanthanum

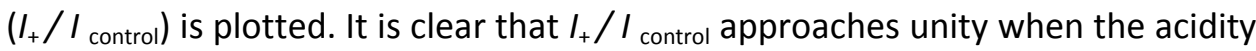
is increased, which means that lanthanum does not produce change in channel conductance. An alternative way to evaluate the effect of lanthanum on channel conductance is by the asymmetry ratio $\left(I_{-v} / I_{+v}\right)$ (Figure $3.10 \mathrm{~B}$ ). Both plots indicate that as acidity increases, the asymmetry response decreases.

Thus, the $\mathrm{pH}$ modifies noticeably the effect of lanthanum ions on OmpF current. It comes out that around $\mathrm{pH} 3$ the lanthanum-induced rectification vanishes. These results indicate that $\mathrm{pH}$ is able to regulate the lanthanum effect on OmpF channel conductance. It may suggest that protons interfere with the blocking mechanism of lanthanum. 


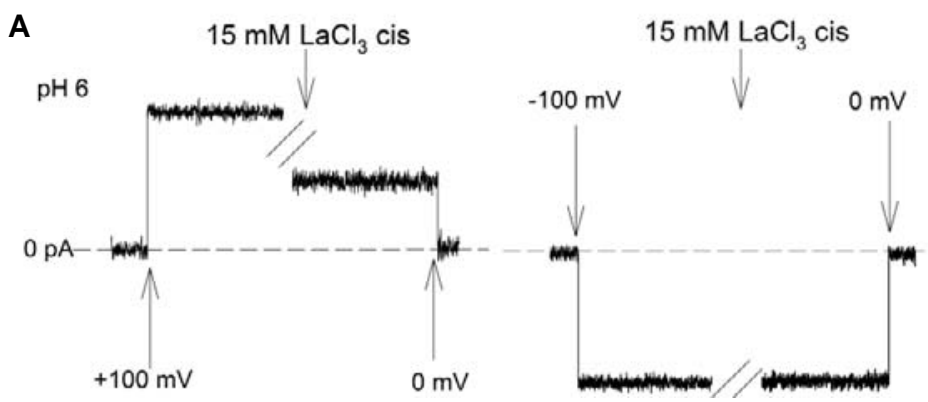

B

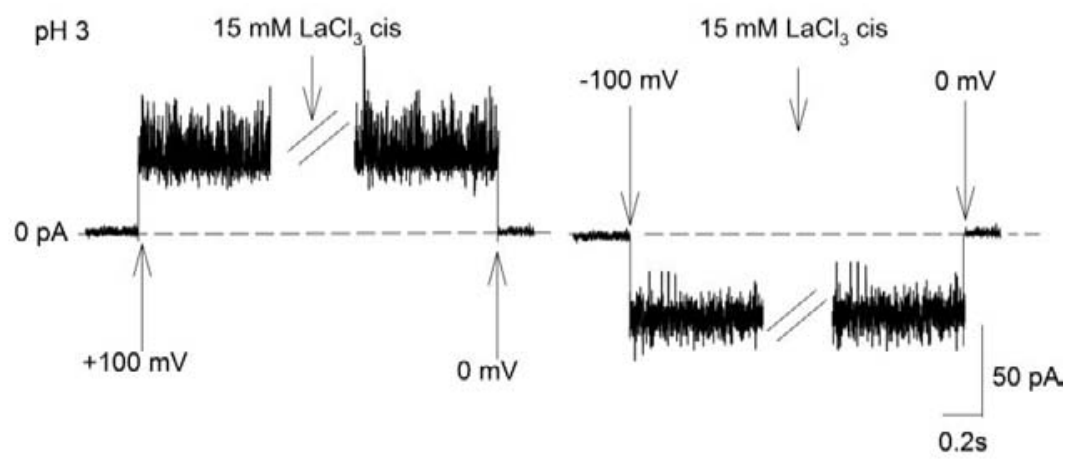

Figure 3.9 Single channel current recordings show the effect of $\mathrm{pH}$ solutions on $\mathrm{La}^{3+}$ induced channel rectification. (A) At $\mathrm{pH} 6$ the addition of $15 \mathrm{mM}$ of $\mathrm{LaCl}_{3}$ salt reduces $\mathrm{OmpF}$ current level at positive potential. (B) At pH 3 no channel rectification is observed. Experiments were performed in $0.1 \mathrm{M} \mathrm{KCl}$.

A

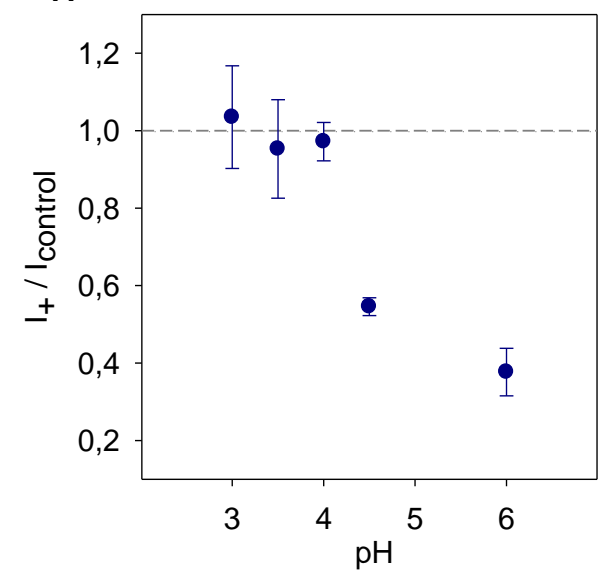

B

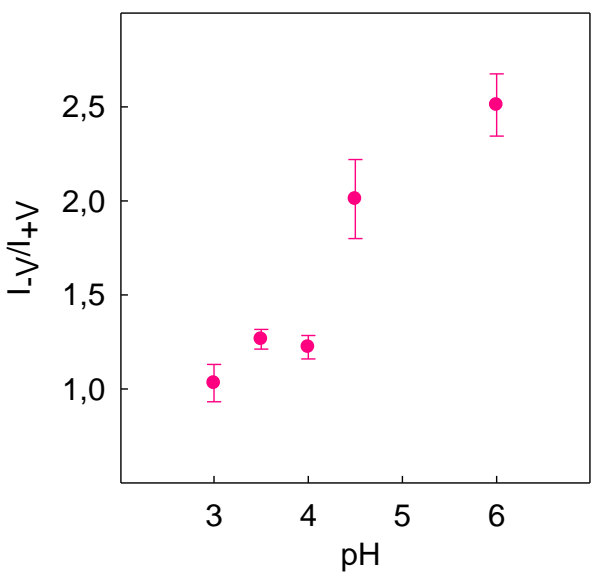

Figure 3.10 Dependence of the OmpF current rectification on the acidity of the solution $0.1 \mathrm{M} \mathrm{KCl}$ $+5 \mathrm{mM} \mathrm{LaCl}_{3}$. (A) Plot of the ratio between the current at $+100 \mathrm{mV}$ after and before $\mathrm{LaCl}_{3}$ addition $I_{+} / I_{\text {control }}$; (B) Plot of the asymmetry ratio, defined as $I_{-\mathrm{V}} / I_{+\mathrm{V}}$, at $\pm 100 \mathrm{mV}$ before and after the addition of $\mathrm{LaCl}_{3}$. Current rectification vanishes near $\mathrm{pH} 3$. 


\subsubsection{Insights on the lanthanum block mechanism}

To figure out what type of block describes the lanthanum interaction with the channel we adapted a formalism from enzyme kinetics considering that current (charges per second) for an ion channel is analogous to velocity (products per second) for an enzyme, and concentration of permeant ions for ion channels is analogous to concentration of substrate for an enzyme ( Hille 1975). By plotting $1 /$ velocity vs $1 /$ [substrate] the nature of the block can be investigated. In our case we plotted $1 /$ conductance vs $1 /[\mathrm{KCl}]$. The theoretical plots for competitive and non-competitive blocks are shown in Figure 3.11. For a competitive block the inverse conductance values with and without blocker intersect on the $y$-axis, pointing that virtual infinite concentration of substrate, in our case $\mathrm{K}^{+}$cations, fully relieves the effect of the blocker, $\mathrm{La}^{3+}$ cations. On the contrary, for a non-competitive block, the results with and without the presence of blocker intersect on the $x$-axis indicating that the block cannot be surmounted even at infinite substrate ( $\mathrm{K}^{+}$cations) concentration.

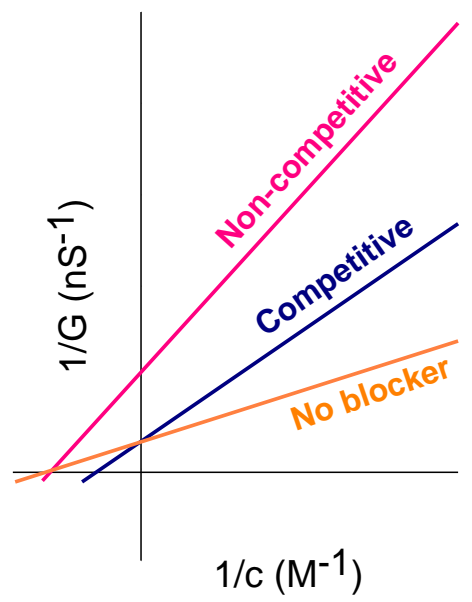

Figure 3.11 Ideal double reciprocal plots of conductance versus [KCl] illustrate non-competitive and competitive blocks.

We performed experiments at different $\mathrm{KCl}$ concentration in the absence of $\mathrm{LaCl}_{3}$ and in the presence of 2 and $5 \mathrm{mM} \mathrm{LaCl}_{3}$ and represented the reciprocal plot (Figure 3.12). The experimental results show that $\mathrm{La}^{3+}$-induced current reduction is consistent with a competitive block, which suggests that lanthanum cations and potassium cations try to occupy the same binding site in OmpF channel. 


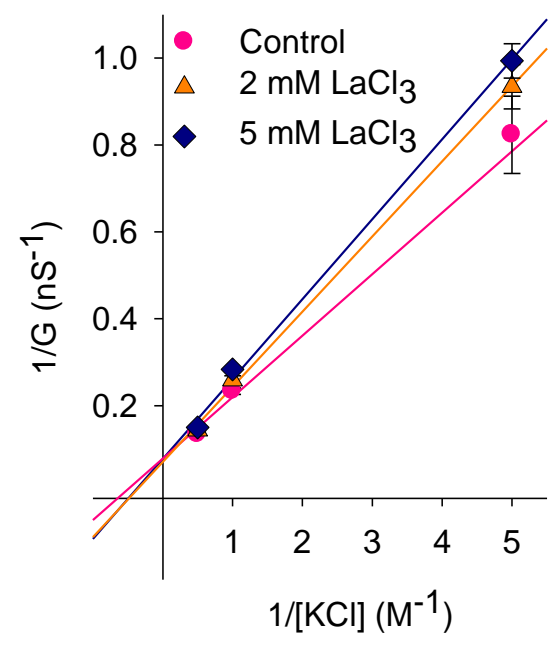

Figure 3.12 Double reciprocal plots of measured single channel conductance versus [KCl] for control (pink circles) and for 2 and $5 \mathrm{mM} \mathrm{LaCl}_{3}$ concentrations (orange triangles and blue diamonds, respectively). For plots with blocker, the intersection with the Y-axis indicates that lanthanum blocking is a competitive block.

\subsubsection{Investigating the voltage dependence}

As shown in the previous section, the $\mathrm{La}^{3+}$ ions block OmpF channels in a voltage and $\left[\mathrm{La}^{3+}\right]$-dependent manner. For charged compounds that act as blockers, voltage dependence is typically described with the Woodhull model (Woodhull 1973). Here inhibition results from a simple binding reaction in which the charged blocker $X$ binds to an open channel $O$ at a site located within the electric field producing a blocked channel $B$. We analyze the voltage dependence of the lanthanum block by incorporating the competitive interaction between $\mathrm{La}^{3+}$ and $\mathrm{K}^{+}$into the Woodhull model. This contribution is included by using the equations from the enzyme kinetics.

The Hill equation describes the ion current in the presence of a substrate $\left(\mathrm{K}^{+}\right)$:

$$
\frac{i_{0}}{i_{\max }}=\frac{\left[K^{+}\right]^{n}}{\left[K^{+}\right]^{n}+k_{K^{+}}^{n}}
$$

where $\left[K^{+}\right]$is the concentration of the substrate, $k_{K}^{+}$corresponds to the dissociation constant for $\mathrm{K}^{+}, i_{\max }$ is the saturation current, and $n$ is the Hill coefficient that measures the level of cooperativity (Hill 1910). In the presence 
of a competitive interaction between the blocker and the substrate it is necessary to change the dissociation constant by apparent constant $k$ :

$$
k=k_{K^{+}}\left(1+\frac{\left[L a^{3+}\right]}{k_{L a^{3+}}}\right)
$$

where $\left[\mathrm{La}^{3+}\right]$ is the concentration of the blocker, and ${\mathrm{k}_{\mathrm{La}}}^{3+}$ is the dissociation constant for the blocking ion (Stryer 1981). By introducing equation 3.2 into equation 3.1 the following expression is got:

$$
\frac{i_{b}}{i_{\max }}=\frac{\left[K^{+}\right]^{n}}{\left[K^{+}\right]^{n}+k_{K^{+}}^{n}\left(1+\frac{\left[L a^{3+}\right]}{k_{L a^{3+}}}\right)^{n}}
$$

By dividing equation 3.3 between 3.1 , the ratio of current in the presence $\left(i_{b}\right)$ and absence $\left(i_{0}\right)$ of the blocker is obtained:

$$
\frac{i_{b}}{i_{0}}=\frac{\left[K^{+}\right]^{n}+k_{K^{+}}^{n}}{\left[K^{+}\right]^{n}+k_{K^{+}}^{n}\left(1+\frac{\left[L a^{3+}\right]}{k_{L a^{3+}}}\right)^{n}}
$$

Then the voltage dependence is introduced by the Woodhull model. This model has been extensively used to describe the voltage dependence of channel blocking by charged molecules or compounds (Blatz \& Magleby 1984; Yellen 1984; Vergara et al. 1984). In the Woodhull model the concentration of substrate and blocker at the binding site is given by:

$$
\begin{gathered}
{\left[K^{+}\right]=\left[K^{+}\right]_{0} \exp \left(\frac{z F \delta}{R T} V\right)} \\
{\left[L a^{3+}\right]=\left[L a^{3+}\right]_{0} \exp \left(\frac{z F \delta}{R T} V\right)}
\end{gathered}
$$

The subscript 0 refers to the ion concentration in the bath solution, $z$ is the valence of the ion, $V$ is the voltage drop across the membrane, and $\delta$ is the fraction of potential traversed in reaching the binding site. 
We fitted the experimental data to this modified Woodhull model. Figure 3.13 displays the best fits to the I-V curves with $0,2,5$ and $10 \mathrm{mM} \mathrm{LaCl}_{3}$ concentrations. The values of the dissociation constants $k_{L a}{ }^{3+}$ and $k_{K}^{+}$offer estimation about the affinity between the blocker and the binding site of the protein. The values obtained are consistent with the range of concentrations that produce the channel blockage, which are in the millimolar range of concentrations. The value of $n$ is lower than unity, which suggests a negative cooperativity. This implies that the presence of the first molecules makes difficult the access of the second one to reach the binding site. This concept is consistent with the competitive block characterized in the previous section.

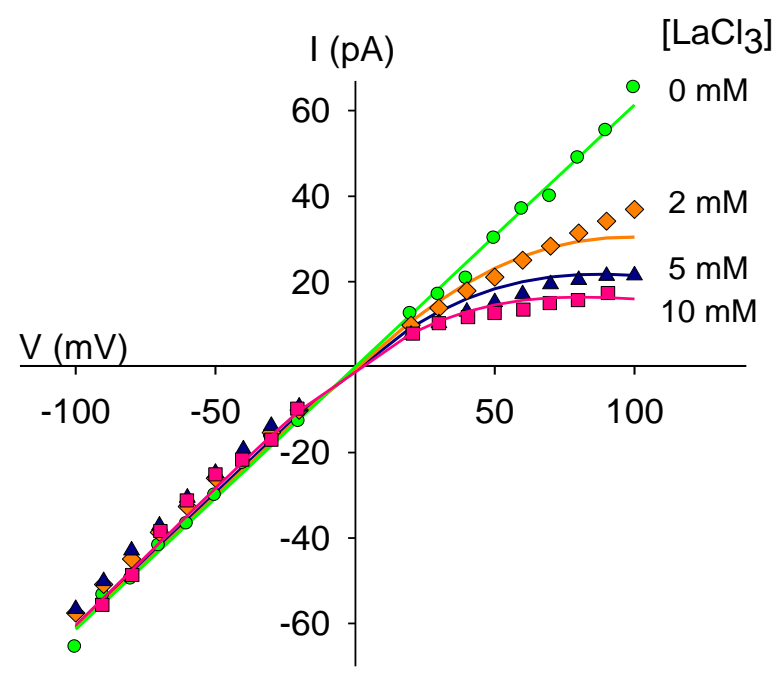

Figure 3.13 Channel conductance of a single OmpF channel is affected by the presence of $\mathrm{LaCl}_{3}$ salt. The addition of $\mathrm{LaCl}_{3}$ reduces the channel current asymmetrically. The green I-V curve is the control value, without $\mathrm{LaCl}_{3}$. The other curves were recorded after the addition of 2, 5 and $10 \mathrm{mM}$ $\mathrm{LaCl}_{3}$ in cis side. Curves correspond to fits to a modified Woodhull model. The best fit was obtained using the parameters $\delta=0.3,{k_{K}}^{+}=150 \mathrm{mM}, k_{L a}{ }^{3+}=7 \mathrm{mM}$, and $n=0.55$.

The electrical distance $(\delta)$ obtained is 0.3 . This factor represents the fraction of the membrane voltage drop in the binding site of the ion channel. In our case $\delta=0.3$ means that the voltage drop at the binding site is $\sim 30 \%$ of the applied voltage. This result is interesting because reveals a voltage asymmetry in the blocking mechanism that may explain why the blocking occurs when lanthanum is added in cis side.

It is known from theoretical studies (MD and BD simulations, PNP equations, electrostatic calculations) that the voltage drop in OmpF channel is not linear at all (Im \& Roux 2002 b; Aguilella-Arzo et al. 2007). The main voltage drop is located around the central constriction, and only low voltage drop 
occurs in the channel mouths. So, it is not obvious that a 30\% fraction of the applied voltage corresponds to a location of the binding site near the channel vestibules. In fact, the binding site may be situated near the central constriction. Additional techniques are required to get information about the residues implicated in the lanthanum interaction.

\subsubsection{Looking for a binding site for $\mathrm{La}^{3+}$ ions}

We have showed that both the proton and lanthanum block seem to be regulated by similar mechanisms, a competitive binding with salt cations. In a previous work the proton block was reported to take place in the OmpF constriction. It is known that at neutral $\mathrm{pH}$ conditions, the clusters of charges of the OmpF constriction creates a transversal electric field that give an effective permeation mechanism in which cations and anions follow well-separated permeation trajectories in a screw-like fashion along the channel (Im \& Roux 2002 b; Schirmer 1998, Phale et al. 2001). Anions cross the pore close to the positively charged arginines whereas cations permeate near the negative residues. This particularly effective pathway is distorted when the acidic negative residues are neutralized (by mutations or via proton titration). Sitedirected mutagenesis allowed for the identification of the residues involved in proton/cation binding and it proved that the proton block takes place in the pore constriction (Alcaraz et al. 2012).

Considering that both $\mathrm{pH}$ and lanthanum seem to be regulated by competitive mechanisms, it could be enlightening to perform current experiments using selected $\mathrm{OmpF}$ mutants to analyze if the residues involved in the $\mathrm{pH}$ block (aspartate D113 and glutamate E117) could be also involved in the lanthanum blocking.

First of all we measured the channel current of the D113R/E117R OmpF mutant, which has the two acidic residues replaced by two positive arginines. Then, once the I-V current control was obtained, the effect of $\mathrm{LaCl}_{3}$ at millimolar concentration was evaluated. The results obtained are shown in Figure 3.14. No changes were observed after the addition of $\mathrm{LaCl}_{3}$. To gain more evidence, the concentration of lanthanum salt was increased up to $150 \mathrm{mM}$ but no effect was produced on channel conductance. 


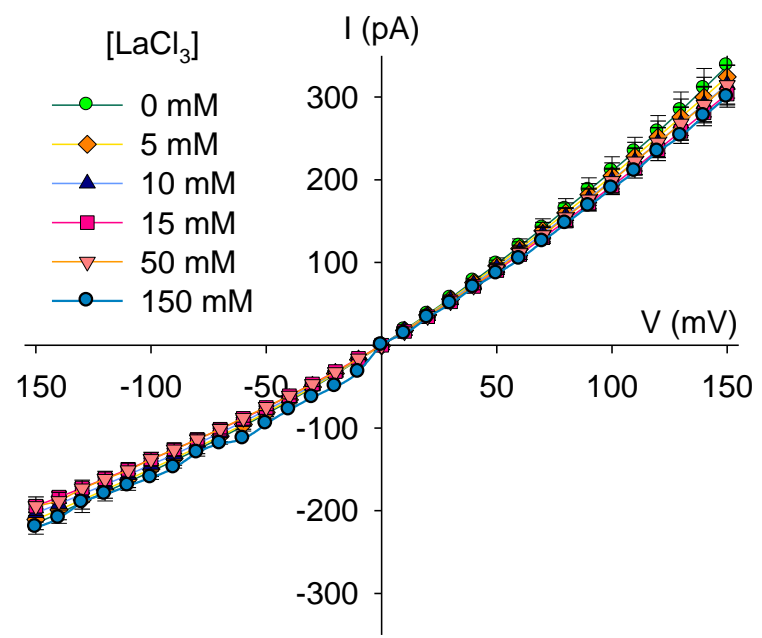

Figure 3.14 No effect induced by $\mathrm{La}^{3+}$ ions was observed in the D133R/E117R OmpF mutant. The single channel current after the addition of $\mathrm{LaCl}_{3}$ is the same than the channel current without the presence of lanthanum salt. Experiments were performed in $1 \mathrm{M} \mathrm{KCl}$ solution at pH 6 .

The fact that conductance did not display any variation supports the important role that the constriction zone plays in the lanthanum blocking. However, these results do not certainly mean that lanthanum cations do interact simultaneously and exclusively with these two acidic residues. Other residues near or in the constriction may be involved in this phenomenon and the replacement of D113 and E117 may be affected their interaction. It is important to note that the presence of five positive residues in the D113R/E117R OmpF mutant may make difficult other interactions between lanthanum and other residues near constriction.

To check to what extent lanthanum block needs the presence of these acidic residues, we investigated the effect of lanthanum on channel conductance of mutants in which only one of the negative residues have been replaced, D113 or E117. The mutants chose were D113C and E117C, in which one of the negative residues was changed by a neutral cysteine, and D113R, in which D113 was replaced by a positive arginine. We measured the channel current under the presence of $15 \mathrm{mM} \mathrm{LaCl}_{3}$ and we calculated the current rectification, which is defined as the current recorded without blocker divided by the current observed under the presence of blocker. As Figure 3.15 displays, the current rectification for $\mathrm{D} 113 \mathrm{C}$ and $\mathrm{E} 117 \mathrm{C} \mathrm{OmpF}$ mutants is higher than in OmpF-wt $\left(I_{0} / I=1.39\right)$, being $I_{0} / I=1.61 \pm 0.35$ and $I_{0} / I=1.66 \pm 0.19$ respectively. On the contrary, for the mutant $D 113 R$ the current rectification is lower than in OmpF-wt, being $I_{0} / I=1.30 \pm 0.13$, which indicates that although the block is still present, the effect of the blocker is smaller than in the wild-type protein (Figure 3.15). 


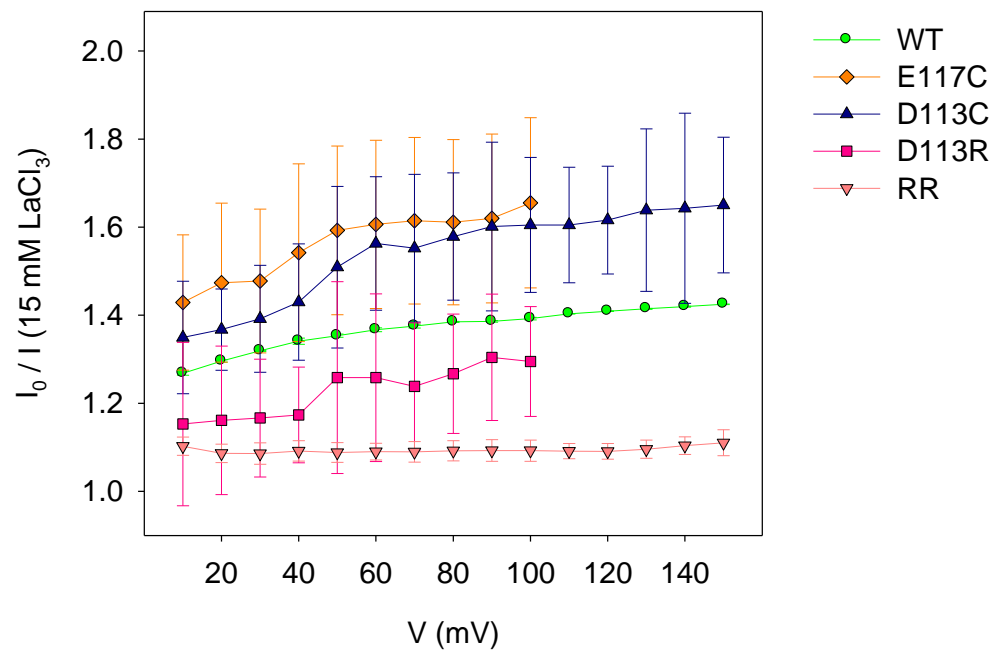

Figure 3.15 Current rectification produced by $\mathrm{La}^{3+}$ ion varies with the OmpF mutant used in the experiment. The rectification here is defined as the current without $\mathrm{La}^{3+}$ divided by the current recorded in the presence of $\mathrm{La}^{3+}$. The experimental conditions were $1 \mathrm{M} \mathrm{KCl}$ solution before and after the addition of $15 \mathrm{mM} \mathrm{LaCl}_{3}$ in the cis side.

The qualitative message of these results is clear: residues D113 and E117 located in the OmpF constriction severely affect the $\mathrm{La}^{3+}$ induced current rectification. Only by removing one or two of these residues, the blocking can be increased, decreased, or even reversed, which stresses that these residues are responsible for the lanthanum-OmpF interaction. However, a quantitative interpretation of the data it not easy, because mutagenesis involves important changes that may affect to other physical properties, such as the spatial distribution of the residues, the possibility for binding...

\subsubsection{Understanding the asymmetry of lanthanum block}

The results obtained up to now can be summarized as follows: the channel partial block induced by lanthanum may be a competitive interaction between $\mathrm{La}^{3+}$ and $\mathrm{K}^{+}$in which the residues located around the channel central constriction play a capital role. Besides, the value for the voltage drop obtained from Woodhull model $(\delta=0.3)$ does not necessarily mean that the binding site is near the pore entrance, but it could be placed around the central constriction. At this point, we wonder how it is possible to explain the asymmetry of the lanthanum effect: the current rectification is only observed when $\mathrm{LaCl}_{3}$ is added into cis side and only for positive voltages.

Putting together the available data, we hypothesize that the asymmetry of the channel block could be originated in the fact that the strong electric field 
in the pore constriction is not perpendicular to the channel axis, but it is tilted laterally ( 30 degrees) (Levadny et al. 2004). Indeed, this tilt is the responsible for the separate pathways of cations and anions in a screw-like fashion which is a distinctive feature of some bacterial porins. In practice, this could mean that the access to the binding site for $\mathrm{La}^{3+}$ may be favored in one direction by the axial component of the electric field, and in the other direction the permeation of $\mathrm{La}^{3+}$ may be difficult. This idea is represented in the cartoon in Figure 3.16.
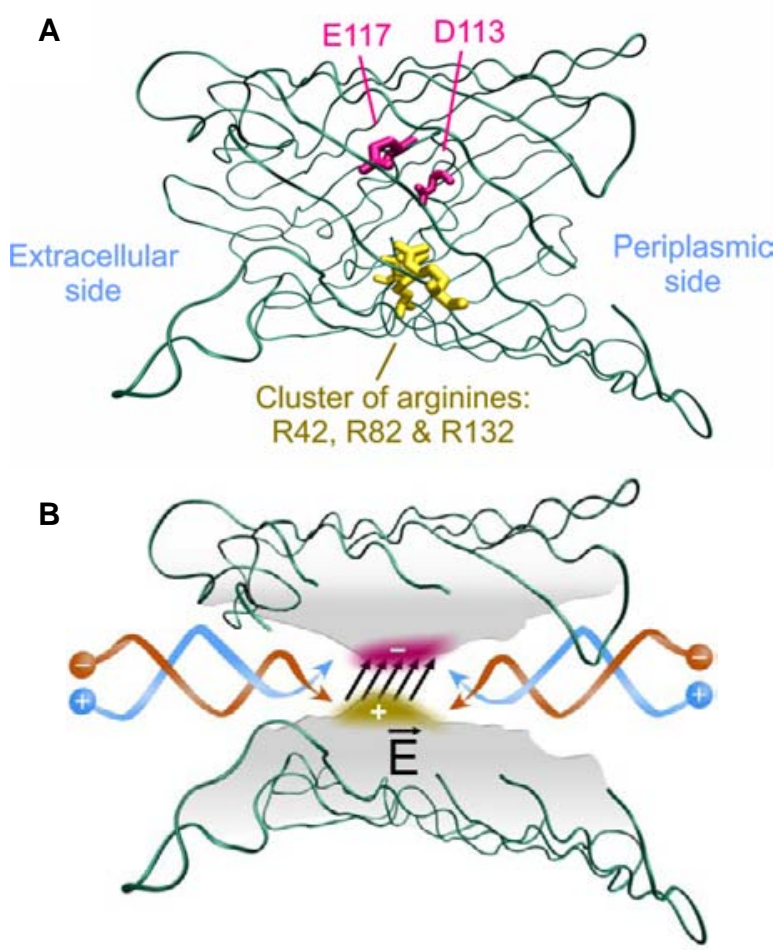

Figure 3.16 (A) Lateral representation of the OmpF channel obtained from the crystal structure (PDB code: 2OMF). The two acidic residues (D113 and E117) and three basic residues (R42, R82 and R132) of the constriction are highlighted. (B) Lateral representation of the OmpF channel showing the $30^{\circ}$ - tilted transversal electrical field.

In order to check this hypothesis, we analyzed the $\mathrm{La}^{3+}$ fluxes through the pore. By inductively coupled plasma mass spectrometry (ICP-MS) the concentration of lanthanum passing through the channel is determined. The experimental protocol is the following: once single channel was inserted at + $100 \mathrm{mV}$ we added $\mathrm{LaCl}_{3}$ into cis side and we recorded for several minutes; next, we took the solution of the trans side and measured the concentration of lanthanum by ICP-MS, to quantify the amount of lanthanum that crosses the channel. Then, we operated in the opposite way: once single OmpF channel was inserted at $+100 \mathrm{mV}, \mathrm{LaCl}_{3}$ was added into trans side and we recorded for 
several minutes and finally we determined the concentration of lanthanum present in the cis side.

The results obtained are plotted in Figure 3.17. The experimental data clearly show that $\mathrm{La}^{3+}$ flows across the channel more efficiently when is added into cis side than in trans side. This result is in agreement with the asymmetry of the blockage, which is only observed when lanthanum is added into cis side. It is clear that cis side favors the lanthanum passage through the channel allowing lanthanum to bind to the site. Lanthanum ion flowing is helped by the local electric field and it disturbs the overall permeation mechanism. Then, $\mathrm{La}^{3+}$ leaves the site when other $\mathrm{La}^{3+}$ ion approaches the site.

On the contrary, when $\mathrm{LaCl}_{3}$ is added to the trans side, the permeation rate of $\mathrm{La}^{3+}$ is lower by a factor of 100 and no effective block in the current is produced. In this situation the direction of the electric field is unfavorable for $\mathrm{La}^{3+}$ permeation across the channel, and the applied voltage that helps $\mathrm{La}^{3+}$ cations to overcome this unfavorable electric field is not enough so the partial block is not observed.

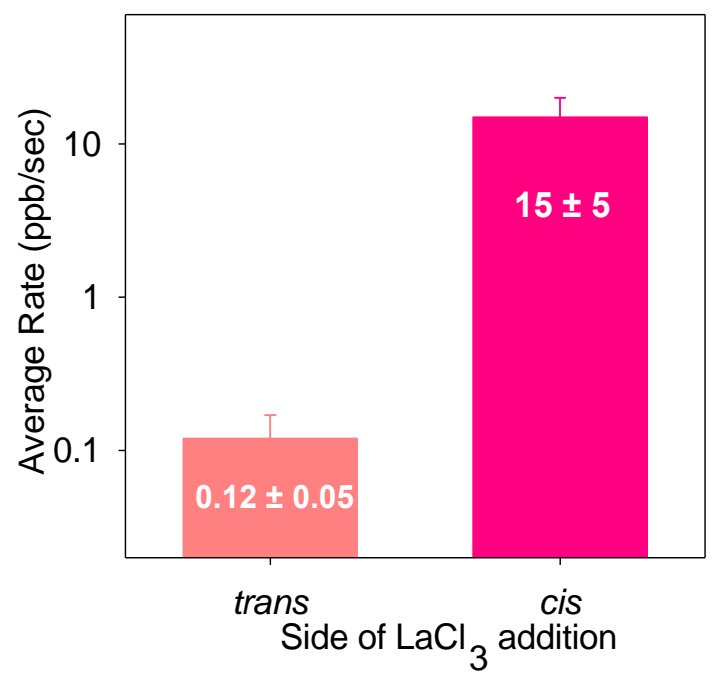

Figure 3.17 Average permeation rate of $\mathrm{La}^{3+}$ cations through OmpF determined by ICP-MS. As cartoon shows, the values obtained are very different for the two situations. When $\mathrm{La}^{3+}$ flows from cis to trans (effective block) the concentration of $\mathrm{La}^{3+}$ is much higher than in the opposite flowing direction. The average rate values are hardly compatible with the magnitude of current observed suggesting neutral salt flowing through the channel so that the OmpF selectivity is neutralized by permeating $\mathrm{La}^{3+}$ cations. 


\subsection{CONCLUSIONS}

The results presented here show that the presence of millimolar $\mathrm{LaCl}_{3}$ concentrations exerts a dramatic impact on OmpF ion selectivity and channel conductance. Reversal potential experiments using $\mathrm{LaCl}_{3}$ as a trace compound show that the presence of lanthanum ions could even invert the OmpF selectivity. The amount of $\mathrm{LaCl}_{3}$ necessary to reverse the OmpF channel selectivity depends on the absolute $\mathrm{KCl}$ concentration. Under a $0.1 / 1 \mathrm{M} \mathrm{KCl}$ gradient the addition of $7 \mathrm{mM} \mathrm{LaCl}_{3}$ turns the cationic selectivity into anionic. However, in $15 / 150 \mathrm{mM} \mathrm{KCl}$ just $4 \mathrm{mM} \mathrm{LaCl}_{3}$ is enough to produce the selectivity inversion. These results indicate that $\mathrm{La}^{3+}$ ions somewhat interact with channel residues modifying the effective density charge of the channel.

As regards conductance experiments, the addition of millimolar $\mathrm{LaCl}_{3}$ concentrations in $\mathrm{KCl}$ electrolyte solutions induces current-rectification. We observe that the side of lanthanum addition is decisive to produce the blocking. Thus, the presence of $\mathrm{LaCl}_{3}$ in cis solution is a necessary and sufficient condition to produce rectification. Other important feature of the lanthanum-induced blocking is that $\mathrm{pH}$ of the bathing solutions modulates the rectification properties. In high acidity solutions no current rectification is observed. By applying formalism from enzyme kinetics we have proved that increasing concentration of $\mathrm{KCl}$ fully relieves the lanthanum block. This indicates that the mechanism responsible for lanthanum blocking is a competitive interaction involving $\mathrm{K}^{+}$and $\mathrm{La}^{3+}$ ions.

Site-directed mutagenesis indicates that the residues located in the pore constriction regulate the lanthanum-induced blocking. By means of selected mutations of one or two key residues of this region, the $\mathrm{La}^{3+}$-induced blocking can be tuned and it can be increased, decreased, or even removed. We have also showed that the particular features of the charge distribution in the pore constriction are behind the asymmetry found in the $\mathrm{La}^{3+}$ ability to block the channel. A binding site located in a central position generates a functional asymmetry possibly due to the existence of a tilted transversal electric field yielding asymmetric access routes to the site. 



SARS-CoV E protein ion

channel activity and its implication on virulence 

Part of the studies included in the present chapter were published in the following articles:

"Coronavirus E protein forms ion channels with functionally and structurally-involved membrane lipids", Virlogy (2012) 432, 485 494.

"Analysis of SARS-COV E protein ion channel activity by tuning the protein and lipid charge", Biochimica et Biophysica Acta (2013) 1828, 2026- 2031.

"Severe acute respiratory syndrome coronavirus envelope protein ion channel activity promotes virus fitness and pathogenesis" (2014) 10, 1-19. 



\subsection{INTRODUCTION}

SARS-CoV E protein is a 76-aminoacid transmembrane protein that is actively synthetized during viral infection. It mainly localizes at the endoplasmatic reticulum Golgi intermediate compartment (ERGIC) of the cell, where the virus budding and morphogenesis take place (Nieto-Torres et al. 2011; DeDiego et al. 2007; Raamsman et al. 2000). Primarily due to the small size and hydrophobic nature, SARS-CoV E protein is a candidate member of a family of virus-encoded proteins that form ion channels, known as viroporins. These viral proteins are generally involved in virus entry, trafficking, maturation, inflammation and apoptosis (Campanella et al. 2004; Wozniak et al. 2010).

It has been observed that the deletion of SARS-CoV E gene attenuates the virus (DeDiego et al. 2007; Dediego et al. 2008; Lamirande et al. 2008; Netland et al. 2010). Previous studies have reported that SARS-CoV E protein forms a pentameric structure that delimits an ion conductive pore in planar lipid bilayers and micelles (Pervushin et al. 2009; Torres et al. 2007; Wilson et al. 2006a; Wilson et al. 2004). Ever since the E protein ion channel activity was discovered, the question of whether this function is involved in virulence has been a goal to study.

In the present chapter we characterized the conductance, ion selectivity and voltage-dependence of $E$ protein ion channel by electrophysiological experiments. The $\mathrm{E}$ protein transport properties were determined under different experimental conditions: varying salt concentration, $\mathrm{pH}$ and membrane lipid composition in order to get extensive information about its ion transport function. In addition, we investigated how the ion channel function affects to virus pathogenesis. To achieve this goal, the residues responsible for the ion channel function were identified. Then, by combining this knowledge with the manipulation of SARS-CoV genome we sought to clarify whether the $E$ protein ion channel activity is a virulence determinant.

\subsection{RESULTS}

\subsubsection{Channel conductance and ion selectivity in neutral membranes}

It has been reported that the transmembrane domain of the SARS-CoV E protein is responsible for the E protein ion channel activity (Wilson et al. 2004; Pervushin et al. 2009). Following this idea, we tested if a synthetic peptide with the same aminoacid sequence as the $E$ protein transmembrane domain displayed similar ion conductance properties to the full E protein. 
We determined the channel conductance of the wild type protein transmembrane domain peptide (E peptide) in $\mathrm{KCl}$ and $\mathrm{NaCl}$ solutions. Single channel conductance was obtained by statistical analysis as follows: we represented in a histogram the current jump amplitudes observed in recordings and then we fitted these data to a Gaussian function in order to get the most probable value for the current jump amplitude. Then the value of unitary conductance was calculated by the quotient between the most probable current jump amplitude and the value of applied voltage $(+100 \mathrm{mV})$. This procedure allows a reliable estimate of the most probable value of the current change every time a new channel is inserted or disappears.

Histograms of current jump amplitudes in $1 \mathrm{M} \mathrm{KCl}$ and $1 \mathrm{M} \mathrm{NaCl}$ are shown in Figure 4.1. The most probable levels correspond to $31 \pm 12 \mathrm{pA}$ in $\mathrm{KCl}$ and to $18 \pm 12 \mathrm{pA}$ in $\mathrm{NaCl}$ which give conductance values of $0.31 \pm 0.12 \mathrm{nS}$ and $0.18 \pm 0.12 \mathrm{nS}$, respectively. Then, the channel conductance for the full E protein was determined under the same experimental conditions. Figure 4.2 shows the homologous histograms for $E$ protein whose conductance values are $0.37 \pm 0.16$ $\mathrm{nS}$ in $\mathrm{KCl}$ and $0.19 \pm 0.06 \mathrm{nS}$ in $\mathrm{NaCl}$.
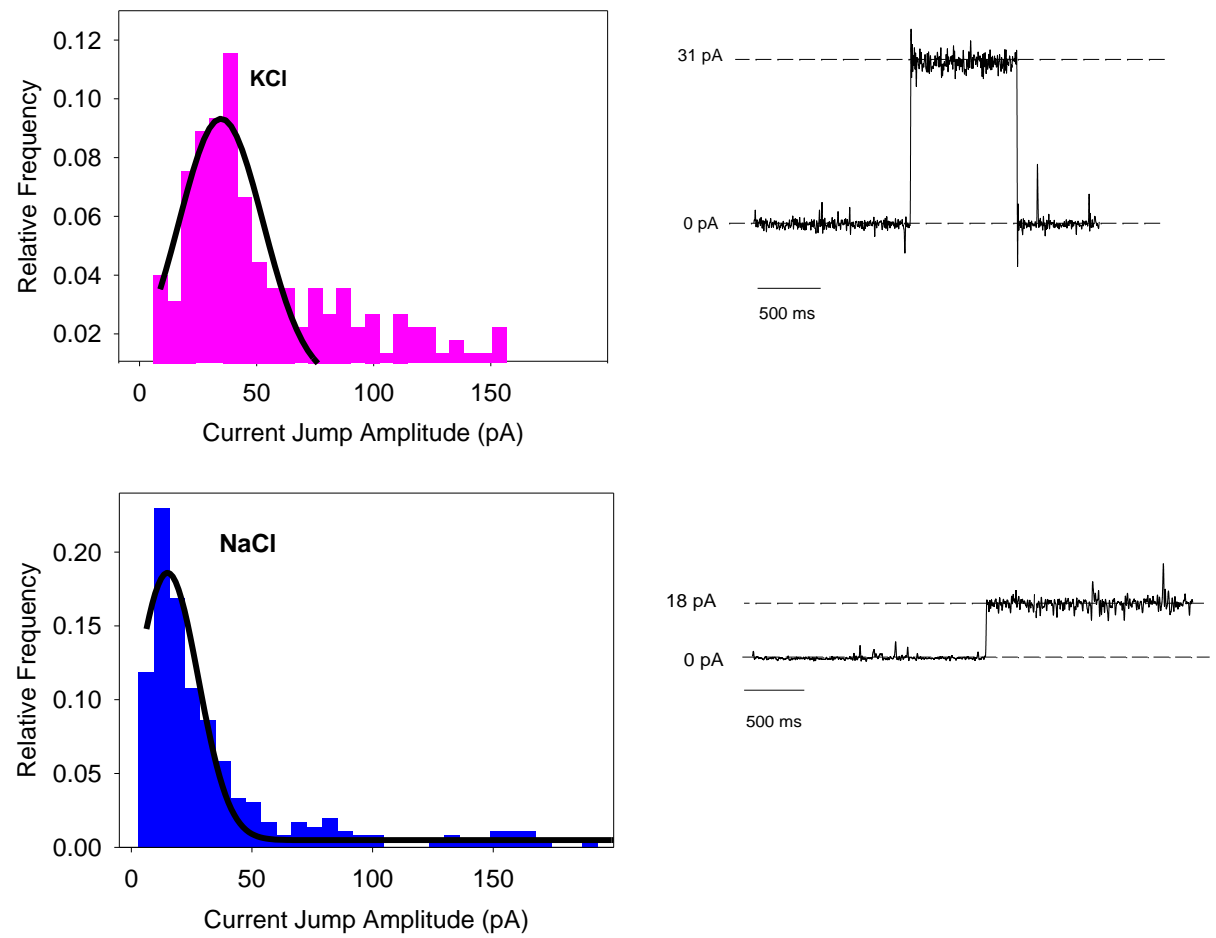

Figure 4.1 Histograms of current jump amplitude at $+100 \mathrm{mV}$ and sample current recording of $\mathrm{E}$ peptide in $1 \mathrm{M} \mathrm{KCl}$ (top) and $1 \mathrm{M} \mathrm{NaCl}$ (bottom). Conductance experiments were performed at room temperature and $\mathrm{pH} 6$ by reconstituting the $\mathrm{E}$ peptide in neutral membranes (DPhPC). Histograms contain values from 300 recording events. 
Both channels exhibit similar values of conductance, a fact that validates the use of the transmembrane domain peptide to measure the ion channel activity of $\mathrm{E}$ protein. We noted that the conductance in $\mathrm{KCl}$ solutions is 1.7 times higher than in $\mathrm{NaCl}$ solutions. This difference can be explained by the intrinsic properties of the electrolytes, as the mobility of potassium ions is 1.66 times higher than the mobility of sodium ions. It indicates that neither the $E$ peptide nor the $\mathrm{E}$ protein showed significant preference for $\mathrm{K}^{+}$over $\mathrm{Na}^{+}$.

The histograms also reveal other current levels with values that are multiple of the most frequent one. These levels of high conductance states could be actually originated by occasional simultaneous insertions of two or three channels rather than by larger independent structures.
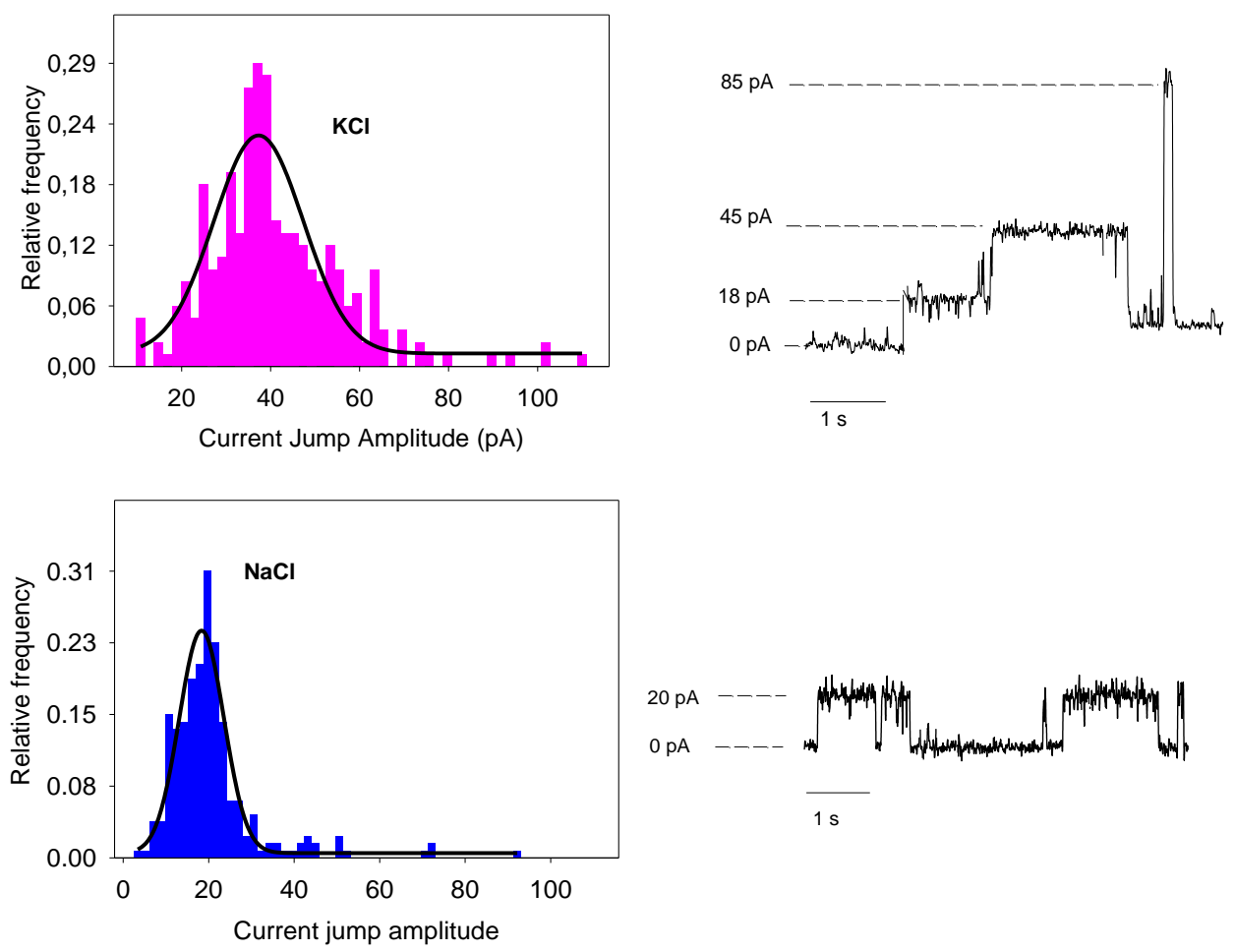

Figure 4.2 Histograms of current jump amplitude at $+100 \mathrm{mV}$ and current recording of $\mathrm{E}$ protein in $1 \mathrm{M} \mathrm{KCl}$ (top) and $1 \mathrm{M} \mathrm{NaCl}$ (bottom). In order to compare with the conductance values of $\mathrm{E}$ peptide, the experiments were carried out at $\mathrm{pH} 6$ and in neutral membranes (DPhPC). Histograms contain 300 recording events. 
Then we analyzed the voltage dependence of the $E$ protein ion channel current. Figure 4.3 displays the current-voltage relationship in $\mathrm{KCl}$ (pink squares) and in $\mathrm{NaCl}$ (blue triangles). E protein exhibits ohmic behavior, which indicates that the number of current carriers is not dependent on the direction of the applied potential neither on its magnitude. Other channel-forming peptides like alamethicin (Hall et al. 1984) or syringomycin E (Malev et al. 2002) show a clear voltage dependence that is related to the existence of several conformational states. The voltage independence of $E$ protein discards the existence of voltageinduced dynamical structures.

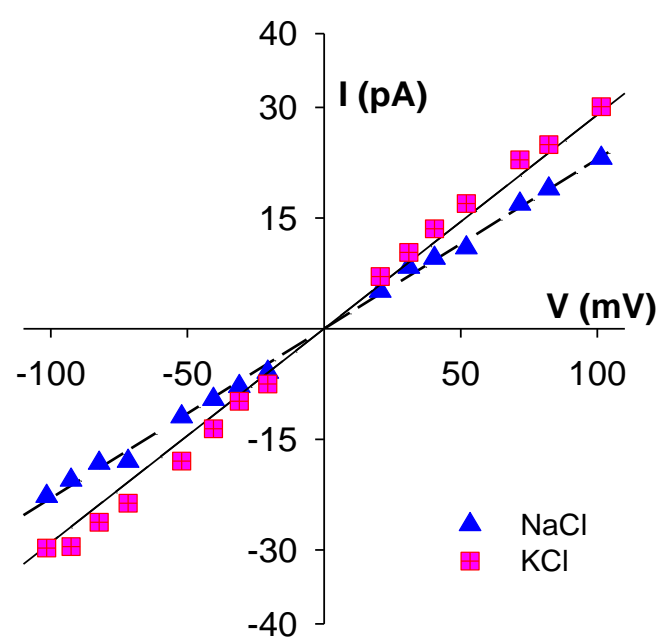

Figure 4.3 $\mathrm{E}$ protein shows a linear current-voltage relationship in $1 \mathrm{M} \mathrm{NaCl}$ (blue triangles) and in $1 \mathrm{M} \mathrm{KCl}$ solutions (pink squares). Each point represents the mean of at least three experiments. Error bars are smaller than the symbol size.

In order to complete the characterization of the E protein and E peptide ion channel activity in neutral membranes, the ion selectivity was determined. The measured reversal potential can be converted into the channel permeability ratio $\left(P_{+} / P_{-}\right)$by means of the Goldman-Hodgkin-Katz equation (GHK) (Hodgkin \& Katz 1949) which indicates the channel preference for cations over anions:

$$
\begin{aligned}
& E_{\text {rev }}=\left(-\frac{k_{B} \cdot T}{z e}\right) \ln \left(\frac{P_{+} c_{+c i s}+P_{-} c_{-t r a n s}}{P_{-} c_{-c i s}+P_{+} c_{+t r a n s}}\right) \\
& \frac{P_{+}}{P_{-}}=\frac{c_{\text {trans }}-e^{\frac{-E_{r e v} \cdot z e}{k_{B} T}} \cdot c_{c i s}}{c_{\text {trans }} \cdot e^{\frac{-E_{r e v} \cdot z e}{k_{B} T}}-c_{c i s}}
\end{aligned}
$$


where $P_{+}$is the cation permeability and $P_{\text {. }}$ the anion permeability, $k_{B}$ is Boltzmann's constant, $E_{r e v}$ is the value of the reversal potential measured, $T$ the temperature, $z$ the valence, and $e$ the elementary charge.

Table 4.1 shows the values of reversal potential and the corresponding permeability ratios. Similarly to what happens in channel conductance values, the ion selectivity of $\mathrm{E}$ peptide and $\mathrm{E}$ protein is almost the same: the $P_{+} / P_{\text {. of }}$ o protein is only $15 \%$ and $10 \%$ higher than $P_{+} / P_{\text {. of }} \mathrm{E}$ peptide in $\mathrm{NaCl}$ and $\mathrm{KCl}$ solutions respectively.

Table 4.1 Reversal potential ( $\mathrm{mV}$ ) measured for $\mathrm{E}$ peptide and $\mathrm{E}$ protein under a 10 -fold $\mathrm{NaCl}$ and $\mathrm{KCl}$ concentration gradient $(500 / 50 \mathrm{mM})$. Experiments were performed at room temperature and $\mathrm{pH} 6$.

\begin{tabular}{ccccc}
\hline & \multicolumn{2}{c}{$\mathbf{N a C l}$} & \multicolumn{2}{c}{$\mathrm{KCl}$} \\
\cline { 2 - 5 } & $\boldsymbol{E}_{\text {rev }}(\mathbf{m V})$ & $\boldsymbol{P}_{+} / \boldsymbol{P}_{-}$ & $\boldsymbol{E}_{\text {rev }}(\mathbf{m V})$ & $\boldsymbol{P}_{+} / \boldsymbol{P}_{-}$ \\
E PEPTIDE & $12.2 \pm 2.0(\mathrm{n}=59)$ & $0.6 \pm 0.1$ & $1.9 \pm 0.8(\mathrm{n}=20)$ & $1.0 \pm 0.1$ \\
E PROTEIN & $8.6 \pm 1.7(\mathrm{n}=20)$ & $0.7 \pm 0.1$ & $5.6 \pm 1.4(\mathrm{n}=7)$ & $1.1 \pm 0.1$ \\
\hline
\end{tabular}

Apparently, these reversal potential results could lead to the wrong conclusion that the $\mathrm{K}^{+}$ions are preferred over $\mathrm{Na}^{+}$ions, since the permeability ratios are greater for $\mathrm{KCl}$ than for $\mathrm{NaCl}$. However, it is important to stress that this parameter (and ion selectivity) is a joint measure of the channel discrimination between ions with different charge (electrostatic exclusion or accumulation) and the electrolyte intrinsic properties (difference between cation and anion mobility). In a neutral pore, which does not exert any interaction with mobile ions, the permeability ratio is related to the difference

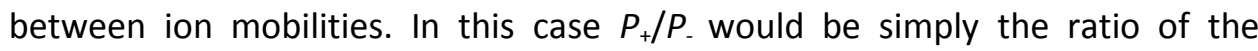
diffusion coefficients in a free solution, which should be $P_{+} / P_{-} \sim 0.5$ for $\mathrm{NaCl}$ and $P_{+} / P_{-} \sim 1$ for $\mathrm{KCl}$. These calculated values are almost identical to the values of Table 4.1, obtained from measurements. Thus, we conclude that both E peptide and $E$ protein form neutral ion channels that do not discriminate cations over anions (Alcaraz et al. 2009).

These results confront with a previous study which claims that the $\mathrm{N}$ terminal 40 amino acids of $\mathrm{E}$ protein forms cation selective channels (Wilson et al. 2004). However it is worth noting that in those experiments the E peptide was reconstituted in a lipid mixture containing $20 \%$ of a negatively charged lipid (membranes were formed by a lipid mix of 3:1:1 POPE: POPS: POPC). Having this in mind the influence of the lipid charge on $E$ protein ion channel activity was examined. 


\subsubsection{Channel conductance and ion selectivity in charged membranes}

To test if the lipid charge could exert any influence on the $E$ protein ion transport properties the channel conductance of $E$ protein and $E$ peptide was characterized in negatively charged membranes (DPhPS). The experimental conditions were the same what were used in neutral membranes in order to compare the values.

The histograms of the current jump amplitudes of $E$ peptide and $E$ protein reconstituted in pure DPhPS are shown in Figure 4.4. The value of the channel conductance in $\mathrm{KCl}$ for the $E$ peptide is $0.15 \pm 0.01 \mathrm{nS}$, whereas for the $\mathrm{E}$ protein it is $0.19 \pm 0.06 \mathrm{nS}$. Analogously as was observed in neutral membranes, the conductance values of peptide and protein are pretty similar.
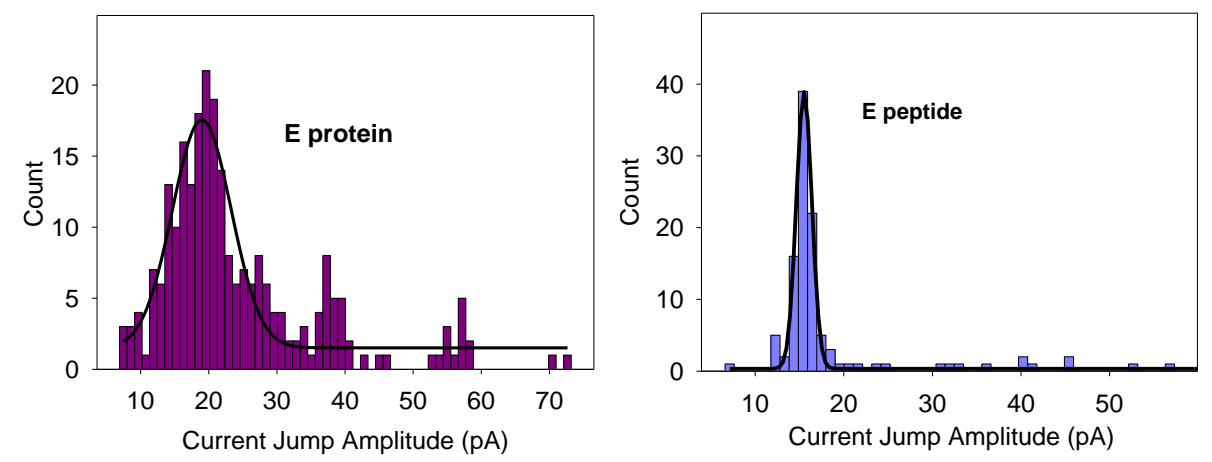

Figure 4.4 Histograms of current jump amplitude for E protein (left) and E peptide (right) in membranes formed by negatively charged lipid, DPhPS. Each histogram contains 300 recording events. The experiments were carried out in $1 \mathrm{M} \mathrm{KCl}$ solutions at $\mathrm{pH} 6$.

However, the comparison with histograms shown in Figure 4.1 and Figure 4.2, which represent the values of conductance in neutral membranes, reveals two important points. On the one hand, it is clear that the lipid charge determines the width of the Gaussian fit and the value of the most probable unitary channel conductance so that the distribution of the current levels is much narrower in DPhPS membranes than in DPhPC membranes. This trend suggests that the multiple insertions are less frequent events in charged membranes. On the other hand, the value of conductance in DPhPC membranes is almost twice than in DPhPS membranes. This result cannot be explained exclusively by electrostatic interactions arising from the surface charge of the lipid membrane. If it was the cause, the accumulation of ions near the channel entrance due to the lipid charge should increase the channel conductance, as in 
the case of alamethicin (Aguilella et al. 2011) and OmpF porin (Aguilella et al. 2014).

These observed differences could be caused by the existence of different pore conformations depending on the membrane charge, so that narrower pores are formed in DPhPS. Other possible explanation could be that lipid molecules would take part in the pore structure.

Next, the influence of the lipid charge on the ion selectivity was evaluated. New series of reversal potential measurements were performed reconstituting E peptide in several lipid mixtures of DPhPC and DPhPS. As Table 4.2 shows, in membranes with higher content of negatively charged lipid, channels display higher cationic selectivity. In pure DPhPS membranes the E peptide is between six and seven-times more permeable to $\mathrm{Na}^{+}$and $\mathrm{K}^{+}$than to $\mathrm{Cl}^{-}$ions (Table 4.2).

Table 4.2 Reversal potential values for E peptide in different lipid bilayers compositions under 10fold concentration gradient of $\mathrm{NaCl}$ and $\mathrm{KCl}(500 / 50 \mathrm{mM})$ at $\mathrm{pH} 6$.

\begin{tabular}{ccccc}
\hline$\%$ & \multicolumn{3}{c}{$\mathrm{NaCl}$} & \multicolumn{2}{c}{$\mathrm{KCl}$} \\
\cline { 2 - 5 } DPhPS & $\boldsymbol{E}_{\text {rev }}(\mathrm{mV})$ & $\boldsymbol{P}_{+} / \boldsymbol{P}_{-}$ & $\boldsymbol{E}_{\text {rev }}(\mathrm{mV})$ & $\boldsymbol{P}_{+} / \boldsymbol{P}_{.}$ \\
$\mathbf{0}$ & $12.2 \pm 2.0(\mathrm{n}=59)$ & $0.6 \pm 0.1$ & $1.9 \pm 0.8(\mathrm{n}=20)$ & $1.0 \pm 0.1$ \\
$\mathbf{2 0}$ & $-7.7 \pm 0.6(\mathrm{n}=7)$ & $1.4 \pm 0.1$ & $-19.9 \pm 0.8(\mathrm{n}=7)$ & $2.7 \pm 0.1$ \\
$\mathbf{5 0}$ & $-11.8 \pm 2.4(\mathrm{n}=7)$ & $2.0 \pm 0.2$ & $-27.3 \pm 2.4(\mathrm{n}=7)$ & $3.9 \pm 0.5$ \\
\hline $\mathbf{1 0 0}$ & $-26.6 \pm 3.5(\mathrm{n}=10)$ & $3.8 \pm 0.7$ & $-35.8 \pm 2.0(\mathrm{n}=10)$ & $6.6 \pm 0.9$ \\
\hline
\end{tabular}

In the light of these results it is clear that membrane lipid charge modulates the ion selectivity of $E$ peptide channels. Similar results were obtained with the E protein (Table 4.3). When E protein is inserted in DPhPS membranes permeability ratio increased to $P_{+} / P_{-}=5.8 \pm 0.4$ for $\mathrm{NaCl}$ and $P_{+} / P_{-}=$ $10.5 \pm 0.9$ for $\mathrm{KCl}$ showing a mild cationic selectivity that differs from the absence of selectivity observed in DPhPC membranes. This indicates that negative lipid charge influences $E$ protein ion channel selectivity, as shown above for $E$ peptide. 
Table 4.3 Reversal potential values for SARS-CoV full length E protein in neutral and in negatively charged membranes under 10 -fold concentration gradient of $\mathrm{NaCl}$ and $\mathrm{KCl}$ solutions $(500 / 50 \mathrm{mM})$ at $\mathrm{pH} 6$.

\begin{tabular}{ccccc}
\hline \% DPhPS & \multicolumn{2}{c}{$\mathrm{NaCl}$} & \multicolumn{2}{c}{$\mathrm{KCl}$} \\
\cline { 2 - 5 } & $\boldsymbol{E}_{\text {rev }}(\mathrm{mV})$ & $\boldsymbol{P}_{+} / \boldsymbol{P}$. & $\boldsymbol{E}_{\text {rev }}(\mathrm{mV})$ & $\boldsymbol{P}_{+} / \boldsymbol{P}_{-}$ \\
$\mathbf{0}$ & $8.6 \pm 1.7(\mathrm{n}=10)$ & $0.7 \pm 0.1$ & $-5.6 \pm 1.4(\mathrm{n}=15)$ & $1.1 \pm 0.1$ \\
$\mathbf{1 0 0}$ & $-34 \pm 2(\mathrm{n}=6)$ & $5.8 \pm 0.4$ & $-43 \pm 3(\mathrm{n}=10)$ & $10.5 \pm 0.9$ \\
\hline
\end{tabular}

The combined evidence from conductance and ion selectivity experiments is the basis of our suggestion that pore is made both of peptide and lipid head groups. Protein-lipid pore formation is favored in membranes with positive curvature (Sobko et al. 2004). Indeed when the membrane is reconstituted using lipids with negative curvature, like phosphatidylethanolamine (PE), is much more difficult to achieve channel insertion because the membrane positive curvature needed for proteolipidic structure becomes energetically unfavorable.

We reconstituted $E$ protein in membranes containing different $P E$ percentages. Two types of membranes were formed: membrane 1 containing DOPE:DOPC:DOPS in 3:1:1 and membrane 2 containing DOPE:DOPC:DOPS in 3:3:1. Under these conditions channel insertion was significantly less efficient than in membranes without negative curvature lipids. In addtiion a higher amount of protein was needed to achieve channel activity (10-15 fold higher than the amount used in DPhPC and DPhPS membranes). It is noteworthy that

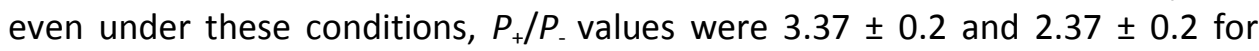
membrane 1 (20\% negatively charged lipids) and membrane 2 (14\% negatively charged lipids), respectively, which revealed that, as previously shown for DPhPC:DPhPS membranes, lipid charge influences ion selectivity.

Finally, it has been described that SARS-CoV E protein locates within ERGIC/Golgi membranes of infected cells (Nieto-Torres et al. 2011). These membranes are composed by lipid mixtures containing around $17 \%$ negatively charged lipids (Van Meer et al. 2008). To analyze whether the effect of lipid charge on $\mathrm{E}$ protein ion channel selectivity may also happen in its physiological context, $E$ protein channels were reconstituted in lipid membranes broadly mimicking ERGIC/Golgi membrane composition and charge: $59 \%$ dioleoyl phosphatidylcholine (DOPC), 24\% dioleoyl phosphatidylethanolamine (DOPE) and $17 \%$ dioleoyl phosphatidylserine (DOPS). Under these conditions, $P_{+} / P_{\text {. }}$ was $3.3 \pm 0.2$, of the same order that the values previously obtained with membranes having $20 \%$ of the negatively charged lipid DPhPS $\left(P_{+} / P_{-}=2.7 \pm 0.1\right)$. 
This indicates that other lipid composition effects exert minor influence on ion selectivity.

\subsubsection{Relevance of the $E$ protein channel activity in virus pathogenesis}

Several reports have analyzed the relevance of CoV E protein transmembrane domain in virus maturation and production. Different requirements of $E$ protein during the virus cycle have been described among coronaviruses. Elimination of $E$ gene in transmissible gastroenteritis coronavirus (TGEV) or MERS-CoV leads to a replication-competent propagation-deficient phenotype (Ortego et al. 2002; Ortego et al. 2007; Almazán et al. 2013). In contrast, deletion of E gene from mouse hepatitis virus (MHV) or SARS-CoV does not abolish virus production, although viral titers are significantly reduced by 1000 to 20-fold (DeDiego et al. 2007; Maeda et al. 2001; Raamsman et al. 2000; Ortego et al. 2002; Ortego et al. 2007; Almazán et al. 2013; Kuo \& Masters 2003).

It is important to note that in the case of SARS-CoV, deletion of E gene (SARS-CoV-DE) confers protection against challenge with parental virus in immunized hamsters, and in young or aged mice, representing a promising vaccine candidate (DeDiego et al. 2007; Dediego et al. 2008; Lamirande et al. 2008; Netland et al. 2010). Moreover, cells infected with SARS-CoV-DE show increased stress and apoptotic markers compared to wild form virus, perhaps resulting in a decreased productivity of infection (DeDiego et al. 2011). Additionally, abolition of the E gene diminishes inflammation.

Viral proteins with ion channel activity influence different aspects of the virus life cycle, but, unfortunately, the role of their ion channel activity in pathogenesis remains still unknown in many cases. Viroporins are generally involved in virus production and maturation processes, which many times are achieved by altering the ion homeostasis of cell organelles. Modulation of the cellular ion equilibrium seems to be a common issue for viruses, as a growing list of viroporins is being identified, especially within RNA viruses (Nieva et al. 2012). Highly pathogenic human viruses such as influenza $A$ virus, human immunodeficiency virus (HIV), hepatitis $\mathrm{C}$ virus (HCV) and several picornaviruses, among others, encode at last one viroporin (Pinto et al. 1992; Ewart et al. 1996; de Jong et al. 2006). Viroporins have been involved in virus entry, trafficking, morphogenesis, maturation and even virulence (Campanella et al. 2004; Wozniak et al. 2010).

Considering that deletion of SARS-CoV E gene attenuates the virus and E gene encodes the $E$ protein that exhibits ion channel activity, we focused on 
investigating the contribution of the $E$ protein ion channel activity in virus pathogenesis. The results show here is the fruit of a close collaboration with Department of Molecular and Cell Biology of the National Center of Biotechnology (CNB-CSIC, Madrid) specifically with the group led by Dr. Luis Enjuanes. In fact most of the experiments shown in this section were carried out at Molecular and Cell Biology laboratory. Our contribution focused on the ion channel characterization.

\subsubsection{Locating residues involved in the ion channel activity}

The transmembrane domain of $\mathrm{E}$ protein contains 29 amino acids, from 9 to 37 amino acids. Considering that it has been observed that this region is the responsible for the ion channel activity of the SARS-CoV E protein, the first main goal was identify the residues involved in this activity. To achieve this purpose, the spatial distribution of the SARS-CoV Urbani strain E protein transmembrane domain amino acids was predicted by helical wheel modeling using Protean (DNASTAR Software, Lasergene) and information from nuclear magnetic resonance (NMR) studies (Pervushin et al. 2009). Moreover, conserved amino acids located within the $\mathrm{E}$ protein transmembrane domain of different $\mathrm{CoV}$ species were identified by sequence alignment (Figure 4.5).

By means of these sources, conserved polar amino acids located at the beginning and at the end of the transmembrane domain, and conserved amino acids central to the CoV E protein transmembrane domain, resulted to be main candidates for the channel formation. It is interesting to stress that these amino acids in many cases were located towards the lumen of the pore. These polar amino acids were replaced by other residues resulting in nine different peptides (Table 4.4 and Figure 4.6 A and B). One of them (wt) represented the wild type protein transmembrane domain and its flanking polar amino acids. The rest of the mutants included different residue substitutions at different positions along the transmembrane domain, or at both the amino- or carboxy- termini of this domain: one substitution (M2 to M7), two (M1) or four (M8).

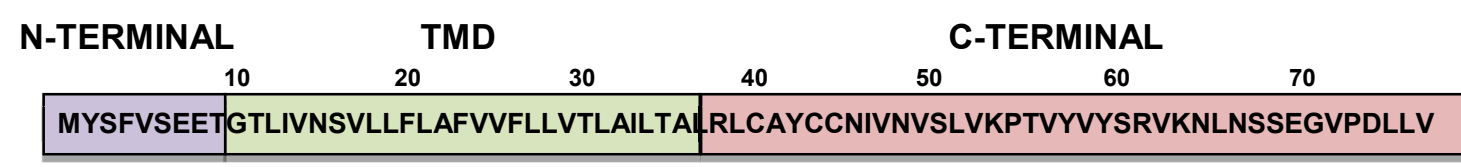

Figure 4.5 Sequence of SARS-CoV E protein. 
Table 4.4 Sequence of CoV-E protein peptides representing the transmembrane domain and closely flanking amino acid. B. Residues in red represent the mutated amino acids.

\section{Peptide}

\section{Sequence}

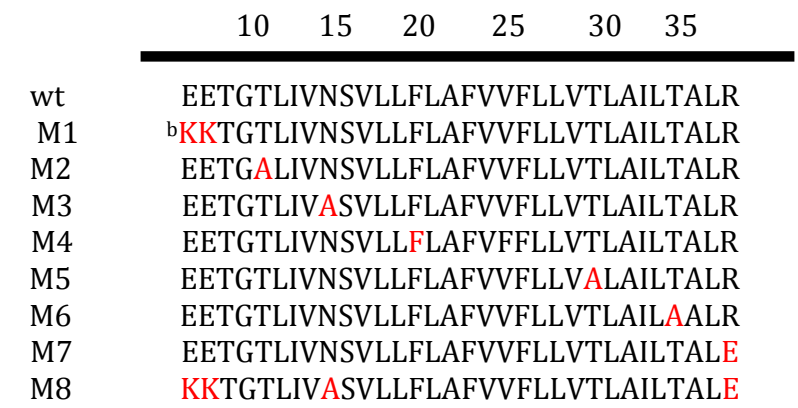

A
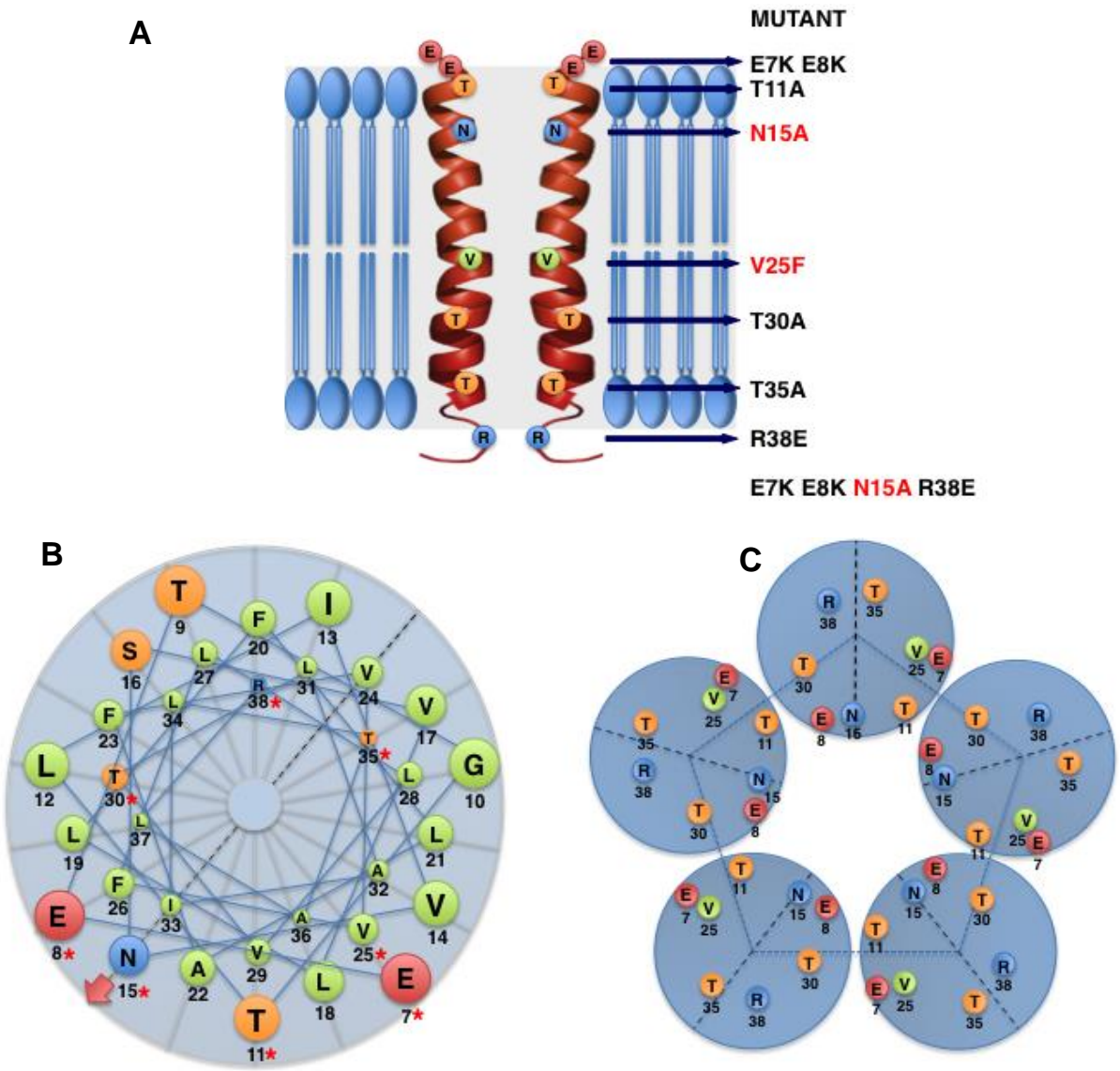

Figure 4.6 Sequence and representation of SARS-CoV E protein peptides representing the transmembrane domain. (A) Cartoon showing two of the several monomers of $E$ protein transmembrane domain. Red circles represent negatively charged residues, blue circles for positively charged residues; orange circles denote uncharged polar amino acids; and green circles correspond to nonpolar amino acids. (B) Alpha helix wheel modeling of SARS-CoV E protein transmembrane domain. Asterisks refer to the amino acids mutated in this study. Red arrows points to the lumen of the pore determined by E peptide oligomerization (Torres et al. 2007). (C) Top view representation of a hypothetical pentameric E peptide ion channel. 
Once the mutants were obtained, the next step was to investigate their channel conductance. Five mutants (M1, M2, M5, M6 and M7) and the wt peptide were observed to display channel activity since they permeabilize the membrane by forming stable current levels (Figure 4.7). These peptides led to current bursts 10-15 min after the peptide addition. These results indicate that residues E7 and E8 (M1), T11 (M2), T30 (M5), T35 (M6) and R38 (M7) are not essential to observe ion channel activity. It is worthy to note that the impact of these mutations on the value of channel conductance depends on the mutated residue. The mutations of $\mathrm{M} 1, \mathrm{M} 5$ and $\mathrm{M} 7$ do not dramatically alter the pore formation since the measured conductance is very similar to the $E$ peptide. However, mutations T11A (M2) and T35A (M6) lead to higher currents than in the $E$ peptide, which might suggest that they form a wider pore.

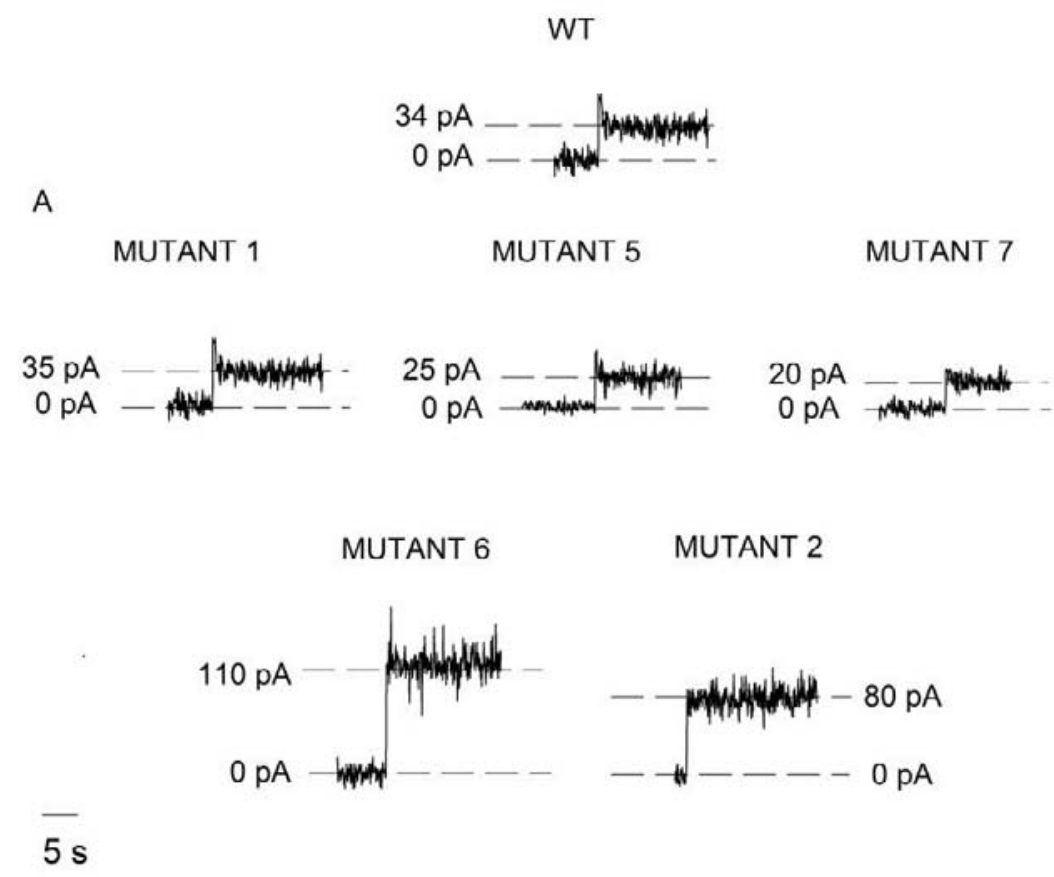

Figure 4.7 Current recordings of wt peptide and SARS-CoV E mutants. Mutants 1,5 and 7 displayed similar current levels than wt peptide. Mutants 6 and 7 showed higher current levels.

Very interesting results were found in three mutant peptides, M3, M4 and M8. These mutants did not show membrane permeabilization and no channel activity was registered. To ensure these results, $0.5-1 \mu \mathrm{L}$ of a $300 \mu \mathrm{g} / \mathrm{mL}$ solution of these synthetic peptides were added successively each 10-15 min. This process was repeated at least 15 times. No conduction in these mutants indicates that substitutions N15A (M3 and M8) and V25F (M4) totally inhibited E protein ion channel activity (Figure 4.8). These results are in agreement with 
previous studies reporting that these residues are vital for channel activity (Torres et al. 2007).

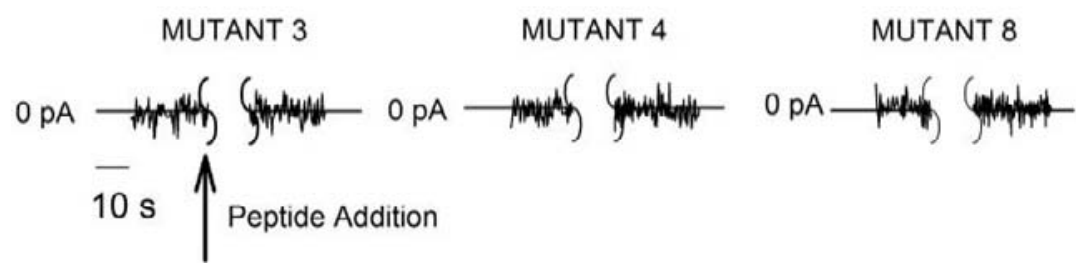

Figure 4.8 Sample current recordings of mutants that do not show ion channel activity. Residues $\mathrm{N} 15$ and V25 are essential to observe membrane permeabilization by channel insertion.

\subsubsection{SARS-COV E protein ion channel activity influence on virus production}

We have showed that residues N15 and V25 are essential for E protein ion channel activity. In order to check the relevance of the E protein ion channel activity in the viral pathogenesis, two recombinant viruses were generated containing these specific mutations that eliminate the ion channel activity: rSARS-CoV-E-N15A (mutant N15A) and rSARS-CoV-E V25F (mutant V25F) (Figure 4.9). A SARS-CoV with a mouse adapted (MA15) genetic background was used to generate these viruses, as infection of mice with SARS-CoV MA15 reproduces the symptoms of human disease (Roberts et al. 2007).

Once the recombinant viruses were obtained, it was tested if the mutations altered the subcellular location of the E protein, which may affect to other functions of the protein. To achieve this goal Vero E6 cells (from the African green monkey) were infected with the wt virus, the viruses lacking ion channel activity (N15A and V25F) and a virus missing E gene (DE) as a control. Immunofluorescence analysis showed similar collocation patterns in all cases suggesting that others possible functions dependent on the subcellular location would not be altered (Figure 4.10). 


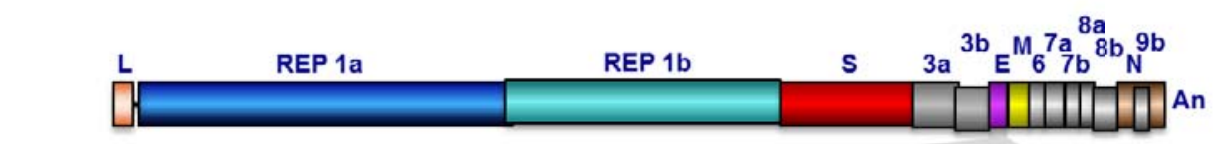

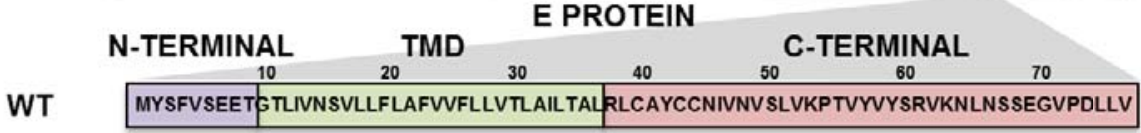

\section{rSARS-CoV-EIC-}

\begin{tabular}{ll|} 
N15A MYSFVSEETGETLIVA SVLLFLAFVVFLLVTLAILTALRLCAYCCNIVNVSLVKPTVYVYSRVKNLNSSEGVPDLLV \\
V25F MYSFVSEETETLIVNSVLLFLAFVFFLLVTLAILTALRLCAYCCNIVNVSLVKPTVYVYSRVKNLNSSEGVPDLLV
\end{tabular}

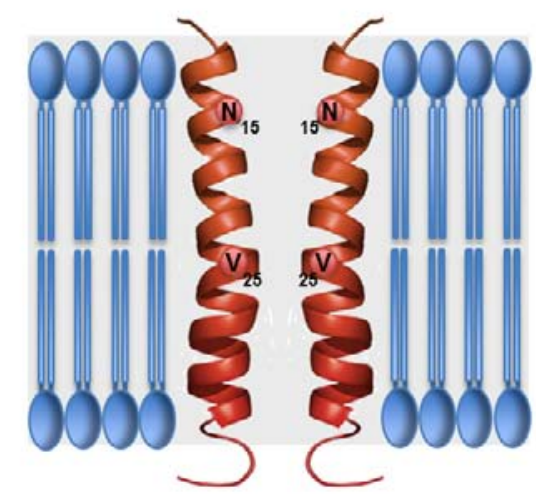

Figure 4.9 SARS-CoV genome is represented at the top, and the region expanded shows wt SARSCoV E protein sequence and the amino terminal ( $\mathrm{N}$-terminal), transmembrane domain (TMD) and carboxy terminal (C-terminal). The amino acids N15 and V25 were replaced to generate two mutants lacking ion channel activity (N15A, V25F). The position of the mutated resides within the transmembrane domain of a simplified $\mathrm{E}$ protein oligomer inserted in a planar lipid membrane are presented at the bottom.
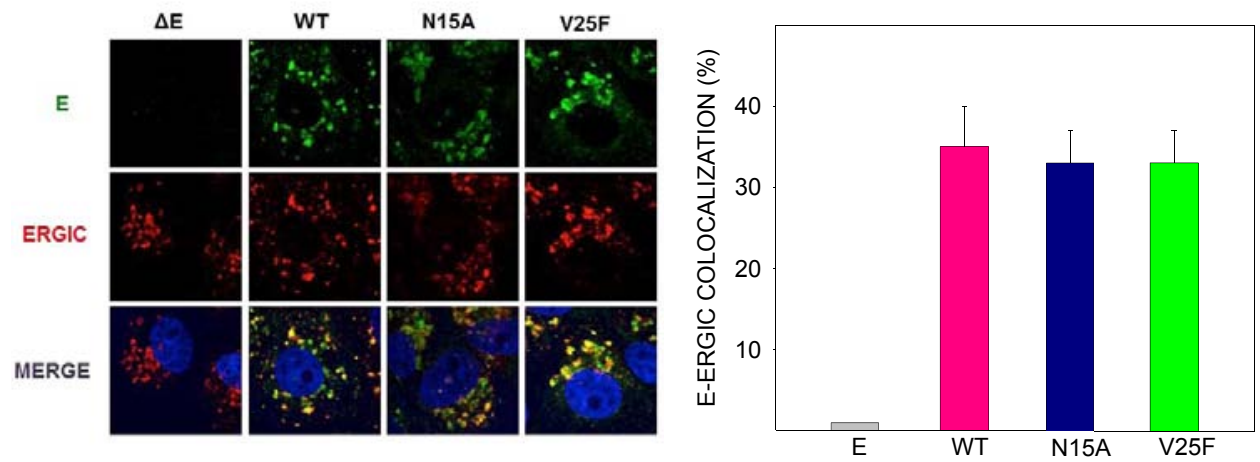

Figure 4.10 Subcellular localization of $r$ SARS-CoV-EIC E proteins. Vero E6 cells were infected either with the mutant viruses lacking ion channel activity (N15A, V25F), the wt virus or a virus lacking $E$ gene $(D E)$ at a multiplicity of infection (MOI) of 0.3 , fixed at 24 hpi and $E$ protein (green) and ERGIC (red) were labeled with specific antibodies. Nuclei were stained with DAPI (blue). Original magnification was 1266 . Right graphic shows the percentage of colocalization between $E$ protein and ERGIC, calculated with Leica LAS AF v2.6.0 software. Experiments carried out by Dr. Luis Enjuanes and collaborators. 
The introduction of mutations or deletions in the E gene may affect to the virus production. Growth kinetics were carried out in the monkey Vero E6 (from the African green monkey) and mouse DBT-mACE2 ( mouse delayed brain tumor) cells (Regla-Nava et al. 2013) to check if inhibition of E channel activity affects to virus production. No significant differences in the viral production were observed (Figure 4.11). These results reveal that the ion channel activity is not essential for the virus production, at least in cell culture.

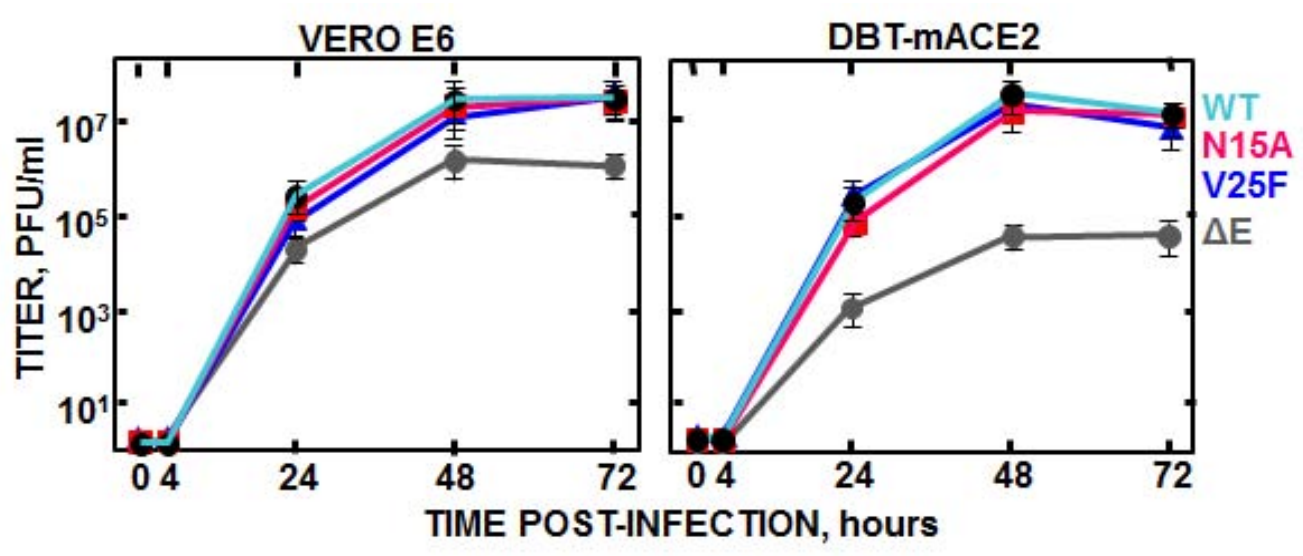

Figure 4.11 Vero E6 and DBT-mA CE2 cells were infected at a $\mathrm{MOI}$ of 0.001 with mutant viruses lacking ion channel function (N15A, V25F), parental virus (wt) or a virus lacking $E$ gene (DE), and a viral progeny was titrated at the indicated times post-infection. Error bars represent the standard deviation of three independent experiments. Experiments carried out by Dr. Luis Enjuanes and collaborators.

To investigate in detail whether the presence of the ion channel activity could favor the virus production, a long-term competition assay was performed between the wt virus and the N15A mutant. Vero E6 cells were co-infected with N15A mutant and the wt virus in a proportion 7:3, and the supernatant was serially passaged for 20 times every 24 hours. The $E$ gene was sequenced every 4 passages, revealing that the proportion of wt virus steadily increased over the passages, accompanied by a decrease in the abundance of the N15A mutant. From passage 8 on, the wt virus took and maintained majority over the N15A mutant (Figure 4.12). These results indicated that E protein ion channel activity for SARS-CoV confers a selective advantage improving virus production. 


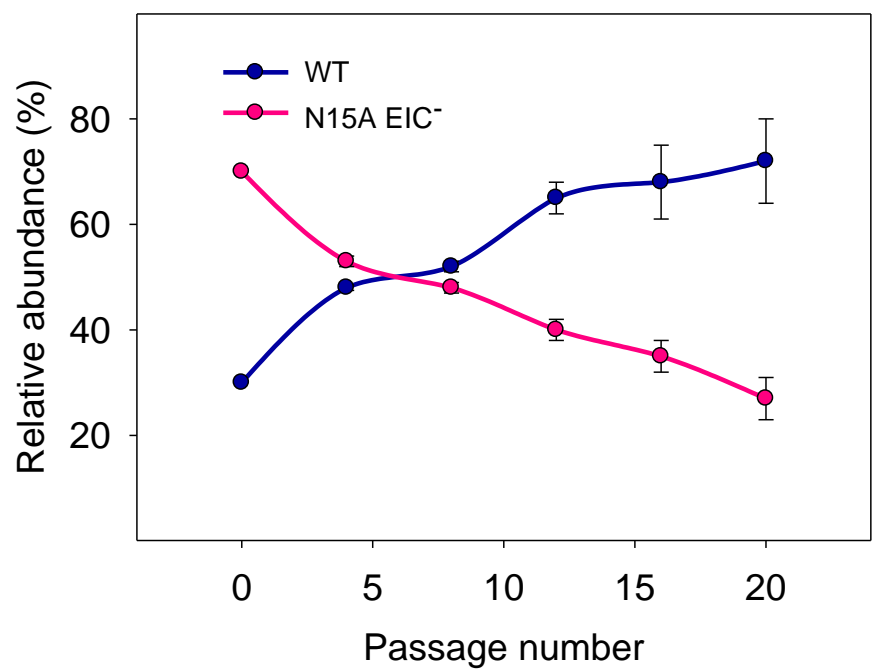

Figure 4.12 Effect of the $E$ protein ion channel activity on viral fitness. Competition assays between wt virus and mutant N15A lacking ion channel activity were performed. Vero E6 cells were co-infected with mutant and parental viruses at a ratio 7:3. As experimental data indicates, the proportion of wt virus increased over the passages, whereas the N15A mutant decreases. The error bars correspond to the standard deviation from three independent experiments. Experiments carried out by Dr. Luis Enjuanes and collaborators.

\subsubsection{Influence of $E$ protein ion channel activity in SARS-CoV virulence}

We investigated the contribution of the $E$ protein ion conduction properties to SARS-CoV virulence. To achieve this goal, specific-pathogen-free 8 week-old BALB/c mice were intranasally inoculated with the wt virus or three clones of the mutant viruses N15A and V25F lacking channel activity and mice were monitored daily for 10 days. All infected mice showed disease symptoms after 2 days of inoculation. The mice infected with wt virus started to lose weight by day 2 and by day 5 all of them died. Animals infected with mutant N15A lost weight in a similar way that mice infected with wt virus, but on day 4 they began to recover from the infection and the survival rate was within 80$100 \%$. In contrast, mice infected with mutant V25F showed similar weight losses and survival rates than those infected with parental virus (Figure $4.13 \mathrm{~A}$ and $\mathrm{B}$ ). 

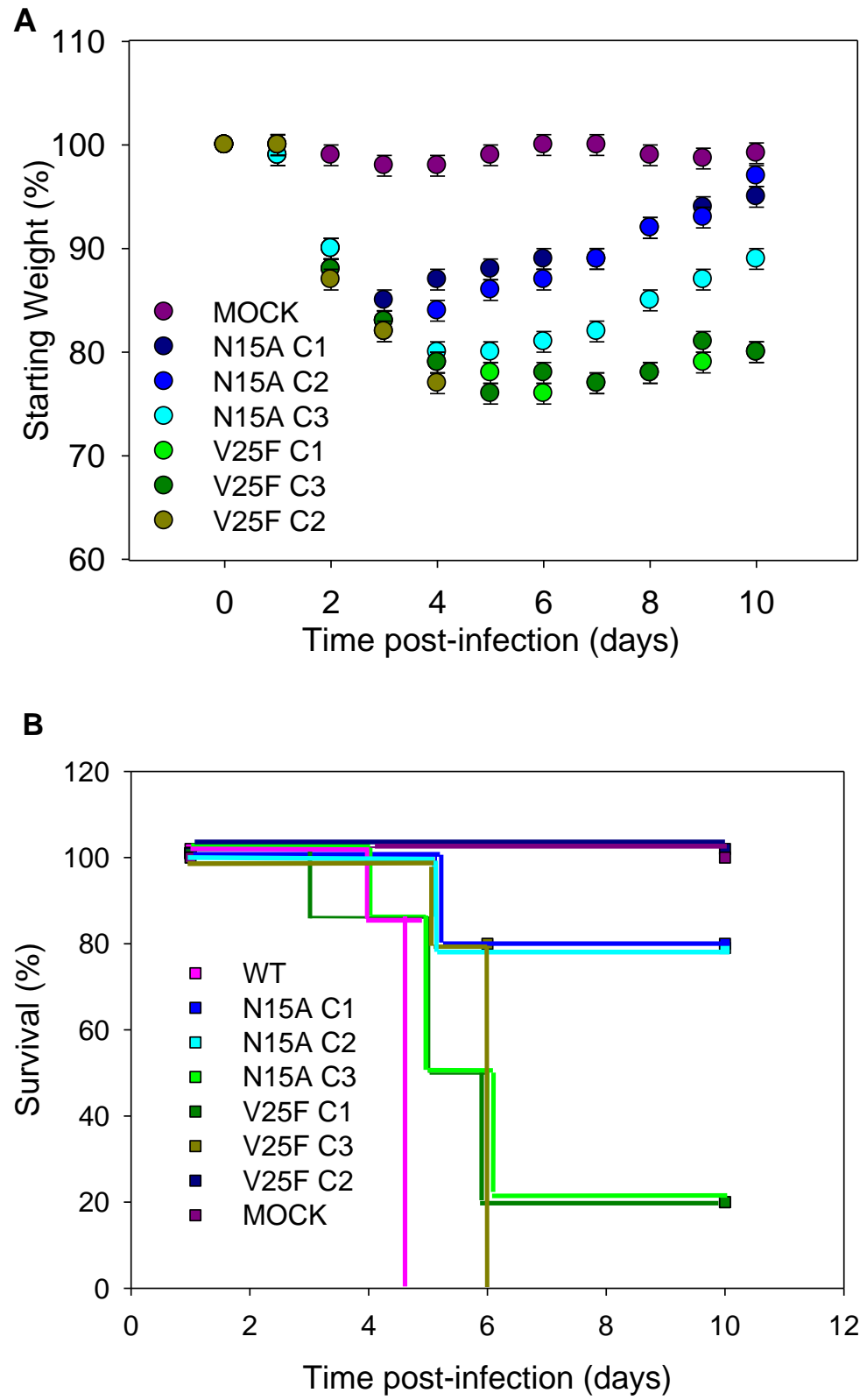

Figure 4.13 Pathogenesis caused by $r$ SARS-CoV EIC in BALB/c MICE. Groups of five 16 week-old $B A L B / c$ mice were mock infected or infected with 100000 PFU (plaque-forming unit) or either the parental virus or several clones of the mutant viruses lacking ion channel function. (A) Evolution of starting weight (\%) of infected animals (B) Survival rate (\%) of infected mice. Experiments carried out by Dr. Luis Enjuanes and collaborators. 
The fact that infection with mutant V25F shows the same trend that the wt virus may be caused by the incorporation of compensatory mutations restoring the ion channel activity. To test this hypothesis the RNA presenting in the lungs of infected mice at 2 and 4 days post-infection or from the lungs of mice that died after infection was extracted and analyzed.

It was found that the E gen of the wt virus and mutant N15A remained stable, since no changes were found in viral RNA extracted either from lungs of several mice at 2 and 4 days post-infection or from dead mice (Figure $4.14 \mathrm{~A}$ ). However, in the case of mutant V25F the mutation incorporated to inhibit the ion channel activity was changed and other point mutations were introduced near the transmembrane domain of the protein: L19A, F20L, F26C, L27S, T30I and L37R (Figure $4.14 \mathrm{~A}$ ). These variants of the V25F virus appeared as early as 2 days after infection and, in some cases, (T30I mutant), completely overgrew the original virus by day 2 .

The tentative compensatory mutations were also present in the viral population on the fourth day post-infection and in dead mice (Figure $4.14 \mathrm{~A}$ ). All these data suggest that $E$ protein ion channel activity is essential for a virulence phenotype.

As we found that compensatory mutations were incorporated in $E$ gene of infected mice, we wanted to analyze the evolution of the mutant viruses lacking $E$ gene protein ion channel activity. To achieve this purpose, two clones of mutants N15A and V25F were serially passaged in cell culture. E gene was sequenced at passages $0,8,16$ and 24 for the two mutant viruses and wt.

Figure 4.14 B shows the data for each passage number and confirms our results in vivo infection. The wt virus remained stable during the passages, whereas the V25F mutant viruses incorporated additional mutations at early passage numbers. In addition, N15A viruses either remained stable or incorporated a mutation (A15D) that appeared late, at passage 24.

The results obtained in cell culture were in agreement with the results obtained in vivo infection. Both experiments suggest that the mutants lacking $E$ protein ion channel activity incorporated mutations at the E gene that changed the original mutations ( $\mathrm{A} 15 \mathrm{D}$ and $\mathrm{F} 25 \mathrm{C}$ ) or modified residues located close transmembrane domain. It is interesting to mention that these modified residues face the original mutation abolishing the ion channel function, when the ion channel is assembled (Figure 4.15). 


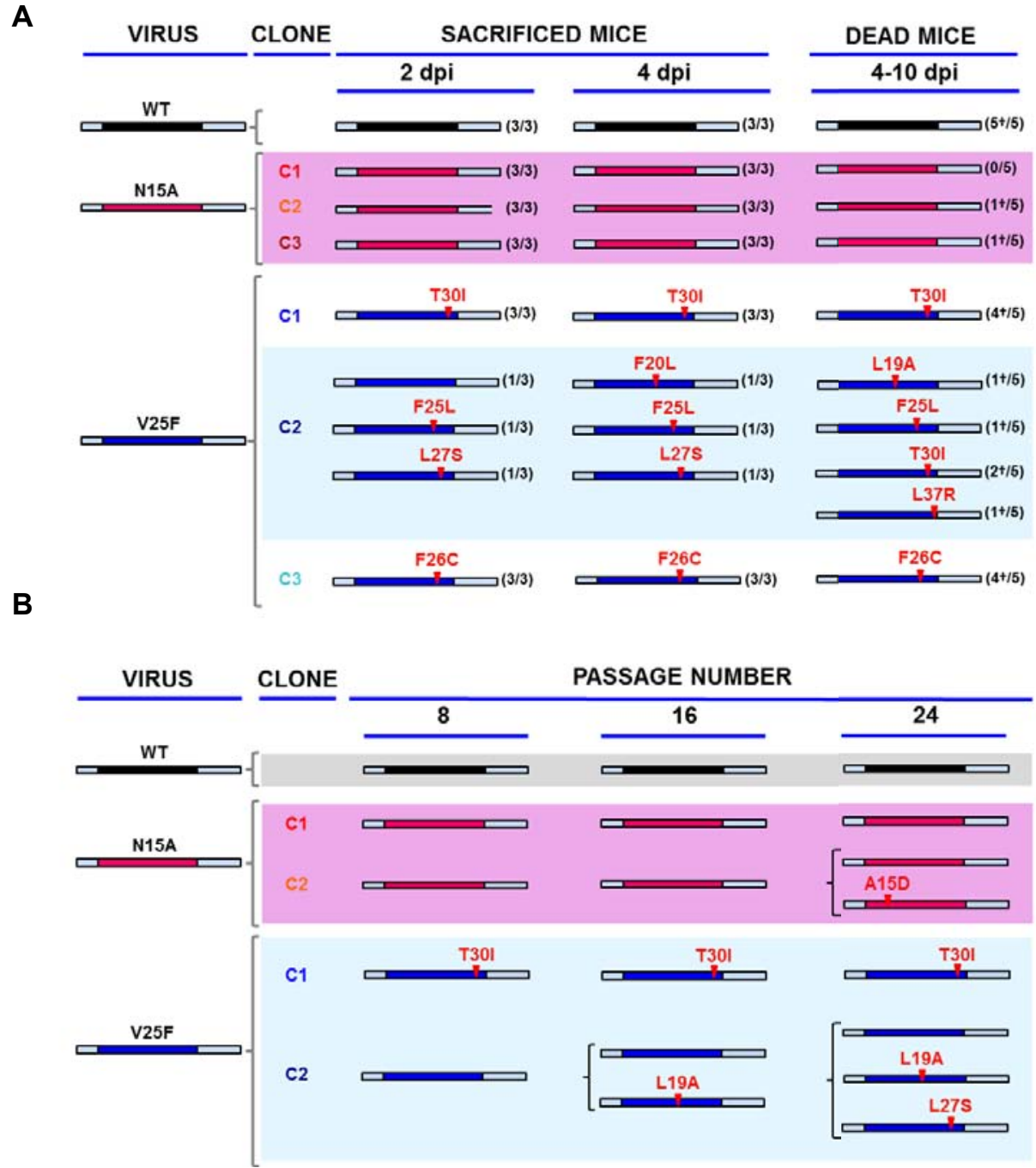

Figure 4.14 $r$ SARS-CoV EIC stability after serial infections. (A) Groups of eleven 16 week-old $\mathrm{BALB} / \mathrm{c}$ mice were infected with $100000 \mathrm{PFU}$ of either the wt virus or three clones of the mutant lacking ion channel activity (N15A C1, N15A C2, N15A C3, V25F C1, V25F C2, and V25F C3). At 2 dpi and 4 dpi 3 mice of each group were sacrificed, lung RNA was extracted, and $E$ gene was sequenced. The rest of the mice ( 5 per group) participated in the weight-loss and survival experiment. When any mouse died, from 4 to $10 \mathrm{dpi}$, lung RNA was extracted and $\mathrm{E}$ gene was sequenced. Bars represent different $E$ protein sequences, either that of parental or the mutant viruses. The central colored part represents the transmembrane domain of the protein. Letters and numbers in red represent the amino acid changes detected after viral evolution and their relative position within transmembrane domain, respectively. Numbers accompanying bars indicate from how many mice (first number) out of the total of the animals analyzed (second number) arose the indicated sequence change. (B) Vero E6 cells were infected with the wt virus or the mutant clones N15A C1 and N15A C2, V25F C1 and V25F C2 at an initial MOI of 0.5, and supernatants were serially passaged for 24 times every 24 hours. E gene in the viral population was sequenced at passages $0,8,16$ and 24 . Colored bars represent the transmembrane domain of different $E$ protein sequences and letters and numbers in red represent the amino acid mutations identified and their relative position, respectively. Experiments carried out by Dr. Luis Enjuanes and collaborators. 
A
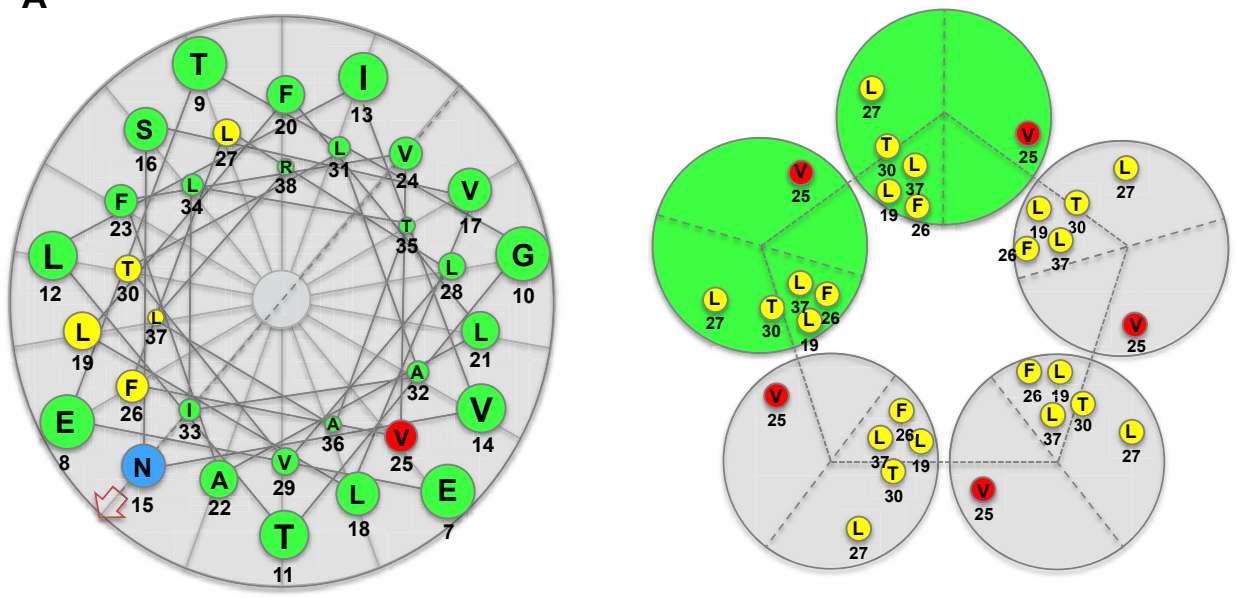

B
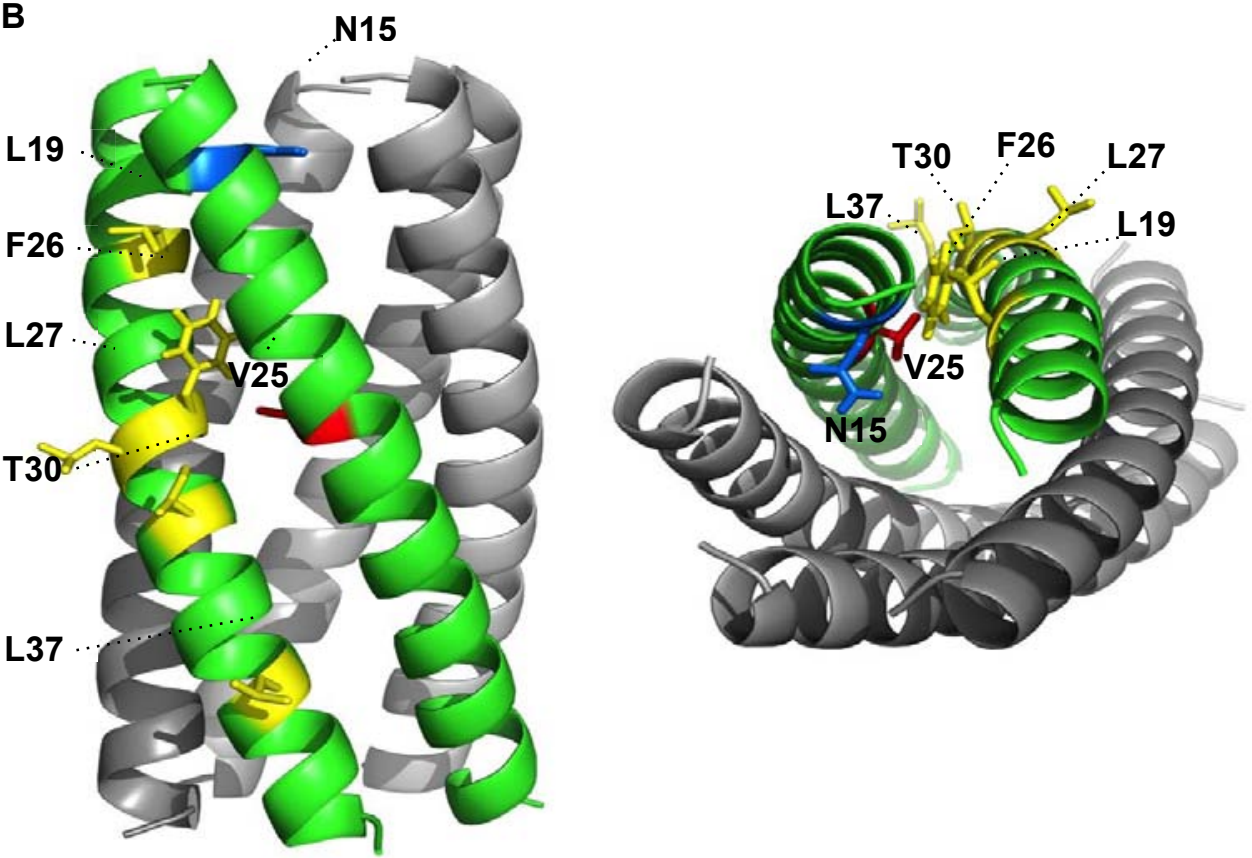

Figure 4.15 Spatial distribution of the mutations obtained in rSARS-CoV-EIC $^{-}$after serial infections. (A) Left diagram represents a top view of $E$ protein transmembrane domain and the spatial distribution of the amino acids within the alpha helix. Blue and red circles correspond to amino acids N15 and V25, respectively, originally mutated to inhibit ion channel activity (IC). Yellow circles surround the amino acids that changed after evolution of V25F mutant. Arrow at position 15 points the lumen of the ion channel pore. Right graphic depicts the pentamer conformation of E protein that forms the ion conductive pore and the positions of both the mutated residue at position 25 and the evolved mutations at positions 19, 25, 26, 27, 30 and 37 . Evolved changes map close to the originally mutated residue in the monomer monomer interface. (B) Pentameric model of SARS-CoV E protein from a lateral (left) or a top view (right). This model was first proposed from linear dichroism of isotopically labeled $E$ protein transmembrane peptides in lipid bilayers (Torres et al. 2006; Parthasarathy et al. 2008a). The residues involved in ion channel inhibition (N15 in blue and V25 in red) or mutated after viral evolution (L19, F26, L27, T30 and L37 in yellow) are highlighted. 


\subsubsection{Analysis of the ion channel activity of revertant viruses}

Once we checked that mutant viruses lacking $E$ protein ion channel activity incorporated compensatory mutations, we analyzed if these revertant mutants showed channel activity. As Figure 4.16 shows these peptides displayed ion channel conductance similar to $E$ protein wt. These results indicate that these compensatory mutations recover $E$ protein ion channel function. These data indicates a correlation between ion channel function and virulence in vivo.

Finally, to evaluate whether the recovery of ion conduction properties was the unique determinant of virulence, and to dismiss effects of other mutations surging outside of the $E$ gene, recombinant viruses containing compensatory mutations that restored the ion channel activity (rSARS-CoV$\left.E I C^{\text {rev }}\right)$ were engineered, rescued and tested in mice. These viruses were: $r S A R S-$ CoV-E-V25F L27S (V25F L27S), rSARS-CoV-E-V25F T30I (V25F T30I), rSARS-CoV-EV25F L37R (V25F L37R).
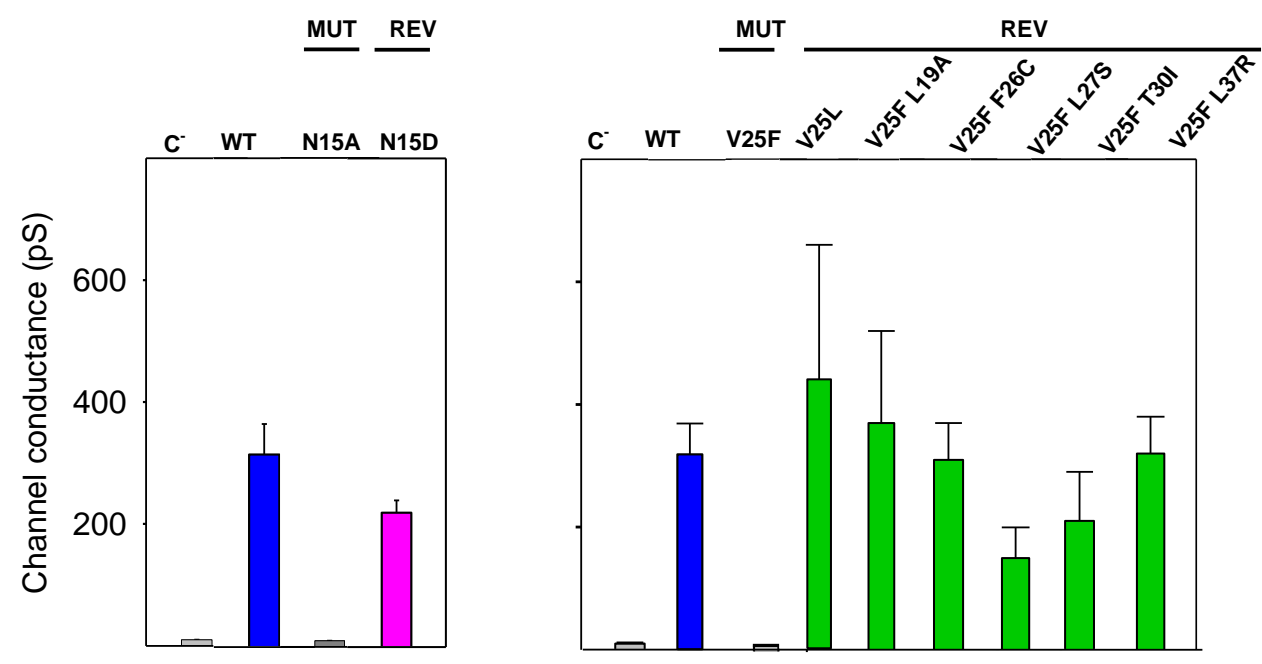

Figure 4.16 E protein IC activity of the rSARS-CoV-EIC evolved variants. Synthetic peptides representing $E$ protein transmembrane domain of the parental virus (wt) the mutant viruses lacking IC activity (N15A and V25F) and their evolved revertants (REV) obtained after infections of mice or cell culture (N15D, V25L, V25F L19A, V25F F26C, V25F L27S, V25F T30I and V25F L37R) were reconstituted in artificial lipid bilayers, and their IC activity was analyzed as mean conductance values. Negative controls $\left(\mathrm{C}^{-}\right)$indicate conductance values obtained in the absence of any peptide. Error bars represent the variations obtained in 100 independent experiments. Channel conductance was determined at $1 \mathrm{M} \mathrm{KCl}$ solution in membranes containing 3:1:1 DOPC:DOPS:DOPE, pH 6.

All the viruses caused similar disease that the wt virus (Figure $4.17 \mathrm{~A}$ and B). In order to confirm these data in other genetic background, a new virus was engineered rSARS-CoV-E-N15D. This virus contained the mutation N15D which 
conferred ion channel activity. Similarly to the V25F mutants, the N15D virus produced similar morbidity and mortality as wt virus confirming that the ion channel activity was a determinant of virus pathogenesis.
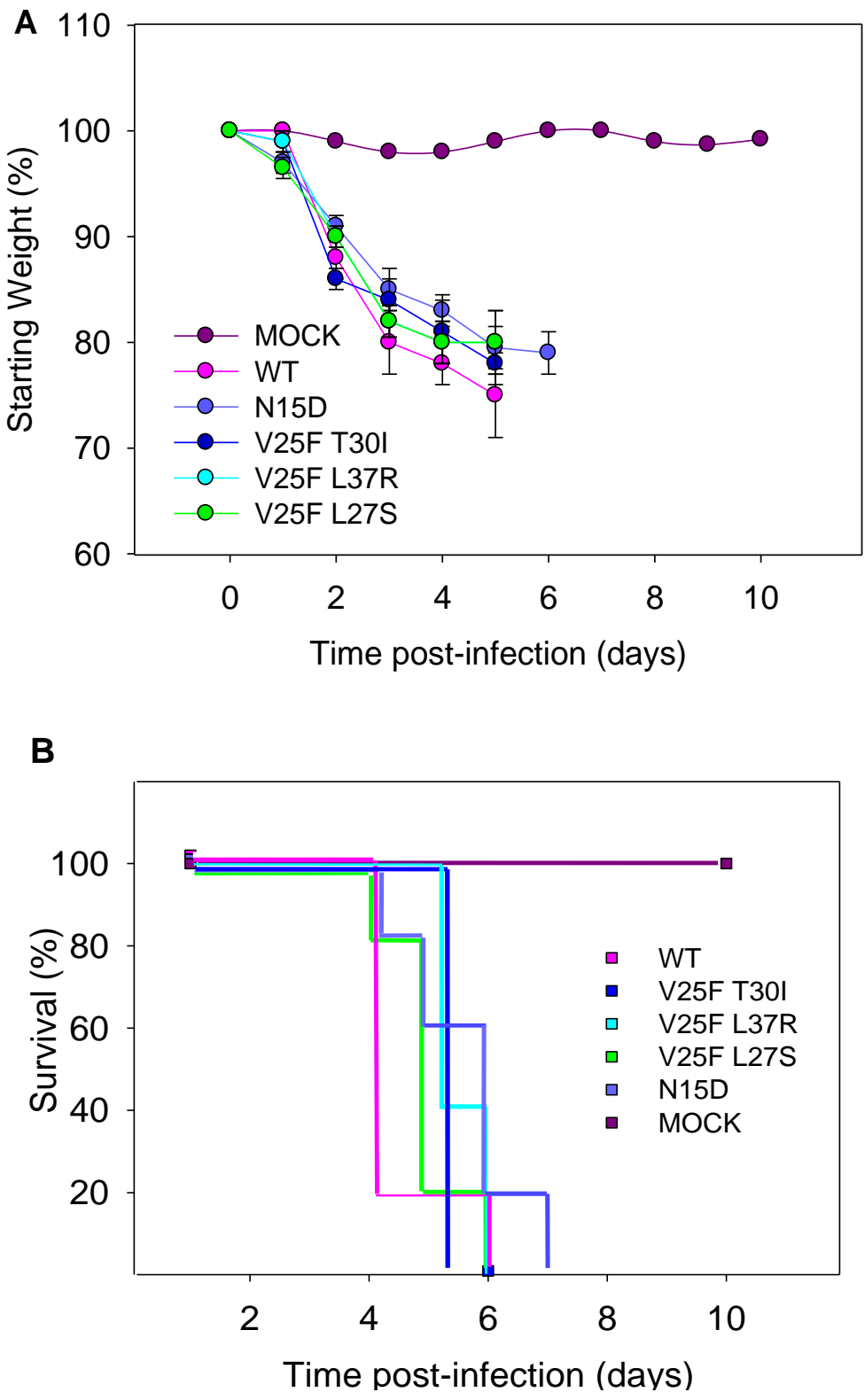

Figure 4.17 Pathogenesis caused by rSARS-CoV-EICrev in BALB/c mice. (A) Mean weight losses and (B) survival during 10 days are represented for each group. Error bars represent the standard deviation for mice weights per experimental condition. Groups of five 16 week-old BALB/c mice were mock infected (Mock, purple) or infected with 100000 PFU of either the parental virus (wt, pink) or the genetically engineered revertant viruses recovering ion channel activity: N15D (blue ), V25F L27S (green), V25F T30I (deep blue) and V25F L37R (light blue). Experiments carried out by Dr. Luis Enjuanes and collaborators. 


\subsubsection{SARS-COV E protein ion channel activity influence on growth in vivo}

We observed that the E protein ion channel function was not essential for the growth in cell culture, but it could be possible that production of virus in vivo was correlated to the ion channel activity. In order to check if the low virulence of the ion channel inactive mutants was due to lower virus production, 16 week-old BALB/c mice were intranasally inoculated with the wt virus, the genetically engineered revertant viruses N15D and V25F T30I displaying ion channel properties or with the N15A lacking ion channel function. Mice lungs were collected after infection and viral titers were determined.

As Figure 4.18 displays the mutant viruses lacking ion channel activity grew similar than wt and better than revertant viruses. These results suggest that $E$ protein ion channel function does not influence virus production in vivo. As a result, the minor virulence observed for mutant viruses lacking ion channel activity may be likely due to a host-specific effect regulated by the ion channel function and not to a decrease in virus growth.

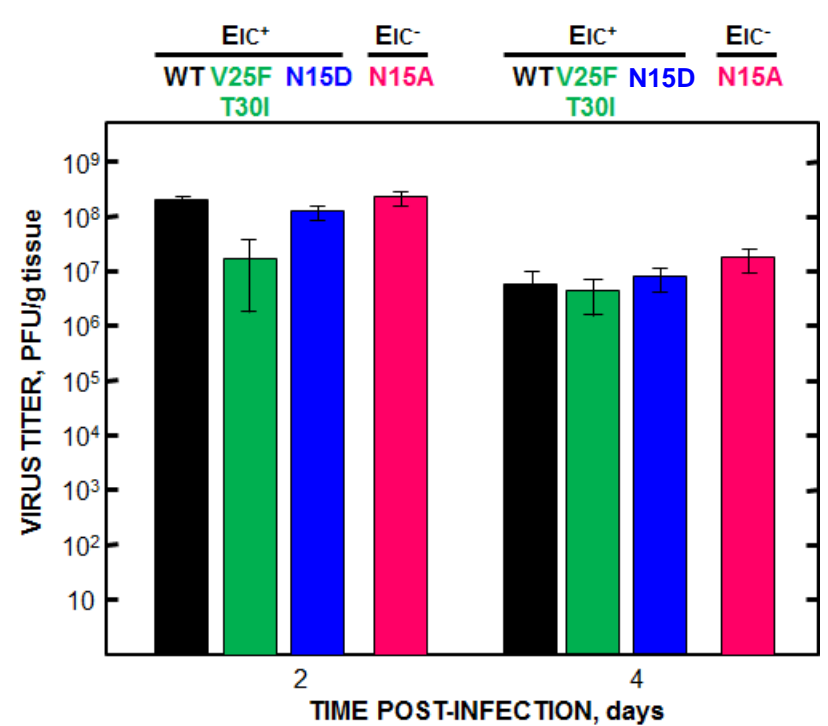

Figure 4.18 Effects of SARS-CoV E protein IC activity on virus growth in BALB/c mice lungs. Groups of six 16 week-old BALB/c mice were infected with 100000 PFU of viruses displaying E protein IC activity $\left(\mathrm{EIC}^{+}\right.$), either the parental virus (wt, black columns) or the genetically engineered revertant viruses V25F T30I (green columns) and N15D (blue columns) or with the mutant lacking IC activity (EIC) N15A (pink columns). At 2 and 4 days post infection (dpi) 3 mice from each group were sacrificed to determine virus titers. Experiments carried out by Dr. Luis Enjuanes and collaborators. 


\subsection{CONCLUSIONS}

The experiments reported here provide a further characterization of the ion channel conducting properties of SARS-CoV E protein and its implication in virulence by means of combining a variety of molecular biology techniques, genetics, microscopy, fluorometry and electrophysiology.

We have checked that the ion conductivity of the E peptide and the full length $E$ protein is pretty similar, supporting that the ion conduction comes from the transmembrane domain of the $E$ protein. It has been found that the ion transport properties of these ion channels are highly influenced by the membrane lipid charge. When channels were reconstituted in neutral membranes the channels behaved almost as neutral channels with channel conductance values corresponding to wide pores. In contrast, reconstitution into negatively charged membranes turned the non-selectivity observed in neutral membranes into mild cationic selectivity and the channel conductance value was much smaller than in neutral membranes.

Putting together the conductance and ion selectivity results we suggest that pores are made both of peptide helices and lipid head groups. Most likely, lipid molecules may assemble with the peptide oligomers to form the pore structure, similarly to what has been described for ascecropin, magainin and dermaseptin channels (Oren 1998). More evidences are needed to support this hypothesis but the reported structure for E protein channel (Pervushin et al. 2009) seems compatible with the insertion of lipid head groups within the wider domains of the oligomer. This functional involvement of the lipids can be achieved in different ways in a similar way to antimicrobial peptides (Eleftheriou et al. 2009). Protein-lipid formation is favored in membranes with positive curvature (Sobko et al. 2004). Thus, in lipids with negative curvature the channel insertion is lowered because the formation of proteolipidic pores becomes energetically unfavorable. We have checked that in membranes containing negative curvature the probability of $\mathrm{E}$ channel insertion was lowered.

Then we have identified the main residues responsible for the ion channel activity. Residues N15 and V25 resulted to be essential for E protein ion channel activity. The identification of these residues allowed us to investigate the role of the $E$ protein ion channel activity in SARS virulence by the manipulation of SARS-CoV genome. Upon competition during several passages, the viruses lacking ion channel activity were clearly overgrown by the parental virus, which replicated better. Nevertheless, these differences in viral growth needed several replication cycles to be detected, as only slight no significant changes in virus production were observed after 72 hours growth kinetics. These observations indicate that ion channel function although is not essential for virus production, confers an advantage to the virus enhancing its fitness and growth. Besides we observed that the mutant viruses disrupting the ion channel 
activity tended to incorporate additional mutations that restored the channel conduction. Ion channel activity restoration suggests that this function is important for the virus. Restoration of the ion channel function produced similar virus pathogenesis, which correlates the presence of the channel conduction function to virulence.

We conclude that SARS-CoV E protein ion channel activity is strongly dependent on membrane composition and it is a determinant of virulence. These novel findings open the possibility to explore the lipid involvement into the $E$ protein ion channel structure. In addition, the correlation between $E$ ion channel function and virulence is a very important outcome that can possibly be translated in order to find therapies for their associated diseases. 





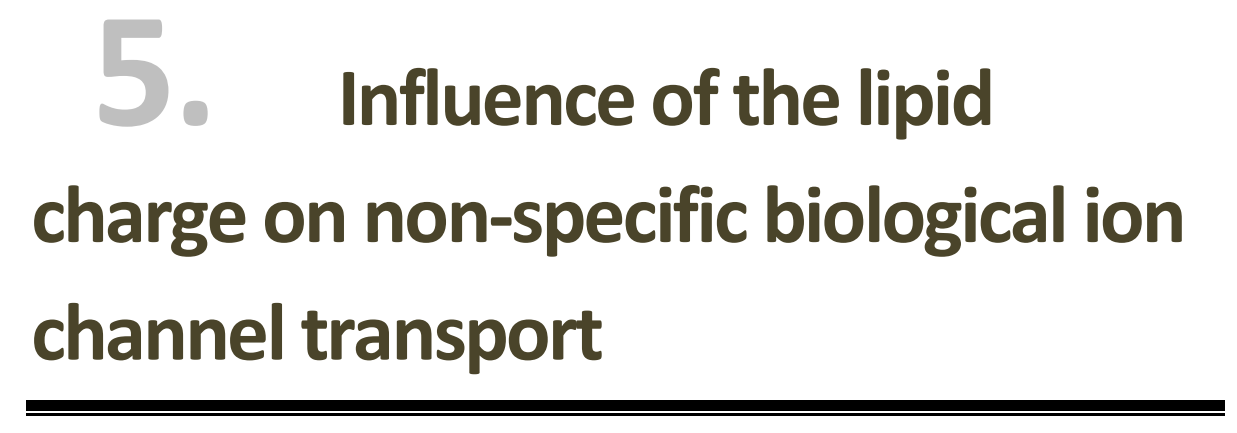



Part of the studies included in the present chapter were published in the following articles:

"Lipid charge regulation of non-specific biological ion channels" Physical Chemistry Chemical Physics (2014) 16, 3881 - 3893. 



\subsection{INTRODUCTION}

Elucidating the role of the lipid membrane in the ion channel activity of proteins is crucial for the understanding of their physiological function (Tucker \& Baukrowitz 2008). Since most biological membranes contain a significant fraction of charged lipids, electrostatic interactions between proteins and membrane lipids are of vital importance. The electrical environment of the membrane influences not only the initial stage of channel formation and insertion (Zakharov et al. 2004; Zakharov et al. 2002) but also the permeation mechanisms by which ions and charged solutes flow through the channels (Zakharov et al. 2002). Furthermore, lipid molecules control also other important physicochemical properties of the membrane, such as fluidity, curvature strain, hydrophobic thickness, etc. (Lundbaek et al. 2010; Lundbaek 2008; Yoshimura \& Sokabe 2010).

In this chapter we analyze the electrostatic effects of lipid charge in OmpF porin and in SARS-CoV E protein channel using electrophysiological techniques. By reconstituting different channels in model membranes whose lipid composition can be controlled at will, we can identify and characterize nonspecific charge effects associated with both the protein ionizable residues and the membrane polar lipids. The analysis of a well-characterized protein channel, as OmpF, is a useful complement to understand the effect of lipid charge on other types of channels, like SARS-CoV E, whose structure is still unknown.

\subsection{LIPID CHARGES REGULATE CHANNEL CONDUCTANCE}

Experimental evidence of the impact of lipid charge on ion permeation through channels has been developed over the last few decades (Rostovtseva et al. 1998; Gurnev et al. 2012; Apell \& Bamberg 1979; Bell \& Miller 1984; Moczydlowski et al 1985; Coronado \& Affolter 1986; Alvis et al. 2003; Yan et al. 2013; Parra et al. 2013). The modulation of ionic concentration exerted by the lipid charges has been rationalized traditionally by means of Gouy-Chapman theory (Rostovtseva et al. 1998; Aguilella \& Bezrukov 2001; Gurnev \& Bezrukov 2012; Lang et al. 2013). This theory claims that the extent of counterion accumulation or coion depletion near a charged surface is dependent on the ratio between the Debye length of the solution $\left(\lambda_{D}=\left(\varepsilon \varepsilon_{0} R T / I F^{2}\right)^{1 / 2}\right)$ and the average distance from the channel mouth to the nearest charged lipid polar head. 
Even though the Gouy-Chapman theory has been extensively used, it presents some limitations. The most important are considering ions as point charges exposed just to Coulombic interactions and regarding the solvent as a structureless continuum with homogeneous dielectric permittivity. Some theoretical developments have surmounted these limitations, particularly those relative to the effect of the discreteness of surface charge both in protein ion channels and in biological membranes (McLaughlin 1989). Interestingly, despite the fact that charge on membranes is discrete, models that assume a uniform density of charge in the plane of the membrane predict potentials in agreement both with experiments (Winiski et al. 1986; Hartsel 1986) and Molecular Dynamics simulations (Yi et al. 2008).

\subsubsection{The bacterial porin $\mathrm{OmpF}$, a protein channel}

The classical way to investigate the interactions between the channel and the permeating ions is to analyze how channel conductance varies with salt concentration. In neutral or weakly charged pores, the channel conductance should be proportional to the solution conductivity and hence to the ion concentration (Hille 1978). In charged pores, one could speculate that the relationship between conductance and concentration should basically depend on the amount of carriers that are inside the channel once the electroneutrality requirements are fulfilled. Thus, some studies allegedly report a linear dependence of the channel conductance on the square root of salt concentration that could be tentatively attributed to charge screening effects. The rationale would be supposedly related to the proportionality between the inverse Debye length and the square root of ionic strength (Malev et al. 2002). However, other experiments show no unique trend but a variety of charge screening effects depending on the pore size, the ionization state of the pore charges and the complicated balance between protein and lipid charges.

Taking this into account we determined the OmpF channel conductance in neutral and negatively charged membranes over a wide range of $\mathrm{KCl}$ salt concentrations (Figure $5.1 \mathrm{~A}$ ). Regardless the lipid composition and the salt concentration, the pore displays almost ohmic conduction, so that the conductance is independent of the applied voltage even at the lowest concentration, $30 \mathrm{mM}$ (Figure 5.1 B). As Figure 5.1 A shows, the conductance in concentrated solutions is almost independent of the lipid bilayer composition and it scales with salt concentration. Linearity conductance is typical of neutral or weakly charged pores. However a close inspection shows that the dependence is not exactly linear, but somewhat like $G \sim c^{0.7}$. In contrast, the influence of membrane lipid charge in diluted solutions is remarkable. In decimolar salt concentrations the conductance in charged membranes is higher than in neutral ones by a factor of 2 . The fact that the conductance is higher in 
charged membranes than in neutral ones may be explained considering the modulation of ion concentration exerted by lipid charges.

This modulation has been qualitatively and semi-quantitatively explained in terms of GC theory (Rostovtseva et al. 1998; Aguilella \& Bezrukov 2001; Gurnev et al. 2012; Gurnev \& Bezrukov 2012; Lang et al. 2013). This theory predicts that the extent of counterion accumulation or coion depletion near a charged surface (in this case the lipid-solution interface) is critically dependent on the ratio between the Debye length of the solution and the average distance from the channel mouth to the nearest charged lipid polar head. In this scenario, the more diluted concentration, the more influence exerted by charges, resulting in counterion accumulation.
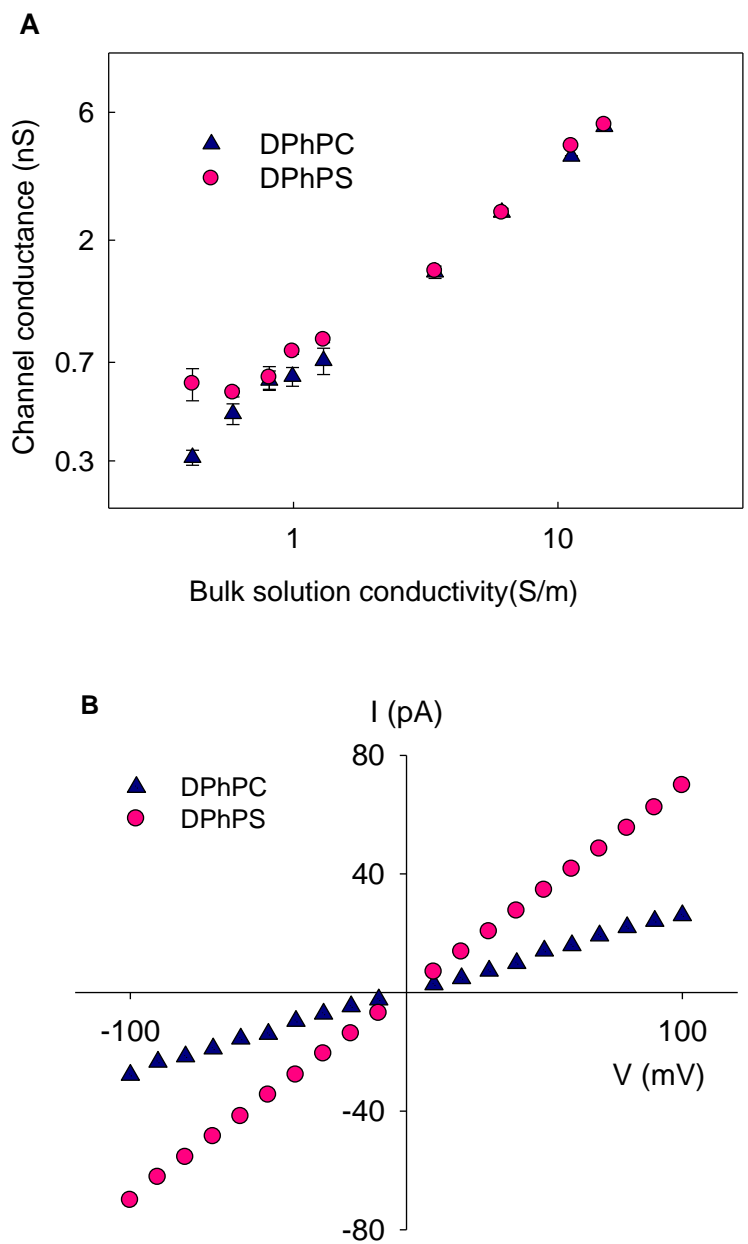

Figure 5.1 (A) Double logarithmic plot of the change of the OmpF single channel conductance with the conductivity of the bathing $\mathrm{KCl}$ solution at neutral $\mathrm{pH}$. Two sets of measurements are shown, corresponding to channel reconstitution in negatively charged DPhPS membranes (circles) and in neutral DPhPC membranes (triangles). (B) Current-voltage curve obtained from single channel experiments at $30 \mathrm{mM} \mathrm{KCl}$ in DPhPC (triangles) and DPhPS (circles) membranes as labeled. 
To analyze in detail how conductance varies with lipid charge in concentrated and diluted solutions, we determined the conductance in membranes with different lipid charge percentage. Figure 5.2 shows that there is an appreciable quantitative difference: despite the fact that in both cases the channel conductance increases with DPhPS, the conductance change from pure DPhPC to pure DPhPS membranes is negligible in high solution concentration ( 10\%), when compared with the two-fold increase seen in diluted $\mathrm{KCl}$ solutions. These results can be explained in terms of the relative distance between the closest lipid headgroup charges and the pore. In $1 \mathrm{M} \mathrm{KCl}$ Debye length is $\lambda_{D} \sim 0.3 \mathrm{~nm}$ whereas in $30 \mathrm{mM} \mathrm{KCl}$ this distance is $\lambda_{D} \sim 1.8 \mathrm{~nm}$. Comparing these two values it is obvious that in diluted solutions the influence of the lipid charges must be more significant than in concentrated solutions. At low concentrations the impact of the lipid charges may extend up to the channel mouth strongly enough to change the effective concentration of cations in the channel entrance modifying the electroneutrality.
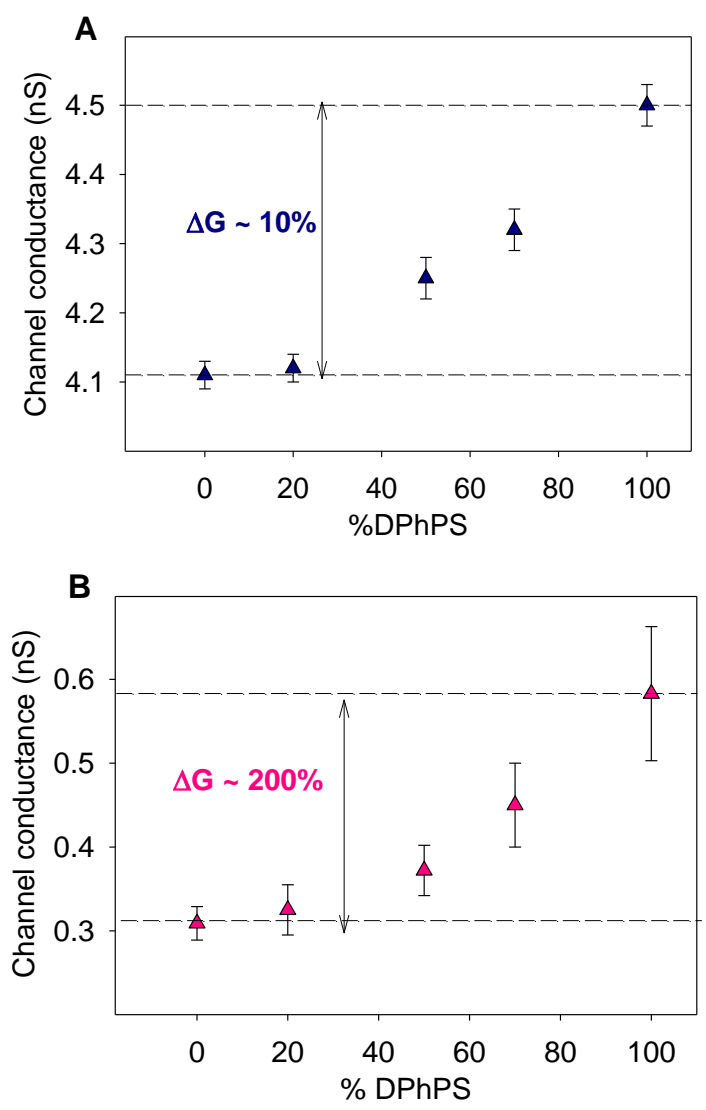

Figure 5.2 Change of single channel conductance with lipid surface charge density (proportional to the percentage of negatively charged DPhPS lipid in a DPhPC:DPhPS membrane). Variation of OmpF channel conductance with DPhPS percentage at high $(1 \mathrm{M})(\mathrm{A})$ and low $(30 \mathrm{mM}) \mathrm{KCl}$ concentration (B). 
In other channels like gramicidin A the influence of membrane charge is much more noticeable because of the much smaller size of the channel (Rostovtseva et al. 1998). This channel is formed by two peptide dimers that open a very narrow aqueous channel for single file transport of ions. In this channel only at very high salt concentration the conductance values in both membranes (DPhPC and DPhPS) are similar, whereas for dilute solutions the effect of the lipid charge increases the channel conductance in one order of magnitude (Rostovtseva et al. 1998) (Figure 5.3). Thus, the effect of the membrane charge is much more significant than in the case of OmpF because of the much smaller size of the channel. Gramicidin A is a cylinder-shaped pore with radius of about $0.2 \mathrm{~nm}$ while OmpF porin is an hour-glass shaped pore of about $0.7 \mathrm{~nm}$ in the narrowest part of the channel with the vestibules about 2 $\mathrm{nm}$ wide.

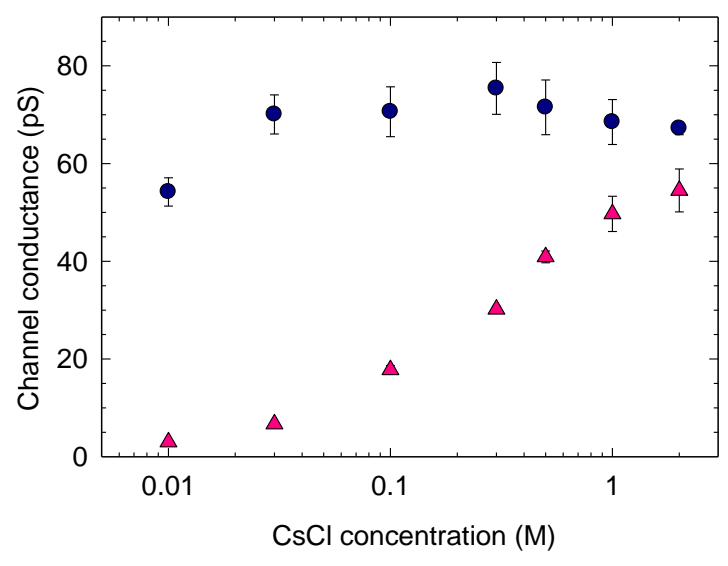

Figure 5.3 Double logarithmic plot of the change of gramicidin A channel conductance with $\mathrm{CsCl}$ concentration at $\mathrm{pH}$ 7.4. Circles denote measurements in negatively charged DPhPS membranes and triangles correspond to neutral DPhPC membranes (Rostovtseva et al. 1998).

The results obtained for OmpF channel can be summarized as follows: (a) low electrolyte concentrations enhance the effect of the lipid charges; (b) concentrated solutions screen the effect of the lipid charges making the conductance values for neutral membranes and charged ones almost identical; (c) as lipid charges surrounding the pore vestibules are responsible for the alteration of local ion concentrations, the smaller the channel entrance the higher the effect of the charged lipid (d) cationic or anionic selectivity is a key factor in the increase or decrease of channel conductance. This last assumption means that depending on the channel ion selectivity the membrane charge can enhance or decrease the amount of current carriers. For instance, if the pore is cationic selective, as $\mathrm{OmpF}$ porin, and it is reconstituted in a negatively charged membrane, the negative charges coming from the membrane tend to accumulate cations in the channel mouth. The number of current carriers 
increases which causes a conductance increase. However, if the pore is anionic selective, the negative lipid charge produces a depletion of anions, so quantitatively the number of current carries decrease. As a consequence, the channel conductance decreases.

Once we described the effect of lipid charge on a channel whose tertiary structure is known, this knowledge can be applied to figure out charge related effects on protein ion channels whose structure is still unknown.

\subsubsection{SARS-COV E protein: evidence for a proteolipidic pore}

As we showed in chapter 4 , the ion transport properties of the SARSCoV $\mathrm{E}$ protein are strongly influenced by the lipid membrane composition. In neutral membranes at concentrated $\mathrm{KCl}$ and $\mathrm{NaCl}$ solutions channel conductance is almost twice than in negatively charged membranes (Figure 5.4).

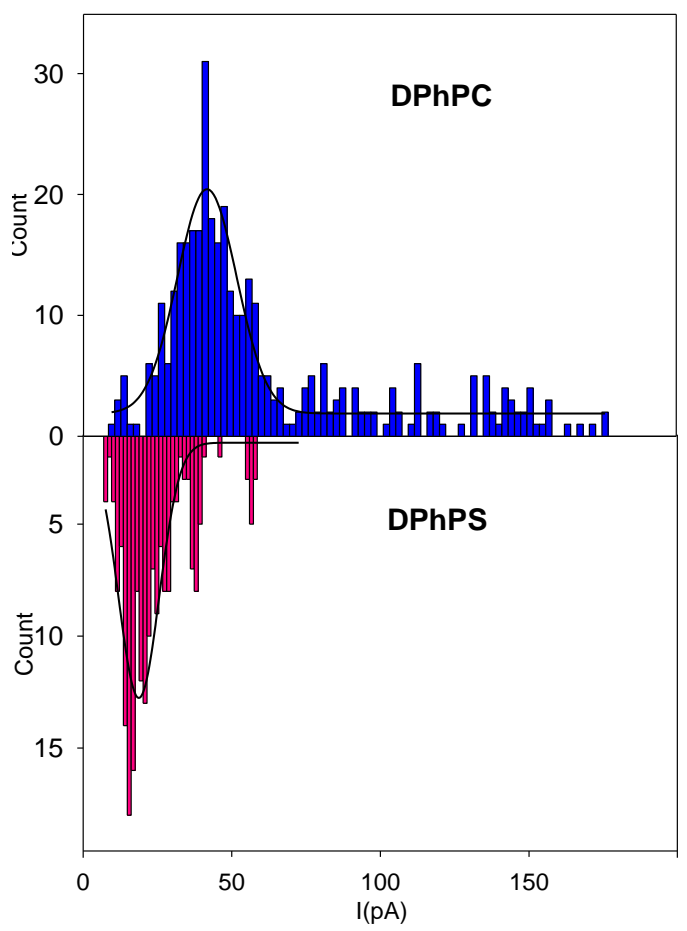

Figure 5.4 Histograms of the current jump amplitudes for E protein in neutral mebranes (top) and in negatively charged ones (down). Experiments were performed in $1 \mathrm{M} \mathrm{KCl} \mathrm{pH} 6$ at room temperature. Each histogram contains 300 recording events. 
This result could be explained if the pore exhibited anionic selectivity, because lipid negative charges would produce the depletion of anions in the pore entrance. Therefore, current should decrease. On the contrary, the $E$ protein channel exhibits a weak cationic selectivity in negatively charged membranes. A plausible explanation for this huge difference could be that the value obtained for the unitary channel conductance in neutral membranes is simply the result of two simultaneous insertions.

To check this issue, we determined the channel conductance in membranes with variable lipid composition between pure DPhPC and pure DPhPS. The results are shown in Figure 5.5. The channel conductance varies from $380 \pm 160 \mathrm{pS}$ in pure DPhPC to $190 \pm 60 \mathrm{pS}$ in pure DPhPS. The smooth transition observed supports that the channel conductance in DPhPC membranes was correctly determined.

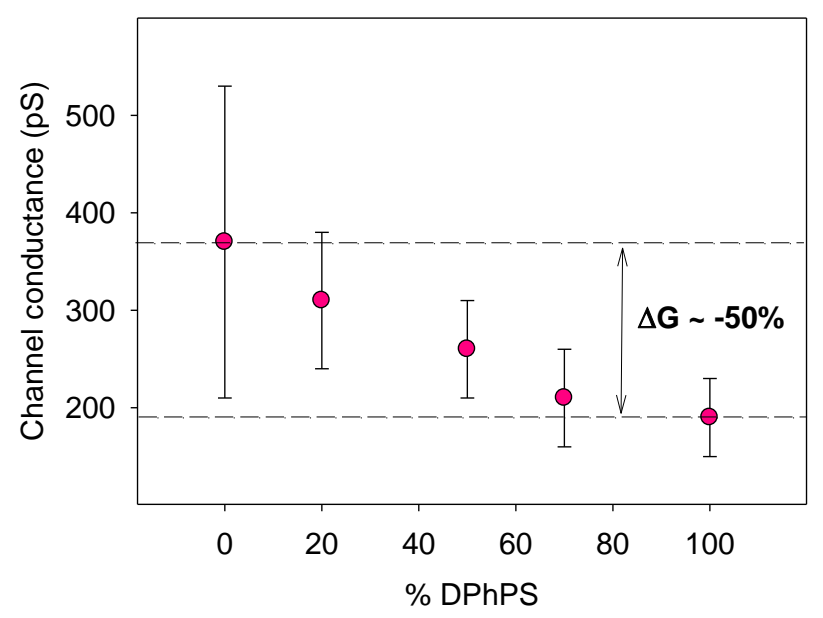

Figure 5.5 Variation of $\mathrm{E}$ protein channel conductance in high $\mathrm{KCl}$ salt concentrations $(1 \mathrm{M} \mathrm{KCl}$ solutions). All measurements were made at $\mathrm{pH} 6$. The values of channel conductance were extracted from the histograms of current jump amplitudes ( 300 events).

According to Gouy-Chapman theory the accumulation of ions near the pore mouth due to the lipid charge should give just the opposite effect. Thus, we could think whether the differences in conductance could be explained by a change in the pore size due to a different lipid-protein conformation. To verify this assumption new series of channel conductance experiments in membranes of variable lipid composition using diluted $\mathrm{KCl}$ solutions were carried out. The new results are plotted in Figure 5.6. Channel conductance follows a transition from neutral membranes to charged ones but in opposite direction to that observed in concentrated solutions. The channel conductance in pure neutral membranes is lower ( $28 \pm 8 \mathrm{pS}$ ) than in pure negatively charged membranes (68 $\pm 10 \mathrm{pS})$. 


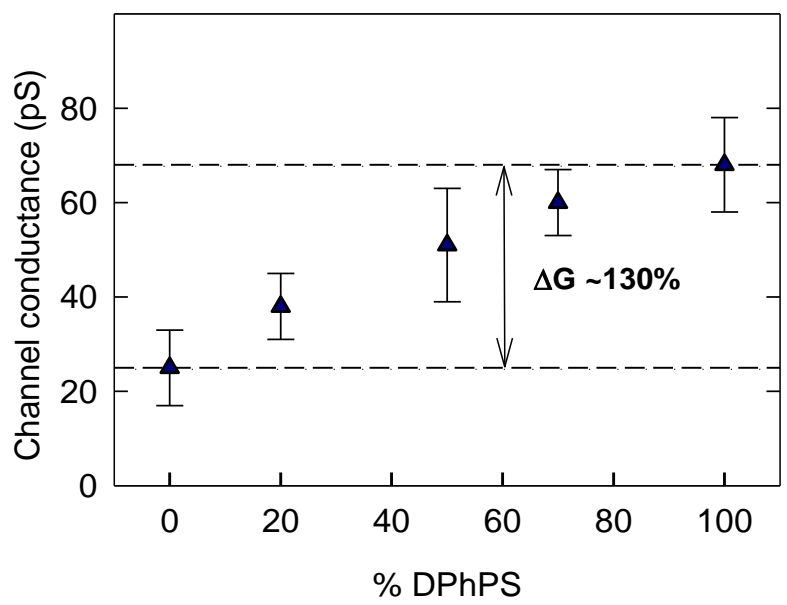

Figure 5.6 Variation of $\mathrm{E}$ protein channel conductance in low $\mathrm{KCl}$ salt concentration. All measurements were made at $\mathrm{pH} 6$. The values of channel conductance were extracted from the histograms of current jump amplitudes ( 300 events).

The fact that in diluted solutions the variation of conductance with lipid charge is opposite to that observed in concentrated solutions allows us to discard that the difference in conductance is a consequence of different proteinlipid conformations yielding changes in the pore size and structure. A change in channel size would display the same trend in both situations, and channel conductance should decrease or increase in a similar way independently of salt concentration.

The most likely explanation for this increase in conductance must be sought in the lipid polar head involvement in the channel pore. If this was the case, the overall conductance should reflect a balance between two effects working in opposite directions. The tight lipid-ion interaction could increase the number of available carries in the pore but could as well decrease their effective ion mobilities (Aguilella et al. 2011). To check this hypothesis, we evaluated the relationship between channel conductance and bulk solution conductivity.

Figure 5.7 shows the variation of the channel conductance with solution conductivity for a wide range of concentrations. In DPhPC membranes channel conductance scales linearly with solution conductivity indicating that the channel barely exerts any influence on the permeating ions, as OmpF channel does. In other words, the interaction between channel and permeating ions is so weak that ion conduction through the pore is very similar to ion conduction in bulk solution. This result is consistent with the almost non-selectivity observed in neutral membranes. 
In DPhPS membranes, the concentration dependence of channel conductance displays two different regimes. In low concentrated solutions channel conductance is not conductivity dependent, being the value of conductance constant. When the salt concentration increases, conductance increases with conductivity, but does not scale with bulk conductivity, which is a typical trend of charged pores (Malev et al. 2002). This data are in agreement with the cationic selectivity of the E protein channel in DPhPS membranes and with the fact that the preference for $\mathrm{K}^{+}$ions should be reflected on the channel conductance, particularly when $\mathrm{KCl}$ concentration is smaller than the effective negative charge concentration in the pore.

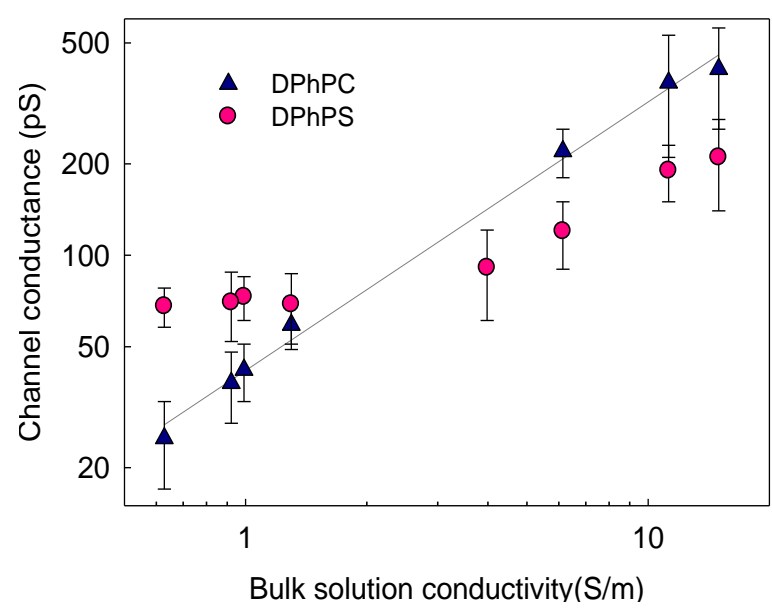

Figure 5.7 Double logarithmic plot of channel conductance versus bulk solution conductivity for $E$ protein. In pure neutral membranes (DPhPC) channel conductance changes linearly with bulk solution conductivity, whereas in pure charged membranes (DPhPS) two regimes appeared: at low concentration, the channel conductance is constant and increases with conductivity in more concentrated solutions. Both axes are represented in logarithmic scale Experiments were performed at room temperature at $\mathrm{pH} 6$ in $\mathrm{KCl}$ solutions, from $30 \mathrm{mM}$ to $1.5 \mathrm{M} \mathrm{KCl}$. The values of channel conductance were extracted from the histograms of current jump amplitudes ( 300 events).

Next, we consider that channel conductance is proportional to the total concentration of mobile ions inside the channel $G \propto\left(c_{+}+c_{-}\right)$and the $\mathrm{K}^{+}$and $\mathrm{Cl}^{-}$ average concentrations inside the channel are calculated by applying Donnan equilibrium equations:

$$
\begin{aligned}
& c_{+}=-\frac{\rho}{2}+\left(c^{2}+\frac{\rho^{2}}{4}\right)^{1 / 2} \\
& c_{-}=\frac{\rho}{2}+\left(c^{2}+\frac{\rho^{2}}{4}\right)^{1 / 2}
\end{aligned}
$$


In these expressions, $c$ is the salt bulk concentration and $\rho$ corresponds to the average fixed charge concentration inside the pore, taking into account the corresponding sign. Next, the conductance was normalized to the lowest value (the corresponding value to $30 \mathrm{mM} \mathrm{KCl}$ ) and $\rho$ was a fitting parameter:

$$
\frac{G(c)}{G(30 m M)}=\left(c^{2}+\frac{\rho^{2}}{4}\right)^{1 / 2}
$$

In Figure 5.8 the best fits were plotted: for DPhPC $\rho=0.14 \mathrm{M}$ and for DPhPS $\rho=0.94 \mathrm{M}$. Regardless of the apparent simplicity of the theory, the values obtained were in agreement with the data obtained. The value of $\rho=$ $0.14 \mathrm{M}$ for neutral membranes is consistent with the fact that the only residues contributing to the fixed channel charge are those of the transmembrane domain of the SARS-CoVE protein (Parthasarathy et al. 2008; Wilson et al. 2004). In fact, the transmembrane domain contains only two negative residues near the amino terminus: E7 and E8. However in the case of DPhPS we obtained $\rho=$ $0.94 \mathrm{M}$.

The high value of $\rho$ for charged membranes could be ascribed to the negative lipid headgroups. In this scenario $E$ protein channels act as charged pores and the value of $\rho$ explains the two regimes observed in the conductanceconductivity plot: as long as the bulk concentration is smaller than $\rho$, the ionic concentration inside the pore rises to match $\rho$, being the local electroneutrality ensured. Once the electroneutrality is ensured, as bulk concentration becomes comparable to $\rho$, counterions (ions of opposite charge to $\rho$ ) accumulate and coions (ions with same charge as $\rho$ ) are excluded obeying Donnan equilibria. Finally, when salt concentration is much higher than $\rho$, the Donnan exclusion is negligible so conductance almost increases linearly with the total ion concentration in the channel, in a similar way to a neutral pore.

Taking all these results into account, it seems that the difference in channel conductance in different bilayer compositions should be explained assuming that the lipid molecules take part in the channel structure. With this protein-lipid arrengement the lipid charge would exert an important influence as we have discussed. Although we cannot exclude totally a different arrangement of protein helices and lipid molecules in neutral and charged bilayers, all these experiments gave solid clues for claiming that the charged residues within the $E$ protein cannot explain by themselves the huge differences between ionic current in neutral and charged membranes. 


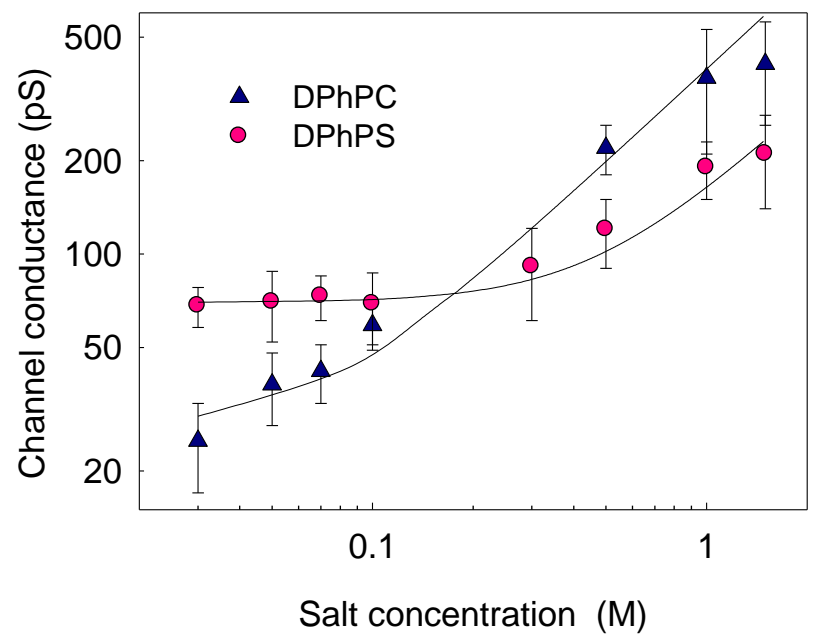

Figure 5.8 Channel conductance of E protein channel in neutral DPhPC (triangles) and negatively charged DPhPS (circles) at pH 6. In DPhPS membranes and low concentration KCl solutions (30$100 \mathrm{mM}$ ) the channel conductance remains unaltered because the ionic concentration within the pore is controlled by the channel fixed charge. In more concentrated solutions (0.3-1.5 M), the conductance increases with the bulk $\mathrm{KCl}$ concentration. The values of channel conductance were extracted from the histograms of current jump amplitudes ( 300 events).

\subsection{LIPID CHARGES INFLUENCE ION SELECTIVITY}

The ion selectivity can be strongly influenced by electrostatic environment that the permeating ions find when crossing the membrane. It is known that ionic selectivity depends on both the characteristics of channel and of ions flowing through the channel (Aguilella et al. 2011).

In this section we performed ion selectivity experiments at different $\mathrm{pH}$ conditions and salt concentrations in neutral and charged membranes. By changing the solution acidity we modulate the effective charge density coming from the ionizable residues of the protein or from the lipid headgroups and evaluate their contribution to the channel selectivity.

\subsubsection{Lipid charges on the membrane surface: the case of $\mathrm{OmpF}$}

Firstly we studied the effect of lipid charge on OmpF. We measured ion selectivity varying $\mathrm{pH}$ conditions. These experiments were performed in neutral DPhPC membranes and in negatively charged DPhPS membranes. 
As Figure 5.9 shows, no significant differences in DPhPC and DPhPS titration curves were observed. The charged lipid headgroups surrounding the pore entrance probably modify the local ionic concentration near the channel entrance, but this effect is not noticeable in terms of ion selectivity. In connection with this, the $p K_{a}$ of the two titration curves reflects the $p K_{a}$ of the most abundant ionizable residues of the $\mathrm{OmpF}$ channel, aspartates and glutamates whose $p K_{a}$ is close to 4 and arginines whose $p K_{a}$ is close to 12 .

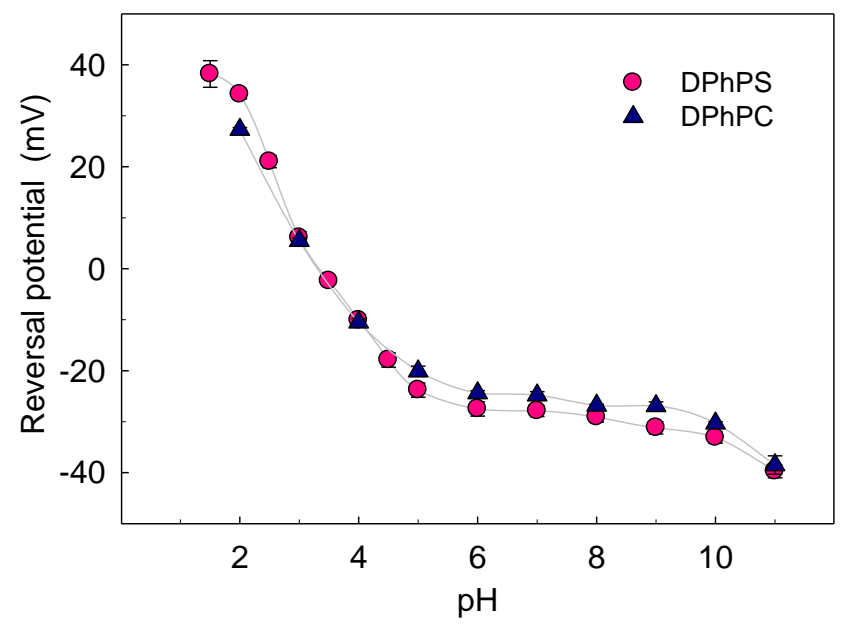

Figure 5.9 OmpF channel selectivity titration. Reversal potential was measured in neutral DPhPC membranes (triangles) and negatively charged DPhPS membranes (circles). Under the conditions of the experiments $(\mathrm{KCl}, 1 \mathrm{M}$ cis $\mid 0.1 \mathrm{M}$ trans), negative and positive reversal potential imply cationic and anionic selectivity, respectively. Each point is the average of measurements in 10-15 channels.

These results reveal that in an ion channel in which lipid molecules do not take part in the pore structure, their effect on ion selectivity is almost negligible. These data can help us to rationalize the effect of lipid charge in other systems in which lipid molecules can participate in ion channel structure.

\subsubsection{Lipid molecules as pore building blocks: the case of SARS-COV E protein}

Similarly to what was performed in OmpF channel, we evaluated the $E$ ion channel selectivity in 10 -fold $\mathrm{KCl}$ concentration gradient varying acidity in neutral and in negatively charged membranes. Figure 5.10 shows the ion selectivity dependence on the net charge of the lipid membrane. Contrary to what was observed in OmpF channel, in this case channel selectivity is strongly dependent on the net charge of the membrane. 
In neutral membranes $\mathrm{E}$ protein presents very mild cationic selectivity at neutral $\mathrm{pH}$ and a moderate anionic selectivity at highly acidic solutions ( $\mathrm{pH} \mathrm{1.5).}$ The change observed in ionic selectivity (see upper titration curve in Figure 5.10) may be ascribed to the protonation of glutamates in the $E$ protein transmembrane domain. However, in charged membranes, the $E$ protein selectivity at neutral $\mathrm{pH}$ is very different and much higher than in neutral membranes: an almost neutral pore like $E$ protein channel in neutral membranes becomes a strongly cation selective channel. In addition, in charged membranes the change in selectivity from $\mathrm{pH} 6$ to $\mathrm{pH} 1.5$ is much more remarkable and the titration of the residues even reverses the ion selectivity from cationic to anionic at pH below 2 (see bottom curve in Figure 5.10).

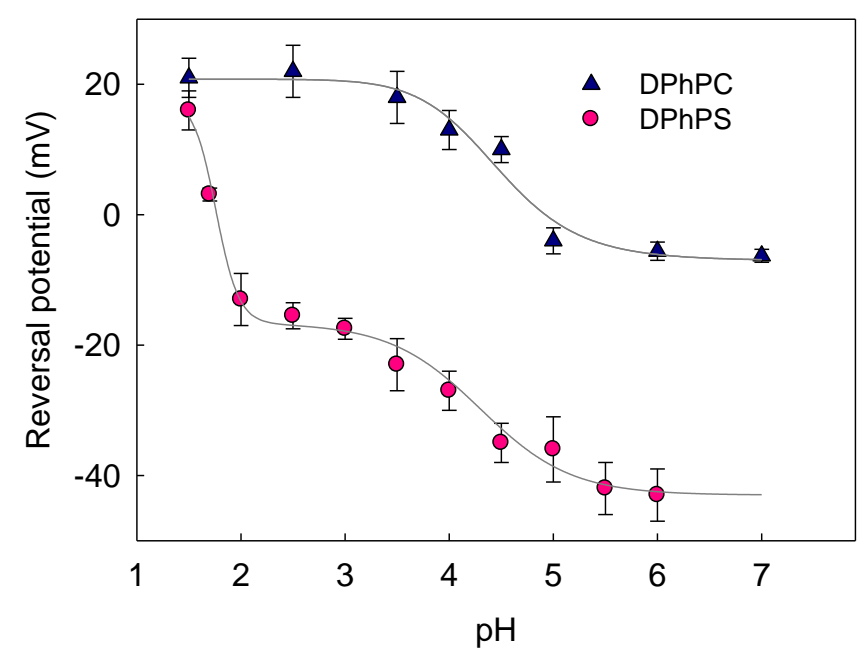

Figure 5.10 E protein channel titration. Reversal potential was measured in neutral DPhPC membranes (triangles) and negatively charged DPhPS membranes (circles). Under the conditions of the experiments ( $500 \mathrm{mM} \mathrm{KCl}$ cis $\mid 50 \mathrm{mM} \mathrm{KCl}$ trans), negative and positive reversal potential imply cationic and anionic selectivity, respectively. Solid lines correspond to the best fit of the data according the typical one-site sigmoidal titration curve (top plot) and two-site titration curve (bottom plot). Each point is the average of measurements in 10-15 channels.

The reversal potential measurements in DPhPC membranes present the typical one-site saturation trend seen in other channels (Alcaraz et al. 2004; Rostovtseva et al. 2000). For this reason we fit this set of $E_{\text {rev }}$ to 5.3 , similar to the standard sigmoidal dose-response curves:

$$
E_{r e v}=E_{\min }+\frac{E_{\max }-E_{\min }}{1+10^{p H-p K a 1}}
$$


To fit the data the $E_{\max }$ and the $E_{\min }$ are taken from the values of reversal potential at low $\mathrm{pH}\left(E_{\max }\right)$ and neutral $\mathrm{pH}\left(E_{\min }\right)$. Only $p K_{a 1}$ is the fitting parameter. This approach has been applied in other weakly selectivity channels, as VDAC (Rostovtseva et al. 2000), OmpF (Alcaraz et al. 2004) and PorA from N. Meningitidis (Cervera et al. 2008). The best fit is for $p K_{a 1}=4.3$. This value could correspond to the $p K_{a}$ of glutamate, which is one of the residues of the transmembrane domain of the $E$ protein. In fact, the transmembrane domain contains only two negative residues near the amino terminus: E7 and E8.

The series of reversal potential measurements in DPhPS membranes does not look like the typical one-site titration curve. In this case the data have two sites, so in order to take into account the double transition we modified equation 5.3 and a "double-site titration curve" was introduced:

$$
E_{\text {rev }}=E_{\text {min }}+\frac{E_{\text {int }}-E_{\text {min }}}{1+10^{p H-p K a l}}+\frac{E_{\text {max }}-E_{\text {int }}}{1+10^{p H-p K a 2}}
$$

By taking the low $\mathrm{pH}\left(E_{\max }\right)$ and neutral $\mathrm{pH}\left(E_{\min }\right)$ values for $E_{\text {rev }}$ from the experimental data and leaving $p K_{a 1}$ and $p K_{a 2}$ as well as $E_{\text {int }}$ as fitting parameters, the best fit is obtained for $E_{i n t}=-19 \mathrm{mV}, p K_{a 1}=4.3$ and $p K_{a 2}=1.73$. The easiest interpretation for this second effective $p K_{a}$ seen in the titration curve is to ascribe it to the carboxyl group of the PS polar head (although titration of the phosphate group cannot be totally excluded). This would support the view that lipids line the pore lumen and not only contribute but also determine the channel selectivity. The model $p K_{a}^{\prime}$ 's of serine carboxyl group reported in the literature are in the range $2.5-4.5$ (Tocanne \& Teissié 1990; Rostovtseva et al. 1998). However, it is important to note that when the ionization occurs in confined spaces as the pore it is expected a significant deviation from the model $p K_{a}$ because protons see a different electric potential near the ionizable site (Rostovtseva et al. 1998). In concentrated solutions, as this case, the apparent $p K_{a}$ (the one obtained from titration curves) should be shifted towards lower values (Tsui et al. 1986).

Interestingly, the fitting value of $p K_{a 1}=4.3$ is the same in both series of measurements: in neutral and in charged membranes. This fact may suggest that the protonation of glutamates in the transmembrane protein domain is not affected by the presence of carboxyl groups of the lipid polar heads despite the presumably tight arrangement of the transmembrane helices and the lipid molecules. This is in agreement with the fact that there are many more carboxyl than glutamate groups lining the pore so that the assembling of helices and lipid molecules in the channel may be such that both types of charged groups are kept apart from each other. 
Other important result is that at very low $\mathrm{pH}$ the values of reversal potential in both lipids are almost equal. The anionic selectivity at low pH only can arise from positively charged residues of the transmembrane domain like arginine $\mathrm{R} 38$, since at this $\mathrm{pH}$ the lipid headgroups are neutral. This fact indicates that the channel selectivity is the same regardless of whether the pore structure includes PS or PC lipids and it may suggest that the charge of the lipid headgroups does not necessarily modify the structural conformation of the channel, in other words, the spatial distribution of positive residues in the pore would be similar in DPhPC and in DPhPS.

\subsection{CONCLUSIONS}

In this chapter we have analyzed the lipid charge effects on the ion transport properties of OmpF porin and E protein channels. In the case of OmpF, the influence of the membrane charge is almost negligible. This result is expected because the lipid molecules do not take part in the pore structure. As regards conductance, only in diluted solutions a difference between neutral and charged membranes is observed. This result can be explained in terms of the relative distance between the closest lipid headgroup charges and the pore. In low concentrated solutions Debye length is six times higher than in high concentrated solutions. This fact explains why only in diluted solutions the effect of the lipid charge is clearly observed. A similar reasoning explains the weak dependence of selectivity on lipid charge. The OmpF channel selectivity titration in neutral membranes and in charged ones is almost identical. Although the DPhPS negative charges probably modify the ion concentration near the channel vestibule in the diluted concentration, their repercussion in the zero current potential is negligible.

In contrast, in the case of $E$ protein the conductance and ion selectivity are strongly influenced by lipid charge. On the one side, channel conductance experiments indicate that the lipid charges contribute to the channel current by accumulating counterions as described by the Donnan equilibrium. The high differences observed in channel current in neutral and charged membranes could be rationalized by means of a balance between the bulk electrolyte concentration and the average fixed charge concentration inside the channel. On the other side, ion selectivity experiments indicate that both protein and lipid charges participate in the overall E protein ion selectivity. Lipid and protein ionizable residues become titrated in an independent manner and the titration curve shows clearly that there are two contributions to the selectivity.

Putting together the experimental data obtained for E protein channel and the results obtained for OmpF porin, it is obvious the participation of the lipid molecules in the $E$ protein channel structure which points to a proteolipidic pore. In this structure the channel would be formed by the combination of lipid 
molecules and E protein monomers, being the lipid molecules only located at the channel mouth, or as building blocks of the pore, stabilized by peptides, lining totally or partially the pore wall. 


0. A viroporin from the human respiratory syncytial virus: channel activity and inhibition 

Part of the studies included in the present chapter were published in the following articles:

"Inhibition of the Human Respiratory Syncytial Virus Small Hydrophobic Protein and Structural variations in a bicelle environment" Journal of Virology (2014) 88, 11899 - 11914. 



\subsection{INTRODUCTION}

The small hydrophobic (SH) protein is a 64- amino acid polypeptide encoded by the human respiratory syncytial virus (hRSV) with a single $\alpha$-helical transmembrane (TM) domain that forms pentameric ion channels (Gan et al. 2012; Gan et al. 2008). In infected cells, most SH proteins accumulate at the membranes of the Golgi complex, but they have also been located in the endoplasmatic reticulum and plasma membranes (Rixon et al. 2004). The role of the SH protein is less clear. Some studies reported that RSV lacking the SH gene was viable, caused formation of syncytia, and grew as well as the wild-type virus in cell culture (Whitehead et al. 1999; Fuentes et al. 2007; Jin et al. 2000). However, RSV lacking SH gene replicated 10-fold less efficiently than the wt in the upper respiratory tract (Jin et al. 2000). In addition, virus without SH gene was attenuated in vivo by virus passage in mouse and chimpanzee models (Whitehead et al. 1999). These results suggest that SH protein is involved in virus pathogenesis.

SH protein channels may constitute novel drug targets. Unfortunately, no inhibitor for this channel activity has been described so far. The availability of $\mathrm{SH}$ channel inhibitors would help further understanding the role of this channel function in the viral life cycle of RSV. In this chapter we report experiments aiming to test a compound that acts as SH channel activity inhibitor, pyronin B.

In addition, we study how the only ionizable residues located in the transmembrane domain of the $\mathrm{SH}$ protein influence the channel function. These residues are His22 and His51 and they are located in the cytoplasmic and luminal site, respectively. Previous studies have claimed that protonation of these residues causes the ion channel inactivation, suggesting that their protonation may abolish the channel function. We reconstituted $\mathrm{SH}$ protein in planar lipid membranes and determined the channel conductance of SH protein at different $\mathrm{pH}$ conditions to determine how the protonation of histidine residues can affect to channel activity. Besides, the ion selectivity of $\mathrm{SH}$ protein and mutants in which histidine residues were replaced was also determined. Considering that $\mathrm{SH}$ protein accumulates at the membranes of the Golgi complex, we characterized the ion transport properties in membranes that mimic the surface charge density and the negative curvature of this type of membranes (3:1:1 DOPC:DOPS:DOPE, which corresponds to $20 \%$ negatively charged lipid, $20 \%$ negative curvature). 


\subsection{RESULTS}

\subsubsection{Ion channel current inhibition}

Since no SH protein channel activity inhibitors have been reported to date, a liposome-based fluorescence assay was used to screen for compounds that can act as potential inhibitors of the channel function. From these assays, five compounds showed significant inhibition of channel activity at $10 \mu \mathrm{M}$ concentration (>50 \%): NSC 526417, NSC 81189, NSC 78627, NSC 77827 and NSC 44690 (see structures in http://pubchem.ncbi.nlm.nih.gov/). These compounds were retested against $\mathrm{SH}$ protein reconstituted in planar lipid membranes. Compound NSC 44690 (pyronin B) turned out to be the most potent inhibitor. A concentration of $10 \mu \mathrm{M}$ led to a $\sim 60 \%$ inhibition of the channel conductance. As Figure 6.1 shows channel conductance changes from $300 \pm 70$ pS to $120 \pm 60$ $\mathrm{pS}$ in the presence of $10 \mu \mathrm{M}$ of pyronin B.
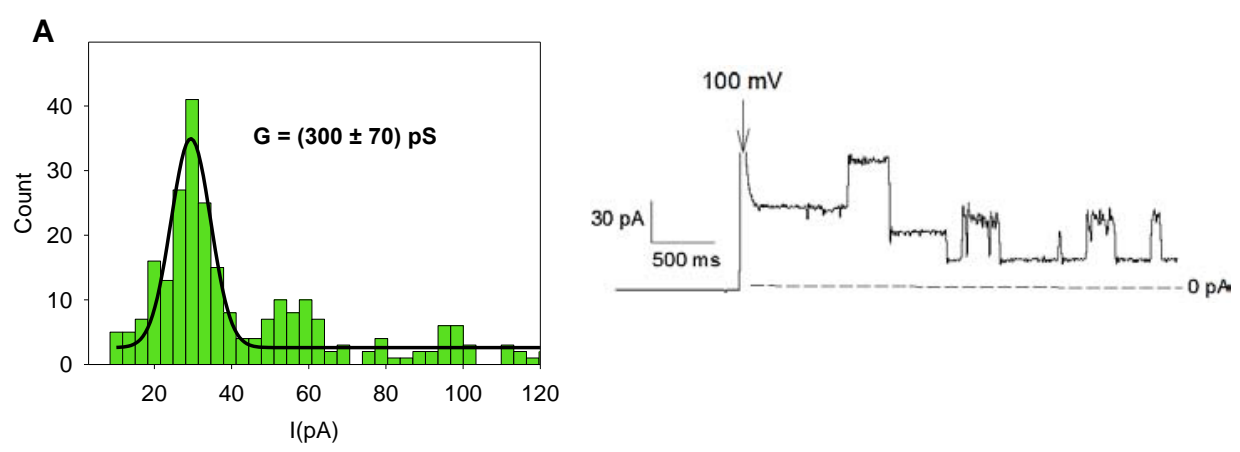

B
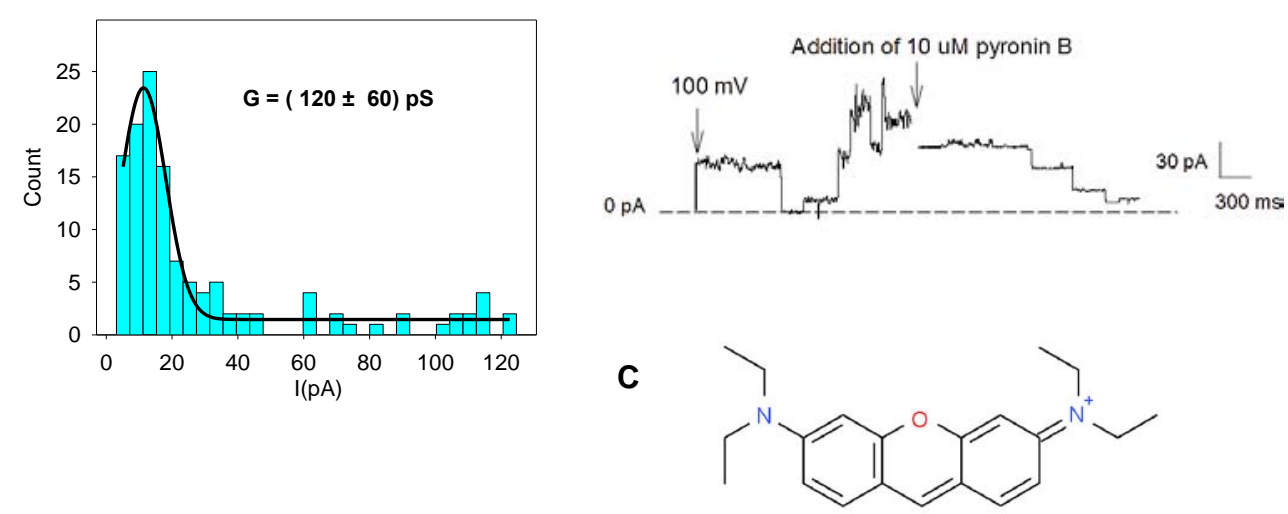

Figure 6.1 SH channel activity and inhibition caused by pyronin B. (A) Histogram of the current jump amplitudes (left) and current recording of SH protein channel activity under $1 \mathrm{M} \mathrm{KCl,} \mathrm{pH} 6$ in membranes containing 3:1:1 DOPC:DOPS:DOPE (right). (B) Histogram of the current jump amplitudes (left) under the presence of $10 \mu \mathrm{M}$ of pyronin $\mathrm{B}$ and current recording of SH activity under the presence of inhibitor (right). The histograms contain 300 events. (C) Structure of pyronin B. 
Then we measured the channel current of $\mathrm{SH}$ under the presence of different pyronin $B$ concentrations and we fitted the experimental data to sigmoidal dose-response to obtain the constant of inhibition. As Figure 6.2 displays the constant of inhibition, $K_{\mathrm{d}}$ is about $6.8 \mu \mathrm{M}$.

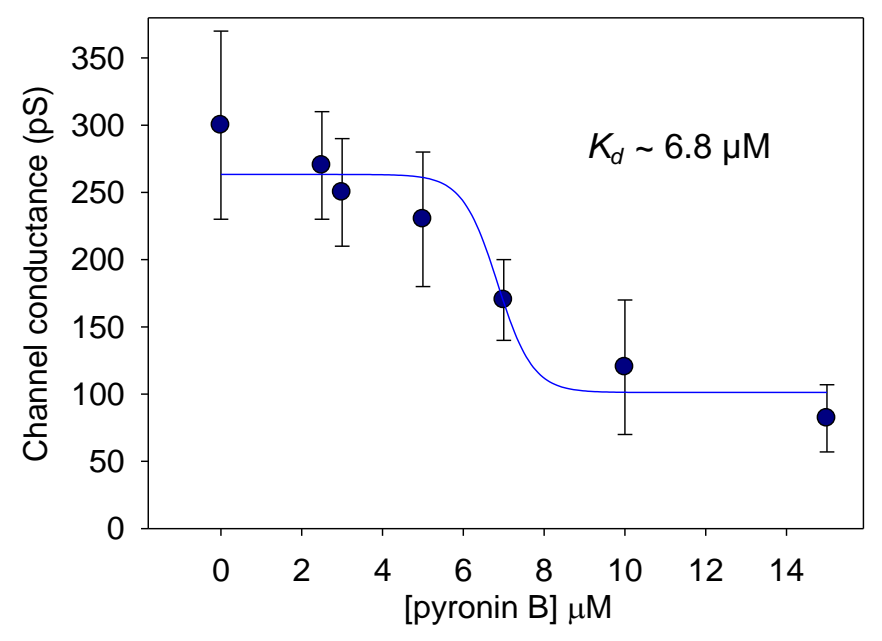

Figure 6.2 Dose-response curve obtained in the presence of $0,2.5,3,5,7,10$ and $15 \mu \mathrm{M}$ pyronin B. The conductance values were obtained from histograms of the current jump amplitudes and then by the quotient of the mean current value and the applied voltage $(+100 \mathrm{mV})$. Histograms contain 300 events corresponding to the current jump amplitudes of 30 independent experiments lasting more than $200 \mathrm{~s}$. The value of $K_{d}$ is $\sim 6.8 \mu \mathrm{M}$. Conductance experiments were performed in $1 \mathrm{M} \mathrm{KCl}$ solution buffered with $5 \mathrm{mM}$ HEPES in 3:1:1 DOPC:DOPE:DOPS membranes.

Next, the binding of pyronin B to the SH protein was monitored with Nuclear Magnetic Resonance 2D spectra recorded in the absence and presence of pyronin $B$ at different concentrations. These experiments were performed by Dr. Jaume Torres and collaborators. They observed that when a $4.5 \mathrm{mM}$ of the compound was added to a $0.6 \mathrm{mM}$ of protein backbone, resonances of different residues in $\mathrm{SH}$ protein were noticeably perturbed (Figure 6.3 A, B and $\mathrm{C}$ ), and large chemical shift perturbations (CSPs) were observed at both ends of the transmembrane domain. The residues more affected at the $\mathrm{N}$-terminal end were Ile6 and Ile21 and at the C-terminal end the residue most affected was Ala39 (Figure 6.3 A, B and C).

It is noteworthy that residues 38 to 43 form a conserved motif in the RSV SH protein, see Figure 6.3 D. This suggests that this is an important region for $\mathrm{SH}$ protein, where emergence of resistance mutations would be difficult for the virus. However, the residues lle6 and Ile21 are not conserved. 
A

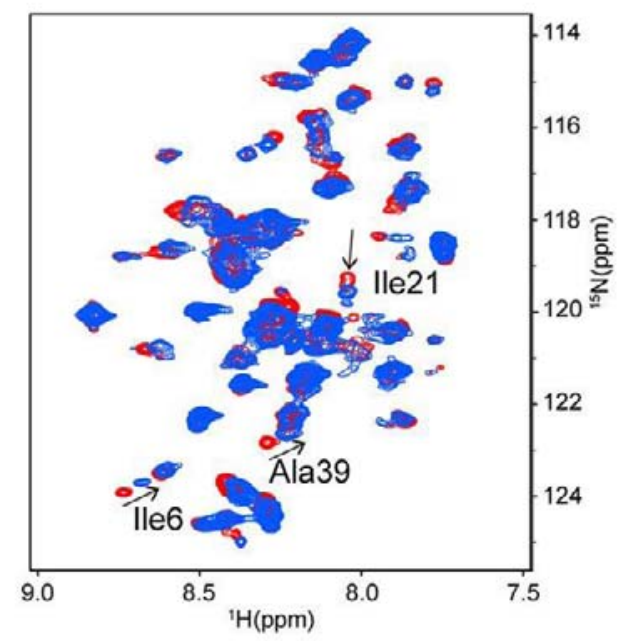

B
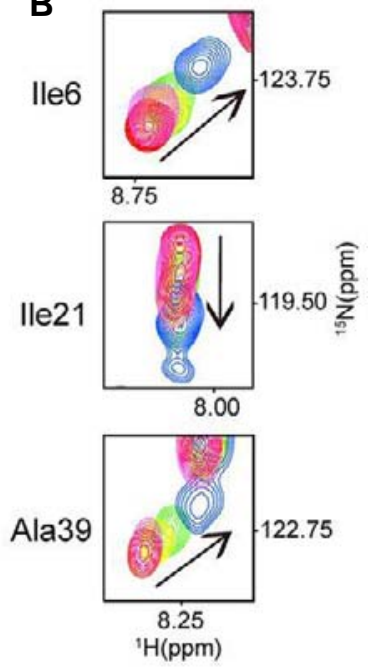

C

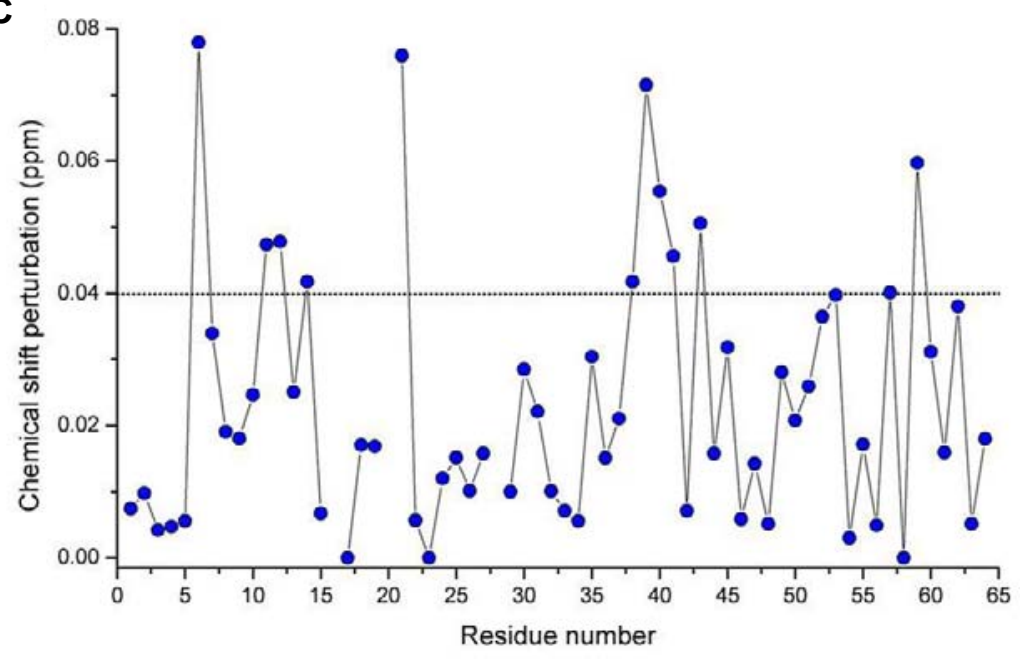

D

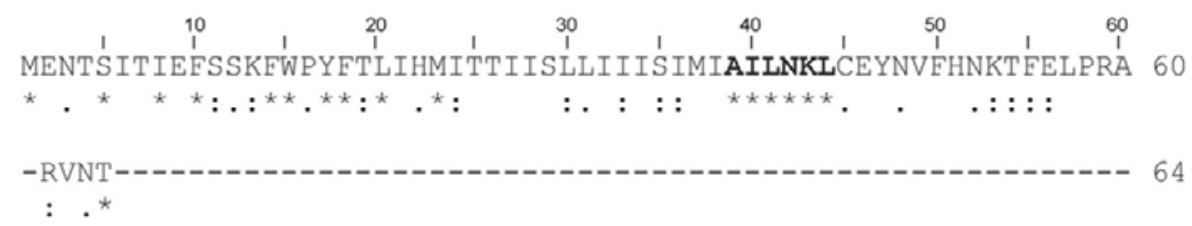

Figure 6.3 Pyronin B binding significantly perturbed the chemical shifts of $\mathrm{SH}$ oligomer. (A) Superposition of $\left[{ }^{1} \mathrm{H}-{ }^{15} \mathrm{~N}\right]$ TROSY-HSQC (transverse relaxation optimized spectroscopyheteronuclear single-quantum coherence, NMR 2D) spectra of uniformly ${ }^{15} \mathrm{~N}$-labeled SH protein (monomer concentration, $0.6 \mathrm{mM}$ ) in the absence (blue) and presence (red) of $4.8 \mathrm{mM}$ pyronin $\mathrm{B}$. Peaks that undergo significant shifts upon complex formation are highlighted. (B) Selected regions in TROSY-HSQC spectrum in the presence of pyronin B concentrations increasing from 0 (red) to 0.3 (pink), 1.2 (yellow), 2.4 (green), and $4.8 \mathrm{mM}$ (blue). (C) Chemical shift perturbation (CSP, ppm) of the backbone amide resonances of $0.6 \mathrm{mM}{ }^{15} \mathrm{~N}$-labeled SH protein upon titration with $4.8 \mathrm{mM}$ pyronin $B$. The missing and overlapping residues were eliminated from the analysis. (D) Result from a Clustal X alignment of $>40$ variants of RSV SH protein where identity (star) and similarity (dot) are indicated. Experiments carried out by Dr. Jaume Torres and collaborators. 

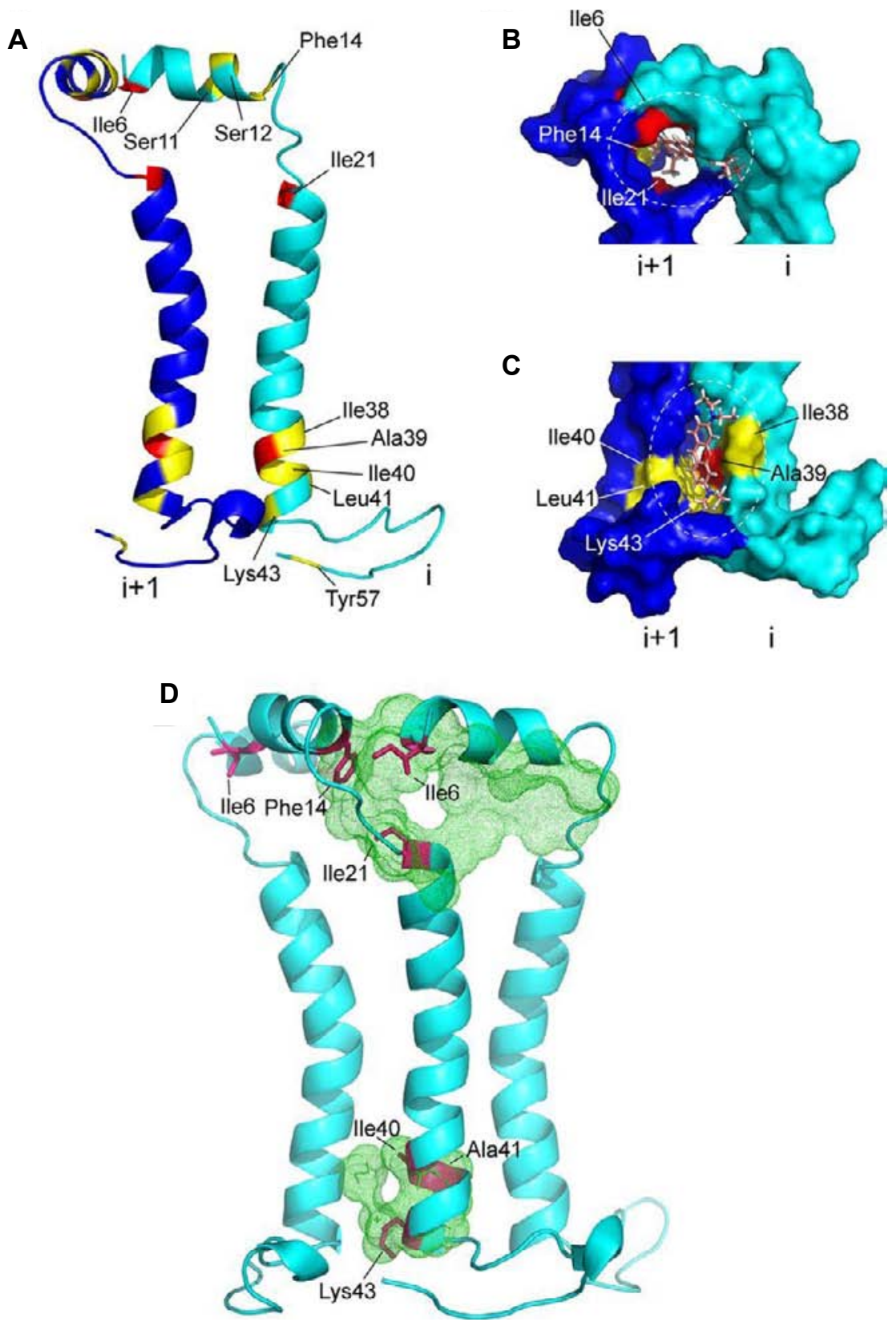

Figure 6.4 Mapping of pyronin B binding to SH protein. The chemical shift perturbation (CSP) values in the presence of pyronin B are mapped onto the structure of SH protein, with residues showing larger (CSP of $0.07 \mathrm{ppm}$ ) and smaller (CSP of $0.04 \mathrm{ppm}$ ) shifts represented in red and yellow, respectively. ( $B$ and $C$ ) Model of the two pyronin $B$ binding sites on the SH pentamer at the $\mathrm{N}$-terminal (B) and C-terminal (C) ends of the TM domain (dotted circles), where residues with a CSP of $0.07 \mathrm{ppm}$ are labeled in red. Only two monomers of SH protein pentamer $(i$ and $i+1)$ are shown for simplicity. (D) Druggable pockets (green mesh) predicted by DoGSiteScorer, an automated pocket detection and druggability assessment tool. For comparison, the main residues that showed largest NMR chemical shift changes are shown in red. Two monomers have been removed from the pentamer for clarity. Experiments carried out by Dr. Jaume Torres and collaborators. 
To provide more insight into the nature of the pyronin $B$ binding sites, Dr. Jaume Torres and collaborators performed docking studies of pyronin B to the $\mathrm{SH}$ protein using as a model for docking the $\mathrm{SH}$ pentameric structure obtained in DPC micelles (Gan et al. 2012). The best ten structures were selected according to the geometric shape complementarity score. Interestingly, in nine of these structures, pyronin B was located near the residues that showed the largest chemical shift perturbation, i.e., lle6, lle21, and Ala39.

Thus, the following search was restricted to regions close to those residues, and led to the prediction of two possible binding sites at both ends of the transmembrane (TM) domain. The N-terminal one is formed by Phe14 and Ile21 in one monomer ( $(+1)$ and lle-6 of the previous monomer (Figure $6.4 \mathrm{~A}$ and B). The C-terminal one is formed by residues Ile40, Leu41, and Lys43 in one monomer ( $\mathrm{i}+1)$ and Ile38 and Ala39 of the previous monomer (i) (Figure $6.4 \mathrm{~A}$ and C). An analysis of the druggable pockets on the SH pentamer surface by the software DogSiteScorer (Volkamer et al. 2012) also identified these same regions (Figure 6.4 D).

\subsubsection{Pyronin B effect on $\mathrm{SH}$ mutants}

Once we identified the residues involved in the pyronin B binding we tested the effect of the drug on $\mathrm{SH}$ peptide corresponding to the transmembrane domain (SH-TM, residues 18 to 43) and full-length mutants at the two proposed binding sites, at the $\mathrm{N}$ or the $\mathrm{C}$ termini of the TM domain (A39S, I21F and I 21Y mutants). The SH-TM contains an intact binding site at the C-terminal juxtamembrane domain (residues 38 to 43), whereas most residues located at the $\mathrm{N}$-terminal end are absent.

All of these mutants, including SH-TM protein, show ion channel activity (Figure 6.5). The channel conductance in all cases is similar to the channel conductance of $\mathrm{SH}$ protein although in $121 \mathrm{~F}$ this is reduced to about $50 \%$, suggesting that this mutant may form a narrower pore. Once we checked that all mutants display ion channel activity, we evaluated the effect of the pyronin B. To compare with the experiments carried out in SH protein, we used $10 \mu \mathrm{M}$ concentration of drug. 

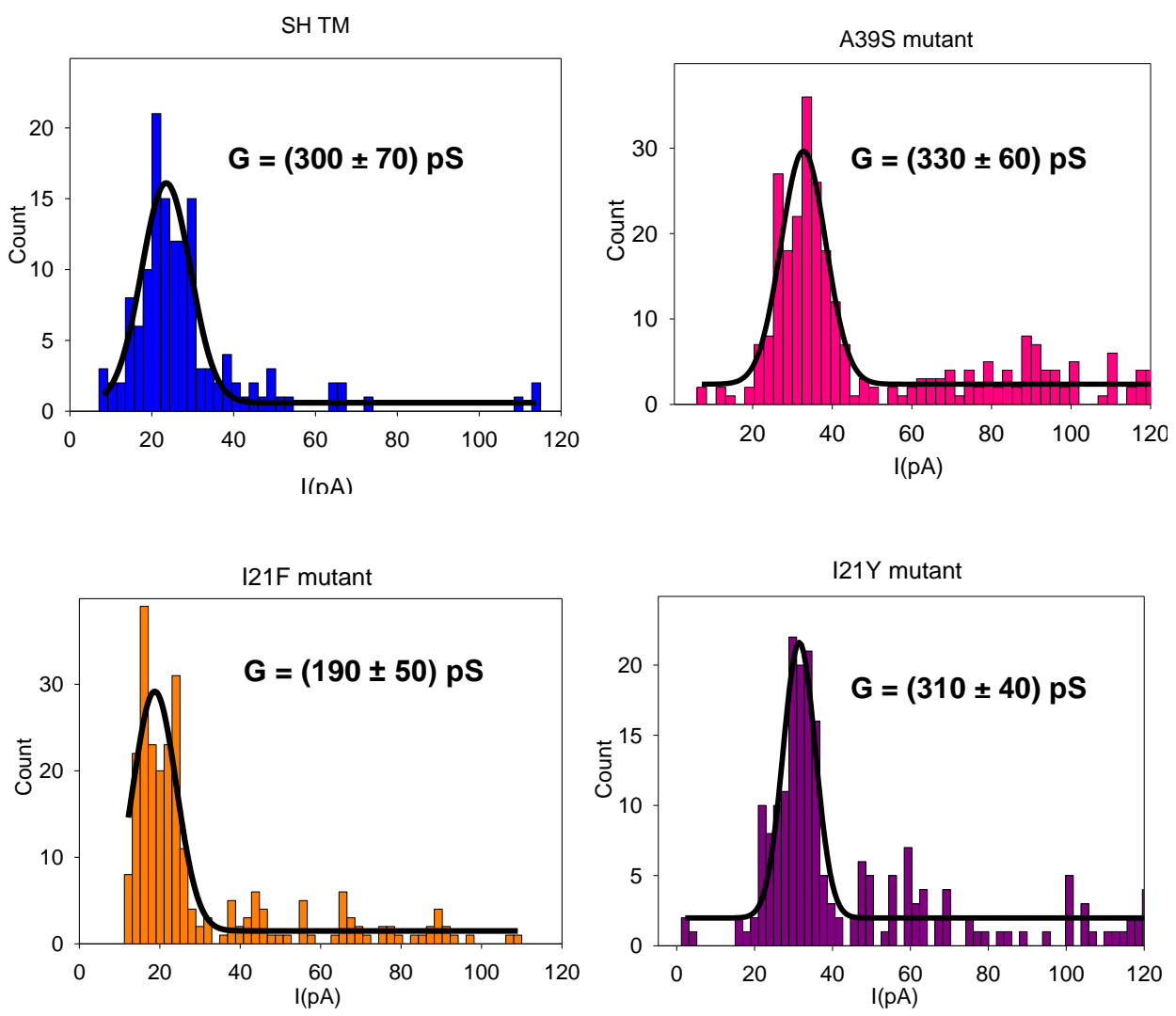

Figure 6.5 Histograms corresponding to the current jump amplitudes of SH TM, A39S, I21F and I21Y mutants. The experiments were carried out in $1 \mathrm{M} \mathrm{KCl}$ in membranes formed by 3:1:1 DOPC: DOPS: DOPE at $+100 \mathrm{mV}$. Each histogram contains approximately 300 events.

Figure 6.6 shows the histograms corresponding to the current levels under the presence of this compound. In addition Figure 6.7 displays the conductance values without inhibitor and in the presence of $10 \mu \mathrm{M}$ of pyronin B.

The effect of pyronin B on SH-TM was similar to full-length protein (40\% and $60 \%$ inhibition, respectively). This result suggests that the intact C-terminal end of the TM domain (residues 38 to 41 ) is sufficient for inhibition. Actually the mutation A39S disrupts the inhibitory effect of pyronin B, since channel conductance is reduced only by $10 \%$. Interestingly, the three other mutants show resistance to inhibition. It is observed a $20 \%$ inhibition in these cases despite the fact that the C-terminal is intact. These data can be explained by assuming a destabilization of the C-terminal binding site in the presence of these mutations at the N-terminal end of the TM domain. $121 \mathrm{~F}$ and $121 \mathrm{Y}$ represent more bulky substitutions that may lead to a modification of the pyronin $\mathrm{B}$ binding site at the $\mathrm{C}$-terminal region. 

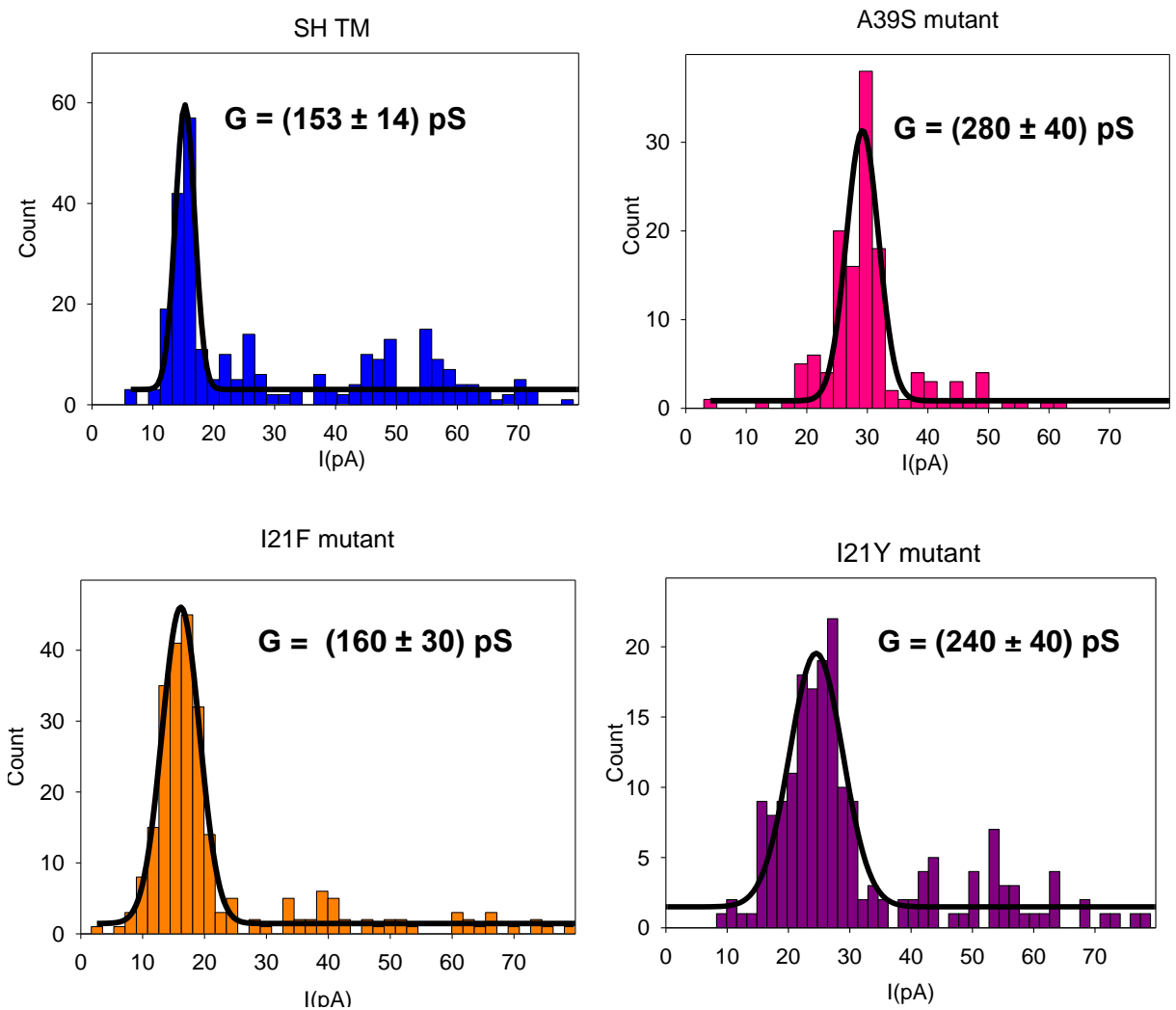

Figure 6.6 Histograms corresponding to the current jump amplitudes of SH TM, A39S, I21F and I21Y mutants in the presence of $10 \mu \mathrm{M}$ pyronin $\mathrm{B}$. The experiments were carried out in $1 \mathrm{M} \mathrm{KCl}$ in membranes formed by 3:1:1 DOPC: DOPS: DOPE at $+100 \mathrm{mV}$. Each histogram contains approximately 300 events.

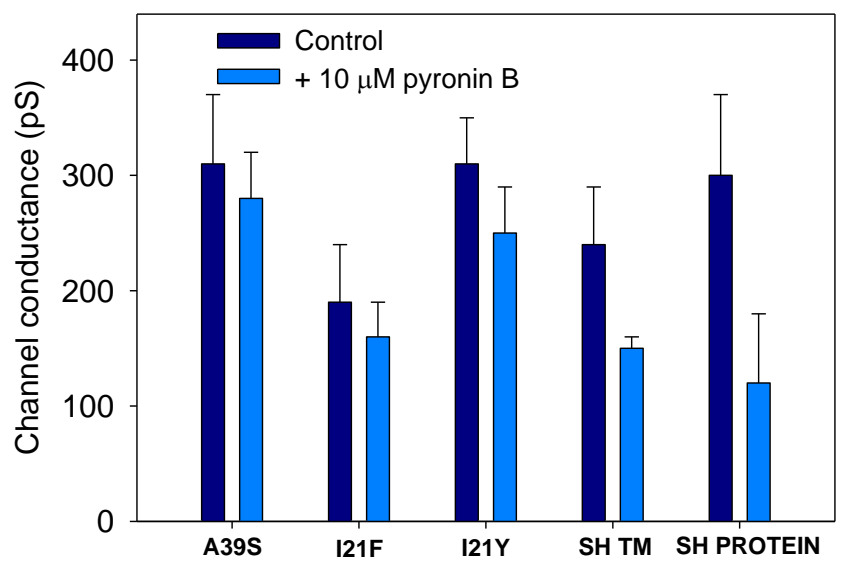

Figure 6.7 Channel conductance of SH protein and mutants and effect of pyronin $\mathrm{B}$ on channel conductance at $1 \mathrm{M} \mathrm{KCl}$ in 3:1:1 DOPC:DOPS:DOPE membranes. 


\subsubsection{Characterization of SH protein ion channel activity}

In a recent paper (Gan et al. 2008) patch clamp data suggested a Hisdependent channel activity, and a low-pH activation. Histidine is the only protonable residue in the SH-TM domain and the $\mathrm{pH}$ dependence was attributed to the presence of both residues, His22 (in the TM domain) and His51 (at the tip of an extramembrane C-terminal hairpin) so this low $\mathrm{pH}$ activation may be caused by protonation of these histidines.

To check these previous results we determined the $\mathrm{SH}$ protein channel conductance at different $\mathrm{pH}$. Figure 6.8 shows the $\mathrm{pH}$-dependent conductance. At acidic $\mathrm{pH}$ solutions, the conductance decreases suggesting that the protonation of the histidines reduces the channel current. However, SH proteins display ion channel activity.

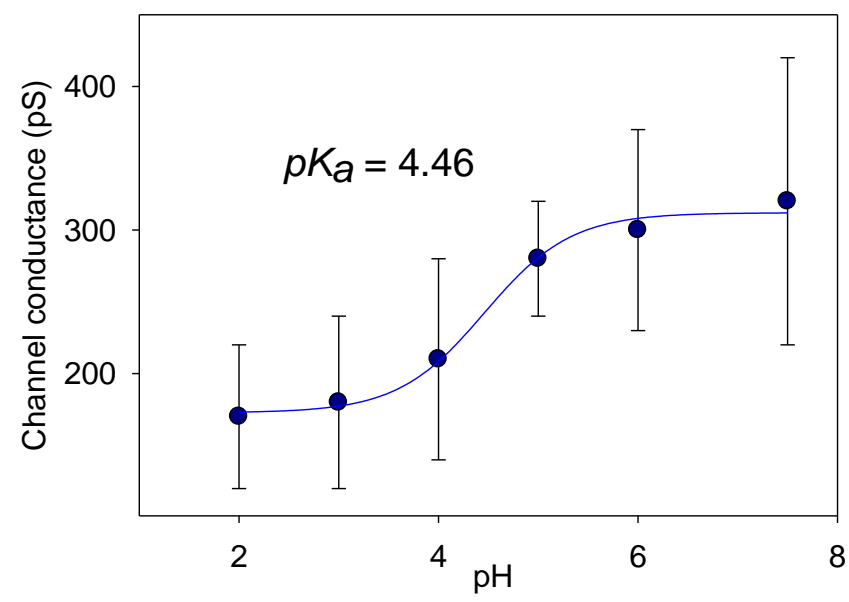

Figure 6.8 Channel conductance of $\mathrm{SH}$ protein at different $\mathrm{pH}$ conditions. Experiments were performed in $1 \mathrm{M} \mathrm{KCl}$ reconstituting SH protein in 3:1:1 DOPC: DOPS: DOPE membranes at +100 $\mathrm{mV}$. Conductance values were obtained from histograms of current jump amplitudes. Data are fitted to a sigmoidal curve.

Then we examined the ion selectivity of SH-protein and three mutants in which His residues were replaced, $\mathrm{H} 51 \mathrm{~F}, \mathrm{H} 22 \mathrm{~F}$ and double mutant $\mathrm{H} 22 \mathrm{~F}-\mathrm{H} 51 \mathrm{~F}$. The ion selectivity was determined at acidic and basic $\mathrm{pH}$ solutions to analyze how the protonation of the histidine residues affects to channel selectivity (Table 6.1). At pH 7.5 all channels display a mild cationic selectivity and ohmic behavior (Figure 6.9). In contrast, at pH 3 the channels show a weak anionic selectivity.

A more detailed examination indicates that at basic $\mathrm{pH}, \mathrm{H} 22 \mathrm{~F}, \mathrm{H} 51 \mathrm{~F}$ and H22F-H51F show lower cationic selectivity compared with SH-protein. In these proteins the net charge is similar, so the small differences observed in selectivity 
may reflect structural changes caused by mutations. In acidic solutions the anion selectivity correlates with the net charge of the channels. At this $\mathrm{pH}$ both His residues should be protonated, and thus the charge relative to the $\mathrm{SH}$ protein depends on the number of His residues present. SH protein exhibits higher anion selectivity than mutants, which is in agreement with the net charge of the protein. Interestingly the absence of His22 (H22F) led to a behavior similar to that of $\mathrm{SH}$ protein, indicating that this residue exerts a minor effect on ion selectivity. In contrast, mutants in whom His51 was replaced display a significant reduction in anion selectivity which points to a more important role of this histidine in channel selectivity. These results are somewhat consistent with the orientation of these two histidine residues in the pentameric channel so the structural model of SH protein in bicelles indicates that His51 is more exposed to the lumen.
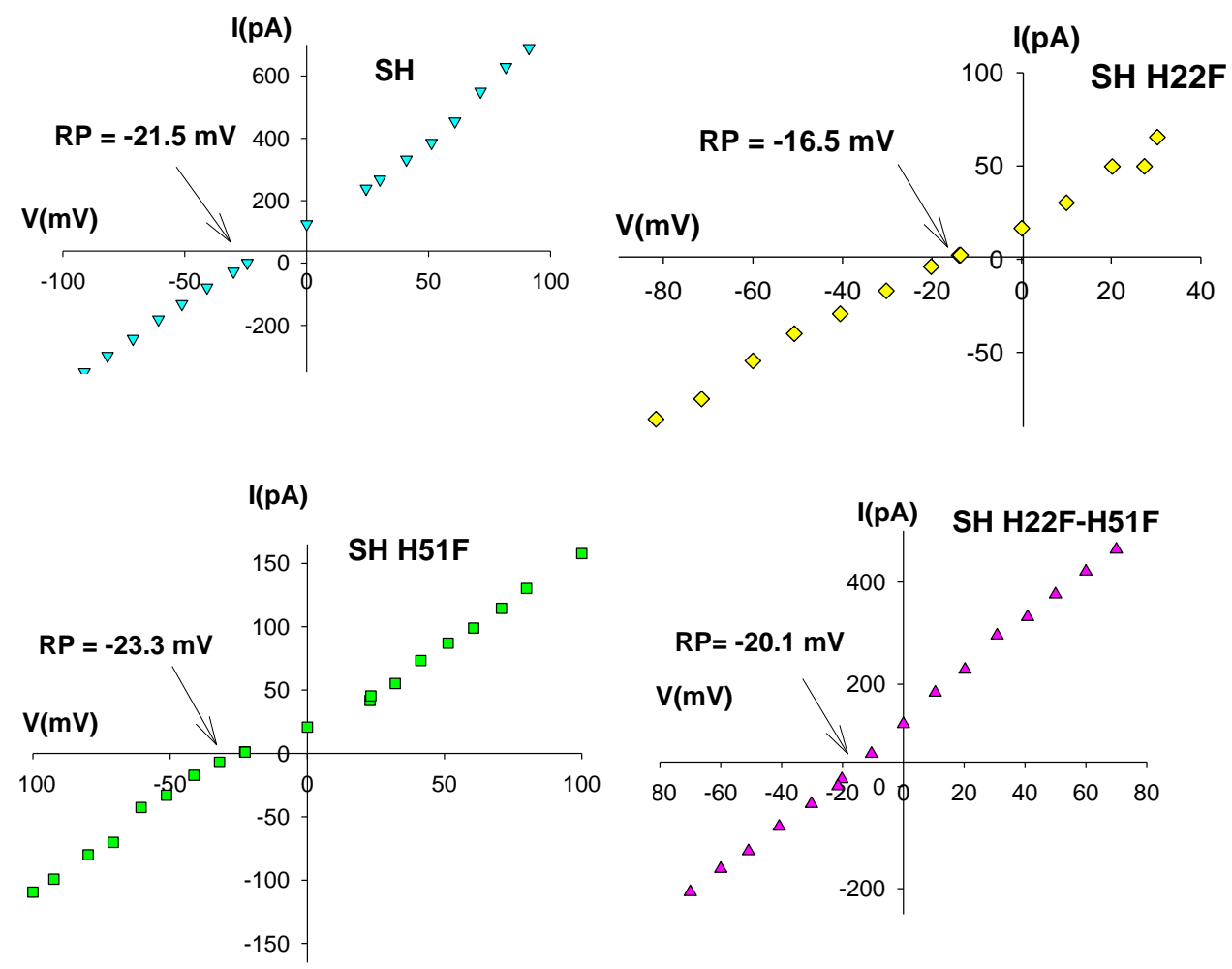

Figure 6.9 Current - voltage curves of SH protein, and mutants H22F, H51F and H22F-H51F. All of them show ohmic behavior and slightly different cationic selectivity. Experiments were carried out in 500/50 $\mathrm{mM} \mathrm{KCl}$ at $\mathrm{pH} 7.5$. 
Table 6.1 Reversal potential of SH protein and mutants. Ion selectivity was determined under $500 / 50 \mathrm{mM} \mathrm{KCl} \mathrm{pH} 6$ in membranes containing 3:1:1 DOPC: DOPS: DOPE. * The charge value represents the difference in charge with respect to the $\mathrm{SH}$ protein at $\mathrm{pH} 3$.

pH $7.5 \quad$ pH 3

\begin{tabular}{cccccc}
\hline PROTEIN & $E_{\text {rev }}(\mathrm{mV})$ & $\left(P_{+} / P_{-}\right)$ & $E_{\text {rev }}(\mathrm{mV})$ & $\left(P_{-} / P_{+}\right)$ & $\begin{array}{c}\text { Charge } \\
*\end{array}$ \\
\hline WT & $-27.3 \pm 2.2(n=9)$ & $3.9 \pm 0.1$ & $40 \pm 3(n=10)$ & $8.9 \pm 0.4$ & 0 \\
\hline SH-H51F & $-25 \pm 3(n=8)$ & $3.5 \pm 0.1$ & $37 \pm 3(n=10)$ & $7.1 \pm 0.3$ & -1 \\
\hline SH-H22F & $-14 \pm 1.5(n=6)$ & $2.00 \pm 0.05$ & $39.4 \pm 2.0(n=9)$ & $8.4 \pm 0.4$ & -1 \\
\hline $\begin{array}{c}\text { SH-H51F- } \\
\text { H22F }\end{array}$ & $-21.6 \pm 2.0(n=13)$ & $2.9 \pm 0.1$ & $36 \pm 3(n=9)$ & $6.7 \pm 0.3$ & -2 \\
\hline
\end{tabular}

An indication of the relative importance of these two His residues can also be obtained by analyzing their conservation in close monologs (Figure 6.10). This comparison is justified since parainfluenza virus 5 (PIV5) SH protein could be replaced by the $\mathrm{SH}$ protein from MuV or RSV SH in strains A2 or B1 to produce a similar phenotype (Fuentes et al. 2007; Wilson et al. 2006b). These data suggest a role of a membrane-permeabilizing pentameric structure common to these species. Alignment of the homologous sequences of RSV SH protein, bovine RSV, PIV5, and MuV shows that there is at least one His residue near the position equivalent to RSV SH His51, i.e., several residues after the TM domain. In fact, in these other sequences a C-terminal His residue is present with a 3 - 4residue periodicity, expected for $\alpha$-helices. Therefore, by comparison with the orientation of hRSV SH His51, these His residues should also have a lumenal orientation. In contrast, the equivalent residue to His 22 is replaced with Phe in these homologous sequences, supporting a more structural role for this residue.

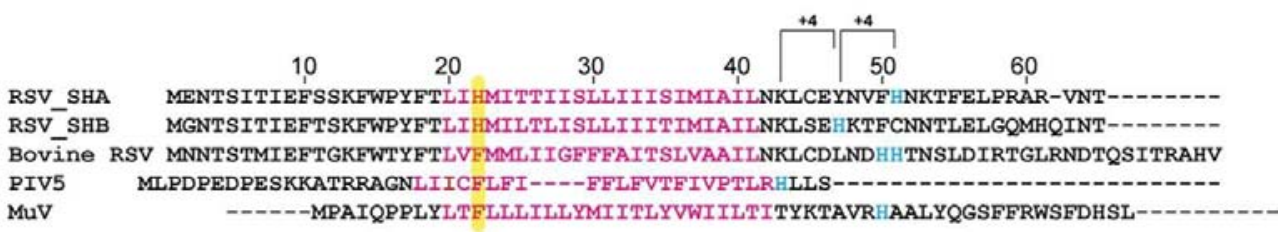

Figure 6.10 Multiple alignment of SH proteins and homologs in human RSV, bovine RSV, parainfluenza virus 5 (PIV 5), and mumps virus (MuV). 


\subsection{CONCLUSIONS}

In this chapter we reported a preliminary electrophysiological characterization of the first compound candidate to inhibit the SH protein channel activity. In addition, the role of the histidine residues in the channel function has been investigated.

We have demonstrated that $10 \mu \mathrm{M}$ of pyronin B inhibits the SH channel activity. Although with modest $K_{d}(\sim 6.8 \mu \mathrm{M})$, pyronin B compares favorably with the $16 \mu \mathrm{M}$ for amantadine inhibition of influenza virus M2 protein (Jing et al. 2008), the $10 \mu \mathrm{M}$ reported for hexamethylene ailoride (HMA) inhibition of SARS-CoV E protein (Wilson et al. 2006a), 50 to $100 \mu \mathrm{M}$ for rimantadine inhibition of HCV p7 (OuYang et al. 2013) or the >100 $\mu$ M HMA for p7 inhibition (Premkumar et al. 2004). This small molecule was found to bind SH protein mostly at the lipid-facing side of the TM $\alpha$ - helices and not into the pore lumen. This mechanism of inhibition is probably allosteric, similar to that proposed for rimantadine binding to the TM domain of $M 2$ (OuYang et al. 2013) or rimantadine to hepatitis C virus (HCV) p7 (OuYang et al. 2013). In fact, the proposed binding site encompassing residues 38 to 43 , is totally conserved in RSV SH proteins, which suggests that inhibition would be more difficult to overcome compensatory mutations.

We have showed that the overall $\mathrm{SH}$ protein conductance was $\mathrm{pH}$ dependent and consistent with the titration of histidines residues. Ion selectivity in $\mathrm{SH}$ protein is poorly cationic at neutral $\mathrm{pH}$, as was also observed in other viroporins, such as SARS-CoV E protein (Verdiá-Báguena et al. 2012; Wilson et al. 2004) or HCV p7 (Premkumar et al. 2004).

Finally, based on these results, we can speculate that SH channel activity can be strongly regulated by lower $\mathrm{pH}$ when present in native biological membranes and the unknown conditions present in the cell. The intravesicular $\mathrm{pH}$ drops along the endocytic pathway from $\mathrm{pH} 6.0$ to 6.5 in early endosomes to $\mathrm{pH} 4.5$ to 5.5 in late endosomes and lysosomes (Sorkin \& Von Zastrow 2002), whereas in the Golgi lumen the $\mathrm{pH}$ is only one unit below that of the cytoplasm. These small $\mathrm{pH}$ changes, together with the low $p K_{a}$ measured in the present paper and the relatively low effect of $\mathrm{pH}$ on both conductance and selectivity, do not suggest that $\mathrm{pH}$ plays a major role in modulating channel activity during the life cycle of the virus. However, mutation of these His residues in the context of the infected cell is an interesting avenue for future experiments, especially since $\mathrm{SH}$ homologs have a conserved His residue at or near the equivalent position to His51 in hRSV and since that current was abolished when SH-TM was exposed to a pH of 4 (Gan et al. 2008). 




\section{Interaction of amphiphilic}

molecules with membranes 

Part of the studies included in the present chapter were published in the following articles:

"Amphiphilic COSAN and $I_{2}$-COSAN crossing synthetic lipid membranes: planar bilayers and liposomes", Chemical Communications (2014), 48, $32-34$. 



\subsection{INTRODUCTION}

All biological membranes are formed by self-assembly of lipid molecules so that their polar head groups are exposed to the aqueous environment and their fatty acid tails face internally within the membrane, creating a hydrophobic barrier (Singer \& Nicolson 1972). Control of biomolecular flow across membranes is an important element for cell regulatory processes. The flux of charged molecules is carried through protein channels that open an aqueous pore in membranes allowing the transport of molecules and ions. However, hydrophobic and amphiphilic substances such as drug molecules can traverse the bilayer either by simple diffusion (Casey et al. 2014). In these different ways of transport, the lipid environment acts depending on the system. In this way, in proteins forming channels the lipid molecules can act as a simple surrounding medium or taking part in the pore structure. Nevertheless amphiphilic molecules cross lipid bilayer directly so, in this case, the lipid molecules are transport means and the translocation is possible due to the similar physicochemical properties such us hydrophobicity.

However, the interplay between the majority of small-molecule compounds and biological membranes remains poorly understood, despite the intense investment and research from both academia and industry. Synthetic membrane vesicles offer the potential to interact with cells and modify their behavior. Membrane forming properties are not unique to biological or synthetic lipids, and the inorganic, boron-based molecule cobaltabisdicarbollide, (COSAN), [3, 3'-Co(1,2- $\left.\left.\mathrm{C}_{2} \mathrm{~B}_{9} \mathrm{H}_{11}\right)_{2}\right]^{-}$, also forms membranes, but of a very different chemical composition to their biological counterparts.

Structurally, COSAN is very different from the polarized lipid molecules that make up biological membranes, comprising a cobalt atom sandwiched by two carboranyl clusters (Figure 7.1). Its properties are remarkable: it is a monoanionic anion with a peculiar peanut shape with two globules that are responsible for its characteristic physicochemical properties: the net negative charge is dispersed over the whole molecule (Masalles et al. 2002) and its weakly polarized $\mathrm{B}-\mathrm{H}$ and $\mathrm{C}-\mathrm{H}$ bonds promote intermolecular interactions (Juárez-Pérez et al. 2010). This duality imparts an unusual physicochemical property of being simultaneously hydrophobic and hydrophilic, and makes COSAN soluble in both water and oils.

In contrast to their lipid counterparts, at lower concentrations COSAN molecules form small, monolayer vesicles and above a critical aggregation concentration begin to form micelles (Bauduin et al. 2011). Unlike lipid bilayer membranes, the membranes of COSAN vesicles are monolayers (Bauduin et al. 2011). Recently, [3,3' - Co(8-I-1,2- $\left.\left.\mathrm{C}_{2} \mathrm{~B}_{9} \mathrm{H}_{10}\right)_{2}\right]^{-}, \mathrm{I}_{2}$-COSAN, has also been found to self-assemble into a lyotropic lamellar phase with sufficient curvature to create closed vesicles. 
The lamellae formed by $\mathrm{I}_{2}$-COSAN are made of monomolecular sheets such as clay systems, but with the sole difference that they are not covalently bound. The lamella formation presumably originates from intermolecular dihydrogen bonds, $\mathrm{C}-\mathrm{H}^{\delta \ldots \delta} \mathrm{H}-\mathrm{B}$ (Brusselle et al. 2013). The amphiphilic properties of COSAN and $\mathrm{I}_{2}$-COSAN in water are essential to have realistic applications in medicine for drug delivery or in boron-neutron capture therapy (BNCT). In fact, it has been reported that COSAN and $\mathrm{I}_{2}$-COSAN accumulate within living cells (Tarrés et al. 2014).

A

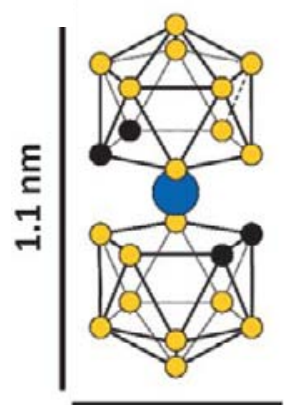

$0.6 \mathrm{~nm}$
B

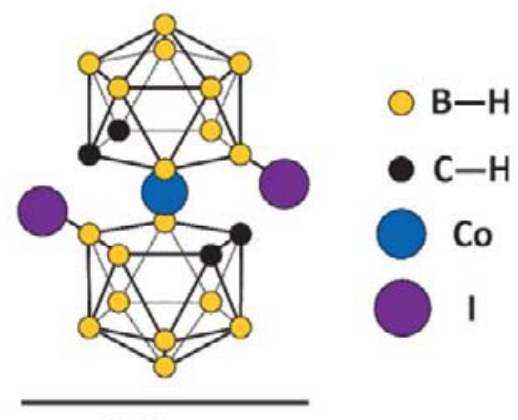

Figure 7.1 (A) COSAN cluster (B) 3,3'- Co- $\left.\left(8-1-1,2-\mathrm{C}_{2} \mathrm{~B}_{9} \mathrm{H}_{11}\right)_{2}\right]^{\prime}, \mathrm{I}_{2}-\operatorname{COSAN}$

The unusual amphiphilic character of COSAN and $\mathrm{I}_{2}$-COSAN raises the question of how synthetic COSAN membranes interact with their natural lipid based counterparts. In this chapter we focused on studying the ability of COSAN in protonated form ( $\mathrm{H}$ [COSAN]), in salt form ([Na [COSAN]) and $\mathrm{I}_{2}$-COSAN to cross synthetic planar lipid membranes. To achieve this goal, the kinetics of the translocation process was studied in micromolar range concentration and in membranes of different lipid composition.

\subsection{RESULTS}

\subsubsection{Interaction of COSAN and $I_{2}-\operatorname{COSAN}$ with membranes}

We investigated the interaction of COSAN with artificial lipid membranes. Firstly neutral membranes were used in order to exclude any effect caused by electrostatic interactions coming from the charge of the membrane. For this reason lipid membranes were formed of 1,2-dioleoyl-sn-glycero-3phosphocholine (DOPC), a neutral lipid. Once the bilayer was formed, a $100 \mu \mathrm{M}$ COSAN solution in different forms ( $\mathrm{I}_{2}$-COSAN, H-COSAN and Na-COSAN) was added into one side of the chamber (cis side). After the COSAN addition a strong 
transient current was registered, which was stabilized after 5 min approximately as a steady negative current (Figure 7.2). This occurs without application of any transmembrane voltage, indicating that COSAN directly translocates across the membrane.

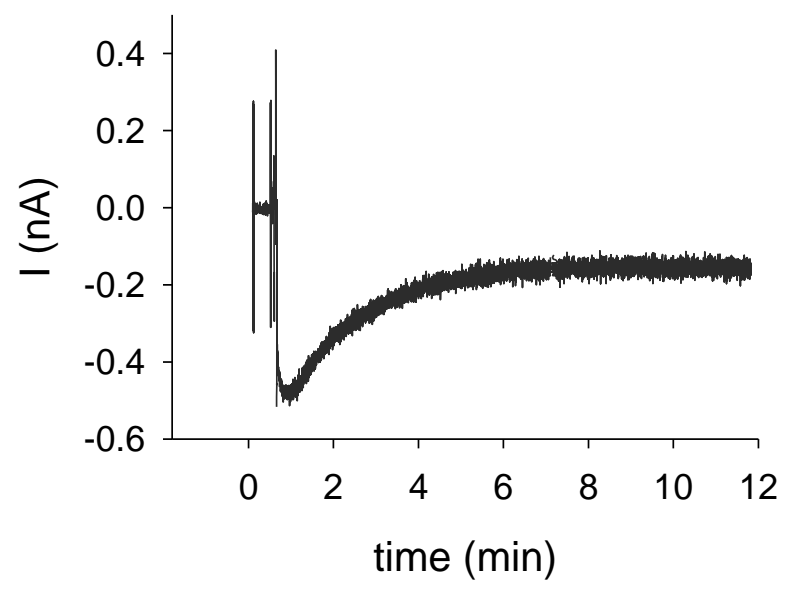

Figure 7.2 Typical current recording against time when COSAN is added into one side of the experimental chamber containing $10 \mu \mathrm{M} \mathrm{NaCl}$ at $\mathrm{pH}$ 6. The trace is characterized by a strong, transient negative current before stabilizing as a continuous, steady negative current.

The membrane capacitance at the beginning of the experiment was between $80-90 \mathrm{pF}$ and membrane was impermeable to ions. Membrane electrical capacitance was monitored constantly for two reasons. First, because it provides an idea of the thickness of the membrane, telling us if the central part of the membrane is actually a bilayer or not. A constant capacity does not discard COSAN partitioning into the multilamellar region of the membrane. It only indicates that the central part of the bilayer is still intact. Second, because the shape of the test signal lets us to know if pore formation has occurred because the typical pure capacitive stepwise signal is distorted when a resistive pore is formed. During the experiments the capacitance remained constant, indicating that the lipid bilayer was not disrupted and no aqueous pores were formed.

As an anion, COSAN would not be expected to cross directly through lipid membrane due to the high Born energy calculated as $80 \mathrm{~kJ} / \mathrm{mol}$, or more than $30 \mathrm{kT}$, for an ideal COSAN anion (1.1 nm $\times 0.6 \mathrm{~nm}$ ) (Bauduin et al. 2011; Parsegian 1969). However, the unusual dual hydrophilic and lipophilic properties of the COSAN molecule may overcome the high electrostatic energy required to cross a lipid membrane. COSAN permeation may occur via the sequence of absorption at solution-membrane interface, translocation across the lipid phase and desorption at membrane-solution interface. 


\subsubsection{Kinetics of COSAN translocation}

The next step was study the kinetics of COSAN and $\mathrm{I}_{2}$-COSAN permeation. COSAN and $\mathrm{I}_{2}$-COSAN were added into the cis side in their compound forms ( $\mathrm{H}[\mathrm{COSAN}], \mathrm{Na}[\mathrm{COSAN}]$ or $\left.\mathrm{Na}\left[\mathrm{I}_{2}-\mathrm{COSAN}\right]\right)$. Approximately $45-$ 60 minutes after the COSAN addition the concentration in the trans side was determined by Inductively Coupled Plasma Mass Spectrometry (ICP-MS). Then the transport rate was calculated as the quotient between the concentration determined in the trans side and the duration of each measurement.

Figure 7.3 represents the calculated transport rate versus COSAN concentration added. As we can observe, for all the compounds tested, the permeation rate was independent of the initial COSAN concentration. This result suggests that the process obeys zero-order kinetics.

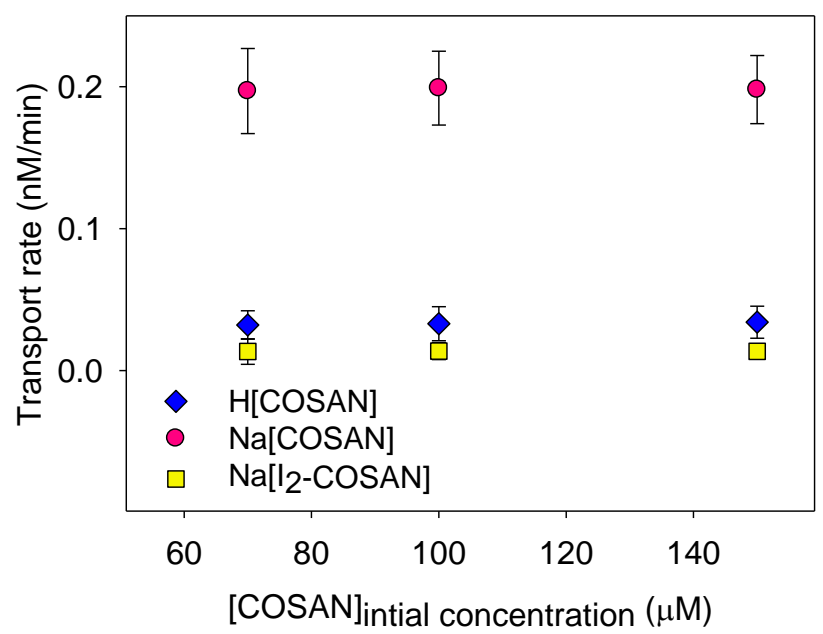

Figure 7.3 Transport rate for different initial concentrations of $\mathrm{H}[\mathrm{COSAN}], \mathrm{Na}[\mathrm{COSAN}]$ and $\mathrm{Na}\left[\mathrm{I}_{2}-\right.$ COSAN]. The average transport rate for all COSAN compounds is virtually the same for any initial concentration within the range studied. 70,100 and $150 \mu \mathrm{M}$ COSAN was added in the trans side containing $10 \mu \mathrm{M} \mathrm{NaCl} \mathrm{pH} 6$.

An alternative way for studying the kinetics is fixing an initial compound concentration and determining the concentration in the other phase at different durations. Following this idea, $100 \mu \mathrm{M}$ of $\mathrm{H}[\mathrm{COSAN}], \mathrm{Na}[\mathrm{COSAN}]$ or $\mathrm{Na}\left[\mathrm{I}_{2}-\right.$ COSAN] was added and experiments of different duration were carried out. Figure 7.4 shows the time evolution of the COSAN concentration in the trans side. The linear relationship between concentration in the trans side and time indicates that COSAN permeation follows zero-order kinetics. 


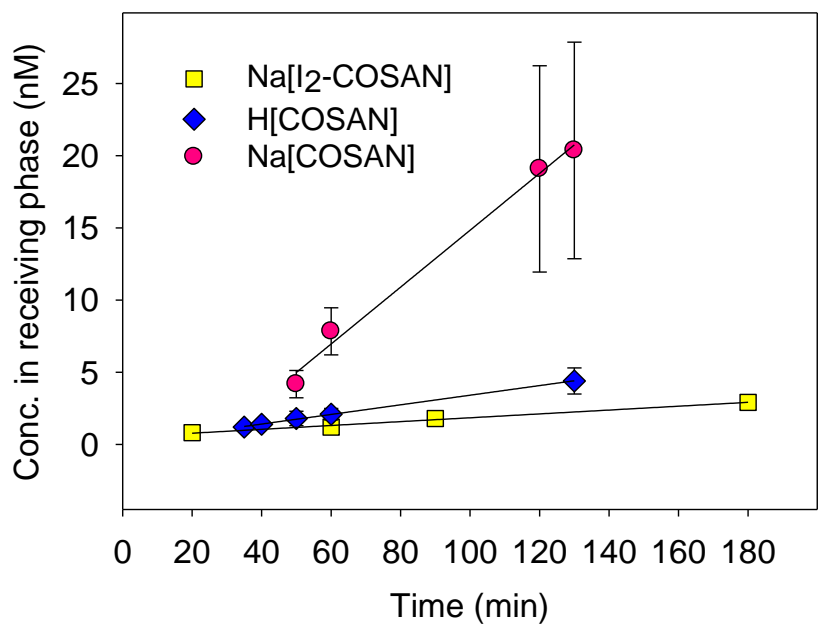

Figure 7.4 Permeation rate of $\mathrm{Na}$ [COSAN], $\mathrm{H}[\mathrm{COSAN}]$ and $\mathrm{Na}\left[\mathrm{I}_{2}-\mathrm{COSAN}\right]$ across neutral planar bilayers. The concentration in the receiving phase was determined by ICP-MS being $100 \mu \mathrm{M}$ the initial concentration in all cases. The linear relation between the accumulative concentration of compound and duration of each experiment indicates a zero-order kinetics. Error bars are standard deviation resulting from 10 independent experiments.

As Figure 7.4 shows, the translocation of $\mathrm{Na}\left[\mathrm{I}_{2}-\mathrm{COSAN}\right]$ is lower than that of $\mathrm{H}[\mathrm{COSAN}]$ and $\mathrm{Na}[\mathrm{COSAN}]$. The reason is still unclear, but previous studies showed that the presence of sodium ions drastically modifies the COSAN aggregation process (Bauduin et al. 2011). Taking this into account, it is possible that $\mathrm{Na}[\mathrm{COSAN}]$ and $\mathrm{H}[\mathrm{COSAN}]$ form aggregates that permeate in a different way across membranes.

It is important to note that the direct measurements of COSAN concentrations by ICP-MS in the stripping phase matched that estimated concentration calculated from ion current measurements. This close agreement between the two independent estimations indicates that the transport of the COSAN molecules is the major contribution to the ionic current so that no other ions were translocated across the membrane. This point is in agreement with the fact that COSAN did not disrupt the membrane.

The fact that the permeation rate did not show any dependence on the initial concentration suggests that the diffusion across the membrane may not be the rate-determining process. If the diffusion were the slowest process in the translocation across membranes the rate transport would be dependent on the initial concentration (Lakshminarayanaiah 1984), but this is not the case. For this reason, we propose that the partitioning of COSAN or $\mathrm{I}_{2}$-COSAN must be the rate-determining step (Figure 7.5). 


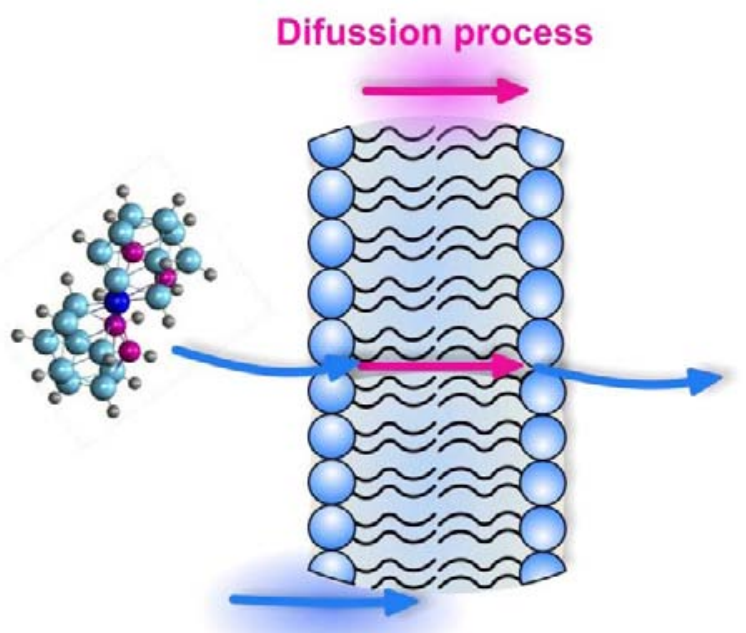

Partitioning process

Figure 7.5 Cartoon that represents the two main processes implicated in the COSAN translocation: the partitioning into lipid phase and the diffusion across the membrane.

Then we extended the permeation study of COSAN to other model membranes, with other neutral lipid compositions such as DPhPC. In addition we evaluated the COSAN permeation in a membrane environment whose surface charge density is similar to a typical plasma membrane (4:1 DOPC/DOPS). These results are shown in Figure 7.6. Comparing COSAN permeation in neutral membranes, DPhPC and DOPC, no significant differences were seen since the permeation rate of COSAN is about the same order of magnitude. Of course, subtle differences can be found, but such differences are comparable to the error of measurements. For instance: the average permeation rate in DOPC is about $10 \%$ higher than in DPhPC. However, the errors are about $10 \%$ of the total value in DOPC, and $30 \%$ in DPhPC. Negatively charged membranes of 4:1 DOPC/DOPS, which resemble typical plasma membranes (as concerns their surface charge density) showed a slightly smaller COSAN permeability than neutral ones. Specifically, in charged membranes the permeation is four times lower than in neutral membranes, but again errors are considerable. Taking these results into account, neither the membrane composition nor the charge of the lipid inhibit or remarkably enhance the transport of COSAN, although both of them induce small but measurable changes on the COSAN permeation. 


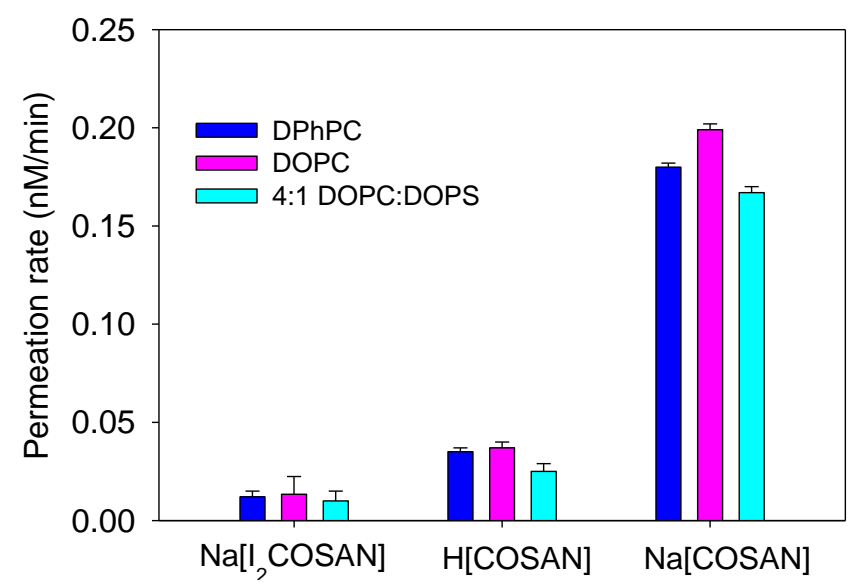

Figure 7.6 Permeation rate (nM/min) for of $\mathrm{H}$ [COSAN], $\mathrm{Na}$ [COSAN] and $\mathrm{Na}\left[\mathrm{I}_{2}-\mathrm{COSAN}\right]$ in different lipid membrane compositions. Cell chamber contained $10 \mu \mathrm{M} \mathrm{NaCl}$ at $\mathrm{pH} 6$ and the compounds were added to the feeding phase at a concentration of $100 \mu \mathrm{M}$.

\subsubsection{COSAN encapsulated into liposomes}

Once we have checked that COSAN is able to cross synthetic lipid bilayers, in order to directly visualize this transferring behavior, mixtures of COSAN nano-vesicles and liposomes solutions were examined using cryo-TEM (Awad et al. 2009). These experiments were performed by Dr. Hiroyuki Nakamura and collaborators at Chemical Resources Laboratory, Tokyo Institute of Technology.

These experiments are useful to investigate directly how COSAN vesicles are able to interact with liposomes membranes, a more realistic biological environment. The ability to transport COSAN within cells is the first step in the applications of COSAN in pharmacological areas, such as anti-cancer agents including boron neutron capture therapy (BNCT) and the inhibition of human immunodeficiency virus 1 (HIV-1) protease in anti-AIDS drug research.

It has been reported that COSAN forms spherical nano-vesicles in water with a radius of approximately $20 \mathrm{~nm}$ and a membrane nearly $1 \mathrm{~nm}$ thick (Bauduin et al. 2011), whereas liposomes form mostly unilamellar bilayer vesicles with a membrane thickness of about $4.5 \mathrm{~nm}$ (Figure 7.7). In COSAN: liposome 1:4 (v:v) mixtures (an equivalent COSAN concentration of $4 \mathrm{mM}$ ), COSAN vesicles fuse with the liposome membrane (Figure $7.7 \mathrm{~A}$ ). At a lower liposome ratio ( $1: 3 \mathrm{v}: \mathrm{v}$, an equivalent COSAN concentration of $5 \mathrm{mM}$ ), additional intermediate effects are seen (Figure 7.7). Often, two or more liposome units become linked via COSAN nano-vesicles. At this interface, COSAN nano-vesicles 
exhibit a dramatic morphological change to form a planar lamellar microstructure (Figure 7.7). This lamellar form of COSAN appeared to diffuse from the membrane into the liposome center recovering its spherical monolayer vesicle morphology (Figure $7.7 \mathrm{~B}$, arrows). These liposome-COSAN double vesicles were larger than the initial liposome population, pointing that the process of COSAN vesicle encapsulated may cause multiple liposomes to fuse.

A

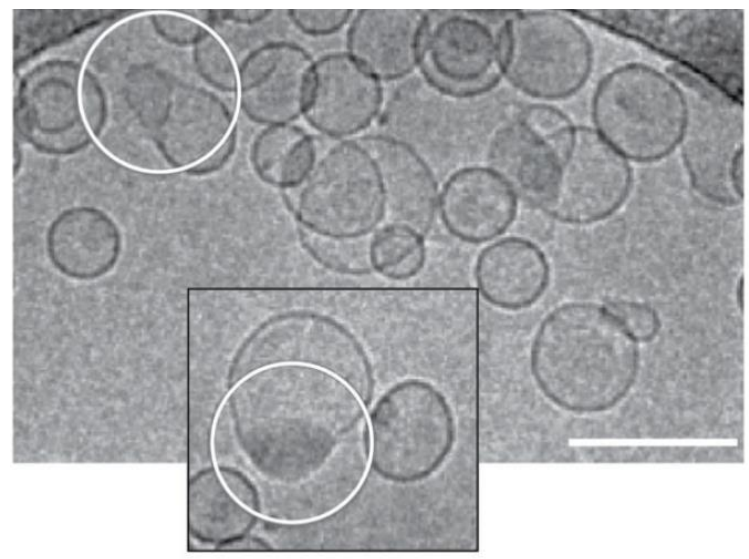

B

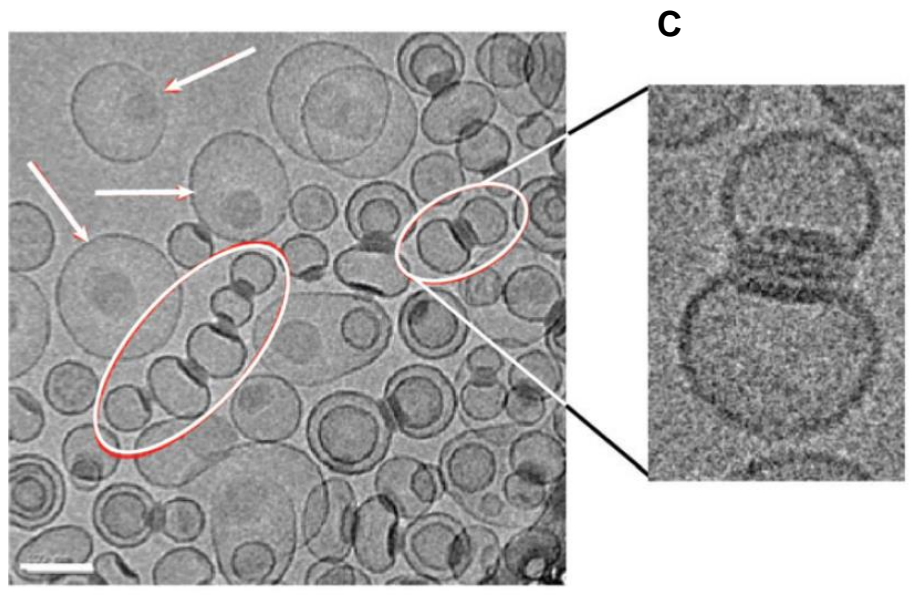

Figure 7.7 Direct visualization of the interaction between COSAN vesicles and liposomes.(A) Cryo TEM image of COSAN:liposomes mixtures (1:4). Circles highlight fusion between COSAN vesicles and liposomes. Scale bar is $200 \mathrm{~nm}$. (B) Cryo TEM image of COSAN:liposome (1:3). The circles highlight the joining of two or more liposome units linked by COSAN. Arrows indicate the complete penetration of the COSAN inside the liposome and the recovery of the monolayer vesicle form. Scale bar $200 \mathrm{~nm}$.(C) X50000 zoom shows the planar multilayer morphology of COSAN at the interface of two liposomes. These experiments were carried out by the group of Dr. Hiroyuki Nakamura and collaborators. 
The next step was studying the translocation of encapsulated COSAN in the protonated form ( $\mathrm{H}[\mathrm{COSAN}])$ in samples containing 1:3 COSAN:liposome (v:v). The transport rate of encapsulated $\mathrm{H}$ [COSAN] varies with time differently compared with bare COSAN (Figure 7.8).

Two main differences were observed: firstly, the passive translocation across the planar bilayer of the encapsulated $\mathrm{H}$ [COSAN] was more efficient than that of bare $H[C O S A N]$; secondly, the permeation rate of the encapsulated $\mathrm{H}[\mathrm{COSAN}]$ showed initial-concentration dependence, so the accumulated concentration of COSAN in the trans side increased exponentially with the experimental time. This concentration dependence indicates that in the case of the encapsulated $\mathrm{H}[\mathrm{COSAN}]$, the rate-determining step may be the diffusion process across the lipid membrane and not the solution-partitioning observed for bare $\mathrm{H}[\mathrm{COSAN}]$. For the encapsulated $\mathrm{H}[\mathrm{COSAN}$ ] the absorption-desorption at the solution-membrane interfaces would be much faster than the bare COSAN. The physicochemical properties of encapsulated H[COSAN] may be different, so that the encapsulation may favor the passage from the aqueous phase to the lipid phase. In this sense, the encapsulation into liposomes would make COSAN a more hydrophobic compound, resulting the pass from aqueous solution to the membrane easier.

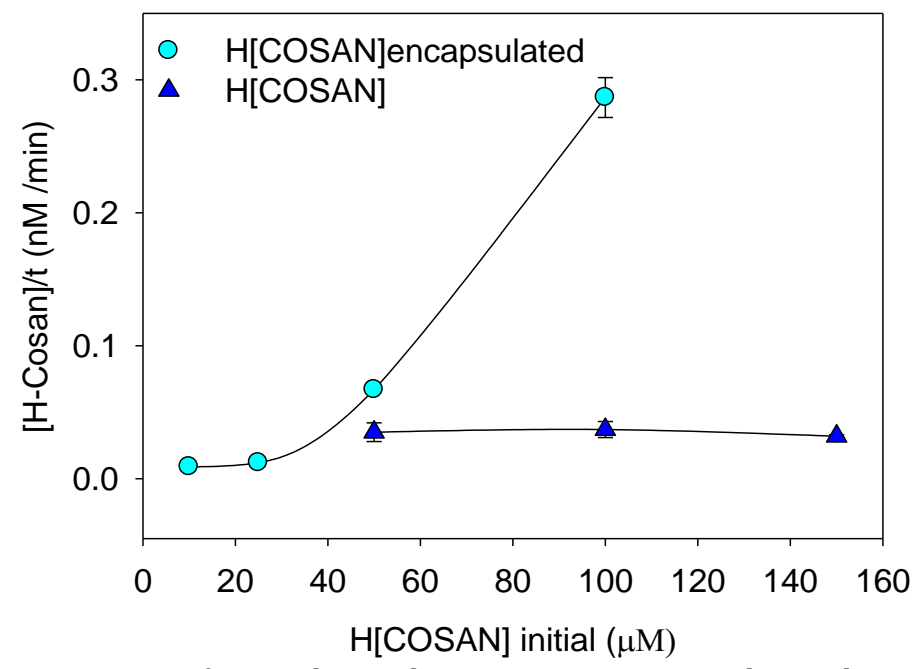

Figure 7.8 Transport rate of bare $H[C O S A N]$ and the encapsulated $H[C O S A N]$ through synthetic neutral planar membranes. The different response indicates two different mechanisms for COSAN translocation. As figure shows in the case of encapsulated $H$ [COSAN] the permeation rate is strongly dependent on the initial concentration of COSAN, whereas for bare H[COSAN] is not. 


\subsection{CONCLUSIONS}

In this chapter we have shown that the anion COSAN and its derivative $\mathrm{I}_{2}$-COSAN are able to cross lipid membranes without any externally applied voltage. In addition, COSAN transits not only planar lipid membranes, but is able to fuse into liposome units too.

The permeation of these anions may occur via the sequence of absorption at the solution-membrane interface, translocation across the lipid phase and desorption at the other membrane-solution interface. The special dual hydrophilic and lipophilic properties may overcome the high Born energy necessary to allow the transport of an anion as COSAN across a low dielectric constant medium.

By means of planar lipid bilayer reconstitution and Inductively Coupled Plasma Mass Spectrometry we have studied the translocation kinetics. COSAN and $\mathrm{I}_{2}$-COSAN permeation rates follow a zero-order kinetics, which means that the flux is not dependent on the initial concentration. This result indicates that the rate-determining step is the partitioning process into the lipid phase and not the diffusion across the membrane. However, depending on the COSAN counterion the transport rate is different. Thus, H[COSAN] showed higher permeation rate than $\mathrm{Na}$ [COSAN]. The reason for this is not clear. Previous studies have showed that the presence of sodium ions changes the COSAN aggregation process (Bauduin et al. 2011). Sodium ions favor larger nanovesicles (diameter from 80 to $890 \mathrm{~nm}$ ) than protons do (diameter nearly $40 \mathrm{~nm}$ ). The absorption-desorption rate may depend on the structural form of COSAN molecules.

Finally we have compared the translocation of $\mathrm{H}[\mathrm{COSAN}]$ and $\mathrm{H}[\mathrm{COSAN}]$ encapsulated into liposomes. Interestingly when H[COSAN] is encapsulated the translocation is more efficient and it is dependent on the initial COSAN concentration. This indicates that the rate-determining step is the diffusion across the membrane. The encapsulation of COSAN may favor the passage from aqueous phase to lipid phase.

These results reveal unexpected properties of COSAN and these particular features offer new opportunities for cancer therapy, drug design and molecular delivery systems. These novel findings can be very useful in the use of carborane derivatives to load boron into tumor cells for boron neutron capture therapy (BNCT) and in the inhibition of the human immunodeficiency virus 1 (HIV-1) protease in anti-AIDS drug research. Both topics have been mentioned in recent reviews on the medicinal chemistry of carboranes (Armstrong \& Valliant 2007), or enzyme inhibition (Pokorná et al. 2009). Thus, these results may have immediate value for both current and future medical applications, and open up new possibilities in the areas of biomedical research and synthetic biology. 


8. References 

Agirre, A., Barco, A., Carrasco, L. \& Nieva, J.L., 2002. Viroporin-mediated membrane permeabilization: Pore formation by nonstructural poliovirus $2 \mathrm{~B}$ protein. Journal of Biological Chemistry, 277, pp.40434-41.

Aguilella, V.M. \& Bezrukov, S.M., 2001. Alamethicin channel conductance modified by lipid charge. European Biophysics Journal, 30, pp.233-41.

Aguilella, V.M., Queralt-Martín, M., Aguilella-Arzo, M. \& Alcaraz, A., 2011. Insights on the permeability of wide protein channels: measurement and interpretation of ion selectivity. Integrative biology : quantitative biosciences from nano to macro, 3(3), pp.159-72.

Aguilella, V.M., Verdiá-Báguena, C. \& Alcaraz, A., 2014. Lipid charge regulation of non-specific biological ion channels. Physical chemistry chemical physics : PCCP, 16(9), pp.3881-93.

Aguilella-Arzo, M., Andrio, A., Aguilella, V.M. \& Alcaraz, A., 2009. Dielectric saturation of water in a membrane protein channel. Physical chemistry chemical physics : PCCP, 11(2), pp.358-65.

Aguilella-Arzo, M., García-Celma, J.J., Cervera, J., Alcaraz, A. \& Aguilella, V.M., 2007. Electrostatic properties and macroscopic electrodiffusion in OmpF porin and mutants. Bioelectrochemistry (Amsterdam, Netherlands), 70(2), pp.320-7.

Alcaraz, A., Nestorovich, E.M., Aguilella-Arzo, M., Aguilella, V.M. \& Bezrukov, S.M., 2004. Salting out the ionic selectivity of a wide channel: the asymmetry of OmpF. Biophysical journal, 87(2), pp.943-57.

Alcaraz, A., Nestorovich, E.M., López, M.L., García-Giménez, E., Bezrukov, S.M. \& Aguilella, V.M., 2009. Diffusion, exclusion, and specific binding in a large channel: a study of OmpF selectivity inversion. Biophysical journal, 96(1), pp.56-66.

Alcaraz, A., Queralt-Martín, M., García-Giménez, E. \& Aguilella, V.M., 2012. Increased salt concentration promotes competitive block of OmpF channel by protons. Biochimica et Biophysica Acta - Biomembranes, 1818, pp.2777-82.

Alcaraz, A., Ramirez, P., Garcia-Gimenez, E., Lopez, M.L., Andrio, A. \& Aguilella, V.M., 2006. A pHtunable nanofluidic diode: Electrochemical rectification in a reconstituted single ion channel. Journal of Physical Chemistry B, 110(42), pp.21205-09.

Alcaraz, A., Ramírez, P., García-Giménez, E., López, M.L., Andrio, A. \& Aguilella, V.M., 2006. A pHtunable nanofluidic diode: electrochemical rectification in a reconstituted single ion channel. The journal of physical chemistry. B, 110(42), pp.21205-9.

Almazán, F., DeDiego, M.L., Sola, I., Zuñiga, S., Nieto-Torres, J.L., Marquez-Jurado, S., Andrés, G. \& Enjuanes, L., 2013. Engineering a replication-competent, propagation-defective Middle East respiratory syndrome coronavirus as a vaccine candidate. mBio, 4(5), pp.e00650-13.

Alvis, S.J., Williamson, I.M., East, J.M. \& Lee, A.G., 2003. Interactions of Anionic Phospholipids and Phosphatidylethanolamine with the Potassium Channel KcsA. Biophysical Journal , 85(December), pp.3828-38. 
Apell, H.J., Bamberg, E. L.P., 1979. Effects of surface charge on the conductance of the gramicidin channel. Biochimica et biophysica acta, 552(3), pp.369-78.

Armstrong, A.F. \& Valliant, J.F., 2007. The bioinorganic and medicinal chemistry of carboranes: from new drug discovery to molecular imaging and therapy. Dalton Transactions, p.4240.

Awad, D., Damian, L., Winterhalter, M., Karlsson, G., Edwards, K. \& Gabel, D., 2009. Interaction of Na2B12H11SH with dimyristoyl phosphatidylcholine liposomes. Chemistry and Physics of Lipids, 157, pp.78-85.

Bauduin, P., Prevost, S., Farràs, P., Teixidor, F., Diat, O. \& Zemb, T., 2011. A theta-shaped amphiphilic cobaltabisdicarbollide anion: transition from monolayer vesicles to micelles. Angewandte Chemie (International ed. in English), 50(23), pp.5298-300.

Bell, J. \& Miller, C., 1984. Effects of phospholipid surface charge on ion conduction in the K+ channel of sarcoplasmic reticulum. Biophysical journal, 45(January), pp.279-286.

Benz, R., Schmid, A. \& Hancock, R.E., 1985. Ion selectivity of gram-negative bacterial porins. Journal of bacteriology, 162(2), pp.722-27.

Bezrukov, S.M. \& Vodyanoy, I., 1993. Probing alamethicin channels with water-soluble polymers. Effect on conductance of channel states. Biophysical journal, 64, pp.16-25.

Blatz, A.L. \& Magleby, K.L., 1984. Ion conductance and selectivity of single calcium-activated potassium channels in cultured rat muscle. The Journal of general physiology, 84(1), pp.123.

Bockris J.O. \& Reddy A.K.N., 1998. Modern Electrochemisty I: Ionics, NewYork: Luwer Academis/Plenum Publishers.

Brusselle, D., Bauduin, P., Girard, L., Zaulet, A., Viñas, C., Teixidor, F., Ly, I. \& Diat, O., 2013. Lyotropic lamellar phase formed from monolayered $\theta$-shaped carborane-cage amphiphiles. Angewandte Chemie (International ed. in English), 52(46), pp.12114-8.

Campanella, M., De Jong, A.S., Lanke, K.W.H., Melchers, W.J.G., Willems, P.H.G.M., Pinton, P., Rizzuto, R. \& Van Kuppeveld, F.J.M., 2004. The coxsackievirus 2B protein suppresses apoptotic host cell responses by manipulating intracellular $\mathrm{Ca}^{2+}$ homeostasis. The Journal of biological chemistry, 279(18), pp.18440-50.

Carrasco, L., Sonenberg, N. \& Wimmer, E., 1993. Modification of membrane permeability by animal viruses. Regulation of Gene Expression in Animal Viruses, pp. 283-305.

Casey, D., Charalambous, K., Gee, A., Law, R. V \& Ces, O., 2014. Amphiphilic drug interactions with model cellular membranes are influenced by lipid chain-melting temperature. Journal of the Royal Society, Interface / the Royal Society, 11(94), p.20131062.

Cervera, J., Komarov, A.G. \& Aguilella, V.M., 2008. Rectification properties and pH-dependent selectivity of meningococcal class 1 porin. Biophysical journal, 94(4), pp.1194-202.

Chan, C. M., Tsoi, H., Chan, W. M., Zhai, S., Wong, C.O., Yao, X., Chan, W.Y., Tsui, S.K.W. \& Chan, H.Y.E., 2009. The ion channel activity of the SARS-coronavirus 3a protein is linked to its pro- 
apoptotic function. The international journal of biochemistry \& cell biology, 41(11), pp.2232-9.

Chan, J.F.W., Lau, S.K.P. \& Woo, P.C.Y., 2013. The emerging novel Middle East respiratory syndrome coronavirus: The "knowns" and "unknowns." Journal of the Formosan Medical Association, 112, pp.372-81.

Chan, J.F.W., Li, K.S.M., To, K.K.W., Cheng, V.C.C., Chen, H. \& Yuen, K.Y., 2012. Is the discovery of the novel human betacoronavirus 2c EMC/2012 (HCoV-EMC) the beginning of another SARS-like pandemic?. Journal of Infection, 65, pp.477-89.

Chen, M.D., Vazquez, M., Buonocore, L. \& Kahn, J.S., 1999. Conservation of the Respiratory Syncytial Virus SH Gene. Journal Infectious Diseases, pp.1228-33.

Collins, P.L. \& Mottet, G., 1993. Membrane orientation and oligomerization of the small hydrophobic protein of human respiratory syncytial virus. Journal of General Virology, 74, pp.1445-50.

Collins, P.L., Olmstedt, R.A. \& Johnson, P.R., 1990. The small hydrophobic protein of human respiratory syncytial virus : comparison between antigenic subgroups $A$ and B. Journal of General Virology, 2, pp.1571-76.

Coronado, R. \& Affolter, H., 1986. Insulation of the conduction pathway of muscle transverse tubule calcium channels from the surface charge of bilayer phospholipid. The Journal of general physiology, 87(June), pp.933-53

Corry, B., 2006. Understanding ion channel selectivity and gating and their role in cellular signalling. Molecular bioSystems, 2, pp.527-35.

Corse, E. \& Machamer, C.E., 2000. Infectious Bronchitis Virus E Protein Is Targeted to the Golgi Complex and Directs Release of Virus-Like Particles Infectious Bronchitis Virus E Protein Is Targeted to the Golgi Complex and Directs Release of Virus-Like Particles. Journal of Virology, 74(9), pp. 149-60.

Cowan, S., Garavito, R., Jansonius, J., Jenkins, J., Karlsson, R., König, N., Pai, E., Pauptit, R., Rizkallah, P., Rosenbusch, J., Rummel, G. \& Schirmer, T., 1995. The structure of OmpF porin in a tetragonal crystal form. Structure, 3(10), pp.1041-50.

Danelon, C., Suenaga, A., Winterhalter, M. \& Yamato, I., 2003. Molecular origin of the cation selectivity in OmpF porin: Single channel conductances vs. free energy calculation. Biophysical Chemistry, 104(3), pp.591-603.

DeDiego, M.L., Alvarez, E., Almazán, F., Rejas, M.T., Lamirande, E., Roberts, A., Shieh, W. J., Zaki, S.R., Subbarao, K. \& Enjuanes, L., 2007. A severe acute respiratory syndrome coronavirus that lacks the $E$ gene is attenuated in vitro and in vivo. Journal of Virology, 81(4), pp.170113.

DeDiego, M.L., Nieto-Torres, J.L., Jiménez-Guardeño, J.M., Regla-Nava, J. a, Alvarez, E., Oliveros, J.C., Zhao, J., Fett, C., Perlman, S. \& Enjuanes, L., 2011. Severe acute respiratory syndrome coronavirus envelope protein regulates cell stress response and apoptosis. PLoS pathogens, 7(10), p.e1002315. 
Dediego, M.L., Pewe, L., Alvarez, E., Rejas, M.T., Perlman, S. \& Enjuanes, L., 2008. Pathogenicity of severe acute respiratory coronavirus deletion mutants in hACE-2 transgenic mice. Virology, 376(2), pp.379-89.

Delcour, A.H., 2003. Solute uptake through general porins. Frontiers in bioscience : a journal and virtual library, 8, pp.d1055-71.

Dowell, S.F., Anderson, L.J., Gary, H.E., Erdman, D.D., Plouffe, J.F., File, T.M., Marston, B.J. \& Breiman, R.F., 1996. Respiratory Syncytial Virus Is an Important Cause of CommunityAcquired Lower Respiratory Infection among Hospitalized Adults. Journal Infectious Diseases, 1995(September 1995), pp.456-62.

Drosten, C., Günther, S., Preiser, W., van der Werf, S., Brodt, H.-R., Becker, S., Rabenau, H., Panning, M., Kolesnikova, L., Fouchier, R. a M., Berger, A., Burguière, A.-M., Cinatl, J., Eickmann, M., Escriou, N., Grywna, K., Kramme, S., Manuguerra, J.-C., Müller, S., Rickerts, V., Stürmer, M., Vieth, S., Klenk, H.-D., Osterhaus, A.D.M.E., Schmitz, H. \& Doerr, H.W., 2003. Identification of a novel coronavirus in patients with severe acute respiratory syndrome. The New England journal of medicine, 348(20), pp.1967-76.

Eleftheriou, D., Melo, M., Marks, S.D., Tullus, K., Sills, J., Cleary, G., Dolezalova, P., Ozen, S., Pilkington, C., Woo, P., Klein, N., Dillon, M.J. \& Brogan, P. a, 2009. Biologic therapy in primary systemic vasculitis of the young. Rheumatology (Oxford, England), 48(8), pp.97886.

Enjuanes, L., Almazán, F., Sola, I. \& Zuñiga, S., 2006. Biochemical aspects of coronavirus replication and virus-host interaction. Annual review of microbiology, 60, pp.211-30.

Ewart, G.D., Sutherland, T., Gage, P.W. \& Cox, G.B., 1996. The Vpu protein of human immunodeficiency virus type 1 forms cation-selective ion channels. Journal of Virology, 70, pp.7108-15.

Faraudo, J., Calero, C. \& Aguilella-Arzo, M., 2010. Ionic partition and transport in multi-ionic channels: a molecular dynamics simulation study of the OmpF bacterial porin. Biophysical journal, 99(7), pp.2107-15.

Feng, L., Xiao, H., He, X., Li, Z., Li, F., Liu, N., Zhao, Y., Huang, Y., Zhang, Z. \& Chai, Z., 2006. Neurotoxicological consequence of long-term exposure to lanthanum. Toxicology letters, 165(2), pp.112-20.

Fuentes, S., Tran, K.C., Luthra, P., Teng, M.N. \& He, B., 2007. Function of the respiratory syncytial virus small hydrophobic protein. Journal of Virology, 81, pp.8361-66.

Gan, S.W., Ng, L., Lin, X., Gong, X. \& Torres, J., 2008. Structure and ion channel activity of the human respiratory syncytial virus (hRSV) small hydrophobic protein transmembrane domain. Protein science : a publication of the Protein Society, 17, pp.813-20.

Gan, S. W., Tan, E., Lin, X., Yu, D., Wang, J., Tan, G.M. Y., Vararattanavech, A., Yeo, C.Y., Soon, C.H., Soong, T.W., Pervushin, K. \& Torres, J., 2012. The small hydrophobic protein of the human respiratory syncytial virus forms pentameric ion channels. The Journal of biological chemistry, 287(29), pp.24671-89. 
García-Giménez, E., Alcaraz, A. \& Aguilella, V.M., 2010. Overcharging below the nanoscale: Multivalent cations reverse the ion selectivity of a biological channel. Physical Review E, 81(2), p.021912.

García-Giménez, E., Alcaraz, A., Aguilella, V.M. \& Ramírez, P., 2009. Directional ion selectivity in a biological nanopore with bipolar structure. Journal of Membrane Science, 331(1-2), pp.13742.

Gonzalez, M.E. \& Carrasco, L., 2003. Viroporins. FEBS Letters, 552(1), pp.28-34.

Grice, A.L., Kerr, I.D. \& Sansom, M.S.P., 1997. Ion channels formed by HIV-1 Vpu: A modelling and simulation study. FEBS Letters, 405, pp.299-304.

Grimes, R.N., 2011a. Carboranes, London: Burlington, MA, Academic Press.

Grimes, R.N., 2011b. Chapter 16 - Carboranes in medicine. In Carboranes (Second Edition). pp. 1053-82.

Gurnev, P.A. \& Bezrukov, S.M., 2012. Inversion of membrane surface charge by trivalent cations probed with a cation-selective channel. Langmuir, 28, pp.15824-30.

Gurnev, P.A., Queralt-Martin, M., Aguilella, V.M., Rostovtseva, T.K. \& Bezrukov, S.M., 2012. Probing tubulin-blocked state of VDAC by varying membrane surface charge. Biophysical journal, 102(9), pp.2070-6.

Hall, J.E., Vodyanoy, I., Balasubramanian, T.M. \& Marshall, G.R., 1984. Alamethicin. A rich model for channel behavior. Biophysical journal, 45, pp.233-47.

Hartsel, C.D., 1986. A test of discreteness-of-charge effects in phospholipid vesicles: measurements using paramagnetic amphiphiles. Biochemistry, 16(25), pp.8214-9.

Hill, A.V., 1910. The possible effects of the aggregation of the molecules of hemoglobin on its dissociation curves. Journal of physiology, 10 (40), pp.i-vi.i

Hille, B., 1978. Ionic Channels in Excitable membranes. Biophysical Journal, 22, pp.283-94.

Hille, B., 1975. Ionic Selectivity, Saturation, and Block in Sodium Channels. The Journal of General Physiology , 66, pp. 535-60.

Hodgkin, A.L. \& Katz, B., 1949. The effect of sodium ions on the electrocal activity of the giant axon of the squid. Journal of Physiology, 108, pp.37-77.

Holmes, K. V., 2003. SARS-Associated Coronavirus. The New England journal of medicine pp.194851.

Van der Hoek, L., Pyrc, K., Jebbink, M.F., Vermeulen-Oost, W., Berkhout, R.J.M., Wolthers, K.C., Wertheim-van Dillen, P.M.E., Kaandorp, J., Spaargaren, J. \& Berkhout, B., 2004. Identification of a new human coronavirus. Nature medicine, 10, pp.368-73. 
Hui, K., Lipkind, G., Fozzard, H. a \& French, R.J., 2002. Electrostatic and steric contributions to block of the skeletal muscle sodium channel by mu-conotoxin. The Journal of general physiology, 119(1), pp.45-54.

Im, W. \& Roux, B., 2002a. Ion Permeation and Selectivity of OmpF Porin: A Theoretical Study Based on Molecular Dynamics, Brownian Dynamics, and Continuum Electrodiffusion Theory. Journal of Molecular Biology, 322(4), pp.851-69.

Im, W. \& Roux, B., 2002b. Ions and counterions in a biological channel: a molecular dynamics simulation of OmpF porin from Escherichia coli in an explicit membrane with $1 \mathrm{M} \mathrm{KCl}$ aqueous salt solution. Journal of molecular biology, 319(5), pp.1177-97.

Jin, H., Zhou, H., Cheng, X., Tang, R., Munoz, M. \& Nguyen, N., 2000. Recombinant respiratory syncytial viruses with deletions in the NS1, NS2, SH, and M2-2 genes are attenuated in vitro and in vivo. Virology, 273, pp.210-8.

Jing, X., Ma, C., Ohigashi, Y., Oliveira, F.A., Jardetzky, T.S., Pinto, L.H. \& Lamb, R.A., 2008. Functional studies indicate amantadine binds to the pore of the influenza A virus M2 proton-selective ion channel. Proceedings of the National Academy of Sciences of the United States of America, 105, pp.10967-72.

Jong, A.S., Visch, H.J., de Mattia, F., Van Dommelen, M.M., Swarts, H.G., Luyten, T., Callewaert, G., Melchers, W.J., Willems, P.H. \& Van Kuppeveld, F.J., 2006. The coxsackievirus 2B protein increases efflux of ions from the endoplasmic reticulum and Golgi, thereby inhibiting protein trafficking through the Golgi. The Journal of biological chemistry, 281(20), pp.14144-50.

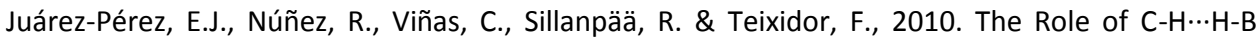
Interactions in Establishing Rotamer Configurations in Metallabis(dicarbollide) Systems. European Journal of Inorganic Chemistry, 2010(16), pp.2385-92.

Karshikoff, A., Spassov, V., Cowan, S.W., Ladenstein, R. \& Schirmer, T., 1994. Electrostatic properties of two porin channels from Escherichia coli. Journal of molecular biology, 240(4), pp.372-84.

Kobayashi, Y., Nakae, T., 1985. The mechanism of ion selectivity of OmpF-porin pores of Escherichia coli. FEBS , 236, pp.231-6.

Krusat, T. \& Streckert, H., 1997. Heparin-dependent attachment of respiratory syncytial virus ( RSV ) to host cells Brief Report. Archives of Virology, pp.1247-54.

Ksiazek, T.G., Erdman, D., Goldsmith, C.S., Zaki, S.R., Peret, T., Emery, S., Tong, S., Urbani, C., Comer, J.A., Lim, W., Rollin, P.E., Dowell, S.F., Ling, A.-E., Humphrey, C.D., Shieh, W.-J., Guarner, J., Paddock, C.D., Rota, P., Fields, B., DeRisi, J., Yang, J.-Y., Cox, N., Hughes, J.M., LeDuc, J.W., Bellini, W.J. \& Anderson, L.J., 2003. A novel coronavirus associated with severe acute respiratory syndrome. The New England journal of medicine, 348, pp.1953-66.

Kuo, L. \& Masters, P.S., 2003. The Small Envelope Protein E Is Not Essential for Murine Coronavirus Replication. Journal of Virology, 77(8), pp. 4597-608

Lachaud, C., Da Silva, D., Cotelle, V., Thuleau, P., Xiong, T.C., Jauneau, A., Brière, C., Graziana, A., Bellec, Y., Faure, J.-D., Ranjeva, R. \& Mazars, C., 2010. Nuclear calcium controls the 
apoptotic-like cell death induced by d-erythro-sphinganine in tobacco cells. Cell calcium, 47(1), pp.92-100.

Lamb, R.A., 1993. Paramyxovirus fusion: a hypothesis for changes. Virology, 197(1), pp.1-11.

Lamirande, E.W., DeDiego, M.L., Roberts, A., Jackson, J.P., Alvarez, E., Sheahan, T., Shieh, W.-J., Zaki, S.R., Baric, R., Enjuanes, L. \& Subbarao, K., 2008. A live attenuated severe acute respiratory syndrome coronavirus is immunogenic and efficacious in golden Syrian hamsters. Journal of virology, 82, pp.7721-24.

Lang, A.E., Konukiewitz, J., Aktories, K. \& Benz, R., 2013. TcdA1 of Photorhabdus luminescens: electrophysiological analysis of pore formation and effector binding. Biophysical journal, 105(2), pp.376-84.

Levadny, V., Aguilella, V., Aguilella-Arzo, M. \& Belaya, M., 2004. Interaction of a polar molecule with an ion channel. Physical Review E, 70(4), p.041912.

Lim, K.P. \& Liu, D.X., 2001. The missing link in coronavirus assembly. Retention of the avian coronavirus infectious bronchitis virus envelope protein in the pre-Golgi compartments and physical interaction between the envelope and membrane proteins. The Journal of biological chemistry, 276(20), pp.17515-23.

López, M.L., Aguilella-Arzo, M., Aguilella, V.M. \& Alcaraz, A., 2009. Ion selectivity of a biological channel at high concentration ratio: insights on small ion diffusion and binding. The journal of physical chemistry. $B, 113(25)$, pp.8745-51.

Lundbaek, J.A, 2008. Lipid bilayer-mediated regulation of ion channel function by amphiphilic drugs. The Journal of general physiology, 131(5), pp.421-9.

Lundbaek, J.A, Collingwood, S.A, Ingólfsson, H.I., Kapoor, R. \& Andersen, O.S., 2010. Lipid bilayer regulation of membrane protein function: gramicidin channels as molecular force probes. Journal of the Royal Society, Interface / the Royal Society, 7(44), pp.373-95.

Macrae, M.X., Blake, S., Jiang, X., Capone, R., Estes, D.J., Mayer, M. \& Yang, J., 2009. A SemiSynthetic Ion Channel Platform for Detection of Phosphatase and Protease Activity. ACS Nano, 3(11), pp.3567-80.

Maeda, J., Repass, J.F., Maeda, a \& Makino, S., 2001. Membrane topology of coronavirus E protein. Virology, 281(2), pp.163-9.

Maglia, G., Heron, A.J., Hwang, W.L., Holden, M.A., Mikhailova, E., Li, Q., Cheley, S. \& Bayley, H., 2009. Droplet networks with incorporated protein diodes show collective properties. Nature Nanotechnology, 4(June), pp.437-40.

Majd, S., Yusko, E.C., Billeh, Y.N., Macrae, M.X., Yang, J. \& Mayer, M., 2010. Applications of biological pores in nanomedicine, sensing, and nanoelectronics. Current opinion in biotechnology, 21(4), pp.439-76.

Malev, V. V., Schagina, L. V., Gurnev, P.A., Takemoto, J.Y., Nestorovich, E.M. \& Bezrukov, S.M., 2002. Syringomycin E channel: a lipidic pore stabilized by lipopeptide? Biophysical journal, 82(4), pp.1985-94. 
Masalles, C., Llop, J., Viñas, C. \& Teixidor, F., 2002. Extraordinary Overoxidation Resistance Increase in Self-Doped Polypyrroles by Using Non-conventional Low Charge-Density Anions. Advanced Materials, 14(11), pp.826-35.

McLaughlin, S., 1989. The electrostaitc properties of membranes. Annu Rev Biophys Biophys Chem, 18, pp.113-36.

Melton, J.V., Ewart, G.D., Weir, R.C., Board, P.G., Lee, E. \& Gage, P.W., 2002. Alphavirus 6K proteins form ion channels. Journal of Biological Chemistry, 277, pp.46923-31.

Miedema, H., Meter-Arkema, A., Wierenga, J., Tang, J., Eisenberg, B., Nonner, W., Hektor, H., Gillespie, D. \& Meijberg, W., 2004. Permeation properties of an engineered bacterial OmpF porin containing the EEEE-locus of $\mathrm{Ca}^{2+}$ channels. Biophysical journal, 87(5), pp.3137-47.

Moczydlowski, E., Alvarez, O. \& Vergara, C., 1985. Effect of phospholipid surface charge on the conductance and gating of a $\mathrm{Ca}^{2+}$-activated $\mathrm{K}^{+}$channel in planar lipid bilayers. J Membr Biol., 83(3), pp.273-82.

Montal, M. \& Mueller, P., 1972. Formation of bimolecular membranes from lipid monolayers and a study of their electrical properties. Proceedings of the National Academy of Sciences of the United States of America, 69(12), pp.3561-6.

Mueller, P., Rudin, D.O., Tien, H.T. \& Wescott, W.C., 1962. Reconstitution of Excitable Cell Membrane Structure in Vitro. Circulation, 26(5), pp.1167-71.

N.Lakshminarayanaiah, 1984. Equations of membrane biophysics, London: Academic Press.

Nal, B., Chan, C., Kien, F., Siu, L., Tse, J., Chu, K., Kam, J., Staropoli, I., Crescenzo-Chaigne, B., Escriou, N., van der Werf, S., Yuen, K.-Y. \& Altmeyer, R., 2005. Differential maturation and subcellular localization of severe acute respiratory syndrome coronavirus surface proteins $\mathrm{S}, \mathrm{M}$ and $\mathrm{E}$. The Journal of general virology, 86(Pt 5), pp.1423-34.

Nestorovich, E.M., Danelon, C., Winterhalter, M. \& Bezrukov, S.M., 2002. Designed to penetrate: time-resolved interaction of single antibiotic molecules with bacterial pores. Proceedings of the National Academy of Sciences of the United States of America, 99(15), pp.9789-94.

Nestorovich, E.M., Rostovtseva, T.K. \& Bezrukov, S.M., 2003. Residue ionization and ion transport through OmpF channels. Biophysical journal, 85(6), pp.3718-29.

Netland, J., DeDiego, M.L., Zhao, J., Fett, C., Alvarez, E., Nieto-Torres, J.L., Enjuanes, L. \& Perlman, S., 2010. Immunization with an attenuated severe acute respiratory syndrome coronavirus deleted in E protein protects against lethal respiratory disease. Virology, 399(1), pp.120-8.

Nguyen, V.P. \& Hogue, B.G., 1997. Protein Interactions during Coronavirus Assembly. Journal of Virology , 71(12), pp.9278-84.

Nieto-Torres, J.L., Dediego, M.L., Alvarez, E., Jiménez-Guardeño, J.M., Regla-Nava, J.A., Llorente, M., Kremer, L., Shuo, S. \& Enjuanes, L., 2011. Subcellular location and topology of severe acute respiratory syndrome coronavirus envelope protein. Virology, 415(2), pp.69-82. 
Nieva, J.L., Madan, V. \& Carrasco, L., 2012. Viroporins: structure and biological functions. Nature Reviews Microbiology, 10, pp.563-74.

Nikaido, H., 2003. Molecular basis of bacterial outer membrane permeability revisited. Microbiology and molecular biology reviews : MMBR, 67(4), pp.593-656.

Nikaido, H., 1989. Outer membrane barrier as a mechanism of antimicrobial resistance. Antimicrobial agents and chemotherapy, 33(11), pp.1831-6.

Oren Z.S.Y., 1998. Mode of action of linear amphipathic alpha-helical antimicrobial peptidese. biopolymers, 47(6), pp.451-63.

Ortego, J., Ceriani, J.E., Patiño, C., Plana, J. \& Enjuanes, L., 2007. Absence of E protein arrests transmissible gastroenteritis coronavirus maturation in the secretory pathway. Virology, 368(2), pp.296-308.

Ortego, J., Escors, D., Laude, H. \& Enjuanes, L., 2002. Generation of a Replication-Competent , Propagation-Deficient Virus Vector Based on the Transmissible Gastroenteritis Coronavirus Genome Generation of a Replication-Competent , Propagation-Deficient Virus Vector Based on the Transmissible Gastroenteritis. Journal of Virology. 76(22), pp.11518-29.

OuYang, B., Xie, S., Berardi, M.J., Zhao, X., Dev, J., Yu, W., Sun, B. \& Chou, J.J., 2013. Unusual architecture of the $\mathrm{p} 7$ channel from hepatitis $C$ virus. Nature, 498, pp.521-5.

Parra, E., Alcaraz, A., Cruz, A., Aguilella, V.M. \& Pérez-Gil, J., 2013. Hydrophobic pulmonary surfactant proteins SP-B and SP-C induce pore formation in planar lipid membranes: evidence for proteolipid pores. Biophysical journal, 104(1), pp.146-55.

Parsegian, A., 1969. Energy of an ion crossing a low dielectric membrane: solutions to four relevant electrostatic problems. Nature, 221, pp.844-846.

Parthasarathy, K., Ng, L., Lin, X., Liu, D.X., Pervushin, K., Gong, X. \& Torres, J., 2008. Structural flexibility of the pentameric SARS coronavirus envelope protein ion channel. Biophysical journal, 95(6), pp.L39-41.

Peiris, J.S.M., Lai, S.T., Poon, L.L.M., Guan, Y., Yam, L.Y.C., Lim, W., Nicholls, J., Yee, W.K.S., Yan, W.W., Cheung, M.T., Cheng, V.C.C., Chan, K.H., Tsang, D.N.C., Yung, R.W.H., Ng, T.K. \& Yuen, K.Y., 2003. Coronavirus as a possible cause of severe acute respiratory syndrome. Lancet, 361, pp.1319-25.

Perez, M., 1997. Membrane Permeability Changes Induced inEscherichia coliby the SH Protein of Human Respiratory Syncytial Virus. Virology, 235(2), pp.342-51.

Pervushin, K., Tan, E., Parthasarathy, K., Lin, X., Jiang, F.L., Yu, D., Vararattanavech, A., Soong, T.W., Liu, D.X. \& Torres, J., 2009. Structure and inhibition of the SARS coronavirus envelope protein ion channel. PLoS pathogens, 5(7), p.e1000511.

Phale, P.S., Philippsen, A., Widmer, C., Phale, V.P., Rosenbusch, J.P. \& Schirmer, T., 2001. Role of Charged Residues at the OmpF Porin Channel Constriction Probed by mutagenesis and simulation. Biochemistry, 21, pp.6319-25. 
Pinto, L.H., Dieckmann, G.R., Gandhi, C.S., Papworth, C.G., Braman, J., Shaughnessy, M.A., Lear, J.D., Lamb, R.A. \& DeGrado, W.F., 1997. A functionally defined model for the M2 proton channel of influenza A virus suggests a mechanism for its ion selectivity. Proceedings of the National Academy of Sciences of the United States of America, 94, pp.11301-6.

Pinto, L.H., Holsinger, L.J. \& Lamb, R.A., 1992. Influenza virus M2 protein has ion channel activity. Cell, 69(3), pp.517-28.

Pokorná, J., Machala, L., Rezáčová, P. \& Konvalinka, J., 2009. Current and Novel Inhibitors of HIV Protease. Viruses, 3, pp. 1209-39.

Premkumar, A., Wilson, L., Ewart, G.D. \& Gage, P.W., 2004. Cation-selective ion channels formed by $\mathrm{p} 7$ of hepatitis $\mathrm{C}$ virus are blocked by hexamethylene amiloride. FEBS Letters, 557, pp.99-103.

Raamsman, M.J.B., Locker, J.K., Hooge, D., Vries, A.A.F. De, Griffiths, G. \& Rottier, P.J.M., 2000. Characterization of the Coronavirus Mouse Hepatitis Virus Strain A59 Small Membrane Protein E Characterization of the Coronavirus Mouse Hepatitis Virus Strain A59 Small Membrane Protein E. Journal of Virology, 74(5), pp.2333-42.

Regla-Nava, J.A., Jimenez-Guardeño, J.M., Nieto-Torres, J.L., Gallagher, T.M., Enjuanes, L. \& DeDiego, M.L., 2013. The replication of a mouse adapted SARS-CoV in a mouse cell line stably expressing the murine SARS-CoV receptor mACE2 efficiently induces the expression of proinflammatory cytokines. Journal of Virological Methods, 193, pp.639-46.

Rixon, H.W.M., Brown, G., Aitken, J., McDonald, T., Graham, S. \& Sugrue, R.J., 2004. The small hydrophobic (SH) protein accumulates within lipid-raft structures of the Golgi complex during respiratory syncytial virus infection. Journal of General Virology, 85, pp.1153-65.

Rixon, H.W.M., Brown, G., Murray, J.T. \& Sugrue, R.J., 2005. The respiratory syncytial virus small hydrophobic protein is phosphorylated via a mitogen-activated protein kinase p38dependent tyrosine kinase activity during virus infection. Journal of General Virology, 86, pp.375-84.

Roberts, A., Deming, D., Paddock, C.D., Cheng, A., Yount, B., Vogel, L., Herman, B.D., Sheahan, T., Heise, M., Genrich, G.L., Zaki, S.R., Baric, R. \& Subbarao, K., 2007. A mouse-adapted SARScoronavirus causes disease and mortality in BALB/c mice. PLoS Pathogens, 3, pp.00230037.

Robinson, R.A. \& Stokes, R.H., 2002. Electrolyte Solutions Second Rev., Dover Publications.

Rostovtseva, T.K., Aguilella, V.M., Vodyanoy, I., Bezrukov, S.M. \& Parsegian, V.A., 1998. Membrane surface-charge titration probed by gramicidin A channel conductance. Biophysical journal, 75, pp.1783-92.

Rostovtseva, T.K., Liu, T.T., Colombini, M., Parsegian, V.A. \& Bezrukov, S.M., 2000. Positive cooperativity without domains or subunits in a monomeric membrane channel. Proceedings of the National Academy of Sciences of the United States of America, 97(14), pp.7819-22.

Rostovtseva, T.K., Nestorovich, E.M. \& Bezrukov, S.M., 2002. Partitioning of differently sized poly(ethylene glycol)s into OmpF porin. Biophysical journal, 82(1 Pt 1), pp.160-9. 
Ruch, T.R. \& Machamer, C.E., 2012. The coronavirus E protein: assembly and beyond. Viruses, $4(3)$, pp.363-82.

Saint, N., Lou, K.L., Widmer, C., Luckey, M., Schirmer, T. \& Rosenbusch, J.P., 1996. Structural and functional characterization of OmpF porin mutants selected for larger pore size. II. Functional characterization. The Journal of biological chemistry, 271, pp.20676-80.

Schaecher, S.R., Mackenzie, J.M. \& Pekosz, A., 2007. The ORF7b protein of severe acute respiratory syndrome coronavirus (SARS-CoV) is expressed in virus-infected cells and incorporated into SARS-CoV particles. Journal of virology, 81(2), pp.718-31.

Schindler, H. \& Rosenbusch, J.P., 1978. Matrix protein from Escherichia coli outer membranes forms voltage-controlled channels in lipid bilayers. Proceedings of the National Academy of Sciences of the United States of America, 75(8), pp.3751-5.

Schirmer, T., 1998. General and specific porins from bacterial outer membranes. J Struct Biol, 121(2), pp.101-9.

Singer, S.J. \& Nicolson, G.L., 1972. The fluid mosaic model of the structure of cell membranes. Science (New York, N.Y.), 175(4023), pp.720-31.

Siwy, Z.S. \& Howorka, S., 2010. Engineered voltage-responsive nanopores. Chemical Society reviews, 39(3), pp.1115-32.

Sobko, A. a, Kotova, E. a, Antonenko, Y.N., Zakharov, S.D. \& Cramer, W. a, 2004. Effect of lipids with different spontaneous curvature on the channel activity of colicin E1: evidence in favor of a toroidal pore. FEBS letters, 576(1-2), pp.205-10.

Sorkin, A. \& Von Zastrow, M., 2002. Signal transduction and endocytosis: close encounters of many kinds. Nature reviews. Molecular cell biology, 3, pp.600-14.

Stryer, L., 1981. Biochemistry, Freeman and Company: San Francisco, CA.

Suenaga, A., Komeiji, Y., Uebayasi, M., Meguro, T., Saito, M. \& Yamato, I., 1998. Computational observation of an ion permeation through a channel protein. Bioscience Reports, 18(1), pp.39-48.

Surya, W., Samsó, M., Torres,. J., 2013, Respiratory Disease and Infection: A New Insight, Book chapter.

Tarrés, M., Canetta, E., Viñas, C., Teixidor, F. \& Harwood, A.J., 2014. Imaging in living cells using vB-H Raman spectroscopy: monitoring COSAN uptake. Chemical communications (Cambridge, England), 50(25), pp.3370-2.

Tatulian, S.A., 1999. Surface chemistry and electrochemistry of membranes, p.877, Dekker, New York.

Techaarpornkul, S., Barretto, N. \& Peeples, M.E., 2001. Functional analysis of recombinant respiratory syncytial virus deletion mutants lacking the small hydrophobic and/or attachment glycoprotein gene. Journal of virology, 75, pp.6825-34. 
Tieleman, D.P. \& Berendsen, H.J., 1998. A molecular dynamics study of the pores formed by Escherichia coli OmpF porin in a fully hydrated palmitoyloleoylphosphatidylcholine bilayer. Biophysical journal, 74(6), pp.2786-801.

Tocanne, J. F. \& Teissié, J., 1990. Ionization of phospholipids and phospholipid-supported interfacial lateral diffusion of protons in membrane model systems. Biochimica et Biophysica Acta (BBA) - Reviews on Biomembranes, 1031(1), pp.111-42.

Torres, J., Maheswari, U.M.A., Parthasarathy, K., Ng, L., Liu, D.X. \& Gong, X., 2007. Conductance and amantadine binding of a pore formed by a lysine-flanked transmembrane domain of SARS coronavirus envelope protein. Protein Science, 16 (9), pp.2065-71.

Torres, J., Parthasarathy, K., Lin, X., Saravanan, R., Kukol, A. \& Liu, D.X., 2006. Model of a putative pore: the pentameric alpha-helical bundle of SARS coronavirus $E$ protein in lipid bilayers. Biophysical journal, 91, pp.938-47.

Tsui, F.C., Ojcius, D.M. \& Hubbell, W.L., 1986. The intrinsic $p K_{a}$ values for phosphatidylserine and phosphatidylethanolamine in phosphatidylcholine host bilayers. Biophysical journal, 49(2), pp.459-68.

Tucker, S.J. \& Baukrowitz, T., 2008. How highly charged anionic lipids bind and regulate ion channels. The Journal of general physiology, 131(5), pp.431-8.

Varma, S. \& Jakobsson, E., 2004. Ionization states of residues in OmpF and mutants: effects of dielectric constant and interactions between residues. Biophysical journal, 86(2), pp.690704.

Vazquez, G., Wedel, B.J., Aziz, O., Trebak, M. \& Putney, J.W., 2004. The mammalian TRPC cation channels. Biochimica et biophysica acta, 1742(1-3), pp.21-36.

Verdiá-Báguena, C., Nieto-Torres, J.L., Alcaraz, A., DeDiego, M.L., Torres, J., Aguilella, V.M. \& Enjuanes, L., 2012. Coronavirus E protein forms ion channels with functionally and structurally-involved membrane lipids. Virology, 432(2), pp.485-94.

Vergara, C., Moczydlowski, E. \& Latorre, R., 1984. Conduction, Blockade and Gating in a Ca activated K Channel Incorporated into Planar Lipid Bilayers. Biophysical journal, 45(1), pp.73-6.

Volkamer, A., Kuhn, D., Rippmann, F. \& Rarey, M., 2012. Dogsitescorer: A web server for automatic binding site prediction, analysis and druggability assessment. Bioinformatics, 28 , pp.2074-75.

Vrouenraets, M., Wierenga, J., Meijberg, W. \& Miedema, H., 2006. Chemical modification of the bacterial porin OmpF: gain of selectivity by volume reduction. Biophysical journal, 90(4), pp.1202-11.

Wang, L.H., Jiang, N., Zhao, B., Li, X.D., Lu, T.H., Ding, X.L. \& Huang, X.H., 2010. Structural basis for the decrease in the outward potassium channel current induced by lanthanum. Journal of biological inorganic chemistry: JBIC : a publication of the Society of Biological Inorganic Chemistry, 15(7), pp.989-93. 
Whitehead, S.S., Bukreyev, A., Teng, M.N., Firestone, C.Y., St Claire, M., Elkins, W.R., Collins, P.L. \& Murphy, B.R., 1999. Recombinant respiratory syncytial virus bearing a deletion of either the NS2 or SH gene is attenuated in chimpanzees. Journal of virology, 73, pp.3438-42.

Wilson, L., Gage, P. \& Ewart, G., 2006a. Hexamethylene amiloride blocks E protein ion channels and inhibits coronavirus replication. Virology, 353(2), pp.294-306.

Wilson, L., McKinlay, C., Gage, P. \& Ewart, G., 2004. SARS coronavirus E protein forms cationselective ion channels. Virology, 330(1), pp.322-31.

Wilson, N.A., Abu-Shumays, R., Gyarfas, B., Wang, H., Lieberman, K.R., Akeson, M. \& Dunbar, W.B., 2009. Electronic control of DNA polymerase binding and unbinding to single DNA molecules. ACS nano, 3(4), pp.995-1003.

Wilson, R.L., Fuentes, S.M., Wang, P., Taddeo, E.C., Klatt, A., Henderson, A.J. \& He, B., 2006 b. Function of small hydrophobic proteins of paramyxovirus. Journal of virology, 80(4), pp.1700-09.

Winiski, A.P., McLaughlin, A.C., McDaniel, R. V, Eisenberg, M. \& McLaughlin, S., 1986. An experimental test of the discreteness-of-charge effect in positive and negative lipid bilayers. Biochemistry, 25, pp.8206-14.

Woo, P.C.Y., Lau, S.K.P., Chu, C., Chan, K., Tsoi, H., Huang, Y., Wong, B.H.L., Poon, R.W.S., Cai, J.J., Luk, W., Poon, L.L.M., Wong, S.S.Y., Guan, Y., Peiris, J.S.M. \& Yuen, K., 2005. Characterization and complete genome sequence of a novel coronavirus, coronavirus HKU1, from patients with pneumonia. Journal of virology, 79, pp.884-95.

Woodhull, A.M., 1973. Ionic blockage of sodium channels in nerve. The Journal of general physiology, 61(6), pp.687-708.

Wozniak, A.L., Griffin, S., Rowlands, D., Harris, M., Yi, M., Lemon, S.M. \& Weinman, S. a, 2010. Intracellular proton conductance of the hepatitis $C$ virus $p 7$ protein and its contribution to infectious virus production. PLoS pathogens, 6(9), pp.1001087.

Yamashita, E., Zhalnina, M. V, Zakharov, S.D., Sharma, O. \& Cramer, W. a, 2008. Crystal structures of the OmpF porin: function in a colicin translocon. The EMBO journal, 27(15), pp.2171-80.

Yan, X., Porter, C.J., Hardy, S.P., Steer, D., Smith, A.I., Quinsey, N.S., Hughes, V., Cheung, J.K., Keyburn, A.L., Kaldhusdal, M., Moore, R.J., Bannam, T.L. \& Whisstock, J.C., 2013. Structural and Functional Analysis of the Pore-Forming Toxin NetB . Clostridium perfringens. , 4(1), pp.1-9.

Yellen, G., 1984. Ionic permeation and blockade in $\mathrm{Ca}^{2+}$-activated $\mathrm{K}^{+}$channels of bovine chromaffin cells. The Journal of general physiology, 84(2), pp.157-86.

Yi, M., Nymeyer, H. \& Zhou, H. X., 2008. Test of the Gouy-Chapman Theory for a Charged Lipid Membrane against Explicit-Solvent Molecular Dynamics Simulations. Physical Review Letters, 101(3), pp.038103-10.

Yoshimura, K. \& Sokabe, M., 2010. Mechanosensitivity of ion channels based on protein-lipid interactions. Journal of the Royal Society, Interface / the Royal Society, 7 Suppl 3(March), pp.S307-20. 
Zakharov, S.D., Kotova, E.A., Antonenko, Y.N. \& Cramer, W.A., 2004. On the role of lipid in colicin pore formation. Biochimica et biophysica acta, 1666(1-2), pp.239-49.

Zakharov, S.D., Rokitskaya, T.I., Shapovalov, V.L., Antonenko, Y.N. \& Cramer, W. a, 2002. Tuning the membrane surface potential for efficient toxin import. Proceedings of the National Academy of Sciences of the United States of America, 99(13), pp.8654-9.

Zaki, A.M., van Boheemen, S., Bestebroer, T.M., Osterhaus, A.D.M.E. \& Fouchier, R.A.M., 2012. Isolation of a Novel Coronavirus from a Man with Pneumonia in Saudi Arabia. New England Journal of Medicine, pp. 1814-20.

Ziervogel, B.K. \& Roux, B., 2013. The binding of antibiotics in OmpF porin. Structure, 21(1), pp.7687. 





\title{
Electrostatic Interactions Drive the Nonsteric Directional Block of OmpF Channel by $\mathrm{La}^{3+}$
}

\author{
María Queralt-Martín, Carmina Verdiá-Báguena, Vicente M. Aguilella, and Antonio Alcaraz* \\ Laboratory of Molecular Biophysics, Department of Physics, Universitat Jaume I, 12071 Castellón, Spain
}

Supporting Information

\begin{abstract}
Ion channels regulate the transport of molecules and the electric signal transduction in living cells by means of complex and even highly sophisticated mechanisms. We focus here on the crucial role that polyvalent ions, well-known modulators of many biological nanosystems, play in ion channel function. In particular, we show that trace amounts of lanthanum are able to block the bacterial porin $\mathrm{OmpF}$, a large biological pore of Escherichia coli wide enough to exchange antibiotics and other larger molecules. The underlying mechanism has a strong directional character: it is sensitive to the sign of the applied

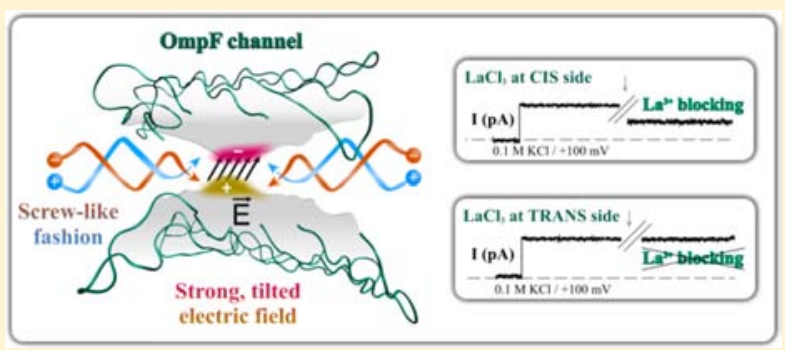
voltage and to the side of the blocker addition. We explore these channel features by combining planar lipid bilayer electrophysiology at the single channel level, site-directed mutagenesis, and inductively coupled plasma mass spectrometry (ICPMS). In contrast to other well-described channel blockers, which seem to occlude the narrower part of the pore, we envisage a nonsteric mechanism based on electrostatic interactions.
\end{abstract}

\section{INTRODUCTION}

Electrical signaling provided by ion channels is essential in many physiological processes like contraction of heart and skeletal muscle and operation of the nervous system, among others. ${ }^{1,2}$ These specialized functions require not only paths to communicate the intracellular and the extracellular worlds, but also specific control of the transport of ions and other hydrophilic solutes so that the cellular membrane could serve as a selective permeation barrier. ${ }^{3}$ Among other effects, the presence of multivalent ions is important for the electrostatic regulation of the cell signaling by modifying the membrane surface charge as well as the ion channel function. ${ }^{4}$ The fine sensitivity observed in many ion channels for tiny amounts of multivalent ions reinforces the idea that these pores are not passive filters but rather could act as externally activated valves within the biological membrane. ${ }^{5-7}$ Specifically, we consider here the block of OmpF channel induced by $\mathrm{La}^{3+}$ ions. The blocking activity of lanthanum has been reported in such different systems like connexin hemichannels, TRPC channels, murin frontal cortex networks, tobacco BY-2 cells, or the outward $\mathrm{K}^{+}$channel. $^{8-11}$ Most of these channels share the feature of having pore dimensions comparable to the size of the permeating ions, and it is common to observe that only one ion at a time can cross the narrower parts of the channel (what is known as single file transport). ${ }^{2,5}$ In these systems, the blocking is mainly due to steric reasons: the channel eyelet is totally or partially obstructed by the blocker. ${ }^{12}$ The $\mathrm{La}^{3+}$-induced block observed in $\mathrm{OmpF}$ is particularly interesting because this is not a narrow channel, but a relatively wide one. OmpF is a homotrimer with a 16-stranded $\beta$-barrel that spans the lipid bilayer and acts as a water-filled, voltage-gated pore. It is located at the outer membrane of the bacteria E. coli, supporting the influx of nutrients and the extrusion of waste products from the bacteria. $^{3}$ It belongs to the family of the so-called mesoscopic channels, pores having dimensions that allow simultaneous passage of water molecules, positive and negative ions of several types that may enter the pore without losing their hydration layer. ${ }^{13}$ The fact that the OmpF channel is wide enough to transport not only ions, but also larger molecules like $\beta$-lactam antibiotic and quinolones, ${ }^{14}$ stresses a distinctive feature with respect to other narrower channels and synthetic devices that could be highly relevant for a variety of biotechnology, analytical, and medical applications. ${ }^{6,15,16}$ Here we combine different experimental techniques-site-directed mutagenesis, voltage-clamp measurements, and inductively coupled plasma mass spectrometry (ICP-MS) - to characterize the channel blocking by $\mathrm{La}^{3+}$ and to elucidate the residues involved. Our observations suggest that the mechanism of channel blocking is a competitive interaction between the substrate and the blocker implicating residues located in the central constriction of the channel. The particular structure of this narrow region generates a strong transverse electric field that is probably behind the fact that both the channel block and the $\mathrm{La}^{3+}$ flux through the channel depend decisively on the side of lanthanum addition.

Received: July 16, 2013

Revised: November 14, 2013

Published: November 20, 2013 


\section{MATERIALS AND METHODS}

Ion Channel Recording. Isolation and lab handling of $\mathrm{OmpF}$ channels was analogous to the method described elsewhere. ${ }^{17-19}$ Wildtype OmpF, kindly provided by Dr. S. M. Bezrukov (NIH, Bethesda, USA), was isolated and purified from an E. coli culture. Mutants D113C (aspartic acid replaced by a neutral cysteine), E117C (glutamic acid replaced by a neutral cysteine), D113R (aspartic acid replaced by a basic arginine), and D113R/E117R (both acidic residues replaced by basic arginines) ${ }^{20}$ were a generous gift from Dr. H. Miedema (Wetsus, The Netherlands). Planar membranes were formed by the apposition of diphytanoyl phosphatidylcholine monolayers ${ }^{21}$ across orifices with diameters of $70-100 \mu \mathrm{m}$ on a $15-\mu \mathrm{m}$-thick Teflon partition. The orifices were pretreated with a $1 \%$ solution of hexadecane in pentane. An electric potential was applied using $\mathrm{Ag} / \mathrm{AgCl}$ electrodes in $2 \mathrm{M}$ $\mathrm{KCl}, 1.5 \%$ agarose bridges assembled within standard $250 \mu \mathrm{L}$ pipet tips. The potential was defined as positive when it was higher on the side of the protein addition (the cis side of the membrane chamber), whereas the trans side was set to ground. An Axopatch 200B amplifier (Molecular Devices, Sunnyvale, CA) in the voltage-clamp mode was used to measure the current and to apply potentials. The chamber and the head stage were isolated from external noise sources with a double metal screen (Amuneal Manufacturing Corp., Philadelphia, PA). The $\mathrm{pH}$ was adjusted by adding $\mathrm{HCl}$ or $\mathrm{KOH}$ and controlled during the experiments with a GLP22 $\mathrm{pH}$ meter (Crison). Except where noted, measurements were obtained at $T=(23.0 \pm 1.5)^{\circ} \mathrm{C}$ and $\mathrm{pH}=6$. The average open channel conductance was obtained from the current measurement at an applied potential of $\pm 100 \mathrm{mV}$ in symmetrical salt solutions. Each experiment was repeated 3-4 times to ensure reproducibility.

Fitting the Experimental Data. The ion current in the presence of a substrate, $\mathrm{K}^{+}$, can be described by the Hill equation:

$$
\frac{i_{0}}{i_{\max }}=\frac{\left[\mathrm{K}^{+}\right]^{n}}{\left[\mathrm{~K}^{+}\right]^{n}+k_{\mathrm{K}^{+}}^{n}}
$$

where $\left[\mathrm{K}^{+}\right]$is the concentration of substrate, $k_{\mathrm{K}}{ }^{+}$is the dissociation constant for $\mathrm{K}^{+}, i_{\max }$ is the saturation current, and $n$ is the Hill coefficient that measures the level of cooperativity. ${ }^{22}$ In the presence of a competitive interaction between the substrate $\mathrm{K}^{+}$and a blocker, $\mathrm{La}^{3+}$, eq 1 is still valid but the dissociation constant will change into an apparent $k$ :

$$
k=k_{\mathrm{K}^{+}}\left(1+\frac{\left[\mathrm{La}^{3+}\right]}{k_{\mathrm{La}^{3+}}}\right)
$$

where $\left[\mathrm{La}^{3+}\right]$ is the concentration of blocker, and $k_{\mathrm{La}}{ }^{3+}$ is the dissociation constant of the blocking ion. ${ }^{23}$ By introducing the apparent $k$ into eq 1 we obtain the current in the presence of blocker:

$$
\frac{i_{b}}{i_{\max }}=\frac{\left[\mathrm{K}^{+}\right]^{n}}{\left[\mathrm{~K}^{+}\right]^{n}+k_{\mathrm{K}^{+}}^{n}\left(1+\frac{\left[\mathrm{La}^{3+}\right]}{k_{\mathrm{La}^{3+}}}\right)^{n}}
$$

The ratio of current in the presence $\left(i_{b}\right)$ and absence $\left(i_{0}\right)$ of blocker can be obtained from the quotient of eqs 3 and 1 :

$$
\frac{i_{b}}{i_{0}}=\frac{\left[\mathrm{K}^{+}\right]^{n}+k_{\mathrm{K}^{+}}^{n}}{\left[\mathrm{~K}^{+}\right]^{n}+k_{\mathrm{K}^{+}}^{n}\left(1+\frac{\left[\mathrm{Laa}^{3+}\right]}{k_{\mathrm{La}^{3+}}}\right)^{n}}
$$

The voltage-dependence is introduced by the Woodhull model, developed to describe the blocking effect of protons on whole-cell $\mathrm{Na}^{+}$ currents. $^{24}$ It is typically used to describe the voltage dependence of channel blocking by many charged compounds. ${ }^{25-28}$ Within the Woodhull model, the concentration of substrate and blocker at the binding site will be given by:

$$
\left[\mathrm{K}^{+}\right]=\left[\mathrm{K}^{+}\right]_{0} \exp \left(\frac{\mathrm{zF} \delta}{\mathrm{RT}} \mathrm{V}\right)
$$

$$
\left[\mathrm{La}^{3+}\right]=\left[\mathrm{La}^{3+}\right]_{0} \exp \left(\frac{\mathrm{zF} \delta}{\mathrm{RT}} \mathrm{V}\right)
$$

where subscript 0 is used for the ion concentration in the bath, $z$ is the valence of the ion, $V$ is the voltage drop across the membrane, and $\delta$ is the fraction of potential traversed in reaching the binding site.

Inductively Coupled Plasma Mass Spectrometry. ICP-MS measurements were performed using a quadrupole mass spectrometer Agilent $7500 \mathrm{cx}$ with a collision cell (Agilent technologies, USA) from the Central Services for Scientific Instrumentation (SCIC) of Universitat Jaume I. Additional samples were analyzed by the Technological and Scientific Centers of Universitat de Barcelona (CCiTUB) using a Perkin-Elmer Elan 6000 mass spectrometer. Control samples were prepared following the experimental protocol for channel reconstitution without performing any $\mathrm{LaCl}_{3}$ addition. These samples allowed us to dismiss contamination as a source for the presence of $\mathrm{La}^{3+}$ and to ensure that the results obtained with ICP-MS can be attributed to the transport of ions through the channel.

\section{RESULTS AND DISCUSSION}

Lanthanum lons Block Single OmpF Channels. High resolution voltage-clamp measurements allow study of the effect of lanthanum on the OmpF conductance at the single channel level. Figure 1 displays the unitary current traces of the OmpF channel before and after the addition of lanthanum chloride salt into a symmetric $100 \mathrm{mM} \mathrm{KCl}$ solution. Millimolar concentrations of $\mathrm{LaCl}_{3}$ have a huge impact on the channel activity reducing the conductance for positive but not for

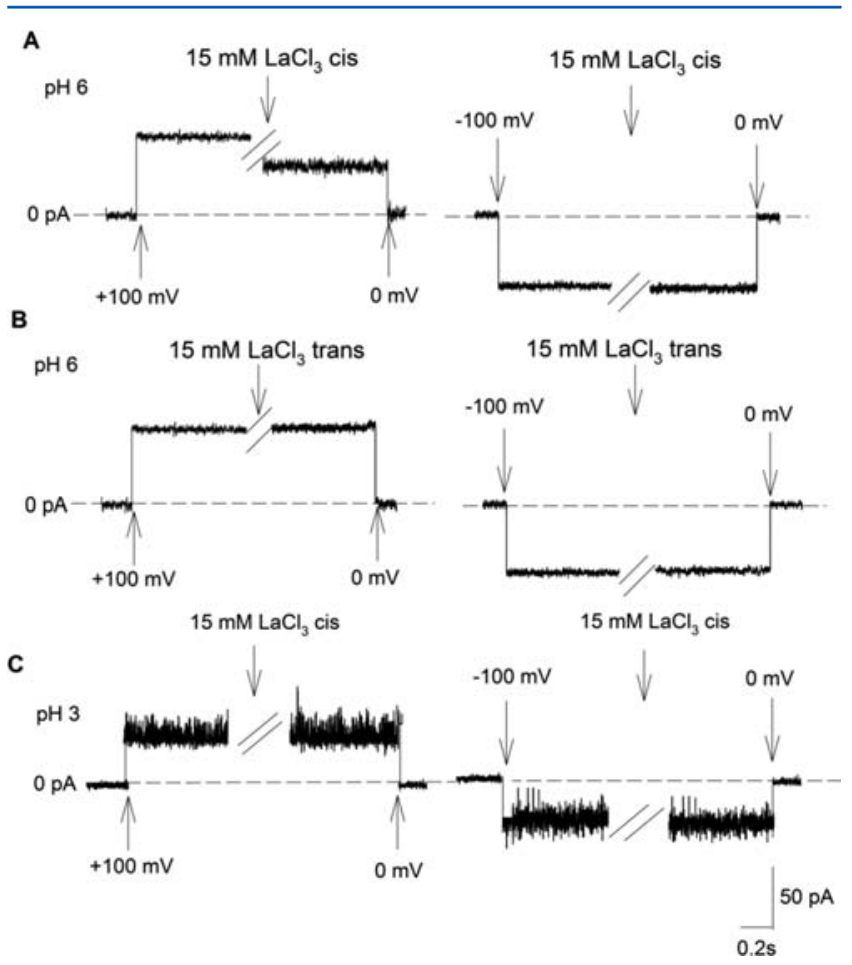

Figure 1. Single channel current recordings show the asymmetry of $\mathrm{La}^{3+}$ blocking. Unitary current traces were recorded under $100 \mathrm{mM}$ $\mathrm{KCl}$ solution added at both sides of the membrane cell. After the insertion of a single OmpF channel, $15 \mathrm{mM} \mathrm{LaCl}_{3}$ was added at the side of protein addition (cis) at $\mathrm{pH} 6$ (A) or at the opposite side (trans) (B). The traces show that lanthanum ions reduce the unitary current only when they are incorporated at the side of protein addition. At $\mathrm{pH} 3$ the traces show a noise increase due to residue protonation, but the addition of $15 \mathrm{mM} \mathrm{LaCl} 3$ does not yield any change in the current level (C). The traces were filtered with an 8-pole Bessel filter with a cutoff frequency of $500 \mathrm{~Hz}$. 

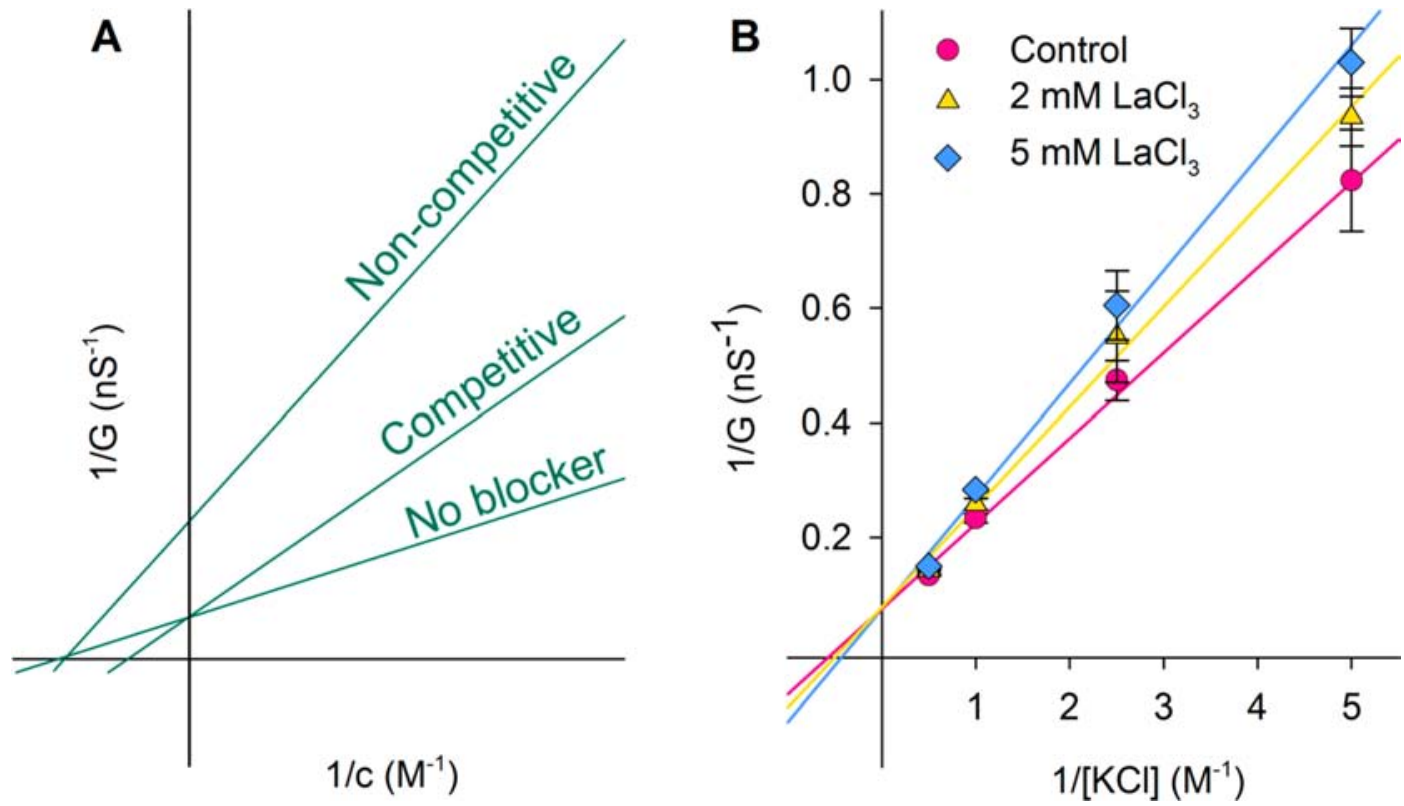

Figure 2. Lanthanum block of $\mathrm{OmpF}$ channel is consistent with a competitive interaction between $\mathrm{La}^{3+}$ and $\mathrm{K}^{+}$ions. (A) Ideal double reciprocal plots of conductance versus $\mathrm{K}^{+}$concentration to illustrate competitive and noncompetitive block. (B) Double reciprocal plots of experimental single channel conductance versus [ $\mathrm{KCl}]$, measured for no blocker (circles) and for 2 and $5 \mathrm{mM}$ blocker concentrations. The regression lines for $2 \mathrm{mM}$ (triangles) and $5 \mathrm{mM}$ (diamonds) $\mathrm{LaCl}_{3}$ intersect at the $y$-axis with the regression line for no blocker measurements, thus showing that the block is competitive in both cases.

negative applied voltages. This effect, observed also in other trivalent cations like spermidine ${ }^{3+}$ ( $N$-(3-Aminopropyl)-1,4butanediamine trihydrochloride) (see Figure S1, Supporting Information), cannot be explained by a decrease of solution conductivity; on the contrary, millimolar $\mathrm{LaCl}_{3}$ increases the ionic conductivity of the initial $\mathrm{KCl}$ solution. We have recently shown that the current rectification induced by $\mathrm{LaCl}_{3}$ can be used to build a switchable diode acting as a molecular ratchet. ${ }^{6}$ One interesting feature of this $\mathrm{La}^{3+}$ induced blocking is that the side of $\mathrm{LaCl}_{3}$ addition is decisive. The drop of the channel current at positive applied potentials is only visible when $\mathrm{La}^{3+}$ ions are added to the cis side (Figure 1A). The addition of trace amounts of $\mathrm{LaCl}_{3}$ to the trans side does not cause any current decrease, either for positive or for negative polarities (Figure 1B). These observations must be considered together with the channel orientation once reconstituted into the bilayer. In the protocol employed here, the protein is added only to the cis side whereas the trans side is set to ground. Control experiments show that the conductance for negative voltages $(G=80 \pm 8 \mathrm{pS}$ in $100 \mathrm{mM} \mathrm{KCl})$ is higher than for positive ones $(G=75 \pm 9 \mathrm{pS}$ in $100 \mathrm{mM} \mathrm{KCl})$ indicating that the channel inserts almost always $(>95 \%)$ in a particular orientation. The combination of all these facts suggests that the interaction of $\mathrm{La}^{3+}$ ions with $\mathrm{OmpF}$ channel has a directional character and hence requires a particular conformation to occur.

Having in mind that $\mathrm{OmpF}$ is a weakly selective wide channel (the narrower part is about $1 \mathrm{~nm}$ in diameter) that allows multi-ionic transport, ${ }^{5}$ the next question that arises naturally is how millimolar concentrations of $\mathrm{La}^{3+}$ can regulate so drastically the transport of decimolar concentrations of $\mathrm{KCl}$. One interesting clue comes from the study of the role of $\mathrm{pH}$. A variety of studies show that $\mathrm{OmpF}$ conductance is critically affected by the quantity of protons present in solution. ${ }^{17,30,31}$ In particular, the channel conductance is severely reduced at $\mathrm{pH}$ below 3 (millimolar concentrations of $\mathrm{H}^{+}$). Thus, protons and
$\mathrm{La}^{3+}$ ions seem to share this interesting feature: trace amounts of them are able to inhibit the flow of the more concentrated supporting electrolyte, but $\mathrm{OmpF}$ is not a narrow channel in which the blocking could be understood as ion-protein binding that physically obstructs the flow of other ions. ${ }^{2} \mathrm{~A}$ more subtle mechanism must be involved here. In the case of protons, we have recently shown that this mechanism is a competitive binding with cations in the narrow central constriction of the channel. ${ }^{31}$ And interestingly, the traces in Figure 1C show that there is a link between the channel sensitivity to $\mathrm{pH}$ and the $\mathrm{La}^{3+}$ blocking effect: the lanthanuminduced current rectification can be totally canceled by lowering the $\mathrm{pH}$ of the bathing solutions. This indicates that the channel residues responsible for the channel $\mathrm{pH}$ sensing are somewhat involved in the lanthanum binding.

$\mathrm{La}^{3+}$ Block Is a Competitive Block. The block of OmpF channel by $\mathrm{La}^{3+}$ ions may be described by a variety of different mechanisms. In the most simple scenario, $\mathrm{La}^{3+}$ ions could just screen the channel negative residues avoiding the accumulation of $\mathrm{K}^{+}$ions near the pore wall and yielding a reduction of channel current. ${ }^{29,32,33}$ However, this possibility is not easy to reconcile with the fact that the lanthanum blocking depends on the sign of the applied voltage and the side of blocker addition (see Figure 1). A more complex mechanism, including only certain key channel residues and a particular conformation, more easily accessible under one polarity, may be behind the blocking by $\mathrm{La}^{3+}$ ions.

In enzyme kinetics, a simple test to investigate the nature of the block is to plot 1 /velocity vs $1 /[$ substrate $] .{ }^{23}$ This formalism can be adapted to the present study considering that current (charges per second) for an ion channel is analogous to velocity (products per seconds) for an enzyme, and concentration of permeant ions for ion channels is analogous to concentration of substrate for an enzyme. ${ }^{34,35}$ Figure $2 \mathrm{~A}$ shows the theoretical plots for competitive and noncompetitive blocks. For a competitive block the results with 
and without blocker intersect on the $y$-axis, indicating that virtual infinite concentration of substrate $\left(\mathrm{K}^{+}\right)$fully relieves the effect of blocker $\left(\mathrm{La}^{3+}\right)$. However, for a noncompetitive block the results with and without blocker intersect on the $x$-axis meaning that the block by a noncompetitive blocker cannot be overcome even at infinite $\mathrm{K}^{+}$concentration. The experimental results are presented in Figure 2B.

Control experiments with no blocker (pink circles) together with single channel currents in the presence of $2 \mathrm{mM}$ and 5 $\mathrm{mM} \mathrm{LaCl}{ }_{3}$ (yellow triangles and blue diamonds, respectively) show that $\mathrm{La}^{3+}$-induced current reduction is consistent with a competitive block. This means that $\mathrm{La}^{3+}$ and $\mathrm{K}^{+}$try to occupy the same binding site and interact either directly or indirectly via an allosteric mechanism. ${ }^{29}$

These findings have interesting implications. Both the $\mathrm{H}^{+}$ and the $\mathrm{La}^{3+}$ block seem to be regulated by similar mechanisms, a competitive binding with salt cations. The coincidence of mechanisms acting upon the same channel residues would be the reason protons are able to inhibit the $\mathrm{La}^{3+}$ block, but further evidence is needed to support this conjecture.

$\mathrm{La}^{3+}$ Block Can Be Described by a Modified Woodhull Model. Figure 3 shows that $\mathrm{La}^{3+}$ ions block OmpF channels in

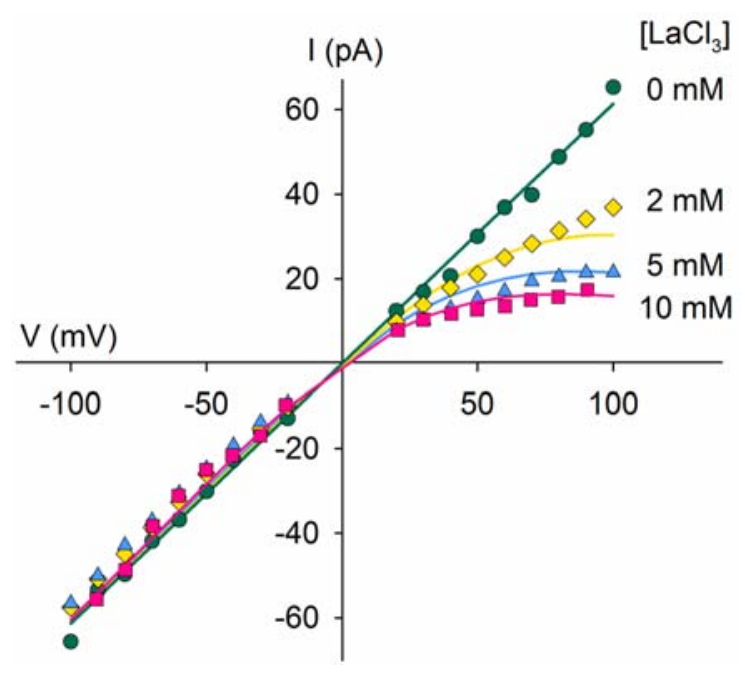

Figure 3. Unitary current amplitude of OmpF channel is asymmetrically affected by $\mathrm{LaCl}_{3}$. The single channel current versus the applied membrane potential was recorded with $100 \mathrm{mM} \mathrm{K}^{+}$ions at both sides of the channel and before and after the addition of aliquots of $\mathrm{LaCl}_{3}$ at the same side of protein addition. The experimental data were simultaneously fitted to a modified Woodhull model (eq 4). The best fit was obtained using the parameters $\delta=0.30, k_{\mathrm{K}}{ }^{+}=150 \mathrm{mM}, k_{\mathrm{La}}{ }^{3+}=$ $7 \mathrm{mM}$, and $n=0.55$.

a voltage- and $\left[\mathrm{La}^{3+}\right]$-dependent manner. To analyze how these two factors determine the channel block we have incorporated the competitive interaction between $\mathrm{K}^{+}$and $\mathrm{La}^{3+}$ into the Woodhull model ${ }^{24}$ by using equations from enzyme kinetics (see Materials and Methods).

Figure 3 shows the simultaneous fit of the Woodhull model to the measured current-voltage curves with $0,2,5$, and 10 $\mathrm{mM} \mathrm{La}{ }^{3+}$ concentrations. The best fits are obtained for $\delta=$ $0.30, k_{\mathrm{K}}^{+}=150 \mathrm{mM},{k_{\mathrm{La}}}^{3+}=7 \mathrm{mM}$, and $n=0.55 . \mathrm{k}_{\mathrm{K}}^{+}$and $\mathrm{k}_{\mathrm{La}}{ }^{3+}$ give an indication about the affinity between the blocker and the binding site of the channel, so that the values obtained seem reasonable having in mind the range of concentrations that induce channel blocking. The fact that the Hill coefficient is less than $1(n=0.55)$ suggests negative cooperativity (the presence of the first molecule makes it more difficult for the second molecule to bind), which is rather consistent with the competitive binding described in the previous sections. ${ }^{31}$

The electrical distance $\delta$ is the fraction of the membrane voltage drop at the binding site. The value obtained, $\delta=0.30$, indicates that the voltage drop at the binding site is $\sim 30 \%$ of the applied voltage. This result is remarkable because it points to an asymmetry of the blocking, and may explain why only the addition of blocker at the cis side causes current reduction.

Although suggestive, this analysis of the voltage dependence of $\mathrm{La}^{3+}$ block is not conclusive. All available theoretical studies ( $\mathrm{MD}$ and BD simulations, PNP equations, electrostatic calculations) indicate that the voltage drop in $\mathrm{OmpF}$ is not linear at all. ${ }^{13,36}$ In fact, these models show that there is little voltage drop in the channel mouths and the main drop occurs in the narrow constriction located at about half of the channel total length. ${ }^{37}$ With this taken into account, there may not be a direct link between this $\sim 30 \%$ fraction of the applied voltage and a putative location of a binding site at the channel vestibules, but the blocking site could be located as well around the central constriction. Other techniques are required to obtain information about the residues involved in the $\mathrm{La}^{3+}$ competitive blocking.

Looking for a Binding Site: Is the Channel Narrow Constriction the Key for the $\mathrm{La}^{3+}$ Blocking? The OmpF channel has an hourglass shape with a narrow constriction located about half of the channel total length. Figure 4 shows in

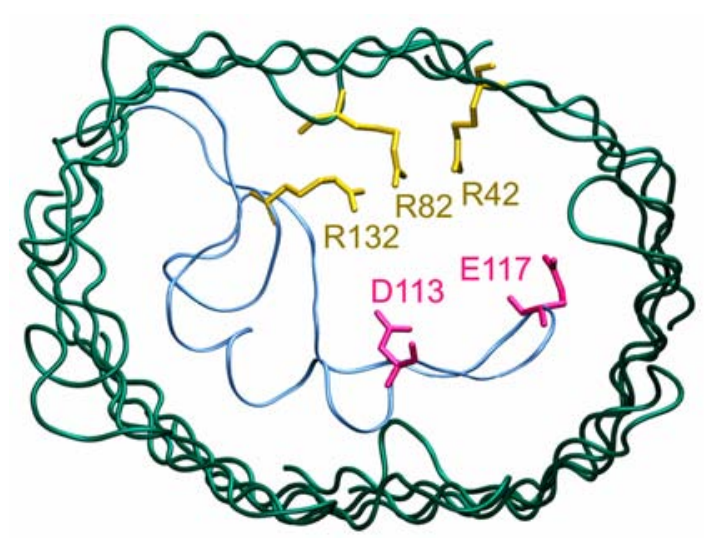

Figure 4. Cross section representation of an OmpF monomer obtained from the crystal structure (PDB code: 2OMF). Two acidic residues (aspartic D113 and glutamic E117 acids, pink) from the loop L3 (blue) are in front of three basic arginines (R42, R82, and R132, yellow), determining the electrostatic properties of the constriction halfway along the channel axis.

detail the key ionizable residues of this pore eyelet. The acidic residues aspartate D113 and glutamate E117 have been reported to be a binding site for monovalent ${ }^{17,38-41}$ and divalent cations. ${ }^{42}$ In particular, site-directed mutagenesis showed that both D113 and E117 play a role in the $\mathrm{pH}$ sensor of the channel. ${ }^{31}$ Having this in mind, this region seems the ideal candidate to host a binding site for $\mathrm{La}^{3+}$ cations. To investigate this possibility, we performed current measurements using selected $\mathrm{OmpF}$ mutants. We first measured the single channel current of the D113R/E117R OmpF mutant, which has the two acidic residues of the constriction (D113, E117) replaced by two positive arginines. 
Figure 5 clearly shows that despite the addition of blocker the channel conductance of the mutant D113R/E117R remains

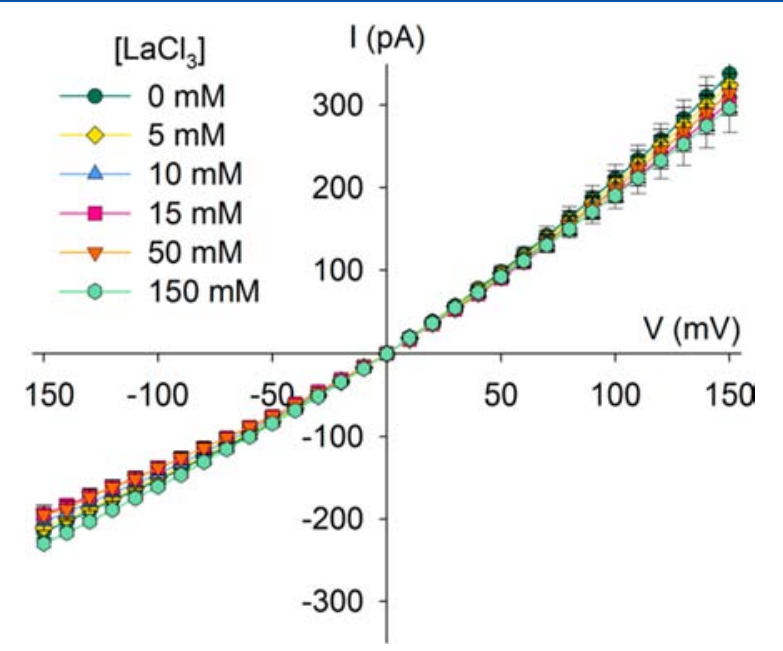

Figure 5. $\mathrm{La}^{3+}$ ions do not induce any current inhibition in the OmpF D113R/E117R mutant. The unitary current was measured before and after the addition of different quantities of blocker in a solution of $1 \mathrm{M}$ $\mathrm{KCl}$ at $\mathrm{pH}$ 6. The use of higher $\mathrm{KCl}$ concentration (experiments with WT OmpF were performed in $\mathrm{KCl} 0.1 \mathrm{M}$ ) was necessary to avoid noise and considerable experimental errors due to the low conductance of mutant D113R/E117R.

unaltered. Indeed, the concentration of $\mathrm{La}^{3+}$ ions used was increased up to $150 \mathrm{mM}$ to ensure that the blocking did not take place. The absence of blocking effects points to the crucial role of the constriction zone in this phenomenon. However, this does not necessarily mean that $\mathrm{La}^{3+}$ ions do interact simultaneously and exclusively with D113 and E117. The actual mechanism may also involve other residues near or in the constriction that are affected by such a drastic replacement of residues yielding five positive charges in this narrow region.

To assess to what extent $\mathrm{La}^{3+}$ block requires the presence of these two acidic residues we examined the effect of the blocker in three mutants in which only one of the negative residues has been changed, D113 or E117 (The $I-V$ curves for these measurements are shown in Figure S2, Supporting Information). We measured the current rectification, which is defined as the current without blocker divided by the current with blocker. First, we chose a mutant in which D113 has been replaced by a neutral cysteine (D113C). As Figure 6 shows (blue triangles), the addition of blocker at $15 \mathrm{mM}$ induced an important current rectification $\left(I_{0} / I=1.61 \pm 0.35\right)$ which exceeds that of OmpF-WT $\left(I_{0} / I=1.39 \pm 0.00\right)$ (green circles). Similar results were obtained when the glutamic acid E117 residue was replaced by a neutral cysteine. As shown in Figure 6 (yellow diamonds), upon addition of $15 \mathrm{mM} \mathrm{LaCl}_{3}, \mathrm{E} 117 \mathrm{C}$ yields current rectification comparable to D113C $\left(I_{0} / I=1.66 \pm\right.$ 0.19), which is significantly higher than in OmpF-WT.

The trend changed when we measured a mutant in which the aspartic acid D113 is replaced by a positive arginine (OmpFD113R, pink squares in Figure 6). In this case, the block is still present, but the effect of the blocker is smaller than in the wildtype protein. Thus, the addition of $15 \mathrm{mM} \mathrm{LaCl}{ }_{3}$ reduces the channel current for positive potentials and yields current rectification $\left(I_{0} / I=1.30 \pm 0.13\right)$. Interestingly, the current rectification of OmpF-D113R was intermediate between those of OmpF-WT and the D113R/E117R mutant.

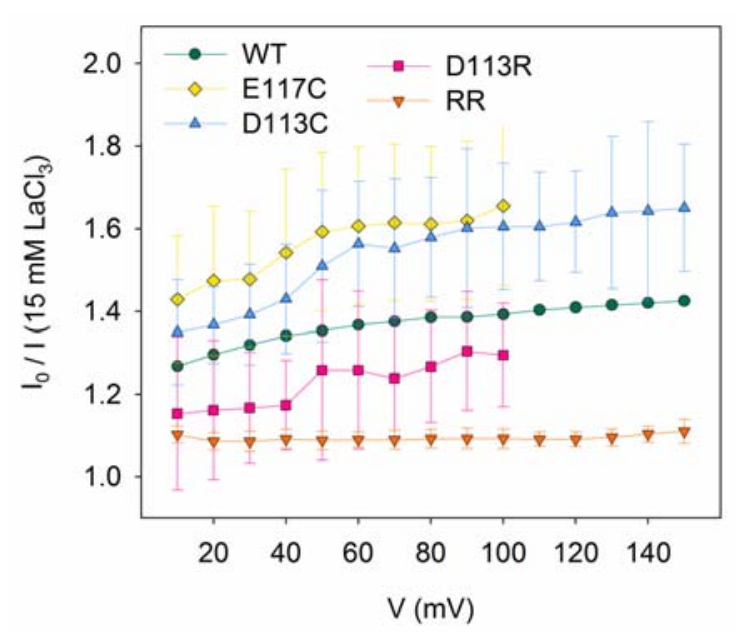

Figure 6. Current rectification induced by $\mathrm{La}^{3+}$ varies considerably with the OmpF mutant used in the experiment. The fraction is defined here as the current without blocker divided by the current with blocker. The measurements were performed in a $1 \mathrm{M} \mathrm{KCl}$ solution before and after the addition of $15 \mathrm{mM} \mathrm{La}^{3+}$ ions at the side of protein addition (cis).

A quantitative interpretation of measured data goes beyond the scope of the present study. Mutagenesis involves simultaneous changes of so many physical quantities (net charge, spatial distribution of residues, possibility of binding, and available volume for permeating ions) that it is extremely complicated to figure out how each mutation affects the overall performance of the channel. However, the qualitative message of the results in Figure 6 is clear: the acidic residues of the constriction critically regulate the $\mathrm{La}^{3+}$-induced blocking of the OmpF channel. By means of selected mutations of one or two key residues located in the selectivity filter, the $\mathrm{La}^{3+}$-induced blocking can be increased, decreased, or even removed.

Structural Features of Channel Blocking. In previous sections we have shown that a plausible mechanism for the channel partial block would be a competitive interaction involving both $\mathrm{La}^{3+}$ and $\mathrm{K}^{+}$taking place in the channel central constriction. OmpF, like other general diffusion porins, has clearly separated clusters of charge in the narrowest part of the pore. ${ }^{43,44}$ As shown in Figure 4 the two acidic residues D113 and E117 directly face a cluster of three positive arginines (R42, R82, R132) creating a high transverse electric field $(E \sim 1 \mathrm{~V} /$ $\mathrm{nm}) .{ }^{37}$ According to $\mathrm{MD}$ simulations, ${ }^{13}$ recently confirmed by $\mathrm{X}$-ray diffraction data, ${ }^{45}$ this electric field gives rise to a highly conductive permeation mechanism in which cations and anions follow well-separated pathways that extend over the height of the $\beta$-barrel. This means that anions cross the eyelet close to the cluster of arginines whereas cations permeate near the negative acids D113 and E117. We can reasonably think that tiny amounts of blocker could yield huge effects, because they obstruct this peculiar and efficient transport mechanism. ${ }^{13,31}$ Once $\mathrm{La}^{3+}$ cations are bound to these acids, the transverse electric field is weakened so that the separation of trajectories is probably abolished yielding in any case a strong reduction of conductance.

The overall picture has now become somewhat clearer, but a lateral view of the channel showing in detail the location of the key residues D113 and E117 (see Figure 7) introduces new questions. The presumed binding for $\mathrm{La}^{3+}$ cation site is located in a symmetrical position, halfway along the channel axis, which 


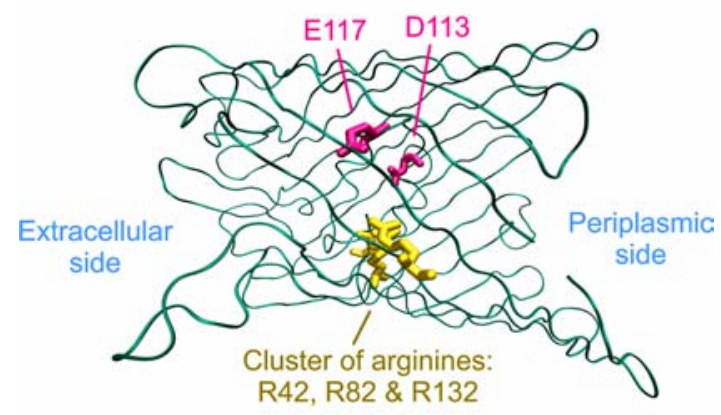

Figure 7. Lateral representation of the $\mathrm{OmpF}$ channel obtained from the crystal structure (PDB code: 2OMF). The two acidic residues (D113 and E117) and three basic residues (R42, R82, and R132) of the constriction are highlighted.

clashes both with the asymmetry found in the side of $\mathrm{La}^{3+}$ addition (Figure 1) and with the outcome of the Woodhull model showing that the voltage drop at the binding site is $\sim 30 \%$ of the applied voltage (Figure 3 ).

Taking into account all the available data, we hypothesize that the asymmetry found in the $\mathrm{La}^{3+}$ ability to block the channel could be originated in the fact that the strong electric field appearing in the central constriction is not perpendicular to the channel axis, but it is considerably $\left(\sim 30^{\circ}\right)$ tilted laterally. ${ }^{46}$ Indeed, this tilt causes that the separate pathways for cations and anions extend in a screw-like fashion over the channel, a distinctive trend of some bacterial porins and, in particular, of OmpF. ${ }^{13}$ In practice, this means that the routes of $\mathrm{La}^{3+}$ ions to reach the binding site when accessing from the cis side or from the trans side could be significantly asymmetric. In one direction, the axial component of the electric field could assist the blocker to permeate through the channel and reach the site, whereas in the opposite direction, the $\mathrm{La}^{3+}$ cation could find serious difficulties to overpass the central constriction due to the unfavorable axial electric field. This would tentatively explain why the voltage drop at the binding site is a low fraction $(\sim 30 \%)$ of the applied voltage and why the site is only accessible from the cis side. This idea is illustrated in the cartoon depicted in Figure 8.

To test this conjecture, we analyzed the $\mathrm{La}^{3+}$ fluxes through the channel using inductively coupled plasma mass spectrom-

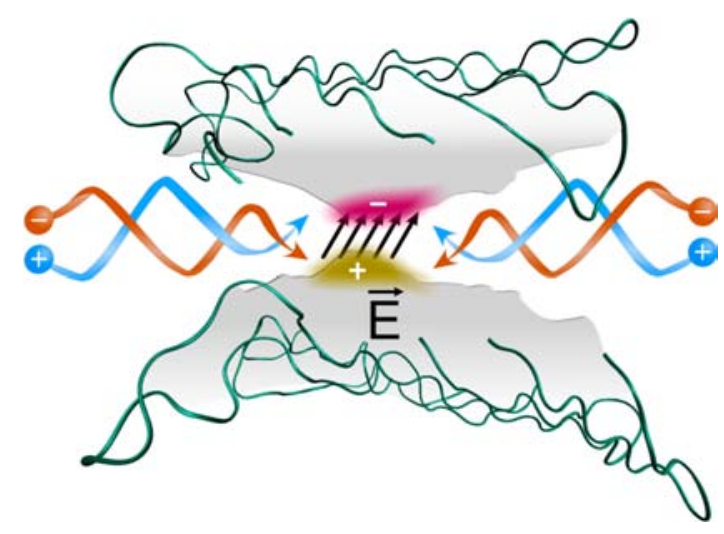

Figure 8. Cartoon illustrating a tentative explanation for the asymmetry of $\mathrm{La}^{3+}$ binding in OmpF. The existence of a favored flowing direction of $\mathrm{La}^{3+}$ ions arises from a $30^{\circ}$-tilted transversal electric field located at the pore eyelet. etry (ICP-MS). ICP-MS is a type of mass spectrometry which is capable of detecting metals and several nonmetals at concentrations as low as one part per trillion. ${ }^{47}$ The experimental protocol was as follows: we added $\mathrm{LaCl}_{3}$ to the cis side and applied a positive $(+100 \mathrm{mV})$ potential for several minutes; then, we took samples of the solution in the trans side to measure the amount of $\mathrm{La}^{3+}$ that passed through the channel during the experiment. Then, we proceeded the other way around. We added $\mathrm{LaCl}_{3}$ to the trans side, applied a negative $(-100 \mathrm{mV})$ potential for several minutes, and took samples of the solution in the cis side. Several experiments were performed with different experimental times to ensure that the results are not biased by the experimental conditions. Finally, we calculated the permeation rate of $\mathrm{La}^{3+}$ through the channel by dividing the quantity of $\mathrm{La}^{3+}$ found in each sample by the recording time of the corresponding experiment. The results are summarized in Figure 9.

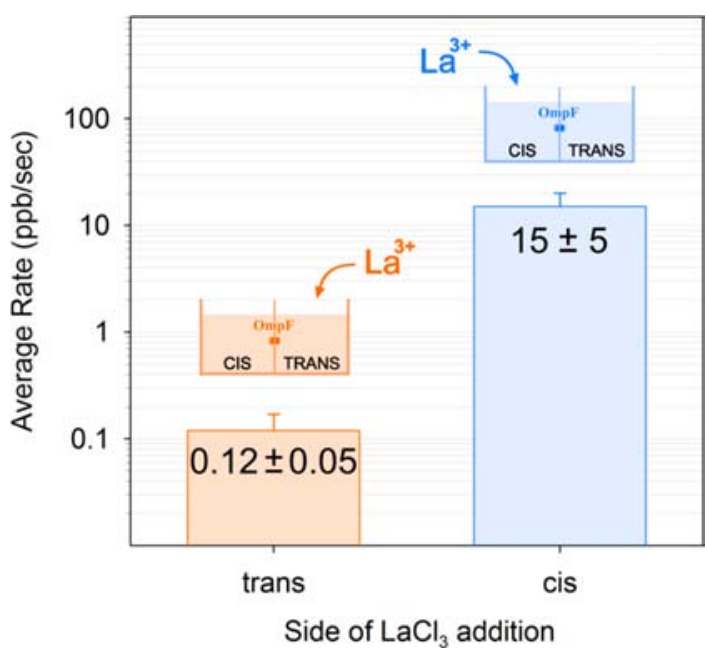

Figure 9. Average permeation rate of $\mathrm{La}^{3+}$ cations through the channel measured using inductively coupled plasma mass spectrometry (ICPMS). The values obtained are significantly different for the two flowing directions. Measured average rates of $\sim 10 \mathrm{ppb} / \mathrm{s}$ are hardly compatible with the magnitude of the electric current and suggest a significant transport of neutral salt through the channel once the pore selectivity is neutralized by permeating $\mathrm{La}^{3+}$.

The experiments show that there is a favorable flowing direction of $\mathrm{La}^{3+}$ cations. When $\mathrm{LaCl}_{3}$ is added to the cis chamber, $\mathrm{La}^{3+}$ cations are able to permeate through the channel and effectively block the current carried by the supporting electrolyte $\mathrm{KCl}$. This suggests that the $\mathrm{La}^{3+}$ cation enters the channel driven by the applied voltage, binds to the site helped by the local electric field, disturbs the overall permeation mechanism, and then leaves the site when the next $\mathrm{La}^{3+}$ cation approaches. The situation is quite different when $\mathrm{LaCl}_{3}$ is added to the trans chamber, as the permeation rate of $\mathrm{La}^{3+}$ through the channel is lower by a factor of 100 , and no effective block of the current is observed. This could mean that in this case the applied voltage can help $\mathrm{La}^{3+}$ cations to surmount the now unfavorable local electric field, but this occurs so rarely that the channel permeation mechanism remains unaltered and so does the recorded current.

\section{CONCLUSIONS}

In this paper, we combine different techniques to describe the asymmetrical blockade of OmpF channel by $\mathrm{LaCl}_{3}$. We show 
that increasing concentration of the substrate $(\mathrm{KCl})$ fully relieves the lanthanum block. This suggests that the mechanism responsible for the blocking could be a competitive interaction involving both $\mathrm{La}^{3+}$ and $\mathrm{K}^{+}$. Site-directed mutagenesis indicates that the residues located in the central constriction crucially regulate the $\mathrm{La}^{3+}$-induced blocking of the OmpF channel. By way of selected mutations of one or two key residues located in this region, the $\mathrm{La}^{3+}$-induced blocking can be tuned almost at will (it can be increased, decreased, or even removed). We also show that the particular features of the charge distribution in the narrow constriction are behind the asymmetry found in the $\mathrm{La}^{3+}$ ability to block the channel. A binding site located in a central position generates a functional asymmetry possibly due to the existence of a tilted transversal electric field yielding asymmetric access routes to the site.

\section{ASSOCIATED CONTENT}

\section{(5) Supporting Information}

$I-V$ curves showing the asymmetric effect of $\mathrm{LaCl}_{3}$ and an additional trivalent cation, spermidine (Figure $\mathrm{S} 1$ ). I-V curves for the WT OmpF and mutants E117C, D113C, D113R, and $\mathrm{D} 113 \mathrm{R} / \mathrm{E} 117 \mathrm{R}$ in $1 \mathrm{M} \mathrm{KCl}$ solution at $\mathrm{pH} 6$ before and after the addition of $15 \mathrm{mM} \mathrm{LaCl}_{3}$ (Figure S2). This material is available free of charge via the Internet at http://pubs.acs.org.

\section{AUTHOR INFORMATION}

\section{Corresponding Author}

*Tel.: (+34) 964728044. Fax: (+34) 964729218. E-mail: alcaraza@uji.es.

\section{Notes}

The authors declare no competing financial interest.

\section{ACKNOWLEDGMENTS}

This work was supported by grants from the Ministry of Science and Innovation of Spain (MICINN, FIS2010-19810), Fundació Caixa Castelló-Bancaixa (P1-1B2012-03), and Generalitat Valenciana (Prometeu/2012/069).

\section{REFERENCES}

(1) Aidley, D. J.; Stanfield, P. R. In Ion Channels: Molecules in Action; Cambridge University Press: New York, 1996.

(2) Hille, B. In Ion Channels of Excitable Membranes; Sinauer Associates Inc: Sunderland, MA, 2001.

(3) Nikaido, H. Molecular Basis of Bacterial Outer Membrane Permeability Revisited. Microbiol. Mol. Biol. Rev. 2003, 67, 593-656.

(4) Tatulian, S. A.; Sorensen, T. S. In Surface Chemistry and Electrochemistry of Membranes; Marcel Dekker: New York, 1999; pp 871.

(5) Aguilella, V. M.; Queralt-Martin, M.; Aguilella-Arzo, M.; Alcaraz, A. Insights on the Permeability of Wide Protein Channels: Measurement and Interpretation of Ion Selectivity. Integr. Biol. 2011, 3, 159-172.

(6) Verdia-Baguena, C.; Queralt-Martin, M.; Aguilella, V. M.; Alcaraz, A. Protein Ion Channels as Molecular Ratchets. Switchable Current Modulation in Outer Membrane Protein F Porin Induced by Millimolar La ${ }^{3+}$ Ions. J. Phys. Chem. C 2012, 116, 6537-6542.

(7) Gurnev, P. A.; Bezrukov, S. M. Inversion of Membrane Surface Charge by Trivalent Cations Probed with a Cation-Selective Channel. Langmuir 2012, 28, 15824-15830.

(8) Thompson, R; Zhou, N.; MacVicar, B. Ischemia Opens Neuronal Gap Junction Hemichannels RID A-3029-2012. Science 2006, 312, 924-927.

(9) Gramowski, A.; Jügelt, K.; Schröder, O. H.; Weiss, D. G.; Mitzner, S. Acute Functional Neurotoxicity of Lanthanum(III) in Primary Cortical Networks. Toxicol. Sci. 2011, 120, 173-183.
(10) Lachaud, C.; Da Silva, D.; Cotelle, V.; Thuleau, P.; Xiong, T. C.; Jauneau, A.; Briere, C.; Graziana, A.; Bellec, Y.; Faure, J.; Ranjeva, R.; Mazars, C. Nuclear Calcium Controls the Apoptotic-Like Cell Death Induced by D-Erythro-Sphinganine in Tobacco Cells. Cell Calcium 2010, 47, 92-100.

(11) Wager, B.; Baslé, A.; Delcour, A. H. Disulfide Bond Tethering of Extracellular Loops does Not Affect the Closure of OmpF Porin at Acidic pH. Proteins 2010, 78, 2886-2894.

(12) Hui, K.; Lipkind, G.; Fozzard, H. A; French, R. J. Electrostatic and Steric Contributions to Block of the Skeletal Muscle Sodium Channel by Mu-Conotoxin. J. Gen. Physiol. 2002, 119, 45-54.

(13) Im, W.; Roux, B. Ion Permeation and Selectivity of OmpF Porin: A Theoretical Study Based on Molecular Dynamics, Brownian Dynamics, and Continuum Electrodiffusion Theory. J. Mol. Biol. 2002, 322, 851-869.

(14) Nestorovich, E. M.; Danelon, C.; Winterhalter, M.; Bezrukov, S. M. Designed to Penetrate: Time-Resolved Interaction of Single Antibiotic Molecules with Bacterial Pores. Proc. Natl. Acad. Sci. U. S. A. 2002, 99, 9789-9794.

(15) Singh, P. R.; Ceccarelli, M.; Lovelle, M.; Winterhalter, M.; Mahendran, K. R. Antibiotic Permeation Across the OmpF Channel: Modulation of the Affinity Site in the Presence of Magnesium. J. Phys. Chem. B 2012, 116, 4433-4438.

(16) Siwy, Z. S.; Howorka, S. Engineered Voltage-Responsive Nanopores. Chem. Soc. Rev. 2010, 39, 1115-1132.

(17) Nestorovich, E. M.; Rostovtseva, T. K.; Bezrukov, S. M. Residue Ionization and Ion Transport through OmpF Channels. Biophys. J. 2003, 85, 3718-3729.

(18) Alcaraz, A.; Nestorovich, E. M.; Aguilella-Arzo, M.; Aguilella, V. M.; Bezrukov, S. M. Salting Out the Ionic Selectivity of a Wide Channel: The Asymmetry of OmpF. Biophys. J. 2004, 87, 943-957.

(19) Alcaraz, A.; Nestorovich, E. M.; Lidon Lopez, M.; GarciaGimenez, E.; Bezrukov, S. M.; Aguilella, V. M. Diffusion, Exclusion, and Specific Binding in a Large Channel: A Study of OmpF Selectivity Inversion. Biophys. J. 2009, 96, 56-66.

(20) Vrouenraets, M.; Wierenga, J.; Meijberg, W.; Miedema, H. Chemical Modification of the Bacterial Porin OmpF: Gain of Selectivity by Volume Reduction. Biophys. J. 2006, 90, 1202-1211.

(21) Montal, M.; Mueller, P. Formation of Bimolecular Membranes from Lipid Monolayers and a Study of their Electrical Properties. Proc. Natl. Acad. Sci. U. S. A. 1972, 69, 3561-3566.

(22) Hill, A. V. The Possible Effects of the Aggregation of the Molecules of hæmoglobin on its Dissociation Curves. J. Physiol. 1910, 40 , iv-vii.

(23) Stryer, L. In Biochemistry; Freeman and Company: San Francisco, CA, 1981.

(24) Woodhull, A. M. Ionic Blockage of Sodium Channels in Nerve. J. Gen. Physiol. 1973, 61, 687-708.

(25) Blatz, A. L.; Magleby, K. L. Ion Conductance and Selectivity of Single Calcium-Activated Potassium Channels in Cultured Rat Muscle. J. Gen. Physiol. 1984, 84, 1-23.

(26) Yellen, G. Ionic Permeation and Blockade in Ca-2+-Activated K + Channels of Bovine Chromaffin Cells. J. Gen. Physiol. 1984, 84, $157-186$.

(27) Vergara, C.; Moczydlowski, E.; Latorre, R. Conduction, Blockade and Gating in a $\mathrm{Ca}^{2+}$-Activated $\mathrm{K}^{+}$Channel Incorporated into Planar Lipid Bilayers. Biophys. J. 1984, 45, 73-76.

(28) Villarroel, A.; Alvarez, O.; Oberhauser, A.; Latorre, R. Probing a $\mathrm{Ca}^{2+}$-Activated $\mathrm{K}^{+}$Channel with Quaternary Ammonium-Ions. Pfluegers Arch. 1988, 413, 118-126.

(29) Brelidze, T. I.; Magleby, K. L. Protons Block BK Channels by Competitive Inhibition with $\mathrm{K}^{+}$and Contribute to the Limits of Unitary Currents at High Voltages. J. Gen. Physiol. 2004, 123, 305319.

(30) Benz, R.; Schmid, A.; Hancock, R. E. W. Ion Selectivity of Gram-Negative Bacterial Porins. J. Bacteriol. 1985, 162, 722-727.

(31) Alcaraz, A.; Queralt-Martín, M.; García-Giménez, E.; Aguilella, V. M. Increased Salt Concentration Promotes Competitive Block of 
OmpF Channel by Protons. Biochim. Biophys. Acta, Biomembr. 2012, 1818, 2777-2782.

(32) Morrill, J. A.; MacKinnon, R. Isolation of a Single CarboxylCarboxylate Proton Binding Site in the Pore of a Cyclic NucleotideGated Channel. J. Gen. Physiol. 1999, 114, 71-83.

(33) Klockner, U.; Isenberg, G. Calcium-Channel Current of Vascular Smooth-Muscle Cells - Extracellular Protons Modulate Gating and Single-Channel Conductance. J. Gen. Physiol. 1994, 103, 665-678.

(34) Hille, B. Ionic Selectivity, Saturation, and Block in Sodium Channels. A Four-Barrier Model. J. Gen. Physiol. 1975, 66, 535-560.

(35) Eisenberg, R. S. Channels as Enzymes. J. Membr. Biol. 1990, 115, $1-12$.

(36) Aguilella-Arzo, M.; Garcia-Celma, J. J.; Cervera, J.; Alcaraz, A.; Aguilella, V. M. Electrostatic Properties and Macroscopic Electrodiffusion in OmpF Porin and Mutants. Bioelectrochemistry 2007, 70, 320-327.

(37) Aguilella-Arzo, M.; Andrio, A.; Aguilella, V. M.; Alcaraz, A. Dielectric Saturation of Water in a Membrane Protein Channel. Phys. Chem. Chem. Phys. 2009, 11, 358-365.

(38) Suenaga, A.; Komeiji, Y.; Uebayasi, M.; Meguro, T.; Saito, M.; Yamato, I. Computational Observation of an Ion Permeation through a Channel Protein. Biosci. Rep. 1998, 18, 39-48.

(39) Danelon, C.; Suenaga, A.; Winterhalter, M.; Yamato, I. Molecular Origin of the Cation Selectivity in OmpF Porin: Single Channel Conductances Vs. Free Energy Calculation. Biophys. Chem. 2003, 104, 591-603.

(40) Kobayashi, Y.; Nakae, T. The Mechanism of Ion Selectivity of OmpF-Porin Pores of Escherichia Coli. Eur. J. Biochem. 1985, 151, 231-236.

(41) López, M. L.; Aguilella-Arzo, M.; Aguilella, V. M.; Alcaraz, A. Ion Selectivity of a Biological Channel at High Concentration Ratio: Insights on Small Ion Diffusion and Binding. J. Phys. Chem. B 2009, 113, 8745-8751.

(42) Yamashita, E.; Zhalnina, M. V.; Zakharov, S. D.; Sharma, O.; Cramer, W. A. Crystal Structures of the OmpF Porin: Function in a Colicin Translocon. EMBO J. 2008, 27, 2171-2180.

(43) Robertson, K. M.; Tieleman, D. P. Orientation and Interactions of Dipolar Molecules during Transport through OmpF Porin. FEBS Lett. 2002, 528, 53-57.

(44) Schirmer, T. General and Specific Porins from Bacterial Outer Membranes. J. Struct. Biol. 1998, 121, 101-109.

(45) Dhakshnamoorthy, B.; Raychaudhury, S.; Blachowicz, L.; Roux, B. Cation-Selective Pathway of OmpF Porin Revealed by Anomalous X-Ray Diffraction. J. Mol. Biol. 2010, 396, 293-300.

(46) Levadny, V.; Aguilella, V. M.; Aguilella-Arzo, M.; Belaya, M. Interaction of a Polar Molecule with an Ion Channel. Phys. Rev. E: Stat., Nonlinear, Soft Matter Phys. 2004, 70, 041912.

(47) Mermet, J. M. In Inductively Coupled Plasma Spectrometry and its Applications; Hill, S. J., Ed.; Blackwell Publishing Ltd: Oxford, UK, 2007. 


\title{
Coronavirus E protein forms ion channels with functionally and structurally-involved membrane lipids
}

\author{
Carmina Verdiá-Báguena ${ }^{\mathrm{a}, 1}$, Jose L. Nieto-Torres ${ }^{\mathrm{b}, 1}$, Antonio Alcaraz ${ }^{\mathrm{a}}$, Marta L. DeDiego ${ }^{\mathrm{b}}$, \\ Jaume Torres ${ }^{c}$, Vicente M. Aguilella ${ }^{\mathrm{a}, *}$, Luis Enjuanes ${ }^{\mathrm{b}, *}$ \\ a Department of Physics, Laboratory of Molecular Biophysics, Universitat Jaume I, 12071 Castellón, Spain \\ b Department of Molecular and Cell Biology, Centro Nacional de Biotecnología (CNB-CSIC), Campus Universidad Autónoma de Madrid, Darwin 3, 28049 Madrid, Spain \\ c School of Biological Sciences, Division of Structural and Computational Biology, Nanyang Technological University, Singapore 637551, Singapore
}

\section{A R T I C L E I N F O}

\section{Article history:}

Received 11 May 2012

Returned to author for revisions

6 June 2012

Accepted 6 July 2012

Available online 24 July 2012

Keywords:

Coronavirus

SARS

Envelope protein

Ion channel

HCoV-229E

Lipid membranes

\begin{abstract}
A B S T R A C T
Coronavirus ( $\mathrm{CoV}$ ) envelope (E) protein ion channel activity was determined in channels formed in planar lipid bilayers by peptides representing either the transmembrane domain of severe acute respiratory syndrome CoV (SARS-CoV) E protein, or the full-length E protein. Both of them formed a voltage independent ion conductive pore with symmetric ion transport properties. Mutations N15A and $\mathrm{V} 25 \mathrm{~F}$ located in the transmembrane domain prevented the ion conductivity. E protein derived channels showed no cation preference in non-charged lipid membranes, whereas they behaved as pores with mild cation selectivity in negatively-charged lipid membranes. The ion conductance was also controlled by the lipid composition of the membrane. Lipid charge also regulated the selectivity of a HCoV-229E E protein derived peptide. These results suggested that the lipids are functionally involved in $\mathrm{E}$ protein ion channel activity, forming a protein-lipid pore, a novel concept for CoV E protein ion channel entity. (c) 2012 Elsevier Inc. All rights reserved.
\end{abstract}

\section{Introduction}

Coronaviruses $(\mathrm{CoV})$ are vertebrate pathogens that cause common colds, bronchiolitis and acute respiratory distress syndrome that may lead to death in humans, and lethal diseases of high economic importance in animals (Perlman and Netland, 2009). In fact, their relevance increased when the causative agent of the severe acute respiratory syndrome (SARS) was identified as a CoV. SARS-CoV emerged at the end of 2002 in Guangdong province, China, causing an epidemic with 8000 infected people and a death rate close to $10 \%$ (Drosten et al., 2003; Rota et al., 2003). SARS-CoV like viruses have been identified in bat reservoirs all over the world (Chu et al., 2008; Drexler et al., 2010; Muller et al., 2007; Quan et al., 2010), making SARS-CoV reemergence a realistic possibility.

Members of the Coronaviridae family (de Groot et al., 2012) have a plus-strand RNA genome of around $30 \mathrm{~kb}$ in length (Enjuanes et al., 2008). CoV viral genome is packed by the nucleocapsid $(\mathrm{N})$ protein, to form a helicoidal nucleocapsid that is protected by a lipid envelope. Several viral proteins, including

\footnotetext{
* Corresponding authors.

E-mail addresses: aguilell@uji.es (V.M. Aguilella), L.Enjuanes@cnb.csic.es (L. Enjuanes).

${ }^{1}$ Both authors equally contributed to this work.
}

the spike (S), envelope (E), and membrane (M) proteins are embedded within this lipid envelope. In addition, a variable set of proteins is also present within the membrane, depending on the $\mathrm{CoV}$ species. In the case of SARS-CoV, proteins 3a, 6, 7a and 7b have also been identified in the viral membrane (Huang et al., 2006, 2007; Schaecher et al., 2007; Shen et al., 2005).

CoV E protein is a small transmembrane protein of between 76 and 109 amino acids in length (Arbely et al., 2004; Raamsman et al., 2000). E protein amino acid sequence is quite divergent among different CoVs, nevertheless its predicted structure is highly conserved and includes a short N-terminal amino acids stretch, an alpha helical transmembrane domain and a carboxy terminal region (Torres et al., 2007).

E protein is incorporated at a low copy number in the viral envelope (Maeda et al., 2001; Raamsman et al., 2000). Nevertheless, high amounts of $E$ protein are accumulated within cells during viral infection, suggesting an important role of this protein during virus cycle. CoV E protein mainly distributes between ER and Golgi apparatus membranes where it actively participates in virus budding, morphogenesis and trafficking (Corse and Machamer, 2000; Lim and Liu, 2001; Nal et al., 2005; Nguyen and Hogue, 1997; Raamsman et al., 2000; Ruch and Machamer, 2012a). Particularly, SARS-CoV E protein mainly localizes in the endoplasmic reticulum-Golgi intermediate compartment (ERGIC) when expressed alone or during virus infection (Nieto-Torres 
et al., 2011). It has been proposed that SARS-CoV E protein sequesters protein associated with lin seven 1 (PALS1), a member of the tight junctions complex, to the ERGIC, disrupting the epithelia and possibly contributing to the lung damage observed in SARS patients (Teoh et al., 2010). The presence of SARS-CoV E protein at the cell plasma membrane has been previously suggested (Pervushin et al., 2009), however, these results have not been confirmed in recent studies (Nieto-Torres et al., 2011).

CoV E protein self-associates forming an oligomeric structure that delimits an ion conductive pore in planar lipid bilayers and micelles (Pervushin et al., 2009; Torres et al., 2006; Wilson et al., $2006,2004)$. Synthetic CoV E proteins of human coronavirus $229 \mathrm{E}$ (HCoV-229E), mouse hepatitis virus (MHV), SARS-CoV and avian infectious bronchitis virus (IBV), behaved as cation-selective channels when they were reconstituted into planar lipid bilayers. Furthermore, it has been reported that HCoV-229E (genus $\alpha \mathrm{CoV}$ ) E protein was more selective to $\mathrm{K}^{+}$than to $\mathrm{Na}^{+}$, whereas MHV and SARS-CoV (genus $\beta$ CoVs) and IBV (genus $\gamma \mathrm{CoV}$ ) E proteins were more selective to $\mathrm{Na}^{+}$than $\mathrm{K}^{+}$ions (Wilson et al., 2006, 2004). Studies using SARS-CoV E protein derived peptides showed that the transmembrane domain had ion conductive properties (Torres et al., 2007; Wilson et al., 2004), and some crucial residues involved in this activity have been identified (Torres et al., 2007).

Generation of MHV recombinant viruses, in which E protein was interchanged by $\operatorname{CoV}$ genus $\alpha, \beta$ and $\gamma$ E proteins indicated that only $E$ proteins corresponding to genus $\beta$ and $\gamma$ could partially replace the function of MHV E protein (Kuo et al., 2006). It was speculated that the selectivity of the channel could be important for the functional replacement. However, the possible biological relevance of ion selectivity in different CoV E proteins requires additional studies.

Other RNA viruses also encode small transmembrane proteins with ion channel properties. Influenza virus M2, hepatitis $C$ virus p7, human immunodeficiency virus (HIV) vpu, and poliovirus 2B proteins are some examples of a growing list of these virally encoded ion channels called viroporins (de Jong et al., 2006; Ewart et al., 1996; Pinto et al., 1992; Wozniak et al., 2010). It has been described that these proteins are involved in diverse processes such as virus entry, trafficking and maturation, inflammation, and apoptosis (Campanella et al., 2004; Ichinohe et al., 2010; Wozniak et al., 2010).

Deletion of E gene in different CoVs may result in a complete abrogation of virus maturation and release, as shown for transmissible gastroenteritis virus (TGEV) (Ortego et al., 2007, 2002) or in a reduction of virus growth, as described for MHV (Kuo and Masters, 2003) and SARS-CoV (DeDiego et al., 2007). In addition, a SARS-CoV lacking E gene (SARS-CoV- $\Delta \mathrm{E}$ ) was attenuated in three animal models (DeDiego et al., 2007, 2008; Netland et al., 2010). Experimental data comparing SARS-CoV- $\Delta \mathrm{E}$ and the parental virus revealed that $\mathrm{E}$ protein reduced cellular stress and virusinduced apoptosis (DeDiego et al., 2011).

Some reports have revealed the importance of $\mathrm{CoV}$ E protein transmembrane domain in virus production and maturation. When alanine residues were introduced in the MHV E protein transmembrane domain, disrupting the alpha helix structure and repositioning polar residues, virus growth was compromised, suggesting an important function for E protein transmembrane domain in virus biogenesis (Ye and Hogue, 2007). Replacement of IBV E transmembrane domain by a heterologous one that lacked ion conductance activity resulted in a virus that was poorly secreted to the extracellular media (Ruch and Machamer, 2011).

In the present work we have characterized the ion conductive properties of the transmembrane domain of the SARS-CoV E protein, with or without amino acid substitutions, and the fulllength $\mathrm{E}$ protein, aiming to determine the functions affected by SARS-CoV E protein ion channel activity. Residues N15 and V25 were essential for SARS-CoV E protein ion channel activity. In all cases where the bilayer membrane was permeabilized, the channel showed symmetric ion transport properties either for positive or negative applied voltages, and its conductance was not regulated by voltage. Interestingly, when E protein was reconstituted in negatively charged lipid bilayers, the ion channel became slightly more selective to cations than to anions. The transmembrane domain of $\mathrm{HCoV}-229 \mathrm{E}$ E protein was also analyzed as a putative $\mathrm{K}^{+}$selective channel. A very weak selectivity for $\mathrm{K}^{+}$over $\mathrm{Na}^{+}$was observed for this peptide and its small preference for cations was also regulated by the charge of the lipid membranes, as was the case of SARS-CoV E protein. We propose that lipids are an integral component of the CoV E protein derived ion channels, a novel finding for these structures.

\section{Results and discussion}

\section{E protein conductance on neutral planar lipid bilayers}

Previous studies attributed the ion channel activity of SARS-CoV E protein to the transmembrane domain of the protein (Torres et al., 2007; Wilson et al., 2004). In order to identify residues involved in ion channel activity, the spatial distribution of SARS-CoV Urbani strain E protein transmembrane domain amino acids was predicted by helical wheel modeling using Protean (DNASTAR Software, Lasergene) and information from nuclear magnetic resonance (NMR) studies (Pervushin et al., 2009) (Fig. 1). In addition, conserved amino acids located within the $\mathrm{E}$ protein transmembrane domain of different $\mathrm{CoV}$ species were identified by sequence alignment (Fig. S1, supplementary data). Using information from these sources, conserved polar amino acids located at the beginning and the end of the transmembrane domain, and conserved amino acids central to the CoV E protein transmembrane domain, which in many cases were tentatively located towards the lumen of the pore formed by SARS-CoV E protein, were mutated (Table 1 and Fig. 1). A total of nine peptides derived from SARS-CoV E protein were synthesized, one of them $(w t)$ representing the wild type protein transmembrane domain and its flanking polar amino acids, and eight mutant peptides including different residue substitutions. One (M2 to M7), two (M1) or four (M8) amino acids were replaced in each peptide at different positions along the transmembrane domain, or at both the amino- or carboxy-termini of this domain (Table 1 and Fig. 1).

The ion channel activity of these peptides was evaluated by electrophysiological measurements in artificial lipid bilayers. Single channel conductance was estimated from a statistical analysis of the current jump amplitudes, not from the total current measured. This procedure allows a reliable estimate of the most probable value of current change every time a new channel is inserted or disappears. Although several channels are being inserted, the magnitude of the current through a single channel could be discriminated. In order to exclude any peptidelipid or peptide-peptide electrostatic interactions previous to peptide insertion (Sani et al., 2012), measurements were initially made in neutral lipid DPhPC bilayers. Six of the peptides investigated were able to permeabilize the phospholipid membrane. Wt as well as mutant peptides M1, M2, M5, M6 and M7 led to spontaneous current bursts $10-15 \mathrm{~min}$ after the peptide was added to the cis chamber (Fig. 2A). These results indicated that residues E7 and E8 (mutated in M1 peptide), T11 (mutated in M2 peptide), T30 (mutated in M5 peptide), T35 (mutated in M6 peptide) and R38 (mutated in M7 peptide) were not completely essential for the ion channel activity of SARS-CoV E protein derived peptides. M1, M5 and M7 peptides displayed conductance 
A
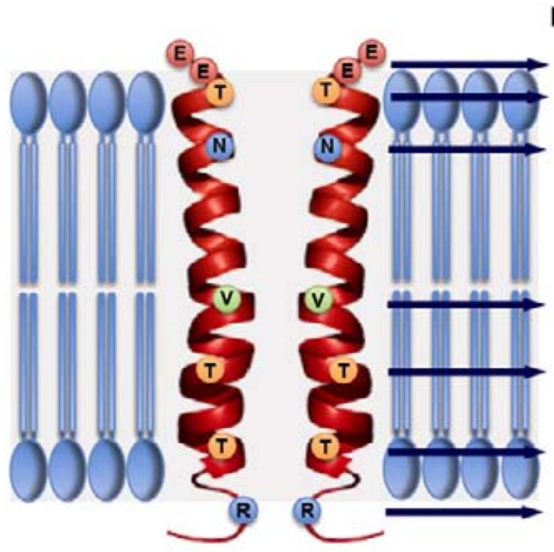

MUTANT MUTATION

M1 E7K E8K

M2 T11A

M3 N15A

M4 V25F

M5 T30A

M6 T35A

M7 R38E

M8 E7K E8K N15A R38E
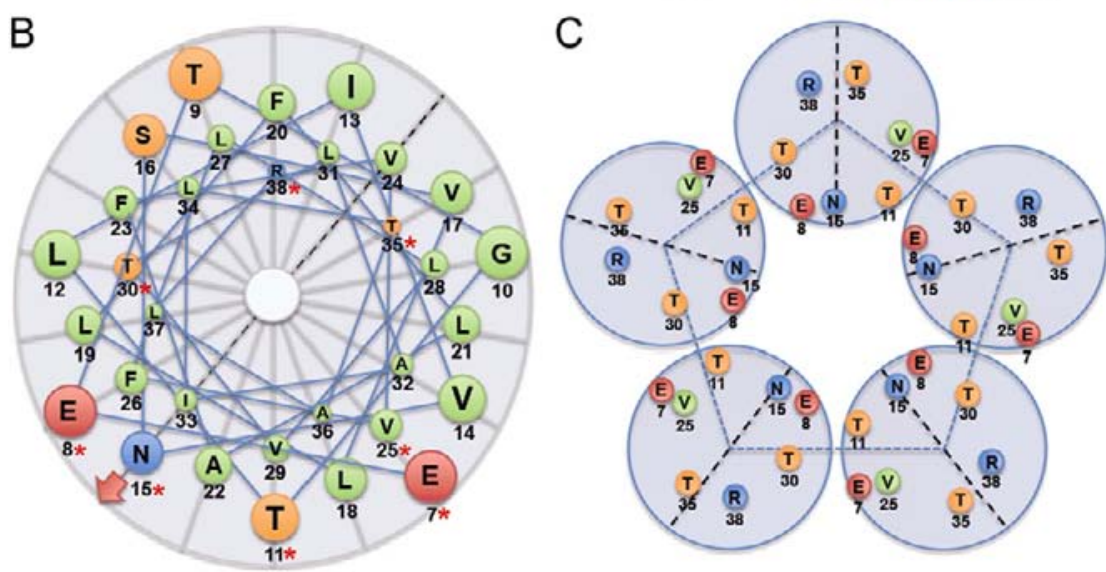

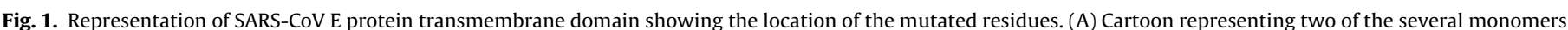

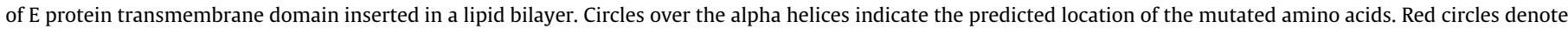

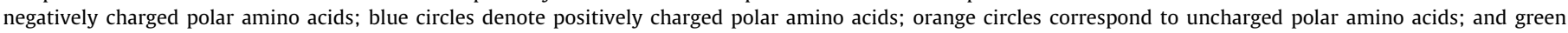

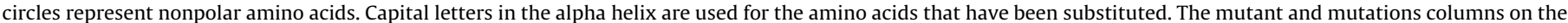

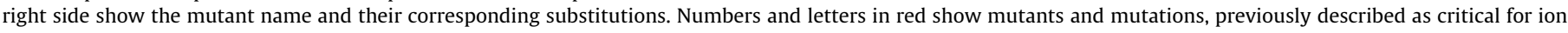

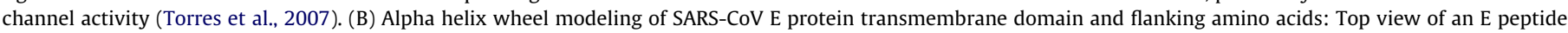

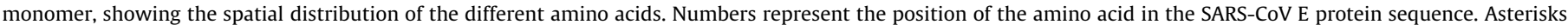

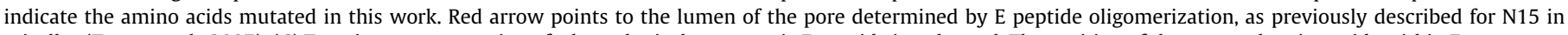

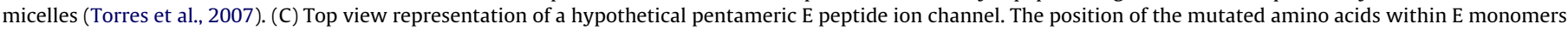
are shown in a plane perpendicular to the pore axis.

Table 1

Sequence of coronavirus $\mathrm{E}$ protein peptides representing the transmembrane domain and closely flanking amino acids.

\begin{tabular}{|c|c|c|c|c|c|c|}
\hline \multirow[t]{2}{*}{ Peptide } & \multicolumn{6}{|c|}{ Sequence } \\
\hline & 10 & 15 & 20 & 25 & 30 & $35^{\mathrm{a}}$ \\
\hline$w t$ & \multicolumn{6}{|c|}{ EETGTLIVNSVLLFLAFVVFLLVTLAILTALR } \\
\hline M1 & \multicolumn{6}{|c|}{${ }^{\mathrm{b}}$ KKTGTLIVNSVLLFLAFVVFLLVTLAILTALR } \\
\hline M2 & \multicolumn{6}{|c|}{ EETGALIVNSVLLFLAFVVFLLVTLAILTALR } \\
\hline M3 & \multicolumn{6}{|c|}{ EETGTLIVASVLLFLAFVVFLLVTLAILTALR } \\
\hline M4 & \multicolumn{6}{|c|}{ EETGTLIVNSVLLFLAFVFFLLVTLAILTALR } \\
\hline M5 & \multicolumn{6}{|c|}{ EETGTLIVNSVLLFLAFVVFLLVALAILTALR } \\
\hline M6 & \multicolumn{6}{|c|}{ EETGTLIVNSVLLFLAFVVFLLVTLAILAALR } \\
\hline M7 & \multicolumn{6}{|c|}{ EETGTLIVNSVLLFLAFVVFLLVTLAILTALE } \\
\hline M8 & \multicolumn{6}{|c|}{ KKTGTLIVASVLLFLAFVVFLLVTLAILTALE } \\
\hline HCoV-229E & \multicolumn{6}{|c|}{ DDHALVVNVLLWCVVLIVILLVCITIIKLIK } \\
\hline
\end{tabular}

a Bar indicates the location of SARS-CoV and $\mathrm{HCoV}-229 \mathrm{E}$ E proteins predicted transmembrane domain.

${ }^{\mathrm{b}}$ Residues in bold represent the mutated amino acids.

values similar to the $w t$ peptide, suggesting that these mutations did not dramatically alter the pore conformation. Interestingly, mutations T11A (present in M2 peptide) and T35A (present in M6 peptide) led to currents of higher intensity than that induced by the $w t$ peptide. In the absence of further structural information, we could speculate that these mutations may lead to a wider pore.

In contrast, three of the mutant peptides studied, M3, M4 and M8, did not permeabilize the bilayer (Fig. 2B). In the case of M3, M4 and M8 peptides, which did not show spontaneous channel activity, a negative potential of increasing magnitude (up to $130 \mathrm{mV}$ ) was applied to check whether their insertion into the lipid membrane could be facilitated. However, no change in channel activity was found for these peptides by increasing voltage differences between chambers (data not shown). In order to ensure that mutants M3, M4 and M8 peptides did not display any ion channel activity, $0.5-1 \mu \mathrm{l}$ of a $300 \mu \mathrm{g} / \mathrm{ml}$ solution of these synthetic peptides were added to the cis chamber and registers were made during $10-15 \mathrm{~min}$. After this time, $0.5-1 \mu \mathrm{l}$ of a $300 \mu \mathrm{g} / \mathrm{ml}$ solution were added successively and the process was repeated at least 15 times in order to check the absence of ion channel activity. No ion conductance was observed (data not shown), strongly suggesting that substitutions N15A (mutated in M3 and M8 peptides) and V25F (mutated in M4 peptide) totally inhibited SARS-CoV E ion channel activity. These data are in agreement with previously reported results using a peptide corresponding to the transmembrane domain of SARS-CoV E 


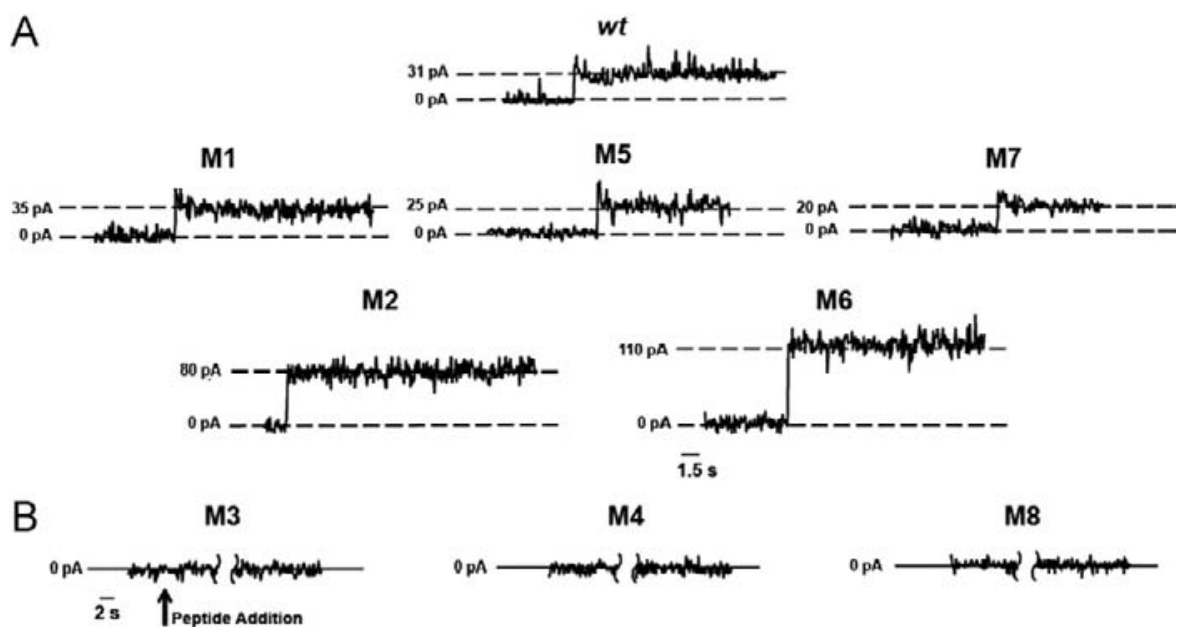

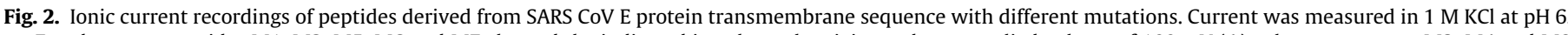

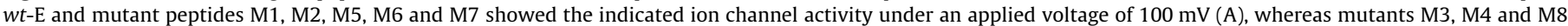
did not permeabilized the membrane (B).
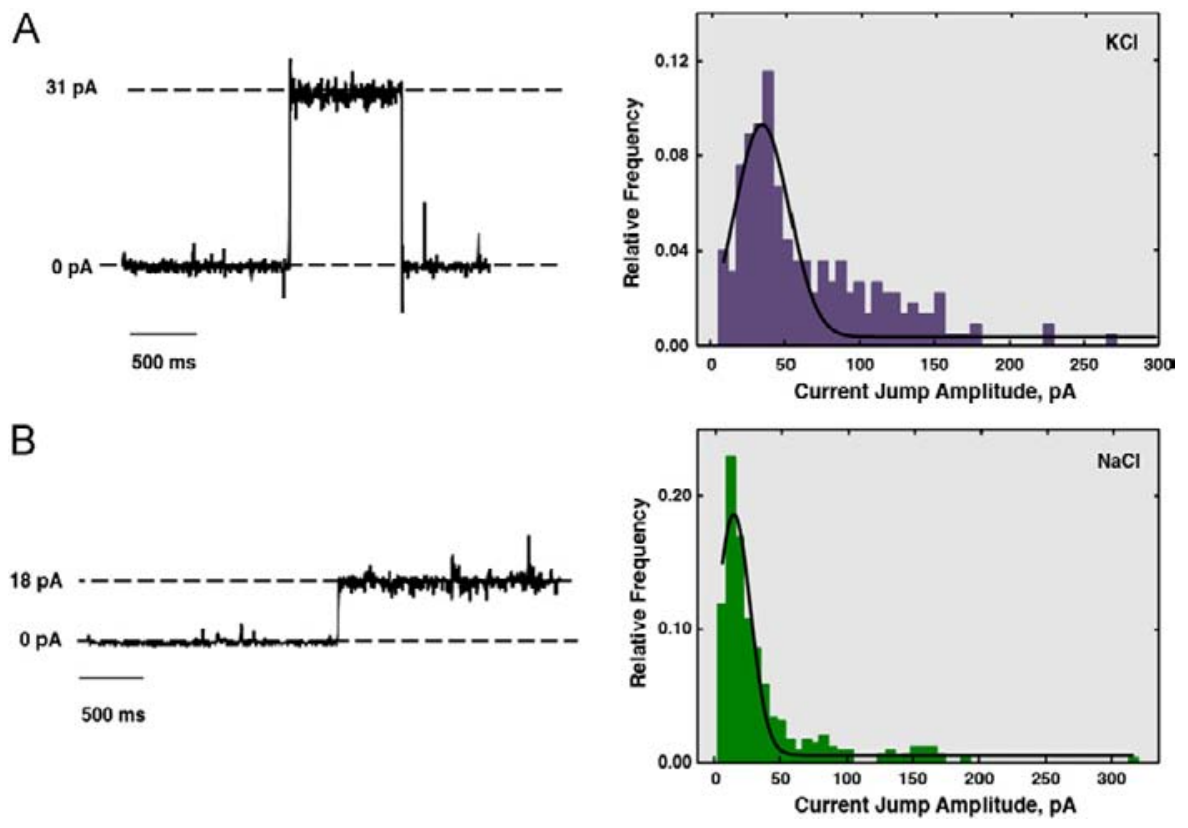

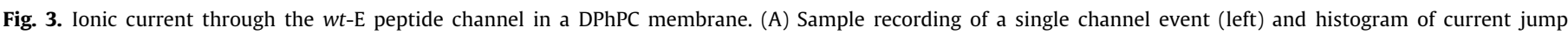

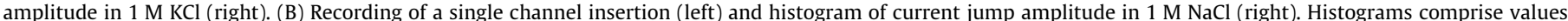
from 300 recording events.

protein flanked by two lysine residues (Torres et al., 2007). Coronavirus $\mathrm{E}$ protein ion channel activity has been related with virus production and secretion (Ye and Hogue, 2007). Modifications by alanine scanning insertion mutagenesis of the E protein transmembrane domain of mouse hepatitis coronavirus, resulted in mutant viruses which exhibited smaller plaque phenotypes, and their production was significantly reduced (between 10 - and 100 -fold). It is interesting to note that mutation of the SARS-CoV E protein amino acid N15 performed in our study, knocking down the ion channel activity, is equivalent to amino acid T16 of infectious bronchitis coronavirus (IBV) (Ruch and Machamer, $2012 b)$. This amino acid is essential for the disruption of the secretory pathway in IBV infected cells but has a limited effect on virus assembly as judged by virus-like particle production, suggesting that secretory pathway disruption and virus assembly are independent activities. In agreement with these results, introduction of amino acid substitutions N15A and V25F within the E protein of a recombinant SARS-CoV led to a slight reduction (lower than five-fold) of virus titers in cultured Vero E6 cells (data not shown). Extrapolation of these results, obtained with the two CoVs, could suggest that ion channel activity of E protein may be required to disrupt the secretory pathway during CoV infection but that it has low impact on virus titers in cells in culture. The introduced changes (single amino acid substitutions) had a lower effect on virus titers as compared with MHV E protein alanine insertion mutants reported in the work by Ye and Hogue (2007), which probably had a higher impact on the structure of E protein and, as consequence, a significant effect on virus production.

To further characterize the ion channel activity of $w t$-E peptide, current traces corresponding to 300 events were measured both in $1 \mathrm{M} \mathrm{KCl}$ and $1 \mathrm{M} \mathrm{NaCl}$ under an applied voltage of $+100 \mathrm{mV}$ (Fig. $3 \mathrm{~A}$ and $\mathrm{B}$, respectively). Histograms of the current jump amplitudes of the recorded traces showed that the most frequent 
events corresponded to single channel conductances of $0.31 \pm 0.12 \mathrm{nS}$ and $0.18 \pm 0.12 \mathrm{nS}$ in $\mathrm{KCl}$ and $\mathrm{NaCl}$, respectively (Fig. $3 \mathrm{~A}$ and $\mathrm{B}$, respectively, right panels) indicating that the peptide derived from SARS-CoV E protein transmembrane domain behaved as an ion channel either in $\mathrm{KCl}$ and $\mathrm{NaCl}$ solutions. These results almost matched the ones obtained using a full-length SARS-CoV E synthetic protein $(0.37 \pm 0.16 \mathrm{nS}$ and $0.19 \pm 0.06 \mathrm{nS}$ for $\mathrm{KCl}$ and $\mathrm{NaCl}$, respectively) (data not shown), further validating the use of the transmembrane domain derived peptides to measure the ion channel activity of SARS-CoV $\mathrm{E}$ protein. The conductance results obtained in $\mathrm{KCl}$ and $\mathrm{NaCl}$ solutions showed no enhanced selectivity of $\mathrm{E}$ protein for $\mathrm{K}^{+}$than for $\mathrm{Na}^{+}$. Indeed, the higher conductance shown for $\mathrm{KCl}(\sim 1.7$ times larger than in $\mathrm{NaCl}$ ) in Fig. $3 \mathrm{~A}$ is due to the intrinsic properties of these electrolytes, as the mobility of $\mathrm{K}^{+}$is 1.66 times higher than the mobility of $\mathrm{Na}^{+}$. Interestingly, a few current jump amplitudes were observed in $1 \mathrm{M} \mathrm{KCl}$ with values multiple of the most frequent current step of $31 \mathrm{pA}$ (18\% of these currents to double and $10 \%$ to triple) (Fig. $3 \mathrm{~A}$, right panel). In $\mathrm{NaCl}$ solutions, these events were rare, as jump amplitudes double or triple of the most frequent one were only $5 \%$ and $3 \%$, respectively (Fig. 3B, right panel). These results suggested that high conductance states could be actually originated by occasional simultaneous insertion of two or three channels rather than by wider independent structures.

To analyze whether SARS-CoV E protein behaves as a voltagegated ion channel, its ion channel activity was measured under different voltages. Single channel current-voltage $(I-V)$ curves (Fig. 4) exhibited an ohmic behavior and therefore, a voltage independent conductance. The linear intensity to voltage $(I-V)$ relationship revealed that the number of current carriers did not depend on the direction of the applied voltage difference and, therefore, the channel displayed symmetric ion transport properties when positive or negative voltage differences were applied. These results indicated that SARS-CoV E protein ion channel activity was not regulated by the applied electric potential. This constitutes a distinctive trend at odds with other channel forming peptides like alamethicin (Hall et al., 1984) or syringomycin E (Malev et al., 2002), which display voltage dependent current that has been linked to the existence of several conformational states. The fact that SARS-CoV wt-E peptide exhibited the same conductance regardless of the applied voltage discards the existence of voltage-induced dynamical structures and provides some support to the hypothesis that the variety of high conductance states found in Fig. 3A and B were actually originated by clusters of small structures and not by different conformational states.

\section{Conductance of native E peptide ion channel in polar membranes}

To examine the influence of a charged lipid on the $w t$-E channel properties, current recordings in a negatively charged DPhPS membrane were performed. The histograms of the $w t$-E peptide channel conductance in pure DPhPS membranes point to a single channel conductance of $0.15 \pm 0.01 \mathrm{nS}$ in $1 \mathrm{M} \mathrm{KCl}$ (Fig. 5). The comparison with Fig. $3 \mathrm{~A}$ indicates that the host lipid not only determines the width of the conductance histograms but also the single channel conductance. Thus, the distribution of current jump amplitudes for the wt-E peptide in DPhPS charged membranes was much narrower than in neutral DPhPC membranes, suggesting that simultaneous multi-channel insertions were rare events when the peptide was reconstituted in DPhPS. But more important is the fact that the $w t$-E peptide channel conductance in a negatively charged lipid is less than half the value in a neutral membrane. This cannot be explained exclusively by the electrostatic interactions arising from the surface charge of the lipid membrane. The accumulation of ions near the pore entrance due to the membrane surface charge should give just the opposite effect, i.e., greater channel conductance in DPhPS, as occurs in alamethicin (Aguilella et al., 2011). Our results suggest that lipids are much more than inert scaffolds but they are functionally involved in the channel formation so that the observed dependence of $w t$-E channel conductance on the lipid type could be associated to the existence of different conformations in such a way that the aqueous pore in DPhPS membranes is narrower than in DPhPC membranes. Therefore, we can reasonably hypothesize that $w t$-E peptides induce permeabilization changes in membranes via the formation of protein-lipid pores, and lipid polar
A

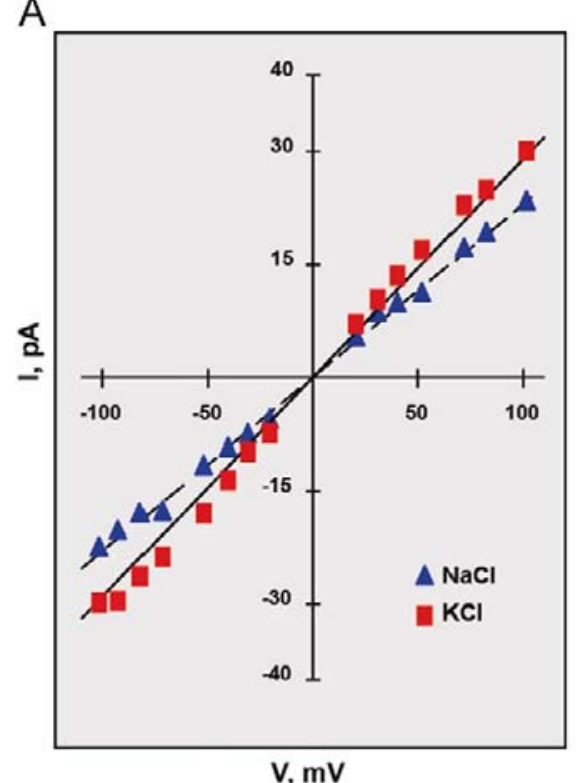

B

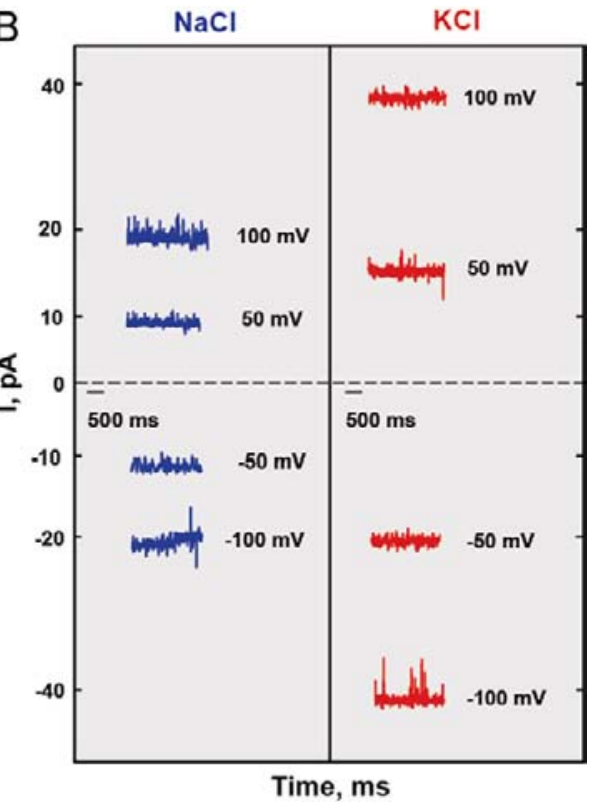

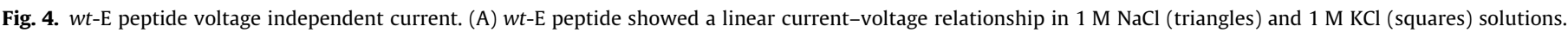

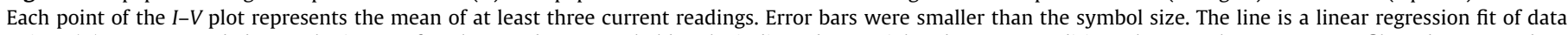

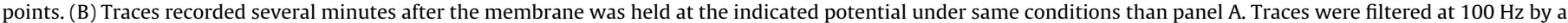
digital eight-pole Bessel low pass filter (Clampfit 10.2, Molecular Devices). Smaller conductances correspond to NaCl. 

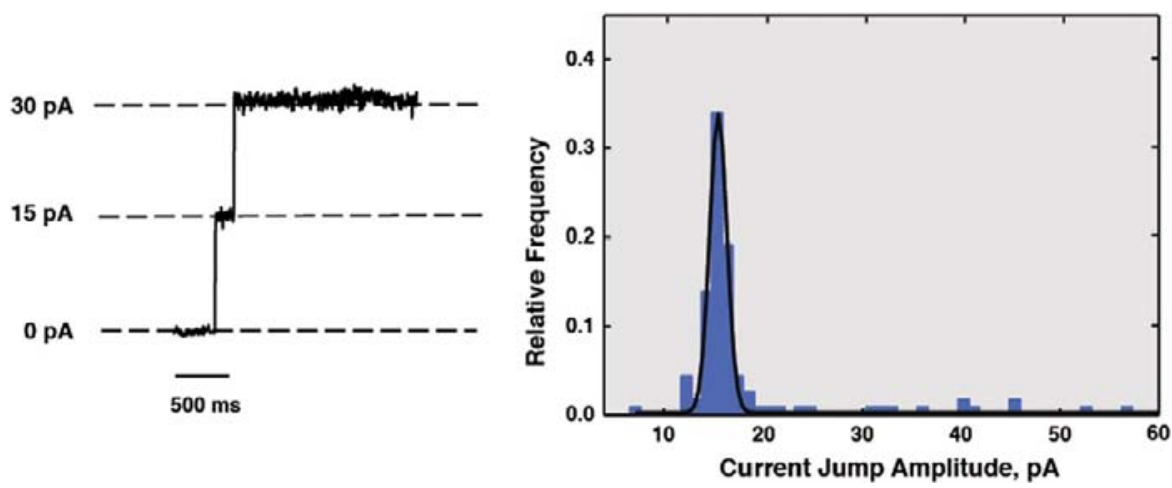

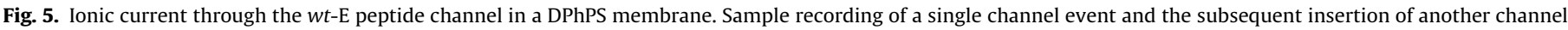
(left) and histogram of current jump amplitude in $1 \mathrm{M} \mathrm{KCl}$ (right). Histograms comprise values from 300 recording events.

Table 2

Reversal potential of native SARS-CoV transmembrane $w t$-E peptide in artificial membranes with different lipid bilayer composition under a 10-fold concentration gradient.

\begin{tabular}{|c|c|c|c|c|}
\hline \multirow[t]{2}{*}{ \%DPhPS } & \multicolumn{2}{|l|}{$\mathrm{NaCl}^{\mathrm{a}}$} & \multicolumn{2}{|l|}{$\mathrm{KCl}^{\mathrm{c}}$} \\
\hline & $E_{\text {rev }}(\mathrm{mV})$ & $\boldsymbol{P}_{+} / \boldsymbol{P}_{-}{ }^{b}$ & $E_{\text {rev }}(\mathbf{m V})$ & $\boldsymbol{P}_{+} / \boldsymbol{P}_{-}^{b}$ \\
\hline 0 & $12.2 \pm 2.0(n=59)$ & $0.6 \pm 0.1$ & $1.9 \pm 0.8(n=20)$ & $1.0 \pm 0.1$ \\
\hline 20 & $-7.7 \pm 0.6(n=7)$ & $1.4 \pm 0.1$ & $-19.9 \pm 0.8(n=7)$ & $2.7 \pm 0.1$ \\
\hline 50 & $-11.8 \pm 2.4(n=7)$ & $2.0 \pm 0.2$ & $-27.3 \pm 2.4(n=7)$ & $3.9 \pm 0.5$ \\
\hline 100 & $-26.6 \pm 3.5(n=10)$ & $3.8 \pm 0.7$ & $-35.8 \pm 2.0(n=10)$ & $6.6 \pm 0.9$ \\
\hline
\end{tabular}

a $\mathrm{NaCl}$ and ${ }^{\mathrm{C}} \mathrm{KCl}$ concentrations of $500 \mathrm{mM}$ in cis chamber and $50 \mathrm{mM}$ in trans chamber were used.

${ }^{\mathrm{b}} P_{+} / P_{-}$, ratio of the permeability to positive versus negative ions.

heads line totally or partially the pore wall together with several peptide monomers.

\section{Modulation of E peptide ion selectivity by lipid bilayer composition}

The reversal potential $\left(E_{\mathrm{rev}}\right)$ is defined as the applied transmembrane voltage that yields zero electric current when there is a concentration gradient across the membrane. $E_{\mathrm{rev}}$ is the method of choice to quantify selectivity for the sake of simplicity: the sign of the $E_{\text {rev }}$ provides a quick estimation of the channel selectivity and its preference for cations or anions (Aguilella et al., 2011; Hille, 2001). The measured $E_{\text {rev }}$ can be converted into the channel permeability $\left(P_{+} / P_{-}\right)$by means of the Goldman-Hodgkin-Katz (GHK) (Hodgkin and Katz, 1949) equation, being $P_{+}$cation permeability and $P_{-}$anion permeability.

$E_{\text {rev }}$ was measured under a 10 -fold salt gradient $(500 \mathrm{mM} /$ $50 \mathrm{mM} \mathrm{KCl}$, and $500 \mathrm{mM} / 50 \mathrm{mM} \mathrm{NaCl}$ ) with different lipid bilayer compositions. In planar membranes of neutral lipid DPhPC the native $\mathrm{E}$ peptide channel permeability ratios were $P_{+} / P_{-}=$ $0.6 \pm 0.1$ for $\mathrm{NaCl}$ and $P_{+} / P_{-}=1 \pm 0.1$ for $\mathrm{KCl}$ (Table 2, first row). The interpretation of these permeability ratios must take into account that $P_{+} / P_{-}$is a joint measure of the channel discrimination between ions with different charge (electrostatic exclusion or accumulation) and the electrolyte intrinsic properties (difference between cation and anion mobility). This means that in a hypothetical neutral pore devoid of any interaction, the corresponding cation/anion permeability ratios, which represent the ratio of the diffusion coefficients in a free solution, should be $P_{+} / P_{-} \sim 0.5$ for $\mathrm{NaCl}$ and $P_{+} / P_{-} \sim 1$ for $\mathrm{KCl}$. Thus, the calculated $P_{+} / P_{-}$ratios in the first row of Table 2 offer two interesting conclusions. On one hand, the $w t$-E peptide induced channels in DPhPC bilayers behaved almost like a neutral pore because they did not discriminate cations over anions. On the other hand, the
Table 3

Reversal potential measured for SARS-CoV full-length E protein in planar bilayer membranes with different lipid composition under a 10 -fold concentration gradient.

\begin{tabular}{|c|c|c|c|c|}
\hline \multirow[t]{2}{*}{ \%DPhPS } & \multicolumn{2}{|l|}{$\mathrm{NaCl}^{\mathrm{a}}$} & \multicolumn{2}{|l|}{$\mathrm{KCl}^{\mathrm{c}}$} \\
\hline & $E_{\mathrm{rev}}(\mathrm{mV})$ & $\boldsymbol{P}_{+} / \boldsymbol{P}_{-}{ }^{\mathrm{b}}$ & $E_{\text {rev }}(\mathbf{m V})$ & $\boldsymbol{P}_{+} / \boldsymbol{P}_{-}{ }^{\mathrm{b}}$ \\
\hline 0 & $8.6 \pm 1.7(n=10)$ & $0.7 \pm 0.1$ & $-5.6 \pm 1.4(n=15)$ & $1.1 \pm 0.1$ \\
\hline 100 & $-34 \pm 2(n=6)$ & $5.8 \pm 0.4$ & $-43 \pm 3(n=10)$ & $10.5 \pm 0.9$ \\
\hline
\end{tabular}

${ }^{\mathrm{a}} \mathrm{NaCl}$ and ${ }^{\mathrm{C}} \mathrm{KCl}$ concentrations of $500 \mathrm{mM}$ in cis chamber and $50 \mathrm{mM}$ in trans chamber were used.

${ }^{\mathrm{b}} P_{+} / P_{-}$, ratio of the permeability to positive versus negative ions.

observed differences between $P_{+} / P_{-}$ratios for $\mathrm{NaCl}$ or $\mathrm{KCl}$ in the first row of Table 2 reflects the different mobility of $\mathrm{Na}^{+}$and $\mathrm{K}^{+}$, indicating that the channel has no specificity for $\mathrm{Na}^{+}$or $\mathrm{K}^{+}$ (Alcaraz et al., 2009).

The observed lack of selectivity is in apparent contradiction with previous studies reporting that the $\mathrm{N}$-terminal 40 amino acids of SARS-CoV E protein forms cation selective channels (Wilson et al., 2004). However, it is important to note that in those experiments, E transmembrane peptide was inserted in a lipid mixture with a $20 \%$ of a negatively charged lipid, instead of the neutral lipid bilayer used in the above reported experiments (Table 2, first row). Having in mind the crucial role that the lipid has on the channel conductance (compare Figs. 3A and 5), new series of reversal potential measurements were performed using a lipid mixture of DPhPC (neutral lipid): DPhPS (negatively charged lipid) (4:1) so as to mimic the lipid membrane charge density used by Wilson et al. (2004). In these charged membranes, permeability ratios were $P_{+} / P_{-}=1.4 \pm 0.1$ for $\mathrm{NaCl}$ and $P_{+} / P_{-}=$ $2.7 \pm 0.1$ for $\mathrm{KCl}$ (Table 2, second row), showing that the ion channel was between two and three-fold more permeable to cations $\left(\mathrm{Na}^{+}\right.$and $\mathrm{K}^{+}$) than in the neutral lipid bilayer. Higher percentages of DPhPS within the lipid bilayer, further increased permeability ratios for $\mathrm{NaCl}$ and $\mathrm{KCl}$, being $P_{+} / P_{-}=2.0 \pm 0.2$ for $\mathrm{NaCl}$ and $P_{+} / P_{-}=3.9 \pm 0.5$ for $\mathrm{KCl}$ in $50 \%$ DPhPS membranes, and $P_{+} / P_{-}=3.8 \pm 0.7$ for $\mathrm{NaCl}$ and $P_{+} / P_{-}=6.6 \pm 0.9$ for $\mathrm{KCl}$ in $100 \%$ DPhPS membranes (Table 2), indicating that the channel permeability was between three- and four-fold higher to $\mathrm{Na}^{+}$and $\mathrm{K}^{+}$ than to $\mathrm{Cl}^{-}$ions in 50\% DPhPS membranes and between six and seven times more permeable to $\mathrm{Na}^{+}$and $\mathrm{K}^{+}$than to $\mathrm{Cl}^{-}$ions in $100 \%$ DPhPS membranes (Table 2, last row). Overall, these data showed that the charge of the lipid modulated the ionic selectivity of the peptide channel. Equivalent results were obtained with the full-length SARS-CoV E protein (Table 3). When the lipid bilayer was constituted by DPhPC uncharged lipids permeability ratios were $P_{+} / P_{-}=0.7 \pm 0.1$ for $\mathrm{NaCl}$ and $P_{+} / P_{-}=1.1 \pm 0.1$ for 
$\mathrm{KCl}$, whereas when E protein was inserted in DPhPS negatively charged lipids permeability ratios increased to $P_{+} / P_{-}=5.8 \pm 0.4$ for $\mathrm{NaCl}$ and $P_{+} / P_{-}=10.5 \pm 0.9$ for $\mathrm{KCl}$. These data indicated that lipid charge influenced $E$ protein ion channel selectivity, as shown above for E protein derived peptide.

This mild selectivity is consistent with the fact that in all cases the peptides form relatively wide pores in which the interaction of the permeating ions with the channel residues is weak and the electrodiffusion of ions across the channel is not very different from bulk solution.

In previous studies (Wilson et al., 2006) it has been suggested that $\mathrm{HCoV}-229 \mathrm{E}$ envelope protein was assembled in ion channels with a preference for $\mathrm{K}^{+}$over $\mathrm{Na}^{+}$. To further study if the influence of the artificial membrane polarity on the ion channel activity is a general issue for other CoV E proteins, we measured the selectivity of channels formed by a synthetic peptide having the same amino acid sequence than the transmembrane domain of $\mathrm{HCoV}-229 \mathrm{E}$ E protein in neutral lipid membranes (Table 4). Permeability ratios $\left(P_{+} / P_{-}\right)$were $1.1 \pm 0.1$ for $\mathrm{NaCl}$ and $2.5 \pm 0.3$ for $\mathrm{KCl}$, indicating that the channel formed by $\mathrm{HCoV}-229 \mathrm{E} \mathrm{E}$ protein was more permeable to cations than to anions in DPhPC. In addition to its mild cationic selectivity, the channel showed a slight preference for $\mathrm{K}^{+}$over $\mathrm{Na}^{+}$ions. In experiments with membranes formed by negatively charged DPhPS, the channel cationic selectivity increased up to a $P_{+} / P_{-}$ratio of $3.1 \pm 0.2$ for $\mathrm{NaCl}$ and $6.2 \pm 0.9$ for $\mathrm{KCl}$, also showing a slight preference for $\mathrm{K}^{+}$ over $\mathrm{Na}^{+}$(Table 4). Therefore, there is an increase in the channel cationic selectivity in DPhPS with respect to DPhPC. This indicates that the lipid charged head groups modulated the ion specificity, similarly to what has been shown above for SARS-CoV E peptide and full-length protein.

Apparently, reversal potential measurements (Tables 2-4) could lead to the conclusion that the $\mathrm{K}^{+}$ions are preferred over $\mathrm{Na}^{+}$in all three channels ( $w t$-E peptide, the full-length SARS-CoV $\mathrm{E}$ protein and $\mathrm{HCoV}-229 \mathrm{E}$ envelope protein), since permeability ratios are greater for $\mathrm{KCl}$ than for $\mathrm{NaCl}$. We want to stress again (as done above in the discussion of Fig. $3 \mathrm{~A}$ and $\mathrm{B}$ ) that these small differences between $E_{\text {rev }}$ measured in $\mathrm{KCl}$ and $\mathrm{NaCl}$ are only due to the electrolyte intrinsic properties (ion mobility). Actually, the difference between the $E_{\mathrm{rev}}$ values of columns 2 and 4 (Tables 2 and 3 ) is very close to $11.3 \mathrm{mV}$, which corresponds to the difference between $\mathrm{NaCl}$ and $\mathrm{KCl}$ diffusion potentials for a 10fold concentration ratio in free solution (Alcaraz et al., 2009). Even in $\mathrm{HCoV}-229 \mathrm{E}$ peptide where the difference between $E_{\mathrm{rev}}$ for $\mathrm{KCl}$ and $\mathrm{NaCl}$ seems a bit larger, the preference for $\mathrm{K}^{+}$over $\mathrm{Na}^{+}$is not significant at all (a factor 2.3-2.7, depending on the lipid charge) as shown in Table 4. Furthermore, it is worth to mention that the permeability ratios obtained here are very far from the values usually associated to specific selectivity. In the channel literature (Aguilella et al., 2011), to consider that a channel is specific to a certain ion, the permeability to other ions should be extremely low. For instance, potassium channels have a permeability ratio

Table 4

Reversal potential measured for HCoV-229E E protein derived peptide in planar bilayer membranes with different lipid composition under a 10 -fold concentration gradient.

\begin{tabular}{clllll}
\hline \%DPhPS & \multicolumn{2}{l}{$\mathbf{N a C l}^{\mathrm{a}}$} & & \multicolumn{2}{l}{$\mathbf{K C l}^{\mathrm{c}}$} \\
\cline { 2 - 3 } \cline { 5 - 6 } & $\boldsymbol{E}_{\mathbf{r e v}}(\mathbf{m V})$ & $\boldsymbol{P}_{+} / \boldsymbol{P}_{-}{ }^{\mathrm{b}}$ & & $\boldsymbol{E}_{\mathbf{r e v}}(\mathbf{m V})$ & $\boldsymbol{P}_{+} / \boldsymbol{P}_{-}{ }^{\mathrm{b}}$ \\
\hline 0 & $-2.4 \pm 1.8(n=13)$ & $1.1 \pm 0.1$ & & $-19 \pm 4(n=24)$ & $2.5 \pm 0.3$ \\
100 & $-17.4 \pm 2.1(n=6)$ & $3.1 \pm 0.2$ & & $-35 \pm 4(n=15)$ & $6.2 \pm 0.9$ \\
\hline
\end{tabular}

${ }^{a} \mathrm{NaCl}$ and ${ }^{\mathrm{C}} \mathrm{KCl}$ concentrations of $500 \mathrm{mM}$ in cis chamber and $50 \mathrm{mM}$ in trans chamber were used.

${ }^{\mathrm{b}} P_{+} / P_{-}$, ratio of the permeability to positive versus negative ions. for $\mathrm{K}^{+}$over $\mathrm{Na}^{+}>100: 1$ and calcium channels select for $\mathrm{Ca}^{2+}$ over $\mathrm{Na}^{+}$with a ratio $>1000: 1$.

In conclusion, full-length SARS-CoV E protein and $\mathrm{E}$ protein transmembrane peptide, form non-voltage-gated ion channels. Mutations N15A and V25F disrupt this ion conductive property of the $\mathrm{E}$ protein transmembrane peptide. Interestingly, SARS-CoV E and $\mathrm{HCOV}-229 \mathrm{E}$ E protein derived peptide, when reconstituted in lipid membranes, behaved as ion channels with an activity highly influenced by the charge of the lipids. Marked differences in conductance and $E_{\text {rev }}$ were observed for E protein ion channels depending on whether they were formed in neutral or charged lipid bilayers. Due to lipid head charge repulsion, lipids may change their spacing within a membrane. Therefore, in principle, we could not completely exclude that the lipid charge could have affected the structure of the pore and, as a consequence, its conductance. The results previously described, showed that channel conductance in fully negatively charged lipids (DPhPS) was much smaller than in neutral lipids (DPhPC). These results are consistent with a more tight arrangement of helices in the pore induced by a higher lipid lateral pressure. However, such a conformation (narrower pore) does not seem sufficient to explain the increased channel selectivity in membranes containing charged lipids (from $+2 \mathrm{mV}$ in DPhPC to $-36 \mathrm{mV}$ in DPhPS for $\mathrm{KCl}$ in the case of SARS-CoV E protein derived peptide; from $-6 \mathrm{mV}$ in DPhPC to $-43 \mathrm{mV}$ in DPhPS for $\mathrm{KCl}$ in the case of fulllength SARS-CoV E protein; and from $-19 \mathrm{mV}$ in DPhPC to $-35 \mathrm{mV}$ in DPhPS for $\mathrm{KCl}$ in the case of $\mathrm{HCoV}-229 \mathrm{E}$ e protein derived peptide). The combined evidence from conductance and selectivity measurements is the basis of our suggestion that the pore is made both of peptide helices and lipid head groups. Most likely, lipid molecules assembled with the peptide oligomers, to form the channel, similarly to what has been described for ascecropin, magainin and dermaseptin channels (Oren and Shai, 1998). The reported oligomeric structure of the E protein based on NMR data (Pervushin et al., 2009) suggests that E derived channel is essentially different from a classical barrel-stave model where peptides are tightly assembled in parallel, defining a regular open pore. Indeed, E peptides self associate with a certain slope, defining an irregular pore with a clear constriction in the middle. This type of structure seems compatible with the insertion of lipid head groups within the wider domains of the oligomer. This functional involvement of lipids in the channel structure can be accomplished in different ways as it happens with antimicrobial peptides (Eleftheriou et al., 2009). In one of them, the toroidal pore structure represents a membrane-spanning pore lined with polar peptide surfaces as well as phospholipid head groups.

Protein-lipid pores formation is favored in membranes with positive curvature (Sobko et al., 2004). Indeed, when using lipids inducing negative curvature of membranes like phosphatidylethanolamine (PE), the probability of channel formation is lowered because the membrane positive curvature needed for proteolipidic pores becomes energetically unfavorable. To reinforce the concept of $\mathrm{CoV} \mathrm{E}$ protein derived channel as a protein-lipid entity, ion channel activity of SARS-CoV E transmembrane peptide was measured in membranes containing PE and different amounts of negatively charged lipid PS. Two types of membranes were reconstituted: (i) membrane 1 (PE:PC:PS, 3:1:1), and (ii) membrane 2 (PE:PC:PS, $3: 3: 1$ ). Channel insertion was significantly diminished under these conditions and amounts of peptide 10- to 15-fold higher than those used in PC or PC:PS membranes were needed to detect channel activity (data not shown). These data confirmed that E protein most likely formed a protein-lipid pore. It is noteworthy that even under these conditions, $P_{+} / P_{-}$values were $3.3 \pm 0.2$ and $2.3 \pm 0.2$ for membrane 1 (20\% negatively charged lipids) and membrane 2 (14\% negatively charged lipids), respectively, which revealed that, as previously shown for PC:PS membranes, lipid charge influenced 
ion channel selectivity. The structure of these pores may also be a consequence of the direct interaction between specific domains of $\mathrm{E}$ protein monomers. Further work to clarify lipid-peptide channel conformation is in progress.

Finally, it has been described that $\mathrm{CoV}$ E protein locates within ERGIC/Golgi membranes of infected cells (Corse and Machamer, 2000; Lim and Liu, 2001; Nal et al., 2005; Nieto-Torres et al., 2011; Raamsman et al., 2000). These membranes are composed by lipid mixtures containing around $17 \%$ negatively charged lipids (van Meer et al., 2008). To analyze whether the effect of lipid charge on E protein ion channel selectivity may also happen in its physiological context, E protein derived ion channels were reconstituted in lipid membranes broadly mimicking ERGIC/Golgi membrane composition and charge: $59 \%$ dioleoyl phosphatidylcholine (DOPC), 24\% dioleoyl phosphatidylethanolamine (DOPE) and $17 \%$ dioleoyl phosphatidylserine (DOPS). Ion channel selectivity was measured using a 10 -fold $\mathrm{KCl}$ concentration gradient. Under these conditions, $P_{+} / P_{-}$was $3.3 \pm 0.2$, of the same order that the values previously obtained with membranes having $20 \%$ of the negatively charged lipid DPhPC $(2.7 \pm 0.1)$ (Table 2 , right column), indicating that lipid charge influenced $\mathrm{E}$ protein ion selectivity in a more physiological context, and excluding major effects of lipid composition on ion selectivity. In such scenario, CoV E proteins integrated in lipid bilayers of subcellular compartments should behave more as channels with preference for cations.

\section{Materials and methods}

\section{Peptide synthesis}

The peptides corresponding to full-length SARS-CoV E protein, SARS-CoV E protein transmembrane domain (from residue 7 to 38 ) either in wild type or mutant versions, and $\mathrm{HCoV}-229 \mathrm{E}$ E protein transmembrane domain (from residue 7 to 37) were synthesized using standard solid phase FMOC chemistry peptide synthesizer (Intavis ResPep Gladbach, Germany). The peptides were cleaved from the resin with trifluoroacetic acid (TFA) and purified by high-performance liquid chromatography (HPLC). To this end, lyophilized peptides were dissolved in isopropanol and acetonitrile $(3: 2, v / \mathrm{v})$ at a final peptide concentration of $\sim 5 \mathrm{mg} / \mathrm{ml}$, and injected into a Zorbax SB-C18 $9.4 \mathrm{~mm} \times 250 \mathrm{~mm}$ column (Agilent) equilibrated with $\mathrm{H}_{2} \mathrm{O}$. Peptide elution was performed using a Waters 600 HPLC system and three solvents: A $\left(94.9 \% \mathrm{H}_{2} \mathrm{O}, 5 \%\right.$ acetonitrile, $0.1 \%$ trifluoroacetic acid), B (94.9\% acetonitrile, $5 \% \mathrm{H}_{2} \mathrm{O}$, $0.1 \%$ trifluroacetic acid) and C (94.9\% isopropanol, $5 \%$ acetonitrile, $0.1 \%$ trifluoroacetic acid). The elution process started with $80 \%$ solvent A, $8 \%$ of solvent B and $12 \%$ of solvent $C$ following a linear gradient to reach after 30 min a mixture of $40 \%$ solvent B and $60 \%$ solvent C. Finally, a gradient ending with a composition of $20 \%$ solvent B and $80 \%$ solvent C after 40 min was performed. The resulting fractions were pooled and lyophilized. Peptide purity was confirmed by mass spectrometry.

\section{Ion channel reconstitution and ionic current recording}

Planar bilayers were formed by apposition of two monolayers prepared from a solution of $1 \%$ pure diphytanoyl phosphatidylcholine (DPhPC), pure diphytanoyl phosphatidylserine (DPhPS), or a mixture of both lipids (Avanti polar lipids, Inc., Alabaster, AL) in pentane. Lipids were added on 70-90- $\mu$ m diameter orifices in the $15-\mu m$-thick Teflon partition that separated two identical chambers (Bezrukov and Vodyanoy, 1993; Montal and Mueller, 1972). The orifices were pretreated with a $1 \%$ solution of hexadecane in pentane. Aqueous solutions of $\mathrm{KCl}$ and $\mathrm{NaCl}$ were buffered with
5 mM HEPES at pH 6. All measurements were performed at room temperature $\left(23 \pm 1{ }^{\circ} \mathrm{C}\right)$. Ion channel insertion was achieved by adding $0.5-1 \mu \mathrm{l}$ of a $300 \mu \mathrm{g} / \mathrm{ml}$ solution of synthetic protein or peptides in the buffer containing acetonitrile:isopropanol (40:60) on one side of the chamber (hereafter referred to as cis side).

An electric potential was applied using $\mathrm{Ag} / \mathrm{AgCl}$ electrodes in $2 \mathrm{M} \mathrm{KCl}, 1.5 \%$ agarose bridges assembled within standard $250 \mu \mathrm{l}$ pipette tips. The potential was defined as positive when it was higher on the side of the peptide addition (cis side), whereas the trans side was set to ground. An Axopatch 200B amplifier (Molecular Devices, Sunnyvale, CA) in the voltage-clamp mode was used to measure the current and the applied potential. The chamber and the head stage were isolated from external noise sources with a double metal screen (Amuneal Manufacturing Corp., Philadelphia, PA). The single-channel conductance was obtained from current measurements under an applied potential of $+100 \mathrm{mV}$ in symmetrical salt solutions of $1 \mathrm{M} \mathrm{KCl}$ and $\mathrm{NaCl}$ buffered with $5 \mathrm{mM}$ HEPES at $\mathrm{pH}$ 6. The conductance values were evaluated using the Gaussian fit tool of Sigma Plot 10.0 (Systat Software, Inc).

The reversal potential, $E_{\text {rev }}$, was obtained as follows. First, a lipid membrane was formed at a given salt concentration gradient. Second, one or several channels were inserted into the bilayer and a net ionic current appeared due to the concentration gradient. Third, the ionic current through the channel was manually set to zero by adjusting the applied potential. The potential needed to achieve zero current was then corrected by the liquid junction potentials of the electrode salt bridges (Alcaraz et al., 2009) to obtain the $E_{\mathrm{rev}}$. The measured $E_{\text {rev }}$ was converted into the channel permeability $\left(P_{+} / P_{-}\right)$by means of the Goldman-Hodgkin-Katz (GHK) (Hodgkin and Katz, 1949) equation:

$E_{\text {rev }}=\frac{R T}{F} \ln \left(\frac{P_{+}\left[A^{+}\right]_{\text {trans }}+P_{-}\left[B^{-}\right]_{\text {cis }}}{P_{+}\left[A^{+}\right]_{\text {cis }}+P_{-}\left[B^{-}\right]_{\text {trans }}}\right)$

\section{Acknowledgements}

This work was supported by grants from the Ministry of Science and Innovation of Spain (MICINN. FIS2010-19810) and (BIO2007-60978 and BIO2010-16705), Fundació Caixa CastellóBancaixa (P1-1A2009-13), Generalitat Valenciana (Prometeu/ 2012/069), the European Community's Seventh Framework Programme (FP7/2007-2013) under the project "EMPERIE" EC Grant Agreement number 223498, and U.S. National Institutes of Health (NIH) (2P01AI060699-06A1, W000306844). CVB received a fellowship from UJI. JLN received a fellowship from CSIC. We thank Fernando Roncal (CNB, Proteomics facility) for peptides purification, and Marga Gonzalez for her technical assistance.

\section{Appendix A. Supplementary material}

Supplementary data associated with this article can be found in the online version at http://dx.doi.org/10.1016/j.virol.2012.07.005.

\section{References}

Aguilella, V.M., Queralt-Martin, M., Aguilella-Arzo, M., Alcaraz, A., 2011. Insights on the permeability of wide protein channels: measurement and interpretation of ion selectivity. Integr. Biol. (Camb.) 3, 159-172.

Alcaraz, A., Nestorovich, E.M., Lopez, M.L., Garcia-Gimenez, E., Bezrukov, S.M., Aguilella, V.M., 2009. Diffusion, exclusion, and specific binding in a large channel: a study of OmpF selectivity inversion. Biophys. J. 96, 56-66. 
Arbely, E., Khattari, Z., Brotons, G., Akkawi, M., Salditt, T., Arkin, I.T., 2004. A highly unusual palindromic transmembrane helical hairpin formed by SARS coronavirus E protein. J. Mol. Biol. 341, 769-779.

Bezrukov, S.M., Vodyanoy, I., 1993. Probing alamethicin channels with watersoluble polymers. Effect on conductance of channel states. Biophys. J. 64, $16-25$.

Campanella, M., de Jong, A.S., Lanke, K.W., Melchers, W.J., Willems, P.H., Pinton, P., Rizzuto, R., van Kuppeveld, F.J., 2004. The coxsackievirus 2B protein suppresses apoptotic host cell responses by manipulating intracellular $\mathrm{Ca}^{2+}$ homeostasis. J. Biol. Chem. 279, 18440-18450.

Chu, D.K., Peiris, J.S., Chen, H., Guan, Y., Poon, L.L., 2008. Genomic characterizations of bat coronaviruses (1A, 1B and HKU8) and evidence for co-infections in Miniopterus bats. J. Gen. Virol. 89, 1282-1287.

Corse, E., Machamer, C.E., 2000. Infectious bronchitis virus E protein is targeted to the Golgi complex and directs release of virus-like particles. J. Virol. 74, 4319-4326.

de Groot, R.J., Baker, S.C., Baric, R., Enjuanes, L., Gorbalenya, A.E., Holmes, K.V. Perlman, S., Poon, L., Rottier, P.J.M., Talbot, P.J., Woo, P.C.Y., Ziebuhr, J., 2012. Coronaviridae. In: King, A.M.Q., Adams, M.J., Carstens, E.B., Lefkowitz, E.J. (Eds.), Virus Taxonomy: Ninth Report of the International Committee on Taxonomy of Viruses. Elsevier Academic Press, San Diego, pp. 774-796.

de Jong, A.S., Visch, H.J., de Mattia, F., van Dommelen, M.M., Swarts, H.G., Luyten, T., Callewaert, G., Melchers, W.J., Willems, P.H., van Kuppeveld, F.J., 2006. The coxsackievirus 2B protein increases efflux of ions from the endoplasmic reticulum and Golgi, thereby inhibiting protein trafficking through the Golgi. J. Biol. Chem. 281, 14144-14150.

DeDiego, M.L. Alvarez, E., Almazan, F., Rejas, M.T., Lamirande, E., Roberts, A., Shieh, W.J., Zaki, S.R., Subbarao, K., Enjuanes, L., 2007. A severe acute respiratory syndrome coronavirus that lacks the E gene is attenuated in vitro and in vivo. J. Virol. 81, 1701-1713.

DeDiego, M.L., Nieto-Torres, J.L., Jimenez-Guardeno, J.M., Regla-Nava, J.A., Alvarez, E., Oliveros, J.C., Zhao, J., Fett, C., Perlman, S., Enjuanes, L., 2011. Severe acute respiratory syndrome coronavirus envelope protein regulates cell stress response and apoptosis. PLoS Pathog. 7, e1002315.

DeDiego, M.L., Pewe, L., Alvarez, E., Rejas, M.T., Perlman, S., Enjuanes, L., 2008 Pathogenicity of severe acute respiratory coronavirus deletion mutants in hACE-2 transgenic mice. Virology 376, 379-389.

Drexler, J.F., Gloza-Rausch, F., Glende, J., Corman, V.M., Muth, D., Goettsche, M. Seebens, A., Niedrig, M., Pfefferle, S., Yordanov, S., Zhelyazkov, L., Hermanns, U., Vallo, P., Lukashev, A., Muller, M.A., Deng, H., Herrler, G., Drosten, C., 2010. Genomic characterization of severe acute respiratory syndrome-related coronavirus in European bats and classification of coronaviruses based on partial RNA-dependent RNA polymerase gene sequences. J. Virol. 84 11336-11349.

Drosten, C., Gunther, S., Preiser, W., van der Werf, S., Brodt, H.R., Becker, S. Rabenau, H., Panning, M., Kolesnikova, L., Fouchier, R.A., Berger, A., Burguiere A.M., Cinatl, J., Eickmann, M., Escriou, N., Grywna, K., Kramme, S., Manuguerra, J.C., Muller, S., Rickerts, V., Sturmer, M., Vieth, S., Klenk, H.D., Osterhaus, A.D., Schmitz, H., Doerr, H.W., 2003. Identification of a novel coronavirus in patient with severe acute respiratory syndrome. N. Engl. J. Med. 348, 1967-1976.

Eleftheriou, D., Melo, M., Marks, S.D., Tullus, K., Sills, J., Cleary, G., Dolezalova, P. Ozen, S., Pilkington, C., Woo, P., Klein, N., Dillon, M.J., Brogan, P.A., 2009. Biologic therapy in primary systemic vasculitis of the young. Rheumatology $48,978-986$

Enjuanes, L., Gorbalenya, A.E., de Groot, R.J., Cowley, J.A., Ziebuhr, J., Snijder, E.J. 2008. The Nidovirales. In: Mahy, B.W.J., Van Regenmortel, M., Walker, P., Majumder-Russell, D. (Eds.), Encyclopedia of Virology, third ed. Elsevier Ltd. Oxford, pp. 419-430.

Ewart, G.D., Sutherland, T., Gage, P.W., Cox, G.B., 1996. The Vpu protein of human immunodeficiency virus type 1 forms cation-selective ion channels. J. Virol 70, 7108-7115.

Hall, J.E., Vodyanoy, I., Balasubramanian, T.M., Marshall, G.R., 1984. Alamethicin. A rich model for channel behavior. Biophys. J. 45, 233-247.

Hille, B., 2001. Ion Channels of Excitable Membranes, third ed. Sinauer Associates, Sunderland, MA

Hodgkin, A.L., Katz, B., 1949. The effect of sodium ions on the electrical activity of giant axon of the squid. J. Physiol. 108, 37-77.

Huang, C., Ito, N., Tseng, C.T., Makino, S., 2006. Severe acute respiratory syndrome coronavirus 7a accessory protein is a viral structural protein. J. Virol. 80, 7287-7294.

Huang, C., Peters, C.J., Makino, S., 2007. Severe acute respiratory syndrome coronavirus accessory protein 6 is a virion-associated protein and is released from 6 protein-expressing cells. J. Virol. 81, 5423-5426.

Ichinohe, T., Pang, I.K., Iwasaki, A., 2010. Influenza virus activates inflammasomes via its intracellular M2 ion channel. Nat. Immunol. 11, 404-410.

Kuo, L., Hurst, K.R., Masters, P.S., 2006. Exceptional flexibility in the sequence requirements for coronavirus small envelope protein (E) function. J. Virol. 81 2249-2262.

Kuo, L., Masters, P.S., 2003. The small envelope protein E is not essential for murine coronavirus replication. J. Virol. 77, 4597-4608.

Lim, K.P., Liu, D.X., 2001. The missing link in coronavirus assembly. Retention of the avian coronavirus infectious bronchitis virus envelope protein in the preGolgi compartments and physical interaction between the envelope and membrane proteins. J. Biol. Chem. 276, 17515-17523.

Maeda, J., Repass, J.F., Maeda, A., Makino, S., 2001. Membrane topology of coronavirus E protein. Virology 281, 163-169.
Malev, V.V., Schagina, L.V., Gurnev, P.A., Takemoto, J.Y., Nestorovich, E.M., Bezrukov, S.M., 2002. Syringomycin E channel: a lipidic pore stabilized by lipopeptide? Biophys. J. 82, 1985-1994.

Montal, M., Mueller, P., 1972. Formation of bimolecular membranes from lipid monolayers and a study of their electrical properties. Proc. Nat. Acad. Sci. U.S.A. 69, 3561-3566.

Muller, M.A., Paweska, J.T., Leman, P.A., Drosten, C., Grywna, K., Kemp, A., Braack, L., Sonnenberg, K., Niedrig, M., Swanepoel, R., 2007. Coronavirus antibodies in African bat species. Emerg. Infect. Dis. 13, 1367-1370.

Nal, B., Chan, C., Kien, F., Siu, L., Tse, J., Chu, K., Kam, J., Staropoli, I., CrescenzoChaigne, B., Escriou, N., van der Werf, S., Yuen, K.Y., Altmeyer, R., 2005. Differential maturation and subcellular localization of severe acute respiratory syndrome coronavirus surface proteins S, M and E. J. Gen. Virol. 86, 1423-1434.

Netland, J., DeDiego, M.L., Zhao, J., Fett, C., Alvarez, E., Nieto-Torres, J.L., Enjuanes, L. Perlman, S., 2010. Immunization with an attenuated severe acute respiratory syndrome coronavirus deleted in $\mathrm{E}$ protein protects against lethal respiratory disease. Virology 399, 120-128.

Nguyen, V.P., Hogue, B.G., 1997. Protein interactions during coronavirus assembly. J. Virol. 71, 9278-9284.

Nieto-Torres, J.L., Dediego, M.L., Alvarez, E., Jimenez-Guardeno, J.M., Regla-Nava, J.A., Llorente, M., Kremer, L., Shuo, S., Enjuanes, L., 2011. Subcellular location and topology of severe acute respiratory syndrome coronavirus envelope protein. Virology 415, 69-82.

Oren, Z., Shai, Y., 1998. Mode of action of linear amphipathic alpha-helical antimicrobial peptides. Biopolymers 47, 451-463.

Ortego, J., Ceriani, J.E., Patino, C., Plana, J., Enjuanes, L., 2007. Absence of E protein arrests transmissible gastroenteritis coronavirus maturation in the secretory pathway. Virology 368, 296-308.

Ortego, J., Escors, D., Laude, H., Enjuanes, L., 2002. Generation of a replicationcompetent, propagation-deficient virus vector based on the transmissible gastroenteritis coronavirus genome. J. Virol. 76, 11518-11529.

Perlman, S., Netland, J., 2009. Coronaviruses post-SARS: update on replication and pathogenesis. Nat. Rev. Microbiol. 7, 439-450.

Pervushin, K., Tan, E., Parthasarathy, K., Lin, X., Jiang, F.L., Yu, D., Vararattanavech, A., Soong, T.W., Liu, D.X., Torres, J., 2009. Structure and inhibition of the SARS coronavirus envelope protein ion channel. PLoS Pathog. 5, e1000511.

Pinto, L.H., Holsinger, L.J., Lamb, R.A., 1992. Influenza virus M2 protein has ion channel activity. Cell 69, 517-528.

Quan, P.L., Firth, C., Street, C., Henriquez, J.A., Petrosov, A., Tashmukhamedova, A., Hutchison, S.K., Egholm, M., Osinubi, M.O., Niezgoda, M., Ogunkoya, A.B. Briese, T., Rupprecht, C.E., Lipkin, W.I., 2010. Identification of a severe acute respiratory syndrome coronavirus-like virus in a leaf-nosed bat in Nigeria. MBio 1, e00208-00210.

Raamsman, M.J.B., Locker, J.K., de Hooge, A., de Vries, A.A.F., Griffiths, G., Vennema, H., Rottier, P.J.M., 2000. Characterization of the coronavirus mouse hepatitis virus strain A59 small membrane protein E. J. Virol. 74, 2333-2342.

Rota, P.A., Oberste, M.S., Monroe, S.S., Nix, W.A., Campganoli, R., Icenogle, J.P., Peñaranda, S., Bankamp, B., Maher, K., Chen, M.-H., Tong, S., Tamin, A., Lowe, L., Frace, M., DeRisi, J.L., Chen, Q., Wang, D., Erdman, D.d., Peret, T.C.T., Burns, C., Ksiazek, T.G., Rollin, P.E., Sanchez, A., Liffick, S., Holloway, B., Limor, J., McCaustland, K., Olsen-Rassmussen, M., Fouchier, R., Gunther, S., Osterhaus, A.D.M.E., Drosten, C., Pallansch, M.A., Anderson, L.J., Bellini, W.J., 2003. Characterization of a novel coronavirus associated with severe acute respiratory syndrome. Science 300, 1394-1399.

Ruch, T.R., Machamer, C.E., 2011. The hydrophobic domain of infectious bronchitis virus $\mathrm{E}$ protein alters the host secretory pathway and is important for release of infectious virus. J. Virol. 85, 675-685.

Ruch, T.R., Machamer, C.E., 2012a. The Coronavirus E protein: assembly and beyond. Viruses 4, 363-382.

Ruch, T.R., Machamer, C.E., 2012b. A single polar residue and distinct membrane topologies impact the function of the infectious bronchitis coronavirus $\mathrm{E}$ protein. PLoS Pathog. 8, e1002674.

Sani, M.A., Whitwell, T.C., Separovic, F., 2012. Lipid composition regulates the conformation and insertion of the antimicrobial peptide maculatin 1.1. Biochim. Biophys. Acta 1818, 205-211.

Schaecher, S.R., Mackenzie, J.M., Pekosz, A., 2007. The ORF7b protein of SARS-CoV is expressed in virus-infected cells and incorporated into SARS-CoV particles. J. Virol. 81, 718-731.

Shen, S., Lin, P.S., Chao, Y.C., Zhang, A., Yang, X., Lim, S.G., Hong, W., Tan, Y.J., 2005. The severe acute respiratory syndrome coronavirus $3 a$ is a novel structural protein. Biochem. Biophys. Res. Commun. 330, 286-292.

Sobko, A.A., Kotova, E.A., Antonenko, Y.N., Zakharov, S.D., Cramer, W.A., 2004 Effect of lipids with different spontaneous curvature on the channel activity of colicin E1: evidence in favor of a toroidal pore. FEBS Lett. 576, 205-210.

Teoh, K.T., Siu, Y.L., Chan, W.L., Schluter, M.A., Liu, C.J., Peiris, J.S., Bruzzone, R., Margolis, B., Nal, B., 2010. The SARS coronavirus E protein interacts with PALS1 and alters tight junction formation and epithelial morphogenesis. Mol. Biol. Cell 21, 3838-3852.

Torres, J., Maheswari, U., Parthasarathy, K., Ng, L., Liu, D.X., Gong, X., 2007. Conductance and amantadine binding of a pore formed by a lysine-flanked transmembrane domain of SARS coronavirus envelope protein. Protein Sci. 16, 2065-2071.

Torres, J., Parthasarathy, K., Lin, X., Saravanan, R., Liu, D.X., 2006. Model of a putative pore: the pentameric alpha-helical bundle of SARS coronavirus E protein in lipid bilayers. Biophys. J. 91, 938-947. 
van Meer, G., Voelker, D.R., Feigenson, G.W., 2008. Membrane lipids: where they are and how they behave. Nat. Rev. Mol. Cell Biol. 9, 112-124.

Wilson, L., Gage, P., Ewart, G., 2006. Hexamethylene amiloride blocks E protein ion channels and inhibits coronavirus replication. Virology 353, 294-306.

Wilson, L., McKinlay, C., Gage, P., 2004. SARS coronavirus E protein forms cationselective ion channels. Virology 330, 322-331.
Wozniak, A.L., Griffin, S., Rowlands, D., Harris, M., Yi, M., Lemon, S.M., Weinman, S.A., 2010. Intracellular proton conductance of the hepatitis $C$ virus p7 protein and its contribution to infectious virus production. PLoS Pathog. 6, e1001087.

Ye, Y., Hogue, B.G., 2007. Role of the coronavirus E viroporin protein transmembrane domain in virus assembly. J. Virol. 81, 3597-3607. 


\title{
Analysis of SARS-CoV E protein ion channel activity by tuning the protein and lipid charge
}

\author{
Carmina Verdiá-Báguena a , Jose L. Nieto-Torres ${ }^{\mathrm{b}}$, Antonio Alcaraz ${ }^{\mathrm{a}}$, Marta L. DeDiego ${ }^{\mathrm{b}}$, \\ Luis Enjuanes ${ }^{\text {b }}$, Vicente M. Aguilella ${ }^{\text {a,* }}$ \\ a Department of Physics, Laboratory of Molecular Biophysics, Universitat Jaume I, 12071 Castellón, Spain \\ ${ }^{\mathrm{b}}$ Department of Molecular and Cell Biology, Centro Nacional de Biotecnología (CNB-CSIC), Campus Universidad Autónoma de Madrid, Darwin 3, 28049 Madrid, Spain
}

\section{A R T I C L E I N F O}

Article history:

Received 9 January 2013

Received in revised form 24 April 2013

Accepted 9 May 2013

Available online 18 May 2013

\section{Keywords:}

Coronavirus

Ion channel

Lipid charge

Envelope protein

SARS

\begin{abstract}
A B S T R A C T
A partial characterization of the ion channels formed by the SARS coronavirus (CoV) envelope (E) protein was previously reported (C. Verdiá-Báguena et al., 2012 [12]). Here, we provide new significant insights on the involvement of lipids in the structure and function of the CoV E protein channel on the basis of three series of experiments. First, reversal potential measurements over a wide range of $\mathrm{pH}$ allow the dissection of the contributions to channel selectivity coming from ionizable residues of the protein transmembrane domain and also from the negatively charged groups of diphytanoyl phosphatidylserine (DPhPS) lipid. The corresponding effective pKas are consistent with the model pKas of the acidic residue candidates for titration. Second, the change of channel conductance with salt concentration reveals two distinct regimes (Donnan-controlled electrodiffusion and bulk-like electrodiffusion) fully compatible with the outcomes of selectivity experiments. Third, by measuring channel conductance in mixtures of neutral diphytanoyl phosphatidylcholine (DPhPC) lipids and negatively charged DPhPS lipids in low and high salt concentrations we conclude that the protein-lipid conformation in the channel is likely the same in charged and neutral lipids. Overall, the whole set of experiments supports the proteolipidic structure of SARS-CoV E channels and explains the large difference in channel conductance observed between neutral and charged membranes.
\end{abstract}

(c) 2013 Elsevier B.V. All rights reserved.

\section{Introduction}

Coronaviruses are enveloped viruses that cause common colds in humans and other serious diseases in birds and mammals [1]. One of these coronaviruses is responsible for the severe acute respiratory syndrome (SARS-CoV), which, between 2002 and 2003, affected 8000 people worldwide and resulted lethal in the $10 \%$ of the cases. All coronaviruses express the envelope (E) protein, a multifunctional short polypeptide involved in virus morphogenesis and virulence [2-5]. SARS-CoV E protein is 76 amino acid long and contains an alpha-helical transmembrane (TM) domain that spans the lipid membrane with 28 residues [6] (Fig. 1) SARS-CoV E protein oligomerizes forming a pentameric structure that displays ion channel activity [7-12] a remarkable function for this protein that may affect virus host interaction.

In a recent paper [12] we reported that SARS-CoV E protein channels (as well as a synthetic peptide representing just the protein TM) exhibit different functional properties when reconstituted in neutral or charged planar lipid membranes. This data suggested that lipid molecules likely assemble with E protein oligomers to form a combined proteolipidic structure. In this structure the lipids could be only located at the channel entrances, or alternatively, within the

\footnotetext{
* Corresponding author. Tel.: + 34 964728045; fax: + 34964729218.

E-mail address: aguilell@uji.es (V.M. Aguilella).
}

lipid polar heads, stabilized by peptides, lining totally or partially the pore wall. The ion channel activity of a number of transmembrane proteins, as well as of small peptides and antimicrobial peptides, is strongly dependent on the lipid environment $[13,14]$. Actually, evidence on the lipid involvement in the channel structure is often obtained from the sensitivity of the pore-forming activity to the curvature of the lipid bilayer membranes [15]. The reason for that lies in the high energy cost of assembling lipidic structures in membranes with intrinsic curvature that usually inhibits the channel activity [16]. In this sense, we observed a lower probability of pore formation by SARS-CoV E protein in membranes containing phosphatidylethanolamine (DOPE), a lipid with negative intrinsic curvature [12], which suggests a significant involvement of lipid molecules in channel structure.

However, the correlation between the pore forming potency of peptides and the spontaneous curvature of the lipid is not a definitive argument to elucidate the actual structure of the SARS-CoV E channels. Similar correlations have been reported in well-known proteinaceous pores like alamethicin. In this case, the sensitivity of the channel to the lipid charge comes from a peptide-induced membrane thinning $[13,17]$. Therefore, in the case of SARS-CoV E protein, it seems important to obtain additional lines of evidence on the mechanism of pore formation and the functional properties of the resulting ion channels [12]. 


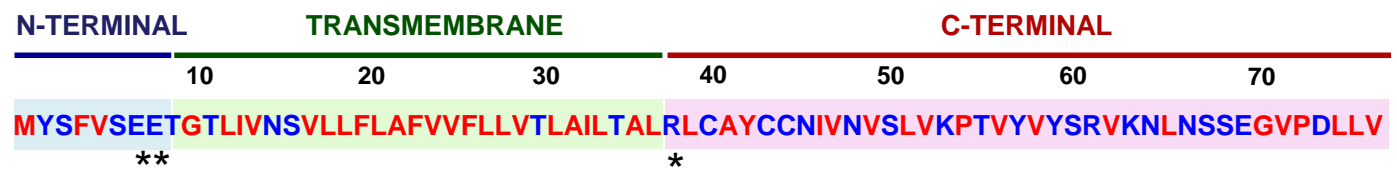

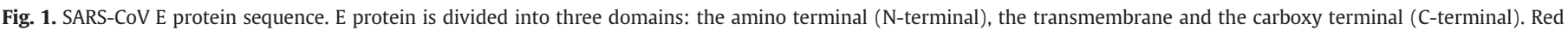

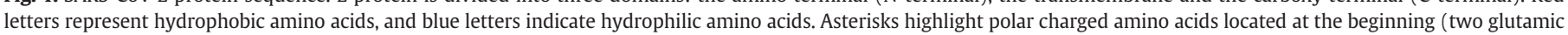
acid residues) and at the end (an arginine) of the transmembrane domain, respectively.

To address these issues a different strategy has been adopted in this manuscript, which is complementary to other structural studies [7]. We generated useful information on the CoV E channel structure by focusing on the effect of lipid charge on channel conductance and ionic selectivity under a variety of conditions. Several series of experiments are reported that have in common the modulation of the effective protein and lipid charge presented to the small ions crossing the aqueous pore [18]. First, reversal potential measurements under different $\mathrm{pH}$ conditions enabled us to identify the contributions of ionizable residues of the protein TM and also of the negatively charged groups of DPhPS lipid to channel selectivity. Secondly, the change of channel conductance in membranes containing varying ratios of neutral DPhPC lipids and charged DPhPS lipids in low and high salt concentrations was studied. Finally, protein and lipid charges were modified by changing the salt concentration of the solution both in neutral and charged membranes and the corresponding channel conductance and the solution conductivity were determined.

These three ways of modifying the effective fixed charge in CoV E channels strongly supported a proteolipidic structure of the channel that is likely to be the same in charged and neutral membranes. In other words, if this assumption proves correct, the large difference (two-fold change) between channel conductance in $1 \mathrm{M} \mathrm{KCl}$ in DPhPS and DPhPC host membranes would be simply an effect of the partial Donnan exclusion of anions in the aqueous pore [19].

Overall, exploring the lipid charge effects on channel conductance and selectivity over a wide range of lipid compositions, salt concentration and solution $\mathrm{pH}$ provided a unitary message for the protein-lipid composition of the channel. The results supported a proteolipidic structure without the need of additional sophisticated structural techniques.

\section{Materials and methods}

\subsection{Protein synthesis}

Full-length SARS-CoV E protein was kindly provided by Dr. Jaume Torres and synthesized and purified as previously described [12].

\subsection{Ion channel reconstitution and ionic current recording}

Planar bilayers were formed by apposition of two monolayers prepared from a solution of $1 \%$ pure diphytanoyl phosphatidylcholine (DPhPC), pure diphytanoyl phosphatidylserine (DPhPS), or a mixture of both lipids (Avanti polar lipids, Inc., Alabaster, AL) in pentane. Lipids were added on 70-90 $\mu \mathrm{m}$ diameter orifices in the $15 \mu \mathrm{m}$-thick Teflon partition that separated two identical chambers [20,21]. The orifices were pretreated with a $1 \%$ solution of hexadecane in pentane. Aqueous solutions of $\mathrm{KCl}$ were buffered with $5 \mathrm{mM}$ HEPES at pH 6 . All measurements were performed at room temperature $\left(23 \pm 1{ }^{\circ} \mathrm{C}\right)$. Ion channel insertion was achieved by adding $0.5-1 \mu \mathrm{l}$ of a $300 \mu \mathrm{g} / \mathrm{ml}$ solution of synthetic protein in the buffer containing acetonitrile:isopropanol (40:60) on one side of the chamber (hereafter referred to as cis side).

An electric potential was applied using $\mathrm{Ag} / \mathrm{AgCl}$ electrodes in $2 \mathrm{M}$ $\mathrm{KCl}, 1.5 \%$ agarose bridges assembled within standard $250 \mu \mathrm{l}$ pipette tips. The potential was defined as positive when it was higher on the side of the peptide addition (cis side), whereas the trans side was set to ground. An Axopatch 200B amplifier (Molecular Devices,
Sunnyvale, CA) in the voltage-clamp mode was used to measure the current and the applied potential. The chamber and the head stage were isolated from external noise sources with a double metal screen (Amuneal Manufacturing Corp., Philadelphia, PA). The channel conductance was obtained from current measurements under an applied potential of $+100 \mathrm{mV}$ in symmetrical salt solutions of variable $\mathrm{KCl}$ concentration. The conductance values were evaluated using the Gaussian fit tool of Sigma Plot 10.0 (Systat Software, Inc.).

The reversal potential, $E_{\mathrm{rev}}$, was obtained as follows. First, a lipid membrane was formed at a given salt concentration gradient. Second, one or several channels were inserted into the bilayer and a net ionic current appeared due to the concentration gradient. Third, the ionic current through the channel was manually set to zero by adjusting the applied potential. The potential needed to achieve zero current was then corrected by the liquid junction potentials of the electrode salt bridges [22] to obtain the $E_{\text {rev }}$.

\section{Results and discussion}

\subsection{Ion channel activity in planar lipid bilayers}

The spontaneous formation of full-length SARS-CoV E protein ion channels in DPhPC and DPhPS membranes as well as their current recording did not show significant differences to the analogous process done previously for synthetic peptides derived from the SARS-CoV E protein TM domain [12]. The reversal potential was measured in multichannel experiments as the voltage required to null the ionic current. To estimate the most probable value of channel conductance, we recorded more than 40 long duration ( $200 \mathrm{~s}$ each) current traces and made a statistical analysis of all the current jump events, including positive (increase) and negative (decrease) bursts.

Fig. 2 shows typical current traces recorded in DPhPC membranes (panel A) and DPhPS membranes (panel C) of SARS-CoV E channel. As already observed in electrophysiological measurements with synthetic peptides [12], CoV E channels formed in DPhPS membranes showed a better defined conductance ( $190 \pm 60 \mathrm{pS}$ ), compared with channels formed in DPhPC membranes, which exhibited a higher dispersion in the magnitude of the current bursts $(370 \pm 160 \mathrm{pS})$. This trend can be clearly observed in the histograms included in Fig. 2 . The origin of this different conductance variability depending on the host lipid remains unexplained.

\subsection{Channel selectivity change with $\mathrm{pH}$}

The SARS-CoV E channel was reported to be slightly cationic selective in negatively charged membranes and almost non-selective in neutral membranes at $\mathrm{pH} 6[8,12]$. From those results it became apparent the large influence of the lipid charge on the channel preference for cations. To further analyze this effect, channel selectivity in solutions of varying acidity was measured using the same concentration gradient used in previous studies $(500 \mathrm{mM}$ cis $\mid 50 \mathrm{mM}$ trans). Two series of reversal potential measurements were performed over a wide range of $\mathrm{pH}$ (1.5-7): first in neutral membranes (DPhPC) and then, using negatively charged membranes (DPhPS). The channel selectivity was strongly dependent on the net charge of the host lipid (Fig. 3). When reconstituted in DPhPC, the channel displayed a very 
A

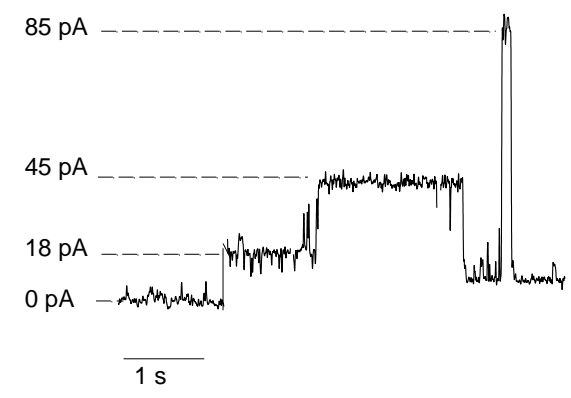

C

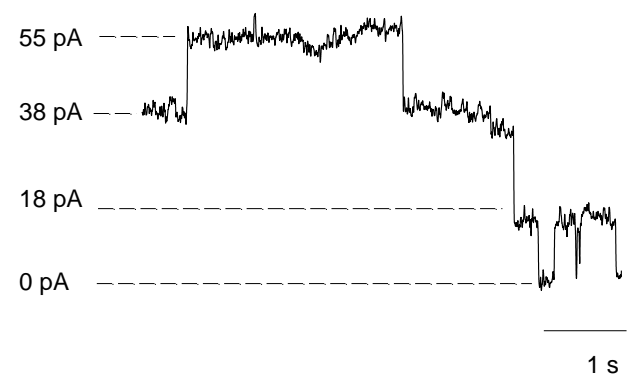

B

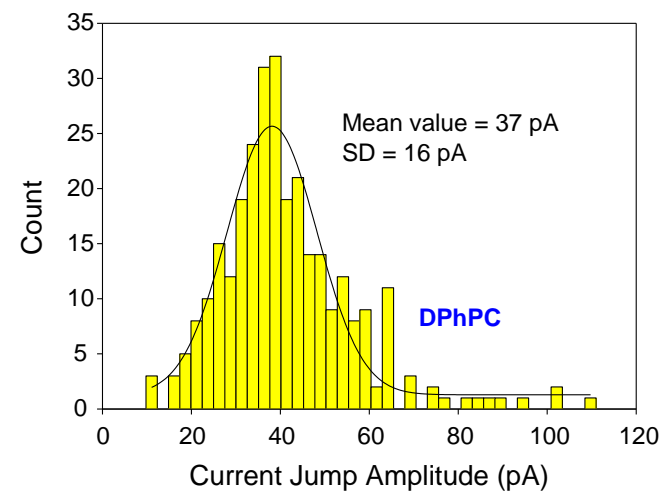

D

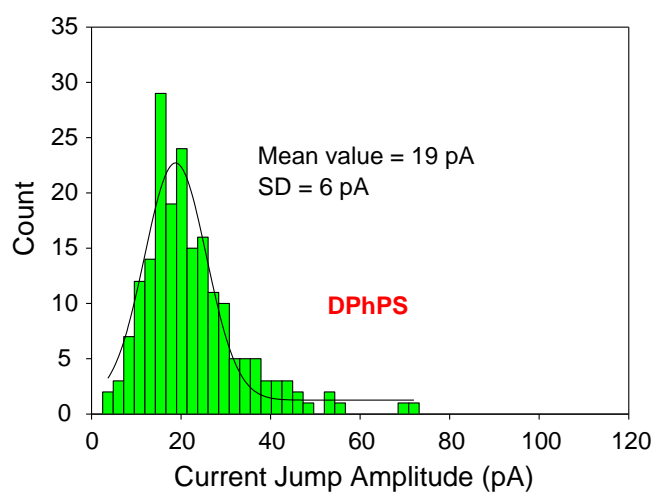

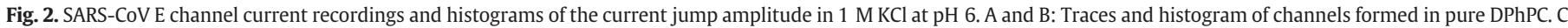

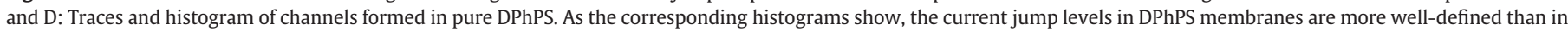

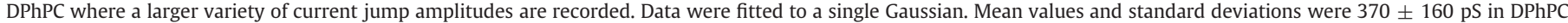
and $190 \pm 60 \mathrm{pS}$ in DPhPS.

mild cationic selectivity at neutral $\mathrm{pH}$ (ratio of the permeability to positive versus negative ions, $\left.\mathrm{P}_{+} / \mathrm{P}_{-}=1 \pm 0.1\right)$ and a moderate anionic selectivity in highly acidic solutions $(\mathrm{pH} 1.5)\left(\mathrm{P}_{+} / \mathrm{P}_{-}=0.3 \pm\right.$ 0.1 ). This change may be attributed to the protonation of some ionizable residues of the CoV E protein TM domain.

However, when the channels were inserted in DPhPS membranes, the change in selectivity from $\mathrm{pH} 6$ to $\mathrm{pH} 1.5$ was much more significant and titration of charges even reversed the channel selectivity from cationic selectivity to anionic one.

The reversal potential measurements performed in DPhPC membranes displayed the typical one-site titration trend seen in other channels [18,23-27]. We have fitted this set of $E_{\text {rev }}$ values to Eq. (1), similar to the standard sigmoidal dose-response curves.

$E_{\text {rev }}=E_{\min }+\frac{E_{\max }-E_{\min }}{1+10^{\mathrm{pH}-\mathrm{pKa} 1}}$

The low $\mathrm{pH}\left(E_{\max }\right)$ and neutral $\mathrm{pH}\left(E_{\min }\right)$ values for $E_{\text {rev }}$ were taken from the experimental data and pKa1 was the only fitting parameter. This approach has been successfully used in other weakly selective ion channels $[23,24,28]$. The best fit (solid line of upper plot in Fig. 3) corresponds to pKa1 $=4.3$, a value that is close to the model pKa of glutamate, one of the charged residues of the TM domain of SARS-CoV E protein. Actually, the amino acid sequence of that domain contains only two negative residues near the amino terminus: E7 and E8.

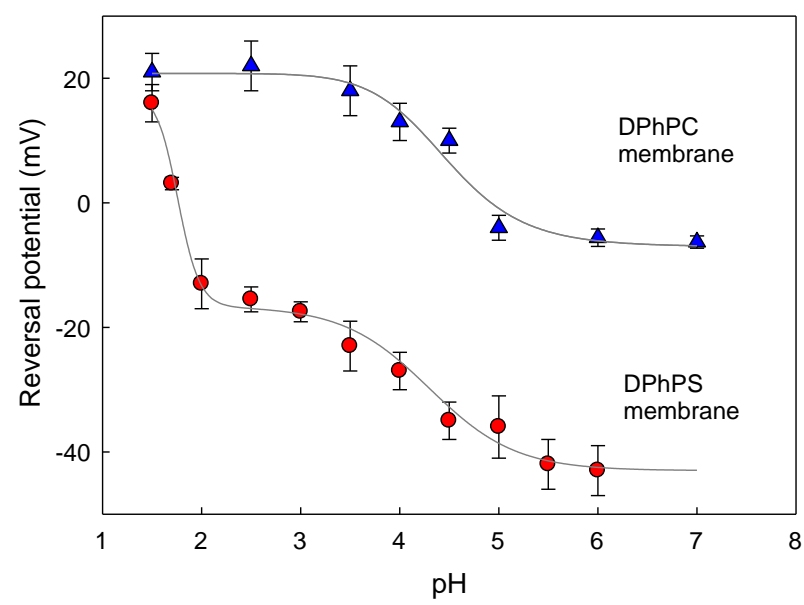

Fig. 3. E protein channel titration. Reversal potential was measured for SARS-CoV E protein channels in neutral DPhPC membranes (triangles) and negatively charged DPhPS membranes (circles). Under the conditions of the experiments $(500 \mathrm{mM} \mathrm{KCl}$ cis $\mid 50 \mathrm{mM} \mathrm{KCl}$ trans), negative and positive reversal potentials imply cationic and anionic selectivity, respectively. The lipid charge is the main determinant of channel ion selectivity but the subsequent titration of negative groups eventually switches the cationic selectivity into anionic in a high acidity medium, regardless of the nature of the host lipid. Solid lines denote the best fit of the data according to Eq. (1) (top plot) and Eq. (2) (bottom plot). Each point is the average of measurements in 10-15 channels. 
The series of $E_{\text {rev }}$ measurements in DPhPS membranes (red circles in Fig. 3) cannot be fitted to a classical one-site titration curve. We have slightly modified Eq. (1) to account for the double transition observed in selectivity and we have used Eq. (2):

$E_{\text {rev }}=E_{\min }+\frac{E_{\text {int }}-E_{\min }}{1+10^{\mathrm{pH}-\mathrm{pKa} 1}}+\frac{E_{\mathrm{max}}-E_{\text {int }}}{1+10^{\mathrm{pH}-\mathrm{pKa} 2}}$.

By taking the low $\mathrm{pH}\left(E_{\max }\right)$ and neutral $\mathrm{pH}\left(E_{\min }\right)$ values for $E_{\text {rev }}$ from the experimental data and leaving pKa1 and pKa2 as well as $E_{\text {int }}$ as fitting parameters, the best fit was obtained for $E_{i n t}=-19 \mathrm{mV}$, $\mathrm{pKa} 1=4.3$ and $\mathrm{pKa} 2=1.73$. The easiest interpretation of this second effective pKa seen in the titration curve is to ascribe this value to the carboxyl group of the PS polar head although titration of the phosphate group cannot be totally excluded. This would support the view that lipids line the pore lumen and not only contribute but also determine the channel selectivity. The model pKas of serine carboxyl group reported in the literature are in the range $2.5-4.5$ [29,30]. However, when the ionization occurs in confined spaces as the pore, where protons see a different electric potential near the ionizable site, it is expected a significant deviation from the model pKa [30]. In concentrated solutions the apparent pKa (the one obtained from titration curves) should be shifted towards lower values [31]. Interestingly, the fitting value of pKa $1=4.3$ is the same in both series of measurements. This fact may indicate that the protonation of glutamates in the TM protein domain is not affected by the presence of carboxyl groups of the lipid polar heads despite the presumably tight arrangement of the TM helices and the lipid molecules. This is consistent with the fact that there are many more carboxyl than glutamate groups lining the pore so that the organization of helices and lipid molecules in the pore may be such that both types of charged groups are kept apart from each other.

The reversal potential measurements for both kinds of lipids (DPhPC and DPhPS) are almost equal in solutions of high acidity. This implies that the channel preference for $\mathrm{Cl}^{-}$ions over $\mathrm{K}^{+}$ions at $\mathrm{pH} \sim 1.5$ is the same no matter whether the pore structure includes PC or PS lipids. Bearing in mind that lipid polar heads are neutral at such low $\mathrm{pH}$, this anionic selectivity can only arise from positively charged residues of the TM helices like arginine R38. This suggests that the charge of the lipid heads does not necessarily change the structural conformation of the aqueous pore: the spatial distribution of positive residues in the channel could be similar when the protein channel is formed either in DPhPC or DPhPS membranes.

\subsection{Conductance is strongly dependent on the net charge of the host lipid}

In a recent study [12], we reported that the conductance of SARS-CoV E protein channel in $1 \mathrm{M} \mathrm{KCl}$ and $\mathrm{pH} 6$ was $G=370 \pm$ $160 \mathrm{pS}$ in DPhPC membranes and $G=190 \pm 60$ pS in DPhPS membranes. These values raise relevant questions. The main one is how to interpret the result obtained for DPhPC that is almost twice the value obtained for DPhPS. This, together with huge standard deviations found in the experiments could question whether the unitary channel conductance reported in neutral membranes is truly a single-channel conductance or it is the result of two simultaneous insertion events. To address this issue, we measured channel conductance in membranes with variable lipid composition between pure DPhPC and pure DPhPS. The values of channel conductance were extracted from the histograms of current jump amplitudes. Both new insertions as well as channel closures were considered as events for the statistics [12]. The experimental results in $1 \mathrm{M} \mathrm{KCl}$ solutions and $\mathrm{pH} 6$ are shown at the top panel of Fig. 4 (circles). There is a smooth transition from $370 \mathrm{pS}$ (DPhPC membranes) to $190 \mathrm{pS}$ (DPhPS membranes) and the channel conductance decreases with the mass percentage of DPhPS lipid. This result clearly supports the interpretation already given in the preliminary version of these experiments [12], confirming that the channel conductance in $1 \mathrm{M} \mathrm{KCl} \mathrm{de-}$ creases as the charge of the lipid increases (Fig. 4).
This directly leads to the next question. According to intuitive electrostatic arguments, the accumulation of ions near the pore entrance due to the lipid charge should give just the opposite effect, i.e. greater channel conductance in DPhPS. Thus, we may ask whether the difference in conductance requires more elaborated arguments or if it could just be explained by a change in the aqueous pore size caused by a different lipid-protein conformation. A new series of conductance measurements performed in membranes of variable composition using diluted $\mathrm{KCl}$ solutions ( $30 \mathrm{mM}$ ) could shed some light on this issue. The experiments reported at the bottom panel of Fig. 4 (triangles) show that channel conductance in neutral membranes is lower (almost one third) than in fully charged membranes, exactly opposite to what was observed in concentrated salt solutions. If the changes in conductance with the lipid composition were simply a consequence of different protein-lipid conformations yielding changes in the pore size, the ionic current should decrease or increase in a similar way at low and high salt concentrations. Although a change in the pore size between DPhPC and DPhPS membranes cannot be categorically excluded, the main cause for this large change in channel conductance between them must be sought elsewhere.

\subsection{Change of channel conductance with salt concentration}

A classical way of analyzing the transport properties of a membrane channel is to compare channel conductance and bulk solution conductivity change at different salt concentrations [32,33]. The relation between channel conductance versus bulk solution conductivity for a wide range of salt concentration $(30 \mathrm{mM}-1.5 \mathrm{M} \mathrm{KCl})$ at $\mathrm{pH} 6$ was determined (Fig. 5).

In neutral membranes, channel conductance changes linearly with solution conductivity (the slope of the double logarithmic plot is very close to unity). This means that the interaction between the permeating ions and the channel is so weak that ion conduction in the pore and in bulk solution is pretty similar to each other. This is consistent with the weak selectivity of the channel at neutral pH (see Fig. 3, top plot) [12]. The channel resembles a neutral nanopore and ion permeation is barely influenced by the low fixed charge density in the protein TM domain. In contrast, when channel conductance is measured in DPhPS membranes, two distinct regimes were observed. In low concentration solutions (30-100 mM KCl), channel conductance is $\sim 70 \mathrm{pS}$ and is independent of conductivity. In contrast, in more concentrated solutions (0.3$1.5 \mathrm{M} \mathrm{KCl}$ ) conductance increases with conductivity but does not scale with bulk conductivity, as it is the case in charged pores [14]. This result

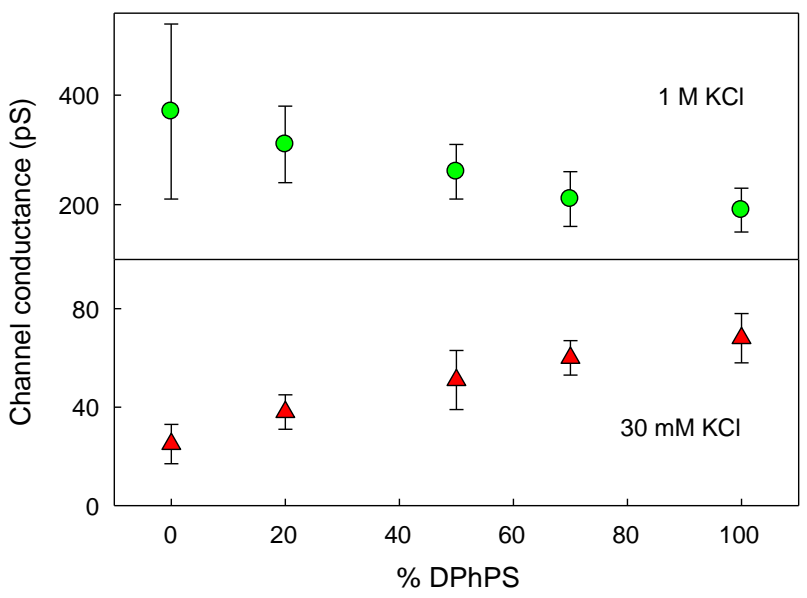

Fig. 4. Channel conductance for SARS-CoV E protein in different lipid compositions and salt concentration. E protein conductance in planar membranes made of different mixtures of neutral DPhPC and negatively charged DPhPS lipids in $1 \mathrm{M} \mathrm{KCl}$ (top panel) and $30 \mathrm{mM} \mathrm{KCl}$ solutions (bottom panel) at pH 6. For clarity, the vertical axis scaling is different in each panel. The fraction of charged lipid is given in mass percentage. 


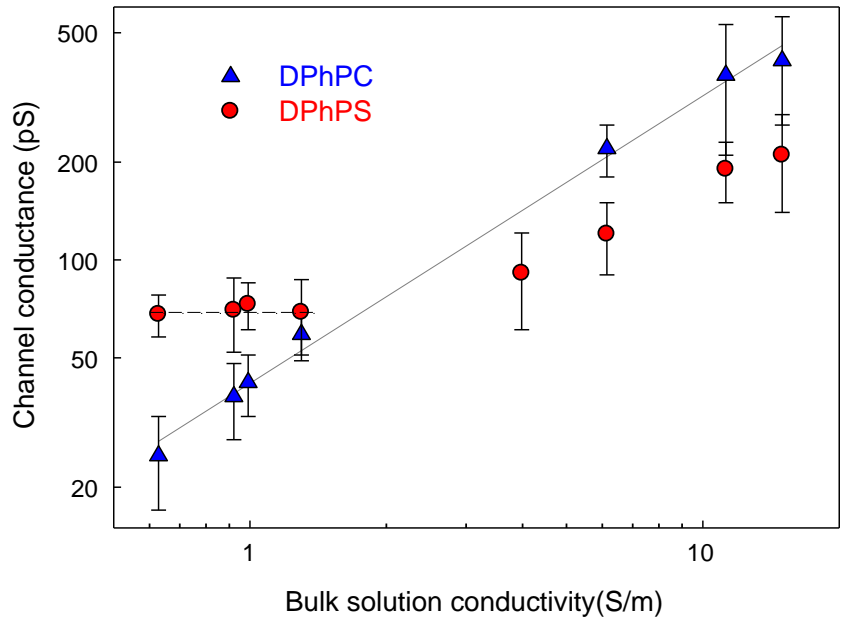

Fig. 5. Double logarithmic plot of channel conductance of the SARS-CoV E versus bulk solution conductivity. Channel conductance in DPhPC (triangles) is proportional to bulk solution conductivity. However, in DPhPS (circles), conductance is independent from conductivity in low concentration $\mathrm{KCl}$ solutions $(30-100 \mathrm{mM})$ but increases with conductivity in more concentrated solutions $(0.3-1.5 \mathrm{M})$.

is in line with the cationic selectivity of the CoV E channel in negatively charged membranes (see Fig. 3, bottom plot) and with the fact that the preference for $\mathrm{K}^{+}$ions should be reflected on the channel conductance, particularly when $\mathrm{KCl}$ concentration is smaller than the effective negative fixed charge concentration in the pore.

To go a step further of this qualitative explanation of the conductance vs. conductivity dependence in neutral and charged membranes, we assumed that channel conductance is proportional to the total concentration of mobile ions inside the channel, i.e. $G \propto\left(c_{+}+c_{-}\right)$and the $\mathrm{K}^{+}$and $\mathrm{Cl}^{-}$average concentrations inside the pore were calculated by using Donnan equilibrium equations [18].

$$
\begin{aligned}
& c_{+}=-\rho / 2+\left(c^{2}+\rho^{2} / 4\right)^{1 / 2} \\
& c_{-}=\rho / 2+\left(c^{2}+\rho^{2} / 4\right)^{1 / 2}
\end{aligned}
$$

where $c$ is the salt bulk concentration and $\rho$ is the average fixed charge concentration inside the channel (with the corresponding sign). Then, conductance was normalized to the lowest value (the one measured in $30 \mathrm{mM} \mathrm{KCl}$ ) and $\rho$ was regarded as a fitting parameter:

$G(c) / G(30 \mathrm{mM})=\left(c^{2}+\rho^{2} / 4\right)^{1 / 2}$.

The best fits of the conductance vs. concentration dependence were determined (Fig. 6, solid lines). For the series of measurements in $\operatorname{DPhPC} \rho=0.14 \mathrm{M}$. For conductance values in DPhPS $\rho=0.94 \mathrm{M}$. Despite the simplicity of the theory invoked, both values give accurate fits of the respective measurements and are consistent with the change of conductance with solution conductivity. In DPhPC, only the negative residues of the protein TM domain contribute to the fixed charge concentration and their effect is of minor importance. In DPhPS membranes, as long as the bulk concentration is smaller than $\rho$, the ion concentration inside the pore rises to match $\rho$ so that local electroneutrality is ensured. Charge neutrality is then the reason why in this regime, channel conductance is higher than in a neutral pore and almost independent of bulk concentration. When bulk concentration becomes comparable to $\rho$, counterions (ions of opposite charge to $\rho$ ) accumulate and coions (ions with the same charge as $\rho$ ) are excluded following Donnan equilibria. Finally, when salt concentration is much greater than $\rho$, Donnan exclusion comes to be negligible and conductance increases almost linearly with the total ion concentration in the pore, similarly to a neutral pore.

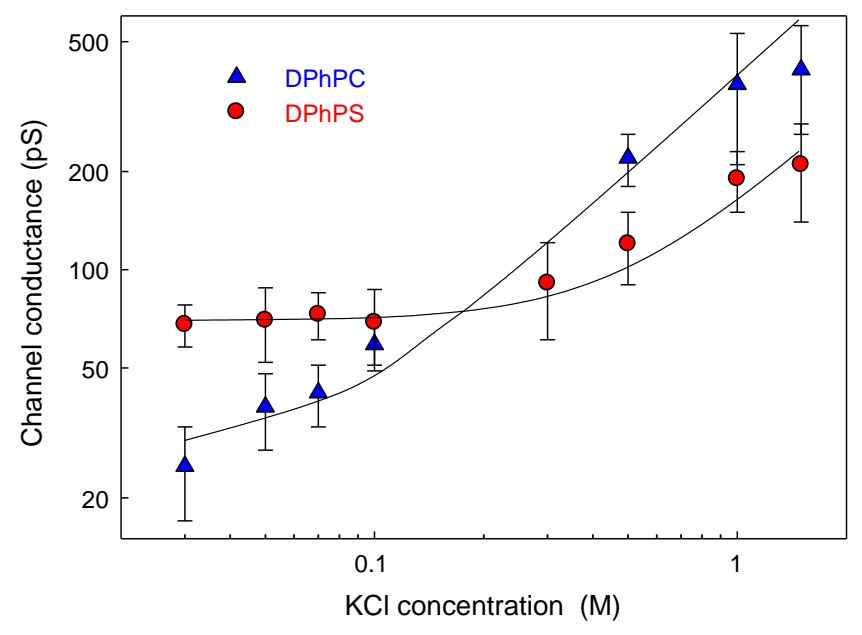

Fig. 6. Channel conductance of SARS-CoV E protein channel in neutral DPhPC (triangles) and negatively charged DPhPS (circles) at pH 6. In DPhPS membranes and low concentration $\mathrm{KCl}$ solutions $(30-100 \mathrm{mM}$ ) the channel conductance remains unaltered because the ionic concentration within the pore is controlled by the channel fixed charge. In more concentrated solutions (0.3-1.5 M), the conductance increases with the bulk $\mathrm{KCl}$ concentration following fairly well the dependence given by Eq. (4).

The values obtained for the average fixed charge concentration in the pore are also consistent with the difference in reversal potential measured at pH 6 in DPhPC and DPhPS membranes. Although we cannot exclude completely a different arrangement of protein helices and lipid molecules in neutral and charged membranes, our experiments provide strong evidence that the charged groups within the pore can account by themselves for the higher ionic current measured in charged membranes.

\section{Concluding remarks}

Novel insights on the involvement of lipids in the structure and function of the $\mathrm{CoV}$ E protein channel are presented here by analyzing the reconstituted ion channels in artificial membranes under a variety of different conditions. On one side, reversal potential experiments indicate that although both the protein and the lipid charges participate in the overall ionic selectivity of the pore, they play separate roles that can be clearly dissected. On the other side, channel conductance measurements suggest that the lipid charges contribute to the channel current by accumulating counterions as described by the well-known Donnan equilibrium. However, this simple effect must be handled with care because it leads to distinct regimes depending on the balance between the bulk electrolyte concentration and the average fixed charge concentration inside the channel. Interestingly, both kinds of experiments performed in neutral and charge lipids can be rationalized with no need to appeal to different channel conformations. This does not exclude the existence of different protein-lipid conformations, but stresses how important is the understanding of charge regulation effects that otherwise could be mistakenly attributed to changes in pore size.

\section{Acknowledgements}

This work was supported by grants from the Ministry of Science and Innovation of Spain (MICINN. FIS2010-19810, BIO2007-60978 and BIO2010-16705), Fundació Caixa Castelló-Bancaixa (P11B2012-03), Generalitat Valenciana (Prometeu/2012/069), the European Community's Seventh Framework Programme (FP7/ 2007-2013) under the project “EMPERIE" EC grant agreement number 223498, and the U.S. National Institutes of Health (NIH) (2P01AI060699-06A1, W000306844). CVB received a fellowship from UJI. JLN received a fellowship from CSIC. We thank Jaume Torres for providing reagents, and Marga Gonzalez for her technical assistance. 


\section{References}

[1] L. Enjuanes, F. Almazán, I. Sola, S. Zuñiga, Biochemical aspects of coronavirus replication and virus-host interaction, Annu. Rev. Microbiol. 60 (2006) 211-230.

[2] J. Ortego, J.E. Ceriani, C. Patiño, J. Plana, L. Enjuanes, Absence of E protein arrests transmissible gastroenteritis coronavirus maturation in the secretory pathway, Virology 368 (2007) 296-308.

[3] M.L. DeDiego, E. Álvarez, F. Almazán, M.T. Rejas, E. Lamirande, A. Roberts, W.-J. Shieh, S.R. Zaki, K. Subbarao, L. Enjuanes, A severe acute respiratory syndrome coronavirus that lacks the $\mathrm{E}$ gene is attenuated in vitro and in vivo, J. Virol. 81 (2006) 1701-1713.

[4] M.L. DeDiego, L. Pewe, E. Alvarez, M.T. Rejas, S. Perlman, L. Enjuanes, Pathogenicity of severe acute respiratory coronavirus deletion mutants in hACE-2 transgenic mice, Virology 376 (2008) 379-389.

[5] M.L. DeDiego, J.L. Nieto-Torres, J.M. Jiménez-Guardeño, J.A. Regla-Nava, E. Álvarez, J.C. Oliveros, J. Zhao, C. Fett, S. Perlman, L. Enjuanes, Severe acute respiratory syndrome coronavirus envelope protein regulates cell stress response and apoptosis, PLoS Pathog. 7 (2011) e1002315.

[6] J.L. Nieto-Torres, M.L. DeDiego, E. Alvarez, J.M. Jiménez-Guardeño, J.A. Regla-Nava, M. Llorente, L. Kremer, S. Shuo, L. Enjuanes, Subcellular location and topology of severe acute respiratory syndrome coronavirus envelope protein, Virology 415 (2011) 69-82.

[7] K. Pervushin, E. Tan, K. Parthasarathy, X. Lin, F.L. Yu Jiang, D.A. Vararattanavech, T.W. Soong, D.X. Liu, J. Torres, Structure and inhibition of the SARS coronavirus envelope protein ion channel, PLoS Pathog. 5 (2009) e1000511.

[8] L. Wilson, C. McKinlay, P. Gage, SARS coronavirus E protein forms cation-selective ion channels, Virology 330 (2004) 322-331.

[9] J. Torres, J. Wang, K. Parthasarathy, D.X. Liu, The transmembrane oligomers of coronavirus protein E, Biophys. J. 88 (2005) 1283-1290.

[10] J. Torres, K. Parthasarathy, X. Lin, R. Saravanan, A. Kukol, D.X. Liu, Model of a putative pore: the pentameric $\alpha$-helical bundle of SARS coronavirus E protein in lipid bilayers, Biophys. J. 91 (2006) 938-947.

[11] J. Torres, U. Maheswari, K. Parthasarathy, L. Ng, D. Xiang Liu, X. Gong, Conductance and amantadine binding of a pore formed by a lysine-flanked transmembrane domain of SARS coronavirus envelope protein, Protein Sci. 16 (2007) 2065-2071.

[12] C. Verdiá-Báguena, J.L. Nieto-Torres, A. Alcaraz, M.L. DeDiego, J. Torres, V.M. Aguilella, L. Enjuanes, Coronavirus E protein forms ion channels with functionally and structurally-involved membrane lipids, Virology 432 (2012) 485-494.

[13] A.A. Sobko, E.A. Kotova, Y.N. Antonenko, S.D. Zakharov, W.A. Cramer, Lipid dependence of the channel properties of a colicin E1-lipid toroidal pore, J. Biol. Chem 281 (2006) 14408-14416.

[14] V.V. Malev, L.V. Schagina, P.A. Gurnev, J.Y. Takemoto, E.M. Nestorovich, S.M. Bezrukov, Syringomycin E channel: a lipidic pore stabilized by lipopeptide? Biophys. J. 82 (2002) 1985-1994

[15] A.A. Sobko, E.A. Kotova, Y.N. Antonenko, S.D. Zakharov, W.A. Cramer, Effect of lipids with different spontaneous curvature on the channel activity of colicin E1: evidence in favor of a toroidal pore, FEBS Lett. 576 (2004) 205-210.
[16] S.M. Bezrukov, Functional consequences of lipid packing stress, Curr. Opin. Colloid Interface Sci. 5 (2000) 237-240.

[17] M.T. Lee, W.C. Hung, F.Y. Chen, H.W. Huang, Many-body effect of antimicrobial peptides: in the correlation between lipid's spontaneous curvature and pore formation, Biophys. J. 89 (2005) 4006-4016.

[18] A. Alcaraz, E.M. Nestorovich, M. Aguilella-Arzo, V.M. Aguilella, S.M. Bezrukov, Salting out the ionic selectivity of a wide channel: the asymmetry of OmpF, Biophys. J. 87 (2) (2004) 943-957.

[19] N. Lakshminarayanaiah, Equations of Membrane Biophysics, Academic Press, New York, 1984.

[20] S.M. Bezrukov, I. Vodyanoy, Probing alamethicin channels with water-soluble polymers. Effect on conductance of channel states, Biophys. J. 64 (1993) 16-25.

[21] M. Montal, P. Mueller, Formation of bimolecular membranes from lipid monolayers and a study of their electrical properties, Proc. Natl. Acad. Sci. U. S. A. 69 (1972) 3561-3566.

[22] A. Alcaraz, E.M. Nestorovich, M.L. López, E. García-Giménez, S.M. Bezrukov, V.M. Aguilella, Diffusion, exclusion, and specific binding in a large channel: a study of OmpF selectivity inversion, Biophys. J. 96 (2009) 56-66.

[23] J. Cervera, A.G. Komarov, V.M. Aguilella, Rectification properties and pH-dependent selectivity of Meningococcal class 1 porin, Biophys. J. 94 (2008) 1194-1202.

[24] T.K. Rostovtseva, T.-T. Liu, M. Colombini, V.A. Parsegian, S.M. Bezrukov, Positive cooperativity without domains or subunits in a monomeric membrane channel, Proc. Natl. Acad. Sci. U. S. A. 97 (2000) 7819-7822.

[25] L. Raymond, S.L. Slatin, A. Finkelstein, Channels formed by colicin E1 in planar lipid bilayers are large and exhibit pH-dependent ion selectivity, J. Membr. Biol. 84 (1975) 173-181.

[26] J.O. Bullock, Ion selectivity of colicin E1: modulation by $\mathrm{pH}$ and membrane composition, J. Membr. Biol. 125 (1992) 255-271.

[27] P.G. Merzlyak, M.P. Capistrano, A. Valeva, J.J. Kasianowicz, O.V. Krasilnikov, Conductance and ion selectivity of a mesoscopic protein nanopore probed with cysteine scanning mutagenesis, Biophys. J. 89 (2005) 3059-3070.

[28] A. Alcaraz, M. Queralt-Martín, E. García-Giménez, V.M. Aguilella, Increased salt concentration promotes competitive block of OmpF channel by protons, BBA Biomembr. 1818 (2012) 2777-2782.

[29] J.F. Tocanne, J. Teissie, Ionization of phospholipids and phospholipid-supported interfacial lateral diffusion of protons in membrane model systems, Biochim. Biophys. Acta 1031 (1990) 111-142.

[30] T.K. Rostovtseva, V.M. Aguilella, I. Vodyanoy, S.M. Bezrukov, V.A. Parsegian, Membrane surface-charge titration probed by gramicidin A channel conductance, Biophys. J. 75 (1998) 1783-1792.

[31] F.C. Tsui, D.M. Ojcius, W.L. Hubbel, The intrinsic pKa values for phosphatidylserine and phosphatidylethanolamine in phosphatidylcholine host bilayers, Biophys. J. 49 (1986) 459-468.

[32] B. Hille, Ion Channels of Excitable Membranes, 3rd ed. Sinauer, Sunderland, MA, 2001.

[33] F. Helfferich, Ion Exchange, McGraw-Hill, New York, 1962. 


\title{
Severe Acute Respiratory Syndrome Coronavirus Envelope Protein Ion Channel Activity Promotes Virus Fitness and Pathogenesis
}

\author{
Jose L. Nieto-Torres ${ }^{1}$, Marta L. DeDiego ${ }^{10}$, Carmina Verdiá-Báguena ${ }^{2}$, Jose M. Jimenez-Guardeño ${ }^{1}$, \\ Jose A. Regla-Nava ${ }^{1}$, Raul Fernandez-Delgado ${ }^{1}$, Carlos Castaño-Rodriguez ${ }^{1}$, Antonio Alcaraz ${ }^{2}$, \\ Jaume Torres ${ }^{3}$, Vicente M. Aguilella ${ }^{2}$, Luis Enjuanes ${ }^{1 *}$
}

1 Department of Molecular and Cell Biology, Centro Nacional de Biotecnología (CNB-CSIC), Campus Universidad Autónoma de Madrid, Madrid, Spain, 2 Department of Physics, Laboratory of Molecular Biophysics. Universitat Jaume I, Castellón, Spain, $\mathbf{3}$ School of Biological Sciences, Division of Structural and Computational Biology, Nanyang Technological University, Singapore, Singapore

\begin{abstract}
Deletion of Severe Acute Respiratory Syndrome Coronavirus (SARS-CoV) envelope (E) gene attenuates the virus. E gene encodes a small multifunctional protein that possesses ion channel (IC) activity, an important function in virus-host interaction. To test the contribution of E protein IC activity in virus pathogenesis, two recombinant mouse-adapted SARSCoVs, each containing one single amino acid mutation that suppressed ion conductivity, were engineered. After serial infections, mutant viruses, in general, incorporated compensatory mutations within $\mathrm{E}$ gene that rendered active ion channels. Furthermore, IC activity conferred better fitness in competition assays, suggesting that ion conductivity represents an advantage for the virus. Interestingly, mice infected with viruses displaying E protein IC activity, either with the wild-type E protein sequence or with the revertants that restored ion transport, rapidly lost weight and died. In contrast, mice infected with mutants lacking IC activity, which did not incorporate mutations within E gene during the experiment, recovered from disease and most survived. Knocking down E protein IC activity did not significantly affect virus growth in infected mice but decreased edema accumulation, the major determinant of acute respiratory distress syndrome (ARDS) leading to death. Reduced edema correlated with lung epithelia integrity and proper localization of $\mathrm{Na}^{+} / \mathrm{K}^{+}$ATPase, which participates in edema resolution. Levels of inflammasome-activated IL-1 $\beta$ were reduced in the lung airways of the animals infected with viruses lacking $E$ protein IC activity, indicating that E protein IC function is required for inflammasome activation. Reduction of IL-1 $\beta$ was accompanied by diminished amounts of TNF and IL- 6 in the absence of E protein ion conductivity. All these key cytokines promote the progression of lung damage and ARDS pathology. In conclusion, E protein IC activity represents a new determinant for SARS-CoV virulence.
\end{abstract}

Citation: Nieto-Torres JL, DeDiego ML, Verdiá-Báguena C, Jimenez-Guardeño JM, Regla-Nava JA, et al. (2014) Severe Acute Respiratory Syndrome Coronavirus Envelope Protein Ion Channel Activity Promotes Virus Fitness and Pathogenesis. PLoS Pathog 10(5): e1004077. doi:10.1371/journal.ppat.1004077

Editor: Mark R. Denison, Vanderbilt University, United States of America

Received December 23, 2013; Accepted March 5, 2014; Published May 1, 2014

Copyright: (c) 2014 Nieto-Torres et al. This is an open-access article distributed under the terms of the Creative Commons Attribution License, which permits unrestricted use, distribution, and reproduction in any medium, provided the original author and source are credited.

Funding: This work was supported by grants from the Ministry of Science and Innovation of Spain (BIO2010-16705), the European Community's Seventh Framework Programme (FP7/2007-2013) under the project "EMPERIE" EC Grant Agreement number 223498, and U.S. National Institutes of Health (NIH) (2P01Al060699 and 0258-3413/HHSN266200700010C). Financial support from Generalitat Valenciana (Prometeu 2012/069) and Fundacion Caixa Castello-Bancaixa (Project No. P1-1B2012-03) is also acknowledged. JLN received a contract from NIH. JAR and CCR received fellowships from Fundacion La Caixa. The funders had no role in study design, data collection and analysis, decision to publish, or preparation of the manuscript.

Competing Interests: The authors have declared that no competing interests exist.

* E-mail: L.Enjuanes@cnb.csic.es

a Current address: David H. Smith Center for Vaccine Biology and Immunology, University of Rochester Medical Center, Rochester, New York, United States of America

\section{Introduction}

Coronaviruses $(\mathrm{CoVs})$ are vertebrate pathogens that cause severe diseases in a wide range of animals and infections in humans that until recently were limited to common colds [1]. Nevertheless, by the end of 2002, a novel coronavirus causing the severe acute respiratory syndrome (SARS-CoV) emerged in China and rapidly spread worldwide causing around 8000 infections leading to death in $10 \%$ of the cases [2,3]. Since then, $\mathrm{CoVs}$ surveillance programs were intensified, and two additional human coronaviruses, already circulating in the human population, were identified as the causative agents of several cases of pneumonia and bronchiolitis (HCoV-HKU1 and HCoV-NL63) [4]. Furthermore, in 2012 a novel coronavirus infecting humans, the Middle East Respiratory Syndrome Coronavirus (MERS$\mathrm{CoV}$ ) appeared in Saudi Arabia and disseminated to nine additional countries [5,6]. To date, 182 cases of MERS-CoV have been reported, which has led to 79 fatalities (http://www. who.int). Clinical presentation of infected individuals involves acute pneumonia, sometimes accompanied by renal disease [7]. CoVs similar to SARS-CoV and MERS-CoV have also been isolated from bats widely distributed throughout the world [8-13], which represents a potential reservoir for outbreaks of novel zoonoses into humans. Therefore, understanding the virulence 


\section{Author Summary}

Several highly pathogenic viruses encode small transmembrane proteins with ion-conduction properties named viroporins. Viroporins are generally involved in virus production and maturation processes, which many times are achieved by altering the ion homeostasis of cell organelles. Cells have evolved mechanisms to sense these imbalances in ion concentrations as a danger signal, and consequently trigger the innate immune system. Recently, it has been demonstrated that viroporins are inducers of cytosolic macromolecular complexes named inflammasomes that trigger the activation of key inflammatory cytokines such as IL-1 $\beta$. The repercussions of this system in viral pathogenesis or disease outcome are currently being explored. SARS-CoV infection induces an uncontrolled inflammatory response leading to pulmonary damage, edema accumulation, severe hypoxemia and eventually death. In this study, we report that SARS-CoV E protein ion channel activity is a determinant of virulence, as the elimination of this function attenuated the virus, reducing the harmful inflammatory cytokine burst produced after infection, in which inflammasome activation plays a critical role. This led to less pulmonary damage and to disease resolution. These novel findings may be of relevance for other viral infections and can possibly be translated in order to find therapies for their associated diseases.

mechanisms of these pathogens, will allow the development of effective therapies in order to prevent and control future outbreaks.

SARS-CoV is an enveloped virus containing a positive sense RNA genome of $29.7 \mathrm{~kb}$, one of the largest viral RNA genomes known. The genome encodes a viral replicase involved in the synthesis of new genomes and in the generation of a nested set of subgenomic messenger RNAs, encoding both structural proteins present in all CoVs: Spike (S), Envelope (E), Membrane (M) and Nucleoprotein $(\mathrm{N})$, and a group of proteins specific for SARSCoV: 3a, 3b, 6, 7a, 7b, 8a, 8b, and 9b [14]

SARS-CoV E protein is a 76-amino acid transmembrane protein actively synthesized during viral infection, that mainly localizes at the ERGIC region of the cell, where virus budding and morphogenesis take place [15-18]. Different requirements of $\mathrm{E}$ protein during the virus cycle have been described among CoVs. Elimination of $\mathrm{E}$ gene in transmissible gastroenteritis coronavirus (TGEV) or MERS-CoV leads to a replication-competent propagation-deficient phenotype [19-21]. In contrast, deletion of $\mathrm{E}$ gene from mouse hepatitis virus (MHV) or SARS-CoV does not abolish virus production, although viral titers are significantly reduced by 1000 to 20-fold, respectively [16,22]. Interestingly, E gene deleted SARS-CoV (SARS-CoV- $\Delta \mathrm{E}$ ) was attenuated in three animal models, and confers protection against challenge with parental virus in immunized hamsters, and in young or aged mice, representing a promising vaccine candidate [16,23-27]. Cells infected with SARS-CoV- $\Delta \mathrm{E}$ show increased stress and apoptotic markers compared to wild type virus, perhaps resulting in a decreased productivity of infection [28]. Additionally, elimination of the $\mathrm{E}$ gene diminishes inflammation induced by SARS-CoV through the NF- $\kappa$ B pathway [27].

Remarkably, SARS-CoV E protein was found to self-interact forming a pentameric structure that delimits an ion conductive pore, which may play a role in virus-host interaction [29-32]. E protein ion conductivity was also confirmed for a set of CoVs from different genera [33]. The ion channel (IC) activity of SARS-CoV $\mathrm{E}$ protein was mapped within the transmembrane domain of the protein by using synthetic peptides [31,34,35]. Recent studies determined that both ion conductance and selectivity of $\mathrm{E}$ protein ion channel were highly controlled by the charge of the lipid membranes in which the pores were assembled. This suggests that lipid head-groups are components of the channel structure facing the lumen of the pore, a novel concept for $\mathrm{CoV} \mathrm{E}$ protein ion channel [34,36]. Chemically synthesized SARS-CoV E protein showed slight preference for cations over anions when reconstituted in lipids that mimicked both charge and composition of ERGIC membranes, and displayed no specific selectivity for a particular cation $[34,36]$. In addition, point mutations that suppressed SARS-CoV E protein IC activity (N15A and V25F) have been identified and confirmed [34,35].

Several reports have analyzed the relevance of $\mathrm{CoV}$ E protein transmembrane domain, which contains ion-conduction properties, in virus maturation and production. Insertion of alanine residues within the transmembrane domain of MHV $\mathrm{E}$ protein rendered crippled viruses that evolutionary reverted to restore a proper structure of the alpha helix within the transmembrane domain [37]. Interchanging the genus $\beta \mathrm{CoV}$ MHV E protein transmembrane domain by those of $\mathrm{CoV}$ s from different genera revealed that only domains belonging to genus $\beta$, and $\gamma$, but not $\alpha$, functionally replaced MHV E transmembrane domain in terms of viral production. It was speculated that this effect was a consequence of the possible different ion selectivity of these domains [38]. Replacement of genus $\gamma \mathrm{CoV}$ infectious bronchitis virus (IBV) $\mathrm{E}$ protein transmembrane domain, which displays IC activity, for vesicular stomatitis virus (VSV) G protein transmembrane domain lacking this function, interfered with an efficient trafficking and release of the viral progeny in the infected cells [39]. In contrast, mutation of threonine at position 16 to alanine, which is the amino acid change predicted to inhibit IC activity in IBV E protein did not affect virus-like particles formation, suggesting a multifunctional role of $\mathrm{E}$ protein [40].

Besides the E protein, SARS-CoV encodes two other ionconducting proteins, $3 \mathrm{a}$ and $8 \mathrm{a}[41,42]$. In a related virus, human coronavirus 229E (HCoV-229E), novel IC activity has been described within the $4 \mathrm{a}$ protein [43]. The abundance and conservation of IC activity suggests an importance of influencing ion homeostasis within cells during the $\mathrm{CoV}$ infection cycle.

Modulation of the cellular ion balance seems to be a common issue for viruses, as a growing list of viroporins are being identified, especially within RNA viruses [44]. Highly pathogenic human viruses such as influenza $A$ virus, human immunodeficiency virus (HIV), hepatitis $\mathrm{G}$ virus (HCV) and several picornaviruses, among others, encode at least one viroporin [45-49]. Viroporins have been involved in virus entry, trafficking, morphogenesis, maturation and even virulence [50-53]. Influenza virus M2 is essential for viral RNA release from infections virions within the endosome into the cell cytoplasm [45] and also for raising the $\mathrm{pH}$ at the transGolgi network lumen, which prevents premature activation of hemaglutinin, which may render non-infectious virions [54]. Similarly, HCV p7 protein equilibrates the $\mathrm{pH}$ at the Golgi apparatus, protecting acid-sensitive intracellular virions [51]. Coxsackievirus 2B protein alters Golgi and endoplasmic reticulum (ER) $\mathrm{Ca}^{2+}$ and $\mathrm{H}^{+}$concentrations, which in turn delay protein transport through the secretory pathway facilitating virus assembly and preventing major histocompatibility complex (MHC) molecules from reaching the cell surface $[48,55,56]$. A recent finding described that influenza M2 protein IC activity triggers NOD-like receptor family, pyrin domain containing 3 (NLRP3) inflammasome activation [52]. Furthermore, mutant versions of M2 protein that conduct $\mathrm{Na}^{+}$and $\mathrm{K}^{+}$ions apart from $\mathrm{H}^{+}$ions more strongly elicited the inflammasome response [52]. This novel mechanism of 
immune system activation has also been proven for other viroporins [53,57-59].

Viral proteins with IC activity impact different aspects of the virus life cycle, however, the involvement of their IC activity in pathogenesis remain to be further explored. Previous findings demonstrated that SARS-CoV E protein is a virulence determinant. In this manuscript we analyze the contribution of $\mathrm{E}$ protein IC activity in pathogenesis. Two recombinant viruses, each one containing a single point mutation suppressing IC activity, were generated by reverse genetics. Mutant viruses showed a tendency to evolve and restore $\mathrm{E}$ protein IC architecture and activity after serial infections, and viruses with deficient IC activity were outcompeted by those displaying this function after co-infections. This highlights the importance of IC activity in virus fitness. Interestingly, infection of mice with a set of viruses lacking or displaying $\mathrm{E}$ protein $\mathrm{IC}$ activity, revealed that the activation of inflammasome pathway, and the exacerbated inflammatory response induced by SARS-CoV was decreased in infections by on channel deficient viruses. In addition, less lung damage and proper localization of $\mathrm{Na}^{+} / \mathrm{K}^{+}$ATPase within epithelia, which prevents edema accumulation, was detected for the mice infected with the viruses lacking $\mathrm{E}$ protein IC activity. As a consequence, increased survival of the infected animals was observed when $\mathrm{E}$ protein ion conductivity was absent. Therefore, E protein IC activity is required for inflammasome activation and a novel determinant for the virulence of highly pathogenic SARS-CoV.

\section{Results}

\section{SARS-CoV E protein IC activity is not essential for virus production in cell culture}

Deletion of SARS-CoV E gene resulted in a virus that was attenuated in three animal models, as we have previously shown $[16,23,24,26,27]$. E gene codes for the small multifunctional $\mathrm{E}$ protein, which displays IC activity [31,34-36]. To specifically test the relevance of IC activity in virus virulence, residues involved in E protein ion conductance were firstly identified. To this end a set of synthetic peptides representing the transmembrane domain of $\mathrm{E}$ protein were evaluated for their IC activity. These peptides contained point mutations that affect different conserved residues, or residues predicted to face the lumen of the channel pore [34]. Mutations N15A and V25F within the transmembrane domain of E protein completely disrupted IC activity [34,35]. Accordingly, two recombinant viruses containing each of these two changes in the E gene, rSARS-CoV-E-N15A (N15A) and rSARS-CoV-EV25F (V25F), were engineered (Fig. 1). A SARS-CoV with a mouse adapted (MA15) genetic background [27,60] was used to generate these viruses, as infection of mice with SARS-CoV MA15 accurately reproduces the symptoms of human disease $[27,60]$. The mutant viruses were efficiently rescued, cloned by three rounds of plaque purification, and their sequence was confirmed (data not shown). To test whether the introduced mutations may alter $\mathrm{E}$ protein subcellular localization affecting other functions of the protein, Vero E6 cells were infected with the wt virus, the viruses lacking IC activity (N15A and V25F) or a virus missing $\mathrm{E}$ gene $(\Delta \mathrm{E})$ as a control. Immunofluorescence analysis showed similar colocalization patterns of $\mathrm{E}$ protein and ERGIC, the subcellular compartment where E protein mainly accumulates during infection, for both the wt and the mutant viruses (Fig. 2A), indicating that other functions of $\mathrm{E}$ protein associated with its localization are most likely not affected.

Deletions or mutations within the $\mathrm{E}$ gene of several CoVs sometimes led to crippled viruses or to lower virus yields $[16,20-$ $22,37,39]$. To test whether inhibition of $\mathrm{E}$ protein IC activity affects virus production, growth kinetics were performed in the monkey Vero E6 and mouse DBT-mACE2 cells [61]. Minor differences in growth rates were observed between the parental virus (wt), that contains $\mathrm{E}$ protein $\mathrm{IC}$ activity, and the mutant viruses that lack $\mathrm{E}$ protein IC activity $(\mathbf{F i g}$. 2B), indicating that this function was not essential for virus growth in cell culture. More striking differences in plaque phenotypes were observed. Mutant viruses lacking $\mathrm{E}$ protein IC activity, apparently formed smaller plaques than wt virus, and $\mathrm{V} 25 \mathrm{~F}$ virus plaques were smaller than N15A virus (Fig. 2C). A possible explanation for all these data could be that infection foci productivity and area may be quite similar regardless of $\mathrm{E}$ protein IC activity, as determined by viral titration, but higher cytopathic effect may be induced when $\mathrm{E}$ protein IC is present, rendering bigger plaques. Elimination of fulllength E protein induced more severe growth defects (Fig. 2B and Fig. 2C), suggesting that other functions of the protein contributing to virus production, apart from IC activity, may be affected.

\section{SARS-CoV E protein IC activity improves viral fitness}

Inhibition of $\mathrm{E}$ protein $\mathrm{IC}$ activity slightly reduced virus production in cell culture in a relatively short period of time, but these differences were not significant. To further explore whether ion conductivity could improve viral growth and fitness, a longterm competition assay was performed between the wt virus and the N15A mutant lacking IC activity, that was relative stable through passages as will be described below. Vero E6 cells were co-infected with $\mathrm{N} 15 \mathrm{~A}$ mutant and the wt virus in a proportion $7: 3$, and the supernatant was serially passaged for 20 times every 24 hours. The $\mathrm{E}$ gene was sequenced every 4 passages, revealing that the proportion of wt virus steadily increased over the passages, accompanied by a decrease in the abundance of the N15A mutant. From passage 8 on, the wt virus took and maintained majority over the N15A mutant (Fig. 3). These results suggested that E protein IC activity for SARS-CoV confers a selective advantage improving virus production.

\section{SARS-CoV E protein IC activity confers virulence in vivo}

To specifically analyze the contribution of E protein IC activity to SARS-CoV virulence, BALB/c mice were intranasally inoculated with the wt virus displaying $\mathrm{E}$ protein $\mathrm{IC}$ activity, or three independently-isolated clones of the mutant viruses $\mathrm{N} 15 \mathrm{~A}$ and V25F lacking E protein IC activity, and mice were monitored daily for 10 days $(n=5$ /virus clone). All infected animals showed disease symptoms at 2 days post infection (dpi), reflected by slower movements and ruffled fur (data not shown). Mice infected with the wt virus started to lose weight by day 2, and by day 5 all of them died (Fig. 4). Interestingly, although mice infected with the three clones of N15A mutant started to lose weight in a similar fashion, at day 4 almost all of them started to regain weight, recover from the disease, and $80-100 \%$ survived (Fig. 4). In contrast to $\mathrm{N} 15 \mathrm{~A}$, mice infected with $\mathrm{V} 25 \mathrm{~F}$ virus experimented similar weight losses and survival rates (from 0 to $20 \%$ ) than the wt virus $(\mathbf{F i g}$. 4). A possible explanation for this apparent discrepancy was the reversion of the introduced mutation or the incorporation of compensatory mutations restoring $\mathrm{E}$ protein IC activity. To test whether this was the case, total RNA was collected from the lungs of infected mice at 2 and 4 dpi or from the lungs of mice that died after infection. The virus genome region containing $\mathrm{E}$ gene was sequenced, as it was the target of the point mutations inhibiting IC activity, and therefore a likely place to incorporate compensatory mutations. E genes from wt virus and N15A mutant virus remained stable during the course of the experiment, since no changes were found in viral RNA extracted either from lungs of 


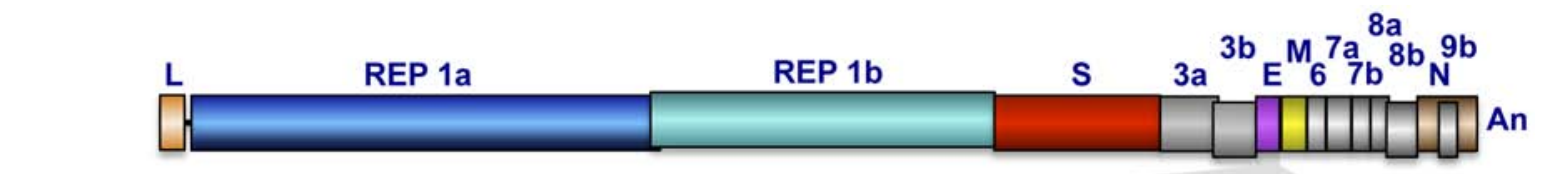
E PROTEIN

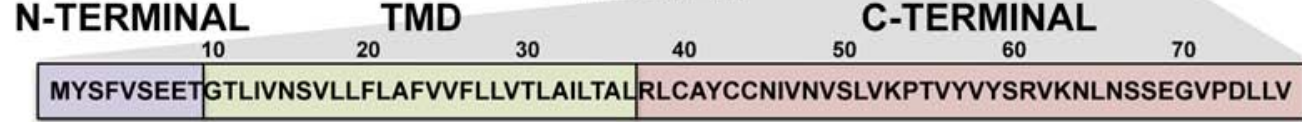

\section{rSARS-CoV-EIC-}

\begin{tabular}{ll|l|l|} 
N15A & MYSFVSEETGTLIVASVLLFLAFVVFLVTLAILTALRLCAYCCNIVNVSLVKPTVYVYSRVKNLNSSEGVPDLLV \\
V25F MYSFVSEETGTLIVNSVLLFLAFVFFLLVTLAILTALRLCAYCCNIVNVSLVKPTVYVYSRVKNLNSSEGVPDLLV
\end{tabular}

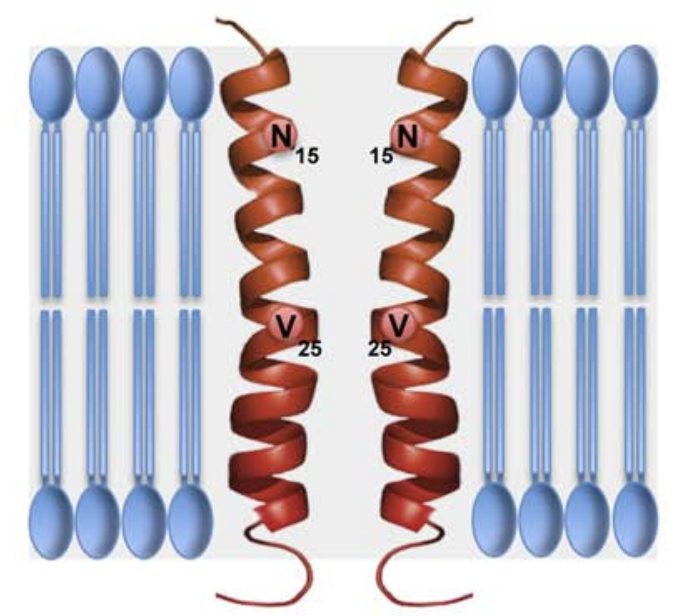

Figure 1. Engineering of rSARS-CoVs lacking E protein ion channel (IC) activity. SARS-CoV genome is represented at the top, and the region expanded shows wild type SARS-CoV E protein sequence $(\mathrm{wt})$ and its different domains: amino terminal (N-terminal), transmembrane (TMD) and carboxy terminal (C-terminal). To generate viruses lacking E protein ion channel activity (rSARS-CoV-EIC ${ }^{-}$) the amino acid changes N15A or V25F were introduced within viral genome to generate two recombinant viruses. The positions of the mutated residues within the transmembrane domain of a simplified E protein oligomer inserted in a lipid membrane are shown at the bottom.

doi:10.1371/journal.ppat.1004077.g001

several mice at 2 and 4 dpi or from dead mice (Fig. 5A). In contrast, $\mathrm{V} 25 \mathrm{~F}$ viruses incorporated mutations in the $\mathrm{E}$ gene that led to amino acid changes either in the same position of the mutation that abolished IC activity $(\mathrm{F} 25 \mathrm{C}$ ) or in relatively close positions within the $\mathrm{E}$ protein transmembrane domain: L19A, F20L, F26L, L27S, T30I and L37R (Fig. 5A). These evolved variants of the $\mathrm{V} 25 \mathrm{~F}$ virus appeared as early as 2 days after mice infection and, in some cases (T30I mutant), completely overgrew the original virus by day 2 . The tentative compensatory mutations were also present in the viral population at $4 \mathrm{dpi}$ and in dead mice (Fig. 5A). Overall, the data obtained with wt and N15A viruses, which were genetically stable throughout the experiment, suggest that $\mathrm{E}$ protein $\mathrm{IC}$ activity is required for a virulent phenotype.

Viruses missing $\mathrm{E}$ protein IC activity are prone to evolve and restore ion conductivity

To further analyze the evolution of the mutant viruses lacking $\mathrm{E}$ protein IC activity, two clones of the mutants $\mathrm{N} 15 \mathrm{~A}$ and $\mathrm{V} 25 \mathrm{~F}$ were serially passaged in cell culture. Throughout the 24 serial passages, E gene was sequenced at passages $0,8,16$ and 24 for the two mutant viruses and wt as control. As observed during in vivo infection, the wt virus remained stable during the passages
(Fig. 5B). V25F viruses rapidly incorporated additional mutations within E gene (L19A, L27S and T30I), reproducing our in vivo observations. The viruses incorporating T30I mutation completely out-competed the original V25F mutant by passage $8($ Fig. $5 \mathbf{B})$. In contrast, N15A viruses either remained stable or incorporated a mutation in the $\mathrm{E}$ gene (A15D) that appeared late, at passage 24, suggesting that this mutant was more stable, confirming our in vivo results $($ Fig. 5B). The data obtained in cell culture or after mice infection indicate that SARS-CoVs lacking $\mathrm{E}$ protein IC activity incorporated mutations at the $\mathrm{E}$ gene that directly reverted the original mutation that suppressed IC activity (A15D and F25C) or modified residues mapping to a close position of the $\mathrm{E}$ protein transmembrane domain. These modified residues face the original mutation inhibiting IC activity, when the ion channel is assembled (Fig. 6). To analyze whether these mutations restored IC activity, synthetic peptides representing the $\mathrm{E}$ protein transmembrane domain containing the mutations obtained after viral evolution in vivo and in cell culture (N15D, V25L, V25F L19A, V25F F26C, V25F L27S, V25F T30I, V25F L37R), were synthesized. The IC activity of these peptides was evaluated in artificial lipid membranes as previously described [34]. Whereas peptides containing the original mutations N15A and V25F did not show 
A

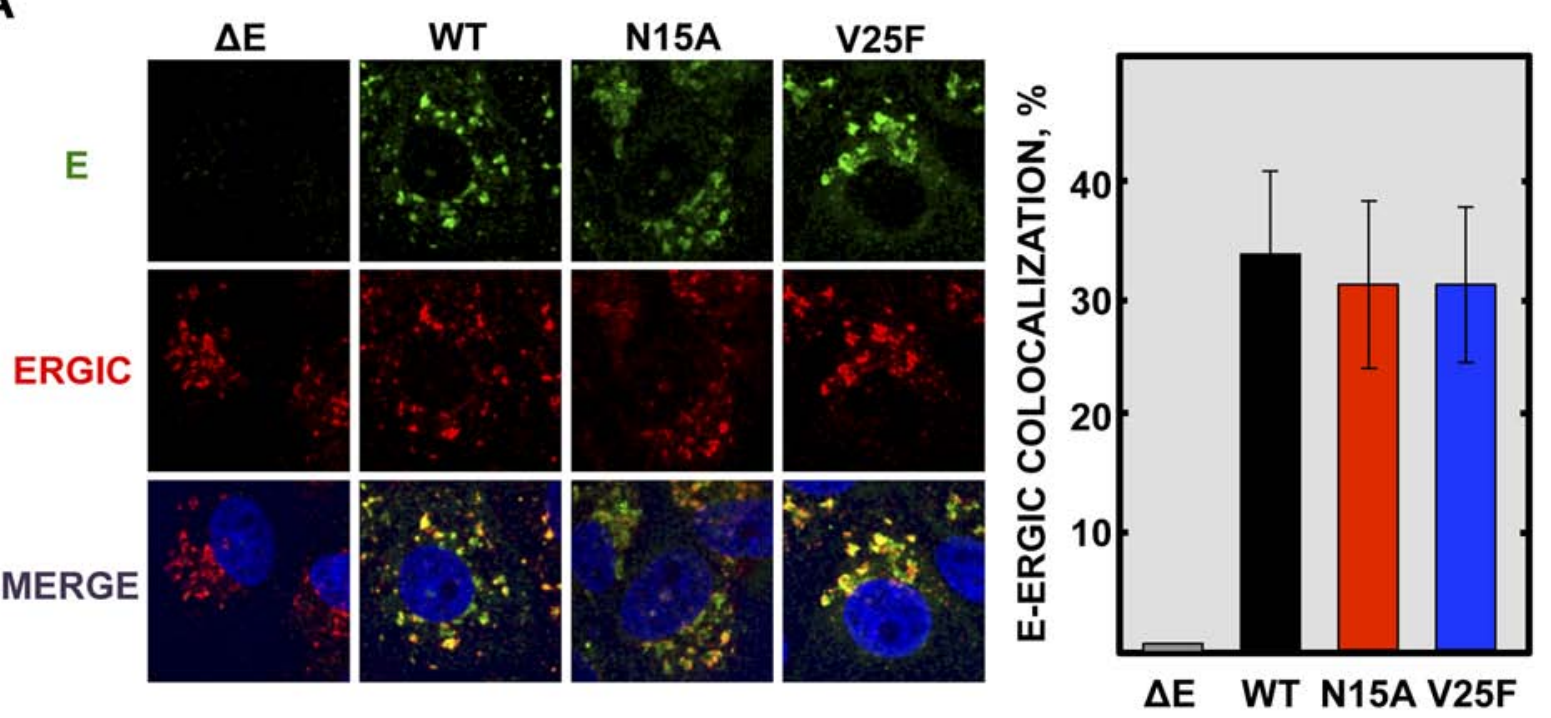

B

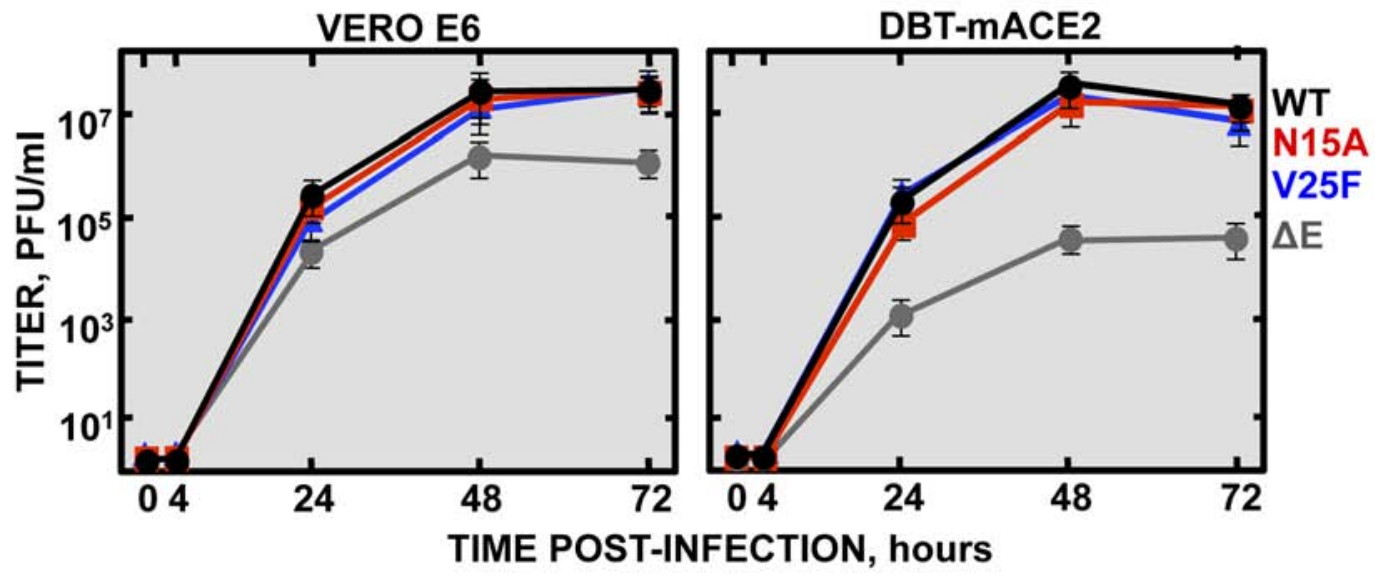

C
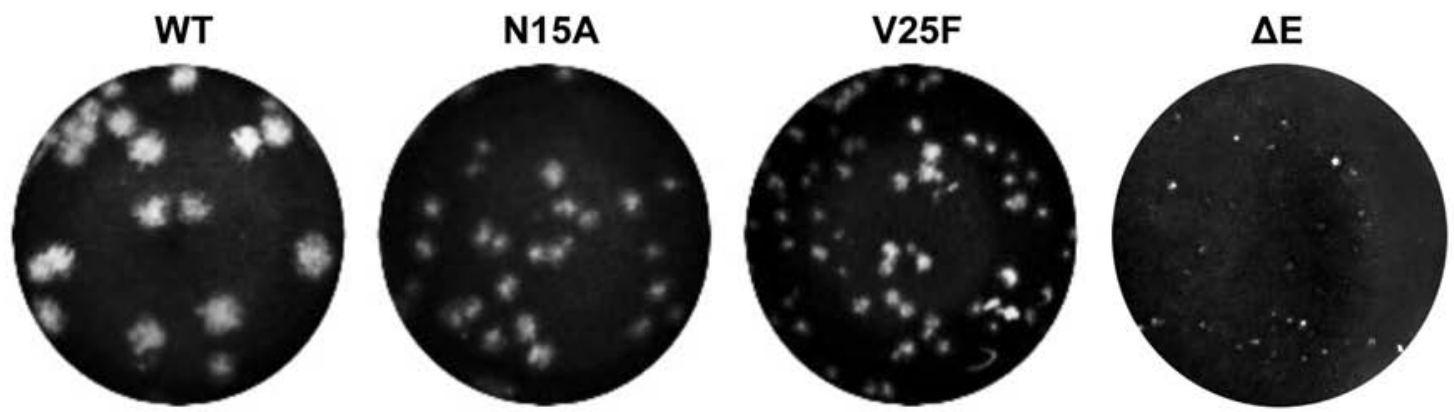

Figure 2. Subcellular localization of rSARS-CoV-EIC ${ }^{-}$E proteins, growth kinetics and plaque size. (A) Vero E6 cells were infected either with the mutant viruses (N15A and V25F), the parental virus (wt) or a virus lacking E gene $(\Delta \mathrm{E})$ at an $\mathrm{MOI}$ of 0.3 , fixed at $24 \mathrm{hpi}$ and $\mathrm{E}$ protein (green) and ERGIC (red) were labeled with specific antibodies. Nuclei were stained with DAPI (blue). Original magnification was $126 \times$. Right graphic on the panel represents the percentage of colocalization between E protein and ERGIC, calculated with Leica LAS AF v2.6.0 software. (B) Vero E6 and DBTmACE2 cells were infected at an MOI of 0.001 with mutant viruses lacking IC activity (N15A and V25F), the parental virus (wt) or a virus lacking E gene $(\Delta \mathrm{E})$, and viral progeny was titrated at the indicated times post-infection. Error bars represent the standard deviation of three independent experiments. (C) Plaque morphology of the parental, the mutant viruses N15A and V25F and a $\Delta \mathrm{E}$ virus.

doi:10.1371/journal.ppat.1004077.g002 


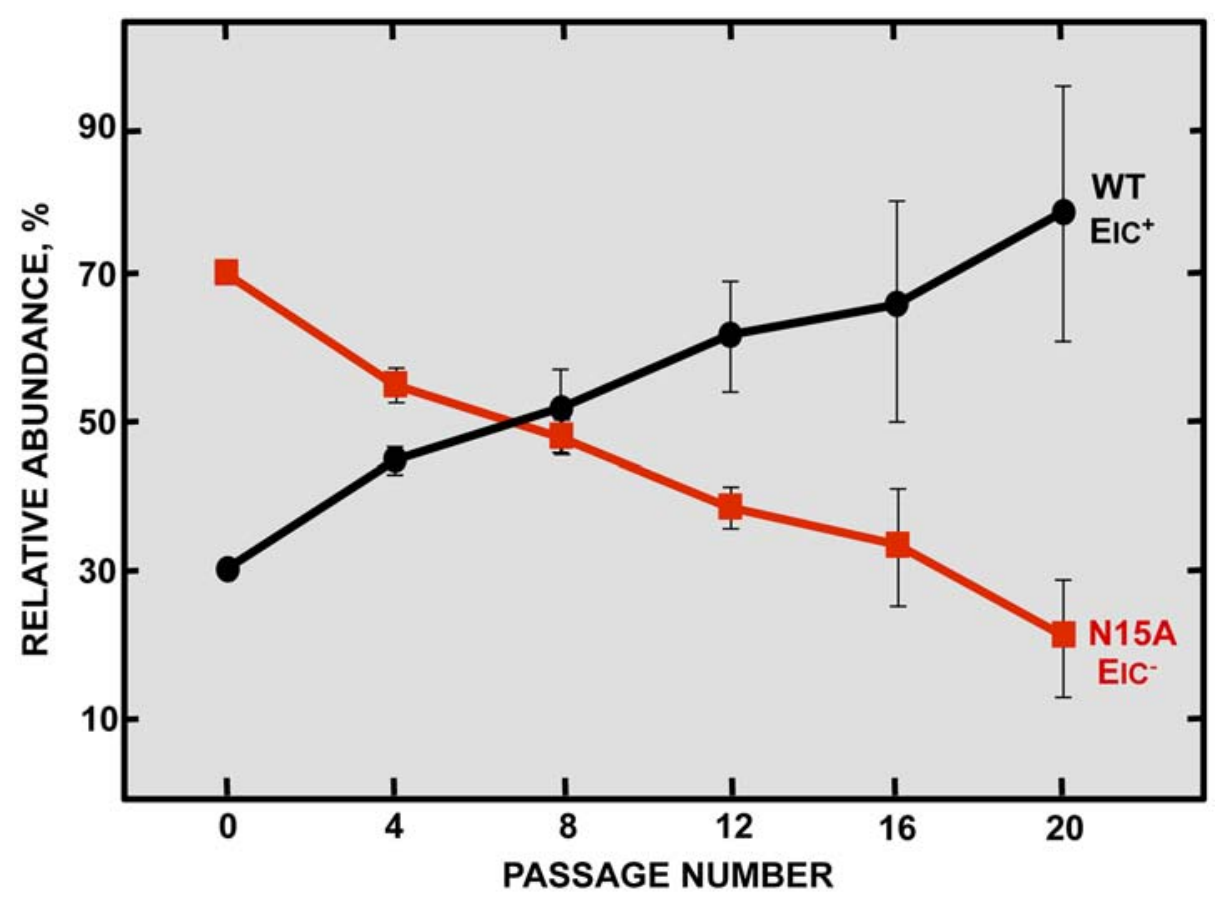

Figure 3. Effect of SARS-CoV E protein IC activity on viral fitness. Competition assays between the parental virus (wt, black circles) displaying IC activity (EIC ${ }^{+}$) and a mutant virus (N15A, red squares) lacking IC activity (EIC ${ }^{-}$) were performed. Vero E6 cells were co-infected with mutant and parental viruses at a ratio 7:3 and supernatants were serially passaged 20 times every 24 hours. Relative abundance of each virus was determined by sequencing $E$ gene within viral progeny. Error bars represent the standard deviation from three independent experiments.

doi:10.1371/journal.ppat.1004077.g003

any conductance, all the peptides containing the mutations obtained after viral evolution displayed similar conductance values than a wild type peptide (Fig. 7), indicating that all these compensatory mutations restored E protein IC activity.

Genetically engineered revertant viruses restoring $E$ protein IC activity show a virulent phenotype in mice

A correlation between IC activity and virulence was found in vivo, where $\mathrm{N} 15 \mathrm{~A}$ viruses lacking $\mathrm{IC}$ activity were attenuated compared to wt virus competent in $\mathrm{IC}$ activity. Mutant virus
$\mathrm{V} 25 \mathrm{~F}$, originally lacking ion conductivity, rapidly incorporated compensatory mutations upon infection in vivo that restored IC activity and thus caused pathogenicity. To test whether the recovery of IC activity was the unique determinant of virulence, and to rule out effects of other mutations arising outside of the $\mathrm{E}$ gene, recombinant viruses containing a set of the compensatory mutations that restored IC activity (rSARS-CoV-EIC ${ }^{\text {rev }}$ ): rSARSCoV-E-V25F L27S (V25F L27S), rSARS-CoV-E-V25F T30I (V25F T30I), rSARS-CoV-E-V25F L37R (V25F L37R) were engineered, rescued and tested in mice. These viruses were

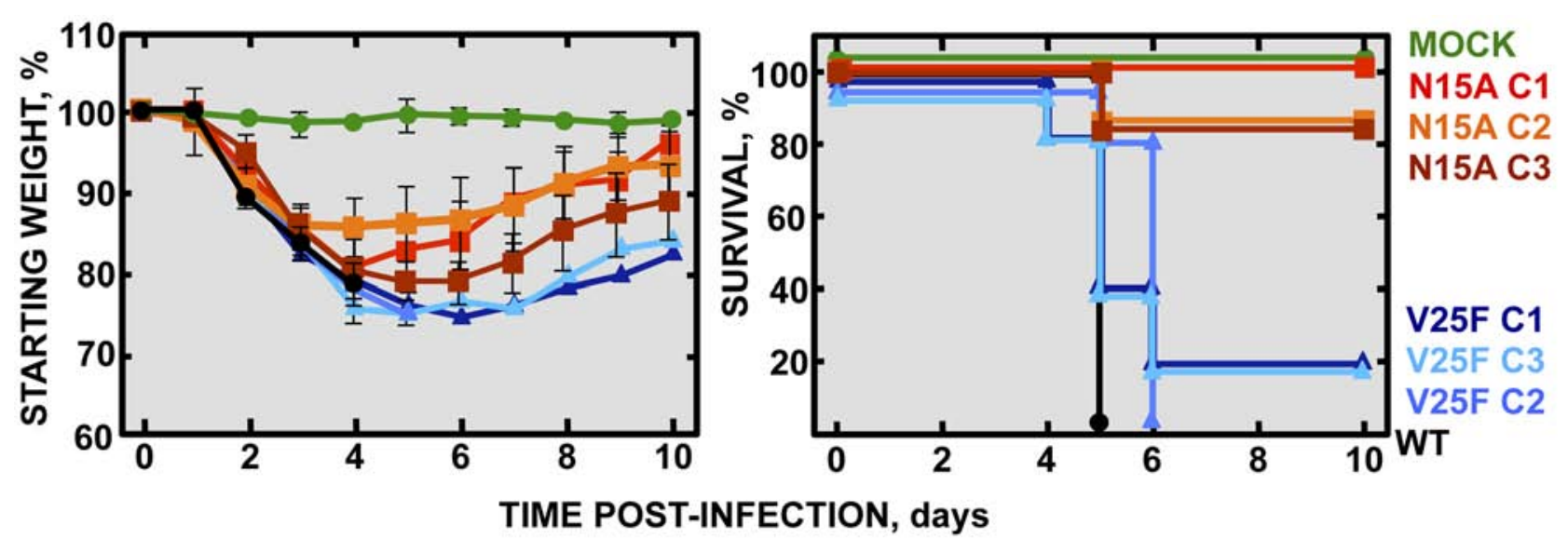

Figure 4. Pathogenesis caused by rSARS-CoV-EIC ${ }^{-}$in BALB/c mice. Groups of five 16 week-old BALB/c mice were mock infected (Mock, green circles) or infected with 100000 PFU of either the parental virus (wt, black circles) or several clones of the mutant viruses missing IC activity: N15A C1, N15A C2 and N15A C3 (red, orange and deep-red squares, respectively), and V25F C1, V25F C2 and V25F C3 (dark blue, blue and light blue triangles, respectively). Mean weight losses (left graph) and survival (right graph) during 10 days following infection are represented for each group. Error bars represent the standard deviation for mice weights per experimental condition. doi:10.1371/journal.ppat.1004077.g004 
A

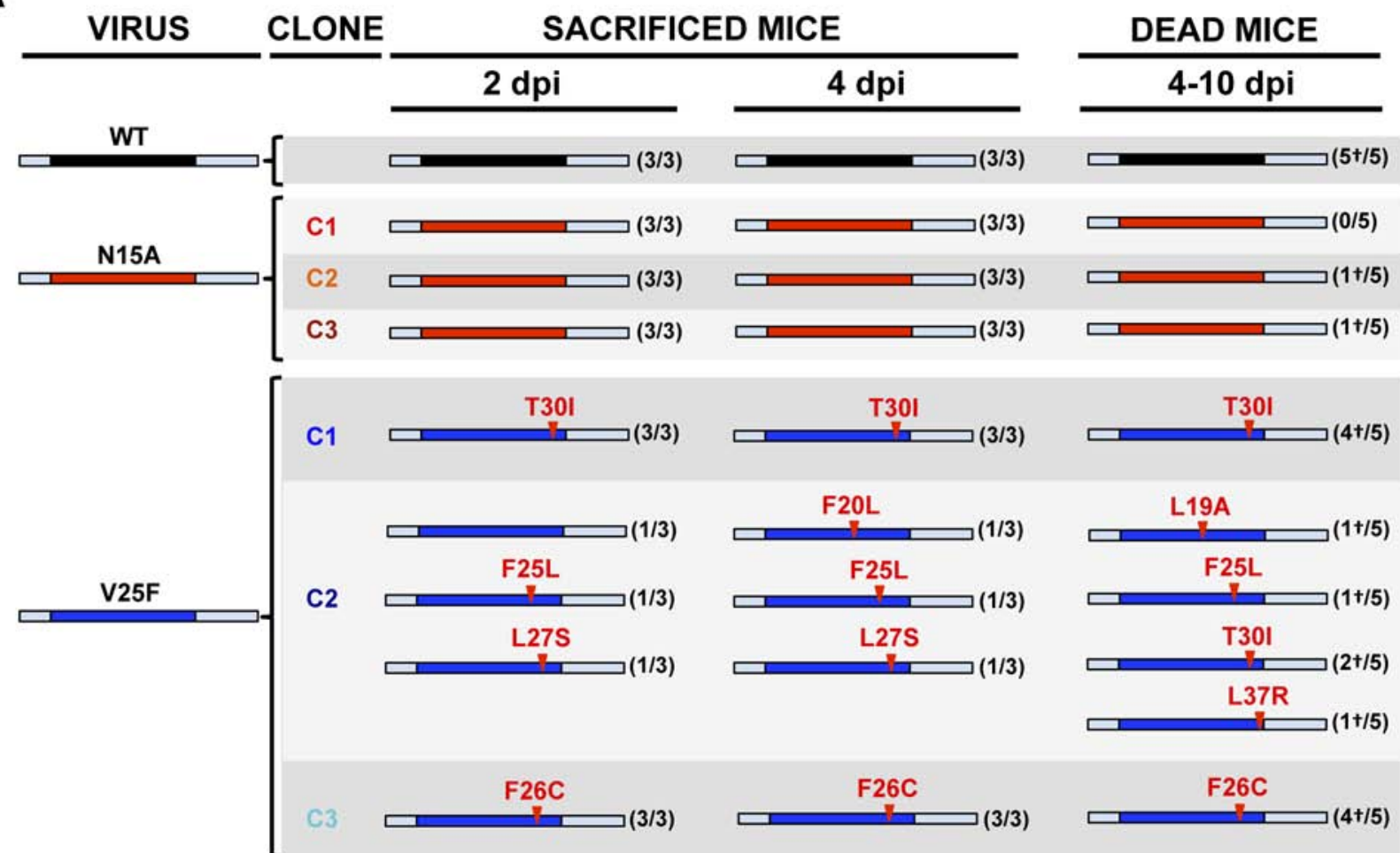

B

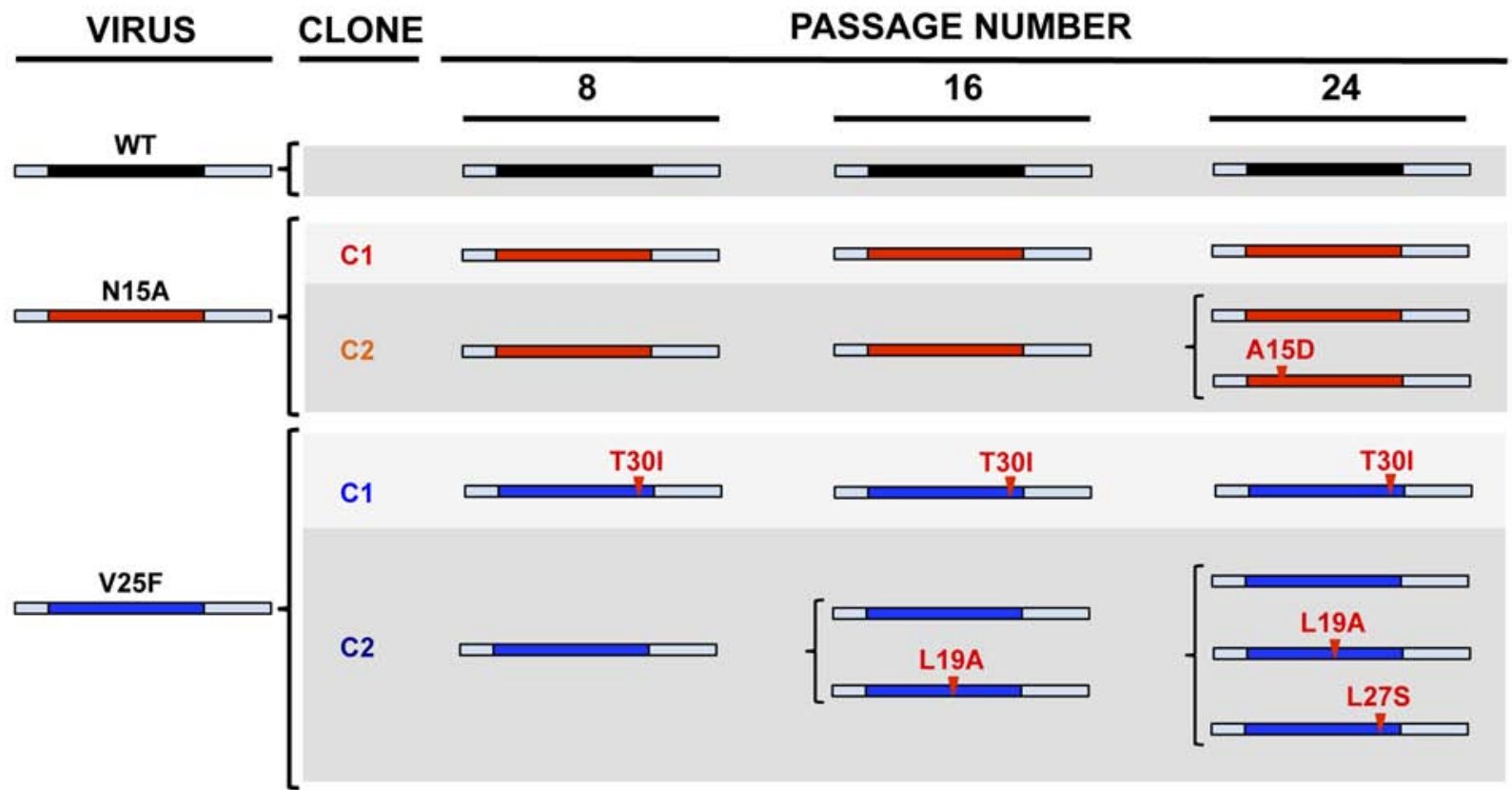

Figure 5. Stability of rSARS-CoV-EIC ${ }^{-}$after serial infections. (A) Groups of eleven 16 week-old BALB/C mice were infected with 100000 PFU of either the parental virus (wt) or three clones of the mutant viruses missing IC activity: N15A C1, N15A C2, N15A C3, V25F C1, V25F C2 and V25F C3. At $2 \mathrm{dpi}$ and 4 dpi 3 mice of each group were sacrificed, lung RNA was extracted, and E gene was sequenced. The rest of the mice (5 per group) participated in the weight-loss and survival experiment. When any mouse died, from 4 to $10 \mathrm{dpi}$, lung RNA was extracted and $E$ gene was sequenced. Bars represent different E protein sequences, either that of parental or the mutant viruses. The central colored part represents the transmembrane domain of the protein. Letters and numbers in red represent the amino acid changes detected after viral evolution and their relative position within transmembrane domain, respectively. Numbers accompanying bars indicate from how many mice (first number) out of the total of the animals analyzed (second number) arose the indicated sequence change. Dead mice are indicated by a $\dagger$. (B) Vero E6 cells were infected with the wt virus or the mutant clones N15A C1 and N15A C2, V25F C1 and V25F C2 at an initial MOI of 0.5, and supernatants were serially passaged for 24 times every 24 hours. E gene in the viral population was sequenced at passages $0,8,16$ and 24 . Colored bars represent the transmembrane domain of different $\mathrm{E}$ protein sequences and letters and numbers in red represent the amino acid mutations identified and their relative position, respectively. doi:10.1371/journal.ppat.1004077.g005 
A

MONOMER

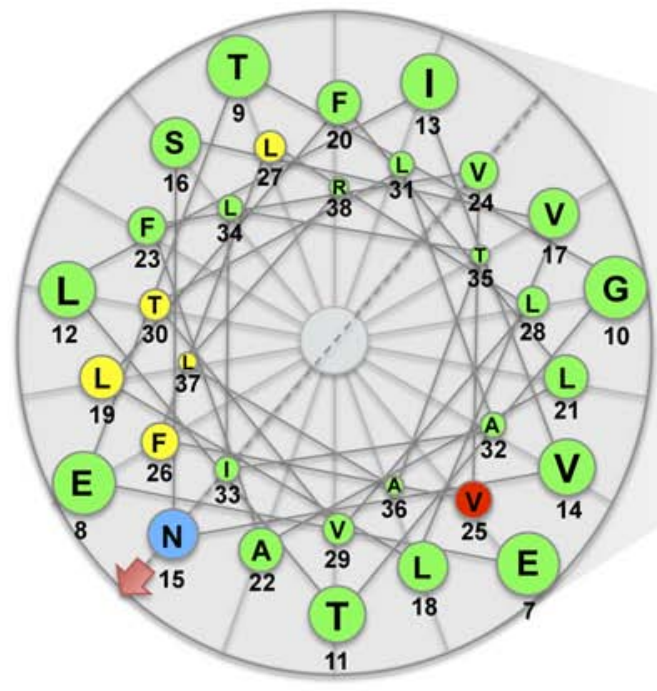

B

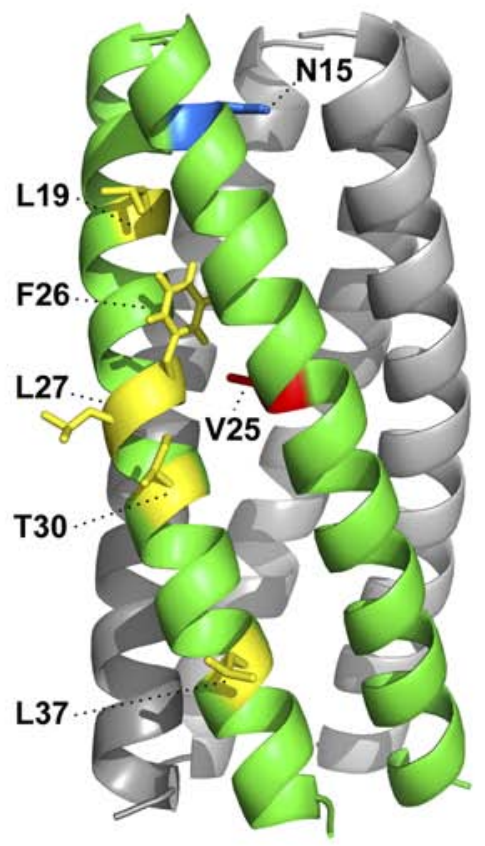

PENTAMER
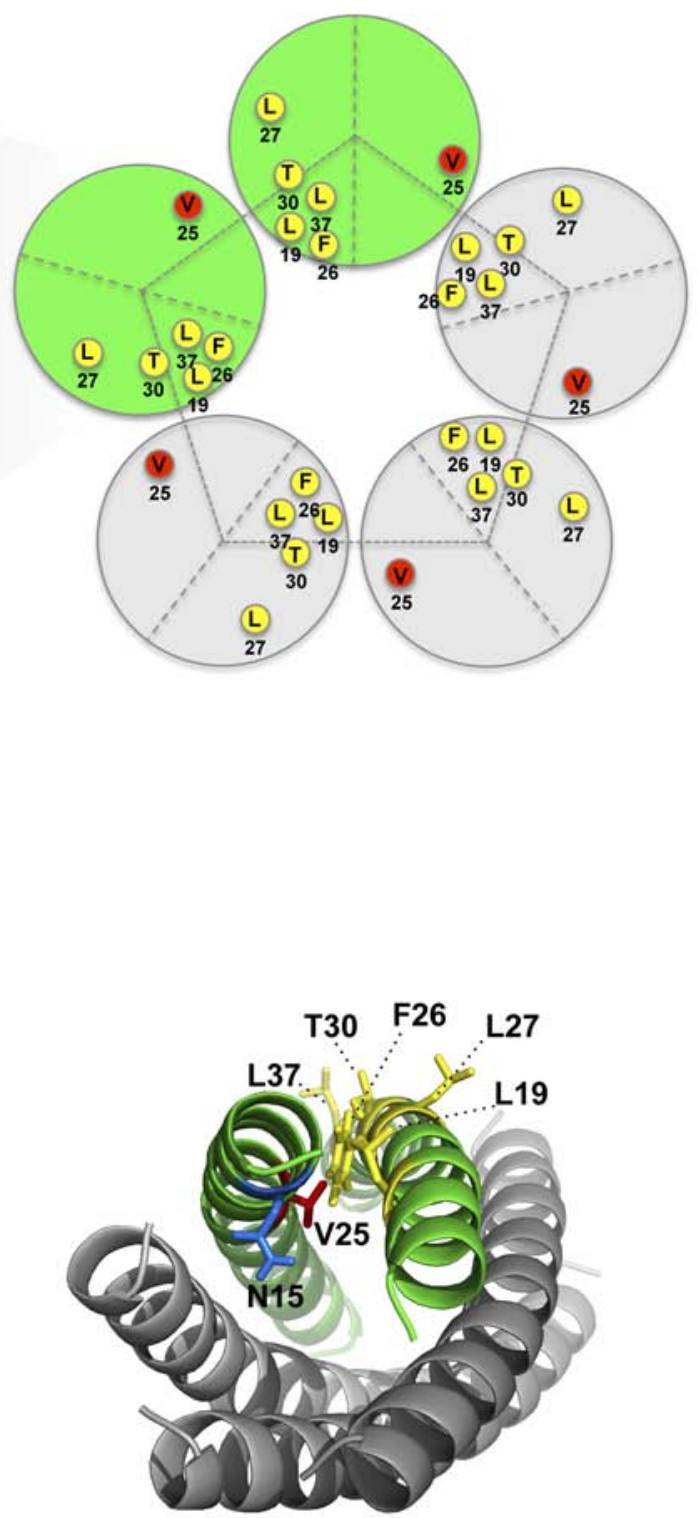

Figure 6. Spatial distribution of the mutations obtained in rSARS-CoV-EIC ${ }^{-}$after serial infections. (A) Left diagram represents a top view of E protein transmembrane domain and the spatial distribution of the amino acids within the alpha helix. Blue and red circles correspond to amino acids N15 and V25, respectively, originally mutated to inhibit IC activity. Yellow circles surround the amino acids that changed after evolution of V25F mutant. Arrow at position 15 points the lumen of the ion channel pore. Right graphic depicts the pentamer conformation of $E$ protein that forms the ion conductive pore and the positions of both the mutated residue at position 25 and the evolved mutations at positions 19, 25, 26, 27, 30 and 37 . Evolved changes map close to the originally mutated residue in the monomer-monomer interface. (B) Pentameric model of SARS-CoV E protein from a lateral (left) or a top view (right). This model was first proposed from linear dichroism of isotopically labeled $\mathrm{E}$ protein transmembrane peptides in lipid bilayers [29,32]. The residues involved in ion channel inhibition (N15 in blue and V25 in red) or mutated after viral evolution (L19, F26, L27, T30 and L37 in yellow) are highlighted. doi:10.1371/journal.ppat.1004077.g006 


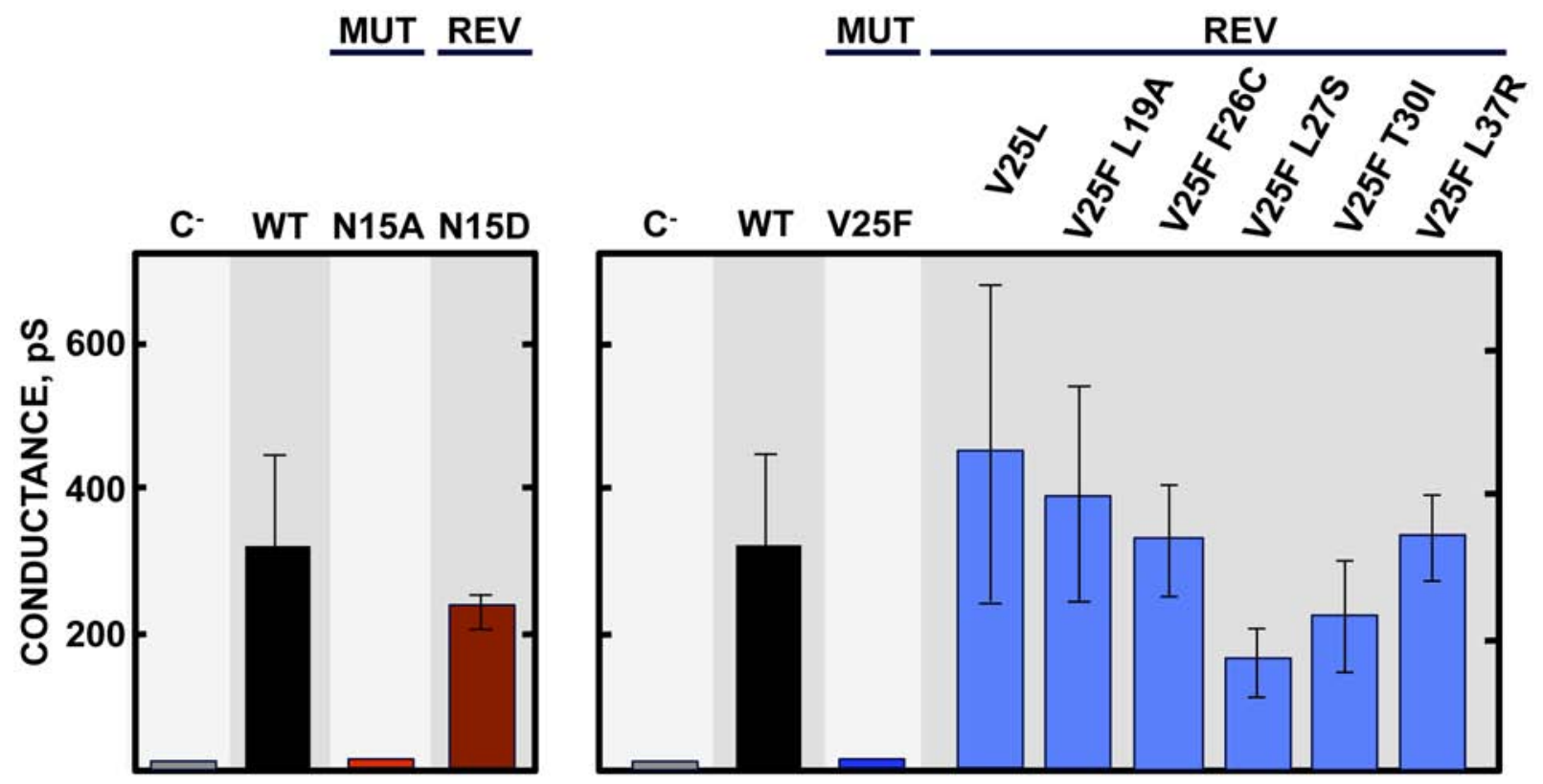

Figure 7. E protein IC activity of the rSARS-CoV-EIC ${ }^{-}$evolved variants. Synthetic peptides representing E protein transmembrane domain of the parental virus (wt) the mutant viruses (MUT) lacking IC activity (N15A and V25F) and their evolved revertants (REV) obtained after infections of mice or cell culture (N15D, V25L, V25F L19A, V25F F26C, V25F L27S, V25F T30I and V25F L37R) were reconstituted in artificial lipid bilayers, and their IC activity was analyzed as mean conductance values. Negative controls $\left(\mathrm{C}^{-}\right)$indicate conductance values obtained in the absence of any peptide. Error bars represent the variations obtained in 100 independent experiments.

doi:10.1371/journal.ppat.1004077.g007

virulent in mice in terms of weight loss and survival rates, causing similar disease as that caused by the wt virus (Fig. 8). We sought to confirm this data on another genetic background, so a recombinant SARS-CoV containing the mutation that restored IC activity in N15A mutant after cell culture passage was engineered rSARS-CoV-E-N15D (N15D) and evaluated. In agreement with the $\mathrm{V} 25 \mathrm{~F}$ revertants, the mutant N15D induced similar morbidity and mortality as wt (Fig. 8), confirming that E protein IC activity is a determinant of virus pathogenesis.
SARS-CoV E protein IC activity is dispensable for efficient growth in vivo

Although E protein IC activity is not essential for virus growth in cell culture (Fig. 2B), it is possible that production of virus in vivo further depends on ion conductivity. To test if the attenuation observed in vivo with $\mathrm{IC}$ inactive viruses is due to lower virus production, 16 week-old $\mathrm{BALB} / \mathrm{c}$ mice were intranasally inoculated with the wt virus, the genetically engineered revertant viruses N15D and V25F T30I displaying IC activity, or the N15A mutant lacking IC activity. Mice lungs were collected at 2 and 4 days post

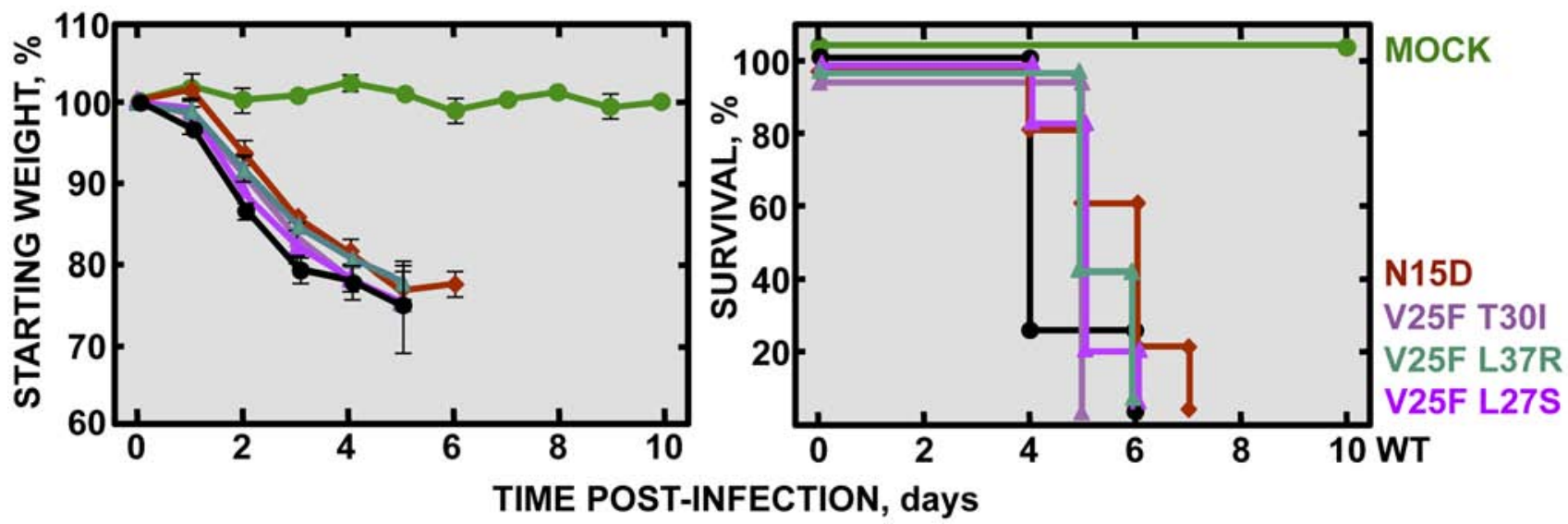

Figure 8. Pathogenesis caused by rSARS-CoV-EIC ${ }^{\text {rev }}$ in BALB/c mice. Groups of five 16 week-old BALB/C mice were mock infected (Mock, green circles) or infected with 100000 PFU of either the parental virus (wt, black circles) or the genetically engineered revertant viruses recovering IC activity: N15D (deep-red diamonds), V25F L27S (fuchsia triangles), V25F T30l (pink triangles) and V25F L37R (green triangles). Mean weight losses (left graph) and survival (right graph) during 10 days are represented for each group. Error bars represent the standard deviation for mice weights per experimental condition.

doi:10.1371/journal.ppat.1004077.g008 


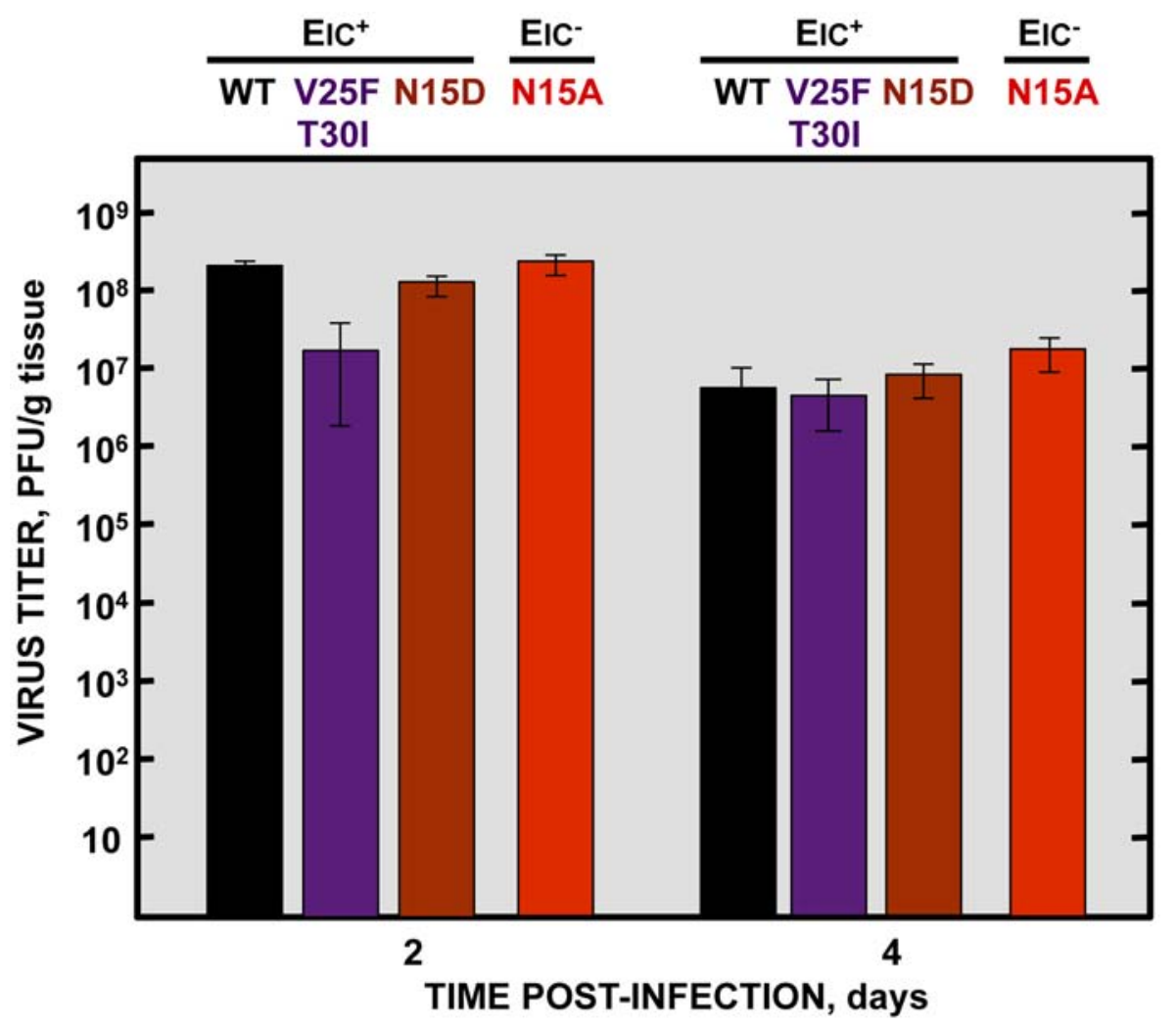

Figure 9. Effects of SARS-CoV E protein IC activity on virus growth in BALB/c mice lungs. Groups of six 16 week-old BALB/C mice were infected with 100000 PFU of viruses displaying E protein IC activity $\left(E I C^{+}\right)$, either the parental virus (wt, black columns) or the genetically engineered revertant viruses V25F T30I (purple columns) and N15D (deep-red columns) or with the mutant lacking IC activity (EIC ${ }^{-}$) N15A (red columns). At 2 and 4 days post infection (dpi) 3 mice from each group were sacrificed to determine virus titers.

doi:10.1371/journal.ppat.1004077.g009

infection, homogenized, and viral titers were determined. Interestingly, the virus lacking IC activity (N15A) grew to the same extent or even better than the wt and the revertant viruses, respectively, reaching titers higher than $10^{8}$ and $10^{7} \mathrm{PFU} / \mathrm{gr}$ of lung tissue at 2 and $4 \mathrm{dpi}$, respectively (Fig. 9). These data indicate that $\mathrm{E}$ protein $\mathrm{IC}$ activity does not significantly affect virus production in vivo, under these experimental conditions. Therefore the attenuation of the virus lacking IC activity is likely due to a host-specific effect mediated by the ion channel in the mouse, and not to a reduction in virus yields.

\section{Viruses with E protein IC activity induced edema accumulation after SARS-CoV infection}

To analyze the mechanisms by which IC inactivity confers less virulence, lung sections of mock-infected mice, or of those infected with the wt virus, IC revertants and N15A mutant were collected at 2 and 4 dpi, stained with hematoxylin and eosin and examined for histopathological changes. Mock-infected animals showed wide free alveolar and bronchiolar airways and no evidence of leukocyte infiltrates $($ Fig. 10A). Animals infected with the viruses displaying IC activity, presented swollen alveoli walls and leukocyte infiltrates in the infected areas at both time points (Fig. 10A). The histopathology caused by IC proficient viruses was even more dramatic at $4 \mathrm{dpi}$, where cell infiltrates were more abundant, and air spaces were collapsed by a profuse lung edema, which is the ultimate cause of acute respiratory distress syndrome (ARDS) that leads to lung failure and death $($ Fig. 10A). Edema accumulation at 4 dpi was also reflected by a marked increase $(>1.5$ fold) in the weight of lungs in animals infected with viruses competent in $\mathrm{E}$ protein ion conductivity (Fig. 10B). In contrast, mice infected with the virus lacking IC activity (N15A) showed moderate swollen lung epithelia and lung infiltrates that reflected a productive viral infection. However, at 4dpi, lung airways remained free from pulmonary edema, reflected by both the lung sections and in the minimal change of lung weight (Fig. 10A and 10B). Such moderate changes in the lung may retain efficient oxygen exchange. These data suggested that $\mathrm{E}$ protein $\mathrm{IC}$ activity contributes to SARS-CoV induced lung edema.

\section{SARS-CoV displaying E protein IC activity induces disassembly of bronchoalveolar epithelia}

ARDS caused by SARS-CoV infection originates from the accumulation of a protein rich edema, leading to severe hypoxemia and eventually to death. Lung epithelial cells create an osmotic gradient between airways and lung interstitium controlling water levels within air spaces. Damage to the epithelium is therefore a major cause of edema accumulation. To test the correlation between presence of $\mathrm{E}$ protein IC activity and an increase in epithelial damage leading to edema accumulation, lungs from mock-infected and from mice infected with the wt or the N15A virus were processed at 2 and 4 dpi for immunofluorescence. Epithelium integrity was evaluated using a specific antibody for $\mathrm{Na}^{+} / \mathrm{K}^{+}$ATPase, a key factor in establishing the osmotic gradient necessary for edema clearance, and infection was tracked using an antibody specific for $\mathrm{N}$ protein. At 2 dpi many infected cells (around 16\%) were observed in lungs of mice infected with either wt or N15A virus (Fig. 11A and S1), overlapping with the most productive time of viral infection. Both 
A

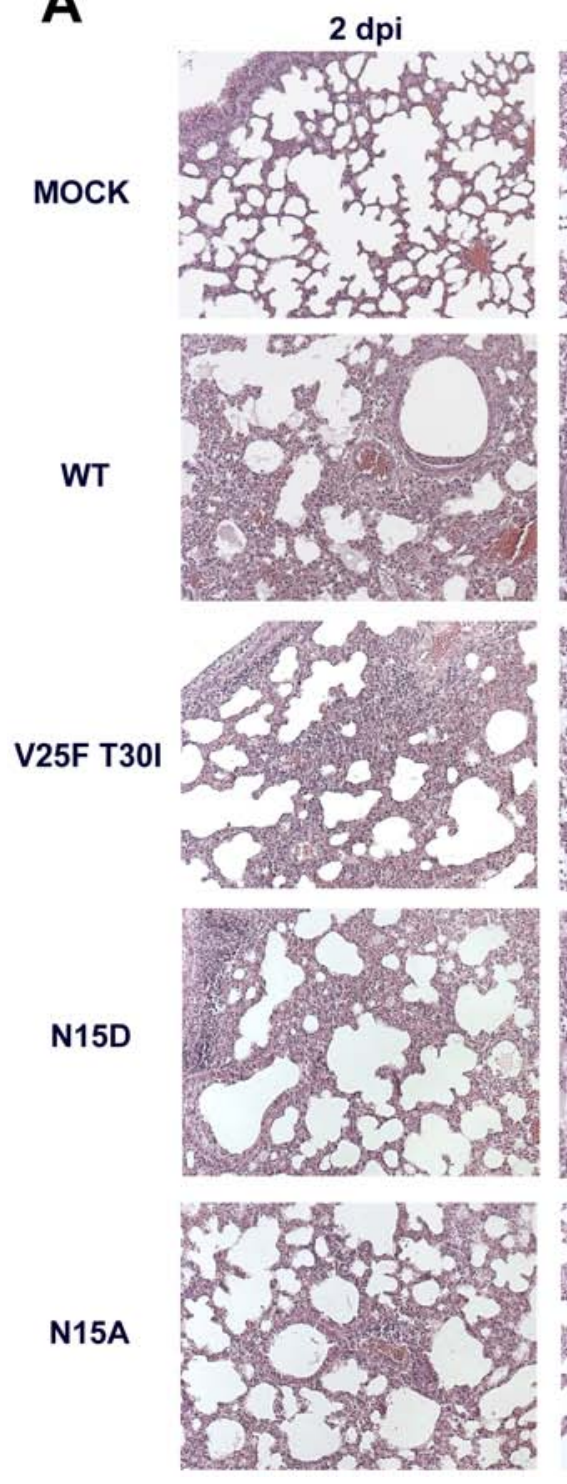

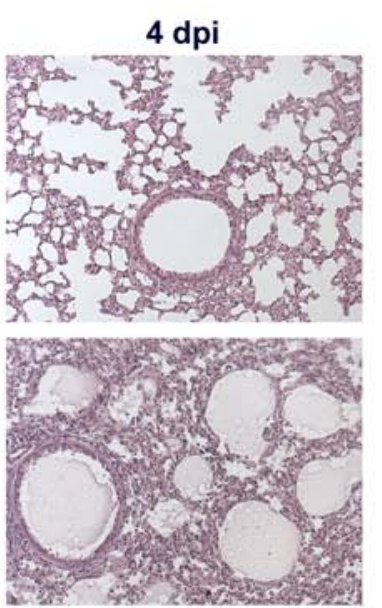
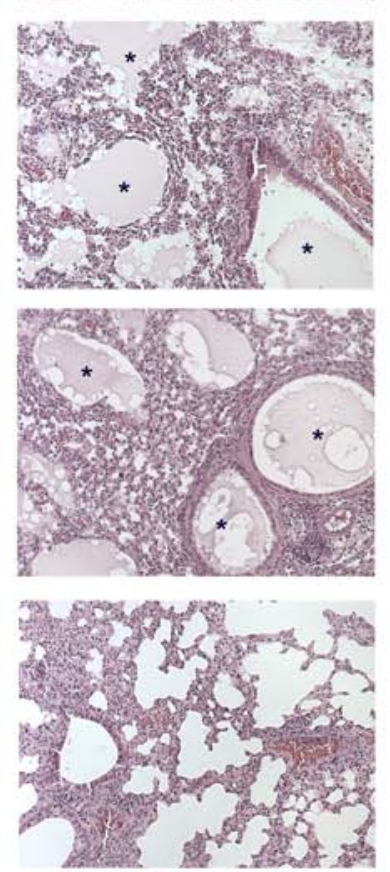

B

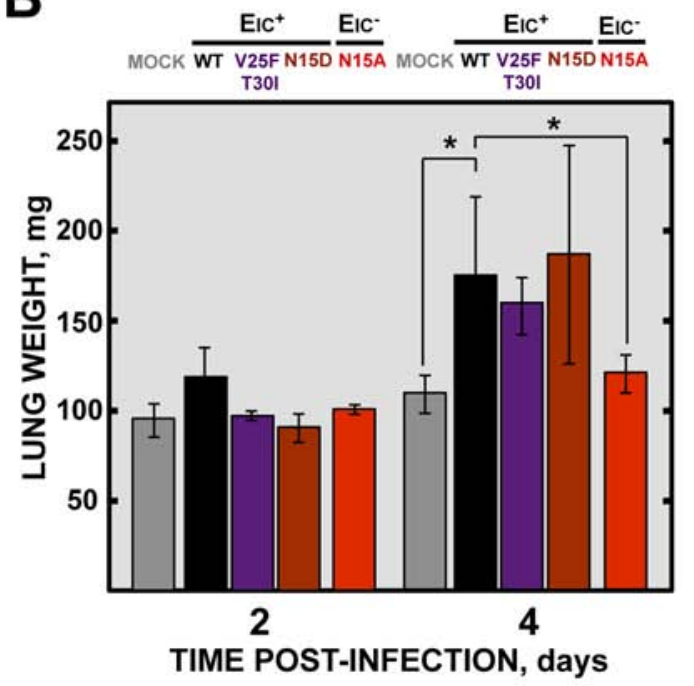

Figure 10. SARS-CoV E protein IC activity and lung pathology. Groups of six 16 week-old BALB/c mice were mock infected (Mock) or infected with 100000 PFU of viruses displaying E protein IC activity $\left(\mathrm{EIC}^{+}\right)$, either the parental virus (wt) or the genetically engineered revertant viruses V25F T30l and N15D or with the mutant lacking IC activity (EIC ${ }^{-}$) N15A. At 2 and 4 dpi 3 mice from each group were sacrificed and their lungs were collected. (A) Lungs were fixed in formalin, paraffin embedded, sectioned and processed for hematoxylin and eosin staining. Asterisks indicate edema accumulation in both bronchiolar and alveolar airways. Original magnification was $20 \times$. (B) When collected and prior to fixation lungs were weighted. Error bars indicate the standard deviation from 3 mice lungs per each condition. Statistically significant data are indicated with an asterisk (Student's t-test $\mathrm{p}$-value $<0.05)$.

doi:10.1371/journal.ppat.1004077.g010

viruses presented similar cell tropisms within lungs, infecting bronchiolar epithelium (between $60-70 \%$ of the cells) and alveolar epithelium (around $10 \%$ of the cells) (Fig. 11A and S1). Viral infections caused cell death leading to desquamation, especially at the bronchiolar barrier (Fig. 11A). At 4 dpi the number of infected cells was dramatically reduced (close to 1\%) (Fig. 11B and S1), accompanying viral titer decrease. Interestingly, wt infected mice showed abundant epithelia disassembly at this time point, especially in the bronchioles. $\mathrm{Na}^{+} / \mathrm{K}^{+}$ATPase was mislocated from its basolateral position within the plasma membrane of epithelial cells as a consequence of bronchiolar barrier destruction, and detected in desquamated cells or cell debris present at air spaces (Fig. 11B), where edema accumulation was also observed (Fig. 10). The removal of $\mathrm{Na}^{+} / \mathrm{K}^{+}$ATPase from its native position within the epithelial barrier most likely prevented its function in edema clearance. In contrast, animals infected with N15A mutant, presented less damaged epithelia and $\mathrm{Na}^{+} / \mathrm{K}^{+}$ATPase location was not disturbed (Fig. 11B), which may allow edema resolution, as no accumulation of protein rich edema was observed under these conditions (Fig. 10).

E protein IC activity triggers the production of IL-1 $\beta$, TNF and IL-6, key inflammatory cytokines in lung damage and edema accumulation

Severe damage caused to the epithelial barrier is associated with an acute inflammatory response in the lung parenchyma along 
A
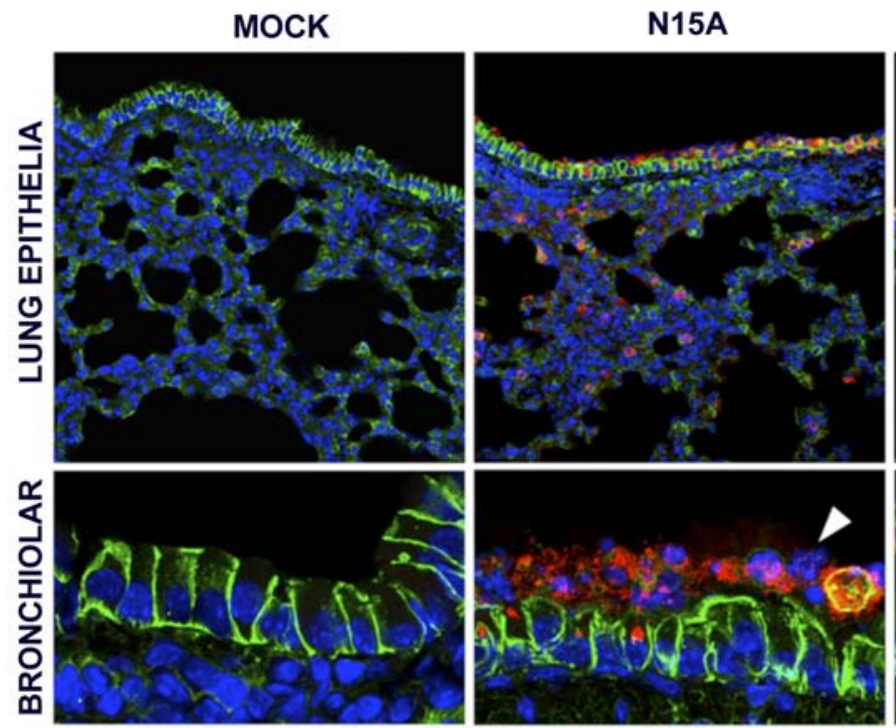

B
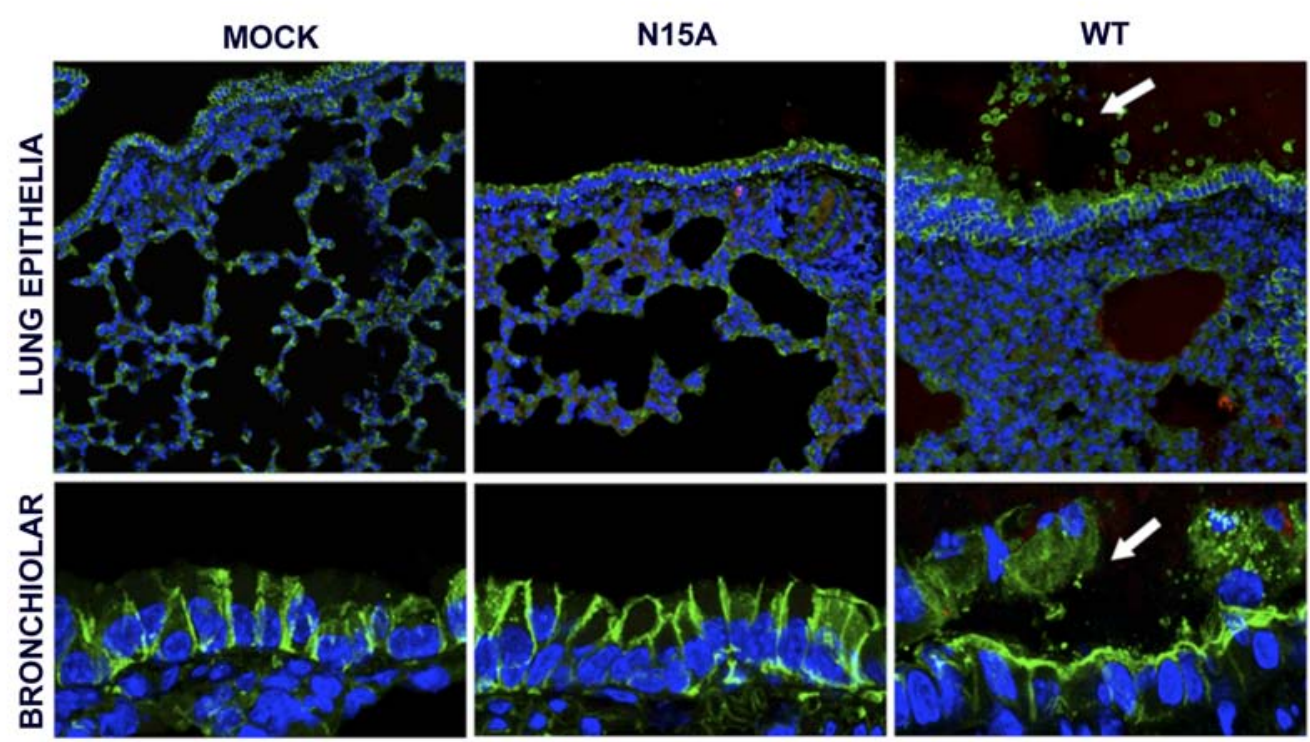

Figure 11. Lung epithelia disassembly in SARS-CoV infected BALB/c mice. 16 week-old BALB/c mice were mock infected (Mock) or infected with 100000 PFU of the parental virus (wt) displaying E protein IC activity or the mutant virus lacking IC activity N15A. At 2 (A) and 4 (B) dpi mice were sacrificed and their lungs were fixed in formalin, paraffin embedded, sectioned and processed for immunofluorescence. Na ${ }^{+} / \mathrm{K}^{+}$ATPase was labeled in green, SARS-CoV N protein was labeled in red to detect infected cells and cell nuclei are shown in blue. A general view of lung epithelia at an original magnification of $40 \times$ is shown in the upper rows of the panels. Magnified bronchiolar epithelia at an original magnification of $189 \times$ are shown in the rows of the bottom. White arrowheads indicate cell desquamation in the bronchiolar barrier. White arrows show epithelium disassembly and mislocated $\mathrm{Na}^{+} / \mathrm{K}^{+}$ATPase staining away from basolateral cell membranes, and present within air spaces.

doi:10.1371/journal.ppat.1004077.g011

with edema accumulation. Elevated levels of inflammatory cytokines IL-1 $\beta$, TNF and IL-6 are found in the lungs of ARDS patients and play a key role in the progression of the disease [62]. IL-1 $\beta$ is an early response highly inflammatory cytokine that is tightly regulated. During viral infection, recognition of pathogen molecular associated patterns (PAMPs) by the cells, such as double stranded viral RNA, induces IL-1 $\beta$ mRNA expression and translation to generate the inactive form of the protein pro-IL$1 \beta$. Upon certain stimuli, pro-IL-1 $\beta$ is then cleaved by caspase- 1 through inflammasome activation, generating the active form IL$1 \beta$, which is subsequently secreted to exert its function [52].
Interestingly, viral proteins with IC activity have been recently found to activate the inflammasome, which finally leads to the secretion of active IL-1 $\beta$ to the extracellular media [52,59]. We thus sought to test whether $\mathrm{E}$ protein IC activity was implicated in the production of active IL- $1 \beta$ in the lungs of SARS-CoV infected mice. First, the expression of pro-IL-1 $\beta$ mRNA and the amounts of its derived protein, inactive pro-IL-1 $\beta$, were measured in wtand N15A-infected mice at 2dpi. Infections with both wt and N15A mutant viruses induced similar overexpression of pro-IL-1 $\beta$ mRNA as compared with the mock-infected animals (Fig. 12A). The increased levels of pro-IL-1 $\beta$ mRNA found in infected mice, 
A

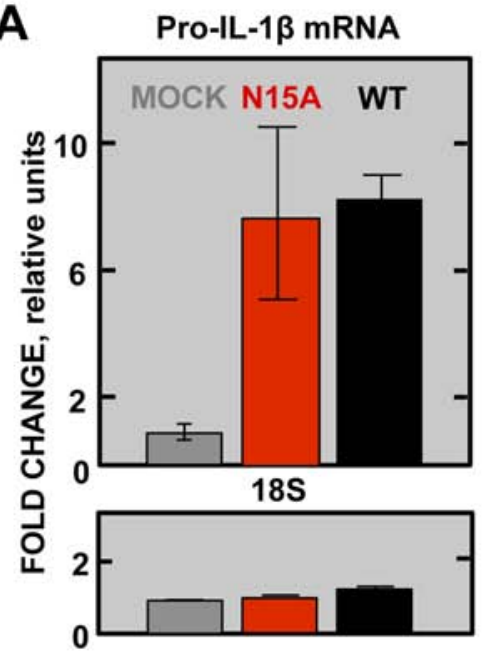

D

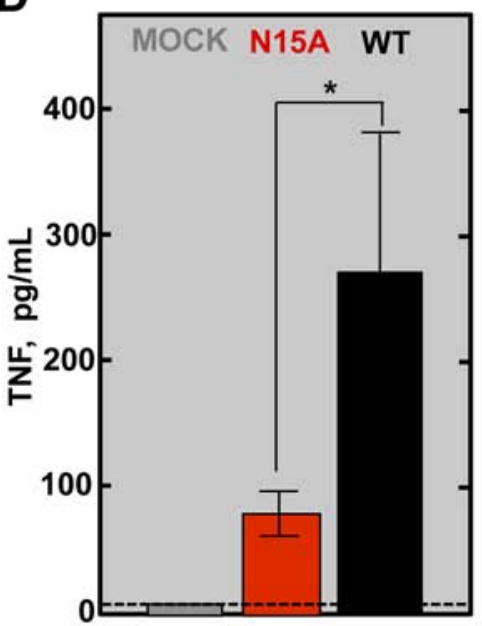

B
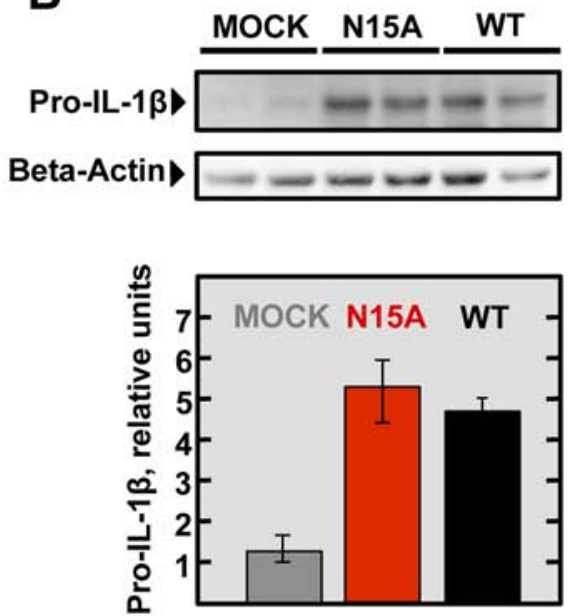

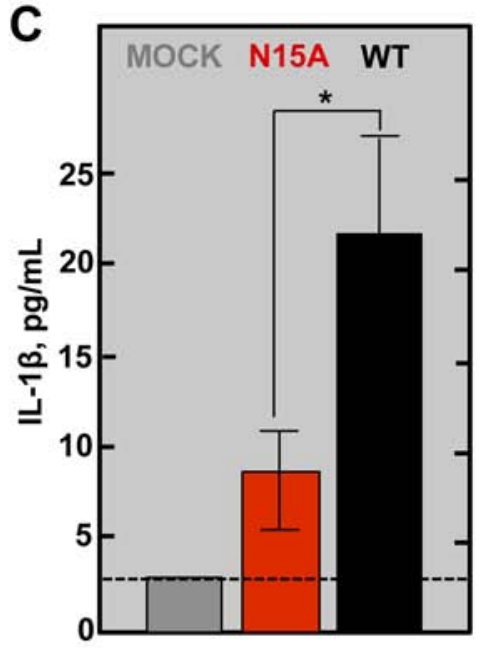

$\mathbf{E}$

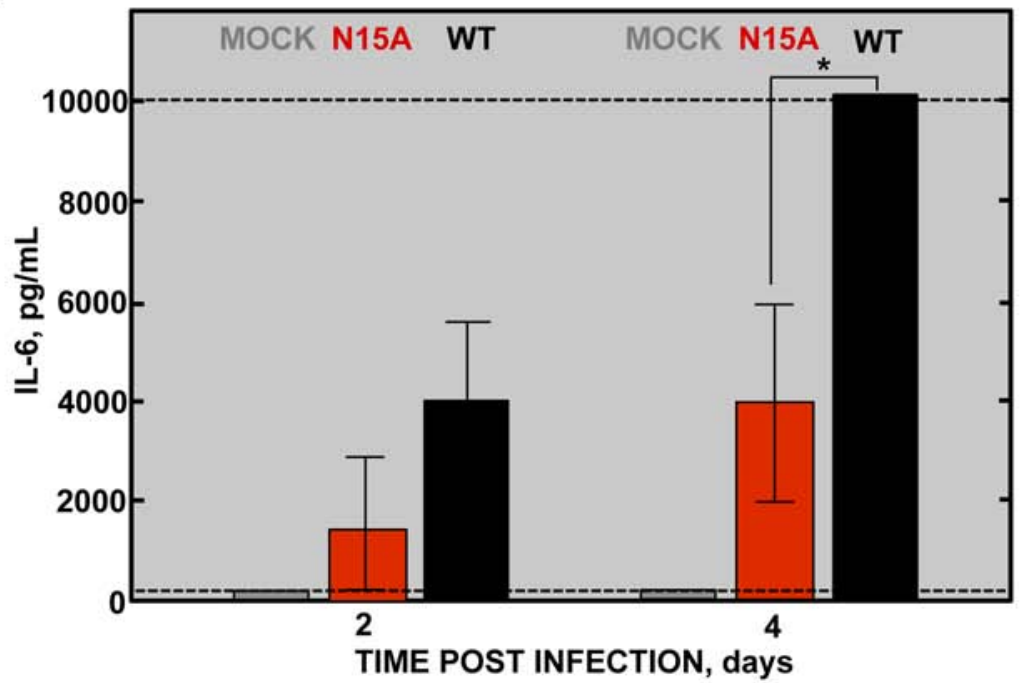

Figure 12. SARS-CoV E protein IC activity and induction of inflammatory cytokines involved in lung injury. Groups of six 16 week-old $\mathrm{BALB} / \mathrm{c}$ mice were mock infected or infected with 100000 PFU of the parental virus (wt) displaying E protein IC activity or the mutant virus lacking IC activity N15A. At 2 dpi 3 mice from each group were sacrificed and their lungs were collected. (A) Total RNA was extracted and levels of pro-lL-1 $\beta$ mRNA, and 18s rRNA (18S), as a control, were analyzed by RT-qPCR. Error bars indicate the standard deviation from samples of 3 mice per experimental setting. (B) Lung protein extracts were prepared and levels of inactive pro-IL-1 $\beta(35 \mathrm{kDa})$ and beta-actin, as a loading control, were detected by Western blot and quantified by densitometry analysis. Bottom of the figure represents the ratio pro-IL-1 $\beta /$ beta-actin relative to the mockinfected animals levels, as a reference. Bronchoalveolar lavages (BAL) of infected mice were collected and the concentration of (C) the active form of IL-1 $\beta$ protein at $2 \mathrm{dpi}$, (D) TNF protein at 2 dpi and (E) IL-6 protein at 2 and 4 dpi within the lavages were determined using the Luminex technology. Error bars indicate the standard deviation from samples of 3 mice per condition. Discontinuous lines indicate the limit of the detection of the technique. Statistically significant data are indicated with an asterisk (Student's t-test $p$-value $<0.05$ ).

doi:10.1371/journal.ppat.1004077.g012

correlated with enhanced amounts of inactive pro-IL-1 $\beta$, which reached similar values in wt and N15A infections (Fig. 12B). To analyze the levels of active, secreted IL-1 $\beta$, bronchoalveolar lavages were performed at 2 dpi. The amount of IL-1 $\beta$ in the airways was significantly higher in the mice infected with the wt virus displaying $\mathrm{E}$ protein $\mathrm{IC}$ activity, over those infected with the mutant N15A missing this function (Fig. 12G). Collectively, these data indicated that $\mathrm{E}$ protein $\mathrm{IC}$ activity promotes the secretion of mature IL-1 $\beta$, without increasing pro-IL-1 $\beta$ transcription or synthesis.

IL-1 $\beta$ enhances the production of TNF, another key early response cytokine, and IL-6, which follows a more sustained increase over time [62-64]. Therefore, it is not surprising that both TNF and IL-6 levels were more dramatically increased in wtinfected mice in comparison with the N15A-infected mice at 2 dpi (Fig. 12D and 12E). Furthermore, analysis of IL-6 levels in the bronchoalveolar lavages of infected mice at $4 \mathrm{dpi}$, revealed that overwhelming amounts of this cytokine, exceeding $10000 \mathrm{pg} / \mathrm{mL}$, accumulated in wt-infected mice, whereas IL-6 levels were at least 2.5-fold lower when E protein IC activity was absent during infection (Fig. 12E). All these results indicate that the presence of E protein IC activity correlates with the activation of the inflammasome and an acute inflammatory response that is deleterious for lung tissue. 


\section{Discussion}

Several viruses that cause severe diseases in humans encode small transmembrane proteins containing IC activity [44]. The alteration of host cell ion balance by these proteins is usually necessary for virus production and maturation, but the effect of IC activity in pathogenesis is less well understood. Coronaviruses are the causative agent of recent and likely future serious diseases. We have focused this study on SARS-CoV E protein, a virulence determinant displaying IC activity. In this manuscript, we sought to elucidate the role of $\mathrm{E}$ protein IC activity in virus pathogenesis by combining our knowledge of residues essential for $\mathrm{E}$ protein ion conductivity with the manipulation of SARS-CoV genome. To this end we used a mouse adapted genetic background (MA15) assembled in a bacterial artificial chromosome (BAC). Two rSARS-CoVs, each one containing mutation N15A or V25F in the transmembrane domain of $\mathrm{E}$ protein were generated to knock down its IC activity. Upon competition during several passages, the viruses lacking $\mathrm{E}$ protein $\mathrm{IC}$ activity were clearly overgrown by the parental virus, which replicated better. Nevertheless, these differences in viral growth needed several replication cycles to be amplified and detected, as only slight no significant changes in virus production were observed after 72 hours growth kinetics. In agreement with this result, when T16A mutation was introduced within IBV E protein, which represents the equivalent mutation to SARS-CoV E protein N15A, no alterations in the production of virus like particles (VLPs) were detected after 48 hours [40]. The fact that deeper alterations of $\mathrm{CoV} \mathrm{E}$ protein transmembrane domain cause much more dramatic effects in virus production $[37,39]$ may be due to additional structural or functional changes in $\mathrm{E}$ protein, besides their effect on ion conductivity. In conclusion, E protein IC activity, although not essential for virus production, confers and advantage to the virus by enhancing its fitness and growth. Accordingly, a selective advantage of IC activity has also been shown for influenza virus. Mutants lacking M2 protein IC activity were overgrown by the parental virus in competition assays in an even faster manner than in SARS-CoV, probably because the influenza virus lacking IC activity has more profound replication defects $[65,66]$. SARS-CoV encodes other two proteins, $3 \mathrm{a}$ and $8 \mathrm{a}$, which also contain IC properties $[41,42]$. Therefore, an essential contribution of IC activity to virus production cannot formally be excluded for SARS-CoV, as $3 \mathrm{a}$ and $8 \mathrm{a}$ derived ion channels could functionally compensate the absence of $\mathrm{E}$ protein IC activity.

SARS-CoV mutant viruses lacking E protein IC activity showed a clear tendency to revert both in cell culture and in vivo after mice infection. N15A and V25F mutant viruses, devoid of $\mathrm{E}$ protein ion conductivity, incorporated additional mutations in the $\mathrm{E}$ gene to restore IC activity, suggesting that this function confers a selective advantage to the virus. This trend was more evident in the case of $\mathrm{V} 25 \mathrm{~F}$ virus, which evolved more quickly and frequently than the N15A mutant virus. No reversion of $\mathrm{E}$ protein IC activity was observed for N15A mutant in mice, at least during the first five days post infection. Attempts to sequence the viral progeny at 9 and 10 days after the inoculation were unsuccessful, probably because the virus was mostly cleared by those time points. Nevertheless, as N15A mutant restored its ion channel activity after long number $(>24)$ of passages in cell culture, it is possible that after serial passages in vivo this mutant could also revert, as ion conductivity confers better fitness for the virus. Although both N15A and V25F mutations equally disrupted IC activity, the mechanisms by which this is achieved could be different. Replacement of $\mathrm{N}$ at position 15 to $\mathrm{A}$, an amino acid predicted to be located facing the channel lumen, is not likely to affect the channel architecture. In fact, the rotational orientation in lipid bilayers of a labeled synthetic transmembrane peptide bearing this mutation was entirely consistent with that of a pentameric model [29]. In contrast, mutation at V25 implies the introduction of a larger side chain (replacement of $\mathrm{V}$ to $\mathrm{F}$ ) at the monomermonomer interface, which is likely to affect the overall structure of the homo-oligomer and therefore inhibit ion conductivity by causing larger structural changes. This may also explain the higher number of compensatory mutations found in $\mathrm{V} 25 \mathrm{~F}$ with respect to N15A virus, as the ways to recover a stable oligomer are more varied than those needed to recover channel activity. The compensatory mutations incorporated by the $\mathrm{V} 25 \mathrm{~F}$ mutant mapped to the opposite face of the transmembrane helix, although they are adjacent when the $\mathrm{E}$ protein pentamer is formed. Therefore, the compensatory mutations most likely restored the interaction and assembly between the mutated monomers, reinforcing our hypothesis (Fig. 6). IC activity restoration through virus passage suggests that this function is important for the virus. Several of the mutations restoring ion channel activity appeared both in mice and in cell culture. Therefore, it seems that reverting $\mathrm{E}$ protein ion conductivity, and not adaptation to mice, was its main goal. Nevertheless, the possibility that these mutations could also improve mouse adaptation through an ion channel dependent or independent mechanism cannot be fully excluded.

$\mathrm{E}$ protein IC activity was also involved in SARS-CoV pathogenesis as tested in the mouse model. Viruses lacking IC activity that were stable during multiple passages (N15A mutants) caused reduced mortality, whereas the wt and the mutant viruses restoring IC activity during mice infection (V25F backgroundevolved variants) caused high mortality rates. Furthermore, genetically engineered viruses containing the point mutations necessary to recover $\mathrm{E}$ protein $\mathrm{IC}$ activity induced similar mortality as wt virus, reinforcing that $\mathrm{E}$ protein IC activity contributes to SARS-CoV pathogenicity. The relevance of viroporins in virus virulence has also been shown in other viruses, such as respiratory syncytial virus $\mathrm{SH}$ protein, influenza A virus M2 protein and classical swine fever virus $\mathrm{p} 7$ protein [67-70], by deleting a large fraction of or the entire protein. Viroporins may play other critical functions apart from ion conduction. Therefore, a direct correlation between IC activity and virulence could not be formally established. To our knowledge, this is the first time in which the IC activity of a viroporin is directly linked to the virulence of the virus.

The infection with highly pathogenic respiratory viruses, including SARS-CoV, is one of the causative agents of acute lung injury (ALI) and its most severe form, ARDS [71]. Just in the United States, 200,000 ARDS cases are reported annually with a $40 \%$ mortality rate [72]. Late stages of ARDS are characterized by development of pulmonary edema that leads to an impaired gas exchange, hypoxemia and eventually death. Infection of mice with rSARS-CoV-MA15 resulted in an abundant edema accumulation both in alveolar and bronchiolar spaces at late times post infection (4 dpi), which correlated with mortality. This phenotype was reproduced upon mice infection with other highly-virulent SARS$\mathrm{CoVs}$ displaying IC activity based on alternative $\mathrm{E}$ protein sequences (revertant viruses). On the other side, infection of mice with the attenuated mutant lacking $\mathrm{E}$ protein IC activity (N15A) caused significantly reduced edema accumulation, likely contributing to a majority of the animals surviving. Collectively, these data indicate that $\mathrm{E}$ protein IC activity in vivo promotes lung pathology through edema accumulation.

The pulmonary epithelia regulate water levels present within air spaces, a critical parameter for gas exchange, and play a critical role in edema clearance $[72,73]$. Epithelial cells create an osmotic 
gradient mainly through a coordinated $\mathrm{Na}^{+}$transport first from the airways to the cell cytoplasm through epithelial sodium channels $(\mathrm{ENaC})$, located at the apical part of the plasma membrane, and then to the interstitium by $\mathrm{Na}^{+} / \mathrm{K}^{+}$ATPase, present at the basolateral region of the plasma membrane. This vectorial transport of $\mathrm{Na}^{+}$is accompanied by a water removal from the airspace and edema resolution [72,73]. The integrity of alveolar and bronchiolar epithelia was analyzed by labeling of $\mathrm{Na}^{+} / \mathrm{K}^{+}$ATPase in the lungs of mice infected with the virus containing or lacking IC activity. Interestingly, animals infected with the wt virus presented a strong disassembly of bronchiolar epithelia and mislocalization of $\mathrm{Na}^{+} / \mathrm{K}^{+}$ATPase from its basolateral distribution within cells at late times, coincident with edema accumulation. In contrast, epithelia integrity was clearly preserved in the lungs of animals infected with the virus missing $\mathrm{E}$ protein IC activity. Intact lung epithelia may be required for proper function of the main components involved in edema resolution $\left(\mathrm{Na}^{+} / \mathrm{K}^{+}\right.$ATPase and $\left.\mathrm{ENaC}\right)$, which may explain the lack of edema and therefore the attenuation observed for this virus. As previously described for SARS-CoV, differences in viral tropism within lung cells, without affecting viral production, can induce different pathologies [74]. Nevertheless, we have observed no significant differences in the infection patterns in the presence or absence of $\mathrm{E}$ protein ion channel activity, suggesting that the virulence conferred by $\mathrm{E}$ protein IC activity does not depend on alternative tropisms.

Pulmonary epithelia damage leading to ALI and ARDS is a consequence of a cytokine burst initiated, in this case, by viral infection. One of the key early-response cytokines driving proinflammatory activity in bronchoalveolar spaces is IL- $1 \beta$ [75]. IL- $1 \beta$ is mainly produced by macrophages and dendritic cells through inflammasome activation. Ion imbalances within cells have been described as triggers of this pathway [52]. The levels of active IL- $1 \beta$ secreted to the airways were enhanced when $\mathrm{E}$ protein IC activity was conserved in SARS-CoV infection. Taking into account that the presence or absence of SARS-CoV E protein IC activity did not interfere with the production of IL-1 $\beta$ precursors (mRNA and protein levels of pro-IL-1 $\beta$ ), these results suggest that $\mathrm{E}$ protein ion conduction may induce inflammasome triggering resulting in secretion of mature IL-1 $\beta$. In agreement with this hypothesis, release of active IL-1 $\beta$ has recently been reported for viroporins of other viruses $[52,53,57,59]$. IL- $1 \beta$ is implicated in the development of diverse pathologies, including obesity, atherosclerosis, diabetes and several pulmonary illnesses such as asthma, pulmonary obstructive chronic disease and ARDS progression through edema accumulation [75-78]. Here, we report the implications of this cytokine in SARS-CoV pathology and $\mathrm{E}$ protein ion channel activity as a trigger of its production.

ARDS progression involves the production of TNF, another early response cytokine, and IL-6, which exerts its function in a more sustained manner accumulating during the disease [63]. We found that after SARS-CoV infection, these patterns of cytokine expression were clearly reproduced. TNF and IL-6 accumulated to higher levels in the lungs of animals infected with the wt virus displaying IC activity compared to the mutant lacking ion conductivity. IL-1 $\beta$ enhances the production of TNF, and IL-6 is stimulated by both cytokines providing an integrated amplified inflammatory response, detrimental for pulmonary function [63]. Elevated amounts of these cytokines have been reported in bronchoalveolar lavages of SARS-CoV patients [79]. Therefore, the enhanced amounts of active IL-1 $\beta$ found in the animals infected with the wt virus may explain the increased levels of TNF and IL-6, which leads to severe pathology. It is important to note that the increased damage found in pulmonary epithelia infected with the virus displaying $\mathrm{E}$ protein $\mathrm{IC}$ activity may not be explained by a higher virus production, as suppression of $\mathrm{E}$ protein IC activity rendered similar growth in mice lungs during the analyzed time points. SARS-CoV early replication may be a relevant issue in the induction of pathology. We cannot exclude early replicative defects for the N15A mutant in mice, delaying virus growth during the first hours post-infection. Nevertheless, alternative explanations are also possible, as it has been described that some mutations at SARS-CoV S gene conferred increased virulence without affecting growth within mice, even at early times. This increased pathogenesis was mainly dependent on an exacerbated host response to the viral infection [74]. Accordingly, the enhanced inflammatory response triggered by $\mathrm{E}$ protein ion channel proficient viruses may be a major pathology inducer.

In this study, we have shown that SARS-CoV E protein IC activity is a virulence determinant, influencing inflammatory responses, including those inflammasome-derived, pulmonary damage and disease outcome. Although not essential for virus production, E protein IC activity confers a selective advantage, as the parental virus, competent for ion conductivity, was more fit. Nevertheless, the virulence associated to E protein ion conductivity could represent a non-selectable consequence. SARS-CoV crossed species barriers from zoonotic reservoirs such as bats, palm civets and raccoon dogs to humans, causing a severe disease [71]. Possibly, in SARS-CoV infection of its natural hosts, E protein ion channel activity may not have a relevant impact in SARS-CoV pathogenesis, and therefore it was positively selected before crossing species barrier. In conclusion, this work provides several findings that may have translational relevance for other coronaviruses, such as the highly pathogenic MERS-CoV, and even on other viruses encoding proteins with IC activity.

\section{Materials and Methods}

\section{Ethics statement}

Animal experimental protocols were approved by the Ethical Committee of The Center for Animal Health Research (CISAINIA) (permit numbers: 2011-009 and 2011-09) in strict accordance with Spanish national Royal Decree (RD 1201/2005) and international EU guidelines 2010/63/UE about protection of animals used for experimentation and other scientific purposes and Spanish national law 32/2007 about animal welfare in their exploitation, transport and sacrifice and also in accordance with the Royal Decree (RD 1201/2005). Infected mice were housed in a ventilated rack (Allentown, NJ).

\section{Cells}

The African green monkey kidney-derived Vero E6 cells were kindly provided by Eric Snijder (Medical Center, University of Leiden, The Netherlands). The mouse delayed brain tumor cells stably expressing the murine receptor for SARS-CoV (DBTmACE2) were generated as previously described [61]. Baby hamster kidney cells (BHK-21) were obtained from American Type Culture Collection (ATCC; CCL-10). Cells were grown at $37^{\circ} \mathrm{C}$ with an atmosphere of $98 \%$ humidity, in Dulbecco's modified Eagle medium (DMEM, GIBCO) supplemented with 25 mM HEPES, 2 mM L-glutamine (SIGMA), 1\% non essential amino acids (SIGMA) and $10 \%$ fetal bovine serum (FBS, Biowhittaker).

\section{Mice}

Specific-pathogen-free 8 week-old BALB/c OlaHsd female mice were purchased from Harlan. Mice were maintained for 8 additional weeks in the animal care facility at the National Center 
of Biotechnology (Madrid). All protocols were approved by the Ethical Review Committee at the center for animal health research (CISA-INIA). For infection experiments, 16-week-old mice females were anesthetized with isoflurane and intranasally inoculated with $100000 \mathrm{PFU}$ of the indicated viruses. All work with infected animals was performed in a BSL3 laboratory (CISA, INIA) equipped with a ventilated rack (Animal transport unit-Bio containment unit, Harvard) to store the animals during the experiment.

\section{Construction of mutant rSARS-CoVs-MA15}

An infectious cDNA clone encoding a mouse adapted (MA15) SARS-CoV assembled in a bacterial artificial chromosome (BAC) in our laboratory [26] was used as the background to introduce the mutations that inhibited or restored E protein IC activity. Briefly, DNA fragments representing the nucleotides 26044 to 26779 of SARS-CoV-MA15 genome, flanked by the restriction sites BamHI and MfeI, respectively, were chemically synthesized (Bio Basic Inc). These fragments contained different point mutations within the $\mathrm{E}$ gene, that generated amino acid changes inhibiting IC activity: N15A (AAT to GCG) and V25F (GTA to TTC) or restoring this activity: N15D (GCG to GAC), V25F L19A (GTA to TTC and CTT to GCA), V25F L27S (GTA to TTC and TTG to TCG), V25F T30I (GTA to TTC and ACA to ATA), V25F L37R (GTA to TTC and CTT to GGT). The fragments containing these mutations were digested and exchanged in the original BAC. The genetic integrity of the cloned DNA was verified by restriction analysis and sequencing.

\section{Recovery of recombinant viruses from the cDNAs clones}

BHK cells were grown to $95 \%$ confluency in $12.5 \mathrm{~cm}^{2}$ flasks and transfected with $6 \mu \mathrm{g}$ of the infectious cDNA clones and $18 \mu \mathrm{l}$ of Lipofectamine 2000 (Invitrogen), according to the manufacturer's specifications. At 6 hours post transfection, cells were trypsinized, added to Vero E6 cells confluent monolayers grown in $12.5 \mathrm{~cm}^{2}$ flasks and incubated at $37^{\circ} \mathrm{C}$ for $72 \mathrm{~h}$. Cell supernatants were harvested, passaged once on fresh cells and the recovered viruses were cloned by three rounds of plaque purification following standard procedures.

\section{Growth kinetics and plaque assays}

Vero E6 or DBT-mACE2 cells were grown to confluency on $12.5 \mathrm{~cm}^{2}$ flasks and infected at a multiplicity of infection (MOI) of 0.001 . Cells supernatants were collected at 0, 6, 24, 48 and $72 \mathrm{hpi}$ and titrated on Vero E6 cells. For virus titration and plaque detection, supernatants of infected cells were added to confluent monolayers of Vero E6 cells and incubated for $45 \mathrm{~min}$ at $37^{\circ} \mathrm{C}$. Media was removed and cells were overlaid with DMEM containing $0.6 \%$ of low melting agarose and $2 \%$ of fetal calf serum (FCS). At 72 hpi cells were fixed with $10 \%$ formaldehyde and stained with crystal violet.

\section{Confocal microscopy}

Vero E6 cells were grown to $90 \%$ confluency on glass coverslips and infected with rSARS-CoV- $\Delta \mathrm{E}, \mathrm{rSARS}-\mathrm{CoV}$ wt, rSARS-CoVE-N15A and rSARS-CoV-E-V25F at an MOI of 0.3. At the indicated hpi, media were removed and cells were washed twice with PBS and fixed with 4\% paraformaldehyde in PBS for $30 \mathrm{~min}$ at room temperature. Then, cells were washed twice with PBS and permeabilized for 10 min with $0.2 \%$ saponin and $10 \%$ FBS in PBS. Primary antibody incubations were performed in PBS containing $10 \% \mathrm{FBS}$ and $0.2 \%$ saponin for $1 \mathrm{~h} 30 \mathrm{~min}$ at room temperature. Immunofluorescence was performed using a mouse
mAb specific for ERGIC53 (dilution 1:200, Alexis Biochemicals), and a rabbit pAb specific for E protein [15] at 1:2000 dilution. Coverslips were washed four times with PBS between primary and secondary antibody incubations. Alexa 488- or Alexa 546conjugated antibodies specific for the different species (dilution 1:500, Invitrogen) were incubated for $45 \mathrm{~min}$ at room temperature in PBS containing 10\% FBS. Nuclei were stained using DAPI (dilution 1:200, Sigma). Coverslips were mounted in ProLong Gold anti-fade reagent (Invitrogen) and examined on a Leica SP5 confocal microscope (Leica Microsystems). Colocalization studies were performed using Leica LAS AF v2.6.0 software.

\section{Virus genome sequencing}

The genomic region including nucleotides 26017 to 26447 that contains the $\mathrm{E}$ gene was sequenced after RT and PCR reactions. Briefly, total RNA from infected cells or homogenized mice lungs, was collected and purified using RNeasy kit (Qiagen) according to the manufacturer's specifications. For RT reaction, $1 \mu \mathrm{g}$ of RNA was used as template, random oligonucleotides primers and Thermoscript reverse transcriptase (Invitrogen). The product was subsequently subjected to a PCR reaction using the oligonucleotides E-VS (CTCTTCAGGAGTTGCTAATCGAGCAATGG) and E-RS (TCGAGGAGTTGTTTAAGCTCGTCAACGGTA) and the Vent polymerase (New England Biolabs), following manufacturer's recommendations. Sequence assembly and comparison with the consensus sequence of SARS-CoV-MA15 strain were performed with the SeqMan program (Lasergene, Madison, WI).

\section{Genetic stability through serial infections of SARS-CoVs lacking IC activity}

Confluent monolayers of Vero E6 cells grown in $12.5 \mathrm{~cm}^{2}$ flasks were infected at an MOI of 0.5 with the viruses $\mathrm{rSARS}-\mathrm{CoV}$ wt, rSARS-CoV-E-N15A and rSARS-CoV-E-V25F. At 24 hpi, supernatants were collected and passaged on fresh monolayers of Vero E6 cells, performed 24 times, serially. E gene sequence was analyzed at passages $0,8,16$ and 24 as described.

For in vivo experiments, mice were intranasally inoculates with $100000 \mathrm{PFU}$ of the viruses described above. Lungs were collected at days 2 and 4 post infection and incubated in RNAlater (Ambion) at $4^{\circ} \mathrm{C}$ for 48 hpi prior to $-80^{\circ} \mathrm{C}$ freezing. To extract total RNA, lungs were homogenized in $2 \mathrm{ml}$ of RLT lysis buffer (QIAGEN) containing 1\% $\beta$-mercaptoethanol using gentleMACS Dissociator (Miltenyi Biotec). Samples were centrifuged at $3000 \mathrm{rpm}$ during $10 \mathrm{~min}$, and RNA was purified from supernatants using RNeasy kit (QIAGEN) as previously described.

\section{Peptide synthesis and ion channel measurements in artificial lipid membranes}

Synthetic peptides representing the transmembrane domain of SARS-CoV E protein (amino acids 7 to 38) encoding the point mutations that appeared after serial infections of the mutant viruses were generated by standard phase synthesis, purified by HPLC and their IC activity was tested in artificial lipid membranes, as previously described [34].

\section{Competition assays}

Total RNA from co-infected cells was isolated and $\mathrm{E}$ gene was sequenced as described above. Relative abundance of the rSARS$\mathrm{CoV}$ wt and rSARS-CoV-E-N15A viruses within viral population was determined by quantifying the relative amounts of their 
respective $\mathrm{E}$ gene genetic markers in the sequence obtained from the population.

\section{Mice infection and evaluation of virus virulence}

16 week-old BALB/c mice females were intranasally inoculated with 100000 PFU of the viruses rSARS-CoV wt, rSARS-CoV-EN15A, rSARS-CoV-E-V25F, rSARS-CoV-E-N15D, rSARSCoV-E-V25F L27S, rSARS-CoV-E-V25F T30I and rSARSCoV-E-V25F L37R in $50 \mu \mathrm{l}$ of DMEM containing $2 \%$ FCS. Weight loss and survival of the infected mice were monitored for 10 days. Animals reaching weight losses higher than $25 \%$ of the initial body weight were sacrificed according to the established euthanasia protocols.

\section{Virus growth in mice lungs and lung histology}

Mice were inoculated with 100000 PFU of the virus rSARSCoV wt, rSARS-CoV-E-N15A, rSARS-CoV-E-N15D and rSARS-CoV-E-V25F T30I, sacrificed at days 2 and 4 post infection, and lungs were collected. To analyze viral growth, right lungs were homogenized in $2 \mathrm{ml}$ of Phosphate Buffered Saline (PBS) containing $100 \mathrm{UI} / \mathrm{ml}$ penicillin, $100 \mu \mathrm{g} / \mathrm{ml}$ streptomycin, $50 \mu \mathrm{g} / \mathrm{ml}$ gentamicin and $0.5 \mu \mathrm{g} / \mathrm{ml}$ fungizone using MACS homogenizer (Miltenyi Biotec) according to manufacturer's protocols, and titered as previously described. To examine lung histopathology, left lungs of infected mice were incubated with $10 \%$ zinc formalin for $24 \mathrm{~h}$ at $4^{\circ} \mathrm{C}$, embedded in paraffin, sectioned, and stained with hematoxylin and eosin.

\section{Immunofluorescence in lung sections}

Five micron sections of zinc formalin fixed lungs were deparaffined at $60^{\circ} \mathrm{C}$ and rehydrated by successive incubations in $100 \%$ xylol, $100 \%$ ethanol and $96 \%$ ethanol. Antigen unmask was performed by boiling the samples in citrate buffer $(8.2 \mathrm{mM}$ sodium citrate; $1.8 \mathrm{mM}$ citric acid, $\mathrm{pH}$ 6.5) for $5 \mathrm{~min}$ at $110^{\circ} \mathrm{C}$ in a decloaking chamber (Biocare medical). Samples were then permeabilized with $0.25 \%$ Triton X-100 in PBS for $15 \mathrm{~min}$ and blocked with $10 \%$ bovine serum albumin (BSA) and $0.25 \%$ Triton X-100 in PBS for 30 min. Samples were labeled with a mouse monoclonal antibody specific for SARS-CoV N protein (kindly provided by Ying Fang, South Dakota State University) diluted 1:250 and a rabbit monoclonal antibody specific for $\mathrm{Na}^{+} / \mathrm{K}^{+}$ ATPase alpha subunit (Abcam) diluted 1:100 in 0.25\% Triton X100 and $10 \%$ BSA in PBS for $1 \mathrm{~h} 30 \mathrm{~min}$ at room temperature. Goat anti-mouse and goat anti-rabbit secondary antibodies bound to Alexa 488 and Alexa 594 fluorophores were used respectively at a dilution 1:250 in $0.25 \%$ Triton X-100 and $10 \%$ BSA in PBS for $45 \mathrm{~min}$ at room temperature. Cell nuclei were stained with DAPI (1:200). Tissues were mounted in ProLong antifade reagent (Invitrogen) and analyzed in a Leica TCS SP5 confocal microscope.

\section{RT-qPCR analysis}

RNA extracted from lungs of infected mice was prepared as described above, and subjected to retro transcriptase reactions using a High-Capacity cDNA transcription kit (Applied Biosystems) to generate cDNAs. PCR using Taqman assays specific for IL-1 $\beta$ (Mm01336189-ml) and 18S ribosomal RNA as a control (Mm03928990-gl) [80,81] (Applied Biosystems) were performed. Data were acquired with an ABI Prism 7000 sequence detection system (Applied Biosystems) and analyzed using ABI Prism 7000 SDS v1.0 software. Gene expression relative to mock-infected samples is shown.

\section{Lung protein extracts preparation and western blot assays}

Lungs from infected mice were collected at $2 \mathrm{dpi}$ and the right lung was homogenized in $1.2 \mathrm{~mL}$ of protein lysis buffer containing Tris/HCl 10 mM, EDTA $1 \mathrm{mM}$, NaCl 150 mM, IGEPAL 1\%, and complete protease inhibitor (Roche) pH8, using MACS homogenizer (Miltenyi Biotec). Samples were centrifuged for $1 \mathrm{~h}$ at $4^{\circ} \mathrm{C}$ and $13000 \times \mathrm{g}$ and supernatants were collected. Pro-IL-1 $\beta$ levels were analyzed by Western blotting using a goat anti mouse IL-1 $\beta /$ IL-1F2 antibody (R\&D systems). As a loading control, betaactin was labeled using a mouse monoclonal antibody (Abcam). Bound antibodies were detected using a rabbit anti goat and a rabbit anti mouse HRP conjugated antibodies and the Immobilon Western chemiluminiscence substrate (Millipore), following manufacturer's specifications. Densitometric analysis was performed in non-saturated exposures of several experimental replicates using Quantity One, version 4.5.1 software (BioRad). Levels of pro-IL$1 \beta$ were normalized to the levels of beta-actin.

\section{Bronchoalveolar lavages}

Following euthanasia by cervical dislocation, the trachea was exposed and cannulated through the animal mouth with a 19 gauge tube. Lungs were lavaged three times with $400 \mu$ of cold phosphate buffered saline (PBS). Samples were centrifuged for 10 minutes at $3000 \times \mathrm{g}$ at $4^{\circ} \mathrm{C}$ to separate cellular content, and supernatants were collected to analyze their cytokine levels.

\section{Cytokine multiplex analysis}

Bronchoalveolar lavages were treated with IGEPAL reaching a final concentration of $0.2 \%$, to inactivate sample infectivity. The expression of IL-1 $\beta$, TNF and IL-6 was measured using Luminex technology and a mouse cytokine antibody bead kit (Milliplex map kit, Millipore) according to the manufacturer's specifications.

\section{Supporting Information}

Figure S1 Infection efficiency and cellular tropism within mice lungs, in the presence or absence of SARSGoV E protein IC activity. 16 week-old BALB/c mice were infected with $100000 \mathrm{PFU}$ of the parental virus (wt, black columns) displaying $\mathrm{E}$ protein $\mathrm{IC}$ activity or the mutant virus lacking IC activity N15A (red columns). At 2 and 4 dpi mice were sacrificed and their lungs were fixed in formalin, paraffin embedded, sectioned and processed for immunofluorescence. SARS-CoV N protein and cell nuclei were labeled to discriminate both non-infected and infected cells. The number of alveolar (alveo), bronchiolar (bronch) and overall infected cells (total) were calculated in several representative images, and represented as percentages of their corresponding total cells (infected plus noninfected). Error bars indicate the standard deviation from the data collected from different images.

(TIF)

\section{Acknowledgments}

We thank Marga Gonzalez for her technical assistance.

\section{Author Contributions}

Conceived and designed the experiments: JLNT LE MLD. Performed the experiments: JLNT MLD CVB JMJG JARN RFD. Analyzed the data: JLNT LE MLD GVB JMJG JARN RFD CCR AA VMA. Contributed reagents/materials/analysis tools: JT. Wrote the paper: JLNT LE MLD. Revised the manuscript: JLNT MLD CVB JMJG JARN RFD GCR AA JT VMA LE. 


\section{References}

1. Perlman S, Netland J (2009) Coronaviruses post-SARS: update on replication and pathogenesis. Nat Rev Microbiol 7: 439-450.

2. Rota PA, Oberste MS, Monroe SS, Nix WA, Campganoli R, et al. (2003) Characterization of a novel coronavirus associated with severe acute respiratory syndrome. Science 300: 1394-1399.

3. Drosten C, Gunther S, Preiser W, van der Werf S, Brodt HR, et al. (2003) Identification of a novel coronavirus in patients with severe acute respiratory syndrome. N Engl J Med 348: 1967-1976.

4. Pyrc K, Berkhout B, van der Hoek L (2007) The novel human coronaviruses NL63 and HKU1. J Virol 81: 3051-3057.

5. Zaki AM, van Boheemen S, Bestebroer TM, Osterhaus AD, Fouchier RA (2012) Isolation of a novel coronavirus from a man with pneumonia in Saudi Arabia. N Engl J Med 367: 1814-1820.

6. Danielsson N, Catchpole M (2012) Novel coronavirus associated with severe respiratory disease: case definition and public health measures. Euro Surveill 17 : 20282.

7. Assiri A, McGeer A, Perl TM, Price CS, Al Rabeeah AA, et al. (2013) Hospital outbreak of Middle East respiratory syndrome coronavirus. N Engl J Med 369(5):407-16 doi:10.1056/NEJMoa1306742.

8. Muller MA, Paweska JT, Leman PA, Drosten C, Grywna K, et al. (2007) Coronavirus antibodies in African bat species. Emerg Infect Dis 13: 1367-1370.

9. Chu DK, Peiris JS, Chen H, Guan Y, Poon LL (2008) Genomic characterizations of bat coronaviruses $(1 \mathrm{~A}, 1 \mathrm{~B}$ and HKU8) and evidence for co-infections in Miniopterus bats. J Gen Virol 89: 1282-1287.

10. Drexler JF, Gloza-Rausch F, Glende J, Corman VM, Muth D, et al. (2010) Genomic characterization of severe acute respiratory syndrome-related coronavirus in European bats and classification of coronaviruses based on partial RNA-dependent RNA polymerase gene sequences. J Virol 84: 1133611349.

11. Quan PL, Firth C, Street C, Henriquez JA, Petrosov A, et al. (2010) Identification of a severe acute respiratory syndrome coronavirus-like virus in a leaf-nosed bat in Nigeria. MBio 1: e00208-00210.

12. Annan A, Baldwin HJ, Corman VM, Klose SM, Owusu M, et al. (2013) Human betacoronavirus 2c EMC/2012-related viruses in bats, Ghana and Europe. Emerg Infect Dis 19: 456-459.

13. Falcon A, Vazquez-Moron S, Casas I, Aznar C, Ruiz G, et al. (2011) Detection of alpha and betacoronaviruses in multiple Iberian bat species. Arch Virol 156: 1883-1890.

14. Enjuanes L, Gorbalenya AE, de Groot RJ, Cowley JA, Ziebuhr J, et al. (2008) The Nidovirales. In: Mahy BWJ, Van Regenmortel M, Walker P, MajumderRussell D, editors. Encyclopedia of Virology, Third Edition. Oxford: Elsevier Ltd. pp. 419-430.

15. Nieto-Torres JL, Dediego ML, Alvarez E, Jimenez-Guardeno JM, Regla-Nava JA, et al. (2011) Subcellular location and topology of severe acute respiratory syndrome coronavirus envelope protein. Virology 415: 69-82.

16. DeDiego ML, Alvarez E, Almazan F, Rejas MT, Lamirande E, et al. (2007) A severe acute respiratory syndrome coronavirus that lacks the $\mathrm{E}$ gene is attenuated in vitro and in vivo. J Virol 81: 1701-1713.

17. Maeda J, Repass JF, Maeda A, Makino S (2001) Membrane topology of coronavirus E protein. Virology 281: 163-169.

18. Raamsman MJB, Locker JK, de Hooge A, de Vries AAF, Griffiths G, et al. (2000) Characterization of the coronavirus mouse hepatitis virus strain A59 small membrane protein E. J Virol 74: 2333-2342.

19. Ortego J, Escors D, Laude H, Enjuanes L (2002) Generation of a replicationcompetent, propagation-deficient virus vector based on the transmissible gastroenteritis coronavirus genome. J Virol 76: 11518-11529.

20. Ortego J, Ceriani JE, Patino C, Plana J, Enjuanes L (2007) Absence of E protein arrests transmissible gastroenteritis coronavirus maturation in the secretory pathway. Virology 368: 296-308.

21. Almazan F, Dediego ML, Sola I, Zuniga S, Nieto-Torres JL, et al. (2013) Engineering a replication-competent, propagation-defective Middle East respiratory syndrome coronavirus as a vaccine candidate. MBio 4: e0065000613 .

22. Kuo L, Masters PS (2003) The small envelope protein E is not essential for murine coronavirus replication. J Virol 77: 4597-4608.

23. DeDiego ML, Pewe L, Alvarez E, Rejas MT, Perlman S, et al. (2008) Pathogenicity of severe acute respiratory coronavirus deletion mutants in hACE2 transgenic mice. Virology 376: 379-389.

24. Lamirande EW, DeDiego ML, Roberts A, Jackson JP, Alvarez E, et al. (2008) A live attenuated SARS coronavirus is immunogenic and efficacious in golden Syrian hamsters. J Virol 82: 7721-7724.

25. Netland J, DeDiego ML, Zhao J, Fett C, Alvarez E, et al. (2010) Immunization with an attenuated severe acute respiratory syndrome coronavirus deleted in $\mathrm{E}$ protein protects against lethal respiratory disease. Virology 399: 120-128.

26. Fett C, DeDiego ML, Regla-Nava JA, Enjuanes L, Perlman S (2013) Complete protection against severe acute respiratory syndrome coronavirus-mediated lethal respiratory disease in aged mice by immunization with a mouse-adapted virus lacking E protein. J Virol 87: 6551-6559.

27. Dediego ML, Nieto-Torres JL, Regla-Nava JA, Jimenez-Guardeno JM, Fernandez-Delgado R, et al. (2013) Inhibition of NF-kappaB mediated inflammation in severe acute respiratory syndome coronavirus-infected mice increases survival. J Virol 88(2):913-24 doi10.1128/JVI.02576-02513.

28. DeDiego ML, Nieto-Torres JL, Jimenez-Guardeno JM, Regla-Nava JA, Alvarez E, et al. (2011) Severe acute respiratory syndrome coronavirus envelope protein regulates cell stress response and apoptosis. PLoS pathog 7: e1002315.

29. Torres J, Parthasarathy K, Lin X, Saravanan R, Liu DX (2006) Model of a putative pore: the pentameric alpha-helical bundle of SARS coronavirus E protein in lipid bilayers. Biophys J 91: 938-947.

30. Pervushin K, Tan E, Parthasarathy K, Lin X, Jiang FL, et al. (2009) Structure and inhibition of the SARS coronavirus envelope protein ion channel. PLoS Pathog 5: e1000511.

31. Wilson L, McKinlay C, Gage P (2004) SARS coronavirus E protein forms cation-selective ion channels. Virology 330: 322-331.

32. Parthasarathy K, Ng L, Lin X, Liu DX, Pervushin K, et al. (2008) Structural flexibility of the pentameric SARS coronavirus envelope protein ion channel. Biophys J 95: 39-41.

33. Wilson L, Gage P, Ewart G (2006) Hexamethylene amiloride blocks E protein ion channels and inhibits coronavirus replication. Virology 353: 294-306.

34. Verdia-Baguena C, Nieto-Torres JL, Alcaraz A, Dediego ML, Torres J, et al. (2012) Coronavirus E protein forms ion channels with functionally and structurally-involved membrane lipids. Virology 432: 485-494.

35. Torres J, Maheswari U, Parthasarathy K, Ng L, Liu DX, et al. (2007) Conductance and amantadine binding of a pore formed by a lysine-flanked transmembrane domain of SARS coronavirus envelope protein. Protein Sci 16: 2065-2071.

36. Verdia-Baguena C, Nieto-Torres JL, Alcaraz A, Dediego ML, Enjuanes L, et al. (2013) Analysis of SARS-CoV E protein ion channel activity by tuning the protein and lipid charge. Biochim Biophys Acta 1828: 2026-2031.

37. Ye Y, Hogue BG (2007) Role of the coronavirus E viroporin protein transmembrane domain in virus assembly. J Virol 81: 3597-3607.

38. Kuo L, Hurst KR, Masters PS (2006) Exceptional flexibility in the sequence requirements for coronavirus small envelope protein (E) function. J Virol 81: 2249-2262.

39. Ruch TR, Machamer CE (2011) The hydrophobic domain of infectious bronchitis virus $\mathrm{E}$ protein alters the host secretory pathway and is important for release of infectious virus. J Virol 85: 675-685.

40. Ruch TR, Machamer CE (2012) A single polar residue and distinct membrane topologies impact the function of the infectious bronchitis coronavirus $\mathrm{E}$ protein. PLoS Pathog 8: e1002674.

41. Lu W, Zheng BJ, Xu K, Schwarz W, Du L, et al. (2006) Severe acute respiratory syndrome-associated coronavirus $3 \mathrm{a}$ protein forms an ion channel and modulates virus release. Proc Natl Acad Sci USA 103: 12540-12545.

42. Chen CG, Kruger J, Sramala I, Hsu HJ, Henklein P, et al. (2011) ORF8a of SARS-CoV forms an ion channel: experiments and molecular dynamics simulations. Biochim Biophys Acta 1808: 572-579.

43. Zhang R, Wang K, Lv W, Yu W, Xie S, et al. (2013) The ORF4a protein of human coronavirus $229 \mathrm{E}$ functions as a viroporin that regulates viral production. Biochim Biophys Acta 1838(4):1088-95 doi 10.1016/j.bbamem.2013.1007.1025.

44. Nieva JL, Madan V, Carrasco L (2012) Viroporins: structure and biological functions. Nat Rev Microbiol 10: 563-574.

45. Pinto LH, Holsinger LJ, Lamb RA (1992) Influenza virus M2 protein has ion channel activity. Cell 69: 517-528.

46. Ewart GD, Sutherland T, Gage PW, Cox GB (1996) The Vpu protein of human immunodeficiency virus type 1 forms cation-selective ion channels. J Virol 70: 7108-7115.

47. Pavlovic D, Neville DC, Argaud O, Blumberg B, Dwek RA, et al. (2003) The hepatitis $\mathrm{C}$ virus $\mathrm{p} 7$ protein forms an ion channel that is inhibited by long-alkylchain iminosugar derivatives. Proc Natl Acad Sci USA 100: 6104-6108.

48. de Jong AS, Visch HJ, de Mattia F, van Dommelen MM, Swarts HG, et al. (2006) The coxsackievirus 2B protein increases efflux of ions from the endoplasmic reticulum and Golgi, thereby inhibiting protein trafficking through the Golgi. J Biol Chem 281: 14144-14150.

49. Henkel M, Mitzner D, Henklein P, Meyer-Almes FJ, Moroni A, et al. (2010) The proapoptotic influenza A virus protein PB1-F2 forms a nonselective ion channel. PLoS One 5: el1112.

50. Campanella M, de Jong AS, Lanke KW, Melchers WJ, Willems PH, et al. (2004) The coxsackievirus $2 \mathrm{~B}$ protein suppresses apoptotic host cell responses by manipulating intracellular Ca2+ homeostasis. J Biol Chem 279: 18440-18450.

51. Wozniak AL, Griffin S, Rowlands D, Harris M, Yi M, et al. (2010) Intracellular proton conductance of the hepatitis $\mathrm{C}$ virus $\mathrm{p} 7$ protein and its contribution to infectious virus production. PLoS Pathog 6: e1001087.

52. Ichinohe T, Pang IK, Iwasaki A (2010) Influenza virus activates inflammasomes via its intracellular M2 ion channel. Nat Immunol 11: 404-410.

53. McAuley JL, Tate MD, MacKenzie-Kludas CJ, Pinar A, Zeng W, et al. (2013) Activation of the NLRP3 inflammasome by IAV virulence protein PB1-F2 contributes to severe pathophysiology and disease. PLoS Pathog 9: e1003392.

54. Sakaguchi T, Leser GP, Lamb RA (1996) The ion channel activity of the influenza virus M2 protein affects transport through the Golgi apparatus. J Cell Biol 133: 733-747. 
55. de Jong AS, de Mattia F, Van Dommelen MM, Lanke K, Melchers WJ, et al. (2008) Functional analysis of picornavirus 2B proteins: effects on calcium homeostasis and intracellular protein trafficking. J Virol 82: 3782-3790.

56. Cornell CT, Kiosses WB, Harkins S, Whitton JL (2007) Coxsackievirus B3 proteins directionally complement each other to downregulate surface major histocompatibility complex class I. J Virol 81: 6785-6797.

57. Triantafilou K, Kar S, Vakakis E, Kotecha S, Triantafilou M (2013) Human respiratory syncytial virus viroporin $\mathrm{SH}$ : a viral recognition pathway used by the host to signal inflammasome activation. Thorax 68: 66-75.

58. Zhang K, Hou Q, Zhong Z, Li X, Chen H, et al. (2013) Porcine reproductive and respiratory syndrome virus activates inflammasomes of porcine alveolar macrophages via its small envelope protein E. Virology 442: 156-162.

59. Ito M, Yanagi Y, Ichinohe T (2012) Encephalomyocarditis virus viroporin 2B activates NLRP3 inflammasome. PLoS Pathog 8: e1002857.

60. Roberts A, Deming D, Paddock CD, Cheng A, Yount B, et al. (2007) A mouseadapted SARS-coronavirus causes disease and mortality in BALB/c mice. PLoS Pathog 3: 23-37.

61. Regla-Nava JA, Jimenez-Guardeno JM, Nieto-Torres JL, Gallagher TM, Enjuanes L, et al. (2013) The replication of a mouse adapted SARS-CoV in a mouse cell line stably expressing the murine SARS-CoV receptor mACE2 efficiently induces the expression of proinflammatory cytokines. J Virol Methods 193: 639-646.

62. Meduri GU, Headley S, Kohler G, Stentz F, Tolley E, et al. (1995) Persistent elevation of inflammatory cytokines predicts a poor outcome in ARDS. Plasma IL-1 beta and IL-6 levels are consistent and efficient predictors of outcome over time. Chest 107: 1062-1073.

63. Tisoncik JR, Korth MJ, Simmons CP, Farrar J, Martin TR, et al. (2012) Into the eye of the cytokine storm. Microbiol Mol Biol Rev 76: 16-32.

64. Martinon F, Petrilli V, Mayor A, Tardivel A, Tschopp J (2006) Gout-associated uric acid crystals activate the NALP3 inflammasome. Nature 440: 237-241.

65. Watanabe T, Watanabe S, Ito H, Kida H, Kawaoka Y (2001) Influenza A virus can undergo multiple cycles of replication without M2 ion channel activity. J Virol 75: 5656-5662.

66. Takeda M, Pekosz A, Shuck K, Pinto LH, Lamb RA (2002) Influenza a virus M2 ion channel activity is essential for efficient replication in tissue culture. J Virol 76: 1391-1399.

67. Bukreyev A, Whitehead SS, Murphy BR, Collins PL (1997) Recombinant respiratory syncytial virus from which the entire $\mathrm{SH}$ gene has been deleted grows efficiently in cell culture and exhibits site-specific attenuation in the respiratory tract of the mouse. J Virol 71: 8973-8982.

68. Whitehead SS, Bukreyev A, Teng MN, Firestone CY, St Claire M, et al. (1999) Recombinant respiratory syncytial virus bearing a deletion of either the NS2 or SH gene is attenuated in chimpanzees. J Virol 73: 3438-3442.

69. Watanabe S, Watanabe T, Kawaoka Y (2009) Influenza A virus lacking M2 protein as a live attenuated vaccine. J Virol 83: 5947-5950.

70. Gladue DP, Holinka LG, Largo E, Fernandez Sainz I, Carrillo C, et al. (2012) Classical swine fever virus $\mathrm{p} 7$ protein is a viroporin involved in virulence in swine. J Virol 86: 6778-6791.

71. Graham RL, Donaldson EF, Baric RS (2013) A decade after SARS: strategies for controlling emerging coronaviruses. Nat Rev Microbiol 11: 836-848.

72. Matthay MA, Zemans RL (2011) The acute respiratory distress syndrome: pathogenesis and treatment. Annu Rev Pathol 6: 147-163.

73. Hollenhorst MI, Richter K, Fronius M (2011) Ion transport by pulmonary epithelia. J Biomed Biotechnol 2011: 174306.

74. Rockx B, Baas T, Zornetzer GA, Haagmans B, Sheahan T, et al. (2009) Early upregulation of acute respiratory distress syndrome-associated cytokines promotes lethal disease in an aged-mouse model of severe acute respiratory syndrome coronavirus infection. J Virol 83: 7062-7074.

75. Pugin J, Ricou B, Steinberg KP, Suter PM, Martin TR (1996) Proinflammatory activity in bronchoalveolar lavage fluids from patients with ARDS, a prominent role for interleukin-1. Am J Respir Crit Care Med 153: 1850-1856.

76. Grommes J, Soehnlein O (2011) Contribution of neutrophils to acute lung injury. Mol Med 17: 293-307.

77. dos Santos G, Kutuzov MA, Ridge KM (2012) The inflammasome in lung diseases. Am J Physiol Lung Cell Mol Physiol 303: L627-633.

78. Strowig T, Henao-Mejia J, Elinav E, Flavell R (2012) Inflammasomes in health and disease. Nature 481: 278-286.

79. Wang CH, Liu CY, Wan YL, Chou CL, Huang KH, et al. (2005) Persistence of lung inflammation and lung cytokines with high-resolution CT abnormalities during recovery from SARS. Respir Res 6: 42

80. Frieman MB, Chen J, Morrison TE, Whitmore A, Funkhouser W, et al. (2010) SARS-CoV pathogenesis is regulated by a STAT1 dependent but a type I, II and III interferon receptor independent mechanism. PLoS Pathog 6: e1000849.

81. Sheahan T, Morrison TE, Funkhouser W, Uematsu S, Akira S, et al. (2008) MyD88 is required for protection from lethal infection with a mouse-adapted SARS-CoV. PLoS Pathog 4: e1000240. 
Cite this: Phys. Chem. Chem. Phys., 2014, 16, 3881

Received 6th November 2013, Accepted 3rd January 2014

DOI: $10.1039 / c 3 c p 54690 j$

www.rsc.org/pccp

\title{
Lipid charge regulation of non-specific biological ion channels
}

\author{
Vicente M. Aguilella, * Carmina Verdiá-Báguena and Antonio Alcaraz
}

Ion channels are specialized proteins that enable the movement of charges through otherwise impermeable lipidic membranes. Their action is essential in living organisms facilitating electric signaling, muscle contraction or osmotic stress response among other effects. The protein and the lipid charges configure a polarized interface that yields local ionic concentrations and electric potentials that are very different from those of the bulk electrolyte. The combined effect of gradients of ionic concentration and electric potential causes the transport of ions through channels. Here we analyze charge regulation effects in different protein-lipid conformations, stressing how important is the role of electrostatic interactions in the ion channel function that traditionally has been rationalized paying attention mainly to changes in pore size. Tuning lipid charge combined with conductance and selectivity measurements is shown to be a complementary method to evidence lipid involvement in the structure of a biological ion channel.

\section{Introduction}

It was almost 25 years ago when S. McLaughlin noted that "three of the four known forces are irrelevant to most aspects of molecular and cell biology; the fourth has been ignored by most biologists until recently". ${ }^{1}$ This evident reference to electrical interactions was especially pertinent in the beginning of modern molecular biophysics, but today there is a widespread and increasing awareness of the fundamental role of long range interactions in nanoscale science ${ }^{2}$ and, particularly, in biological macromolecules and their interfaces with ionic solutions. Historically, the understanding of cell signaling and membrane electric currents has been associated with the concept of an ion conducting pore. ${ }^{3}$ Since then, a large variety of transmembrane proteins and other pore-forming peptides have been described that help to communicate the cell or its organelles with their external environment, maintain the osmotic equilibrium and perform essential physiological functions for the metabolism. ${ }^{4}$ They are collectively known as ion channels even though they may display a large variety of characteristics (an extensive survey can be found in the Transport Classification Database). ${ }^{5}$ Here, we review how electrostatic interactions regulate the transport properties of biological channels that display multiionic transport, i.e. pores having dimensions that allow simultaneous passage of water molecules and several types of ions which may enter the pore without losing their hydration shell. ${ }^{6}$ These so-called mesoscopic channels do not show a specific selectivity

Dept. Physics, Lab. Molecular Biophysics, Universitat Jaume I, 12080 Castellón, Spain.E-mail: aguilell@uji.es for a particular ionic species and in some cases are wide enough to let small metabolites like ATP or antibiotic molecules go in. ${ }^{7,8}$ Thus, this perspective is focused more on toxins and large bacterial porins and peptide channels rather than on the canonical mammalian and bacterial channels that perform specialized signalling functions often controlling the passage of a particular ionic species across the membrane. There are many viral protein channels as well as antimicrobial peptides that fall into this category of non-specific channels where the ideas put forward here may be of interest.

Understanding the role of a lipid environment in the channel activity of proteins and peptides is essential in the determination of protein structure and function and it is a novel theme in ion channel biology. ${ }^{9}$ Lipids can modify the ion channel properties by changing the local distribution of charge, the dielectric constant and other physicochemical properties of the membrane, such as its fluidity, curvature strain, etc. ${ }^{10-12}$ And interestingly, this protein-lipid interaction is reciprocal, i.e., there are many perturbations of membrane lipids induced by integral membrane proteins. ${ }^{13}$ This perspective deals almost exclusively with the electrostatic effects of lipid charge on the channel properties. The membrane electrostatic environment may influence the first stage of a peptide channel formation, the membrane binding and subsequent insertion, ${ }^{14,15}$ as well as its transport and selectivity properties. Electrophysiology methods have proved to be the fundamental source of information to identify and characterize non-specific charge effects associated with the protein ionizable residues and with the lipid polar heads of biological membranes. ${ }^{16}$ This technique, historically associated with the detection of neural activity of excitable 
tissues, has become indispensable in the study of channel transport at the molecular level. ${ }^{4}$ By reconstituting the protein channel in model membranes (e.g. planar phospholipid bilayers) whose lipid composition can be controlled and modified at will, the response of a single channel to an external applied voltage difference, a salt concentration gradient or other nonequilibrium perturbations, can be monitored in real time and subsequently analyzed. ${ }^{17}$ Very often merging the outcome of several experiments performed under different conditions helps to understand the ion-protein interactions. ${ }^{6,18,19}$ Many experimental findings associated with lipid charge effects have been traditionally rationalized by means of mean-field electrostatic theories like Gouy-Chapman (GC) double layer theory and PoissonBoltzmann's equation, ${ }^{20-22}$ or the Poisson-Nernst-Planck flux equations. ${ }^{23}$ With the advent of powerful computing techniques and the increasing number of protein ion channels whose tertiary structure has been determined at atomic resolution, ${ }^{24}$ unprecedented microscopic insights have been reported about the role of electrostatic interactions in ion channel function. ${ }^{25,26}$ In spite of this, there are many ion channels where the predictive capability of simulations is still insufficient and lower resolution approaches like the above-mentioned continuum theories are an indispensable complement to figure out charge related effects. ${ }^{6,26}$

\section{The classical view of conductance regulation by lipid charge}

The functional properties of ion channels reconstituted in model phospholipid membranes depend on a number of characteristics of the membrane: lipid composition (polar head and acyl chain), hydrophobic thickness, intrinsic membrane curvature, hydrophobic mismatch, lateral pressure, surface charge, etc. ${ }^{27,28}$ Each one of these features could be of critical or secondary importance depending on the particular aspect of the ion channel under study, e.g., ion conduction, gating, ligand binding, life-time or formation on-rate, among others. Despite this, the surface charge becomes the key factor in the vast majority of membrane proteins given that ion channel activity basically involves translocation of charged solutes. A significant fraction of the phospholipids in many biological membranes bears a net negative charge. These surface charges are located in the polar head groups of lipids and give rise to an electrostatic potential in the aqueous phase adjacent to the membrane.

Experimental evidence of the influence of lipid charge on the conductance of ion channels has built up over the last few decades. ${ }^{20,22,29-37}$ It has been reported that ion accumulation or depletion near a charged membrane surface influences channel ion permeation. Depending on the channel selectivity, the lipid charge can either increase or decrease channel conductance. To mention just a few examples, an increase in channel conductance with surface charge has been reported in experiments with neutral alamethicin $^{21}$ and also with a much smaller, ideally cation selective channel, gramicidin A, when reconstituted in negatively charged bilayers. ${ }^{20}$ In the Voltage Dependent Anion Channel
(VDAC) from the mitochondrial outer membrane, the effect of membrane surface charge has been studied both in negatively charged lipids and positively charged lipids. ${ }^{22}$ The residual channel conductance upon VDAC-tubulin interaction was measured and it was found that in diluted solutions a cationic lipid induced a decrease in conductance relative to the neutral membrane, whereas an anionic lipid induced an increase in conductance.

The modulation of ion concentration exerted by lipid charges has been qualitatively and semi-quantitatively rationalized in terms of GC theory. ${ }^{20-22,38,39}$ According to GC theory, the extent of counterion accumulation or coion depletion near a charged surface (the lipid-solution interface in this case) is critically dependent on the ratio between the Debye length of the solution, $\lambda_{\mathrm{D}}$, and the average distance from the channel mouth to the nearest charged lipid polar head. For an ideal planar membrane, with homogeneous surface charge density $\sigma$, in contact with a solution of ionic strength $I$, the electric potential $\varphi$ at a distance $z$ from the surface (in $R T / F$ units) predicted by GC theory is

$$
\varphi(z)=4 \tanh ^{-1}\left[\tanh \left(\varphi_{\mathrm{o}} / 4\right) \exp \left(-z / \lambda_{\mathrm{D}}\right)\right]
$$

where $\varphi_{\mathrm{o}}$ is the dimensionless electric potential at the membrane surface, given by

$$
\varphi_{\mathrm{o}}=2 \sinh ^{-1}\left[\sigma /\left(2 F \lambda_{\mathrm{D}} I\right)\right]
$$

and Debye length is $\lambda_{\mathrm{D}}=\left(\varepsilon \varepsilon_{\mathrm{O}} R T / I F^{2}\right)^{1 / 2}$. In the above expressions $R$ is the gas constant, $T$ is the absolute temperature, $F$ is the Faraday constant and $\varepsilon \varepsilon_{\mathrm{o}}$ is the electric permittivity of water. By solving numerically Poisson-Boltzmann's equation near a charged planar surface with an embedded neutral hole representing the channel mouth, ${ }^{21}$ one can calculate how the electric potential changes with respect to the normal distance from the lipid surface and also with the radial distance from the edge of the charged surface towards the center of the channel mouth (Fig. 1). This allows estimating the counterion and coion concentrations over the pore mouth from the local electric potential. By using an empiric ${ }^{20}$ or a theoretical ${ }^{21,22}$ relationship between channel

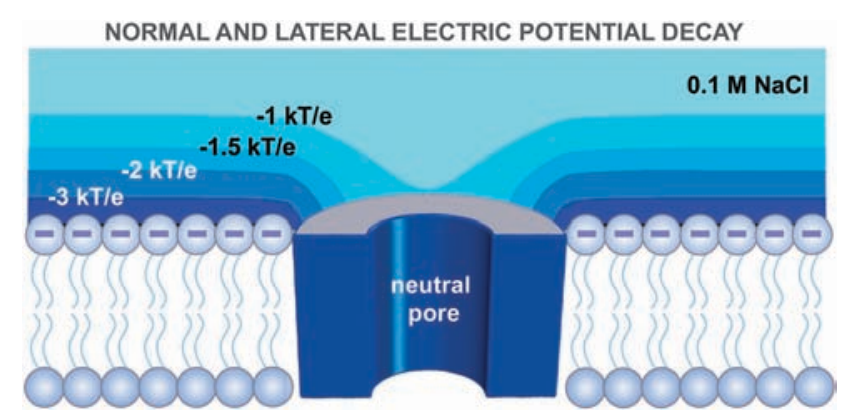

Fig. 1 Cartoon of a wide channel embedded on a charged lipid bilayer with an isopotential contour plot of the electric potential decay in the normal direction from the lipid surface and in the lateral direction from the protein-lipid interface. Labels indicate the value of the electric potential at the limit between regions with different colors. The potential was calculated for a negatively charged $\left(1 e / 0.5 \mathrm{~nm}^{2}\right)$ planar surface with a neutral circular patch of radius $1.4 \mathrm{~nm}$ bathed by a $0.1 \mathrm{M} \mathrm{NaCl}$ solution. The contour plot size is $6 \times 2 \mathrm{~nm}$. Adapted from ref. 21 . 
conductance and ion concentrations at the pore mouth, the lipid charge effect on channel transport properties can be studied. Even though the use of GC theory is widely admitted, it exhibits some limitations, the most important of which are considering ions as point charges exposed just to Coulombic interactions in the diffuse layer and regarding the solvent as a structureless continuum with homogeneous dielectric permittivity. Some theoretical developments have sought to overcome these limitations, particularly those relative to the effect of the discreteness of surface charge both in protein ion channels and in biological membranes. ${ }^{1}$ However, despite the fact that charge on membranes is discrete, models that assume a uniform density of charge in the plane of the membrane predict potentials in agreement with experiments. ${ }^{40-42}$ Furthermore, besides numerous experimental verifications, GC theory has also been validated by Molecular Dynamics simulations. ${ }^{43}$

\section{Lipid charge effects probed by conductance measurements}

The classical way to investigate the interactions between the channel and the permeating ions is to analyze how channel conductance changes with salt concentration. In neutral or weakly charged pores, the channel conductance should be proportional to the solution conductivity and hence to the ion concentration. ${ }^{4}$ In charged pores, one could speculate that the relationship between conductance and concentration should basically depend on the amount of carriers that are inside the channel once the electroneutrality requirements are fulfilled. Thus, some studies allegedly report a linear dependence of the channel conductance on the square root of salt concentration that could be tentatively attributed to charge screening effects. The rationale would be supposedly related to the proportionality between the inverse Debye length and the square root of ionic strength. ${ }^{44,45}$ However, other experiments show no unique trend but a variety of charge screening effects depending on the pore size, the ionization state of the pore charges and the complicated balance between protein and lipid charges. In the following section we pay attention to all these effects by analyzing the conductance concentration dependence in four protein channels whose well known structure is rather different.

\subsection{Four channels of known 3D structure}

The first example brought here is the bacterial porin OmpF, a multiionic, weakly cation selective channel, well characterized both functionally and structurally, ${ }^{46-50}$ which forms large pores in the outer membrane of $E$. coli. We measured the channel conductance in ion channels reconstituted in neutral (DPhPC) and charged (DPhPS) membranes over a wide range of salt concentration (30 mM-1.5 M KCl), as shown in Fig. 2A. In all cases, regardless of the lipid composition and the salt concentration the pore displays almost ohmic conduction, so that the conductance is independent of the applied voltage even at the lowest concentration, $30 \mathrm{mM}$ (see Fig. 2B). Taking into account the size of the OmpF beta-barrel (several nanometers width),

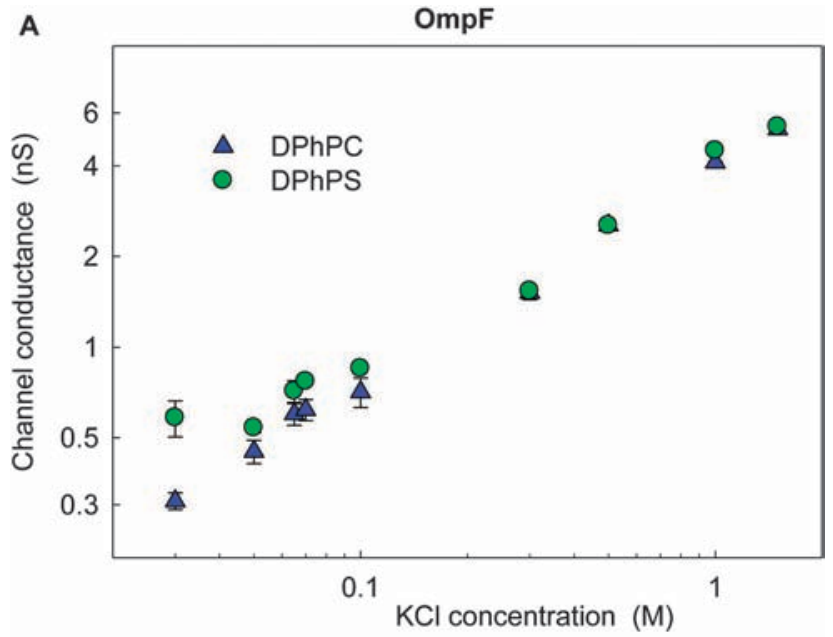

B OmpF I-V Curve $30 \mathrm{mM} \mathrm{KCI}$

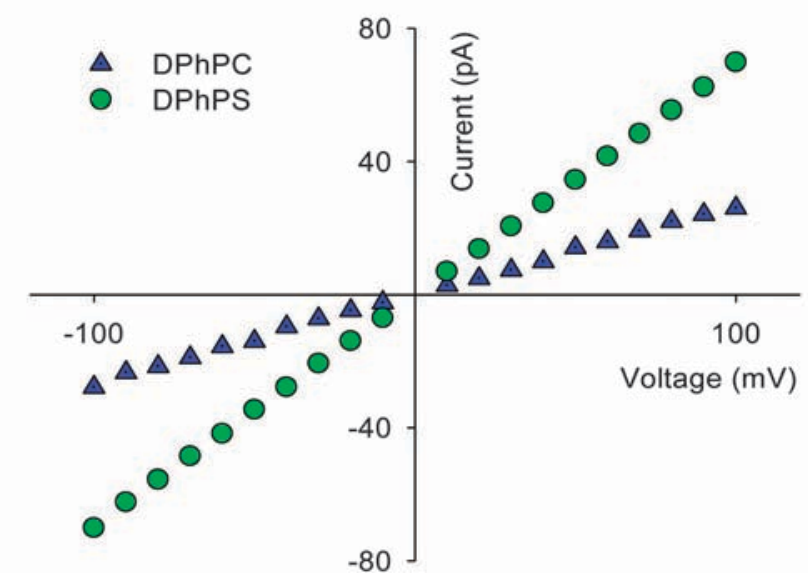

Fig. 2 OmpF single channel conductance in neutral and charged lipid membranes. (A) Double logarithmic plot of the change of the OmpF single channel conductance with the conductivity of the bathing $\mathrm{KCl}$ solution at neutral $\mathrm{pH}$. Two sets of measurements are shown, corresponding to channel reconstitution in negatively charged DPhPS membranes (circles) and in neutral DPhPC membranes (triangles). (B) Current-voltage curve obtained from single channel experiments at $30 \mathrm{mM} \mathrm{KCl}$ in DPhPC and DPhPS membranes as labeled.

the lipid headgroup charges surrounding the channel mouths are likely to exert a minor influence on the channel conductance. Indeed, in concentrated solutions the differences between DPhPC and DPhPS are very small (within experimental error) and in both cases the conductance apparently scales with salt concentration, although the actual dependence is not linear, but somewhat like $G \sim c^{0.7}$. This indicates that the interaction of the permeating ions with lipid and protein charges must be described by something more elaborated than the aforementioned square root of ionic strength that correlated with the inverse of Debye length. Interestingly, the effect of the lipid charges is visible in diluted solutions. At decimolar salt concentrations the channel conductance in pores reconstituted in charged membranes increases by a factor of 2 with respect to neutral membranes. 


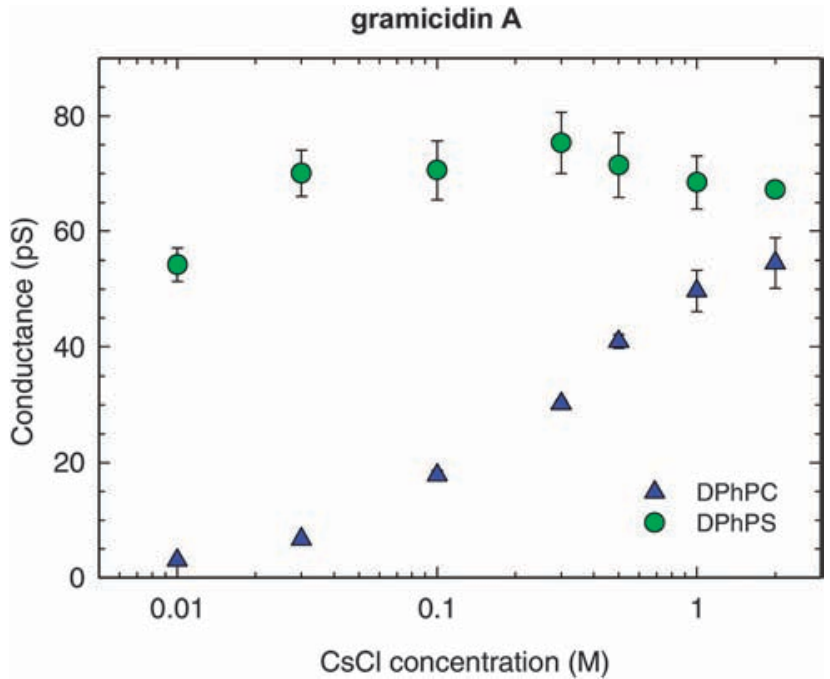

Fig. 3 Double logarithmic plot of the change of gramicidin A channel conductance with $\mathrm{CsCl}$ concentration at $\mathrm{pH}$ 7.4. Circles denote measurements in negatively charged DPhPS membranes and triangles correspond to neutral DPhPC membranes. Adapted with permission from ref. 20.

A completely different channel structure is formed by the antibiotic gramicidin A (gA). This peptide dimer opens a very narrow aqueous pore that only allows for single file transport of ions. Measurements of gA conductance in neutral and charged lipids were performed by Apell et $a .^{29}$ for different $\mathrm{CsCl}$ concentrations and two decades later Rostovtseva et al. ${ }^{20}$ extended the study with measurements at higher salt concentrations and a wide range of $\mathrm{pH}$. Rostovtseva's results are shown in Fig. 3. In this case the effect of the lipid is much more evident. Only at very high salt concentration the conductance in both membranes is similar, whereas for dilute solutions the effect of the lipid charge increases the channel conductance in one order of magnitude. Interestingly, it was found ${ }^{29}$ that the addition of a small $(1 \mathrm{mM})$ amount of $\mathrm{Ca}^{2+}$ ions to the $\mathrm{CsCl}$ solution rendered virtually the same gA conductance in charged and neutral lipid. This is consistent with a reduction in the negative surface potential induced by the divalent cations although a gA blocking effect by $\mathrm{Ca}^{2+}$ ions cannot be excluded. The effect of the lipid is considerably higher than in OmpF because of the much smaller size of the channel. Recall that gA is a cylinder-shaped pore with radius of about $0.2 \mathrm{~nm}$ whereas OmpF porin has an hour-glass shape of about $0.7 \mathrm{~nm}$ in the narrowest part of the pore with vestibules about $2 \mathrm{~nm}$ wide. As it could be expected, the dependence of channel conductance on salt concentration is completely different to that observed in OmpF. As Fig. 3 shows, in charged lipids the channel conductance is almost insensitive to the salt concentration. Quite the opposite, the experiments in neutral lipids show an almost linear dependence at low concentration that saturates as concentration increases and finally almost matches the results with charged lipids. Although these results qualitatively agree with GC theory, there are many more subtle issues apart from pure electrostatic salt screening that should be taken into account for a correct interpretation of lipid charge influence on gA conductance. The effect of lipid lateral tension, given the small size of this channel, and a certain lipid selectivity not directly related to the net charge of the lipid headgroups ${ }^{51}$ are two examples of phenomena that fall beyond the scope of this perspective.

The above examples of a bacterial porin and a small antibiotic share the feature that the channel structure is rather symmetric as regards the pore entrances. But when the channel structure is asymmetric and the lipid-protein interface differs at the two channel entrances, the effect of lipid charge on conductance may be voltage dependent and may also change with the ion current direction. This is what happens in the alpha-hemolysin channel $(\alpha \mathrm{HL})$ from Staphylococcus aureus. Its current-voltage relationship is nonlinear, rectifying, and depends on the bulk pH and the ionic strength. ${ }^{52}$ In addition to its internal asymmetric charge distribution of amino acid residues, it has a bulky cap in the membrane side where the protein is inserted and a smaller stem of cylindrical shape on the other side. ${ }^{53}$ Besides, there is another difference with respect to OmpF and gA. The $\alpha \mathrm{HL}$ channel is anion selective. All these factors make the picture more complex than in the two previously analyzed channels, since there could exist a certain compensation between the protein and the lipid charges working in opposite directions. Even in a neutral membrane, the single conductance measurements plotted in Fig. 4 (triangles) ${ }^{54}$ show a slight (ca. 20\%) difference between $\alpha \mathrm{HL}$ conductance at $+100 \mathrm{mV}$ and $-100 \mathrm{mV}$. When reconstituted in negatively charged lipids (DPhPS), the rectification is enhanced as shown by the circles in Fig. 4. Because the channel distribution of charged residues is different on either pore mouths, a simple explanation in terms of anions as major current carriers and their depletion induced by the negative lipid charge is not possible.

Interestingly, lipid charge may alter channel conductance not only by inducing a change in the amount of charge carriers

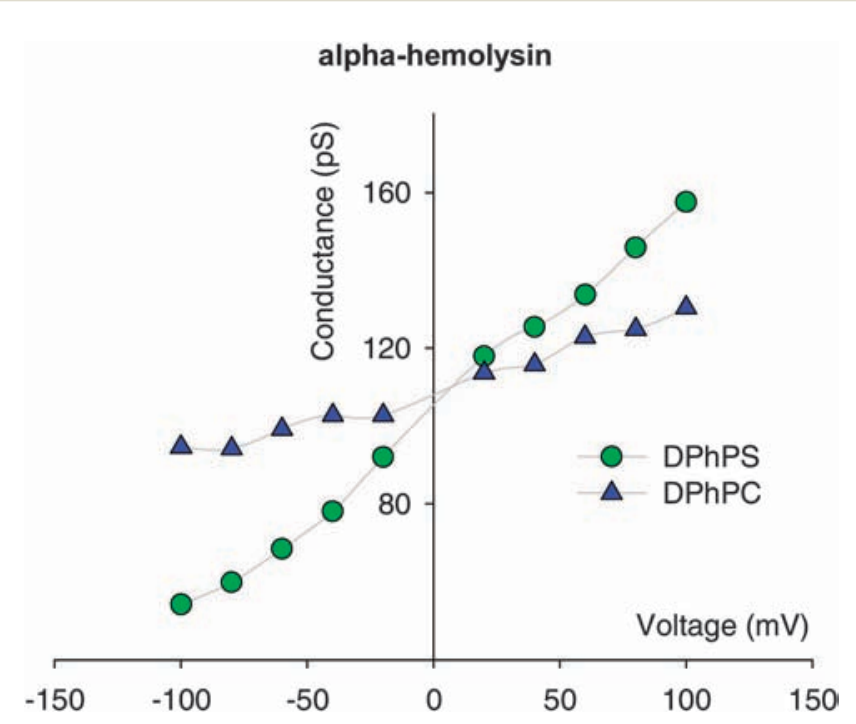

Fig. 4 Voltage dependent single channel conductance of alpha-hemolysin in $0.1 \mathrm{M} \mathrm{KCl}$ at pH 7.5. The same symbol code as in previous figures is used: circles for DPhPS and triangles for DPhPC membranes. Adapted with permission from ref. 54 . 
at the channel entrance. An increase in surface charge, and its concomitant polar head repulsion, may modify the membrane lateral stress and the spontaneous curvature changing then the relative probabilities of different channel conductance states. Both kinds of effects have been reported in Alamethicin channels upon $\mathrm{pH}$ titration of DOPS polar heads in the membrane. ${ }^{55}$ Neutralization of the lipid head group charge by proton binding reduces head-head repulsion and shifts DOPS from the lamellar structure displayed at neutral $\mathrm{pH}$ to a hexagonal $\mathrm{H}_{\mathrm{II}}$-phase of a high curvature (confirmed by $\mathrm{X}$-ray diffraction at $\mathrm{pH} 2$ ) where higher conductance levels of the channel are much more probable. This result is consistent with the current barrelstave model for the alamethicin channel. According to this barrel-stave structure, higher conductance states would correspond to bigger alamethicin aggregates (i.e. a larger number of assembled monomers) with a less energy cost of membrane deformation. Fig. 5 shows single conductance measurements of the two lowest conductance states, labeled L0 and L1, at varying $\mathrm{NaCl}$ concentrations at $\mathrm{pH}$ 6.2. ${ }^{21}$ Apart from a difference of up to an order of magnitude between L0 and L1 conductance, the effect of lipid charge is seen in an almost two-fold increase of channel conductance at physiological salt concentrations. It is much bigger in the L0 state than in L1, which is consistent with the larger size of the pore opening in the latter case and the greater distance between the pore center and the nearest charged lipid polar head. GC theory accounts fairly well for the increase in conductance at different salt concentrations and $\mathrm{pH}$. Furthermore, in this particular case it allows us to estimate the increase in the number of alamethicin assembled monomers from L0 to L1 barrel stave conformations. It is worth mentioning that a neutral form of alamethicin was used in the above experiments. This detail should not be overlooked because it allows analyzing the proton binding just to the lipid head groups and not to any other ionizable residues of the

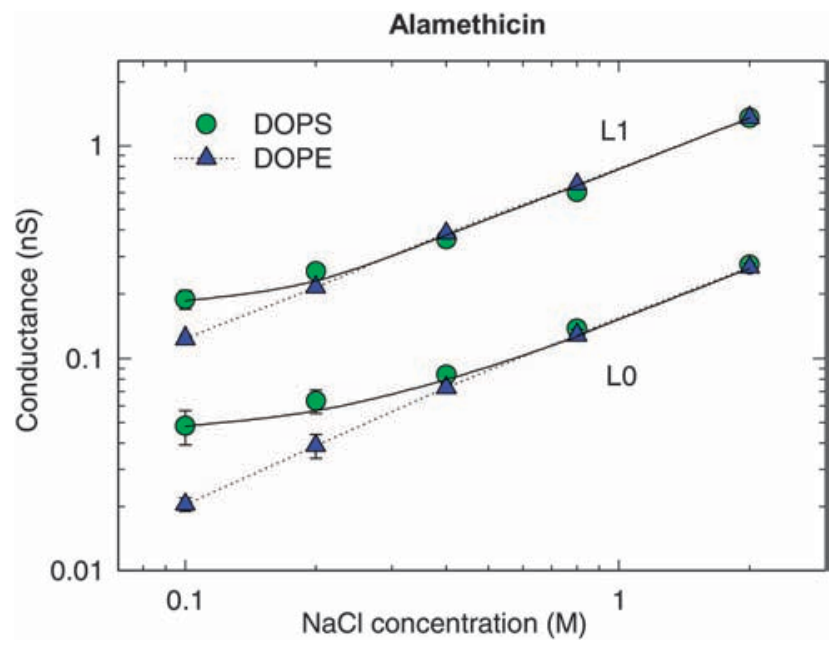

Fig. 5 Double logarithmic plot of the change of two Alamethicin channel conductance states ( $\mathrm{LO}$ and L1) with $\mathrm{NaCl}$ concentration at $\mathrm{pH}$ 6.2. Circles denote measurements in negatively charged DOPS membranes and triangles correspond to neutral DOPE membranes. Adapted with permission from ref. 21. protein channel. Somewhat, this is an exception because in most experiments channel charges and lipid charges can hardly be separately manipulated by proton titration or salt screening.

\subsection{Lipid charge and proteolipidic structures}

The findings in these four examples of channels whose structural information is available can be summarized as follows: (a) channel conductance is different when channels are reconstituted in charged membranes and in neutral membranes; (b) low electrolyte concentrations enhance the effect of the lipid charges whereas concentrated solutions screen the lipid charges up to the point at which channel currents in charged and neutral lipids become almost indistinguishable; (c) as lipid charged headgroups surrounding the pore entrance are responsible for the alteration of local ion concentrations, the smaller the channel mouth the higher the effect of the charged lipid; (d) the cationic or anionic channel selectivity is a key factor in the increase or decrease of ionic conductance.

This knowledge can be used to rationalize the ion channel activity of a protein in which lipid molecules assemble with protein oligomers to form a combined proteolipidic structure. This may occur in proteinaceous channels in which the lipids form the pore vestibule or just the channel mouth (see Fig. 6A), or alternatively, in lipidic channels in which the lipid polar heads, stabilized by peptides, could be actually lining totally or partially the pore wall (see Fig. 6B), ${ }^{44,56}$ a structure known as the toroidal pore. This concept of the toroidal pore was proposed as a mechanism of action of antimicrobial peptides and large toxins. ${ }^{15}$ The lipid surface bends to form the inner part of a torus so that the lipid spontaneous curvature may promote or inhibit the pore formation depending on the pore size. Lipid molecules would display a positive curvature in a cross sectional plane along the pore axis (frontal view in Fig. 6B) and a negative curvature in a plane parallel to the membrane surface. Thus, experiments with lipids of positive and negative curvatures have been used to test whether a peptide forms toroidal pores in the membrane.
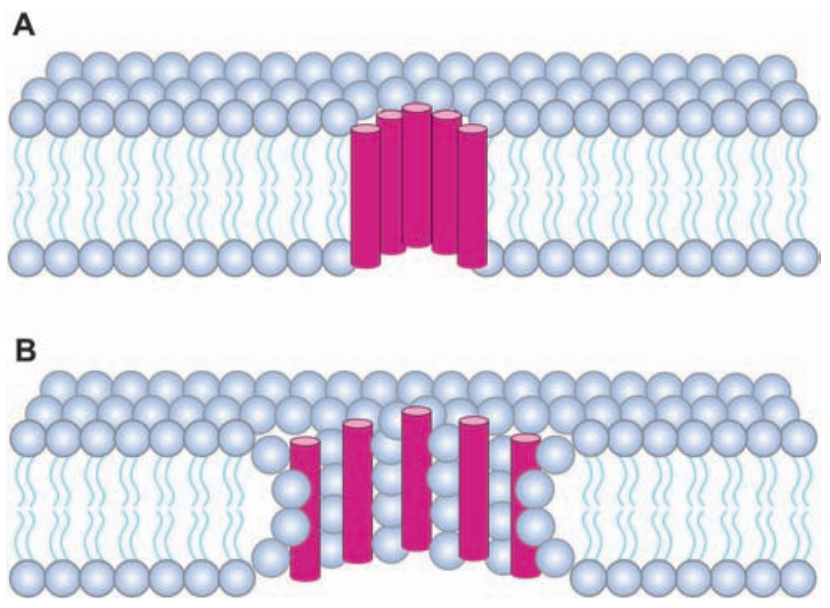

Fig. 6 Sketch of two different kinds of proteolipidic pores where the lipid molecules and the peptide monomers are arranged following the typical barrel stave pore (A) and a toroidal pore (B). 
We show here how new insights into proteolipidic pores can be gained from several series of conductance measurements of a viral protein channel, the envelope protein channel of the SARS coronavirus (SARS-CoV E). ${ }^{57,58}$ It has been reported that SARS-CoV E protein oligomerizes forming a pentameric structure that alters the structure and permeability of phospholipid membranes, a remarkable function for this protein that may affect virus host interaction. ${ }^{57}$ Experiments in neutral DPhPC planar bilayers show that channel conductance changes linearly with solution conductivity. ${ }^{58}$ Such behavior implies that the interaction between the permeating ions and the protein is so weak that ion conduction in the pore and in bulk solution is pretty similar to each other. However, parallel experiments in charged DPhPS membranes raise some important questions because the results differ completely from the experiments reported in the previous section for OmpF, gA, $\alpha \mathrm{HL}$ and Alamethicin. The main unexpected result is that in experiments above physiological salt concentrations, the SARS-CoV E channel conductance is higher in neutral membranes than in charged ones (Fig. 7). According to the classical electrostatic rationale described in the preceding section, the lipid charge induced accumulation of ions near the pore mouth should produce just the opposite effect, i.e. greater channel conductance in DPhPS. Furthermore, screening of charges at high salt concentrations does not lead to similar channel conductance in charged and neutral membranes as was the case in the other channels. Thus, in the search of alternative explanations we might ask if besides the charge-induced change in local ion concentrations at the pore entrances there are other effects that prevail and cause the observed difference in conductance. One could point to the existence of membrane-induced lipid-protein structural rearrangements. This would yield a change in the pore size that could account for variations in conductance.

\section{SARS-CoV E}

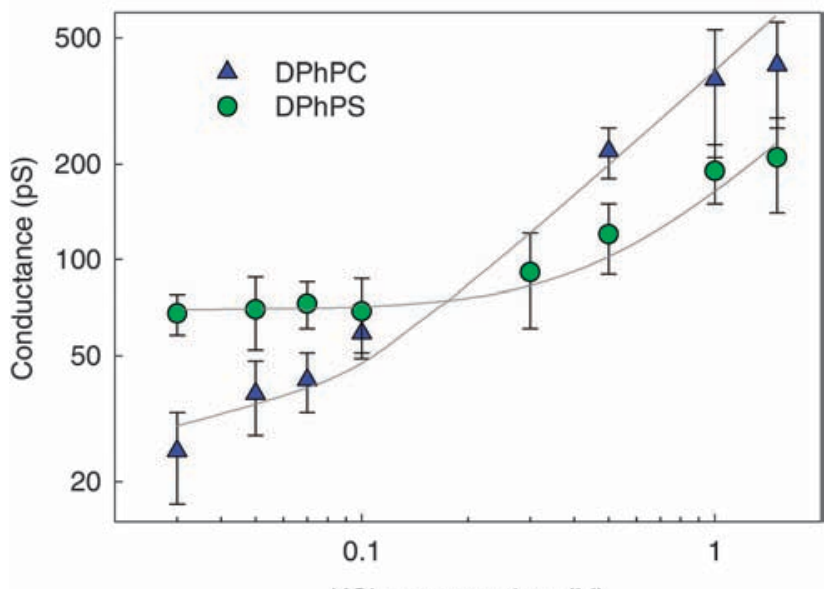

$\mathrm{KCl}$ concentration (M)

Fig. 7 Channel conductance of the SARS-CoV E protein channel in neutral DPhPC (triangles) and negatively charged DPhPS (circles) at $\mathrm{pH} 6$. In DPhPS membranes and low concentration $\mathrm{KCl}$ solutions (30-100 mM) the channel conductance remains unaltered because the ionic concentration within the pore is controlled by the channel fixed charge. In more concentrated solutions $(0.3-1.5 \mathrm{M})$, the conductance increases with the bulk $\mathrm{KCl}$ concentration. Adapted with permission from ref. 58 .
However, this is not the unique possible scenario. It could also occur that lipid polar heads are involved in the pore structure so that lipid charges become part of the channel inner fixed charge distribution, as evidenced by the lower probability of pore formation in SARS-CoV E protein ${ }^{58}$ or other viral proteins ${ }^{59}$ in membranes containing DOPE, a lipid with a negative intrinsic curvature. This would imply that the lipid charges directly interact with the ions that pass through the channel, modifying not only their local concentrations but also other transport properties (such as hydrodynamic hindrance of ions, lipid-protein interactions, ion-ion correlations) that most probably change ion mobilities in the pore. ${ }^{6}$ Interestingly, this allows a simple explanation of the experimental results reported in Fig. 7. SARS-CoV E protein reconstituted in DPhPS membranes becomes a negatively charged pore. Therefore, as long as the bulk concentration is small, the cation concentration inside the pore rises to match the channel fixed charge so that local electroneutrality is ensured. The increase in available carriers due to the lipid charges appears then as the reason why in this regime, channel conductance is higher in charged lipids than in neutral ones. As salt concentration increases, Donnan exclusion becomes less important and conductance increases almost linearly with the total ion concentration in the pore, similarly to a neutral pore. Remarkably, the theoretical Donnan predictions of conductance are able to reproduce the overall trend (lines depicted in the two plots of Fig. 7). ${ }^{58}$

The change of channel conductance with concentration in SARS-CoV E protein reconstituted in DPhPS membranes raises the question of whether it is a lipid-specific effect or it is simply dependent on the lipid surface charge density. To check this lipid charge dependence, a useful strategy to study the influence of lipid charges on channel conductance is performing experiments with membranes of varying composition of neutral and charged lipids. The advantage of this approach is two-fold. On one hand, it allows keeping the protein or peptide charge unmodified. On the other hand, it provides experimental evidence of the lipid involvement in the pore structure by looking at the way channel conductance changes with the bulk electrolyte concentration. Fig. 8 shows measurements of single channel conductance in membranes with varying compositions of (negatively charged) DPhPS and (neutral) DPhPC lipids at neutral $\mathrm{pH}$. Both lipids have lamellar structure so that any effect associated with the membrane spontaneous curvature can be excluded.

Measurements were made in concentrated ( $1 \mathrm{M})$ and diluted (30 mM) KCl solutions for the sake of comparison. Fig. 8A exhibits ion conductance measurements in the bacterial porin OmpF. Although the high and low salt concentration regimes are qualitatively similar, there is a significant quantitative difference: the conductance change from pure DPhPC to pure DPhPS membranes at $1 \mathrm{M} \mathrm{KCl}$ is insignificant $(\sim 10 \%)$ when compared with the two-fold increase seen in $30 \mathrm{mM} \mathrm{KCl}$. Because of OmpF trimeric structure is known at atomic resolution ${ }^{60}$ and there are reliable estimates of the size of the trimer and of the pore mouth, these results can be rationalized in terms of the relative distance between the nearest lipid charges and the three pore openings as mentioned above. In $1 \mathrm{M} \mathrm{KCl}$ Debye length is $\lambda_{\mathrm{D}} \sim 0.3 \mathrm{~nm}$ 

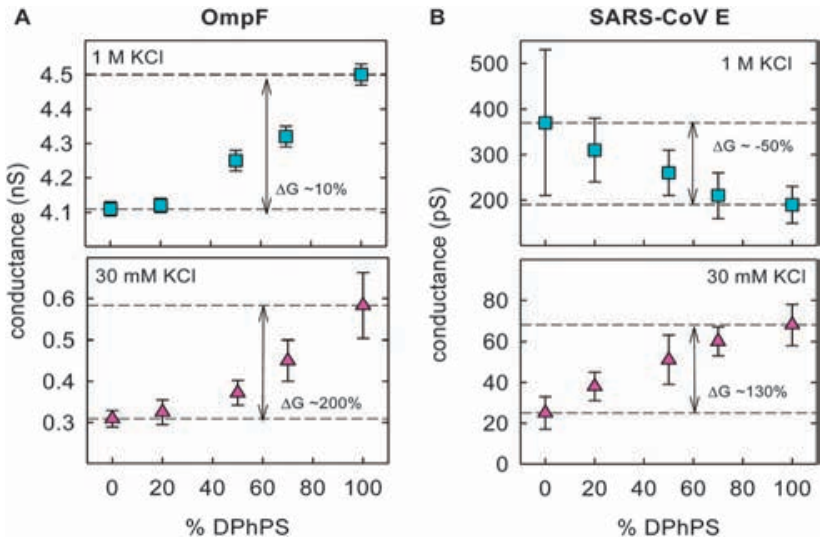

Fig. 8 Change of single channel conductance with lipid surface charge density (proportional to the percentage of negatively charged DPhPS lipid in a DPhPC:DPhPS membrane). (A) Variation of OmpF channel conductance with DPhPS percentage at low $(30 \mathrm{mM})$ and high $(1 \mathrm{M}) \mathrm{KCl}$ concentration. (B) Variation of SARS-CoV E protein channel conductance at the same low and high salt concentrations. All measurements were made at pH 6. Data of SARS-CoV E are taken, with permission, from ref. 58.

whereas in $30 \mathrm{mM} \mathrm{KCl}$, it is $\lambda_{\mathrm{D}} \sim 1.8 \mathrm{~nm}$. At low salt concentrations the influence of the lipid negative charges may extend up to the channel mouth strongly enough to modify the electroneutrality of the bulk solution and to increase locally the concentration of cations, which are the ions preferred by this cationic channel.

Fig. 8B shows the results of SARS-CoV E protein channel conductance measurements $^{57,58}$ in $1 \mathrm{M}$ and $30 \mathrm{mM} \mathrm{KCl} \mathrm{solu-}$ tions (top and bottom plot, respectively). A comparison between the SARS-CoV E and OmpF conductance in neutral (DPhPC) membranes reveals a difference of more than an order of magnitude between them (from 0.37 to $4.1 \mathrm{nS}$ in $1 \mathrm{M} \mathrm{KCl}$ and from 25 to $300 \mathrm{pS}$ in $30 \mathrm{mM} \mathrm{KCl}$ ). This reflects a large difference in pore size between these two weakly selective ion channels. ${ }^{46,57}$ However, the most interesting result of these four sets of measurements is that at high salt concentration, lipid charge modulates SARS-CoV E channel conductance in the opposite way it does in OmpF (as well as in gA and alamethicin): the channel conductance decreases with the amount of negatively charged lipids, which is the opposite behavior to that observed in the previous examples. Note that despite the large variability of SARS-CoV E conductance at $1 \mathrm{M} \mathrm{KCl}$ in pure DPhPC membranes, already reported and discussed elsewhere, ${ }^{57,58}$ the trend is clearly opposite to that in $30 \mathrm{mM} \mathrm{KCl}$. Different protein-lipid conformations in DPhPC and DPhPS, with concomitant changes in pore size, can hardly be the reason behind that change in conductance because if that was the case, the ionic current should decrease or increase similarly at low and high salt concentrations. The most likely explanation of this decrease in channel conductance must be sought in the lipid polar head involvement in the channel pore structure, as mentioned above. If this is the case, the overall conductance should reflect a balance between two effects working in opposite directions. The tight lipid-ion interaction could increase the number of available carriers in the channel but could as well diminish their effective mobilities. ${ }^{6}$ Actually, in diluted solutions the leading effect is the ion accumulation induced by lipid charges to preserve local electroneutrality (see Fig. 7). But, in contrast, as concentration increases and Donnan effects become negligible the key factor is probably the reduction in ion diffusivities that makes the charged pore less conductive than the neutral one. This reasoning does not categorically exclude the hypothetical existence of different protein-lipid conformations, but stresses how important is the understanding of charge regulation effects that otherwise could be mistakenly attributed to changes in pore size. ${ }^{58}$

Interestingly, the proteolipidic structure is shared by a large number of pore-forming peptides, antimicrobial peptides and other pore-forming toxins. ${ }^{61}$ Actually, a similar decrease of channel conductance with lipid charge was found in experiments with Colicin E1 polypeptides by Sobko et al. ${ }^{62}$ In two types of channels (differing in size) the conductance in $1 \mathrm{M} \mathrm{KCl}$ decreased as the membrane content in negatively charged DPhPG lipid was increased. Fig. 9 shows the conductance dependence on the fraction of charged lipid for the smallest polypeptide (P178). The drop in conductance from pure DPhPC $(\sim 66 \mathrm{pS})$ to pure DPhPG $(\sim 6 \mathrm{pS})$ is even larger than that reported above for SARS-CoV $\mathrm{E}$ (Fig. 8B, top plot).

Finally, we would like to focus on a completely different system, in which the mere determination of the channel conductance is a problem in itself. The pulmonary surfactant is a complex mixture of lipids and specific surfactant proteins, including the hydrophobic proteins SP-B and SP-C, in charge of stabilizing the respiratory surface of mammalian lungs. SP-C has been described to be a monomer that forms an extremely hydrophobic $\alpha$-helix with a transmembrane orientation. In contrast, SP-B consists of five amphipathic $\alpha$-helices connected by highly apolar loops and is found parallel to the surface near the interface. ${ }^{63}$ Having in mind these structural details and the high hydrophobicity of both proteins, the involvement of lipid

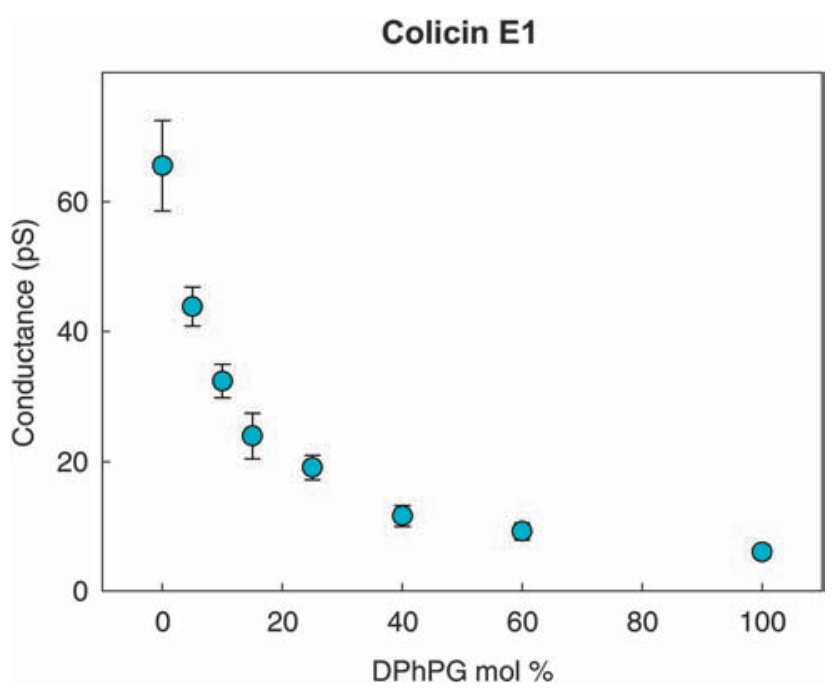

Fig. 9 Single channel conductance of the Colicin E1 channel forming domains (P178) in membranes of varying molar fraction of neutral (DPhPC) and negatively charged (DPhPG) lipids ( $1 \mathrm{M} \mathrm{KCl}, \mathrm{pH}$ 4.0). Adapted, with permission from ref. 62 


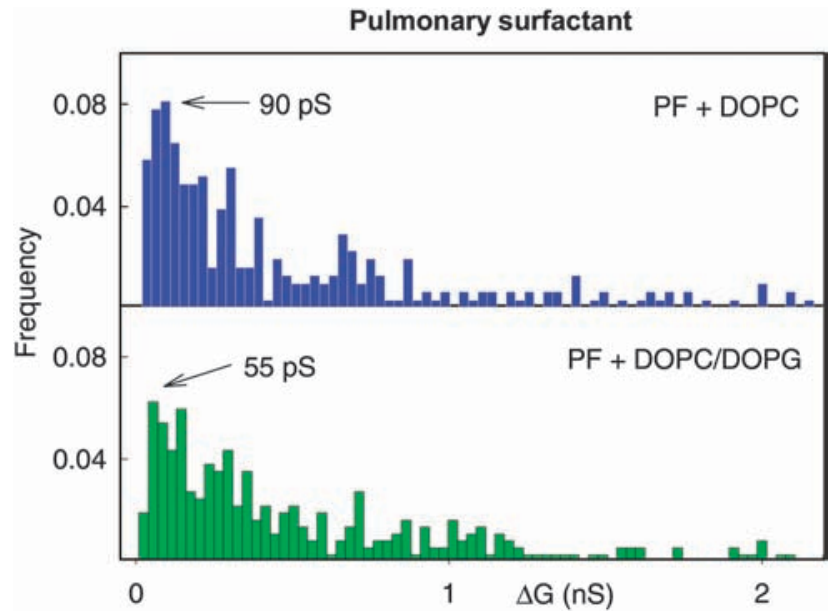

Fig. 10 Normalized histograms representing all the conductance increments $\Delta G$ recorded during the experiments with the hydrophobic protein fraction of native surfactants inserted into DOPC (top panel, blue) or DOPC/DOPG (bottom panel, green) bilayers for a protein/lipid ratio of $0.01 \%$ by weight in $150 \mathrm{mM} \mathrm{KCl}$. Adapted, with permission from ref. 37.

molecules in the pore structure seems to be indispensable. It was recently reported that SP-B and SP-C, both together and also individually, create a huge variety of channel-like structures in phospholipid membranes, with no characteristic size or conformation (see Fig. 10). Indeed, both in zwitterionic and in anionic lipid membranes, a continuous distribution of amplitude of conductance jumps, $\Delta G$, can be observed ranging from tens of $\mathrm{pS}$ to several $\mathrm{nS}$ in experiments performed at physiological salt concentrations. Although no major differences are found, the histograms reveal that, in agreement with the findings of Fig. 8 and 9, the most frequent values of the stepwise changes in conductance are slightly larger in neutral DOPC than in negatively charged DOPC/DOPG membranes.

The high variability of this system, which cannot be compared with other proteolipidic structures having better defined conductance properties, does not allow any quantitative interpretation but simply states the fact that introducing a negatively charged lipid in the protein-lipid mixture generally reduces the conductance. However, in this particular case it is difficult to exclude other nonelectrostatic effects that may play an important role too.

\section{Channel selectivity tuned by lipid charge}

The measurements shown in the preceding section show that channel conductance can be modulated by the membrane charge, particularly when lipid molecules become part of the pore structure and are not simply a passive surrounding medium hosting the transmembrane protein. ${ }^{57}$ The channel selectivity, i.e. the ability to discriminate between ions of different charge, is another channel property that is strongly sensitive to the electrostatic environment that the permeating ions find when crossing the membrane. Therefore, selectivity measurements in charged membranes are also a powerful tool of characterization of any transmembrane protein or a peptide forming channel.

It has been noted that the ionic selectivity cannot be considered as an intrinsic property of the channel but necessarily includes both the characteristics of protein channel and of the electrolyte flowing through it. ${ }^{6,64}$ However, a number of channel selectivity measurements in neutral membranes show that it is largely modulated by the density of fixed charges exposed to the permeating ions in the aqueous pore (i.e. by the amount of charged sites and their spatial distribution in the protein channel). ${ }^{24,46,52,65,66}$

The channel fixed charge density may be tuned by varying: (a) the $\mathrm{pH}$ of the solutions (i.e. by changing the ionization state of the amino acid residues of the channel), (b) the fraction of charged lipids of the membrane, (c) the salt concentration of the solutions (i.e., to screen charges more or less effectively) and (d) the type of permeating ions (from monovalent or multivalent salts, etc.). ${ }^{46,67}$ Furthermore, by means of site directed mutagenesis, channels with different distribution of charged residues can be obtained.

\subsection{Lipid headgroups on the membrane surface}

Most biological membranes contain a significant fraction of charged lipids so that the real channel selective properties are always influenced by the lipid charge no matter its magnitude. Sometimes, to isolate the channel properties, planar bilayer selectivity experiments are performed in neutral membranes. In other cases ${ }^{44,62,68-71}$ experiments seek to mimic the in vivo environment and membranes containing a mixture of neutral and charged lipids are used.

Then, the first question that arises is to what extent lipid charge may modulate the selectivity of a wide multiionic protein channel which does not involve lipid molecules in its aqueous pore structure. To answer this question, the channel selectivity of the bacterial porin OmpF was measured in solutions of varying acidity ( $\mathrm{pH} 1.5-11)$ in a ten-fold concentration gradient ( $1 \mathrm{M}$ cis, the side of protein addition, and 0.1 $\mathrm{M}$ trans). Two series of reversal potential measurements were performed: in neutral DPhPC membranes and in negatively charged DPhPS membranes. Remarkably, almost no difference was found between both sets of measurements, as seen in Fig. 11. Although the DPhPS negative charges probably modify the ion concentration near the channel entrance in the diluted solution $(0.1 \mathrm{M})$, the repercussion in the zero current potential is negligible. Overall, the two superimposed titration curves reflect the effective $\mathrm{p} K_{\mathrm{a}}$ 's of the most abundant ionizable residues of the OmpF protein: aspartates and glutamates with model $\mathrm{p} K_{\mathrm{a}}$ close to 4 and arginines with model $\mathrm{p} K_{\mathrm{a}}$ close to $12 .{ }^{46}$ Therefore, it seems that when lipid headgroups are on the membrane surface and do not face the pore lumen, the channel selectivity is barely influenced by the lipid charge.

\subsection{Lipid headgroups as pore building blocks}

The next question concerns the effect of membrane surface charge on those channels with a proteolipidic structure like that characteristic of toroidal pores. ${ }^{15,72}$ To examine the lipid 


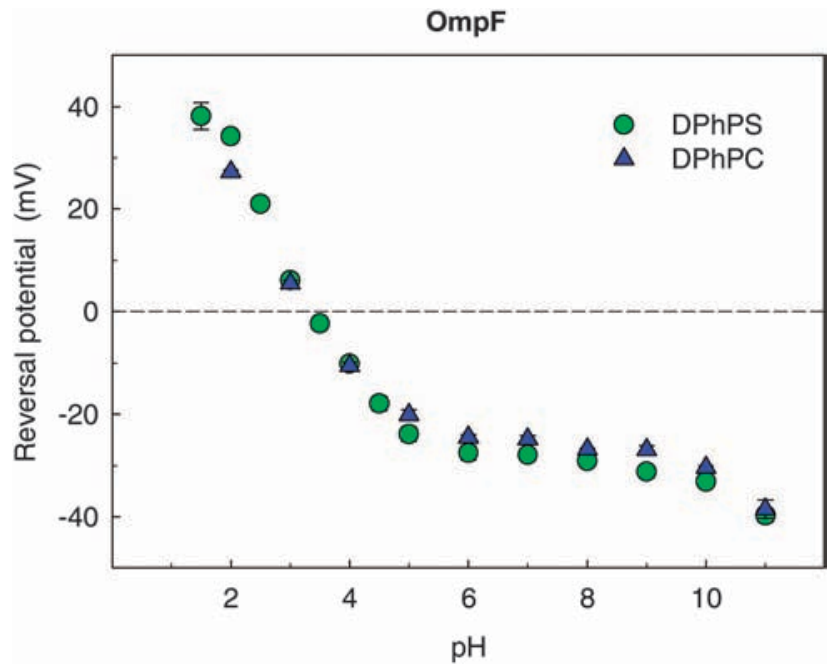

Fig. 11 OmpF channel selectivity titration. Reversal potential was measured in neutral DPhPC membranes (triangles) and negatively charged DPhPS membranes (circles). Under the conditions of the experiments $(\mathrm{KCl}$, $1 \mathrm{M}$ cis $\mid 0.1 \mathrm{M}$ trans), negative and positive reversal potential imply cationic and anionic selectivity, respectively. Each point is the average of measurements in 10-15 channels.

charge effect on channel selectivity, reversal potential measurements were recently performed after reconstitution of SARS-CoV E channels in DPhPC and DPhPS membranes. ${ }^{58}$ The experimental conditions ( $\mathrm{pH} 1.5-7$ and 0.5/0.05 $\mathrm{M} \mathrm{KCl}$ concentration gradient) were analogous to that of Fig. 11. Contrary to what was observed in the bacterial porin, in this case channel selectivity was strongly dependent on the net charge of the host lipid (Fig. 12). In DPhPC membranes

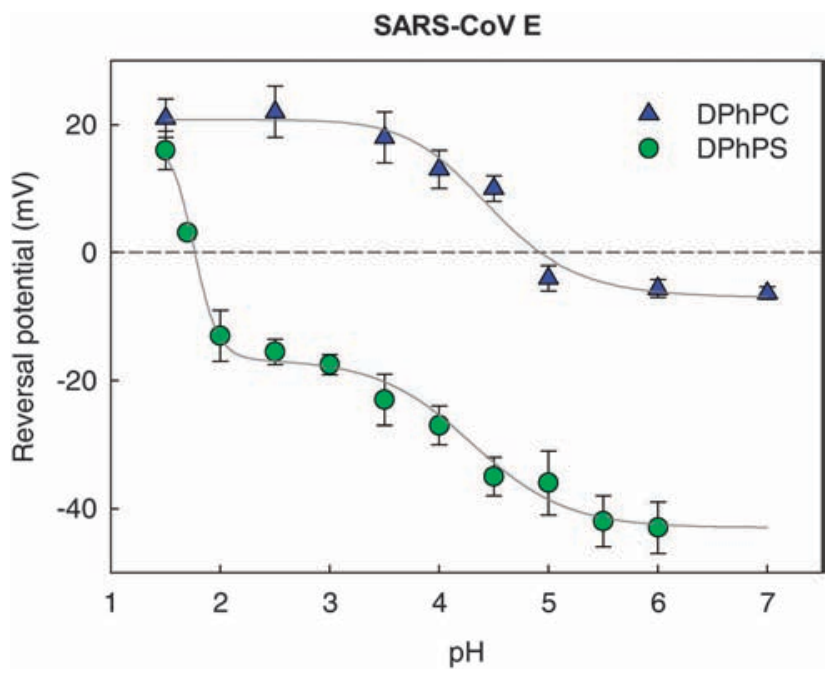

Fig. 12 SARS-COV E protein channel titration. Reversal potential was measured in neutral DPhPC membranes (triangles) and negatively charged DPhPS membranes (circles). Under the conditions of the experiments (500 $\mathrm{mM} \mathrm{KCl}$ cis $150 \mathrm{mM} \mathrm{KCl}$ trans), negative and positive reversal potential imply cationic and anionic selectivity, respectively. Solid lines correspond to the best fit of the data according to the typical one-site sigmoidal titration curve (top plot) and the two-site titration curve (bottom plot). Reprinted, with permission, from ref. 58. the channel displayed a very mild cationic selectivity at neutral $\mathrm{pH}$ (ratio of the permeability to positive versus negative ions, $\left.\mathrm{P}_{+} / \mathrm{P}_{-}=1 \pm 0.1\right)$ and a moderate anionic selectivity in highly acidic $(\mathrm{pH} 1.5)$ solutions $\left(\mathrm{P}_{+} / \mathrm{P}_{-}=0.3 \pm 0.1\right)$. The protonation of the glutamates in the CoV E protein TM domain is likely to be the cause of this selectivity reversal. However, when the channels were reconstituted in DPhPS membranes, the ionic selectivity at neutral $\mathrm{pH}$ was completely different and much higher than in DPhPC: a weakly selective channel like SARS-CoV E appeared as a strongly cation selective pore. Furthermore, the change in selectivity from $\mathrm{pH} 7$ to $\mathrm{pH} 1.5$ was much more significant and the titration of charges even reversed the channel selectivity from cationic to anionic. The reversal potential measurements in DPhPC can be fitted according to the typical one-site titration trend seen in other channels ${ }^{46,73-76}$ with an effective $\mathrm{p} K_{\mathrm{a}}$ of 4.3 (which is fairly consistent with the model $\mathrm{p} K_{\mathrm{a}}$ of glutamate). The measurements in DPhPS can be also fitted to a slightly modified version of the sigmoidal dose-response curve ${ }^{58}$ with the two steep transitions being well represented by effective $\mathrm{p} K_{\mathrm{a}}$ 's 4.3 and 1.7. The last value can be attributed to the shifted $\mathrm{p} K_{\mathrm{a}}$ of the carboxyl or the phosphate group of DPhPS lipid polar heads. Both fitting curves are depicted by solid lines in Fig. 12 .

The two series of reversal potential measurements and the values of apparent $\mathrm{p} K_{\mathrm{a}}$ from the fittings suggest that lipid molecules intercalate between the alpha helices of the SARSCoV E TM domain in such a way that polar head groups take part in the assembling of the pore wall. This picture is in agreement with the conductance measurements in membranes of variable fraction of neutral and charged lipid. $\mathrm{pH}$ effects other than titration of lipid headgroups and channel ionizable residues cannot be excluded but the "titration signature" of proteolipidic pores and proteinaceous pores seems to be remarkably different.

The dependence of ion selectivity on pH and lipid composition in other proteins and channel-forming peptides can also be interpreted by the direct participation of lipid molecules in the channel walls, as in the case of colicin E1, the peptide eumenitin and the lipopeptide antibiotic syringomycin $\mathrm{E}$. In the case of the colicin $\mathrm{E}$, the selectivity is sensitive to the $\mathrm{pH}$ of the solution and the lipid content of the membrane $^{76}$ and the anionic selectivity of the colicin $\mathrm{E}$ is reduced in membranes containing anionic lipids. ${ }^{75}$ An identical behavior is observed in syringomycin $\mathrm{E}$ in which the anionic selectivity of the channel is higher in neutral membranes than in membranes containing negatively charged lipids. ${ }^{44}$ In the case of the peptide eumenitin, the channel exhibits cationic selectivity which is increased in membranes formed by negatively charged lipids. ${ }^{77}$ In summary, selectivity experiments under variable conditions of $\mathrm{pH}$ and membrane lipid composition can provide valuable information about the pore structure of ion channels whose atomic structure has not been resolved yet.

\subsection{Correlation between conductance and selectivity}

In Section 3.2 we showed that pulmonary surfactant proteins SP-B and SP-C induce the permeabilization of phospholipid 


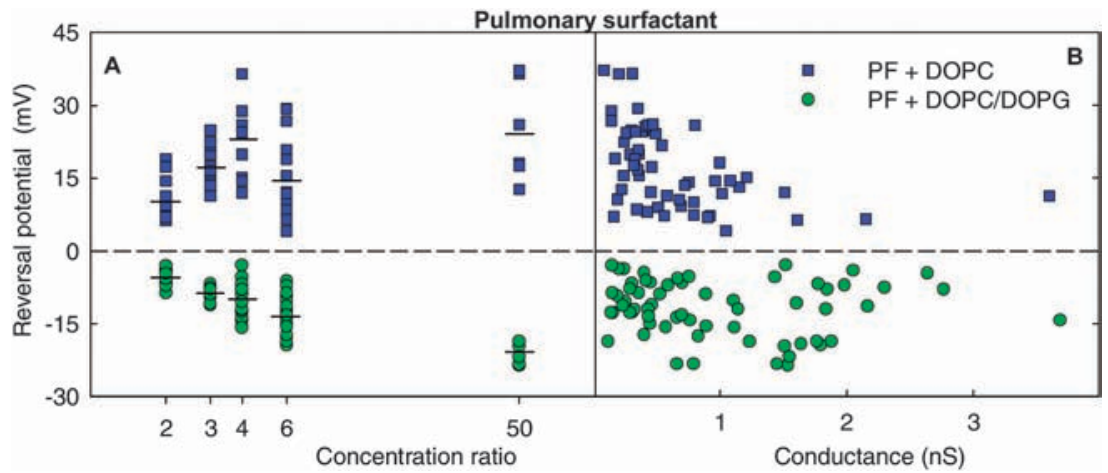

Fig. 13 (A) Reversal potential versus $\mathrm{KCl}$ concentration ratio (50 mM trans side; $100 \mathrm{mM}-2.5 \mathrm{M}$ cis side) for DOPC (squares) or DOPC/DOPG $85: 15$ (circles) bilayers supplemented with the hydrophobic protein fraction at a protein/lipid ratio of $0.01 \%$ by weight. All the measured values have been plotted, and the black line represents the average of the measurements for each concentration ratio. (B) Reversal potential versus conductance for all the experiments performed with the same membranes as in panel A. Reprinted, with permission, from ref. 37.

membranes via pore formation. An almost continuous distribution of conductance values spanning several orders of magnitude was found. In principle, the large values of conductance could correspond to multiple insertions of small pores or, alternatively, to individual wider pores. These results show that lipid composition determines the amplitude histograms, suggesting a direct incorporation of lipid into the pore structure. Selectivity measurements can be extremely useful to investigate both the pore size distribution and the role of the lipid charge in the channel function. Thus, reversal potential experiments were carried out for the entire hydrophobic surfactant protein fraction supplemented to both DOPC and DOPC/DOPG bilayers, as shown in Fig. 13.

In a neutral phospholipid bilayer like DOPC, the pores were selective to anions (upper panel of Fig. 13A), which is compatible with the positive net charge of both SP-B and SP-C. The addition of $15 \%$ of DOPG into DOPC bilayers resulted in an inversion of the channel selectivity: all experiments yielded negative reversal potentials, characteristic of a cation-selective channel (bottom panel of Fig. 13A). Similar results were obtained in DPhPC (zwitterionic) and DPhPC/DPhPS (negatively charged) bilayers, ${ }^{37}$ pointing to the lipid charge as responsible for the selectivity inversion. As regards the pore size distribution, it is important to remember that the reversal potential of a population of identical channels is independent of the actual number of them and should yield the same selectivity as a single channel. ${ }^{4}$ Then, the considerable dispersion found in the reversal potential values displayed in Fig. 13A (clearly beyond the experimental error) is consistent with the existence of multiple independent pore structures as suggested by the data of Fig. 10. Interestingly, the correlation between reversal potential and conductance (Fig. 13B) provides additional interesting clues in this sense. Although the results are visibly scattered, a general trend can be observed particularly in the case of PF + DOPC (squares in the upper panel): higher values of reversal potential correspond to lower conductances (Fig. 13B). Narrow channels display a low conductance and a high discrimination because of the close contact between the permeating ions and the charges in the pore wall, whereas wider pores provide an easier permeation pathway at the expense of losing selectivity. ${ }^{37}$

\section{Other specific lipid charge effects}

We have focused in this perspective on one aspect of the lipid charge regulation of the conductance and ion selectivity of mesoscopic biological ion channels. However, membrane permeabilization by means of ion channels involves not only coulombic interactions but also a complex interplay of other factors like mechanical and hydrophobic-hydrophilic short range interactions. ${ }^{78}$ Hence, in some cases a certain degree of lipid charge specificity is found in some channel functional properties. For instance, certain anionic lipids within the family of phosphoinositides, like phosphatidylinositol 4,5-bisphosphate $\left(\mathrm{PIP}_{2}\right)$, regulate a large number of ion channels by specific direct interaction with a positively charged binding site of the protein channel. ${ }^{9}$ Even though the charge of the lipid is needed for the interaction (charge neutralization abolishes the channel regulation), the electrostatic nature of the lipid regulation is far from a screened coulombic one. The lipid specific interactions include those which regulate the initial stage of the channel insertion in the membrane. In addition, although it cannot be considered as lipid regulation of channel function, the binding of membraneactive proteins or peptides to anionic lipid membranes may facilitate or hinder protein insertion into the lipid bilayer. In some cases, tuning the surface potential of the membrane has proved to be crucial for an efficient toxin import and enhancing channel activity. ${ }^{14}$

Alternatively, there is another aspect of the lipid functional involvement in the channel: its effect on the channel opening and closing kinetics. It has been reported for the lipopeptide antibiotic syringomicin $\mathrm{E}$ that transitions from charged to neutral (or screened) lipids are accompanied by strong changes in the effective gating charge including inversion in the sign of potentials that open (or close) the channels. ${ }^{44}$ Similarly, it has been reported also that interfacial polar interactions can affect 
gramicidin (gA) channel kinetics. ${ }^{79}$ These experiments demonstrate that the regulation of gA lifetime involves both nonspecific (hydrophobic mismatch) and specific (headgroup-peptide) interactions. There are other effects that might be important in some cases and have been briefly mentioned here (like the charge induced lateral stress and a change in the curvature in alamethicin) or simply overlooked: protein conformational changes, dielectric exclusion, specific ion binding to the protein or hydrophobic interactions, to mention just some of them. The use of GC theory and Donnan equilibria may be questionable for attempting a quantitative interpretation of some of the experiments reported here but they prove to be useful to show that electrostatic effects are enough in some cases to qualitatively understand the lipid charge effect without resorting other interactions.

\section{Conclusions and perspectives}

Electrophysiological experiments provide new insights into the involvement of lipids in the structure and function of protein channels. The examples reviewed here of several channels with some similarities (e.g. their multiionic character, with the exception of gA) and many other differences in size, structure, oligomerization, etc., show that the effects of lipid charge on channel transport properties do not follow a simple pattern. There are key factors like the protein size, the channel selectivity and, most importantly, the kind of lipid-protein structural arrangements that should be taken into account to understand qualitatively and quantitatively the lipid charge regulation of channel conductance. Conversely, one can take advantage of this fact to analyze lipid properties and even specific surface interactions of multivalent ions by using a channel as a probe. ${ }^{38}$ Furthermore, channel conductance measurements with variable membrane lipid composition emerge as a useful tool to discriminate between proteinaceous pores and proteolipidic pores, complementary to the experimental evidence based on the use of membranes with intrinsic lipid curvatures. In the case of pure proteinaceous pores, lipid charged headgroups are located only near the pore entrances, accumulating counterions as described by the Donnan equilibrium. As expected, those screening effects are more important in diluted solutions and relatively narrow pores. In proteolipidic pores, lipid charges directly interact with the ions crossing the channel, changing not only their local concentrations but also other transport properties such as ion diffusivities in the pore. In this kind of structures, we show that the experiments can be rationalized paying attention to charge regulation effects with no need to appeal necessarily to different channel conformations.

Selectivity measurements offer a similar scenario. In wide protein channels like OmpF lipid molecules do not become part of the pore structure so that the selectivity is barely influenced by the lipid charge. On the other hand, host lipid determines the ionic selectivity of proteolipidic pores. By comparing reversal potential measurements in OmpF and a viral protein channel we show how selectivity experiments can be useful to dissect the separate roles of lipid and protein charges. Correlations of conductance versus selectivity can help to discriminate between a variety of different conductance states or multiple insertions of a single unitary conductance. Overall, the electrophysiological measurements reported here for different protein-lipid conformations underline the importance of electrostatic interactions in the ion channel functional properties. Tuning lipid charge combined with conductance and selectivity measurements is shown to be a complementary method to evidence lipid involvement in the structure of a biological ion channel. Indirectly, the influence of lipid charge on channel conductance can also be exploited to achieve rectification properties that may be used in biomimetic nanofluidic devices for sensing applications. ${ }^{80,81}$

\section{Acknowledgements}

The authors wish to acknowledge support from the Spanish Ministry of Economy and Competitiveness (MICINN Project FIS2010-19810), Generalitat Valenciana (Prometeu 2012/069) and Fundació Caixa Castelló-Bancaixa (Project No. P1-1B2012-03).

\section{Notes and references}

1 S. McLaughlin, Annu. Rev. Biophys. Biophys. Chem., 1989, 18, 113.

2 R. H. French, V. A. Parsegian, R. Podgornik, R. F. Rajter, A. Jagota, J. Luo, D. Asthagiri, M. K. Chaudhury, Y.-M. Chiang, S. Granick, S. Kalinin, M. Kardar, R. Kjellander, D. C. Langreth, J. Lewis, S. Lustig, D. Wesolowski, J. S. Wettlaufer, W.-Y. Ching, M. Finnis, F. Houlihan, A. O. von Lilienfeld, C. J. van Oss and T. Zemb, Rev. Mod. Phys., 2010, 82, 1887.

3 F. Bezanilla, Neuron, 2008, 60, 456.

4 B. Hille, Ion Channels of Excitable Membranes, 3rd edn, Sinauer Associates, Sunderland, MA, 2001.

5 The Transporter Classification Database, http://www.tcdb. org.

6 V. M. Aguilella, M. Queralt-Martín, M. Aguilella-Arzo and A. Alcaraz, Integr. Biol., 2011, 3, 159.

7 M. Colombini, Mol. Cell. Biochem., 2004, 256, 107.

8 E. M. Nestorovich, C. Danelon, M. Winterhalter and S. M. Bezrukov, Proc. Natl. Acad. Sci. U. S. A., 2002, 99, 9789.

9 S. T. Tucker and T. Baukrowitz, J. Gen. Physiol., 2008, 131, 431.

10 J. A. Lundbaek, J. Gen. Physiol., 2008, 131, 421.

11 J. A. Lundbæk, S. A. Collingwood, H. I. Ingolfsson, R. Kapoor and O. S. Andersen, J. R. Soc. Interface, 2010, 7, 373 .

12 K. Yoshimura and M. Sokabe, J. R. Soc. Interface, 2010, 7, 307.

13 D. Marsh, Biochim. Biophys. Acta, 2008, 1778, 1545.

14 S. D. Zakharov, T. I. Rokitskaya, V. L. Shapovalov, Y. N. Antonenko and W. A. Cramer, Proc. Natl. Acad. Sci. U. S. A., 2002, 99, 8654.

15 S. D. Zakharov, E. A. Kotova, Y. N. Antonenko and W. A. Cramer, Biochim. Biophys. Acta, 2004, 1666, 239. 
16 C. Grewer, A. Gameiro, T. Mager and K. Fendler, Annu. Rev. Biophys., 2013, 42, 95.

17 M. Montal and P. Mueller, Proc. Natl. Acad. Sci. U. S. A., 1972, 69, 3561.

18 P. Van Gelder, F. Dumas and M. Winterhalter, Biophys. Chem., 2000, 85, 153-167.

19 M. L. López, E. García-Giménez, V. M. Aguilella and A. Alcaraz, J. Phys.: Condens. Matter, 2010, 22, 454106.

20 T. K. Rostovtseva, V. M. Aguilella, I. Vodyanoy, S. M. Bezrukov and V. A. Parsegian, Biophys. J., 1998, 75, 1783.

21 V. M. Aguilella and S. M. Beruzkov, Eur. Biophys. J., 2001, 30, 233.

22 P. A. Gurnev, M. Queralt-Martin, V. M. Aguilella, T. K. Rostovtseva and S. M. Bezrukov, Biophys. J., 2012, 102, 2070.

23 N. Lakshminarayanaiah, Equations of membrane biophysics, Academic Press, New York, 1984.

24 C. Maffeo, S. Bhattacharya, J. Yoo, D. Wells and A. Aksimentiev, Chem. Rev., 2012, 112, 6250.

25 P. Tieleman, P. C. Biggin, G. R. Smith and M. S. P. Sansom, Q. Rev. Biophys., 2001, 4, 473.

26 B. Roux, T. Allen, S. Bernèche and W. Im, Q. Rev. Biophys., 2004, 37, 15.

27 N. Tomita, M. M. Mohammad, D. J. Niedzwiecki, M. Ohta and L. Movileanu, Biochim. Biophys. Acta, Biomembr., 2013, 1828, 1057.

28 A. G. Lee, Biochim. Biophys. Acta, Rev. Biomembr., 2004, 1666, 62.

29 H. J. Apell, E. Bamberg and P. Läuger, Biochim. Biophys. Acta, 1979, 552, 369.

30 J. E. Bell and C. Miller, Biophys. J., 1984, 45, 279.

31 E. Moczydlowski, O. Alvarez, C. Vergara and R. Latorre, J. Membr. Biol., 1985, 83, 273.

32 R. Coronado and H. Affolter, J. Gen. Physiol., 1986, 87, 933.

33 W. N. Green and O. S. Andersen, Annu. Rev. Physiol., 1991, 53, 341.

34 S. J. Alvis, I. M. Williamson, J. M. East and A. G. Lee, Biophys. J., 2003, 85, 3828.

35 P. A. Gurnev, R. Ortenberg, T. Dörr, K. Lewis and S. M. Bezrukov, FEBS Lett., 2012, 586, 2529.

36 X. X. Yan, C. J. Porter, S. P. Hardy, D. Steer, A. I. Smith, N. S. Quinsey, V. Hughes, J. K. Cheung, A. L. Keyburn, M. Kaldhusdal, R. J. Moore, T. L. Bannam, J. C. Whisstock and J. I. Rood, mBio, 2013, 4, e00019-13.

37 E. Parra, A. Alcaraz, A. Cruz, V. M. Aguilella and J. Pérez-Gil, Biophys. J., 2013, 104, 146.

38 P. A. Gurnev and S. M. Bezrukov, Langmuir, 2012, 28, 15824.

39 A. E. Lang, J. Konukiewitz, K. Aktories and R. Benz, Biophys. J., 2013, 105, 376.

40 S. McLaughlin, Curr. Top. Membr. Transp., 1977, 9, 71.

41 A. P. Winiski, A. C. McLaughlin, R. V. McDaniel, M. Eisenberg and S. McLaughlin, Biochemistry, 1986, 25, 8206.

42 S. C. Hartsel and D. S. Cafiso, Biochemistry, 1986, 25, 8214.

43 M. Yi, H. Nymeyer and H. X. Zhou, Phys. Rev. Lett., 2008, 101, 038103.
44 V. V. Malev, L. V. Schagina, P. A. Gurnev, J. Y. Takemoto, E. M. Nestorovich and S. M. Bezrukov, Biophys. J., 2002, 82, 1985. 45 A. Schulte, S. Ruamchan, P. Khunkaewla and W. Suginta, J. Membr. Biol., 2009, 230, 101.

46 A. Alcaraz, E. M. Nestorovich, M. Aguilella-Arzo, V. M. Aguilella and S. M. Bezrukov, Biophys. J., 2004, 87, 943.

47 E. M. Nestorovich, T. K. Rostovtseva and S. M. Bezrukov, Biophys. J., 2003, 85, 3718.

48 R. Benz, A. Schmid and R. E. W. Hancock, J. Bacteriol., 1985, 162, 722.

49 H. Nikaido, Microbiol. Mol. Biol. Rev., 2003, 67, 593.

50 A. H. Delcour, Front. Biosci., 2003, 8, d1055.

51 Z. Kóta, T. Páli and D. Marsh, Biophys. J., 2004, 86, 1521.

52 M. Misakian and J. J. Kasianowicz, J. Membr. Biol., 2003, $195,137$.

53 L. Song, M. R. Hobaugh, C. Shustak, S. Cheley, H. Bayley and J. E. Gouaux, Science, 1996, 274, 1859.

54 O. V. Krasilnikov and R. Z. Sabirov, Gen. Physiol. Biophys., 1989, 8, 213.

55 S. M. Bezrukov, R. P. Rand, I. Vodyanoy and V. A. Parsegian, Faraday Discuss., 1998, 111, 173.

56 T. Lazaridis, Y. He and L. Prieto, Biophys. J., 2013, 104, 633. 57 C. Verdiá-Báguena, J. L. Nieto-Torres, A. Alcaraz, M. L. DeDiego, J. Torres, V. M. Aguilella and L. Enjuanes, Virology, 2012, 432, 485.

58 C. Verdiá-Báguena, J. L. Nieto-Torres, A. Alcaraz, M. L. DeDiego, L. Enjuanes and V. M. Aguilella, Biochim. Biophys. Acta, Biomembr., 2013, 1828, 2026.

59 T. Withfield, A. J. Miles, J. C. Scheinost, J. Offer, P. Wentworth, R. A. Dwek, B. A. Wallace, P. C. Biggin and N. Zitzmann, Mol. Membr. Biol., 2011, 28, 254.

60 S. W. Cowan, T. Schirmer, G. Rummel, M. Steiert, R. Ghosh, R. A. Pauptit, J. N. Jansonius and J. P. Rosenbusch, Nature, 1992, 358, 727.

61 M. Zasloff, Nature, 2002, 415, 389.

62 A. A. Sobko, E. A. Kotova, Y. N. Antonenko, S. D. Zakharov and W. A. Cramer, J. Biol. Chem., 2006, 281, 14408.

63 J. Pérez-Gil, Biochim. Biophys. Acta, 2008, 1778, 1676.

64 D. Gillespie and R. S. Eisenberg, Eur. Biophys. J., 2002, 31, 454. 65 M. Aguilella-Arzo and V. M. Aguilella, Eur. Phys. J. E: Soft Matter Biol. Phys., 2010, 31, 429.

66 M. Vrouenraets, J. Wierenga, W. Meijberg and H. Miedema, Biophys. J., 2006, 90, 1202.

67 A. Alcaraz, E. M. Nestorovich, M. L. López, E. GarcíaGiménez, S. M. Bezrukov and V. M. Aguilella, Biophys. J., 2009, 96, 56.

68 A. A. Sobko, E. A. Kotova, Y. N. Antonenko, S. D. Zakharov and W. A. Cramer, FEBS Lett., 2004, 576, 205.

69 A. N. Chanturiya, G. Basañez, U. Schubert, P. Henklein, J. W. Yewdell and J. Zimmerberg, J. Virol., 2004, 78, 6304.

70 A. Premkumar, L. Wilson, G. D. Ewart and P. W. Gage, FEBS Lett., 2004, 557, 99.

71 L. Wilson, C. McKinlay and P. Gage, Virology, 2004, 330, 322.

72 R. M. Epand, Biochim. Biophys. Acta, 1998, 1376, 353.

73 J. Cervera, A. G. Komarov and V. M. Aguilella, Biophys. J., 2008, 94, 1194. 
74 T. K. Rostovtseva, T.-T. Liu, M. Colombini, V. A. Parsegian and S. M. Bezrukov, Proc. Natl. Acad. Sci. U. S. A., 2000, 97, 7819.

75 L. Raymond, S. L. Slatin and A. Finkelstein, J. Membr. Biol., 1985, 84, 173.

76 J. O. Bullock, J. Membr. Biol., 1992, 125, 255.

77 M. Arcisio-Miranda, M. Pérez dos Santos Cabrera, K. Konno, M. Rangel and J. Procopio, Toxicon, 2008, 51, 736.
78 N. S. Wicremasinghe, PhD thesis, Rice University, 2009.

79 T. K. Rostovtseva, H. I. Petrache, N. Kazemi, E. Hassanzadeh and S. M. Bezrukov, Biophys. J., 2008, 94, L23.

80 M. X. Macrae, S. Blake, M. Mayer and J. Yang, J. Am. Chem. Soc., 2010, 132, 1766.

81 M. Tagliazucchi, Y. Rabin and I. Szleifer, ACS Nano, 2013, 7, 9085 . 


\title{
Inhibition of the Human Respiratory Syncytial Virus Small Hydrophobic Protein and Structural Variations in a Bicelle Environment
}

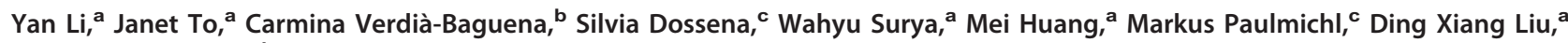 \\ Vicente M. Aguilella, ${ }^{b}$ Jaume Torres ${ }^{a}$ \\ School of Biological Sciences, Nanyang Technological University, Singaporea; Department of Physics, Universitat Jaume I, Castellon, Spain b; Institute of Pharmacology and \\ Toxicology, Paracelsus Medical University, Salzburg, Austriac
}

\begin{abstract}
The small hydrophobic ( $\mathrm{SH}$ ) protein is a 64-amino-acid polypeptide encoded by the human respiratory syncytial virus (hRSV). SH protein has a single $\alpha$-helical transmembrane (TM) domain that forms pentameric ion channels. Herein, we report the first inhibitor of the SH protein channel, pyronin B, and we have mapped its binding site to a conserved surface of the RSV SH pentamer, at the C-terminal end of the transmembrane domain. The validity of the SH protein structural model used has been confirmed by using a bicellar membrane-mimicking environment. However, in bicelles the $\alpha$-helical stretch of the TM domain extends up to His-51, and by comparison with previous models both His-22 and His-51 adopt an interhelical/lumenal orientation relative to the channel pore. Neither His residue was found to be essential for channel activity although His-51 protonation reduced channel activity at low $\mathrm{pH}$, with His-22 adopting a more structural role. The latter results are in contrast with previous patch clamp data showing channel activation at low $\mathrm{pH}$, which could not be reproduced in the present work. Overall, these results establish a solid ground for future drug development targeting this important viroporin.
\end{abstract}

\section{IMPORTANCE}

The human respiratory syncytial virus (hRSV) is responsible for 64 million reported cases of infection and 160,000 deaths each year. Lack of adequate antivirals fuels the search for new targets for treatment. The small hydrophobic (SH) protein is a 64-amino-acid polypeptide encoded by hRSV and other paramyxoviruses, and its absence leads to viral attenuation in vivo and early apoptosis in infected cells. SH protein forms pentameric ion channels that may constitute novel drug targets, but no inhibitor for this channel activity has been reported so far. A small-molecule inhibitor, pyronin B, can reduce SH channel activity, and its likely binding site on the SH protein channel has been identified. Black lipid membrane (BLM) experiments confirm that protonation of both histidine residues reduces stability and channel activity. These results contrast with previous patch clamp data that showed low-pH activation, which we have not been able to reproduce.

T, he human respiratory syncytial virus (hRSV) is an enveloped pneumovirus in the Paramyxoviridae family that causes lower respiratory tract disease in infants and in elderly and immunocompromised populations worldwide (1). Up to 64 million reported cases of hRSV infection and 160,000 deaths occur each year. Although the virus was identified almost half a century ago (2), there are still no vaccines or effective antiviral drugs available. hRSV can cause repeated reinfections throughout life, and its molecular mechanism of pathogenesis is not yet completely understood.

The hRSV genome comprises a nonsegmented negativestranded RNA of $\sim 15 \mathrm{~kb}$ that transcribes 11 proteins, including the three membrane proteins $\mathrm{F}, \mathrm{G}$, and small hydrophobic ( $\mathrm{SH}$ ). Proteins $\mathrm{F}$ and $\mathrm{G}$ are key factors during virus attachment, fusion, and entry into host cells $(3,4)$. In contrast, the role of $\mathrm{SH}$ protein is less clear. RSV lacking the $\mathrm{SH}$ gene $(\mathrm{RSV} \Delta \mathrm{SH})$ was viable, caused formation of syncytia, and grew as well as the wild-type (WT) virus in cell culture (5-8). However, RSV $\Delta \mathrm{SH}$ virus replicated 10 -fold less efficiently than the WT in the upper respiratory tract $(7,8)$. Also, RSV $\Delta \mathrm{SH}$ virus was attenuated in vivo by virus passage in mouse and chimpanzee models $(5,9)$. Overall, these results indicate involvement of $\mathrm{SH}$ protein in the pathogenesis of RSV infection.

Homologs of RSV SH protein are found in parainfluenza virus
5 (PIV5), mumps virus (MuV), and J paramyxovirus (JPV). In all of these systems, $\mathrm{SH}$ protein seems to block apoptosis in infected cells through inhibition of the tumor necrosis factor alpha (TNF- $\alpha$ ) pathway $(6,10-12)$. It is thought that by delaying apoptosis, the virus may evade host inflammatory responses and the premature death of the host cells. Recent reports have also suggested that $\mathrm{SH}$ protein activates the NLRP3 inflammasome (13).

The SH protein is a type II integral membrane protein that is 64 (RSV subgroup A) or 65 (RSV subgroup B) amino acids long. In infected cells, most $\mathrm{SH}$ protein accumulates at the membranes of the Golgi complex, but it has also been detected in the endoplasmic reticulum and plasma membranes (14). During infection, the full-length unmodified form is the major species (15) although a

Received 22 March 2014 Accepted 29 July 2014

Published ahead of print 6 August 2014

Editor: S. Perlman

Address correspondence to Jaume Torres, jtorres@ntu.edu.sg

Y.L., J.T., and C.V.-B. contributed equally to this article.

Copyright $\odot$ 2014, American Society for Microbiology. All Rights Reserved.

doi:10.1128/JVI.00839-14 
truncated form $(4.5 \mathrm{kDa})$ and glycosylated and phosphorylated forms have also been detected $(16,17)$. SH protein has a single predicted $\alpha$-helical transmembrane (TM) domain (15) which is highly conserved $(18,19)$. The $\mathrm{C}$ - and $\mathrm{N}$-terminal extramembrane domains are oriented lumenally/extracellularly and cytoplasmically, respectively.

Both the synthetic TM domain (residues 18 to 43) and fulllength SH protein, which are responsible for channel activity, have been shown to form homopentamers in a variety of detergents $(20,21)$. The mutual orientation of monomers corresponding to the synthetic TM domain in lipidic membranes was determined using site-specific infrared dichroism (20), which showed His-22 to be in a lumenal, close to interhelical, orientation. This TM arrangement was confirmed by nuclear magnetic resonance (NMR) studies that reconstructed the pentameric $\alpha$-helical bundle of the full-length protein in dodecylphosphocholine (DPC) micelles (21). In this micelle model, a single $\alpha$-helical TM domain was flanked $\mathrm{N}$-terminally by an $\alpha$-helix and C-terminally by an extended $\beta$-hairpin.

The availability of $\mathrm{SH}$ channel inhibitors would help further understanding of the role of this channel activity in the viral life cycle of RSV and also have obvious therapeutic potential. However, thus far no compound has been reported that is able to inhibit SH protein channel activity. Here, we report one compound that shows partial inhibition and can constitute a starting point to obtain an effective channel inhibitor. The possible binding sites of this compound on the structure of the SH protein pentameric channel have been mapped using solution NMR in detergent micelles. To confirm that the structure of $\mathrm{SH}$ protein in detergent is representative of the structure present during channel activity assays in black lipid membranes (BLM), we have refined the structure of SH protein in a membrane-mimicking bicellar environment. Overall, the results presented establish a solid ground for future drug development targeting this important viroporin.

\section{MATERIALS AND METHODS}

Cloning of the $\mathrm{SH}$ gene and expression and purification of the HisMBP-SH construct. The SH protein used in this work (strain S2 ts1C; GenBank accession number NP_044594.1) (22), was cloned, expressed, purified as wild type or mutant, and isotopically labeled essentially as described previously (21).

Liposome-based assay to screen for $\mathrm{SH}$ protein inhibitors. Potassium flux into liposomes incorporating $\mathrm{SH}$ protein pentamers was measured by fluorescence changes of the dye Asante potassium green-2 (APG-2; TEFLabs, Austin, TX). The assay conditions, e.g., lipid, proteinto-lipid ratio, fluorophore, buffer type, and $\mathrm{pH}$ (internal and external), were first tested in larger volumes, and fluorescence was measured with a Cary eclipse fluorescence spectrophotometer. Once the conditions were optimized, the assay was implemented in a microplate reader (Tecan M200 Pro). First, 3 mg of 1,2-diphytanoyl-sn-glycero-3-phosphocholine (DPhPC; Avanti Polar Lipids) in chloroform was mixed with $26 \mu \mathrm{g}$ of SH protein in methanol (molar ratio, 1,000:1) and dried under a $\mathrm{N}_{2}$ stream. After samples were dried overnight in a desiccator, $300 \mu \mathrm{l}$ of internal buffer (25 mM tetraethylammonium [TEA]-HEPES, 0.5 mM EDTA, 100 mM TEA-SO, $20 \mu \mathrm{M}$ APG-2, pH 5.5) was added to obtain a lipid concentration of $10 \mathrm{mg} / \mathrm{ml}$. The solution was vortexed for $10 \mathrm{~min}$, sonicated, subjected to three freeze-thaw cycles, and extruded through a $200-\mathrm{nm}$ polycarbonate membrane. Nonincorporated APG-2 was removed by passing the liposomes through an Econo-Pac 10DG (Bio-Rad) size exclusion column preequilibrated with internal buffer in the absence of APG-2. Liposome size was measured using a Brookhaven 90 Plus particle size analyzer. APG-2 fluorescence was measured from $150 \mu \mathrm{l}$ of liposome suspension in a quartz cuvette (excitation wavelength $\left[\lambda_{\text {ex }}\right], 488 \mathrm{~nm}$; emission wavelength $\left.\left[\lambda_{\mathrm{em}}\right], 540 \mathrm{~nm}\right)$. The potassium concentration outside the vesicles was increased to $140 \mathrm{mM}$ by addition of $560 \mathrm{mM} \mathrm{KCl}, 25$ mM TEA-HEPES, and $0.5 \mathrm{mM}$ EDTA, pH 7.5. Finally, $4 \mu \mathrm{l}$ of $25 \%$ Triton X-100 (final 0.5\%) was added.

For the microplate assay, the liposome fraction was diluted 3.5 times with $5 \mathrm{ml}$ of internal buffer. An aliquot $(75 \mu \mathrm{l})$ of the liposome suspension was placed in each well of a microplate (Greiner 96-well Fluotrac 200) containing $1 \mu \mathrm{l}$ of compound dissolved in dimethyl sulfoxide (DMSO) from the National Cancer Institute (NCI). The final drug concentration was $10 \mu \mathrm{M}$. After a 15 -min incubation, $25 \mu \mathrm{l}$ of potassium buffer (560 $\mathrm{mM} \mathrm{KCl}, 25 \mathrm{mM}$ TEA-HEPES, $0.5 \mathrm{mM}$ EDTA, pH 7.5) was added to obtain a final potassium concentration of $140 \mathrm{mM}$. Fluorescence of samples was read after a 5 -min incubation. Finally, $4 \mu \mathrm{l}$ of a solution of $25 \%$ Triton X-100 (to obtain a $0.5 \%$ final concentration) was added, and emission was measured after $5 \mathrm{~min}$.

Plaque assay. Vero cells were placed in 12 -well plates and cultured at $37^{\circ} \mathrm{C}$ overnight to reach about $90 \%$ confluence. Cells were infected with the RSV strain VR-1580 (ATCC) at a multiplicity of infection (MOI) of approximately 1 . At $2 \mathrm{~h}$ postinfection, virus inoculum was removed, and $1 \mathrm{ml}$ of fresh Dulbecco's modified Eagle's medium (DMEM) containing $2 \%$ fetal bovine serum (FBS) and $1 \mu \mathrm{l}$ of DMSO, with and without different concentrations of pyronin B, was added. At $90 \mathrm{~h}$ postinfection, cultured supernatants were collected, and the $50 \%$ tissue culture infective doses $\left(\mathrm{TCID}_{50}\right)$ of RSV were calculated by the Reed-Muench method (23). The experiment was repeated three times, and each sample was titrated twice.

Ion channel reconstitution and ionic current recording in black lipid membranes. SH protein, wild type or mutant, was reconstituted in planar lipid bilayers formed by apposition of two monolayers prepared from a solution of a 3:1:1 mixture of 1,2-dioleoyl-sn-glycero-3-phosphocholine (DOPC)-1,2-dioleoyl-snglycero-3-phosphoethanolamine (DOPE)-1,2-di-(9Z-octadecenoyl)sn-glycero-3-phospho-L-serine (DOPS) (Avanti Polar Lipids) in pentane. Lipids were added on 70 - to $90-\mu \mathrm{m}$-diameter orifices in the $15-\mu \mathrm{m}$-thick Teflon partition that separated two identical chambers $(24,25)$. The orifices were pretreated with a $1 \%$ solution of hexadecane in pentane. Aqueous solutions of $1 \mathrm{M} \mathrm{KCl}$ were buffered with $5 \mathrm{mM}$ HEPES at pH 6. All measurements were performed at room temperature. After the addition of SH protein in one side of the chamber (here referred to as the cis side), $\mathrm{a}+100-\mathrm{mV}$ voltage difference was applied to detect current. The electric potential was applied using $\mathrm{Ag} / \mathrm{AgCl}$ electrodes in $2 \mathrm{M} \mathrm{KCl}-1.5 \%$ agarose bridges, assembled within standard $250-\mu l$ pipette tips. The potential was defined as positive when it was higher on the side of the protein addition (cis side), whereas the trans side was set to ground. An Axopatch $200 \mathrm{~B}$ amplifier (Molecular Devices, Sunnyvale, CA) in the voltage clamp mode was used to measure the current and the applied potential. The chamber and the head stage were isolated from external noise sources with a double metal screen (Amuneal Manufacturing Corp., Philadelphia, PA).

Experiments aimed to determine the conductance at different $\mathrm{pHs}$ were carried out with aqueous solutions of $1 \mathrm{M} \mathrm{KCl}$ buffered with $5 \mathrm{mM}$ HEPES in 3:1:1 DOPC-DOPS-DOPE bilayers. The current amplitude recorded in approximately 30 independent experiments, each one lasting $\sim 200 \mathrm{~s}$, was averaged. Then the data were fitted to a single Gaussian to obtain the mean value of conductance $(G)$ as a function of $\mathrm{pH}$.

The effect of the pyronin B on channel conductance was determined as follows: once a channel activity was recorded, different micromolar concentrations of inhibitor were added into the cis side (protein side addition), and the current amplitude in the presence of the inhibitor was analyzed. The dose-response curve at different pyronin B concentrations was built to obtain the effective $K_{d}$ (dissociation constant).

Ion selectivity was evaluated by measuring the reversal potential (RP) under a 10 -fold gradient concentration of $\mathrm{KCl}(500 \mathrm{mM} / 50 \mathrm{mM} \mathrm{KCl}$, in planar bilayers of 3:1:1 DOPC-DOPS-DOPE). Ion selectivity experiments were also performed at basic $(\mathrm{pH} 7.5)$ and acidic $(\mathrm{pH} 3) \mathrm{pH}$ to compare 
the channel selectivity and to evaluate a possible $\mathrm{pH}$ dependency related to His protonation.

Gel electrophoresis. To perform electrophoresis in the presence of perfluorooctanoic (PFO) acid detergent, we modified Invitrogen's SDSNuPAGE protocol by replacing SDS with PFO acid (26). Lyophilized peptide was dissolved in sample buffer containing $4 \%$ PFO acid and heated at $65^{\circ} \mathrm{C}$ for $5 \mathrm{~min}$ prior to loading. The gel was run at $80 \mathrm{~V}$ for 2 to $3 \mathrm{~h}$ with morpholineethanesulfonic acid (MES) running buffer containing 0.5\% PFO acid. Blue native PAGE (BN-PAGE) was performed as described previously (27) using lyophilized peptide solubilized $(0.1 \mathrm{mM})$ in sample buffer containing a $25 \mathrm{mM}$ concentration of the chosen detergent.

NMR sample preparation. The phospholipid bicelle system was composed of 1,2-dilauroyl-sn-glycero-3-phosphocholine (or dilauroylphosphatidylcholine [DLPC]) (Avanti Polar Lipids) and 1,2-dihexanoyl-snglycero-3-phosphocholine (or dihexanoylphosphatidylcholine [DHPC]) (Avanti Polar Lipids). Peptide-DLPC mixture in hexafluoroisopropanol (HFIP) was dried under a $\mathrm{N}_{2}$ stream followed by high vacuum. DHPC solution in appropriate buffer was added into the dried peptide-DLPC mixture, and the mixture was vortexed and sonicated. In this way, lyophilized $\mathrm{SH}$ peptides were reconstituted into DHPC-DLPC bicelles $(9.5 \%$, $\mathrm{wt} / \mathrm{vol} ; q(\mathrm{DLPC} / \mathrm{DHPC}$ molar ratio $)=0.3$ ) at $0.7 \mathrm{mM}$ (corresponding to approximately 1:200 peptide-to-lipid ratio) buffered with $20 \mathrm{mM}$ sodium phosphate and $50 \mathrm{mM} \mathrm{NaCl}$ at $\mathrm{pH} 5.5$.

Partial alignment of the $\mathrm{SH}$ protein/bicelle complexes relative to magnetic field was obtained by using stretched polyacrylamide hydrogels (28, 29). A $4.2 \%$ polyacrylamide gel was polymerized in a gel chamber having an inner diameter of $5.4 \mathrm{~mm}$. After polymerization was complete, gels were washed in $\mathrm{H}_{2} \mathrm{O}$ overnight and then twice with sample buffer containing $20 \mathrm{mM}$ sodium phosphate and $50 \mathrm{mM} \mathrm{NaCl}$ at $\mathrm{pH} 5.5$. The gels were then completely dried at room temperature. The protein solution containing SH protein/bicelle complex was soaked into the dried gels over 2 days to ensure complete rehydration. The hydrated $4.2 \%$ gel was then radically compressed into an open-ended tube (inner diameter, $4.2 \mathrm{~mm}$ ) using a gel press assembly (New Era Enterprise, Inc.).

NMR spectroscopy. NMR experiments were performed at $40^{\circ} \mathrm{C}(313$ K) using Bruker Avance-II 700 and 600 NMR spectrometers equipped with cryogenic TXI probes (Bruker BioSpin). Sodium 2,2-dimethyl-2silapentane-5-sulfonate (DSS) was used as the internal reference for ${ }^{1} \mathrm{H}$ nuclei. The chemical shifts of ${ }^{13} \mathrm{C}$ and ${ }^{15} \mathrm{~N}$ nuclei were calculated from the ${ }^{1} \mathrm{H}$ chemical shifts. The NMR data were processed using TopSpin, version 3.1 (Bruker, Billerica, MA) and analyzed using CARA (www.nmr.ch). Sequence-specific assignment of backbone ${ }^{1} \mathrm{H}^{\mathrm{N}},{ }^{15} \mathrm{~N},{ }^{13} \mathrm{C}^{\prime}$, and ${ }^{13} \mathrm{C}^{\alpha}$ was achieved by using two-dimensional (2D) $\left[{ }^{1} \mathrm{H}^{15} \mathrm{~N}\right]$ TROSY-HSQC (transverse relaxation optimized spectroscopy-heteronuclear singlequantum coherence) and three-dimensional (3D) HNCO, HN(CA)CO, HNCA, HN(CO)CA, and HNCACB experiments on a ${ }^{15} \mathrm{~N} /{ }^{13} \mathrm{C}$-labeled $\mathrm{SH}$ protein. Side chain resonances were assigned utilizing $3 \mathrm{D}{ }^{15} \mathrm{~N}$-resolved nuclear Overhauser effect spectroscopy (NOESY)-HSQC (mixing time, $150 \mathrm{~ms}) \mathrm{HCC}(\mathrm{CO}) \mathrm{NH}$, and ${ }^{13} \mathrm{C}$-resolved NOESY-HSQC (120-ms mixing time). ${ }^{1} \mathrm{H}-{ }^{15} \mathrm{~N}$ heteronuclear steady-state NOEs were obtained by recording spectra with and without $4-\mathrm{s}{ }^{1} \mathrm{H}$ presaturation at $700 \mathrm{MHz}$ to determine backbone flexibility.

The titration experiment with the drug was performed with ${ }^{15} \mathrm{~N}-\mathrm{la}$ beled SH protein in DPC micelles (21). Chemical shift perturbations were monitored using $\left[{ }^{1} \mathrm{H}_{-}{ }^{15} \mathrm{~N}\right]$ TROSY-HSQC spectra where the magnitude of the perturbation was calculated using the following formula: CSP $(\mathrm{ppm})=\sqrt{ } \Delta \delta \mathrm{H}^{2}+(0.24 \cdot \Delta \delta \mathrm{N})^{2}$, where CSP is chemical shift perturbation and $\delta \mathrm{H}$ and $\delta \mathrm{N}$ are chemical shift increments of proton and nitrogen, respectively.

Structure calculation. NOE distance restraints were obtained from ${ }^{15} \mathrm{~N}$ NOESY-HSQC (mixing time, $150 \mathrm{~ms}$ ) and ${ }^{13} \mathrm{C}$ NOESY-HSQC (mixing time, $120 \mathrm{~ms}$ ) spectra. Backbone dihedral angle restraints $(\varphi$ and $\psi)$ were derived from ${ }^{13} \mathrm{C}^{\prime},{ }^{13} \mathrm{C}^{\alpha},{ }^{13} \mathrm{C}^{\beta},{ }^{1} \mathrm{H}^{\alpha}$, and ${ }^{1} \mathrm{H}^{\beta}$ chemical shift values using TALOS + (30). The short-range and medium-range NOE connectivities were used to establish the sequence-specific ${ }^{1} \mathrm{H}$ NMR assignment
TABLE 1 Structure statistics for the selected 20 structures corresponding to the $\mathrm{N}$-terminal extramembrane domain of $\mathrm{SH}$ protein

\begin{tabular}{ll}
\hline Parameter & Val \\
\hline NMR restraints (no.) & \\
Total unambiguous distance restraints & 228 \\
Intraresidual & 91 \\
Sequential $(|i-j|=1)^{a}$ & 58 \\
Short-range $(|i-j|<=1)$ & 149 \\
Medium $(2 \leq|i-j| \leq 4)$ & 61 \\
Long range $(|i-j| \geq 5)$ & 18 \\
Dihedral angle restraints & 8 \\
Hydrogen bond restraints & \\
RDC restraints &
\end{tabular}

RMSD from the avg atomic coordinates (residues $1-14[\AA])^{d}$

Backbone atoms $\quad 0.33 \pm 0.13$

$\begin{array}{ll}\text { All heavy atoms } & 0.93 \pm 0.23\end{array}$

Ramachandran analysis (\%)

Residues in most favored regions $\quad 72.9$

Residues in additional allowed regions $\quad 26.2$

Residues in generously allowed regions $\quad 0.8$

Residues in disallowed regions

0.0

${ }^{a} i$ and $j$ are the positions in the sequence of two given residues.

${ }^{b}$ Backbone hydrogen bonds of $\alpha$-helix are applied for regions confirmed to be $\alpha$-helix according to local NOE pattern.

${ }^{c} \mathrm{RDC}$, residual dipolar coupling.

${ }^{d}$ Statistics are calculated and averaged over an ensemble of the 20 structures with lowest target function from CYANA.

and to identify elements of the regular secondary structure. Structure calculations were started from 100 random conformers, using the standard simulated annealing protocol in CYANA, version $3.0(31,32)$. Seven cycles of NOE assignment and structure reconstruction resulted in a bundle of 20 conformers. CNS, version $1.3(33,34)$, was used to refine the structure using the standard simulated annealing protocol. A total of 20 structures were calculated, and the structure statistics are summarized in Tables 1and 2.

Cell culture and transient transfection. Standard procedures were utilized for cell culture and transfection, as described by Dossena et al. (35), with modifications. HEK293 Phoenix cells were cultured in minimum essential Eagle medium (MEM; Sigma, Austria) supplemented with $10 \%$ fetal bovine serum (FBS; Lonza), $2 \mathrm{mM} \mathrm{L-glutamine,} 100 \mu \mathrm{g} / \mathrm{ml}$ penicillin, $100 \mathrm{U} / \mathrm{ml}$ streptomycin, and $1 \mathrm{mM}$ pyruvic acid (sodium salt). The cells were maintained at $37^{\circ} \mathrm{C}$ in $5 \% \mathrm{CO}_{2}$ and $95 \%$ air at $100 \%$ humidity. Subcultures were routinely established every second to third day by seeding the cells into 100 -mm-diameter petri dishes following trypsin/ EDTA treatment. For patch clamp experiments, HEK293 Phoenix cells were seeded into 30-mm-diameter petri dishes, grown overnight, and transfected with $3 \mu \mathrm{g}$ of plasmid DNA by the calcium phosphate coprecipitation method. Medium was changed at $8 \mathrm{~h}$ posttransfection, and the cells were seeded on glass coverslips (diameter, $10 \mathrm{~mm}$ ) at $32 \mathrm{~h}$ posttransfection. Electrophysiology measurements were performed at 48 to $58 \mathrm{~h}$ posttransfection.

Electrophysiological recordings. HEK293 Phoenix cells were transfected with the bicistronic mammalian expression vector PIRES-AcGFP1 (Clontech) (where IRES is internal ribosome entry site and AcGFP1 is Aequorea coerulescens monomeric green fluorescent protein) coding either for AcGFP only or for both AcGFP and the full-length SH expressed as separate proteins. Control experiments were conducted in cells transfected with the pIRES-AcGFP1 vector. Single cells expressing AcGFP were selected by fluorescence microscopy and voltage clamped using the whole-cell patch clamp technique. The resistance of the glass pipettes was 
TABLE 2 Structure statistics for the selected 20 structures of the Cterminal extramembrane domain of $\mathrm{SH}$ protein

\begin{tabular}{ll}
\hline Parameter & Value for the parameter \\
\hline NMR restraints (no.) & \\
Total unambiguous distance restraints & 514 \\
Intraresidual & 165 \\
Sequential $(|i-j|=1)^{a}$ & 146 \\
Short-range $(|i-j|<=1)$ & 311 \\
Medium $(2 \leq|i-j| \leq 4)$ & 96 \\
Long range $(|i-j| \geq 5)$ & 107 \\
Dihedral angle restraints & 34 \\
Hydrogen bond restraints & \\
RDC restraints &
\end{tabular}

RMSD from the avg atomic coordinates $(\text { residues 38-64 }[\AA])^{d}$

Backbone atoms

$0.44 \pm 0.17$

All heavy atoms

$0.94 \pm 0.15$

Ramachandran analysis (\%)

Residues in most favored regions

59.4

Residues in additional allowed regions

35.8

Residues in generously allowed regions

4.8

Residues in disallowed regions

0.0

${ }^{a} i$ and $j$ are the positions in the sequence of two given residues.

${ }^{b}$ Backbone hydrogen bonds of $\alpha$-helix are applied for regions confirmed to be $\alpha$-helix according to local NOE pattern.

${ }^{c} \mathrm{RDC}$, residual dipolar coupling.

${ }^{d}$ Statistics are calculated and averaged over an ensemble of the 20 structures with lowest target function from CYANA.

3 to $8 \mathrm{M} \Omega$ when they were filled with the pipette solution $(135 \mathrm{mM}$ potassium gluconate, $10 \mathrm{mM} \mathrm{KCl}, 10 \mathrm{mM}$ HEPES, $0.5 \mathrm{mM}$ EGTA, $2 \mathrm{mM}$ $\mathrm{Mg}^{++}$-ATP, pH 7.3 [adjusted with $\mathrm{KOH}$ ]). The $\mathrm{pH} 7.4$ bath solution was composed of $124 \mathrm{mM} \mathrm{NaCl}, 3.5 \mathrm{mM} \mathrm{KCl}, 0.01 \mathrm{mM} \mathrm{NaH}_{2} \mathrm{PO}_{4}, 26.2 \mathrm{mM}$ $\mathrm{NaHCO}_{3}, 1.3 \mathrm{mM} \mathrm{MgSO}_{4}, 2.5 \mathrm{mM} \mathrm{CaCl}_{2}$, and $10 \mathrm{mM} \mathrm{D}-(+)$-glucose, $\mathrm{pH}$ 7.4 , while the $\mathrm{pH} 5.5$ bath solution was composed of $124 \mathrm{mM} \mathrm{NaCl}, 3.5$ $\mathrm{mM} \mathrm{KCl}, 0.01 \mathrm{mM} \mathrm{NaH}_{2} \mathrm{PO}_{4}, 0.3 \mathrm{mM} \mathrm{NaHCO}, 25.9 \mathrm{mM}$ sodium gluconate, $1.3 \mathrm{mM} \mathrm{MgSO}_{4}, 2.5 \mathrm{mM} \mathrm{CaCl}_{2}$, and $10 \mathrm{mM} \mathrm{D}^{-}(+)$-glucose. Both bath solutions were constantly bubbled with $95 \% \mathrm{O}_{2}$ and $5 \% \mathrm{CO}_{2}$ to maintain their respective $\mathrm{pHs}$. The Henderson-Hasselbalch equation was used to calculate the amount of bicarbonate required to achieve the respective $\mathrm{pH}$ in the presence of $5 \% \mathrm{CO}_{2}$. Fast exchange of the $\mathrm{pH} 7.4$ bath solution with the acidic bath solution was accomplished using a perfusion system with a flow rate of $5 \mathrm{ml} / \mathrm{min}$ and a bath volume of $\sim 300 \mu \mathrm{l}$. All experiments were carried out at room temperature. For data acquisition, an EPC-8 (HEKA Elektronik, Germany) amplifier controlled by a Macintosh computer running the Patch Master (HEKA Elektronik, Germany) software was used. Access resistance as well as fast and slow capacitance were compensated and monitored throughout the recordings. All current measurements were filtered at $5 \mathrm{kHz}$ and digitized at $50 \mathrm{kHz}$. The cells were held at $0 \mathrm{mV}$, and step pulses of 400 -ms duration were applied from $0 \mathrm{mV}$ to $+40 \mathrm{mV}$ every $20 \mathrm{~s}$ to monitor current changes over time. To establish the current-to-voltage $(I / V)$ relationship, step pulses of 500-ms duration were applied every $5 \mathrm{~min}$ from $-120 \mathrm{mV}$ to $+100 \mathrm{mV}$ in $20-\mathrm{mV}$ increments from a holding potential of $0 \mathrm{mV}$. For data analysis, Fit Master (HEKA Elektronik, Germany) and Excel (Microsoft, USA) software were used. The current values were normalized to the membrane capacity to obtain the current density. Membrane potentials were corrected for liquid junction potentials, and membrane currents were leakage subtracted.

\section{RESULTS}

Inhibition of $\mathrm{SH}$ protein channel activity by pyronin $\mathrm{B}$. Since no $\mathrm{SH}$ protein channel inhibitors have been reported to date, a lipo- some-based fluorescence assay was used to screen for compounds that can inhibit SH channel activity (see Materials and Methods). For this assay, four microplates from the NCI library containing 80 compounds each $(10 \mu \mathrm{M})$ were tested against $\mathrm{SH}$ protein reconstituted in liposomes. Of these compounds, five showed significant inhibition of channel activity (>50\%): NSC526417, NSC81189, NSC78627, NSC77827, and NSC44690 (results not shown).

These compounds were then retested against purified SH protein reconstituted in planar lipid bilayers (BLM). The most potent of these was NSC44690 (pyronin B). A concentration of $10 \mu \mathrm{M}$ pyronin $\mathrm{B}$ led to a $\sim 60 \%$ inhibition of channel activity; conductance changed from $300 \pm 70 \mathrm{pS}$ under control conditions (Fig. $1 \mathrm{~A}$ and $\mathrm{B}$ ) to $120 \pm 60 \mathrm{pS}$ in the presence of pyronin $\mathrm{B}$ (Fig. 1C and D). The structure of pyronin B is shown in Fig. 1E. The binding affinity $\left(K_{d}\right)$ of the compound was obtained from the dose-response curve and determined to be around $6.8 \mu \mathrm{M}$ (Fig. 1F). The effect of pyronin B was tested on RSV replication in Vero cells (Fig. $1 \mathrm{G})$, where tissue culture infectivity ( $50 \%$ infective dose, TCID $_{50}$ ) was zero at a drug concentration of $0.25 \mu \mathrm{M}$.

Binding site of pyronin $\mathrm{B}$ on the $\mathrm{SH}$ protein pentameric surface. Binding of pyronin $\mathrm{B}$ to the $\mathrm{SH}$ protein was monitored with a series of $\left[{ }^{1} \mathrm{H}_{-}{ }^{15} \mathrm{~N}\right]$ TROSY-HSQC spectra recorded in the absence and presence of pyronin $\mathrm{B}$ at different concentrations. When a $4.8 \mathrm{mM}$ concentration of the drug was added to $0.6 \mathrm{mM}$ uniformly ${ }^{15} \mathrm{~N}$-labeled $\mathrm{SH}$ protein, backbone resonances of several residues in SH protein were significantly perturbed (Fig. 2A), and large ( $\geq 0.07 \mathrm{ppm}$ ) chemical shift perturbations (CSPs) were observed at both ends of the TM domain. At the $\mathrm{N}$-terminal end, residues more affected were Ile-6 and Ile-21 (Fig. 2B). At the Cterminal end, the residue most affected was Ala-39 (Fig. 2B) and a group of nearby residues, i.e., Ile-38, Ile-40, Leu 41, and Lys-43 (Fig. 2C), located at the C-terminal end of the TM domain. Interestingly, most of these juxtamembrane residues (residues 38 to 43) form a conserved motif in the RSV SH protein, $\mathrm{A}_{39} \mathrm{ILNKL}_{43}$ (Fig. 2D), which suggests that this is a critical region for $\mathrm{SH}$ protein, where emergence of resistance mutations would be difficult for the virus. By comparison, residues at positions 6 and 21 are not conserved. Determination of intermolecular nuclear Overhauser effects (NOEs) for the drug-protein complex was not possible, probably due to weak interaction.

Docking of pyronin B to the $\mathrm{SH}$ protein pentameric surface. To provide more insight into the nature of the pyronin B binding sites, docking studies of pyronin B to the $\mathrm{SH}$ protein were performed, using as a model for docking the $\mathrm{SH}$ pentameric structure obtained in DPC micelles (21). The Patchdock server $(36,37)$ performed first a blind docking search such that pyronin B could explore the entire surface of $\mathrm{SH}$ protein. The ten best structures were selected according to the geometric shape complementarity score. Interestingly, in nine of these structures, pyronin B was located near the residues that showed the largest chemical shift perturbation, i.e., Ile-6, Ile-21, and Ala-39 (Fig. 3). Thus, the following search was restricted to regions close to these residues and led to the prediction of two possible binding sites at both ends of the TM domain. The N-terminal one is formed by Phe-14 and Ile- 21 in one monomer $(i+1)$ and Ile- 6 of the previous monomer (the $i$ th monomer) (Fig. $3 \mathrm{~A}$ and $\mathrm{B}$ ). The $\mathrm{C}$-terminal one is formed by residues Ile-40, Leu-41, and Lys-43 in one monomer $(i+1)$ and Ile-38 and Ala-39 of the previous monomer ( $i$ ) (Fig. 3A to C). An analysis of the druggable pockets on the $\mathrm{SH}$ pentamer surface by 

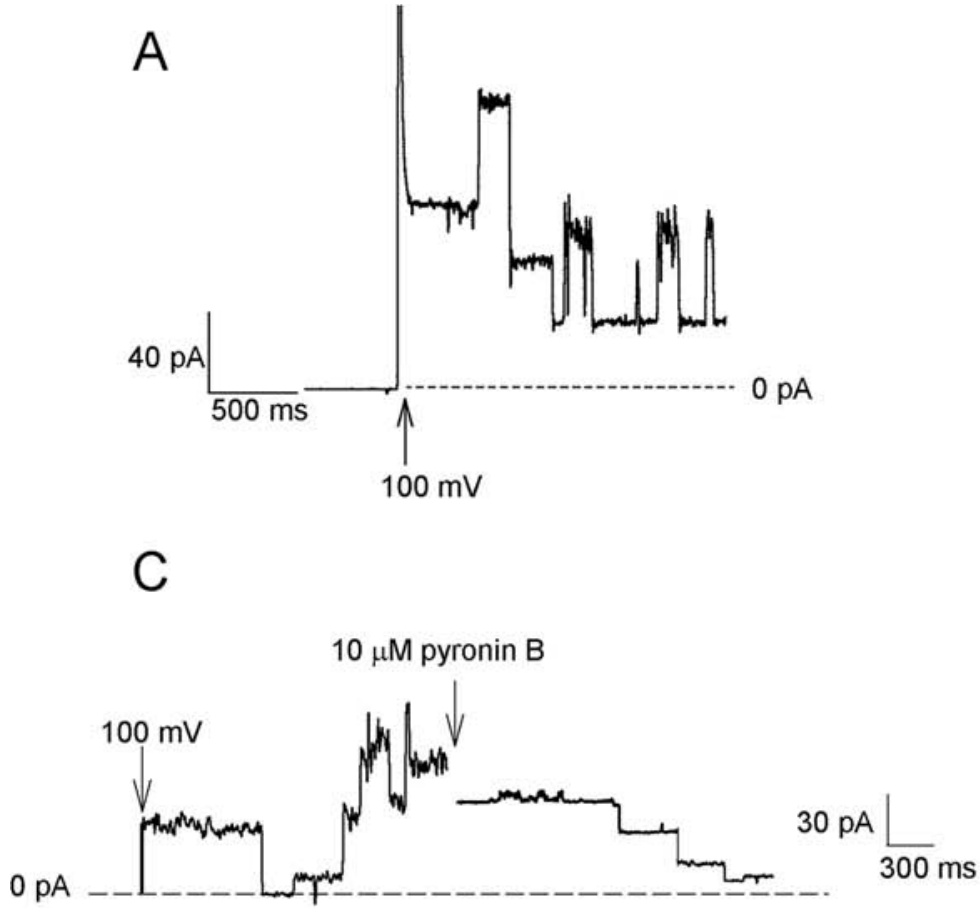

$E$<smiles>CCN(CC)c1ccc2cc3ccc(=[N+](CC)CC)cc3cc2o1</smiles>

G

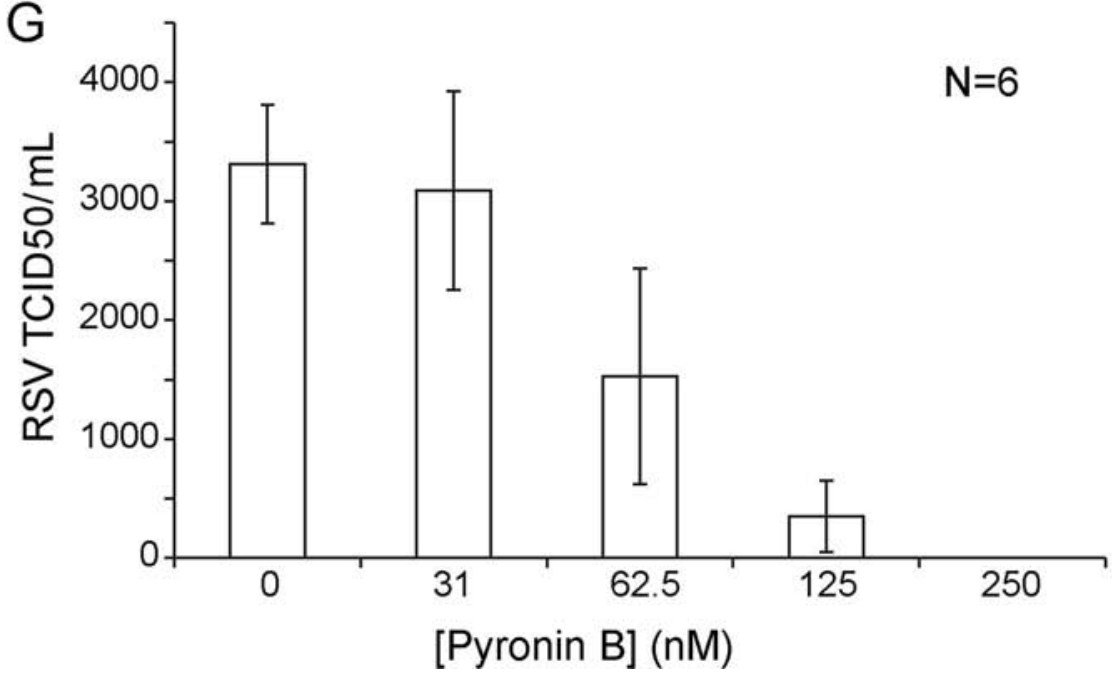

B
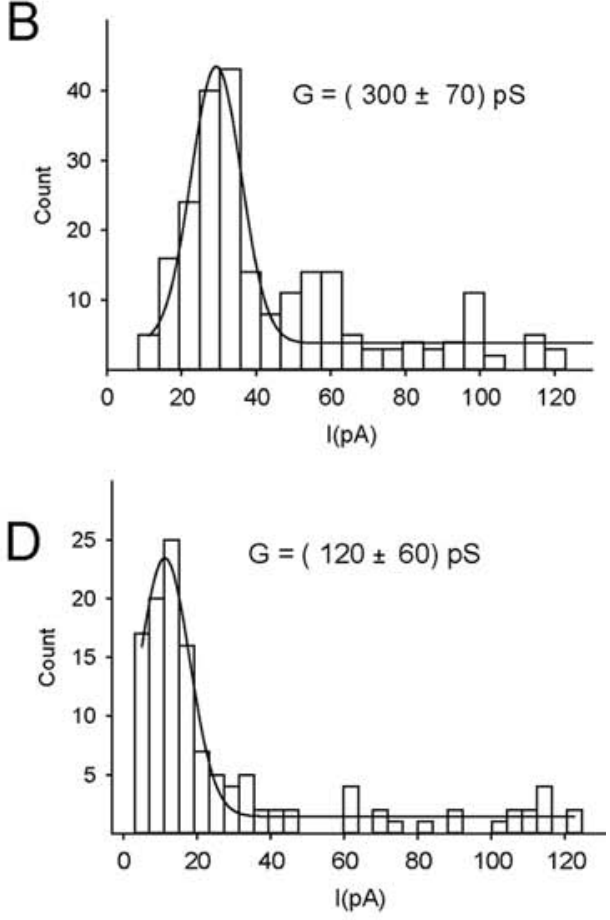

$\mathrm{F}$

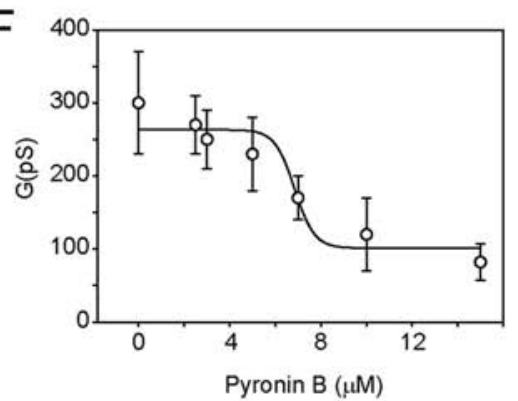

FIG 1 Ionic current and inhibition of SH channel activity. (A) Ionic current through SH protein in a 3:1:1 DOPC-DOPS-DOPE planar membrane in 1 M KCl at pH 6. (B) Histogram of current amplitude. (C) Example of original recording of channel activity before and after addition (arrow) of $10 \mu \mathrm{M}$ compound NSC44690 (pyronin B) under the same conditions as described in panel A. (D) Corresponding current amplitude histogram in the presence of pyronin B. (E) Structure of pyronin B. (F) Dose-response curve obtained in the presence of $0,2.5,3,5,7,10$, and $15 \mu \mathrm{M}$ pyronin B. The conductance values were fitted using a standard sigmoidal dose-response curve to obtain a $K_{d}$ of $\sim 6.8 \mu \mathrm{M}$. (G) Effect of increasing concentration of pyronin B on RSV replication in Vero cells, calculated as the $50 \%$ tissue culture infective dose $\left(\mathrm{TCID}_{50}\right)$. 

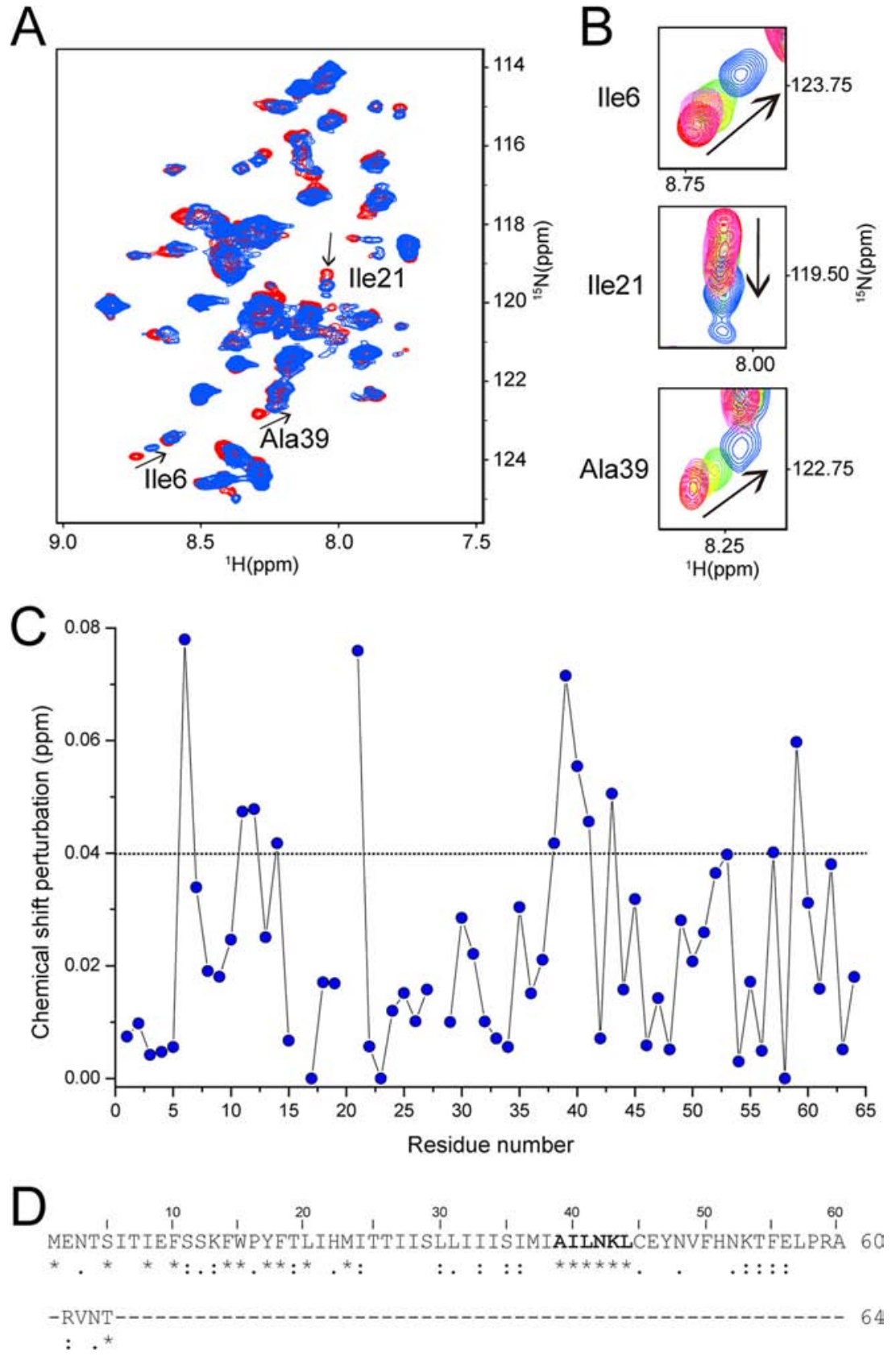

FIG 2 Pyronin B binding significantly perturbed the chemical shifts of SH oligomer. (A) Superposition of TROSY-HSQC spectra of uniformly ${ }^{15} \mathrm{~N}$-labeled SH protein (monomer concentration, $0.6 \mathrm{mM}$ ) in the absence (blue) and presence (red) of $4.8 \mathrm{mM}$ pyronin B. Peaks that undergo significant shifts upon complex formation are highlighted. (B) Selected regions in TROSY-HSQC spectrum in the presence of pyronin B concentrations increasing from 0 (red) to 0.3 (pink), 1.2 (yellow), 2.4 (green), and $4.8 \mathrm{mM}$ (blue). (C) Chemical shift perturbation (CSP, ppm) of the backbone amide resonances of $0.6 \mathrm{mM}{ }^{15} \mathrm{~N}$-labeled SH protein upon titration with $4.8 \mathrm{mM}$ pyronin $\mathrm{B}$. The missing and overlapping residues were eliminated from the analysis. (D) Result from a Clustal X alignment of $>40$ variants of RSV SH protein where identity (star) and similarity (dot) are indicated.

the software DogSiteScorer (38) also identified these same regions (Fig. 3D).

SH mutants abolish inhibition by pyronin B. To more specifically delineate the site(s) of inhibition by pyronin $B$, we tested the effect of the drug on (i) a truncated form of $\mathrm{SH}$ protein, encompassing only its TM domain (SH-TM, residues 18 to 43) and (ii) full-length mutants at the two proposed binding sites, i.e., at the $\mathrm{N}$ or the $\mathrm{C}$ termini of the TM domain. The SH-TM should contain an intact binding site at the C-terminal juxtamembrane domain (residues 38 to 43 ), whereas most residues identified at the $\mathrm{N}$-terminal end are absent. The SH-TM (20) and the four single mutants of the full-length SH protein tested were able to form pentamers: A39S, I21F, and I21Y in PFO gels (Fig. 4A) and H22F in blue native gels (Fig. 4B). All of them also showed channel activity although in $\mathrm{I} 21 \mathrm{~F}$ this was reduced to about $50 \%$ (Fig. 4C). The effect of pyronin B on SH-TM was similar to full-length SH pro- 

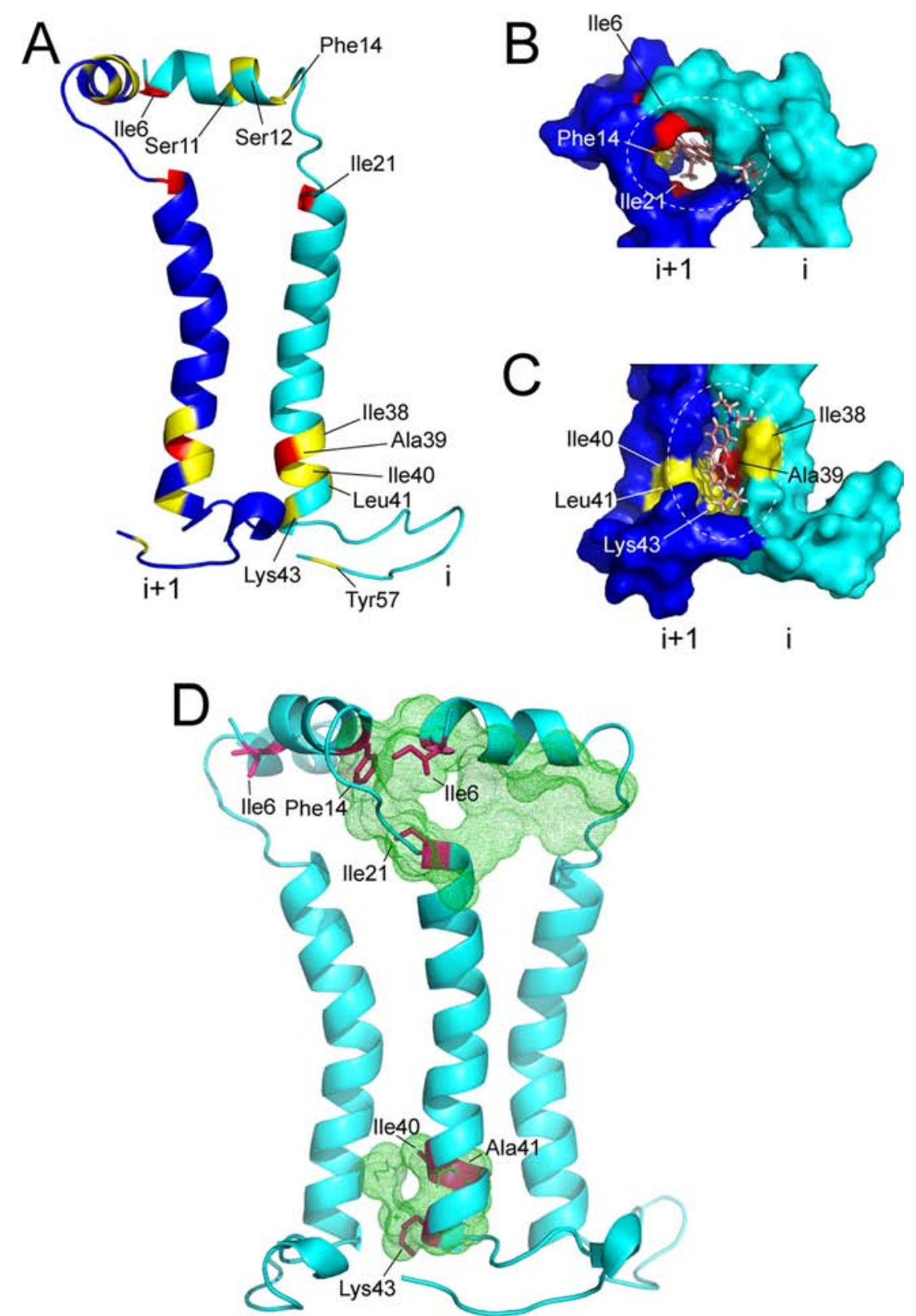

FIG 3 Mapping of pyronin B binding to SH protein. (A) The CSP values in the presence of pyronin B are mapped onto the structure of SH protein, with residues showing larger (CSP of $\geq 0.07 \mathrm{ppm}$ ) and smaller (CSP of $\geq 0.04 \mathrm{ppm}$ ) shifts represented in red and yellow, respectively. (B and C) Model of the two pyronin $B$ binding sites on the SH pentamer at the N-terminal (B) and C-terminal (C) ends of the TM domain (dotted circles), where residues with a CSP of $\geq 0.07$ ppm are labeled in red. Only two monomers of SH protein pentamer (i and $\mathrm{i}+1$ ) are shown for simplicity. (D) Druggable pockets (green mesh) predicted by DoGSiteScorer (38), an automated pocket detection and druggability assessment tool. For comparison, the main residues that showed largest NMR chemical shift changes are shown in red. Two monomers have been removed from the pentamer for clarity.

tein (40 and $60 \%$ inhibition, respectively) at $10 \mu \mathrm{M}$, suggesting that the intact C-terminal end of the TM domain (residues 38 to 41 ) is sufficient for inhibition. Indeed, the conservative mutation A39S in that region almost completely prevented inhibition ( $\sim 10 \%$ inhibition).

Surprisingly, the three other mutants also showed resistance to inhibition by pyronin B ( $\sim 20 \%$ inhibition $)$, despite the intact C-terminal binding site. These results can be rationalized by assuming a destabilization of the C-terminal binding site in the presence of these more disruptive mutations at the N-terminal end of the TM. I21F and I21Y represent more bulky substitutions, whereas $\mathrm{H} 22 \mathrm{~F}$ affects His-22, which was suggested to have a structural role (21). Although $\mathrm{H} 22 \mathrm{~F}$ does not affect pentamerization (Fig. 4B), H22A completely disrupted pentamerization, in contrast to H51A (21). Thus, cross talk between the two ends of the TM may lead to a modification of the pyronin B binding site at the C-terminal region, without affecting channel activity.

Secondary structure of $\mathrm{SH}$ protein reconstituted in bicelles. The comparison between the inhibitory effect of pyronin B (BLM) and its binding to $\mathrm{SH}$ protein (NMR) was performed using lipid 

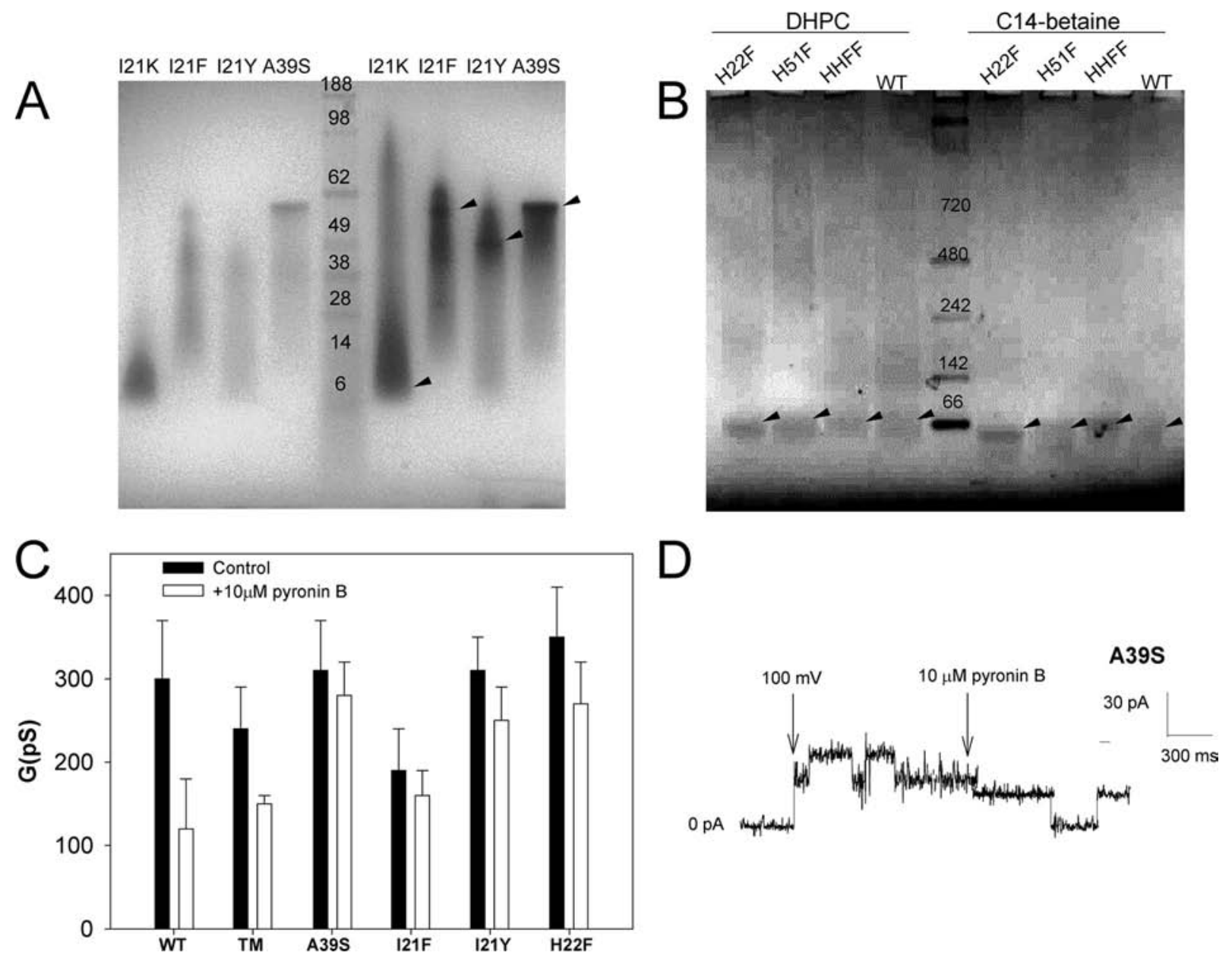

FIG 4 Channel conductance of SH protein mutants and effect of pyronin B on channel activity. (A) PFO gel electrophoresis of several full-length SH mutants at the two proposed binding sites of pyronin B, loaded with $3 \mu \mathrm{g}$ (left) and $12 \mu \mathrm{g}$ (right). Arrowheads indicate the main oligomers. (B) Blue native gel electrophoreses in DHPC and $\mathrm{C}_{14}$-betaine of His-Phe mutants. Arrowheads indicate the bands corresponding to pentamers. (C) Conductance of the wild type (WT), transmembrane domain (SH-TM), and single SH mutants in the absence of inhibitor (control) or in the presence of $10 \mu \mathrm{M}$ pyronin B. (D) Representative ionic current through mutant A39S in a 3:1:1 DOPC-DOPE-DOPS planar membrane at pH 6 before and after the addition of $10 \mu \mathrm{M}$ pyronin B.

membrane and detergent micelle environments, respectively. However, examples exist in the literature of the better suitability of bicelles over micelles in studying membrane protein structure. For example, in $\alpha$ integrins $(39,40)$, the presence of a reverse loop in the juxtamembrane cytoplasmic region was observed in a bicellar or membrane environment but not in detergent micelles or organic solvents (41-43). Therefore, to confirm that proposed binding sites of pyronin $\mathrm{B}$ to $\mathrm{SH}$ protein represent those present in membranes, we analyzed the structure of $\mathrm{SH}$ protein in a membrane-mimicking bicellar environment.

Reconstitution of SH protein in dihexanoylphosphatidylcholine-dilauroylphosphatidylcholine (DHPC-DLPC) bicelles resulted in well resolved ${ }^{1} \mathrm{H}_{-}{ }^{15} \mathrm{~N}$ TROSY-HSQC spectra (Fig. 5A). However, residues 16 to 37 , which form the core of the TM domain (21), were missing from the spectrum. This problem was also found for bicellar compositions 1,2-dimyristoyl-sn-glycero-3-phosphocholine (DMPC)-DHPC, 1-palmitoyl-2-oleoyl-snglycero-3-phosphocholine (POPC)-DHPC, 1,2-dipalmitoyl-snglycero-3-phosphocholine (DPPC)-DHPC, and DLPC-DHPC when spectra were collected at $313 \mathrm{~K}, \mathrm{pH} 5.5$, and the protein concentration was $0.3 \mathrm{mM}$ (data not shown). This broadening may be caused by the TM domain being more structured and has been reported previously for similar viral membrane proteins reconstituted in bicelles (44). Nevertheless, the TM ends, juxtamembrane, and extramembrane parts of the $\mathrm{SH}$ protein were still observable.

The secondary ${ }^{13} \mathrm{C} \alpha$ chemical shifts are highly correlated to secondary structure $(45,46)$. Therefore, the shifts found previously in DPC micelles (21) and those found here in DHPC-DLPC bicelles were compared (Fig. 5B). Only small differences were present at the $\mathrm{N}$-terminal extramembrane fragment, where residues 1 to 7 were close to random-coil values, and the rest were more $\alpha$-helical. Similarly, the region proposed as the pyronin B binding site (residues 38 to 43 ) showed identical $\mathrm{C} \alpha$ chemical shifts.

However, dramatic differences were observed in the C-terminal juxtamembrane fragment Leu-44 to Asn-48 (Fig. 5B, box). NOE connectivities (Fig. 5C and D) show that this fragment is $\alpha$-helical in bicelles, in contrast with the $\beta$-structure previously found in DPC micelles (21). The dynamic properties of the extramembrane domains of $\mathrm{SH}$ protein were studied using a $\left[{ }^{1} \mathrm{H}_{-}{ }^{15} \mathrm{~N}\right]$ steady-state heteronuclear NOE (HNOE) 

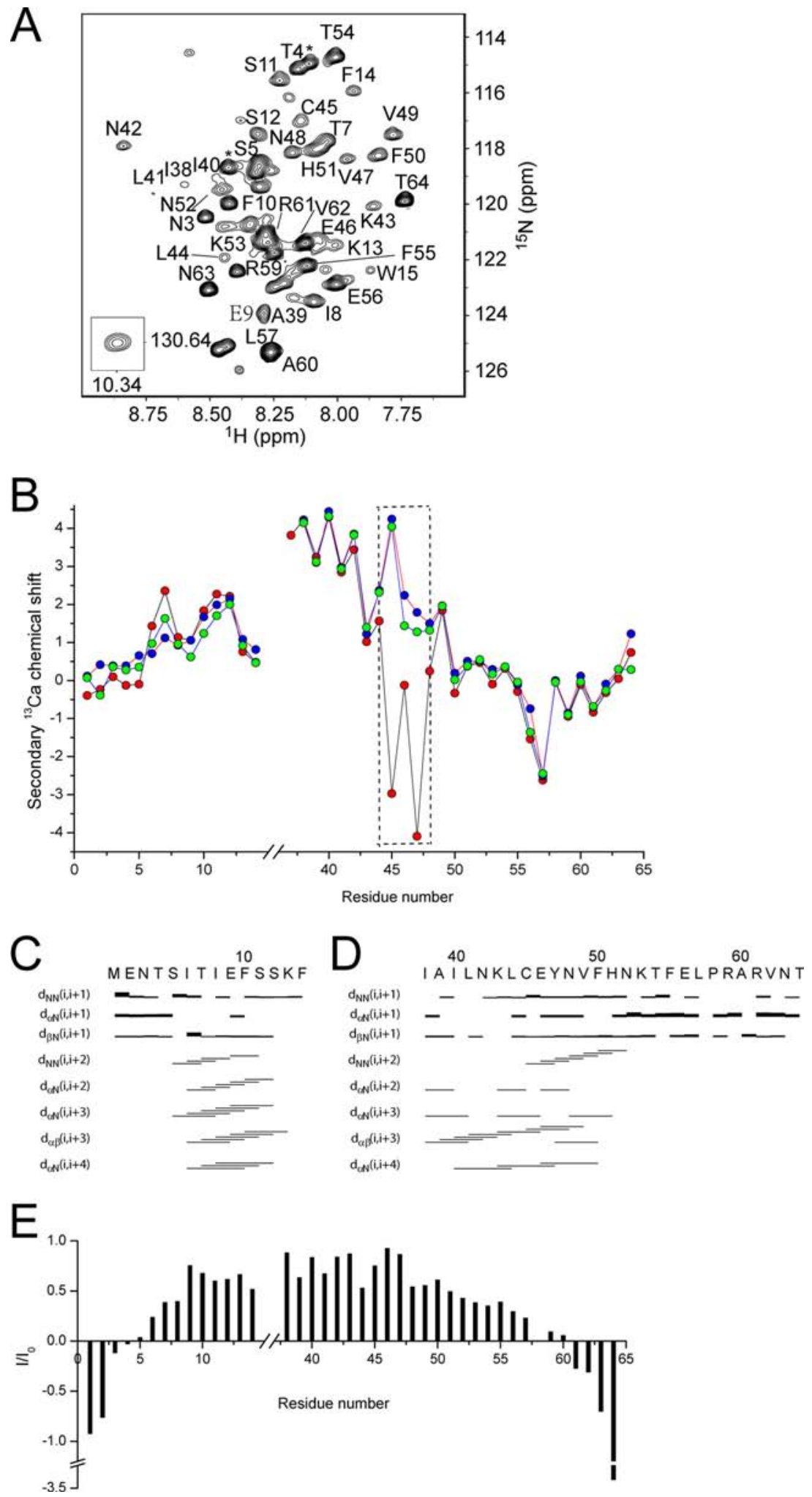

FIG 5 Spectral resolution and secondary structure of SH extramembrane domains in bicelles. (A) $\left[{ }^{1} \mathrm{H}^{-15} \mathrm{~N}\right]$ TROSY-HSQC of SH protein in DHPC-DLPC bicelles. The cross-peaks are labeled by one-letter code and residue number. The Trp-15 indole group is shown in the inset. (B) Comparison of ${ }^{13} \mathrm{C} \alpha$ secondary chemical shifts, i.e., the difference between experimental and tabulated random-coil ${ }^{13} \mathrm{C} \alpha$ chemical shifts, of SH protein in DPC micelles (red), DHPC-DLPC bicelles (green), and DHPC-DMPC bicelles (blue). Regions that exhibit significant ${ }^{13} \mathrm{C} \alpha$ secondary shift differences between bicelle- and micelle-embedded SH protein are indicated by a box. (C and D) Secondary structure of SH protein and NOE connectivity. Sequential and medium-ranged NOE connectivity for extramembrane N-terminal (residues 1 to 14 ) (C) and C-terminal (residues 38 to 64) (D) domains, displayed as bands under the respective residues. (E) Heteronuclear ${ }^{1} \mathrm{H}^{-15} \mathrm{~N}$ NOE (HNOE) experiment. 

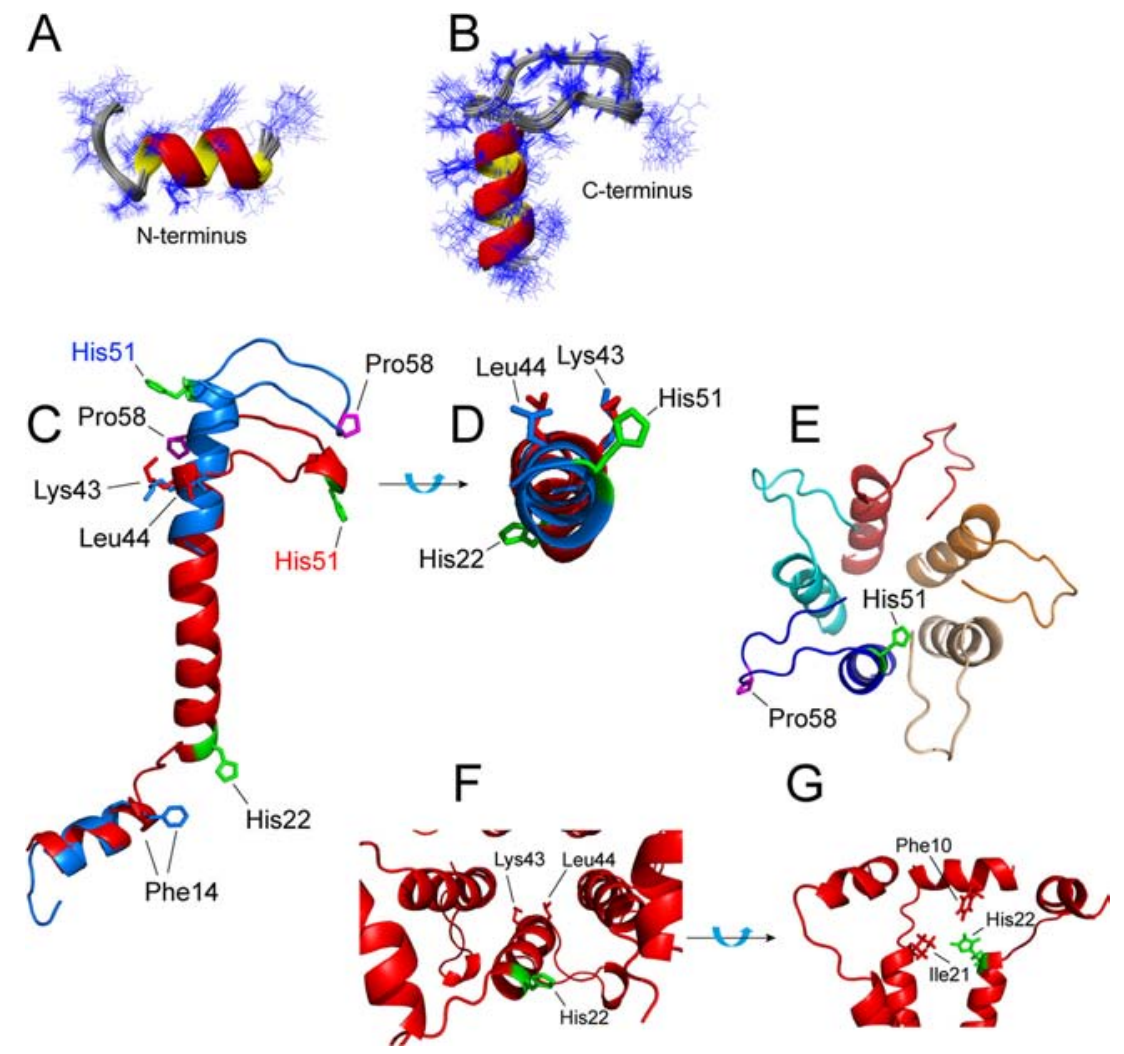

FIG 6 Structural model of SH protein in bicelles. Ensemble of 20 low-energy structures of N-terminal (A) and C-terminal (B) extramembrane domains of SH protein calculated using the NMR restraints summarized in Tables 1 and 2 are shown. The side chains are shown in line representation. (C) Overlay of the structures obtained in DHPC-DLPC bicelles (blue) and DPC micelles (red) (21). Some side chains are indicated for comparison of the two structures. (D) Superposition of the helical stretches of the two models. (E) Lumenal view of the proposed SH protein pentamer structure and orientation of the His-51 side chain. (F) Orientation of His-22 in the pentameric oligomer. (G) Possible contacts of His-22 with Phe-10 and Ile-21, both in a neighboring monomer.

experiment (Fig. 5E). The majority of the HNOE values correspond to a well-folded structure (residues 5 to 14 and 38 to 60 ).

Three-dimensional model of $\mathrm{SH}$ protein monomer in bicelles. The restraints shown in Tables 1 and 2 were used in the calculations to obtain a total of 20 structures for the $\mathrm{N}$ - and C-terminal extramembrane domains of $\mathrm{SH}$ protein (root mean square deviation [RMSD] for backbone atoms of 0.33 and $0.44 \AA$, respectively). The $\mathrm{N}$-terminal domain (residues 5 to 14) forms an $\alpha$-helix (Fig. 6A) similar to that observed in DPC micelles (21). However, in the $\mathrm{C}$-terminal domain (residues 38 to 64 ), the TM $\alpha$-helix extends up to His-51 (Fig. 6B), in contrast with the $\beta$-strand-like loop structure present in micelles. Comparison between these two models (Fig. 6C) shows that Pro-58 is located at the tip of a C-terminal loop formed by the non- $\alpha$-helical residues after His-51. Due to that extended helical region, the total $\alpha$-helical content of SH protein is increased from $\sim 53 \%$ in DPC micelles to $\sim 60 \%$ in bicelles, which is almost identical to the percentage obtained using Fourier transform infrared spectroscopy (FTIR) of SH protein reconstituted in DMPC membranes (21).

A top-down view of the helices superimposed in the two models (Fig. 6D) shows the relative orientation of the two His residues and indicates that residues His-51 and Lys- 43 are aligned. To assess the orientation of His-51 relative to the channel lumen, the SymmDock server $(37,47)$ was used to generate a pentameric oligomer of the C-terminal extramembrane domain using the mutual orientation of the TM domains obtained in DPC micelles (21). This is justified since in the latter model these mutual orientations were also very similar to the ones obtained using infrared dichroism data of synthetic SH-TM in lipidic membranes (20). Further, similar approaches were followed to obtain the pentameric TM model of severe acute respiratory syndrome-corona virus (SARS-CoV) E protein lipid environments that were confirmed in DPC micelles by solution NMR $(48,49)$. In that case, our reported TM-TM orientations were consistent with mutations that recovered channel activity in infected rats (50).

With this TM orientation, His-51 side chains face the lumen of the channel (Fig. 6E) although Leu-44 has even a more evident lumenal position, and His-22 is slightly skewed toward the other helix-helix interface (Fig. 6D). This orientation for the His-22 side chain is obviously retained from the model obtained in micelles (21). The good alignment of His-51 and Lys- 43 (see above) allows visualization of the relative orientation of the two His residues (Fig. 6F). Possible contacts of His-22 with Phe-10 and Ile-21, at a different monomer, may stabilize the pentameric form (Fig. 6G).

Given this proposed lumenal/interfacial orientation of the two His residues, we examined their contribution to channel activity and selectivity using black lipid membranes (BLM) and purified SH protein.

Characterization of $\mathrm{SH}$ protein channel activity. Purified WT SH protein, two single mutants, $\mathrm{H} 22 \mathrm{~F}$ and $\mathrm{H} 51 \mathrm{~F}$, and one double mutant, H22F H51F, were tested in BLM. All of these forms were 
A
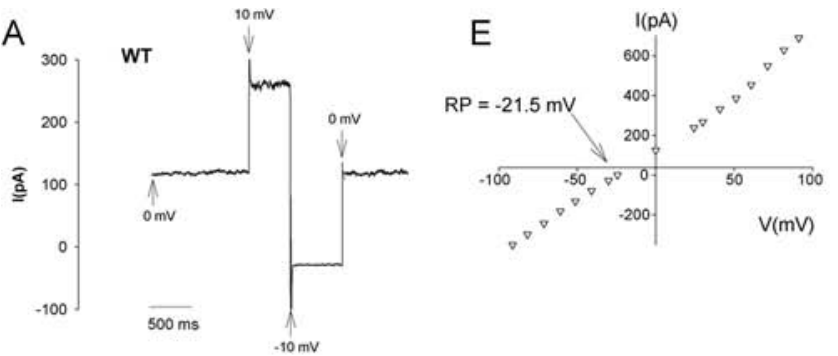

B

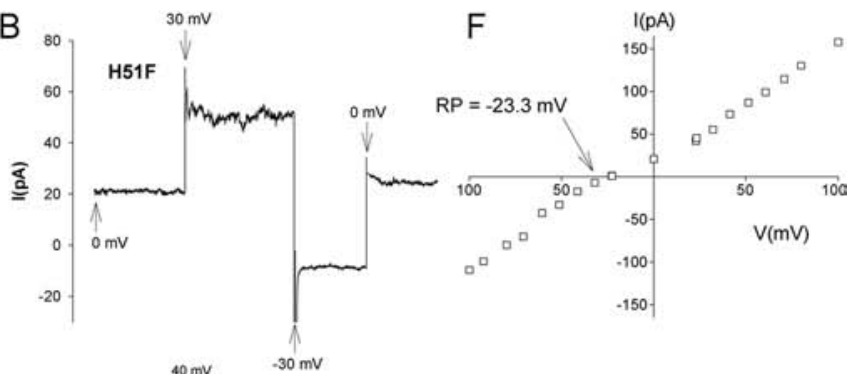

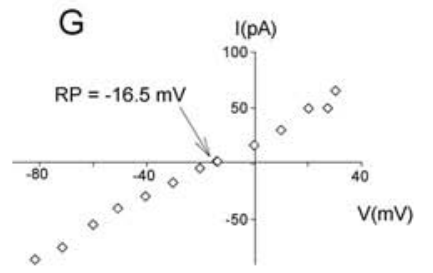
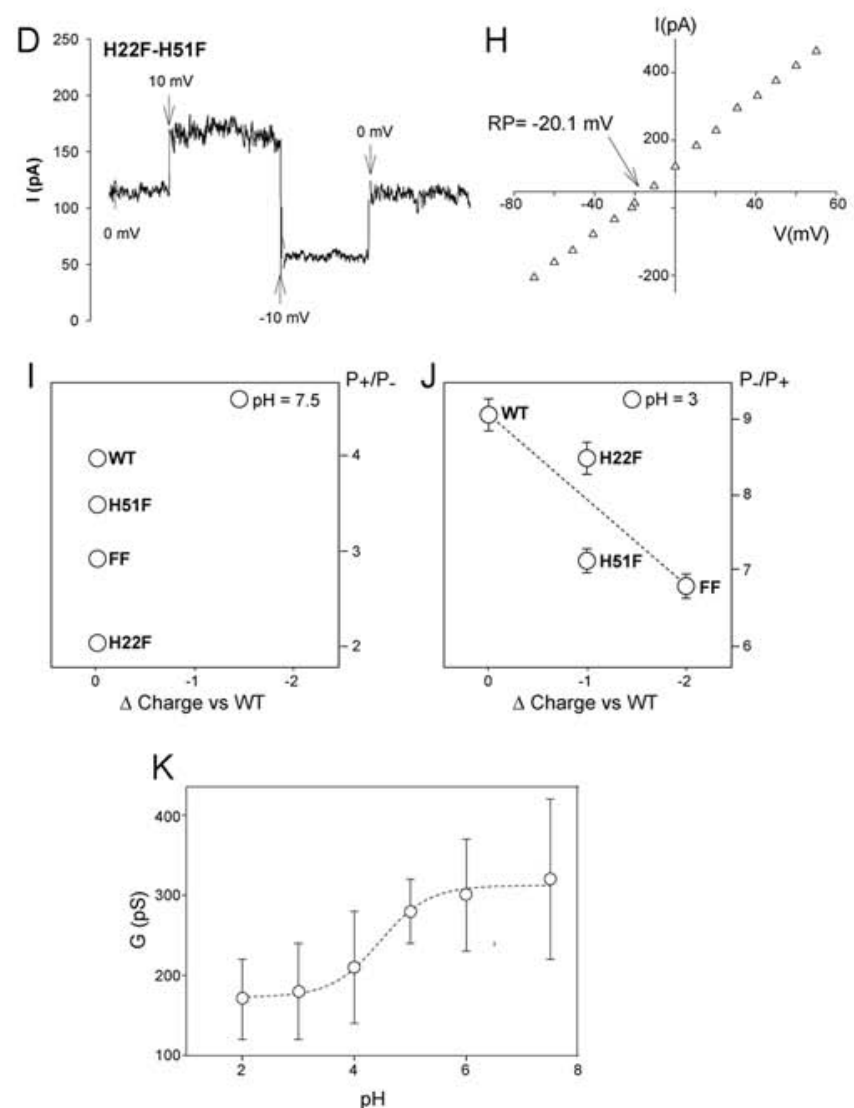

able to form pentameric oligomers (Fig. 4B) and showed channel activity (Fig. 7A to D). When a concentration gradient was used, the reversal potential (RP), i.e., the applied transmembrane voltage that yields zero current, provided an estimate of channel selectivity for anions or cations. At $\mathrm{pH} 7.5$, the RP of all the forms tested showed mild but clear cationic selectivity (Fig. 7E to H). In contrast, at $\mathrm{pH} 3$ all of these forms showed mild anionic selectivity (data not shown). A summary of the averaged results is shown in Table 3.

At $\mathrm{pH} 7.5, \mathrm{H} 22 \mathrm{~F}, \mathrm{H} 22 \mathrm{~F}$, and the double mutant H22F H51F (Fig. 7I) showed lower cation selectivity, $P_{+} / P_{-}$(where $P_{+}$and $P_{-}$ refer to cation and anion permeability, respectively). Since the net charge of $\mathrm{SH}$ protein at this $\mathrm{pH}$ should be similar for all of these variants given the $\mathrm{pK}_{\mathrm{a}}$ of His residues of $\sim 6.5$ (51), the differences observed in RP are likely to reflect structural changes induced by the H22F mutation. These changes, however, do not affect the pentameric structure (Fig. 4B), but in the case of H22F, the mutation may destabilize pyronin binding (Fig. 4C).

At $\mathrm{pH} 3$, anion selectivity $\left(P_{-} / P_{+}\right)$was somewhat correlated with the expected global charge (Fig. 7J and Table 3). At this $\mathrm{pH}$, both His residues should be protonated, and therefore the net charge relative to the WT depends on the number of His residues present. Anion selectivity was higher for WT, lower for the single mutants, and even lower for the H22F H51F double mutant. In this case, the absence of His-22 (H22F) led to a behavior similar to that of the WT, suggesting a small contribution of this residue to ion selectivity. In contrast, mutants where His-51 was absent ( $\mathrm{H} 51 \mathrm{~F}$ and $\mathrm{H} 22 \mathrm{~F} \mathrm{H} 51 \mathrm{~F}$ ) produced a significant reduction in $P_{-} /$ $P_{+}$, suggesting a more important involvement of His-51 in modulating channel selectivity.

These results are somewhat consistent with the respective orientation of these two side chains in the pentameric channel, with His-51 being more exposed to the lumen and His-22 being more rotated toward the helix-helix interface and/or making stabilizing contacts with neighboring monomers (Fig. 6F and G). These data are also consistent with the observed electrophoretic pattern of His mutants (21); mutant H22A showed aberrant mobility and/or aggregation, suggesting a structural role. In contrast, H51A showed mobility similar to that of the WT form. Finally, the overall conductance was $\mathrm{pH}$ dependent and consistent with the titration of histidine residues (Fig. 7K), with less conductance at lower $\mathrm{pH}$, where both His residues are protonated. A dramatic reduction of channel activity at lower $\mathrm{pH}$ was also observed previously for synthetic SH-TM (residues 18 to 43) in planar lipid bilayers (20). In SH-TM, only His-22 was present, suggesting that protonation of this histidine alone can reduce or block channel activity.

Patch clamp studies of transfected HEK293 Phoenix cells. The results obtained by functional reconstitution of the TM domain (20) or the full-length SH protein (Fig. 7) in BLM show (i)

FIG 7 SH channel activity measurements. (A to D) Original current recordings obtained with a $500 / 50 \mathrm{mM} \mathrm{KCl}$ gradient, $\mathrm{pH} 7.5$, showing that a current is observed for WT and mutant $\mathrm{SH}$ proteins at $0 \mathrm{mV}$. (E to H) Data from the current-to-voltage relationships corresponding to panels $\mathrm{A}$ to $\mathrm{D}$ showing the reversal potential (RP) of each SH variant. (I and J) Cation $\left(P_{+} / P_{-}\right)$selectivity at $7.5(\mathrm{I})$ and anion $\left(P_{-} / P_{+}\right)$selectivity and at $\mathrm{pH} 3(\mathrm{~J})$ for each SH variant, shown as a function of the difference of global charge with respect to the WT. (K) Channel conductance $G(\mathrm{pS})$ for the WT SH protein at different $\mathrm{pHs}$ in 1 $\mathrm{M} \mathrm{KCl}$ and 3:1:1 DOPC-DOPS-DOPE. The experimental points were fitted by a sigmoidal curve. Error bars represent standard errors of the means $(n=6)$. 
that channel activity is reduced at low $\mathrm{pH}$ and (ii) that His-to-Phe mutants are channel active. This is in stark contrast with previous patch clamp results (21), which showed channel activation at low $\mathrm{pH}$ and no channel activity for a H22F H51F double mutant. Therefore, we tried to reproduce those original patch clamp experiments, where HEK293 Phoenix cells were transiently transfected with either the pIRES-AcGFP1 vector carrying the SH protein or with the control vector pIRES-AcGFP1. Transfected cells were initially kept in a $\mathrm{pH} 7.4$ bath solution. After the seal was realized and the whole-cell configuration was obtained, channel activity was monitored in a freshly bubbled $\left(95 \% \mathrm{O}_{2}, 5 \% \mathrm{CO}_{2}\right) \mathrm{pH}$ 7.4 bath.

The kinetics of the elicited currents (Fig. 8A) resemble those of outwardly rectifying and voltage-dependent potassium currents of the $\mathrm{K}_{\mathrm{v}}$ channel family (52) previously observed in these cells (53). These channels are stimulated at positive potentials and inactive at negative potentials; therefore, the currents measured at negative potentials (e.g., at $-80 \mathrm{mV}$ ) were considered leakage currents and were subtracted from the measured currents. Comparing currents from control and SH-transfected cells without leakage subtraction did not reveal an $\mathrm{SH}$-dependent current at $\mathrm{pH} 7.4$ (Fig. 8A) or 5.5 (not shown).

Current values representing the maximum activation of channels (Fig. 8A, rectangle) were averaged and plotted in the current density-to-voltage relationships determined at pH 7.4 (Fig. 8B) and pH 5.5 (Fig. 8C). At pH 7.4, no differences were observed between currents measured in cells overexpressing $\mathrm{SH}$ protein and in control cells (Fig. 8A and B). Next, replacing the extracellular solution with a freshly bubbled acidic ( $\mathrm{pH}$ 5.5) bath was performed every $5 \mathrm{~min}$. The switch to an acidic environment did not cause any obvious change of the current density-to-voltage relationship over a period of $10 \mathrm{~min}$ (Fig. 8C).

The hypothesis that the measured currents herein are due to endogenous potassium-selective channels is supported by a separate experiment (data not shown) that shows that the experimental RP was close to the equilibrium potential of potassium predicted by the Nernst law. Thus, the ion channel activity of $\mathrm{SH}$ protein, if any, may have been masked by such current. No significant difference was observed in RPs between control and SHexpressing cells at $\mathrm{pH} 7.4$ and 5.5. This observation points to the conclusion that $\mathrm{SH}$ expression, or $\mathrm{pH}$, did not modify the ion selectivity of the measured current; i.e., the patch clamp experiments revealed only an endogenous current whose characteristics did not change following $\mathrm{SH}$ expression.

In another set of patch clamp experiments, the exact same cell line (HEK293) used in previous studies (21) was analyzed. In these experiments, the currents measured in SH-expressing cells were lower, not higher, than those of the control (data not shown). This effect could have been caused by cellular stress induced by $\mathrm{SH}$ expression, reducing the activity, expression, or membrane trafficking of the endogenous potassium channels. A similarly reduced channel activity was observed previously after expression of another viroporin, SARS-CoV E, in HEK-293T cells (54) and was attributed to an indirect influence of the viroporin on other cellular proteins involved in ion transport. However, in that case, SARS-CoV E was not detected in plasma membrane. In contrast, both expression and plasma membrane localization of FLAGtagged SH protein was shown in HEK293 cells (21).

Thus, the possibility that the full-length nontagged version of $\mathrm{SH}$ protein used in patch clamp experiments was not expressed or
TABLE 3 Reversal potential of SH protein (WT and mutants) ${ }^{a}$

\begin{tabular}{|c|c|c|c|c|c|}
\hline \multirow[b]{3}{*}{ Protein } & \multicolumn{5}{|c|}{ Characterization of channel activity at: } \\
\hline & \multicolumn{2}{|l|}{ pH 7.5} & \multicolumn{3}{|l|}{$\mathrm{pH} 3$} \\
\hline & $\mathrm{RP}(\mathrm{mV})$ & $P_{+} / P_{-}$ & $\mathrm{RP}(\mathrm{mV})$ & $P_{-} / P_{+}$ & Charge $^{b}$ \\
\hline WT & $-27.3 \pm 2.2$ & $3.9 \pm 0.1$ & $40 \pm 3$ & $8.9 \pm 0.4$ & 0 \\
\hline H51F & $-25 \pm 3$ & $3.5 \pm 0.1$ & $37 \pm 3$ & $7.1 \pm 0.3$ & -1 \\
\hline $\mathrm{H} 22 \mathrm{~F}$ & $-14 \pm 1.5$ & $2.00 \pm 0.05$ & $39.4 \pm 2.0$ & $8.4 \pm 0.4$ & -1 \\
\hline H51F H22F & $-21.6 \pm 2.0$ & $2.9 \pm 0.1$ & $36 \pm 3$ & $6.7 \pm 0.3$ & -2 \\
\hline
\end{tabular}

${ }^{a}$ Results are from artificial membranes in the presence of a 10 -fold $\mathrm{KCl}$ concentration gradient (see Materials and Methods). Each reversal potential (RP) value is the average of a minimum of 10 experiments.

${ }^{b}$ The charge value represents the charge versus that of the WT SH protein at $\mathrm{pH} 3$.

did not accumulate at plasma membranes was tested by attempting to observe channel activity in HEK293 Phoenix cells overexpressing a FLAG-tagged (C- or N-terminal) SH protein or a Cand $\mathrm{N}$-terminally truncated $\mathrm{SH}$ protein that encompassed the TM domain. None of these conditions produced channel activity that could be attributed to SH protein in a whole-cell configuration (data not shown). We conclude that previous patch clamp data that showed low-pH activation of $\mathrm{SH}$ protein cannot be reproduced.

\section{DISCUSSION}

Inhibition of SH protein by pyronin B. Small-molecule inhibitors can be used to probe the role of $\mathrm{SH}$ protein channel activity during the cell cycle. Although with modest $K_{d}(\sim 6.8 \mu \mathrm{M})$, pyronin B compares favorably with the $16 \mu \mathrm{M}$ for amantadine inhibition of influenza virus M2 protein (55), the $\sim 10 \mu \mathrm{M}$ reported for hexamethylene amiloride (HMA) inhibition of SARS-CoV E (56), 50 to $100 \mu \mathrm{M}$ for rimantadine inhibition of HCV p7 (57), or the $>100 \mu \mathrm{M}$ HMA for $\mathrm{p} 7$ inhibition (58). Pyronin B was found to bind $\mathrm{SH}$ protein mostly at the lipid-facing side of the TM $\alpha$-helices and not into the pore lumen. This mechanism of inhibition is thus probably allosteric, similar to that proposed for rimantadine binding to the TM domain of M2 (57) or rimantadine to hepatitis $\mathrm{C}$ virus (HCV) p7 (57). In fact, the proposed binding site for pyronin B, encompassing residues 38 to 43 , is totally conserved in RSV SH proteins, which suggests that inhibition would be more difficult to overcome by compensatory mutations. By reference to the pentameric model of SH protein in DPC micelles, the proposed binding site is located at the narrowest region of the channel lumen (Fig. 9A and B). Inhibition is more easily rationalized here than near the N-terminal end (cytoplasmic) of the TM, where the channel lumen opens significantly.

Effect of bicelles on juxtamembrane domains of membrane proteins. The juxtamembrane regions in membrane proteins are sensitive to the hydrophobic environment used experimentally, e.g., micelles versus bicelles. This has been shown for the HIV envelope protein (59), integrin transmembrane domains $(39,40)$, or BtuB (a 22-strand $\beta$-barrel protein) (60). We have shown herein that significant structural differences are observed for $\mathrm{SH}$ protein when it is reconstituted in bicelles or micelles. In this case, these effects are unlikely to derive from the different lengths of hydrophobic tails in the phospholipids or detergents used to reconstitute the protein. Indeed, both DLPC and DPC hydrophobic tails, used in bicelles and micelles, respectively, have 12 carbon atoms. In addition, the secondary ${ }^{13} \mathrm{C} \alpha$ chemical shifts from $\mathrm{SH}$ 
A

$\left.200 \mathrm{pA}\right|_{50 \mathrm{msec}}$

Control, $\mathrm{pH} 7.4$

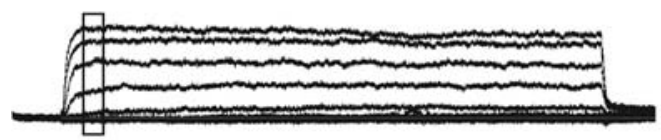

B

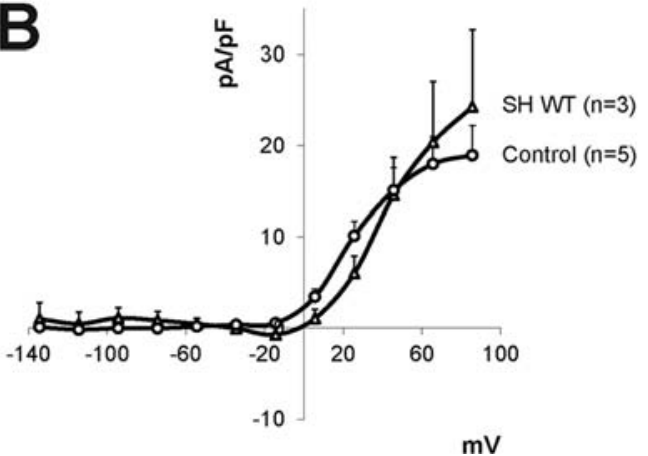

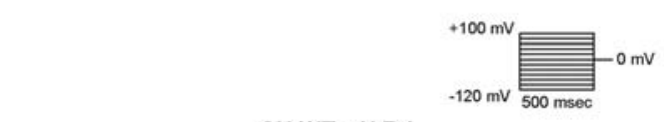

SH WT, pH 7.4
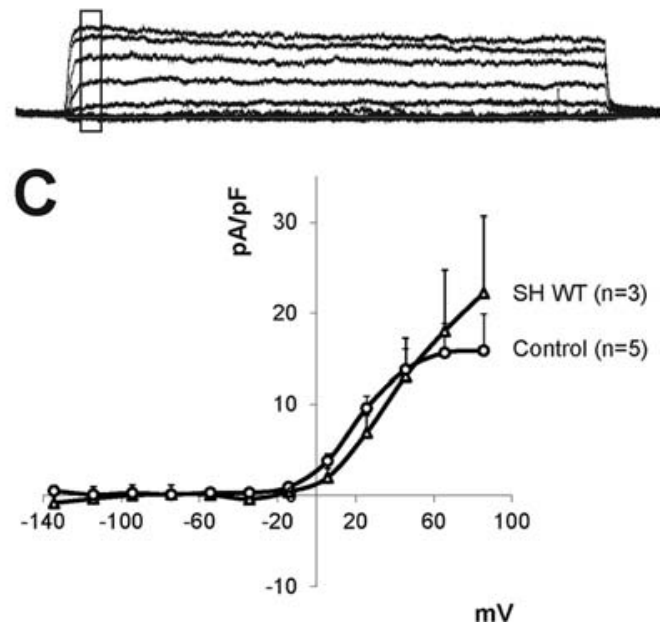

FIG 8 Patch clamp assays in SH-overexpressing cells. (A) Representative original tracings of currents recorded by the patch clamp technique in whole-cell configuration, leakage subtracted and obtained at pH 7.4 in control (left) and SH-transfected (right) cells. Currents were elicited with voltage increments of 20 $\mathrm{mV}$ from -120 to $+100 \mathrm{mV}$ applied from a holding potential of $0 \mathrm{mV}$ (upper right inset). (B and $\mathrm{C}$ ) Current density-to-voltage relationships measured in a pH 7.4 bath solution (B) and at 10 min following replacement of the extracellular solution with an acidic, pH 5.5, bath (C).

protein reconstituted in bicelles of different hydrophobic tail lengths, e.g., DHPC-DLPC versus DHPC-DMPC, were almost identical. All of these data suggest that it is the curvature of the micelle surface that may dramatically affect the structure at the juxtamembrane region.
The role of histidine residues in $\mathrm{SH}$ protein channel activity. The funnel-like architecture adopted by the TM domain in $\mathrm{SH}$ protein (21) has been observed in other viroporins, e.g., influenza virus M2 protein (61), SARS-CoV E protein (48), and HCV p7 (57). All of these viral channels contain narrow regions that prob-

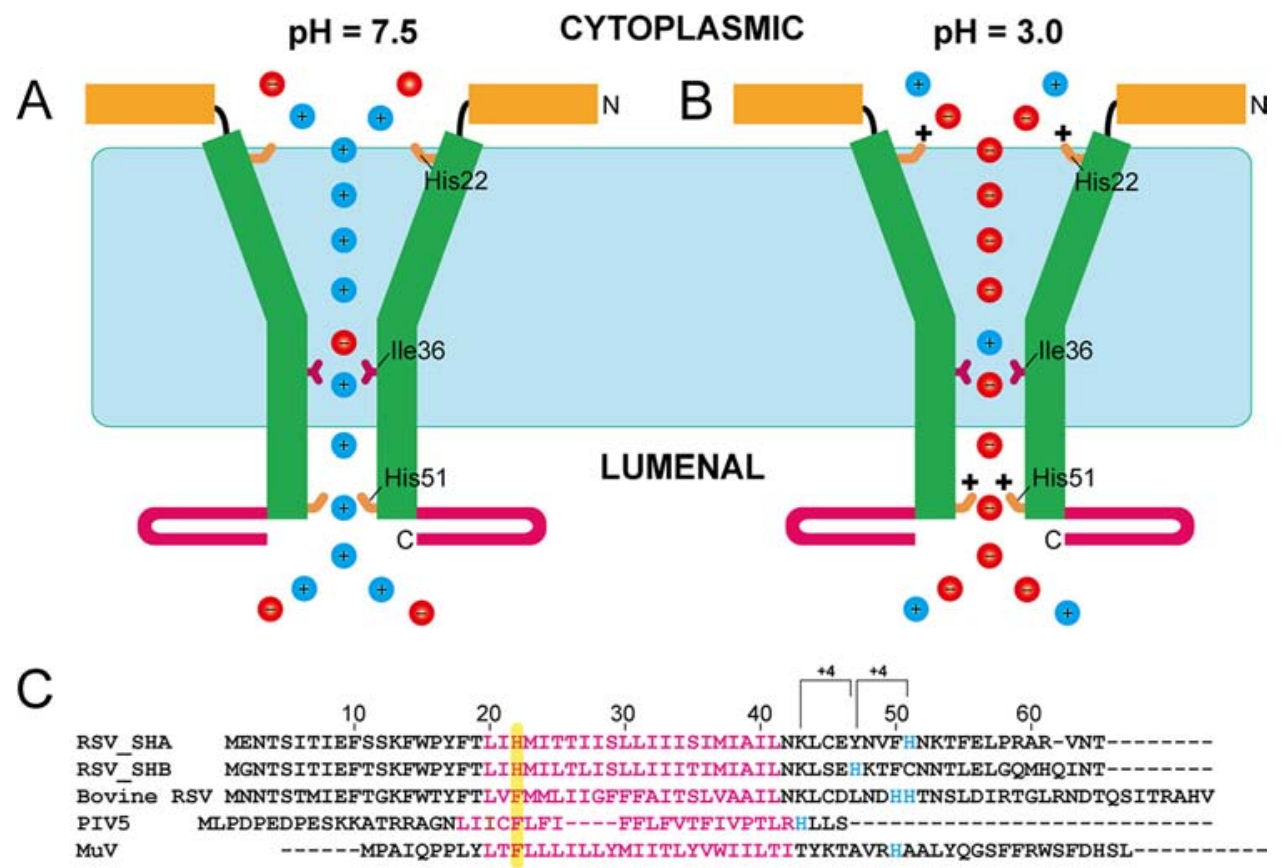

FIG 9 Model of the SH protein channel. Schematic drawing representing a sectional view of the SH protein channel at pH 7.5 (A) and 3.0 (B). (C) FASTA multiple alignment of SH proteins and homologs in human RSV (subgroups A and B), bovine RSV, parainfluenza virus 5 (PIV5), and mumps virus (MuV). The TM domain (purple) predicted using TMHMM (64) and the C-terminal extramembrane His residues (blue) are highlighted. 
ably serve as selectivity filters. In $\mathrm{SH}$ protein, this narrower region (Ser-29 to Cys-45) (21) is lined with hydrophobic side chains (Ile32, Ile-36, Ile-40, and Leu-44), and Ile-36 defines the narrowest point in the channel lumen (Fig. 9A and B). This figure shows that in our present refined model, obtained in bicelles, His-22 is located at the largest opening of this funnel, whereas His-51 is at the tip of the smallest opening. While both His residues are accessible to the lumen of the channel, our structural data point to a stabilizing role for His-22, whereas His-51 is more important for channel activity, consistent with its location in a tighter region of the channel. While at pH 7.5 the channel is mildly selective for cations, at $\mathrm{pH} 3$, His-51 protonation may slow cation transport due to an electrostatic effect (Fig. 9B). Nevertheless, ion selectivity in $\mathrm{SH}$ protein is poor, as also observed in other viroporins, e.g., SARSCoV E protein (62) or HCV p7 (58), and it may be a hallmark of incomplete specialization of these channels.

An indication of the relative importance of these two His residues can also be obtained by analyzing their conservation in close homologs (Fig. 9C). This comparison is justified since PIV5 SH protein could be replaced by the $\mathrm{SH}$ protein from $\mathrm{MuV}$ or RSV SH in strains A2 or B1 to produce a similar phenotype $(6,12)$. These data suggest a role of a membrane-permeabilizing pentameric structure common to these species. Alignment of the homologous sequences of RSV SH protein, bovine RSV, PIV5, and MuV shows that there is at least one His residue near the position equivalent to RSV SH His-51, i.e., several residues after the TM domain. In fact, in these other sequences a C-terminal His residue is present with a 3 - to 4 -residue periodicity, expected for $\alpha$-helices. Therefore, by comparison with the orientation of hRSV SH His-51, these His residues should also have a lumenal orientation. In contrast, the equivalent residue to His-22 is replaced with Phe in these homologous sequences, supporting a more structural role for this residue.

Finally, based on these results, it can only be speculated that $\mathrm{SH}$ channel activity can be strongly regulated by lower $\mathrm{pH}$ when present in native biological membranes and the unknown conditions present in the cell. The intravesicular $\mathrm{pH}$ drops along the endocytic pathway from $\mathrm{pH} 6.0$ to 6.5 in early endosomes to $\mathrm{pH} 4.5$ to 5.5 in late endosomes and lysosomes (63), whereas in the Golgi lumen the $\mathrm{pH}$ is only one unit below that of the cytoplasm. These small $\mathrm{pH}$ changes, together with the low $\mathrm{pK}$ measured in the present paper and the relatively low effect of $\mathrm{pH}$ on both conductance and selectivity, do not suggest that $\mathrm{pH}$ plays a major role in modulating channel activity during the life cycle of the virus. However, mutation of these His residues in the context of the infected cell is an interesting avenue for future experiments, especially since $\mathrm{SH}$ homologs have a conserved His residue at or near the equivalent position to His-51 in hRSV and since that current was abolished when SH-TM was exposed to a $\mathrm{pH}$ of 4 (20).

\section{ACKNOWLEDGMENTS}

J.T. acknowledges the funding of the National Research Foundation (grant NRF-CRP4-2008-02) and Tier 1 grant RG 51/13.

\section{REFERENCES}

1. Dowell SF, Anderson LJ, Gary HE, Jr, Erdman DD, Plouffe JF, File TM, Jr, Marston BJ, Breiman RF. 1996. Respiratory syncytial virus is an important cause of community-acquired lower respiratory infection among hospitalized adults. J. Infect. Dis. 174:456-462. http://dx.doi.org /10.1093/infdis/174.3.456.

2. Blount RE, Jr, Morris JA, Savage RE. 1956. Recovery of cytopathogenic agent from chimpanzees with coryza. Proc. Soc. Exp. Biol. Med. 92:544549. http://dx.doi.org/10.3181/00379727-92-22538.

3. Krusat T, Streckert HJ. 1997. Heparin-dependent attachment of respiratory syncytial virus (RSV) to host cells. Arch. Virol. 142:1247-1254. http: //dx.doi.org/10.1007/s007050050156.

4. Lamb RA. 1993. Paramyxovirus fusion: a hypothesis for changes. Virology 197:1-11. http://dx.doi.org/10.1006/viro.1993.1561.

5. Bukreyev A, Whitehead SS, Murphy BR, Collins PL. 1997. Recombinant respiratory syncytial virus from which the entire $\mathrm{SH}$ gene has been deleted grows efficiently in cell culture and exhibits site-specific attenuation in the respiratory tract of the mouse. J. Virol. 71:8973-8982.

6. Fuentes S, Tran KC, Luthra P, Teng MN, He B. 2007. Function of the respiratory syncytial virus small hydrophobic protein. J. Virol. 81:83618366. http://dx.doi.org/10.1128/JVI.02717-06.

7. Jin H, Zhou H, Cheng X, Tang R, Munoz M, Nguyen N. 2000. Recombinant respiratory syncytial viruses with deletions in the NS1, NS2, $\mathrm{SH}$, and M2-2 genes are attenuated in vitro and in vivo. Virology 273:210218. http://dx.doi.org/10.1006/viro.2000.0393.

8. Karron RA, Buonagurio DA, Georgiu AF, Whitehead SS, Adamus JE, Clements-Mann ML, Harris DO, Randolph VB, Udem SA, Murphy BR, Sidhu MS. 1997. Respiratory syncytial virus (RSV) SH and G proteins are not essential for viral replication in vitro: clinical evaluation and molecular characterization of a cold-passaged, attenuated RSV subgroup B mutant. Proc. Natl. Acad. Sci. U. S. A. 94:13961-13966. http://dx.doi.org/10 $.1073 /$ pnas.94.25.13961.

9. Whitehead SS, Bukreyev A, Teng MN, Firestone CY, St Claire M, Elkins WR, Collins PL, Murphy BR. 1999. Recombinant respiratory syncytial virus bearing a deletion of either the NS2 or SH gene is attenuated in chimpanzees. J. Virol. 73:3438-3442.

10. Li Z, Xu J, Patel J, Fuentes S, Lin YA, Anderson D, Sakamoto K, Wang LF, He BA. 2011. Function of the small hydrophobic protein of J paramyxovirus. J. Virol. 85:32-42. http://dx.doi.org/10.1128/JVI $.01673-10$.

11. Lin Y, Bright AC, Rothermel TA, He B. 2003. Induction of apoptosis by paramyxovirus simian virus 5 lacking a small hydrophobic gene. J. Virol. 77:3371-3383. http://dx.doi.org/10.1128/JVI.77.6.3371-3383.2003.

12. Wilson RL, Fuentes SM, Wang P, Taddeo EC, Klatt A, Henderson AJ, He B. 2006. Function of small hydrophobic proteins of paramyxovirus. J. Virol. 80:1700-1709. http://dx.doi.org/10.1128/JVI.80.4.1700 $-1709.2006$

13. Triantafilou K, Kar S, Vakakis E, Kotecha S, Triantafilou M. 2013. Human respiratory syncytial virus viroporin SH: a viral recognition pathway used by the host to signal inflammasome activation. Thorax 68:6675. http://dx.doi.org/10.1136/thoraxjnl-2012-202182.

14. Rixon HW, Brown G, Aitken J, McDonald T, Graham S, Sugrue RJ. 2004. The small hydrophobic (SH) protein accumulates within lipidraft structures of the Golgi complex during respiratory syncytial virus infection. J. Gen. Virol. 85:1153-1165. http://dx.doi.org/10.1099/vir.0 .19769-0.

15. Collins PL, Mottet G. 1993. Membrane orientation and oligomerization of the small hydrophobic protein of human respiratory syncytial virus. J. Gen. Virol. 74:1445-1450. http://dx.doi.org/10.1099/0022-1317-74-7 -1445 .

16. Olmsted RA, Collins PL. 1989. The 1A protein of respiratory syncytial virus is an integral membrane protein present as multiple, structurally distinct species. J. Virol. 63:2019-2029.

17. Rixon HW, Brown G, Murray JT, Sugrue RJ. 2005. The respiratory syncytial virus small hydrophobic protein is phosphorylated via a mitogen-activated protein kinase p38-dependent tyrosine kinase activity during virus infection. J. Gen. Virol. 86:375-384. http://dx.doi.org/10.1099 /vir.0.80563-0.

18. Chen MD, Vazquez M, Buonocore L, Kahn JS. 2000. Conservation of the respiratory syncytial virus SH gene. J. Infect. Dis. 182:1228-1233. http: //dx.doi.org/10.1086/315829.

19. Collins PL, Olmsted RA, Johnson PR. 1990. The small hydrophobic protein of human respiratory syncytial virus: comparison between antigenic subgroups A and B. J. Gen. Virol. 71:1571-1576. http://dx.doi.org /10.1099/0022-1317-71-7-1571.

20. Gan SW, Ng L, Lin X, Gong X, Torres J. 2008. Structure and ion channel activity of the human respiratory syncytial virus (hRSV) small hydrophobic protein transmembrane domain. Protein Sci. 17:813-820. http://dx .doi.org/10.1110/ps.073366208.

21. Gan SW, Tan E, Lin X, Yu D, Wang J, Tan GM-Y, Vararattanavech A, 
Yeo CY, Soon CH, Soong TW, Pervushin K, Torres J. 2012. The small hydrophobic protein of the human respiratory syncytial virus forms pentameric ion channels. J. Biol. Chem. 287:24671-24689. http://dx.doi.org /10.1074/jbc.M111.332791.

22. Tolley KP, Marriott AC, Simpson A, Plows DJ, Matthews DA, Longhurst SJ, Evans JE, Johnson JL, Cane PA, Randolph VB, Easton AJ, Pringle CR. 1996. Identification of mutations contributing to the reduced virulence of a modified strain of respiratory syncytial virus. Vaccine 14: 1637-1646.

23. Yamada Y, Liu DX. 2009. Proteolytic activation of the spike protein at a novel RRRR/S motif is implicated in furin-dependent entry, syncytium formation, and infectivity of coronavirus infectious bronchitis virus in cultured cells. J. Virol. 83:8744-8758. http://dx.doi.org/10.1128/JVI .00613-09.

24. Bezrukov SM, Vodyanoy I. 1993. Probing alamethicin channels with water-soluble polymers-effect on conductance of channel states. Biophys. J. 64:16-25. http://dx.doi.org/10.1016/S0006-3495(93)81336-5.

25. Montal M, Mueller P. 1972. Formation of bimolecular membranes from lipid monolayers and a study of their electrical properties. Proc. Natl. Acad. Sci. U. S. A. 69:3561-3566. http://dx.doi.org/10.1073/pnas.69.12 .3561 .

26. Li Y, Surya W, Claudine S, Torres J. 2014. Structure of a conserved Golgi complex-targeting signal in coronavirus envelope proteins. J. Biol. Chem. 289:12535-12549. http://dx.doi.org/10.1074/jbc.M114.560094.

27. Gan SW, Vararattanavech A, Nordin N, Eshaghi S, Torres J. 2011. A cost-effective method for simultaneous homo-oligomeric size determination and monodispersity conditions for membrane proteins. Anal. Biochem. 416:100-106. http://dx.doi.org/10.1016/j.ab.2011.05.007.

28. Tycko R, Blanco FJ, Ishii Y. 2000. Alignment of biopolymers in strained gels: a new way to create detectable dipole-dipole couplings in highresolution biomolecular NMR. J. Am. Chem. Soc. 122:9340-9341. http: //dx.doi.org/10.1021/ja002133q.

29. Ulmer TS, Ramirez BE, Delaglio F, Bax A. 2003. Evaluation of backbone proton positions and dynamics in a small protein by liquid crystal NMR spectroscopy. J. Am. Chem. Soc. 125:9179-9191. http://dx.doi.org/10 $.1021 / \mathrm{ja} 0350684$.

30. Cornilescu G, Delaglio F, Bax A. 1999. Protein backbone angle restraints from searching a database for chemical shift and sequence homology. J. Biomol. NMR 13:289-302. http://dx.doi.org/10.1023/A:1008392405740.

31. Guntert P, Mumenthaler C, Wuthrich K. 1997. Torsion angle dynamics for NMR structure calculation with the new program DYANA. J. Mol. Biol. 273:283-298. http://dx.doi.org/10.1006/jmbi.1997.1284.

32. Herrmann T, Guntert P, Wuthrich K. 2002. Protein NMR structure determination with automated $\mathrm{NOE}$ assignment using the new software CANDID and the torsion angle dynamics algorithm DYANA. J. Mol. Biol. 319:209-227. http://dx.doi.org/10.1016/S0022-2836(02)00241-3.

33. Brunger AT. 2007. Version 1.2 of the crystallography and NMR system. Nat. Protoc. 2:2728-2733. http://dx.doi.org/10.1038/nprot.2007.406.

34. Brunger AT, Adams PD, Clore GM, DeLano WL, Gros P, GrosseKunstleve RW, Jiang JS, Kuszewski J, Nilges M, Pannu NS, Read RJ, Rice LM, Simonson T, Warren GL. 1998. Crystallography \& NMR system: a new software suite for macromolecular structure determination. Acta Crystallogr. D Biol. Crystallogr. 54:905-921. http://dx.doi.org/10 $.1107 /$ S0907444998003254.

35. Dossena S, Gandini R, Tamma G, Vezzoli V, Nofziger C, Tamplenizza M, Salvioni E, Bernardinelli E, Meyer G, Valenti G, Wolf-Watz M, Furst J, Paulmichl M. 2011. The molecular and functional interaction between ICln and HSPC038 proteins modulates the regulation of cell volume. J. Biol. Chem. 286:40659-40670. http://dx.doi.org/10.1074/jbc.M111 .260430 .

36. Duhovny D, Nussinov R, Wolfson HJ. 2002. Efficient unbound docking of rigid molecules. Lecture Notes Comput. Sci. 2452:185-200. http://dx .doi.org/10.1007/3-540-45784-4_14.

37. Schneidman-Duhovny D, Inbar Y, Nussinov R, Wolfson HJ. 2005. PatchDock and SymmDock: servers for rigid and symmetric docking. Nucleic Acids Res. 33:W363-W367. http://dx.doi.org/10.1093/nar /gki481.

38. Volkamer A, Kuhn D, Rippmann F, Rarey M. 2012. DoGSiteScorer: a web server for automatic binding site prediction, analysis and druggability assessment. Bioinformatics 28:2074-2075. http://dx.doi.org /10.1093/bioinformatics/bts310.

39. Lau TL, Kim C, Ginsberg MH, Ulmer TS. 2009. The structure of the integrin $\alpha \mathrm{IIb} \beta 3$ transmembrane complex explains integrin transmem- brane signalling. EMBO J. 28:1351-1361. http://dx.doi.org/10.1038 /emboj.2009.63.

40. Surya W, Li Y, Millet O, Diercks T, Torres J. 2013. Transmembrane and juxtamembrane structure of $\alpha \mathrm{L}$ integrin in bicelles. PLoS One 8:e74281. http://dx.doi.org/10.1371/journal.pone.0074281

41. Bhunia A, Tang XY, Mohanram H, Tan SM, Bhattacharjya S. 2009. NMR solution conformations and interactions of integrin $\alpha \mathrm{L} \beta 2$ cytoplasmic tails. J. Biol. Chem. 284:3873-3884. http://dx.doi.org/10.1074/jbc M807236200.

42. Lai C, Liu X, Tian C, Wu F. 2013. Integrin $\alpha 1$ has a long helix, extending from the transmembrane region to the cytoplasmic tail in detergent micelles. PLoS One 8:e62954. http://dx.doi.org/10.1371/journal.pone .0062954 .

43. Vinogradova O, Haas T, Plow EF, Qin J. 2000. A structural basis for integrin activation by the cytoplasmic tail of the alpha(IIb)-subunit. Proc. Natl. Acad. Sci. U. S. A. 97:1450-1455. http://dx.doi.org/10.1073/pnas .040548197

44. Son WS, Park SH, Nothnagel HJ, Lu GJ, Wang Y, Zhang H, Cook GA, Howell SC, Opella SJ. 2012. "q-Titration" of long-chain and short-chain lipids differentiates between structured and mobile residues of membrane proteins studied in bicelles by solution NMR spectroscopy. J. Magn. Reson. 214:111-118. http://dx.doi.org/10.1016/j.jmr.2011.10.011.

45. Spera S, Bax A. 1991. Empirical correlation between protein backbone conformation and C.alpha. and C.beta. 13C nuclear magnetic resonance chemical shifts. J. Am. Chem. Soc. 113:5490-5492. http://dx.doi.org/10 $.1021 / \mathrm{ja} 00014 \mathrm{a} 071$.

46. Xu X-P, Case D. 2001. Automated prediction of $15 \mathrm{~N}, 13 \mathrm{C} \alpha, 13 \mathrm{C} \beta$ and $13 \mathrm{C}^{\prime}$ chemical shifts in proteins using a density functional database. J. Biomol. NMR 21:321-333. http://dx.doi.org/10.1023/A:1013324104681.

47. Schneidman-Duhovny D, Inbar Y, Nussinov R, Wolfson HJ. 2005. Geometry-based flexible and symmetric protein docking. Proteins 60: 224-231. http://dx.doi.org/10.1002/prot.20562.

48. Pervushin K, Tan E, Parthasarathy K, Xin L, Jiang FL, Yu D, Vararattanavech A, Soong TW, Liu DX, Torres J. 2009. Structure and inhibition of the SARS coronavirus envelope protein ion channel. PLoS Pathog. 5:e1000511. http://dx.doi.org/10.1371/journal.ppat.1000511.

49. Torres J, Parthasarathy K, Lin X, Saravanan R, Kukol A, Liu DX. 2006. Model of a putative pore: the pentameric alpha-helical bundle of SARS coronavirus E protein in lipid bilayers. Biophys. J. 91:938-947. http://dx .doi.org/10.1529/biophysj.105.080119.

50. Nieto-Torres JL, Dediego ML, Verdia-Baguena C, Jimenez-Guardeno JM, Regla-Nava JA, Fernandez-Delgado R, Castano-Rodriguez C, Alcaraz A, Torres J, Aguilella VM, Enjuanes L. 2014. Severe acute respiratory syndrome coronavirus envelope protein ion channel activity promotes virus fitness and pathogenesis. PLoS Pathog. 10:e1004077. http://dx .doi.org/10.1371/journal.ppat.1004077.

51. Cymes GD, Ni Y, Grosman C. 2005. Probing ion-channel pores one proton at a time. Nature 438:975-980. http://dx.doi.org/10.1038/nature04293.

52. Paulmichl M, Nasmith P, Hellmiss R, Reed K, Boyle WA, Nerbonne JM, Peralta EG, Clapham DE. 1991. Cloning and expression of a rat cardiac delayed rectifier potassium channel. Proc. Natl. Acad. Sci. U. S. A. 88:7892-7895. http://dx.doi.org/10.1073/pnas.88.17.7892.

53. Dossena S, Maccagni A, Vezzoli V, Bazzini C, Garavaglia ML, Meyer G, Furst J, Ritter M, Fugazzola L, Persani L, Zorowka P, Storelli C, Beck-Peccoz P, Botta G, Paulmichl M. 2005. The expression of wild-type pendrin (SLC26A4) in human embryonic kidney (HEK 293 Phoenix) cells leads to the activation of cationic currents. Eur. J. Endocrinol. 153:693699. http://dx.doi.org/10.1530/eje.1.02018.

54. Nieto-Torres JL, DeDiego ML, Alvarez E, Jimenez-Guardeno JM, Regla-Nava JA, Llorente M, Kremer L, Shuo S, Enjuanes L. 2011. Subcellular location and topology of severe acute respiratory syndrome coronavirus envelope protein. Virology 415:69-82. http://dx.doi.org/10 .1016/j.virol.2011.03.029.

55. Jing X, Ma C, Ohigashi Y, Oliveira FA, Jardetzky TS, Pinto LH, Lamb RA. 2008. Functional studies indicate amantadine binds to the pore of the influenza A virus M2 proton-selective ion channel. Proc. Natl. Acad. Sci. U. S. A. 105:10967-10972. http://dx.doi.org/10.1073 /pnas.0804958105.

56. Wilson L, Gage P, Ewart G. 2006. Hexamethylene amiloride blocks E protein ion channels and inhibits coronavirus replication. Virology 353: 294-306. http://dx.doi.org/10.1016/j.virol.2006.05.028.

57. OuYang B, Xie S, Berardi MJ, Zhao X, Dev J, Yu W, Sun B, Chou JJ. 
2013. Unusual architecture of the $\mathrm{p} 7 \mathrm{channel}$ from hepatitis $\mathrm{C}$ virus. Nature 498:521-525. http://dx.doi.org/10.1038/nature12283.

58. Premkumar A, Wilson L, Ewart GD, Gage PW. 2004. Cation-selective ion channels formed by $\mathrm{p} 7$ of hepatitis $\mathrm{C}$ virus are blocked by hexamethylene amiloride. FEBS Lett. 557:99-103. http://dx.doi.org/10.1016/S0014 $-5793(03) 01453-4$.

59. Chou JJ, Kaufman JD, Stahl SJ, Wingfield PT, Bax A. 2002. Micelleinduced curvature in a water-insoluble HIV-1 Env peptide revealed by NMR dipolar coupling measurement in stretched polyacrylamide gel. J. Am. Chem. Soc. 124:2450-2451. http://dx.doi.org/10.1021 /ja017875d.

60. Fanucci GE, Lee JY, Cafiso DS. 2003. Membrane mimetic environments alter the conformation of the outer membrane protein BtuB. J. Am. Chem. Soc. 125:13932-13933. http://dx.doi.org/10.1021/ja0376442.
61. Schnell JR, Chou JJ. 2008. Structure and mechanism of the M2 proton channel of influenza A virus. Nature 451:591-595. http://dx.doi.org/10 .1038 /nature06531.

62. Verdia-Baguena C, Nieto-Torres JL, Alcaraz A, DeDiego ML, Torres J, Aguilella VM, Enjuanes L. 2012. Coronavirus E protein forms ion channels with functionally and structurally involved membrane lipids. Virology 432:485-494. http://dx.doi.org/10.1016/j.virol.2012.07.005.

63. Sorkin A, von Zastrow M. 2002. Signal transduction and endocytosis: close encounters of many kinds. Nat. Rev. Mol. Cell Biol. 3:600-614. http: //dx.doi.org/10.1038/nrm883.

64. Krogh A, Larsson B, von Heijne G, Sonnhammer ELL. 2001. Predicting transmembrane protein topology with a hidden Markov model: application to complete genomes. J. Mol. Biol. 305:567-580. http://dx.doi.org/10 .1006/jmbi.2000.4315. 


\section{ChemComm}

\section{COMMUNICATION}

Cite this: Chem. Commun., 2014, 50,6700

Received 18th February 2014,

Accepted 24th March 2014

DOI: $10.1039 / c 4 c c 01283 f$

www.rsc.org/chemcomm

\section{Amphiphilic COSAN and 12-COSAN crossing synthetic lipid membranes: planar bilayers and liposomes}

\author{
Carmina Verdiá-Báguena, ${ }^{a}$ Antonio Alcaraz, ${ }^{a}$ Vicente M. Aguilella, ${ }^{a}$ Ana M. Cioran, ${ }^{b}$

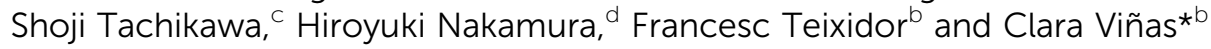

\begin{abstract}
The boron-rich cobaltabisdicarbollide (COSAN) and its $8,8^{\prime}-12$ derivative (12-COSAN), both of purely inorganic nature, are shown to cross through synthetic lipid membranes. These results reveal unexpected properties at the interface of biological and synthetic membranes.
\end{abstract}

All biological membranes are formed by self-assembly of lipid molecules so that their polar head groups are exposed to the aqueous environment and their fatty acid tails face internally within the membrane, creating a hydrophobic barrier. Membrane integrity is essential for cell regulatory processes, maintaining the osmotic equilibrium that ensures the proper distribution of ions and metabolites, and controlling the biomolecular flow and the electrical signal transduction across membranes. The ability to form membranes is not limited to polar lipid molecules. One example is the inorganic, boron-based molecule cobaltabisdicarbollide, $\left[3,3^{\prime}-\mathrm{Co}\left(1,2-\mathrm{C}_{2} \mathrm{~B}_{9} \mathrm{H}_{11}\right)_{2}\right]^{-}$, commonly known as COSAN (Fig. 1), which comprises of a cobalt atom sandwiched by two carboranyl clusters. ${ }^{1}$ Structurally, COSAN is very different from the lipid molecules that make up biological membranes. The structure exhibits both electrostatic interactions, via a dispersed negative ionic charge covering the whole molecule, ${ }^{2}$ and non-bonding intermolecular interactions between its weakly polarized B-H and $\mathrm{C}-\mathrm{H}$ bonds. ${ }^{3}$ This duality imparts a molecular property of being simultaneously hydrophobic and hydrophilic, and makes COSAN soluble in both water and oils. The polarized lipid molecules that make up biological membranes also possess amphiphilic properties, and can assemble into membranes and vesicles formed from lipid bilayers. ${ }^{4,5}$ However, unlike lipid bilayer membranes, the membranes of COSAN vesicles are monolayers. ${ }^{4}$ Recently, $\left[3,3^{\prime}-\mathrm{Co}\left(8-\mathrm{I}-1,2-\mathrm{C}_{2} \mathrm{~B}_{9} \mathrm{H}_{10}\right)_{2}\right]^{-}$, I2-COSAN, has also been found to

\footnotetext{
${ }^{a}$ Laboratory of Molecular Biophysics, Dept. of Physics, Universitat Jaume I, 12071 Castelló, Spain

${ }^{b}$ Institut de Ciència de Materials de Barcelona (CSIC), Campus de la U.A.B., E-08193 Bellaterra, Spain. E-mail: clara@icmab.es; Fax: +34935805729

${ }^{c}$ Department of Life Sciences, Faculty of Science, Gakushuin University, Mejiro, Toshima-ku, Tokyo, 171-8588, Japan

${ }^{d}$ Chemical Resources Laboratory, Tokyo Institute of Technology R1-13, 4259 Nagatsuta-cho, Midori-ku, Yokohama, 226-8503, Japan
}

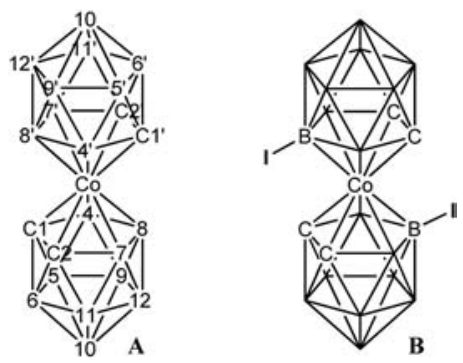

Fig. 1 (A) Vertex numbering of an anionic COSAN cluster. (B) [3, $3^{\prime}-\mathrm{Co}-$ $\left.\left(8-I-1,2-\mathrm{C}_{2} \mathrm{~B}_{9} \mathrm{H}_{10}\right)_{2}\right]^{-}$, I2-COSAN

self-assemble into a lyotropic lamellar phase with sufficient curvature to create closed vesicles. ${ }^{5}$

The lamellae formed by I2-COSAN are made of monomolecular sheets such as clay systems, but with the sole difference that they are not covalently bound. The lamella formation presumably originates from intermolecular dihydrogen bonds, $\mathrm{C}-\mathrm{H}^{\delta+\ldots \delta}{ }^{+-} \mathrm{H}-\mathrm{B},{ }^{1,5}$ The amphiphilic properties of COSAN and I2-COSAN in water are essential, if they are to have realistic applications in medicine as building blocks for drug delivery or in boron-neutron capture therapy (BNCT). Recently, we demonstrated that COSAN and I2-COSAN accumulate within living cells, where they can be detected by $\nu$ B-H Raman microspectroscopy. ${ }^{6}$ In this communication, the ability of COSAN and I2-COSAN to transfer across synthetic and liposome membranes has been studied for the first time. The COSAN and I2-COSAN transit is achieved without disrupting membrane integrity, and this process occurs with zero-order kinetics against the apparent concentration gradient.

We began this work by investigating the interaction of COSAN with cell-free artificial lipid bilayer membranes. The membranes were formed by monolayer apposition using the Montal-Mueller technique, and analysed using planar lipid bilayer electrophysiology. ${ }^{7}$ Monolayers were prepared from a solution of $1 \%$ pure 1,2-dioleoylsn-glycero-3-phosphocholine (DOPC) in pentane. Lipid was added on 70-90 $\mu \mathrm{m}$ diameter orifices in the $15 \mu \mathrm{m}$-thick Teflon partition that separated two identical chambers ${ }^{8}$ with aqueous solutions of $10 \mu \mathrm{M}$ $\mathrm{NaCl}$ at pH 6.0. An Axopatch $200 \mathrm{~B}$ amplifier was used to measure the 


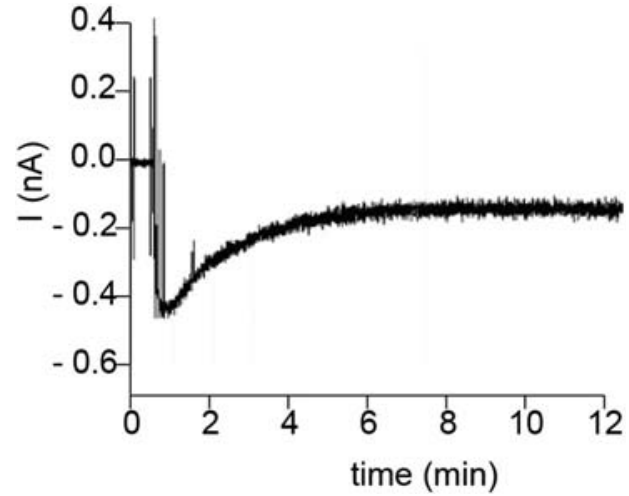

Fig. 2 A typical current recording against time obtained when COSAN is applied to one side of a planar bilayer formed from DOPC. Current initiates as a strong, but transient, depolarization before stabilizing as a continuous, steady negative current across the membrane.

current registered after COSAN addition in the feeding side of the chamber. The COSAN concentration in the stripping side was calculated from the boron concentration determined by ICP-MS. ICP-MS measurements were performed using a quadrupole mass spectrometer Agilent $7500 \mathrm{cx}$ with a collision cell (Agilent technologies, USA).

We found that application of either the protonated form $(\mathrm{H}[\mathrm{COSAN}])$ or the sodium salt $(\mathrm{Na}[\mathrm{COSAN}])$ to the feeding side of the artificial lipid membrane resulted in initial current depolarization, which then stabilized after 5 minutes as a steady negative ionic current across the membrane (Fig. 2). This occurred without application of a trans-membrane voltage, indicating that COSAN directly translocates across the membrane without a driving force. Membrane electrical capacitance remained constant throughout each experiment, indicating that the lipid bilayer remained intact and no aqueous pores were formed in the membrane. Lipid composition does not influence the COSAN transport rate, as no significant permeation differences were seen for model membranes of neutral lipid composition that mimic either prokaryotic (DPhPC: 1,2-diphytanoyl-sn-glycero-3-phosphocholine) or eukaryotic (1,2-dioleoyl-sn-glycero-3-phosphocholine, DOPC) cell membranes. Electrostatic properties of the membrane have small but still measurable effects. A slight reduction of the COSAN transport rate was observed when the negatively charged membranes DOPC/DOPS (4:1), which mimic the surface charge density of a typical plasma membrane, were used.

Next, the electrophysiology of COSAN and I2-COSAN permeating through planar membranes was studied. The translocation of $\mathrm{Na}[\mathrm{I} 2-\mathrm{COSAN}]$ is lower compared with that of $\mathrm{H}[\mathrm{COSAN}]$ and $\mathrm{Na}[\mathrm{COSAN}]$, however, in all cases the permeation rate was independent of the initial concentration, showing zero order kinetics. This indicates that the rate-determining step is not the diffusion across the membrane but the partitioning of COSAN or I2-COSAN into the lipid phase. ${ }^{9}$ Interestingly, different permeation rates were found for $\mathrm{H}[\mathrm{COSAN}]$ and $\mathrm{Na}[\mathrm{COSAN}]$ (Fig. 3). The reason for this is still unclear. Previous studies showed that the presence of sodium ions drastically modifies the COSAN aggregation process. ${ }^{4 a}$ In fact, it was observed that sodium ions favour larger nano-vesicles (diameter from 80 to $890 \mathrm{~nm}$ ) than protons do (diameter nearly

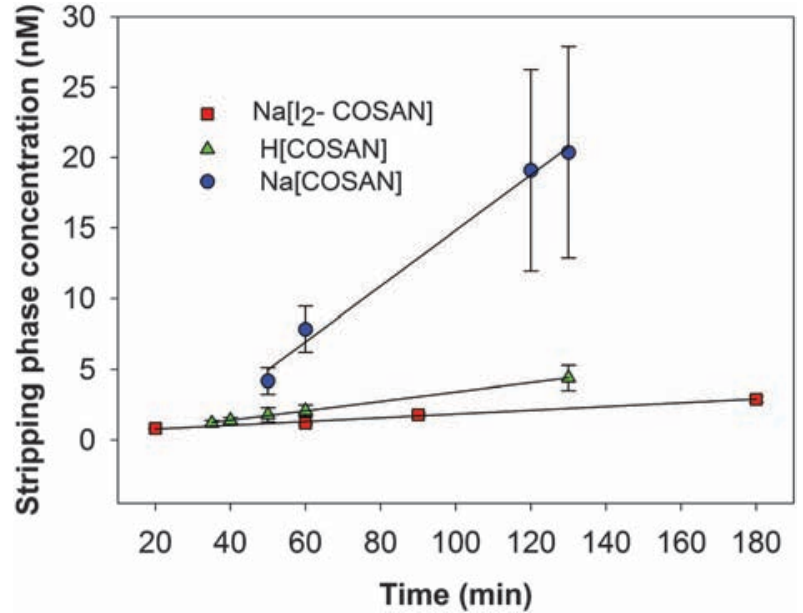

Fig. 3 Permeation rate of $\mathrm{Na}$ [COSAN], H[COSAN] and $\mathrm{Na}$ [I2-COSAN] across neutral planar membranes as measured by ICP-MS. All of them showed zero-order kinetics. Initial concentrations of the three compounds were $100 \mu \mathrm{M}$. Error bars are standard deviations resulting from 10 independent experiments.

$40 \mathrm{~nm}) .{ }^{4 a}$ This suggests that absorption-desorption rates at solutionmembrane interfaces may be determined by the structural form of COSAN molecules.

The direct measurements of COSAN concentrations by inductively coupled plasma mass spectrometry (ICP-MS) in the stripping side matched the estimated concentration calculated from ion current measurements. This close agreement between the two independent estimations indicates that transport of other small ions across the lipid bilayer is minimal, if at all. As an anion, COSAN would not be expected to travel directly through a lipid bilayer due to its high Born energy, ${ }^{10}$ calculated as $\sim 80 \mathrm{~kJ} \mathrm{~mol}^{-1}$, or more than $30 \mathrm{kT}$, for an ideal COSAN anion $(1.1 \mathrm{~nm} \times 0.6 \mathrm{~nm}) .{ }^{4 a}$ We predict that the unusual dual hydrophilic and lipophilic properties of the COSAN structure overcome this energy barrier allowing COSAN ions to cross the lipid membrane. COSAN permeation would occur via the sequence of absorption at the solution-membrane interface, translocation across the lipid phase and desorption at the membranesolution interface.

To directly visualize this transferring behaviour, mixtures of COSAN nano-vesicles ${ }^{12}$ and liposome solutions ${ }^{12}$ were examined using cryo-TEM. ${ }^{11}$ COSAN forms spherical nano-vesicles in water with a radius of approximately $20 \mathrm{~nm}$ and a membrane nearly $1 \mathrm{~nm}$ thick, ${ }^{4 a}$ whereas liposomes form mostly unilamellar bilayer vesicles with a membrane thickness of about $4.5 \mathrm{~nm}$ (Fig. 4). In COSAN: liposome mixtures, $1: 4, \mathrm{v}: \mathrm{v}$ (an equivalent COSAN concentration of $4 \mathrm{mM}$ ), COSAN vesicles fuse with the liposome membrane (Fig. 4a). At a lower liposome ratio (1:3, v:v; an equivalent COSAN concentration of $5 \mathrm{mM}$ ), additional intermediate effects are seen (Fig. 4b). Often, two or more liposome units become linked via COSAN nanovesicles. At this interface, COSAN nano-vesicles exhibit a dramatic morphological change to form a planar lamellar microstructure (Fig. 4c). This lamellar form of COSAN appeared to diffuse from the membrane into the liposome center recovering its spherical monolayer vesicle morphology (Fig. 4b, arrows). These liposomeCOSAN double vesicles were larger than the initial liposome 


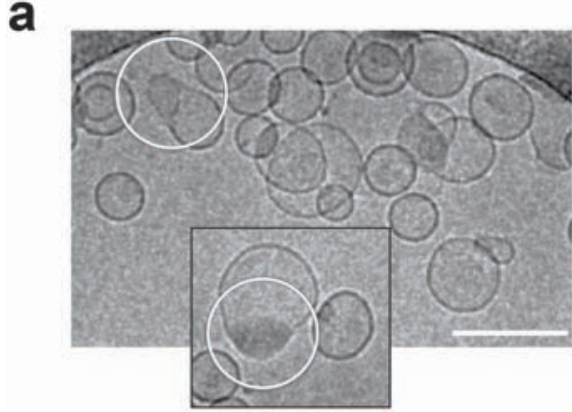

b

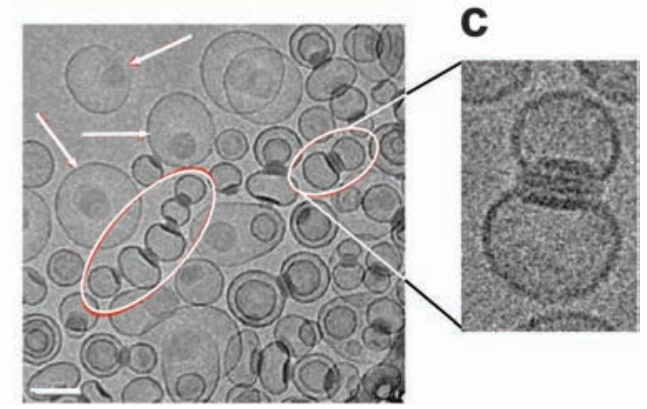

Fig. 4 Visualisation of the interaction between COSAN vesicles and liposomes. (a) CryoTEM image of COSAN : liposomes (1:4) suspended in vitreous ice. Circles highlight fusion between COSAN vesicles and liposomes. Scale bar $200 \mathrm{~nm}$. (b) CryoTEM image of COSAN : liposomes (1:3) suspended in vitreous ice. The circles highlight the joining of two or more liposome units linked by COSAN. Arrows indicate the complete penetration of the COSAN inside the liposome and the recovery of the monolayer vesicle form. Scale bar $200 \mathrm{~nm}$. (c) $50000 \times$ magnification shows the planar multilayer morphology of COSAN at the interface of two liposomes.

population, suggesting that the process of COSAN vesicle encapsulation may cause multiple liposomes to fuse.

The crossing of the encapsulated $\mathrm{H}[\mathrm{COSAN}]$ through planar lipid bilayer electrophysiology membranes was also studied. Samples containing 1:3 COSAN : liposome $(\mathrm{v}: \mathrm{v})$ were prepared with equivalent COSAN concentrations of 10, 25, 50 and $100 \mu \mathrm{M}$.

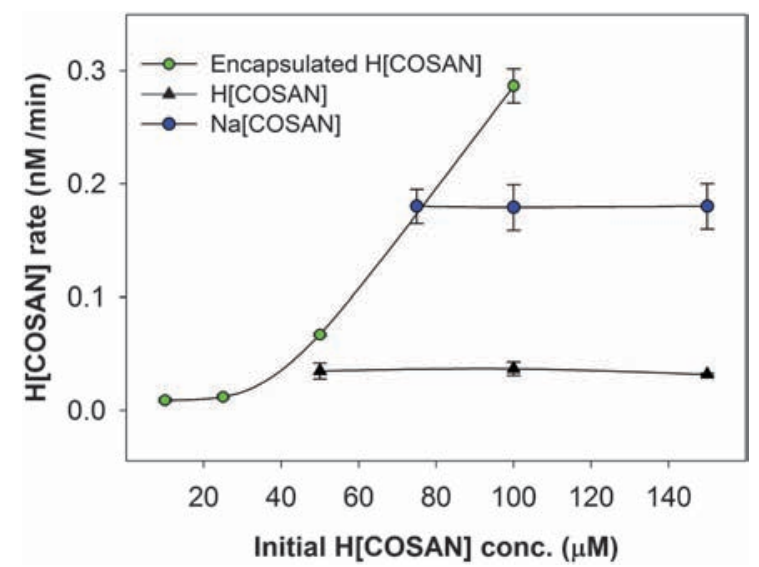

Fig. 5 Translocation of $\mathrm{H}[\mathrm{COSAN}]$ and $\mathrm{Na}[\mathrm{COSAN}]$ through synthetic lipid membranes in their original form and encapsulated into liposomes. The comparison shows two different mechanisms. The permeation rate of encapsulated $\mathrm{H}[\mathrm{COSAN}]$ is strongly dependent on the initial H[COSAN] concentration in the feeding phase, whereas the unencapsulated H[COSAN] is not
As shown in Fig. 5, the encapsulated $\mathrm{H}$ [COSAN] behaves differently from $\mathrm{H}[\mathrm{COSAN}]$. Passive translocation across the planar membrane of the encapsulated COSAN was more efficient than that of plain $\mathrm{H}[\mathrm{COSAN}]$. In addition, the permeation rate of the encapsulated $\mathrm{H}[\mathrm{COSAN}]$ was dependent on the initial concentration, so the accumulated concentration of COSAN in the stripping phase increased exponentially with time. These findings suggest that the rate-determining step for the translocation is the diffusion process across the lipid membrane and not the solution-partitioning seen for plain $\mathrm{H}[\mathrm{COSAN}]$. The absorption and desorption of encapsulated COSAN at solutionmembrane interfaces are much faster than bare COSAN.

All in all, these observations demonstrate that COSAN and I2-COSAN are able to generate vesicles due to their capacity to produce inter-molecular interactions and can transit lipid bilayer membranes without affecting membrane integrity. It has been detected by CryoTEM that two or more liposome units become linked via COSAN nano-vesicles. At this interface, COSAN nano-vesicles exhibit a dramatic morphological change from vesicles to a planar lamellar microstructure that appeared to diffuse from the membrane into the liposome recovering its spherical monolayer vesicle morphology. These results reveal unexpected properties at the interface of biological and synthetic membranes.

This work was supported by Generalitat de Catalunya (2009/ SGR/00279), Generalitat Valenciana (Prometeu 2012/069), Fundació Caixa Castelló-Bancaixa (P1-1B2012-03) and Spanish Ministry of Economy and Competitiveness (CTQ2010-16237 and FIS2010-19810). A.C. thanks MICINN for the FPU grant.

\section{Notes and references}

1 R. N. Grimes, Carboranes, Academic Press, Burlington, MA, 2011.

2 C. Massalles, J. Llop, C. Viñas and F. Teixidor, Adv. Mater., 2002, $14,826$.

3 (a) M. J. Hardie and C. L. Raston, Chem. Commun., 2001, 905; (b) E. J. Juarez-Perez, R. Nuñez, C. Viñas, R. Sillanpää and F. Teixidor, Eur. J. Inorg. Chem., 2010, 2385; (c) C. Viñas, M. Tarrés, P. GonzálezCardoso, P. Farràs, P. Bauduin and F. Teixidor, Dalton Trans., 2014, 5062.

4 (a) P. Bauduin, S. Prevost, P. Farras, F. Teixidor, O. Diat and T. Zemb, Angew. Chem., Int. Ed., 2011, 50, 5298; (b) P. Matějíček, P. Cígler, K. Procházka and V. Král, Langmuir, 2006, 22, 575.

5 D. Brusselle, P. Bauduin, L. Girard, A. Zaulet, C. Viñas, F. Teixidor, I. Ly and O. Diat, Angew. Chem., Int. Ed., 2013, 52, 12114.

6 M. Tarrés, E. Canetta, C. Viñas, F. Teixidor and A. J. Harwood, Chem. Commun., 2014, 50, 3370.

7 M. Montal and P. Mueller, Proc. Natl. Acad. Sci. U. S. A., 1972, 69, 35617; S. M. Bezrukov and I. Vodyanoy, Biophys. J., 1993, 64, 16.

8 V. A. Parsegian, Nature, 1969, 221, 844.

9 N. Lakshminarayanaiah, Equations of membrane biophysics, Academic Press, London, 1984.

10 Vitrified specimens were prepared by placing $3 \mu \mathrm{L}$ of the studied sample suspension on a 400 mesh copper grid with a holey carbon support. Each sample was blotted to a thin film and immediately plunged into liquid ethane in the Leica CPC cryoworkstation. The grids were viewed on a JEOL 2011 transmission electron microscope operating at an accelerating voltage of $200 \mathrm{kV}$. The microscope was equipped with a Gatan cryoholder and the samples were maintained at $-177{ }^{\circ} \mathrm{C}$ during imaging. Electron micrographs were recorded with the Digital Micrograph software package under low electron dose conditions, to minimize electron bean radiation. Images were recorded on a Gatan 794 MSC 600HP cooled charge-coupled device (CCD) camera. 
11 A 2 mM solution of $\mathrm{H}$ [COSAN] in water. $\mathrm{H}$ [COSAN] was prepared from the $\operatorname{Cs}[\mathrm{COSAN}]$ by cationic exchange resin using a wateracetonitrile $(50: 50)$ mixture.

12 Liposomes were prepared from DSPC, DSPE-PEG2000, and cholesterol $(1: 0.11: 1$, molar ratio) according to the reverse-phase evaporation (REV) method. Total lipids of $88 \mathrm{mg}$ were dissolved in $3 \mathrm{~mL}$ of a chloroform-diisopropyl ether mixture $(1: 1, \mathrm{v} / \mathrm{v})$ and $1.5 \mathrm{~mL}$ of distilled water was added to form a w/o emulsion. The emulsion was sonicated for $3 \mathrm{~min}$ and then, the organic solvents were removed under reduced pressure in a rotary evaporator at $60{ }^{\circ} \mathrm{C}$ for $30 \mathrm{~min}$ to obtain a suspension of liposomes. The liposomes obtained were subjected to extrusion 10 times through a polycarbonate membrane filter of $100 \mathrm{~nm}$ pore size (Whatman, 110605, FILTER, 0.1UM, 25MM, Gentaur Molecular Products, Belgium), using an extruder device (LIPEXTM Extruder, Northern Lipids, Canada) thermostated at $60{ }^{\circ} \mathrm{C}$. Purification was accomplished by ultracentrifugation (himac cp $80 \mathrm{wx}$, Hitachi Koki, Japan) at $200000 \mathrm{~g}$ for $60 \mathrm{~min}$ at $4{ }^{\circ} \mathrm{C}$, and the pellets obtained were re-suspended in water $(1.5 \mathrm{~mL})$. 